Universidad | Campus

Politécnica de Excelencia

de Cartagena Internacional

New contributions to frequency control based on virtual synchronous generators: application to power systems with high renewable energy sources integration

Renewable energies \& Energy efficiency

Author: Ana Fernández Guillamón

Director/s: Dr. Ángel Molina García Dr. José Ignacio Sarasúa Moreno

Cartagena (2020) 


\title{
New contributions to frequency control based on virtual synchronous generators: application to power systems with high renewable energy sources integration
}

\author{
Author \\ Ana Fernández-Guillamón \\ Directors \\ Dr. Ángel Molina-García \\ Dr. José Ignacio Sarasúa-Moreno \\ Departamento de Automática, Ingeniería Eléctrica y Tecnología Electrónica \\ Escuela Técnica Superior de Ingeniería Industrial \\ Universidad Politécnica de Cartagena
}

Cartagena, 2020 
Do me a favour: smile!

(Rachel Newsham) 


\section{Agradecimientos}

Cuando uno está solo, es fácil tener miedo. Es fácil concentrarse en lo que podría esconderse en la oscuridad, al final de los escalones del sótano. Es fácil obsesionarse con cosas inútiles, como el disparate de adentrarse en una tormenta de cuchillos giratorios. Cuando uno está solo es fácil sudar, derrumbarse, ser presa del pánico... Pero yo tenía compañía. ("El temor de un hombre sabio", Patrick Rothfuss).

Como bien reflejan las líneas anteriores, estar solo nos hace magnificar los problemas; a veces, simplemente ponerles palabras consigue que veamos las cosas desde otra perspectiva. Por ello, y puesto que ha habido mucha gente que ha estado a mi lado estos años, soportando conmigo el peso de la tesis (y soportándome a mí cuando me pongo pesada), tengo que daros las gracias. Quiero agradecer a todos aquellos que han hecho que llegara hasta aquí; a los que habéis tenido que escuchar mis quejas y miedos; a los que me ayudasteis y apoyasteis en momentos difíciles; $\mathrm{y}$, en general, a todos los que habéis formado parte de mi vida a lo largo de esta época.

En primer lugar, agradezco a mis directores Ángel y J. Ignacio. Particularmente, quiero agradecer a Ángel por ser tan enfático y energético (y Mr. Postureo), que tanto choca con mi forma de ser reservada y tranquila; gracias por hacerme rabiar tantas veces, pero conseguir que siempre salga del despacho con una sonrisa. Y a J. Ignacio, por las incontables e interminables conversaciones por Skype de este último año, que ha sido bastante intenso en todos los aspectos. Gracias a ambos por todos los consejos y la ayuda para que la tesis haya salido adelante; gracias por entenderme (sé que a veces no soy fácil de tratar) y darme mi tiempo y espacio cuando lo he necesitado. Fuera del ámbito académico, no pueden faltar las recomendaciones de tantos (buenos) libros que me habéis dado.

Gracias también a mis amigos; que, aunque ahora son virtuales por la distancia, me escuchan (leen, más bien) cuando me surge algún "dilema existencial". Gracias a Sandra, Patri y Fran, por haberme acompañado en prácticamente toda mi etapa universitaria; por todas las comidas y tardes-noches de entretenimiento de los últimos 7 años (aunque, a veces, fueran en la biblioteca). También a Tania, que ha sido de las personas que más me ha oído quejarme, sobre todo en este último año y medio; ¡aún tenemos pendiente tomar unos edamames juntas! Gracias a Bea, Javi, Joaquín y Vanesa, que siempre intentan sacar un hueco para que nos veamos. Quiero mencionar a Lola, puesto que encontré a la persona indicada en el momento y lugar adecuados. Si tomar un camino siempre es difícil, creo que en mi caso aún lo era más. También a Antonio Vigueras, dado que esta tesis empezó con su colaboración y ayuda. No me olvido de Miguel Cañas, que me alegra alguna mañana con un correo preguntándome cómo me va todo. Y siempre estaré 
agradecida a Garrigós, la persona que puso la primera piedra para que tomara este camino, que al final ha sido más largo de lo esperado; gracias por ser, sin duda, la persona por la que decidí hacerme ingeniera. Gracias por tus inolvidables clases y exámenes (a partes iguales); pero, sobre todo, por demostrarme que trabajar duro tiene su recompensa (aunque después de tantos años, los nervios y la confianza me siguen fallando). Espero algún día saber enseñar y transmitir tan bien como tú.

Doy las gracias a mis compañeros y colegas de la UPCT. Entre ellos, quiero destacar a Jose, por todas las veces que tiene que ayudarme en el laboratorio cuando no consigo hacer que funcione algún montaje. También a Fran Vera, Socorro y M. Carmen, que siempre intentan buscar lo mejor para mí. Fuera de la UPCT, merece especial mención Guillermo, sobre todo por los consejos en estos últimos meses antes de la finalización de la tesis. And also Kaushik and Anca from DTU, for the three months I shared with them in Denmark in 2019.

Para terminar, gracias a mi familia, puesto que aunque ninguno tiene muy claro qué he investigado en estos últimos años, siempre que nos vemos me preguntan cómo va la tesis (no os preocupéis, yo tampoco estoy muy segura). Especial mención tienen mi tía Amalia, por apoyarme cuando tomé la decisión de empezar vida académica; mi padre, que me enseñó desde pequeña que Las tres palabras claves: son paciencia, prudencia y perseverancia; y mi madre, que cuando empecé la universidad siempre decía que $A$ quien hace todo lo que puede, no se le puede exigir más, aunque es una de mis cualidades (¿o quizá defecto?) innatas; gracias también por incluir en mi vida al mejor bandido perruno que uno pueda tener. Por último, gracias a Jose, que lleva tres años deseando saber qué voy a poner de él en los agradecimientos. Gracias simplemente por estar a mi lado, por intentar hacerme reír cada vez que estoy enfurruñada, por los juegos de mesa de los viernes por la tarde, por escuchar una y otra vez los mismos pensamientos repetitivos, incluso por reírte de mí cuando no entiendo los sarcasmos y dobles sentidos...; en general, gracias por hacerme feliz. Y no se me olvida la pareja de orejotas gamberros que me dan tanta ternura (aunque a ti te saquen de quicio).

Gracias a todos por acompañarme en esta etapa. 
La presente tesis doctoral es un compendio de artículos previamente publicados, incluidos en la Sección 3:

- Power systems with high renewable energy sources: A review of inertia and frequency control strategies over time [1]

- An adaptive frequency strategy for variable speed wind turbines: application to high wind integration into power systems [2]

- Fast power reserve emulation strategy for VSWT supporting frequency control in multi-area power systems [3]

- Frequency control analysis based on unit commitment schemes with high wind power integration: A Spanish isolated power system case study [4]

- Analysis of power system inertia estimation in high wind power plant integration scenarios [5]

- An adaptive control scheme for variable speed wind turbines providing frequency regulation in isolated power systems with thermal generation [6]

- Hybrid wind-photovoltaic frequency control strategy under variable weather conditions in isolated power systems [7]

- Extensive frequency response and inertia analysis under high RES integration scenarios: application to the European interconnected power system [8]

En todas ellas, la doctoranda ha sido autor principal. También se ha publicado un capítulo de libro relacionado con la tesis doctoral, con título A review of virtual inertia techniques for renewable energy-based generators.

Junto con esto, se han realizado diferentes ponencias en congresos:

- New fast power reserve emulation strategy for VSWT supporting frequency control en International Conference on renewable energy en el año 2018.

- Inertia changes in power systems with high wind power plant integration. An overview of frequency analysis challenges en European Conference on Operational Research en el año 2018.

- Análisis y simulación de estrategias agregadas de control de frecuencia entre parques eólicos y aprovechamientos hidroeléctricos en Congreso Internacional de Dirección e Ingeniería de Proyectos en el año 2018.

- Comparison of different tools for power flow analysis with high wind power integration en International Conference on Clean Electrical Power Renewable Energy Resources Impact en el año 2019.

- Frequency response and inertia analysis in power systems with high wind energy integration en International Conference on Clean Electrical Power Renewable Energy Resources Impact en el año 2019.

- Comparativa de herramientas de gamificación de acceso libre: aplicación en asignaturas de grados en ingenierías industriales en Congreso Internacional 
de Innovación Docente e Investigación en Educación Superior: un Reto para las Áreas de Conocimiento en el año 2019.

- Comparison of power flow analysis tools under high renewable energy sources integration: application to engineering bachelor degrees en International Technology, Education and Development Conference en el año 2020.

Asimismo, la doctoranda también ha colaborado en trabajos que han quedado fuera del alcance de su tesis:

- Impact of combined demand-response and wind power plant participation in frequency control for multi-area power systems [9]

- Vertical wind profile characterization and identification of patterns based on a shape clustering algorithm [10]

- Categorization and analysis of relevant factors for optimal locations in onshore and offshore wind power plants: A taxonomic review [11]

- Offshore wind power integration into future power systems: Overview and trends [12]

- Modelling type 1 and 2 wind turbines based on IEC 61400-27-1: transient response under voltage dips [13]

- A controller for optimum electrical power extraction from a small grid interconnected wind turbine [14] 
DT-16

\section{CONFORMIDAD DE SOLICITUD DEAUTORIZACIÓN DE DEPÓSITO DE}

\section{TESIS DOCTORAL POR EL/LA DIRECTOR/A DE LA TESIS}

D/Da . Ángel Molina García Director/a de la Tesis doctoral "New contributions to frequency control based on virtual synchronous generators: application to power systems with high renewable energy sources integration".

\section{INFORMA:}

Que la referida Tesis Doctoral, ha sido realizada por Da. Ana Fernández Guillamón, dentro del Programa de Doctorado Energías Renovables y Eficiencia Energética, dando mi conformidad para que sea presentada ante el Comité de Dirección de la Escuela Internacional de Doctorado para ser autorizado su depósito.

\ Informe positivo sobre el plan de investigación y documento de actividades del doctorando/a emitido por el Director/Tutor (RAPI).

La rama de conocimiento en la que esta tesis ha sido desarrollada es:

Ciencias

Ciencias Sociales y Jurídicas

$\otimes \quad$ Ingeniería y Arquitectura

En Cartagena, a 13 de octubre de 2020

EL/LA DIRECTOR/A DE LA TESIS

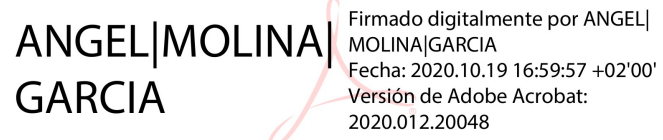

Fdo.: Ángel Molina García 


\section{CONFORMIDAD DE DEPÓSITO DE TESIS DOCTORAL POR LA COMISIÓN ACADÉMICA DEL PROGRAMA}

D. Francisco Vera García, en representación del Presidente/a de la Comisión Académica del Programa Energías Renovables y Eficiencia Energética.

\section{INFORMA:}

Que la Tesis Doctoral titulada, "New contributions to frequency control based on virtual synchronous generators: application to power systems with high renewable energy sources integration ", ha sido realizada, dentro del mencionado Programa de Doctorado, por $\mathrm{D}^{\mathrm{a}}$. Ana Fernández Guillamón, bajo la dirección y supervisión del Dr. Ángel Molina García y Dr. José Ignacio Sarasúa Moreno.

En reunión de la Comisión Académica, visto que en la misma se acreditan los indicios de calidad correspondientes y la autorización del Director/a de la misma, se acordó dar la conformidad, con la finalidad de que sea autorizado su depósito por el Comité de Dirección de la Escuela Internacional de Doctorado.

\ Evaluación positiva del plan de investigación y documento de actividades por el Presidente de la Comisión Académica del programa (RAPI).

La Rama de conocimiento por la que esta tesis ha sido desarrollada es:

Ciencias

Ciencias Sociales y Jurídicas

$\otimes \quad$ Ingeniería y Arquitectura

En Cartagena, a 13 de octubre de 2020

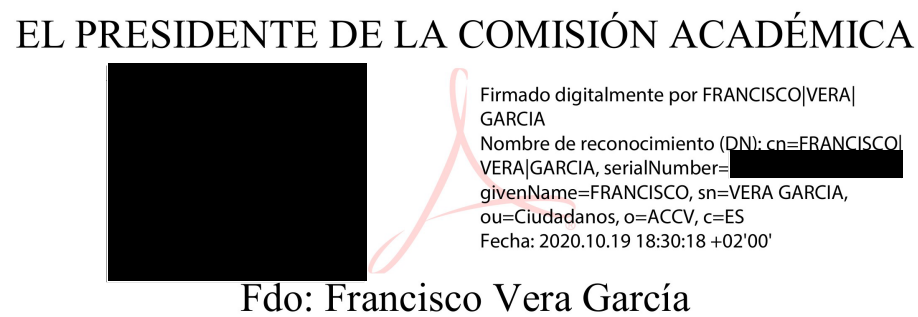


Visto el informe favorable del Director de Tesis y el o Bo de la Comisión Académica del Programa de Doctorado "Energías Renovables y Eficiencia Energética" para la presentación de la Tesis Doctoral titulada: "New contributions to frequency control based on virtual synchronous generators: application to power systems with high renewable energy sources integration" solicitada por DÑA. ANA FERNÁNDEZ GUILLAMÓN, el Comité de Dirección de la Escuela Internacional de Doctorado de la Universidad Politécnica de Cartagena, en reunión celebrada el 26 de octubre de 2020, considerando lo dispuesto en el artículo 23 del Reglamento de Estudios Oficiales de Doctorado de la UPCT, aprobado en Consejo de Gobierno el 17 de diciembre de 2015,

\section{ACUERDA}

Autorizar la presentación de la Tesis Doctoral a Dña. Ana Fernández Guillamón en la modalidad de "compendio de publicaciones".

Contra el presente acuerdo, que no agota la vía administrativa, podrá formular recurso de alzada ante el Sr. Rector-Magnífico de la Universidad Politécnica de Cartagena, en el plazo de un mes a partir de la notificación de la presente.

Cartagena, 26 de octubre de 2020

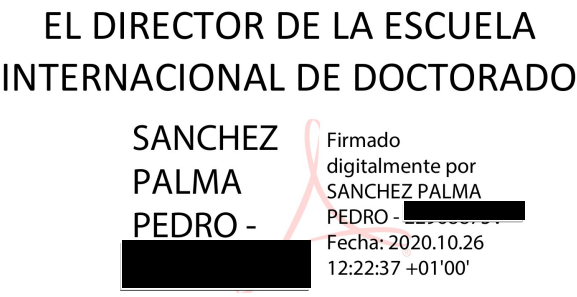

Fdo.: Pedro Sánchez Palma 


\section{General overview}

1 Motivation \& Objectives 1

2 State of the art 3

$\begin{array}{llr}3 & \text { Published papers } & 17\end{array}$

3.1 Power systems with high renewable energy sources: A review of inertia and frequency control strategies over time . . . . . . . . 17

3.2 An adaptive frequency strategy for variable speed wind turbines: application to high wind integration into power systems . . . . . 35

3.3 Fast power reserve emulation strategy for VSWT supporting frequency control in multi-area power systems . . . . . . . . . 59

3.4 Frequency control analysis based on unit commitment schemes with high wind power integration: A Spanish isolated power system case study . . . . . . . . . . . . . . . . . . 81

3.5 Analysis of power system inertia estimation in high wind power plant integration scenarios . . . . . . . . . . . 97

3.6 An adaptive control scheme for variable speed wind turbines providing frequency regulation in isolated power systems with thermal generation . . . . . . . . . . . . . . . . 109

3.7 Hybrid wind-PV frequency control strategy under variable weather conditions in isolated power systems . . . . . . . . . . . 131

3.8 Extensive frequency response and inertia analysis under high RES integration scenarios: application to the European interconnected power system . . . . . . . . . . . . . . . . . . 159

4 Conclusions

5 References 



\section{Motivation \& Objectives}

Over the last decades, most countries have been suffering an electrical energy transition, changing from a model based on non-renewable sources (mainly based on fossil fuels), to a new framework characterised by the integration of renewable energy resources (RES). These important changes have been mainly supported by the development of power electronics, environmental protection policies, and the need to reduce energy dependence on third countries. Moreover, the electrical sector stands out because of the diversity and heterogeneity of sources that can generate electricity. As a result, the current electrical scenario includes a high interest in the integration of variable renewable energy sources (vRES) shifting towards a new generation mix. In fact, these vRES (mainly photovoltaic and wind power installations) already play a relevant role, as some European countries have experienced generation levels over 50\% during some time-periods of last years.

As aforementioned, the two most mature renewable resources integrated into power systems are solar photovoltaic (PV) and wind power (especially variable speed wind turbines, VSWTs). Together with the integration of these two sources, and in contrast to traditional grids based on conventional power plants (i.e., hydro-power, thermal, and nuclear power plants), several important issues have emerged, needing to be analysed, assessed, and resolved. The main concerns include: $(i)$ the reduction of the synchronous inertia of the power system due to the connection of vRES to the grid by means of inverters; (ii) fast power fluctuations because of the variable and 'unpredictable' natural resource (i.e., wind speed and solar irradiation) of vRES; and (iii) the dependence of vRES on the times when the natural resource is available, thus needing some reserves as conventional power plants. Moreover, these problems affect at different time-horizons: very short term (inertia reduction), short-medium term (fluctuations of natural resource) and long term (absence of natural resource). This $\mathrm{PhD}$ focuses on the two first concerns, as the system inertia emerges as a fundamental parameter of the system, affecting the frequency deviations because of power imbalances between generation and demand.

The system inertia is usually understood as rotating elements directly connected to the grid. In fact, these rotating masses (basically generators and synchronous turbines of conventional power plants) have traditionally been responsible for counteracting power imbalances by modifying their rotational speed, subsequently affecting the system frequency. However, with the integration of vRES and the subsequent reduction of the system inertia, it is necessary to study and propose new solutions that allow: $(i)$ to maintain the stability of the electrical systems, and $(i i)$ to soften the frequency excursions that will increase as the inertia of the system decreases. Due to the recent changes suffered by electrical power 
systems in terms of generation mix, ancillary services (such as grid frequency regulation and maintenance, electrical demand supply or spinning reserves) must be shared by all the generation units (instead of only by conventional power plants).

Under this new scenario, it is necessary to develop and adapt new tools and solutions that facilitate the integration of vRES without reducing the capacity of the grid in terms of stability and response to contingencies. Indeed, all the peculiarities and characteristics of vRES must be addressed before proceeding to their massive integration and, therefore, to their independence from conventional power plants based on non-renewable sources. As a result, over the last few years, a line of research that aims to include frequency control and inertial response (IR) with vRES has emerged. In this way, concepts such as 'virtual inertia', 'emulated inertia' and 'hidden inertia' have been developed, with the aim of providing new lines of work to ensure the stability of the power system. In addition, and because of the variable nature of vRES generation units, it is also important for transmission and distribution system operators (TSOs/DSOs) to ensure some power reserves to allow them to act efficiently and faithfully after power imbalances.

The main objective of this $\mathrm{PhD}$ thesis is the study, analysis and evaluation of electrical power systems with high penetration of vRES in order to assess possible solutions to emulate virtual inertia and similar responses to those that would be obtained with conventional power plants. This would allow to effectively integrate vRES to the frequency control of the grid. Therefore, the solutions proposed, studied, and analysed here would ease the massive integration of vRES, maintaining the stability of power systems. Subsequently, it would be possible to gradually replace conventional power plants, by emulating their response with vRES. As a result, the grid would offer the same reliability. These solutions will make possible to promote the large-scale integration of vRES, increasing the share of generation from vRES without this implying a loss of characteristics with respect to classic approaches of the stability of the grid. This is therefore a current issue and totally necessary for the large-scale integration of renewable resources, which is the next and natural step within power systems. 


\section{State of the art}

Over the last decades, power systems have evolve, replacing pollutant generation units (fossil fuels and nuclear) by RES [15], as depicted in Figure 1. As can be seen, fossil fuels and nuclear power plants represented more than $80 \%$ of total electricity supply in 1990, both in the world and in Europe. However, in 2017, more than 25\% and $30 \%$ of electricity generation was provided by RES (including hydro-power, vRES (PV and wind power plants), and others (such as geothermal, solar thermal, biomass, and waste)), respectively. Even though their generation shares are still quite low, ambitious road-maps are being nowadays proposed in order to increase the electrical supply from RES, especially vRES. Examples of several road-maps until year 2050 can be found in [16-18]. In Figure 2, the expected national trends for the electrical supply in Europe in 2025, 2030, and 2040 are shown, expecting that in 2040 more than $75 \%$ of the electricity of Europe will come from RES.

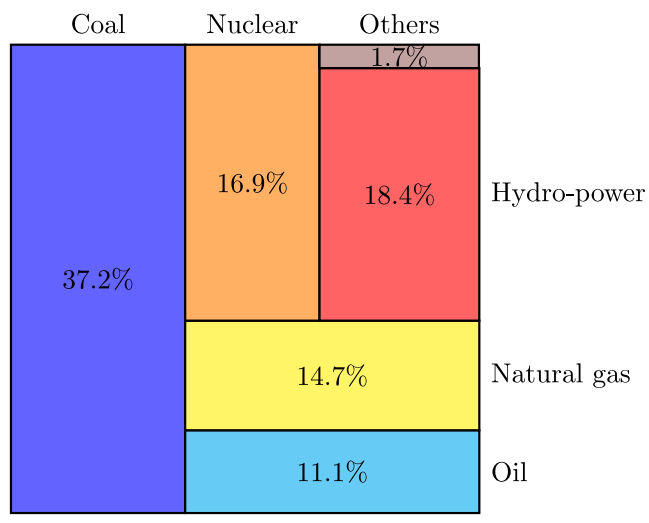

(a) World 1990

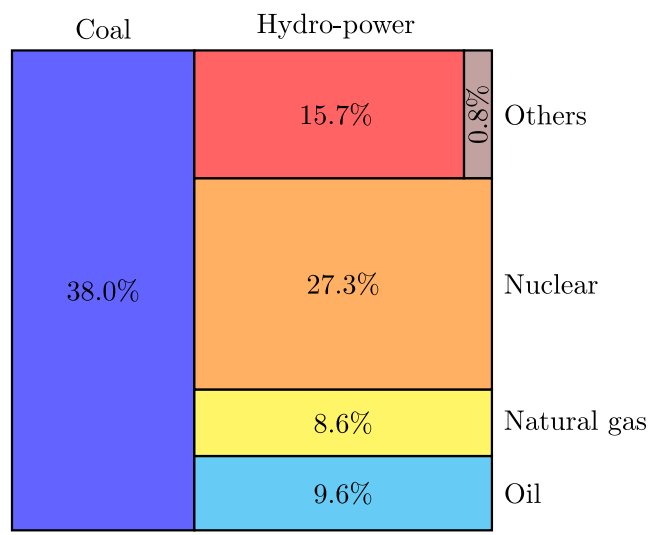

(c) Europe 1990

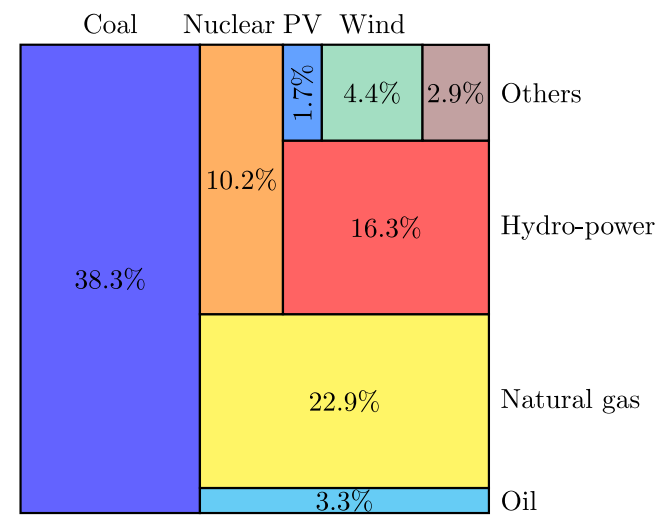

(b) World 2017

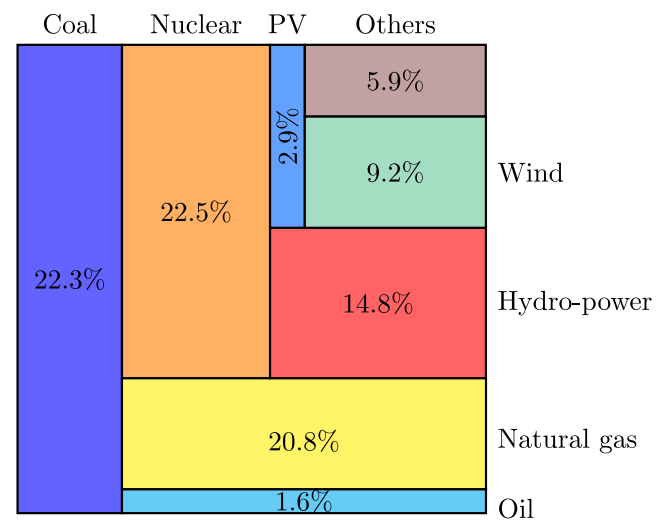

(d) Europe 2017

Figure 1: Evolution of electricity generation. Data from [19]

This important supply-side change is because of the fact that RES can provide an acceptable solution for two important issues of the electricity generation. The first one is related with greenhouse gas emissions (especially $\mathrm{CO}_{2}$ ), as the fossil 


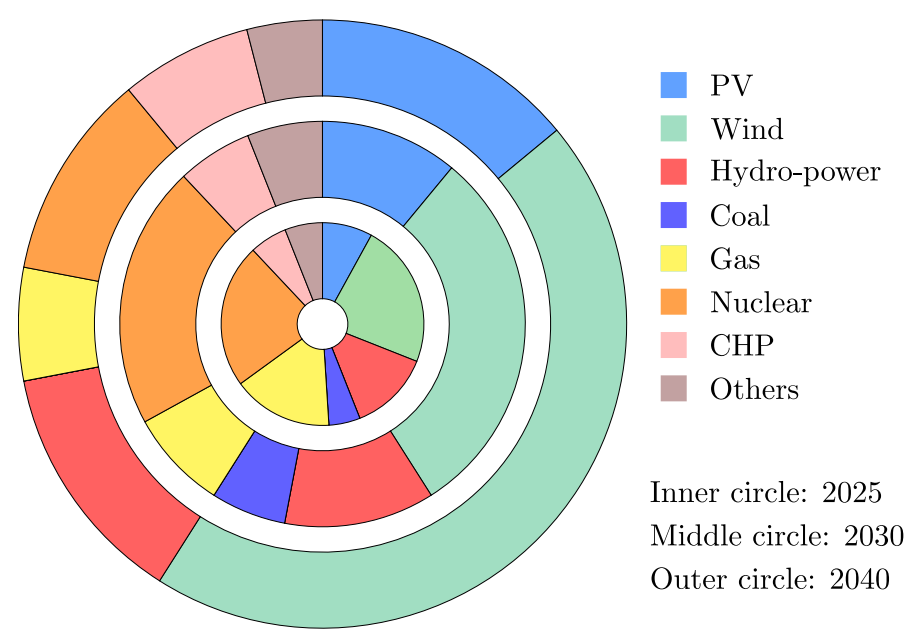

Figure 2: Expected electrical supply in Europe following the national trends

fuels' combustion is considered as the main source of such emissions [20]. In fact, fossil fuels' combustion has been increasing non-stop since 1990 [21]. As a consequence, and in order to fulfil the Paris agreement target (limit the increase of the global average temperature below $2^{\circ} \mathrm{C}$ above the pre-industrial levels), the electricity generation should be de-carbonised by 2050 [22,23]. The other one is mitigating the importation of fuels from other countries [24]. After the oil crises of the 70s, countries started to be aware about the importance of being energy-independent because of the risky consequences of supply disruptions [25]. In fact, depending on third countries means that the electricity supply security is linked to market liberalisation, political stability, and foreign affairs [26]. As a result, the lower the fuel dependence, the better the electricity supply security [27].

However, there are also important problems that should be considered before the massive integration of vRES into the grid [28]. These problems involve the nondispatchable, variable, and unpredictable nature of vRES due to their dependence on weather conditions [29,30]; and the use of power electronics to connect them to the grid [31]. The variable behaviour of vRES pose stress on the operation of power systems [32,33]. In fact, due to the stochastic weather conditions (i.e., wind speed for wind power plants, and solar radiation and temperature for PV), important power variations within small time-periods can occur, causing significant ramps up/down (or even start up/shut down) of conventional power plants [34,35]. As a result, TSO/DSO have to deal with not only the uncontrollable demand, but also uncontrollable generation [36].

The use of inverters to connect vRES to power systems make these generation units to be 'electrically decoupled' from the grid [37]. Indeed, the rotating inertia of the power system may be drastically reduced under high vRES penetration rates [38]. Even though VSWTs store kinetic energy in their blades, drive train, and electrical generators, they cannot naturally provide it to the grid due to the 
power inverter [39]. On the other hand, PV power plants are static elements, subsequently having no stored kinetic energy [40].

The combination of inertia reduction and the non-dispatchable nature of vRES will significantly affect the system reliability in terms of frequency deviations [41]. In fact, the rotational inertia is related to both nadir (minimum frequency) and the rate of change of frequency (ROCOF) [42]. Hence, low rotational inertia values are related with low-frequency nadir values, and steeper (faster) ROCOFs [43]. Large frequency deviations can cause the activation of load shedding programs, generation tripping, and even wide-spread blackouts [44], especially in small isolated power systems [45]. As a consequence, it is important that frequency is kept as closer as possible to its nominal value for the secure operation of any power system [46]. Indeed, the European Normative (EN) entitled Voltage Characteristics in Public Distribution Systems (EN 50160) establishes the maximum frequency variations for interconnected and isolated power systems (refer to Tables 1 and 2) [47]. Loadfrequency control is one of the most crucial ancillary services (AS) [48]. AS involve the different services needed for a reliable and secure power system, including active power and load-frequency control, reactive power and voltage support, harmonics rejection, spinning reserves, and system protection [49-51].

\begin{tabular}{ccc}
\hline$\%$ Variation & Range & Time \\
\hline $50 \pm 1 \%$ & $49.5-50.5 \mathrm{~Hz}$ & $99.5 \%$ of a year \\
$50+4 \% /-6 \%$ & $47-52 \mathrm{~Hz}$ & $100 \%$ \\
\hline
\end{tabular}

Table 1: Interconnected power systems [47]

\begin{tabular}{ccc}
\hline \% Variation & Range & Time \\
\hline $50 \pm 2 \%$ & $49-51 \mathrm{~Hz}$ & $95 \%$ of a week \\
$50 \pm 15 \%$ & $42.5-57.5 \mathrm{~Hz}$ & $100 \%$ \\
\hline
\end{tabular}

Table 2: Isolated power systems [47]

Frequency control (FC) tries to reduce the effects of unpredictable power imbalances between generation and consumption [52]. Actually, it requires that generation units increase/decrease their generation to the grid, in order to match it with the total power demand (plus the power system losses) [53]. In Europe, FC has a hierarchical structure, usually organised in primary (frequency containment reserves), secondary (frequency restoration reserves), and tertiary (replacement reserves) control [54], as depicted in Figure 3. Moreover, conventional generation 


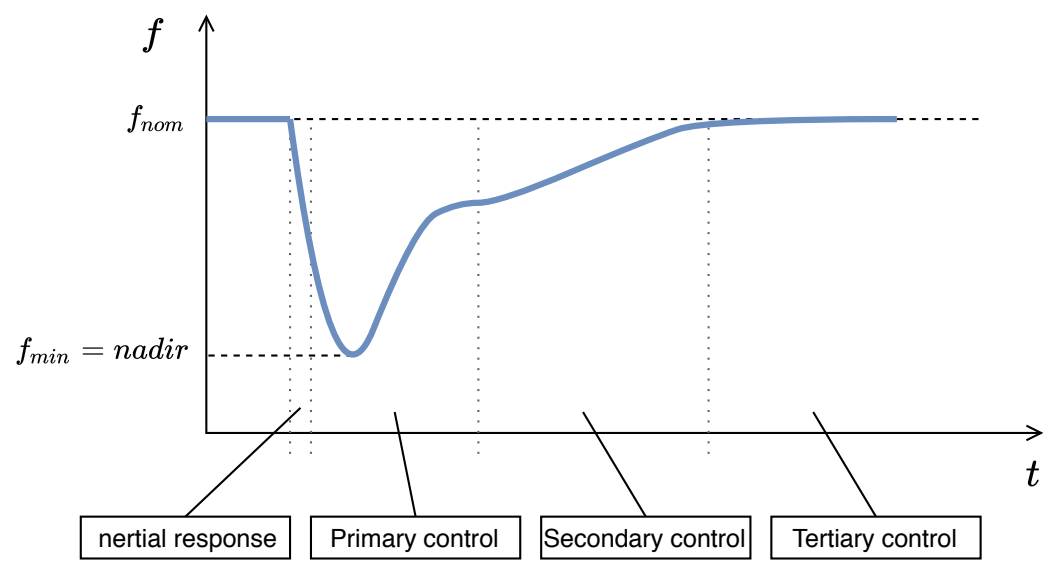

Figure 3: Frequency evolution and controls

units (based on synchronous generators) inherently release or absorb kinetic energy $E_{k i n}$ as an IR to frequency deviations $[55,56]$. This $E_{k i n}$ is calculated following eq. (1):

$$
E_{\text {kin }}=\frac{1}{2} J \omega_{r}^{2}
$$

where $J$ is the moment of inertia and $\omega_{r}$ is the rated rotational frequency of the machine. In electrical grids, it is preferable to use the inertia constant $H$ instead of the moment of inertia $J$. The inertia constant $H$ determines the time interval during which an electrical generator can supply its rated power only by using the kinetic energy $E_{k i n}$ stored in its rotating masses [57]. $H$ is defined following eq. (2), being $S_{r}$ its rated power [58]:

$$
H=\frac{E_{k i n}}{S_{r}}=\frac{1}{2} \frac{J \omega_{r}^{2}}{S_{r}} .
$$

Usually, the inertia constants $H$ of conventional power plants range in between 2 and $10 \mathrm{~s}$ [59].

Primary frequency control (PFC) is locally and automatically activated by the generator's governor within a few seconds after the imbalance. The target of PFC is to balance generation and consumption, thus stabilising the grid frequency to some extent. With this aim, those generators that provide PFC must have some power reserves to deploy (primary frequency reserves, PFR). The power response of the involved generators is proportional to the locally measured frequency deviation $\Delta f$, following eq. (3), being $R$ the droop characteristic [60-63].

$$
\Delta P=-\frac{\Delta f}{R}
$$

According to the European Network of Transmission System Operators for Electricity (ENTSO-E), there is also a dead-band, lying in between $10-30 \mathrm{mHz}$, in which PFC is not activated. ENTSO-E also recommends that the droop $R$ ranges 
2-12\% [64]. Figure 4 depicts the primary frequency response capability of a conventional power plant.

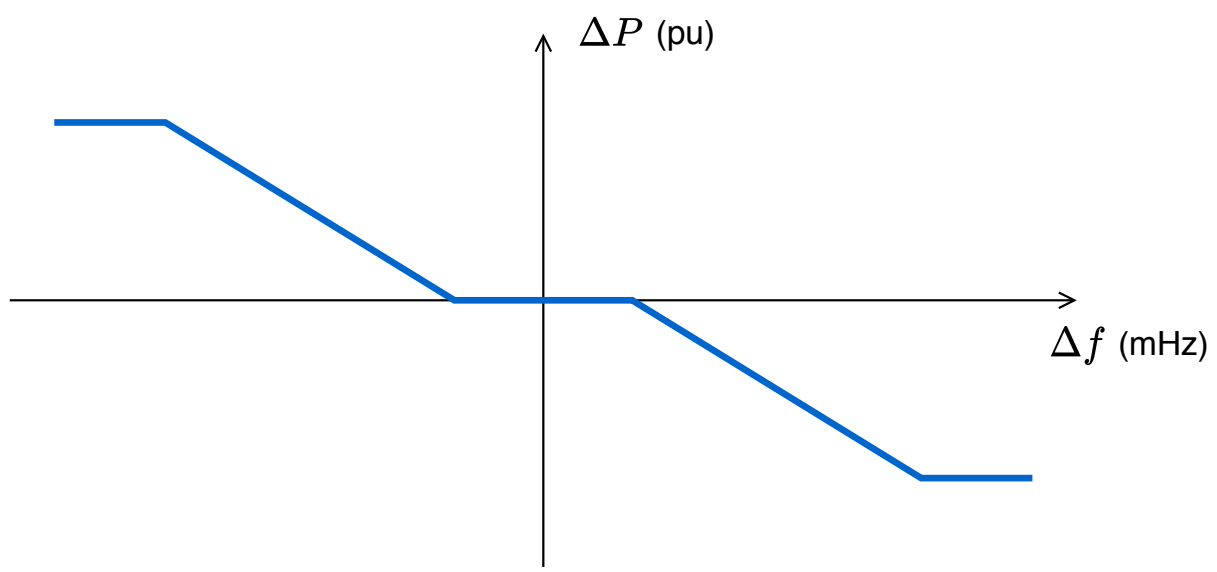

Figure 4: Primary frequency response capability

As the PFC is based on the droop of the generator's governor to be automatic and fast, it implies a permanent error of frequency. Thus, a secondary frequency control (SFC) is needed. SFC is also automatic, and ensures that frequency deviation of the grid goes back towards zero. It is in charge of modifying the nominal set-point of the power plants involved in the SFC (as not all the power plants participate in it), and is usually carried out by an integral controller. The automatic generator control (AGC) coordinates the SFC effort's dispatch among the different conventional power plants that participate in the SFC. Moreover, in case of interconnected power systems, the AGC also restores inter-area power flows exchanges [65-68]. Figure 5 shows the frequency deviation of the same power system by only considering the PFC or both PFC and SFC.

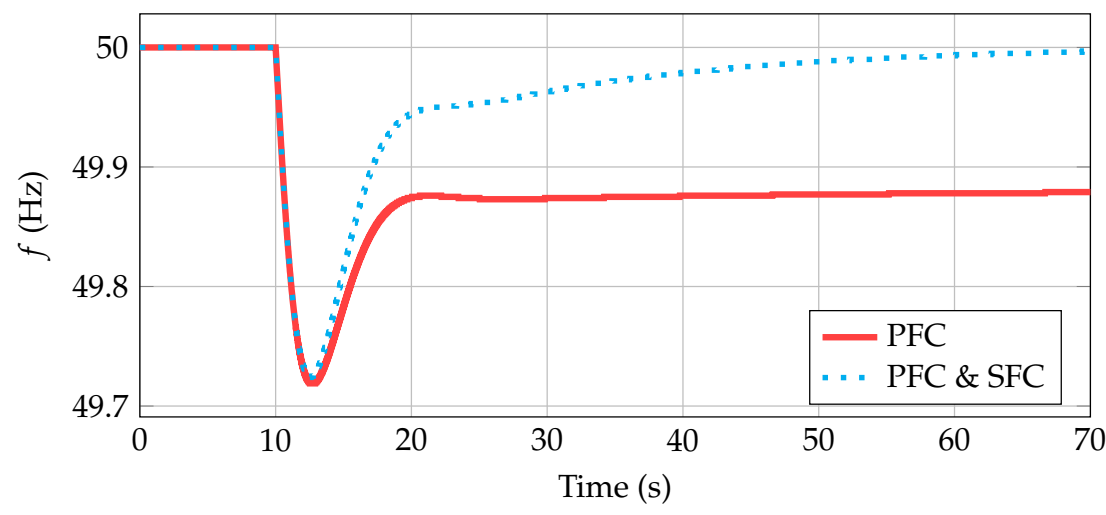

Figure 5: Frequency deviation with PFC and PFC \& SCF

Finally, the tertiary frequency control (TFC) is manually activated. It is in charge of the economic operation of the power system (economic dispatch or unit 
commitment), and to restore primary and secondary frequency reserves. Moreover, if SFC was not able to restore frequency to its nominal value, the TFC will carry out this task [69-73]. As this control is performed manually, it is not usually considered for frequency simulation purposes.

Figure 6 depicts the main blocks needed to analyse frequency deviations in electrical grids by considering an inertial model, in which transmission lines are neglected and frequency is assumed to be exactly the same in the different nodes. This assumption was proposed in classical power system stability books [74, 75]. These blocks include conventional power plants and vRES, the power system, and the frequency control. As nowadays vRES do not usually participate in frequency control, the link between the 'Frequency control' block and 'Variable renewable energy sources' block is dotted. As can be seen from Figure 6, the output of the power system block is the $\Delta \omega_{r}$, which is equal to the frequency deviation of the grid $\Delta f$ when a per unit system is used.

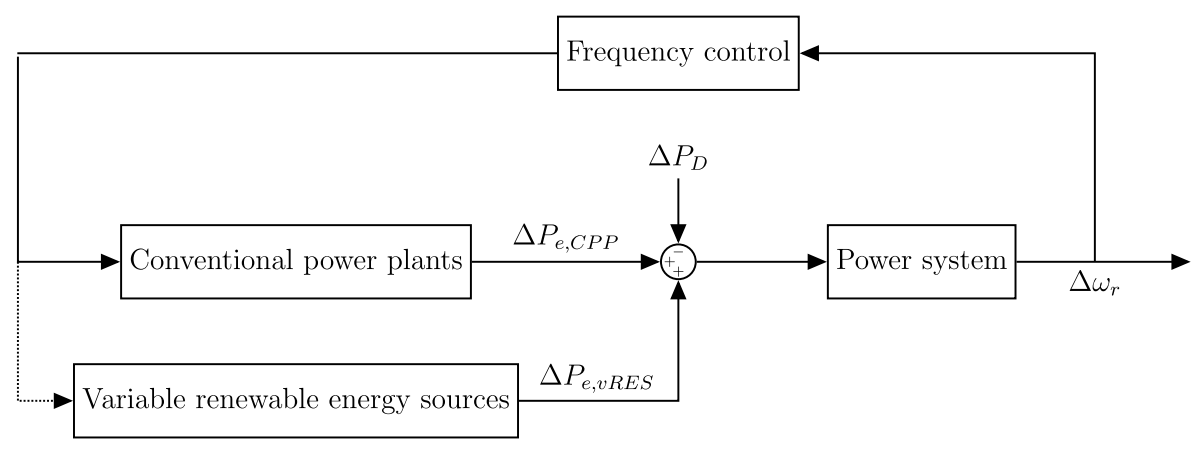

Figure 6: General block diagram of a electrical grid with frequency control

In a power system, the rotational motion of each turbine-generator group follows eq. (4):

$$
2 H \frac{d \omega_{r}}{d t}=T_{m}-T_{e}
$$

being $T_{m}$ and $T_{e}$ the mechanical torque of the turbine and the electromagnetic torque of the generator, respectively. As $P=T \cdot \omega$ and considering the initial status as 0 :

$$
P=P_{0}+\Delta P=\left(T_{0}+\Delta T\right) \cdot\left(\omega_{r 0}+\Delta \omega_{r}\right)
$$

where $\Delta P=\Delta P_{m}-\Delta P_{e}$ and $\Delta T=\Delta T_{m}-\Delta T_{e}$. Moreover, for small variations:

$$
\Delta P \simeq T_{0} \cdot \Delta \omega_{r}+\Delta T \cdot \omega_{r 0}
$$

and in steady-state:

$$
\begin{aligned}
& T_{m 0}=T_{e 0}, \\
& \omega_{r 0}=1 \mathrm{pu} .
\end{aligned}
$$


As a result, by considering small variations around the steady-state, eq. (4) can be re-written as in eq. (5) [76]:

$$
2 H \frac{d \Delta \omega_{r}}{d t}=\Delta P_{m}-\Delta P_{e} .
$$

Moreover, there are some electrical loads which can also change their consumed power depending on the frequency value, thus working as a load resource under frequency deviations (i.e., synchronous machines). In this way, the electrical power can be expressed as:

$$
\Delta P_{e}=\Delta P_{L}+D \cdot \Delta \omega_{r}
$$

where $\Delta P_{L}$ is the power change of those loads independent from frequency deviations, and $D$ is the damping factor (load-frequency response of loads). Subsequently, by considering this frequency dependence of loads, eq. (5) is modified to eq. (7), which is usually referred to as the swing equation:

$$
2 H \frac{d \Delta \omega_{r}}{d t}=\Delta P_{m}-\left(\Delta P_{L}+D \cdot \Delta \omega_{r}\right)
$$

Power systems are also simulated by means of the swing equation [77]. In this case, all synchronous generators of such grid are grouped in an equivalent rotating mass, with an equivalent inertia constant $H_{e q}$. This $H_{e q}$ is estimated with:

$$
H_{e q}=\frac{\sum_{i=1}^{S G} H_{i} \cdot S_{B, i}}{S_{B}},
$$

where $H_{i}$ and $S_{B, i}$ are the inertia constant and rated power of synchronous generator $i$ (respectively), $S G$ is the total number of synchronous generators connected to the grid, and $S_{B}$ is the rated power of the power system. In the same way, loads are reduced to an equivalent one with damping factor $D_{e q}$. Hence, the swing equation for a power system would be:

$$
2 H_{e q} \frac{d \Delta \omega_{r}}{d t}=\Delta P_{e}-\left(\Delta P_{D}+D_{e q} \cdot \Delta \omega_{r}\right)
$$

where $\Delta P_{e}$ is the variation of the active power provided by all the generation units (regardless of being conventional or vRES), and $\Delta P_{D}$ is the variation of the demandside power consumption. Applying the Laplace transform to eq. (9), the block diagram of Figure 7 is obtained.

In case of interconnected power systems, together with the considerations previously mentioned, the tie-line power exchange between areas is determined by:

$$
\Delta P_{t i i_{i, j}}=\frac{2 \cdot \pi \cdot T_{i, j}}{s} \cdot\left(\Delta \omega_{r_{i}}-\omega_{r_{j}}\right)
$$




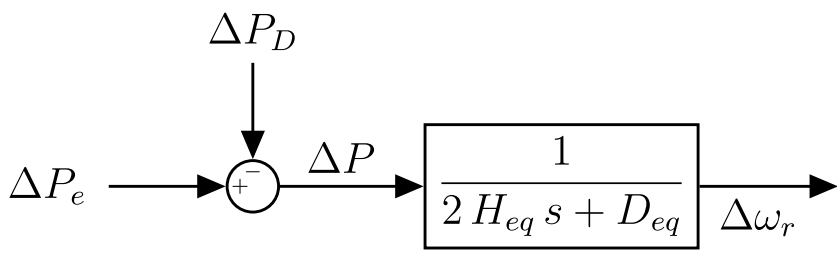

Figure 7: Swing equation of a power system

where $T_{i, j}$ is the synchronising moment coefficient of the tie-line between $i$ and $j$ areas [78]. When there is a frequency deviation in one area, the balance between the interconnected power system is determined by generating the area control error signal (ACE), expressed as a linear combination of the tie-line power exchange and the frequency deviation [79]:

$$
A C E_{i}=B_{i} \cdot \Delta \omega_{r_{i}}+\sum_{\substack{j=1 \\ j \neq i}}^{N} \Delta P_{t i e_{i, j}},
$$

where $i, j$ refers to $i$ and $j$ areas, respectively, $B$ is the bias-factor, $\Delta P_{\text {tie }}$ is the variation in the exchanged tie-line power and $N$ is the total number of interconnected areas. Figure 8 shows an scheme of these power exchanges for a three-area power system.

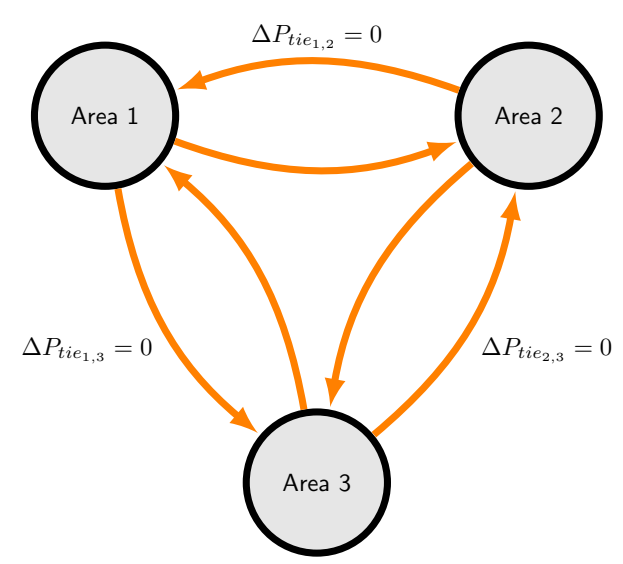

(a) Balanced situation

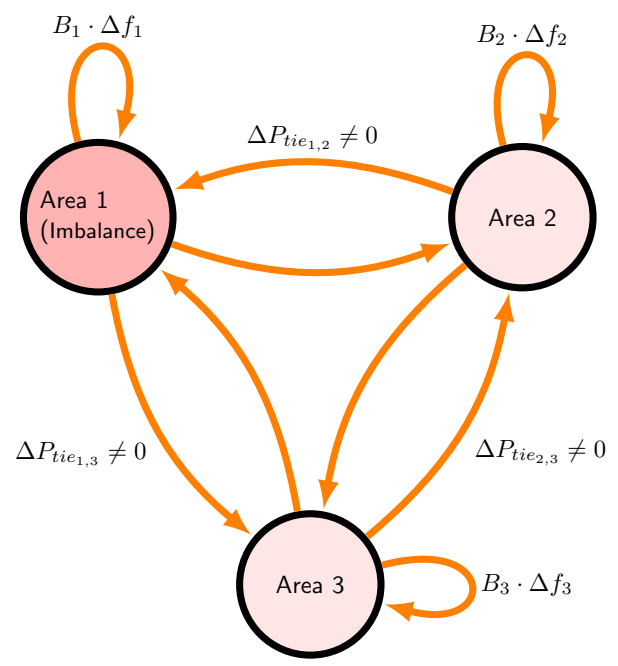

(b) Imbalanced situation in area 1

Figure 8: Multi-area power system. General overview under frequency deviations

As already mentioned, the absence of rotational parts in PV plants make them to have an inertia constant $H \approx 0$ [80]; and the stored kinetic energy (and, subsequently, deployable inertia) of VSWT is not seen from the power system due to the power inverter [81]. As a consequence, the more the vRES penetration into a power system, the weaker it will be in terms of frequency stability due to the 
reduction of $H_{e q}[82,83]$. According to ENTSO-E, conventional power systems used to have an $H_{e q}$ between 5 and $6 \mathrm{~s}$; and the minimum recommended equivalent inertia should be in the range $2-3 \mathrm{~s}[84,85]$. As a consequence, the maximum penetration of vRES for this $H_{e q, \min }$ is between 50-70\%, as depicted in Figure 9. In fact, some authors affirm that with current vRES technologies, only $50 \%$ of the overall electricity demand can be provided by them, which is in line with values presented in Figure 9 [86, 87].

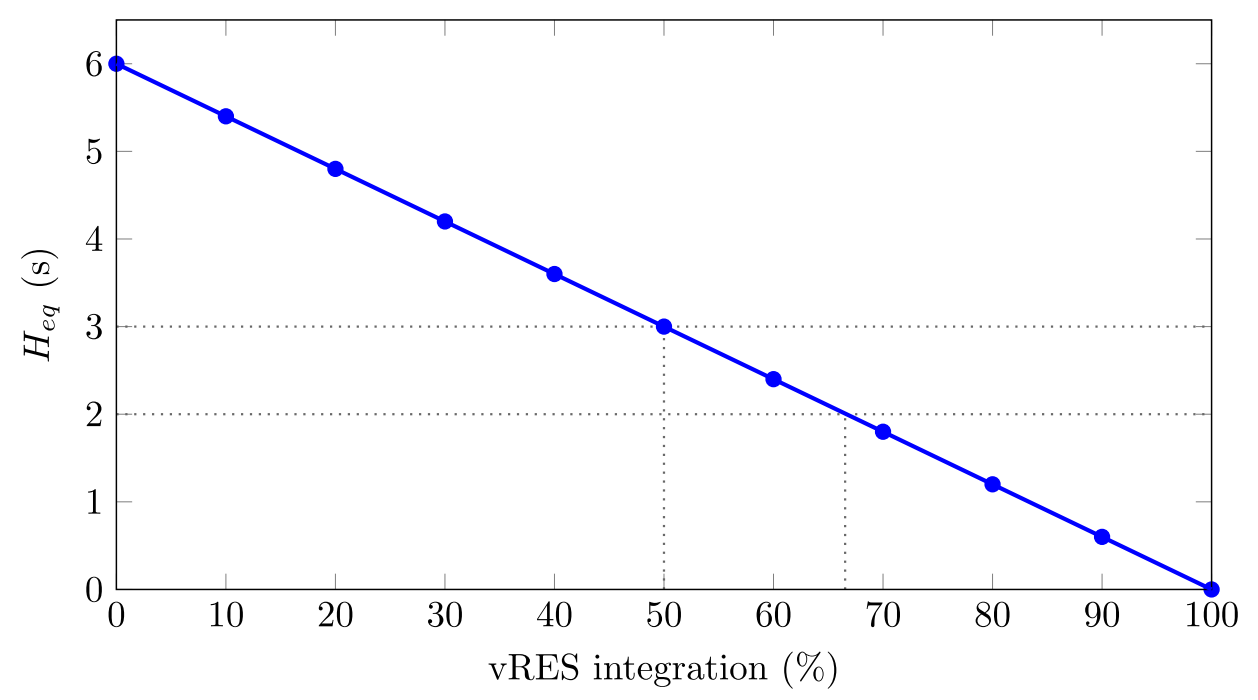

Figure 9: Evolution of $H_{e q}$ depending on the vRES integration

Traditionally, $H_{e q}$ was considered as time-independent. However, nowadays, because of the variation of electricity generation with vRES throughout the day, season of the year, etc., the equivalent inertia constant is assumed to change with the time. In fact, [88] presented the inertia variation of the German power system in 2012. The cumulative frequency curve of such data is presented in Figure 10. It can be seen that the maximum $H_{e q}$ was $6 \mathrm{~s}$, in line with the maximum value given by ENTSO-E. Half of the year, the equivalent inertia was under $5.7 \mathrm{~s}$; and only $10 \%$ of the year, the equivalent inertia constant was lower than $5 \mathrm{~s}$.

In Figure 11, the frequency excursion after a power imbalance $\Delta P=5 \%$ in $t=10$ $\mathrm{s}$ is depicted. It is assumed that the power system consist of reheat thermal $\left(H_{T}=6.7\right.$ s), hydro-power plants $\left(H_{H}=4 \mathrm{~s}\right)$ and vRES. vRES are not providing any inertial nor frequency response. The base power of the isolated power system simulated is $S_{B}=100 \mathrm{MW}$. In the first case under analysis (red continuous line in Figure 11), $80 \%$ of the total power was provided by the thermal power plants ( $80 \mathrm{MW}), 15 \%$ was provided by the hydro-power plants (15 MW), and $5 \%$ came from vRES (5 MW). In the other case (blue dotted line in Figure 11), 25\% of the total power was provided by the thermal power plants $(25 \mathrm{MW}), 15 \%$ was provided by the hydropower plants $(15 \mathrm{MW})$, and 60\% came from vRES (60 MW). As a consequence, the equivalent $H_{e q}$ estimated with eq. (8) reduces from 6 s to $2.3 \mathrm{~s}$. As can be seen, 


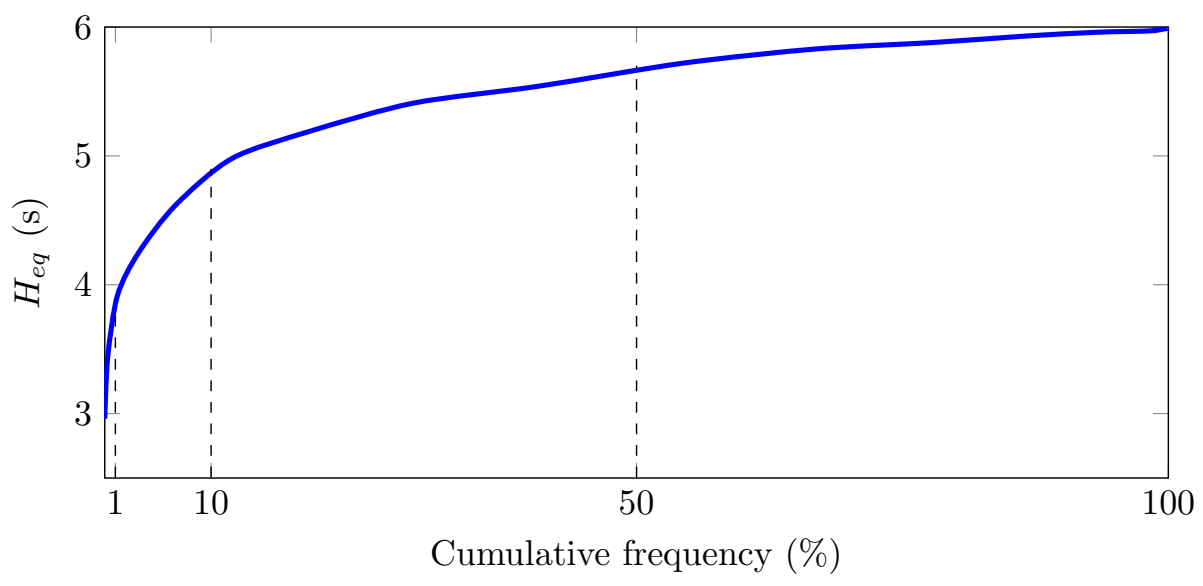

Figure 10: Cumulative frequency of $H_{e q}$ in Germany in 2012

this equivalent inertia reduction causes a larger nadir $\left(49.7 \mathrm{~Hz}\right.$ for $H_{e q}=6 \mathrm{~s} ; 49.4$ $\mathrm{Hz}$ for $\left.H_{e q}=2.3 \mathrm{~s}\right)$ and a steeper ROCOF $\left(180 \mathrm{mHz} / \mathrm{s}\right.$ for $H_{e q}=6 \mathrm{~s} ; 426 \mathrm{mHz} / \mathrm{s}$ for $\left.H_{e q}=2.3 \mathrm{~s}\right)$.

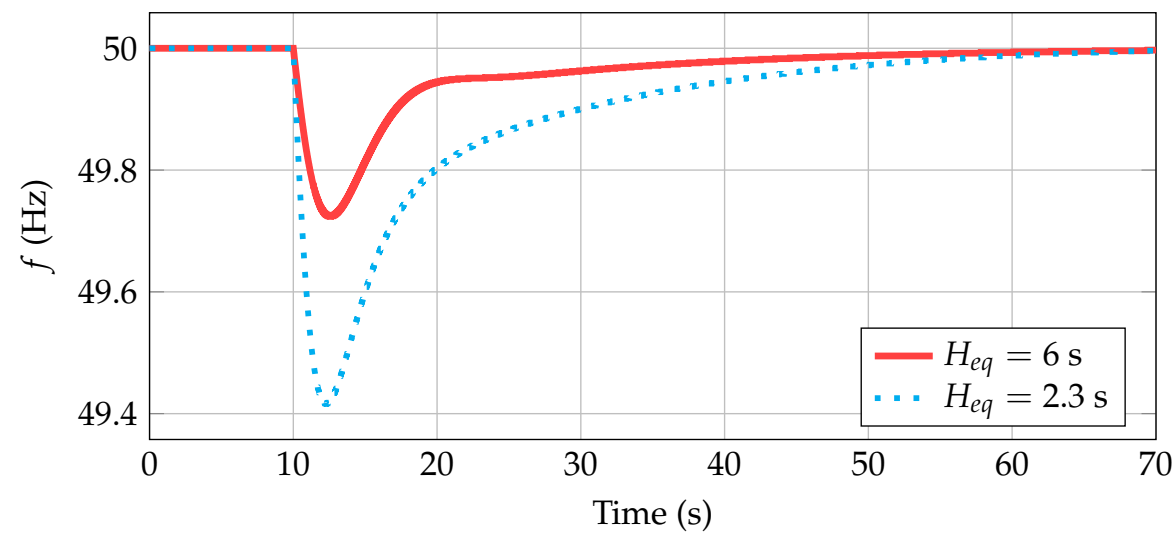

Figure 11: Frequency deviation depending on the $H_{e q}$

As a consequence, in order to avoid (or, at least, minimise) the negative effects of vRES into power systems in terms of frequency stability, concepts such as 'virtual inertia', 'synthetic inertia', 'hidden inertia', and 'emulated inertia' have been under discussion over the last decade [89-92]. Even though these terms have similar meanings, it is important to remark that VSWTs have some inertia based on the kinetic energy stored in their blades, drive train and electrical generators (hidden inertia); whereas PV has no inertia due to the absence of rotating masses (synthetic/virtual/emulated inertia). These terms aim to ensure the stability of the power system by including frequency control and/or IR with vRES. In fact, several strategies have been proposed in the specific literature to allow vRES to participate in frequency control, both for PV and VSWTs power plants, as depicted in Figure 
12. Also energy storage systems have been considered as suitable options to improve the frequency deviations after power imbalances. These strategies will be later explained and detailed within the papers included in this $\mathrm{PhD}$, which focuses on the emulation of inertia and frequency integration of vRES into the grid.

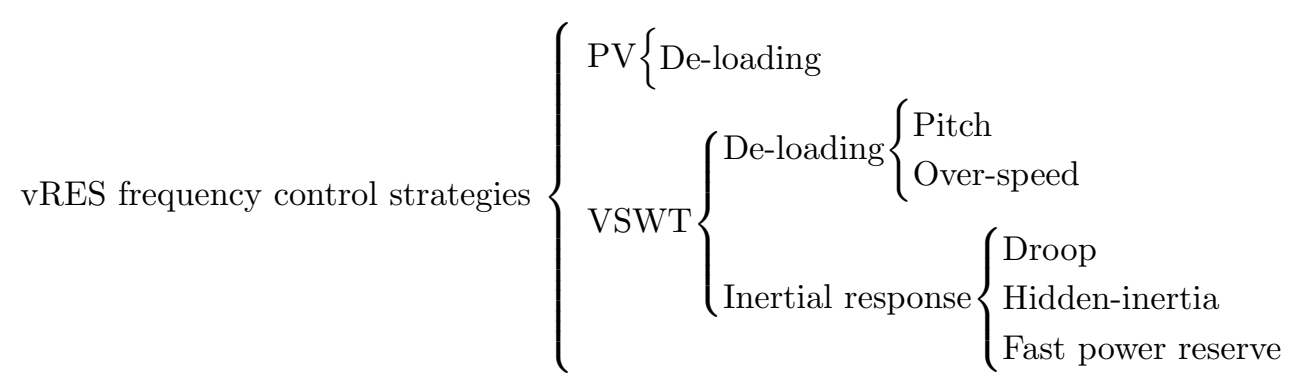

Figure 12: Inertial and frequency control techniques for vRES

- Power systems with high renewable energy sources: A review of inertia and frequency control strategies over time

An extensive review on damping factor values and inertia constants of conventional power plants and VSWT is carried out. An strategy to estimate the equivalent inertia of a power system is also presented. In addition, the different PV and VSWT techniques to participate in inertial and/or frequency control are presented.

- An adaptive frequency strategy for variable speed wind turbines: application to high wind integration into power systems.

A new fast power reserve strategy is proposed for VSWT frequency control. It is tested in an isolated power system made up of thermal, hydro-power and VSWTs following current and future road-maps. Comparing with the current situation (VSWTs do not participate in frequency control), nadir was reduced around 50\%. Moreover, the secondary frequency dip was also improved compared to a previous approach.

- Fast power reserve emulation strategy for VSWT supporting frequency control in multi-area power systems.

The fast power reserve strategy previously proposed was also tested in an interconnected power system of two and three areas. The nadir reductions were maximised (between $40 \%$ and $50 \%$ ) when only wind power plants within the area submitted to imbalances are considered. When wind power responses of all areas were considered, higher frequency oscillations and lower nadir reductions were reached.

- Frequency control analysis based on unit commitment schemes with high wind power integration: A Spanish isolated power system case study.

Frequency excursions are analysed under a realistic framework in the Gran Canaria Island's isolated power system (Spain). The loss of the largest 
conventional generation group is assumed, including a wind frequency control strategy, a load shedding program and realistic energy scenarios obtained from a unit commitment model. Results provide a variety of influences from wind frequency control depending not only on the wind power integration, but also the generation units under operation, the rotational inertia reductions as well as the available reserves from each resource.

- Analysis of power system inertia estimation in high wind power plant integration scenarios.

An analysis, comparison and discussion of the inertia estimation methodologies previously proposed have been carried out by considering the participation of VSWTs into frequency control. Results show that all methodologies considered give an accurate result to estimate the equivalent inertia when wind frequency control is not considered, as inertia was only provided by conventional power plants. However, when wind power plants participate in frequency control, only one methodology was able to estimate the new equivalent inertia as a combination of rotational and virtual inertias, obtaining that the virtual inertia constant of VSWT has a value of $H_{V, W T}=3.57 \mathrm{~s}$.

- An adaptive control scheme for variable speed wind turbines providing frequency regulation in isolated power systems with thermal generation.

A new VSWTs frequency control technique is proposed, determining the overproduction power of VSWTs according to different power system parameters. Results show that the new adaptive control reduces significantly the VSWTs maximum torque variations (23\%), and slightly the speed variations $(5 \%)$ in comparison to previous frequency control strategies, while maintaining similar values for the power shed with the load shedding program. As a result, a longer life span is expected for the VSWTs electrical and mechanical components.

- Hybrid wind-PV frequency control strategy under variable weather conditions in isolated power systems

A hybrid wind-PV frequency control strategy is proposed. VSWTs include a hidden-inertia emulation technique, and PV power plants are working with a $10 \%$ power de-loaded. The difference to previous PV frequency controllers is that the PV controller monitors the VSWTs rotational speed deviation, instead of the frequency deviation, as already proposed in the specific literature. The hybrid wind-PV scheme is compared to other frequency controllers, obtaining better results in terms of frequency deviation (reducing the mean squared error between 20 and 95\%) and rotational speed deviation 
of VSWTs. However, this hybrid strategy requires up to a $30 \%$ reduction in the PV generated energy.

- Extensive frequency response and inertia analysis under high RES integration scenarios: application to the European interconnected power system

An algorithm to estimate the minimum inertia needed to fulfil the ROCOF values following ENTSO-E recommendations is proposed and assessed. Also the additional active power needed to be within the frequency dynamic range is also estimated and determined. Both inertia and additional active power can come from different sources (such as storage solutions, renewable sources decoupled from the grid including some frequency control strategies, interconnections with other grids, or a combination of them). This methodology is applied to more than 700 generation mix scenarios. The results show that an additional power between 0 and $0.32 \mathrm{pu}$ is enough to avoid any frequency excursion lower than $49.2 \mathrm{~Hz}$, even if RES generation is over $50 \%$ and the power imbalance is $40 \%$. Considering a maximum additional inertia of $15 \mathrm{~s}$, the ROCOF values following the ENTSO-E requirements are fulfilled for $85 \%$ of the simulated scenarios. 



\section{Published papers}

\subsection{Power systems with high renewable energy sources: A review of inertia and frequency control strategies over time}

Traditionally, inertia in power systems has been determined by considering all the rotating masses directly connected to the grid. However, over the last decade, the integration of renewable energy sources has led to a significant dynamic characteristic change mainly due to the fact that most renewable sources have power electronics at the grid interface. Consequently, power systems become more dynamic and require a new set of strategies modifying traditional generation control algorithms. A detailed analysis of inertia constants of conventional power plants, considering their type of technology and rated power, as well as damping factors is conducted. The proposed inertia constants of wind turbines are also included. Averaged inertia constants are estimated for different regions and countries for the last two decades considering the electrical generation of each technology. The findings indicate that, nowadays, Europe presents a significant averaged inertia reduction -around $20 \%$ in the last two decades-, mainly due to the renewable integration decoupled from the grid -from $14 \%$ in 1996 to $31 \%$ in 2016-. The contribution of PV to frequency control in terms of storage systems and de-loading techniques are discussed. Inertial response and frequency control with VSWT are also presented, using storage systems, de-loading techniques and/or hidden inertia emulation approaches. The paper provides significant information for PV and wind turbines frequency control strategies and frequency stability studies of current power systems with high renewable energy source integration.

Information of the paper:

- Journal: Renewable and Sustainable Energy Reviews

- DOI: 10.1016/j.rser.2019.109369

- Date of publication: November 2019

- Available online: https://arxiv.org/pdf/2004.02951.pdf

- Reference: [1] 


\title{
Power systems with high renewable energy sources: a review of inertia and frequency control strategies over time
}

\author{
Ana Fernández-Guillamón ${ }^{\mathrm{a}}$, Emilio Gómez-Lázaro ${ }^{\mathrm{b}}$, Eduard Muljadic ${ }^{\mathrm{c}}$ Ángel Molina-García ${ }^{\mathrm{a}}$ \\ ${ }^{a}$ Dept. of Electrical Engineering, Universidad Politécnica de Cartagena, 30202 Cartagena, Spain \\ ${ }^{b}$ Renewable Energy Research Institute and DIEEAC-EDII-AB, Universidad de Castilla-La Mancha, 02071 Albacete, Spain \\ ${ }^{c}$ Dept. of Electrical and Computer Engineering, Auburn University, 220 Broun Hall, Auburn, AL 36849, USA
}

\begin{abstract}
Traditionally, inertia in power systems has been determined by considering all the rotating masses directly connected to the grid. During the last decade, the integration of renewable energy sources, mainly photovoltaic installations and wind power plants, has led to a significant dynamic characteristic change in power systems. This change is mainly due to the fact that most renewables have power electronics at the grid interface. The overall impact on stability and reliability analysis of power systems is very significant. The power systems become more dynamic and require a new set of strategies modifying traditional generation control algorithms. Indeed, renewable generation units are decoupled from the grid by electronic converters, decreasing the overall inertia of the grid. 'Hidden inertia', 'synthetic inertia' or 'virtual inertia' are terms currently used to represent artificial inertia created by converter control of the renewable sources. Alternative spinning reserves are then needed in the new power system with high penetration renewables, where the lack of rotating masses directly connected to the grid must be emulated to maintain an acceptable power system reliability. This paper reviews the inertia concept in terms of values and their evolution in the last decades, as well as the damping factor values. A comparison of the rotational grid inertia for traditional and current averaged generation mix scenarios is also carried out. In addition, an extensive discussion on wind and photovoltaic power plants and their contributions to inertia in terms of frequency control strategies is included in the paper.
\end{abstract}

Keywords: Inertia constant, Power system stability, Frequency regulation, Damping factor, Renewable energy sources, Virtual inertia

\section{Nomenclature}

DFIG Double Fed Induction Generator

EU European Union

FSWT $\quad$ Fixed Speed Wind Turbine

HAWT Horizontal Axis Wind Turbine

PMSG Permanent Magnet Synchronous Generator

PV Photovoltaic

RES Renewable energy sources

ROCOF Rate Of Change Of Frequency

SCIG Squirrel Cage Induction Generator

VSWT Variable Speed Wind Turbine

WPP Wind Power Plant

\section{Introduction}

Presently, power system stability relies on synchronous machines connected to the grid. They are synchronized

Email addresses: ana.fernandez@upct.es (Ana Fernández-Guillamón), emilio.gomez@uclm.es (Emilio Gómez-Lázaro), mze0018@auburn.edu (Eduard Muljadi), angel.molina@upct.es (Ángel Molina-García) to the grid and their stored kinetic energy is automatically extracted in response to a sudden power imbalance. For example, a sudden additional large load or a loss of a large generation unit from the grid, will slow down the machines on the grid and subsequently reduce grid frequency [1]. However, the power systems generation fleet is changing from conventional generation to renewable energy sources (RES) [2]. Limited fossil fuel reserves and the importance of reducing greenhouse gases emissions are the main reasons for this transition in the electrical generation [3]. For instance, wind, solar and biomass generations overtook coal power in the EU for the first time during the year 2017 [4]. However, some authors consider that only half of the overall electricity demand can be provided by RES [5, 6], despite the fact that it is expected that future electrical grids will be based on RES, distributed generation and power electronics [7]. As an example, in Europe, it is expected that 323 and $192 \mathrm{GW}$ of wind and PV will be installed in 2030, which will cover up to $30 \%$ and $18 \%$ of the demand, respectively $[8,9]$.

Among the different renewable sources available, PV and wind (especially doubly fed induction generators, DFIG [10]) are the two most promising resources for generating electrical energy [11]. Apart from their intermit- 
tency, they are connected through power converters which decouple them from the power system grid $[12,13]$. Therefore, the effective inertia of the electrical grid is reduced when conventional generators are replaced by RES $[14,15]$, affecting the system stability and reliability [16]. This fact is considered as one of the main drawbacks of integrating a large amount of non-synchronous generators (i.e. RES) into the grid [17], as the frequency stability and its transient response is compromised [18]. Actually, low system inertia is related with $(i)$ a faster rate of change of frequency (ROCOF) and (ii) larger frequency deviations (lower frequency nadir during frequency dips) within a short-time frame [19].

In this work, we conduct an extensive literature review focusing on the inertia values for power systems and wind power plants. The averaged inertia values are estimated by different countries for the last two decades, by considering the 'effective' rotating masses directly connected to the grid. In addition, the damping factor evolution is also included in the paper based on most of technical contributions and analysis found in the literature. The rest of the paper is organized as follows: inertia and damping factor analysis for power systems is discussed in detail in Section 2, determining the averaged inertia estimation for different countries; control strategies and contributions to integrate RES into grid frequency response is described in Section 3; finally, the conclusion is given in Section 4.

\section{Inertia analysis in power systems}

\subsection{Modeling the inertial response of a rotational syn- chronous generator: inertia constant analysis}

The group turbine-synchronous generator rotates due to two opposite torques: $(i)$ mechanical torque of the turbine, $T_{m}$ and $(i i)$ electromagnetic torque of the generator, $T_{e}$. The motion equation is $[20,21]$ :

$$
2 H \frac{d \omega_{r}}{d t}=T_{m}-T_{e}
$$

where both the $T_{m}$ and the $T_{e}$ are expressed in pu and $H$ the inertia constant in s. $H$ is given by:

$$
H=\frac{1}{2} \cdot \frac{J \cdot \omega_{\text {base }}^{2}}{S_{\text {base }}},
$$

being $J$ the moment of inertia, $\omega_{\text {base }}$ the base frequency and $S_{\text {base }}$ the base power. $H$ determines the time interval during which the generator can supply its rated power only using the kinetic energy stored in the rotational masses of the generator. In Table 1, a review of $H$ values for different types of generation units and rated power is shown.

Expressing Eq. (1) in terms of power, and considering the initial status as $0, P=P_{0}+\Delta P=\left(\omega_{r 0}+\Delta \omega_{r}\right) \cdot\left(T_{0}+\right.$ $\Delta T)$. For small deviations, the second order terms are neglected due to their small values, thus $\Delta P \simeq \omega_{r 0} \cdot \Delta T+$ $T_{0} \cdot \Delta \omega_{r}$, being $\Delta P=\Delta P_{m}-\Delta P_{e}$ and $\Delta T=\Delta T_{m}-\Delta T_{e}$.

\begin{tabular}{ccccc}
\hline Type of generating unit & Rated power & $H(\mathbf{s})$ & Reference & Year \\
\hline Thermal & $500-1500 \mathrm{MW}$ & $2.3-2$ & {$[22]$} & 2008 \\
Thermal & $1000 \mathrm{MW}$ & $4-5$ & {$[23]$} & 2011 \\
Thermal & $10 \mathrm{MW}$ & 4 & {$[24]$} & 2007 \\
Thermal & Not indicated & $4-5$ & {$[25]$} & 2012 \\
Thermal $(2$ poles) & Not indicated & $2.5-6$ & {$[26]$} & 1994 \\
Thermal (4 poles) & Not indicated & $4-10$ & {$[26]$} & 1994 \\
Thermal (steam) & $130 \mathrm{MW}$ & 4 & {$[12]$} & 2012 \\
Thermal (steam) & $60 \mathrm{MW}$ & 3.3 & {$[12]$} & 2012 \\
Thermal (combined cycle) & $115 \mathrm{MW}$ & 4.3 & {$[12]$} & 2012 \\
Thermal (gas) & $90-120 \mathrm{MW}$ & 5 & {$[12]$} & 2012 \\
Thermal & Not indicated & $2-8$ & {$[27]$} & 2011 \\
Hydroelectric $450<n<514 \mathrm{rpm}$ & $10-65 \mathrm{MW}$ & $2-4.3$ & {$[22]$} & 2008 \\
Hydroelectric $200<n<400 \mathrm{rpm}$ & $10-75 \mathrm{MW}$ & $2-4$ & {$[22]$} & 2008 \\
Hydroelectric $138<n<180 \mathrm{rpm}$ & $10-90 \mathrm{MW}$ & $2-3.3$ & {$[22]$} & 2008 \\
Hydroelectric $80<n<120 \mathrm{rpm}$ & $10-85 \mathrm{MW}$ & $1.75-3$ & {$[22]$} & 2008 \\
Hydroelectric & Not indicated & 4,75 & {$[28]$} & 2013 \\
Hydroelectric $n<200 \mathrm{rpm}$ & Not indicated & $2-3$ & {$[29]$} & 1994 \\
Hydroelectric $n>200 \mathrm{rpm}$ & Not indicated & $2-4$ & {$[29]$} & 1994 \\
Hydroelectric & Not indicated & $2-4$ & {$[26]$} & 1994 \\
\hline
\end{tabular}

Table 1: Summary of inertia values $(H)$ for different generation types.

Furthermore, in steady-state $T_{m 0}=T_{e 0}$ and $\omega_{r 0}=1 \mathrm{pu}$. Hence, $\Delta P=\Delta P_{m}-\Delta P_{e} \simeq \Delta T_{m}-\Delta T_{e}$.

Therefore, if small variations around the steady-state conditions are considered, Eq. (1) can be written as Eq. (3) in the time domain, or as Eq. (4) if the Laplace transform is applied.

$$
\begin{gathered}
\frac{d \Delta \omega_{r}}{d t}=\frac{1}{2 H}\left(\Delta P_{m}-\Delta P_{e}\right) \\
\Delta \omega_{r}=\frac{\Delta P_{m}-\Delta P_{e}}{2 H \cdot s}
\end{gathered}
$$

Some loads (especially inverter-based loads) can also be modified to work as a load resource (demand response capability) under frequency deviations (e.g., motors driving compressors, pumps, industry loads, HVAC-heating ventilation air conditioning...). This fact can be modeled by including the damping factor $D$. As an example, for a synchronous machine, the electrical power $P_{e}$ can be then expressed as follows,

$$
\Delta P_{e}=\Delta P_{L}+D \cdot \Delta \omega_{r}
$$

where $P_{L}$ represents the load independent from frequency excursions.

Substituting Eq. (5) into Eq. (4), the mathematical representation of the motion of a synchronous generator is obtained. It is commonly referred to as swing equation, see Eq. (6). It can be expressed in the form of a block diagram as shown in Figure 1. Hence, the initial response of a synchronous generator to a frequency event is governed by its stored kinetic energy at the rated frequency [30],

$$
\Delta \omega_{r}=\frac{\Delta P_{m}-\Delta P_{L}}{2 H \cdot s+D}
$$

2.2. Aggregated swing equation: equivalent inertia constant and damping factor analysis 


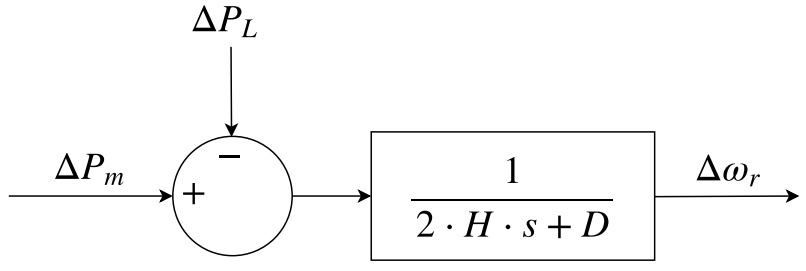

Figure 1: Block diagram representation of the swing equation

\begin{tabular}{cccc}
\hline Ref. & Value $\left(p u_{M W} / p_{H z}\right)$ & Analysis & Year \\
\hline$[26]$ & $1-2$ & Power system stability & 1994 \\
{$[35]$} & 0.83 & Two areas with non-reheat thermal units & 2011 \\
{$[36]$} & 1.66 & Two areas with thermal units & 2011 \\
{$[37]$} & $1-1.8$ & Three areas with non-reheat thermal units & 2012 \\
{$[38]$} & 2 & One area with nuclear, thermal, wind and PV & 2012 \\
{$[39]$} & $0.5-0.9$ & Three areas with non-linear thermal units & 2013 \\
{$[40]$} & 0.83 & Two areas non-reheat thermal units & 2013 \\
{$[41]$} & 0.83 & Two areas with thermal units & 2013 \\
{$[42]$} & 0.83 & Two areas with reheat units & 2015 \\
{$[43]$} & 0.8 & IEEE 9 bus system with hydro-power, gas and wind turbines & 2016 \\
{$[44]$} & $1-1.8$ & One and three areas with non-reheat thermal units & 2017 \\
{$[45]$} & $1-1.8$ & Three areas with non-reheat thermal units & 2018 \\
{$[46]$} & 1 & Two areas with non-reheat thermal units & 2018 \\
\hline
\end{tabular}

Table 2: Damping factor values. Literature review

In order to apply the swing equation to a power system, Eq. (6) is rewritten. All synchronous generators are reduced to an equivalent rotating mass with an equivalent inertia $H_{e q}$,

$$
H_{e q}=\frac{\sum_{i=1}^{G C P S} H_{i} \cdot S_{\text {base }, i}}{S_{\text {base }}},
$$

being GCPS the number of generators coupled to the power system [31], such as conventional power plants and FSWTs. In the past, it was considered that the equivalent inertial constant $H_{e q}$ of a power system was constant and time-independent. However, due to the RES integration and the variation in their generation throughout the day, the season of the year, etc., it is understood that $H_{e q}$ changes with time. An example of this variation is presented for the German power system during 2012 in [32], see Figure 2. From these data, the cumulative frequency curve is obtained and depicted in Figure 3. It can be seen that during $50 \%$ of the year 2012 , the equivalent inertia was under $5.7 \mathrm{~s} ; 10 \%$ of the year, $H_{e q}$ was under $5 \mathrm{~s}$; and only $1 \%$ of the year, its value was under $4 \mathrm{~s}$.

In the same way as synchronous generators, all loads are grouped in an equivalent one with an equivalent damping factor $D_{e q}$. As stated in [33], the impact of an inaccurate value of $D_{e q}$ is relatively small if the power system is stable, but this can be a major contribution under disturbances. Moreover, it is expected to decrease accordingly to the use of variable frequency drives [34]. Table 2 summarizes the different values proposed for the damping factor in the literature over recent decades.

By using Eq. (7), an estimation of the equivalent inertia $H_{e q}$ of several parts of the world has been carried out by the authors. The International Energy Agency (IEA) provides global statistics about energy [47]. By considering

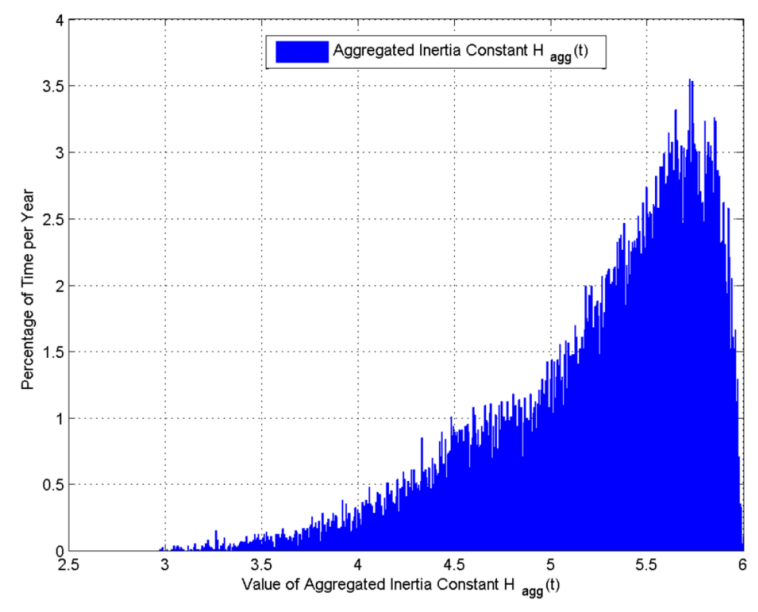

Figure 2: Histogram of equivalent inertia $H_{e q}$ in the German power system during 2012, [32]

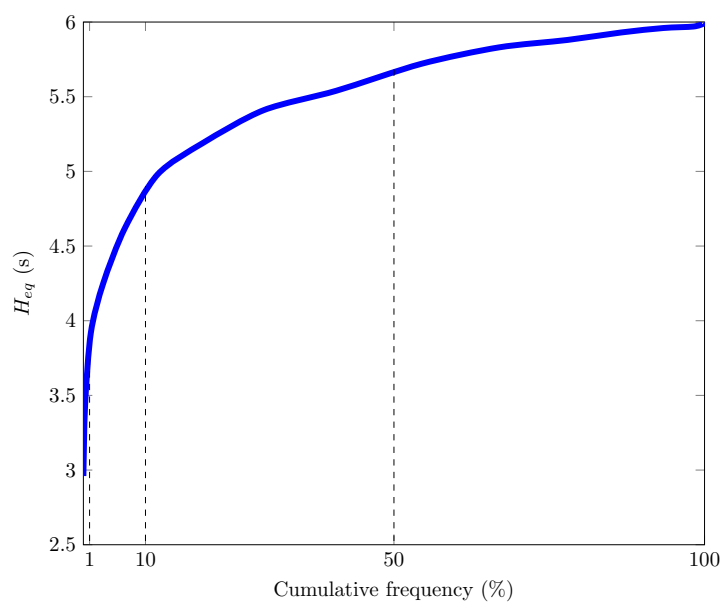

Figure 3: Cumulative frequency of the equivalent inertia $H_{e q}$ in the German power system during 2012 


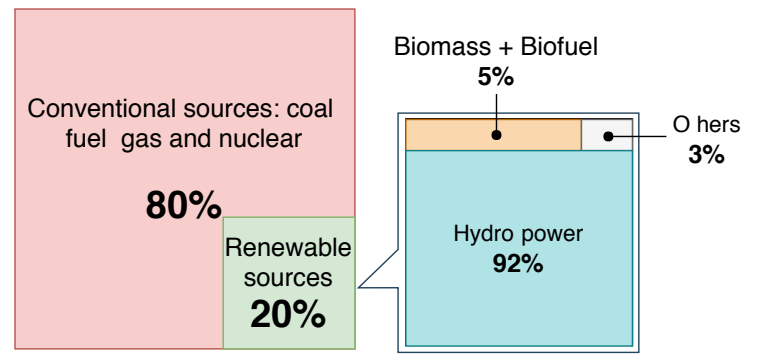

(a) Generation mix in 1996

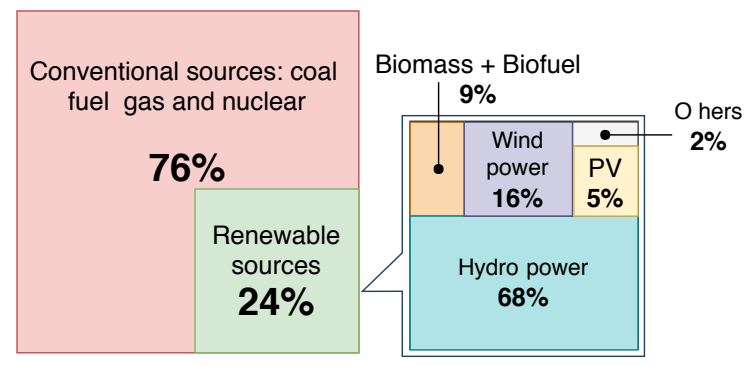

(b) Generation mix in 2016

Figure 4: Generation mix in the world: change between 1996 and 2016

the annual averaged electricity, an averaged equivalent inertia constant $\left(H_{e q}\right)$ provided by such conventional power plants - Table 1 - can be estimated. Note that for this estimation, $S$ of Eq. (7) is replaced by the annual electricity value $\left(E_{g}\right)$. The expression used to estimate the inertia is then Eq. (8), being $E_{g, \text { total }}$ the total electricity supplied (conventional+RES generation) within a year.

$$
H_{e q}=\frac{\sum_{i=1}^{G C P S} H_{i} \cdot E_{g, i}}{E_{g, \text { total }}} .
$$

Figure 4 shows a significant change in the averaged generation mix between 1996 and 2016. The total electricity consumption has been increased by more than $80 \%$ within these two decades. However, RES generation has only increased by $4 \%$ in the same two decades. Moreover, the share of the different renewable sources has changed significantly. Indeed, the contribution share from hydropower has been surpassed by biomass, biofuels, wind, and PV. Based on the approach previously described, Figure 5 depicts the differences between the inertia constant for different continents in 1996 and in 2016. EU has reduced the equivalent inertia constant by nearly $20 \%$. In contrast, the reduction of inertia in Asia, USA, and South America lies between 2.5 and $3 \%$.

A more extensive analysis is conducted for the EU, where an average inertia reduction of $0.6 \mathrm{~s}$ can be estimated. In Figure 6, an overview of the evolution of the equivalent inertia in some EU countries is summarized. Similar information is given in Figure 7, where the reduction of the equivalent inertia is illustrated for those EU

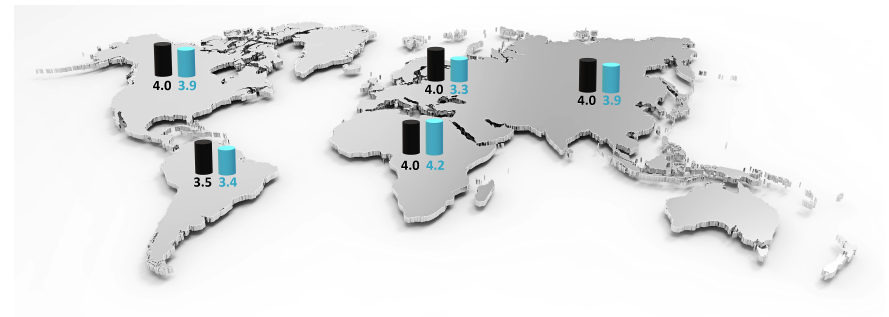

Figure 5: Equivalent inertia constants estimated in the world by continent. Change between 1996 and 2016

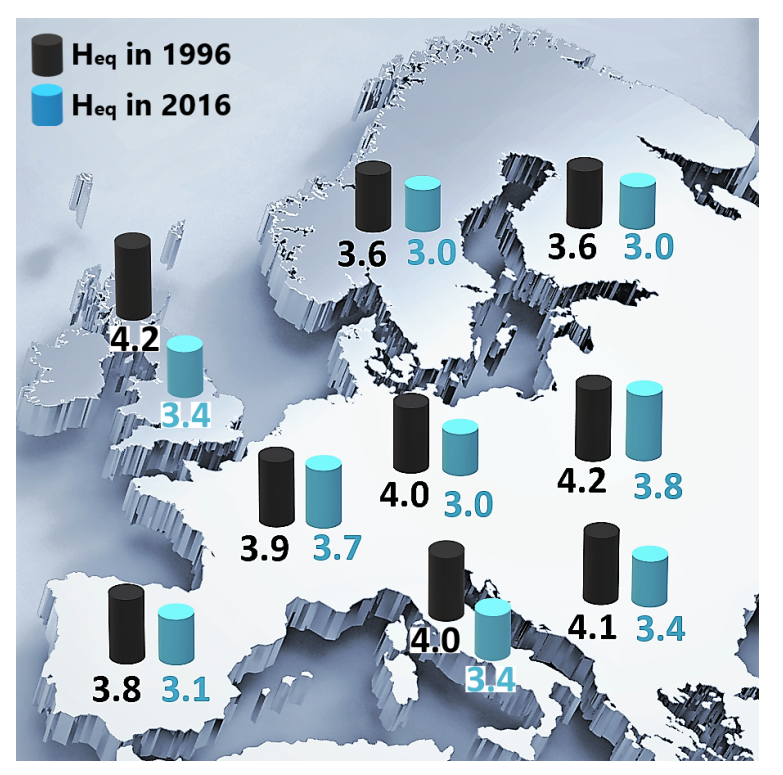

Figure 6: Equivalent inertia constants estimated in EU-28. Change between 1996 and 2016 


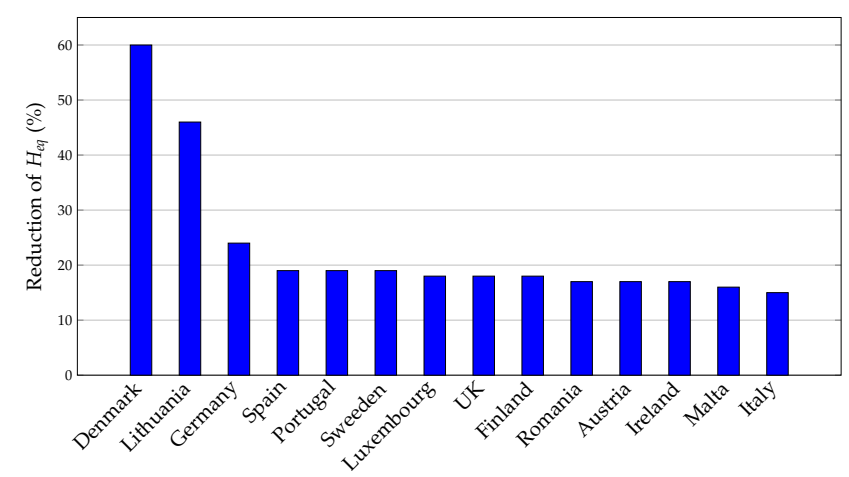

Figure 7: Equivalent inertia reduction in EU-28 between 1996 and 2016.

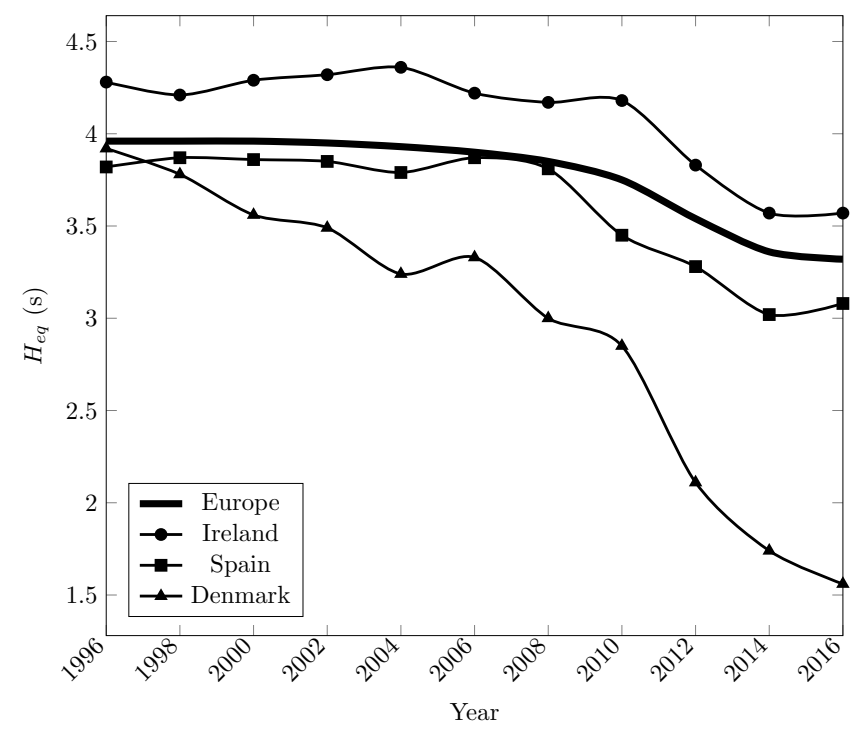

Figure 8: Evolution of equivalent inertia in EU-28 and some countries between 1996 and 2016 .

countries which have suffered a reduction larger than $15 \%$ $\left(H_{e q}\right.$ reduction $\left.>15 \%\right)$. Figure 8 represents the equivalent inertia evolution of EU, as well as in three different countries (Ireland, Spain, and Denmark). For the EU, RES supply has increased nearly by $20 \%$, in line with the reduction of its inertia constant (refer to Figure 9). Similar to the generation mix in the world, wind, biomass, biofuels, and PV have surpassed the development of hydro-power, which has drastically slowed down in recent years.

\subsection{Modified equivalent inertia analysis: emulating hid- den and virtual inertia from RES}

To obtain the maximum power from the natural resource, both wind and PV power plants are controlled by power converters using the maximum power point tracking (MPPT) technique [48]. This power converter prevents wind and PV power plants to directly contribute to the inertia of the system, being thus referred to as

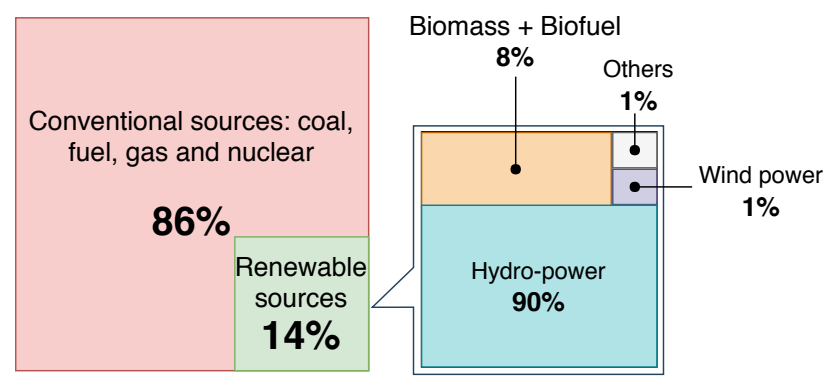

(a) Generation mix in 1996

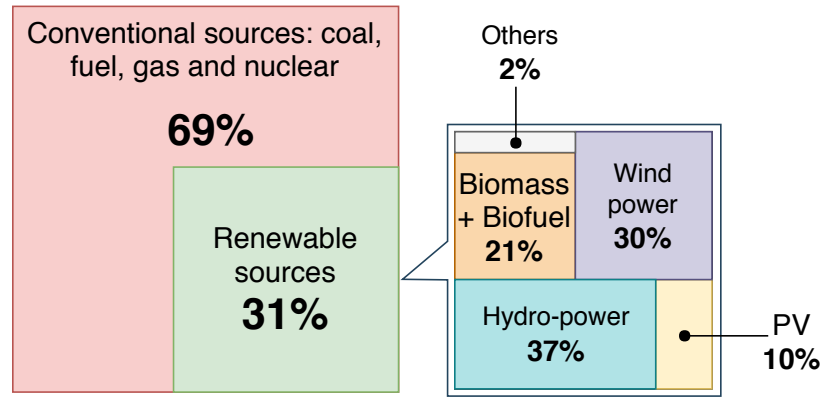

(b) Generation mix in 2016

Figure 9: Generation mix in Europe: change between 1996 and 2016.

'decoupled' from the grid [49]. As a consequence, to effectively integrate RES into the grid, frequency control strategies have been developed $[50,51,52]$. Such methods are commonly named as synthetic, emulated or virtual inertia [53]. If this emulation of inertia coming from RES was included in power systems, it would have to be considered to estimate the equivalent inertia. Then, this modified equivalent inertia would have two different components: (i) synchronous inertia coming from conventional generators, $H_{S}$ and (ii) emulated/virtual inertia coming from RES, $H_{E V}[54,55,34,56,57]$, modifying Eq. (7) to Eq. (9). $E V G$ is the number of RES connected to the grid through emulation/virtual control methods, and $H_{E V}$ is the inertia constant of the emulated/virtual generation unit.

$$
H_{e q}=\frac{\overbrace{\sum_{i=1}^{G C P S} H_{i} \cdot S_{\text {base }, i}}^{H_{S}}+\overbrace{\sum_{j=1}^{E V G} H_{E V, j} \cdot S_{\text {base }, j}}^{H_{E V}}}{S_{\text {base }}} .
$$

This modified equivalent inertia expressed in Eq. (9) is graphically illustrated in Figure 10, based on [58]. Note the different representation between the coupling of VSWT and PV to the grid. The reason to this is that WPP has 'hidden' deployable inertia based on the kinetic energy stored in their blades, drive train and electrical generators, whereas PV has no stored kinetic energy due to the absence of rotating masses. Actually, modern VSWT have rotational inertia constants comparable to those of conventional generators $[30,59,60]$. However, this inertia is 'hidden' from the power system point of view due to the con- 


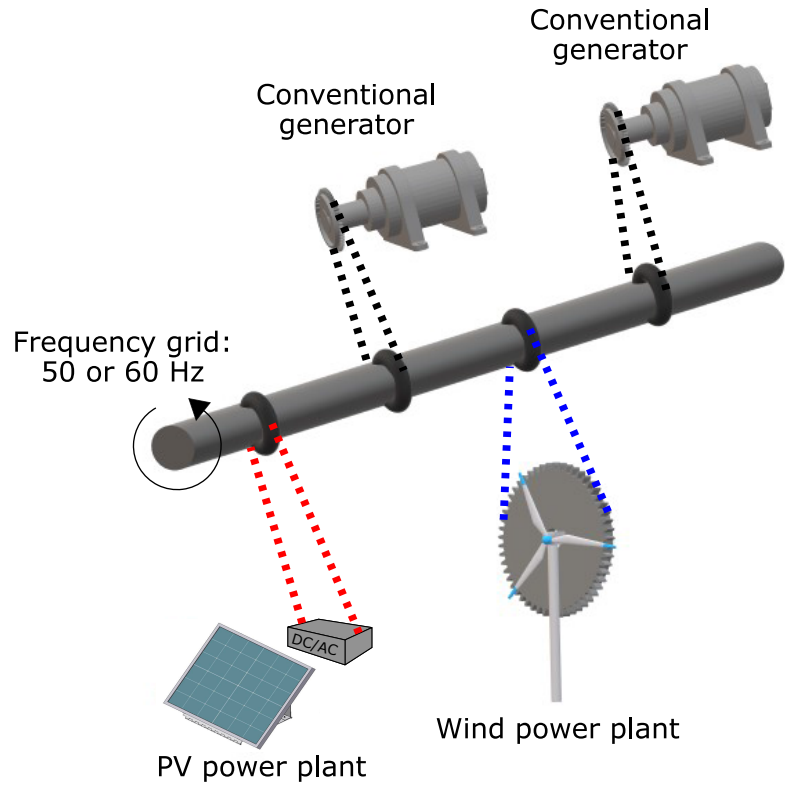

Figure 10: Power system with synchronous, hidden and virtual inertia.

verter [61]. For instance, in Table 3 and Figure 11, the inertia constant of several types of wind turbines are summarized, and most of them are within the range $2-6 \mathrm{~s}$, in line with values presented for conventional units in Table 1. As a consequence, it is commonly considered that VSWT provide 'emulated hidden inertia', as rotational inertia could be provided by them $[62,63,64,65]$. On the other hand, PV installations don't have any rotating masses $[11,66]$, having an inertia constant $H \approx 0$ [67]. Therefore, due to this absence of rotational masses and, subsequently, absence of inertia, the specific literature refers to the 'emulated synthetic/virtual inertia' provided by such PV power plants $[68,69,70,71]$.

With regard to the equivalent inertia estimation for the EU, and considering the averaged hidden inertia of WPP depicted in Table 3, the inertia change is reduced around $0.3 \mathrm{~s}$, corresponding to $50 \%$ of the value determined in Section 2.2. Figure 12 presents the evolution of the equivalent inertia in the same EU countries of Figure 6, being the dark blue values those due to the hidden inertia provided by VSWTs. As can be seen, by considering the hidden inertia of VSWT leads to a smaller reduction of the equivalent inertia.

\section{RES frequency control strategies}

\subsection{Preliminaries}

Generation and load in the power systems must be continuously balanced to maintain a steady frequency. Under any generation-load mismatch, grid frequency changes [94]. Moreover, significant deviations from the nominal value may cause under/over frequency relay operations, and even lead to the disconnection of some loads

\begin{tabular}{ccccc}
\hline Type of wind turbine & Rated power & $H(\mathbf{s})$ & Reference & Year \\
\hline Not indicated & Not indicated & $2-5$ & {$[12]$} & 2012 \\
Not indicated & $2 \mathrm{MW}$ & 4.45 & {$[72]$} & 2007 \\
Not indicated & $2 \mathrm{MW}$ & 2.5 & {$[73]$} & 2003 \\
Not indicated & $16 \cdot 600 \mathrm{~kW}$ & 3.7 & {$[74]$} & 2003 \\
HAWT with SCIG & $200 \mathrm{~kW}$ & 1.2 & {$[75]$} & 2010 \\
FSWT & $10 \cdot 500 \mathrm{~kW}$ & 3.2 & {$[76]$} & 2005 \\
FSWT & Not indicated & 3.5 & {$[77]$} & 2005 \\
VSWT & $2 \mathrm{MW}$ & 6 & {$[78]$} & 2006 \\
VSWT & $3.6 \mathrm{MW}$ & 5.19 & {$[79]$} & 2008 \\
Types $1,2,3$ & $1-5 \mathrm{MW}$ & $2.4-6.8$ & {$[80]$} & 2005 \\
DFIG & $2 \mathrm{MW}$ & 3.5 & {$[81]$} & 2003 \\
DFIG & $660 \mathrm{~kW}$ & 4 & {$[82]$} & 2006 \\
DFIG & $1.5 \mathrm{MW}$ & 6.35 & {$[83]$} & 2009 \\
DFIG & $1.5 \mathrm{MW}$ & 4.41 & {$[83]$} & 2009 \\
DFIG & $3.6 \mathrm{MW}$ & 4.29 & {$[84]$} & 2011 \\
DFIG & $2 \mathrm{MW}$ & 3.5 & {$[85]$} & 2003 \\
DFIG & $2 \mathrm{MW}$ & 2.5 & {$[86]$} & 2004 \\
DFIG & $660 \mathrm{~kW}$ & 4 & {$[24]$} & 2007 \\
DFIG (WPP) & $300 \mathrm{MW}$ & 1 & {$[87]$} & 2007 \\
DFIG & $750 \mathrm{MW}$ & 5.4 & {$[88]$} & 2005 \\
DFIG & $2 \mathrm{MW}$ & 3 & {$[89]$} & 2013 \\
DFIG & $1.5 \mathrm{MW}$ & 3 & {$[90]$} & 2012 \\
DFIG & $2 \mathrm{MW}$ & 0.5 & {$[91]$} & 2006 \\
DFIG & $2 \mathrm{MW}$ & 3.5 & {$[92]$} & 2003 \\
PMSG & $455 \mathrm{~kW}$ & 2.833 & {$[93]$} & 1996 \\
\hline & & & &
\end{tabular}

Table 3: Wind turbines inertia constants $H$ according to rated power and reference

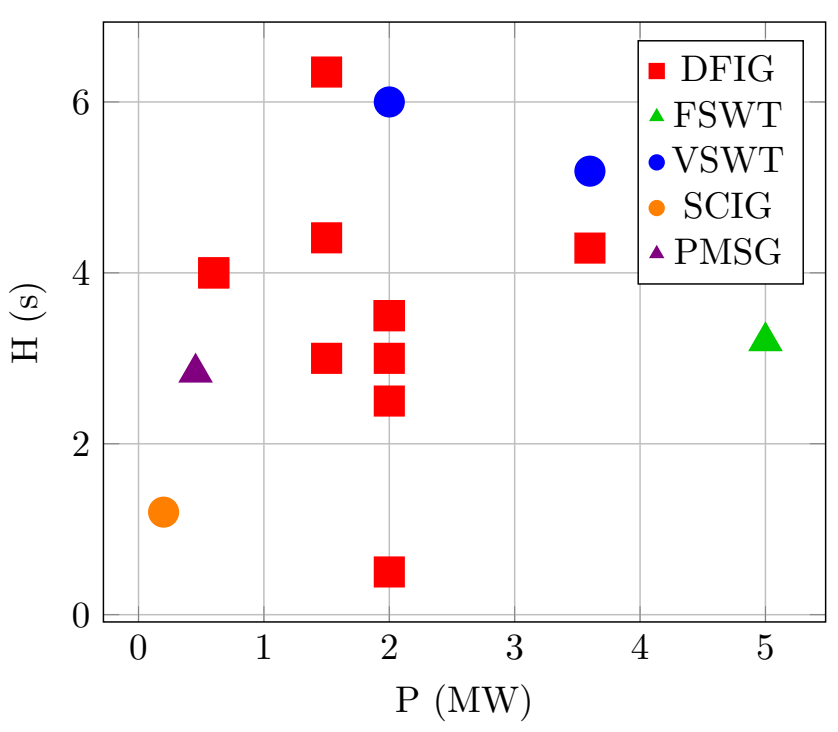

Figure 11: Inertia constant values $(H)$ for different wind turbine technologies 


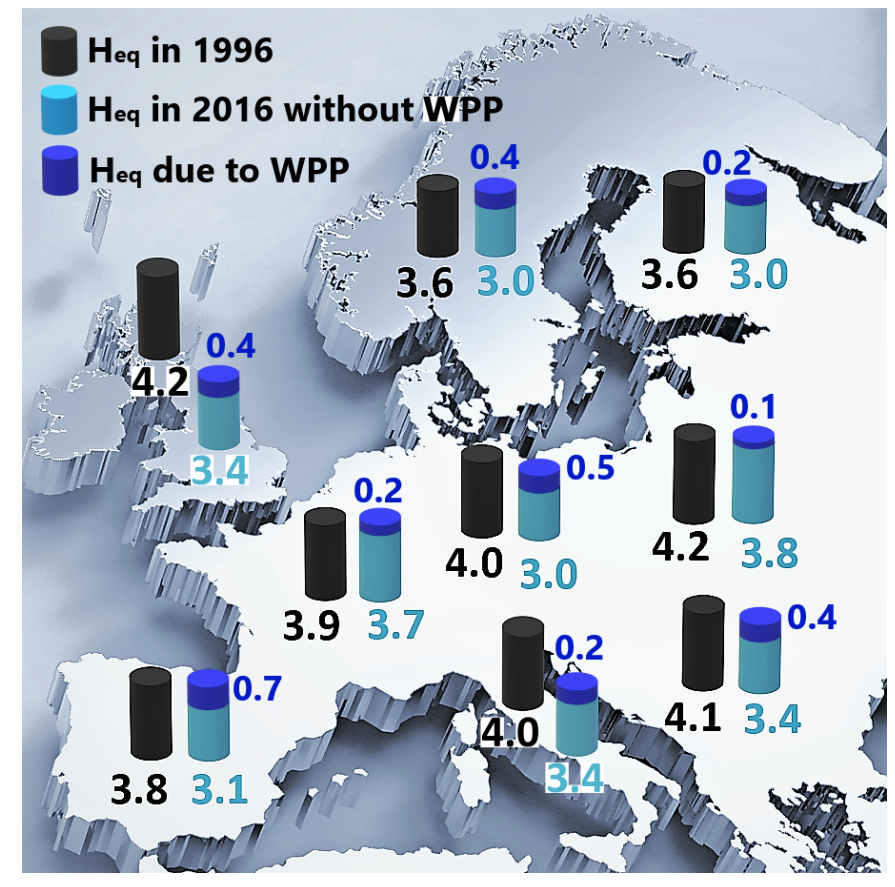

Figure 12: Equivalent averaged inertia constants estimated in EU-28 considering emulated inertia provided by WPPs (1996-2016).

from the grid [95]. Consequently, frequency stability is related to the ability of a power system to maintain the operating frequency close to its nominal value (i.e., 50 or $60 \mathrm{~Hz}$, depending on the region) when an imbalance situation occurs [96]. Hence, frequency control is an essential component of a secure and robust electrical power system [97].

Frequency control is traditionally implemented by adjusting real power generation to balance the load. This traditional scheme has a hierarchical structure, and in Europe it is usually composed of three layers: primary, secondary and tertiary, from fast to slow timescales [98]. The primary and secondary controls are automatic, while tertiary control is manually executed by the transmission system operator [99].

The primary frequency control (PFC) operates at a timescale up to low tens of seconds and uses a governor to adjust the mechanical power input around a set-point based on the local frequency deviation [100]. It is the automatic response of the turbine governors in response to the deviations of the system frequency and depends on the setting of the speed-droop characteristics of each power plant [101]. Therefore, each generating unit can be modeled with its speed governing system [102]. However, it does not restore grid frequency to its nominal value [103]. In Europe, primary control is triggered before the frequency deviation exceeds $\pm 20 \mathrm{mHz}$ [104].

Secondary frequency control or automatic generation control (AGC) removes the steady-state frequency deviation generated by the PFC [105]. An integral controller modifies the turbine governor set-point to bring the fre-

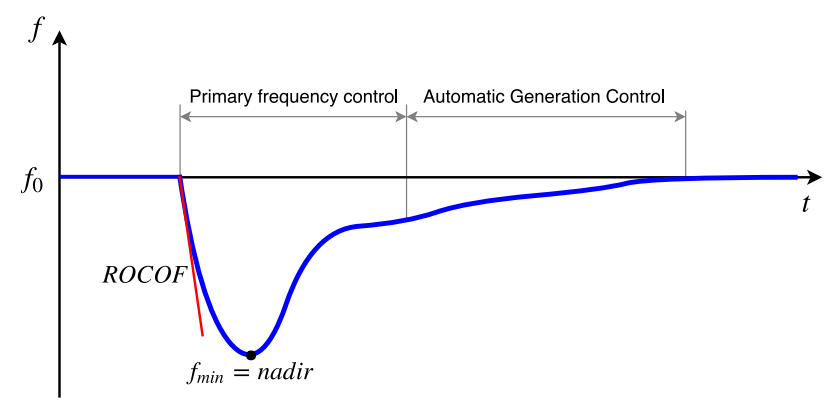

Figure 13: Frequency response after an imbalance

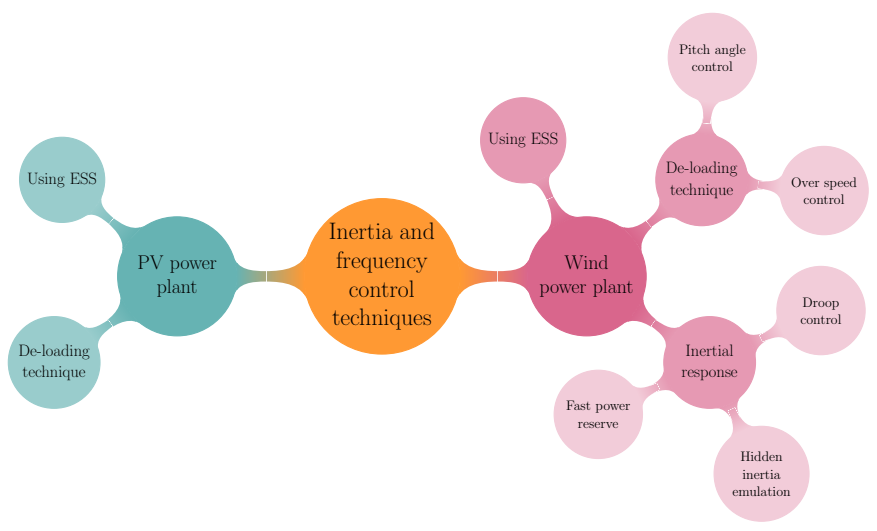

Figure 14: Inertia and frequency control techniques for RES

quency back to its nominal value [106]. It also keeps the scheduled exchanges between the different areas of an interconnected power system to their expected values [107]. In Europe, the time-frame is from seconds up to typically 15 min after an incident [104]. Figure 13 gives an example of a typical frequency excursion, where primary frequency control and AGC time intervals are shown.

Finally, the main objective of the tertiary frequency control is to perform an economically efficient generationdispatch (economic dispatch) [108]. Moreover, it is also intended to relieve transmission congestions and restoring the secondary control reserves [109]. This is also called security-constrained-economic dispatch (SCED).

An increase in the penetration level of RES addresses a decreasing of the number of synchronous generators, leading to an initial decline in system inertia and power reserves for primary and secondary control [110]. Subsequently, low inertia is related to larger frequency deviations after a generation-load mismatch event [111], having implications on frequency related power systems dynamics [112]. It is important to note that the rate of change of frequency (ROCOF) is strongly affected by the inertia available in the system [113]. By this means, it is necessary that RES become an active role in grid frequency regulation, providing active power support under disturbances [114]. The different technologies proposed to give additional inertia and frequency control from RES are usually classified as summarized in Figure 14. 


\subsection{PV power plant frequency control strategies}

$\mathrm{PV}$ power plants can use ESS such as batteries [115, $116,117]$, super-capacitors [118, 119] and flywheels [117] in order to provide additional active power in an imbalanced situation.

A different strategy to be considered is the 'de-loading technique' of the PV plant. It is based on operating these generating units below their optimal generation point, in order to have a certain amount (headroom) of active power to supply real power to the grid in case of a frequency-dip contingency [120]. In general, PV power plants operate at the maximum power point tracking mode according to certain meteorological conditions (i.e., temperature $T$ and irradiation $G$ ), maximizing the revenues from selling energy [121]. Contributions focused on this technique can be found in [122, 123, 124, 125, 126, 127]. By curtailment, we are operating the $\mathrm{PV}$ plant at a de-loaded point $P_{\text {del }}$, below $P_{M P P}$, so that the PV plants are able to support system frequency, as some power reserves $\Delta P=P_{M P P}-P_{d e l}$ are available. As depicted in Figure $15, P_{\text {del }}$ involves two different voltages: $(i)$ over the maximum power point voltage, $V_{d e l, 1}>V_{M P P}$ and $(i i)$ under the maximum power point voltage, $V_{d e l, 2}<V_{M P P}$. Due to stability concerns, the deloaded voltage corresponds to the higher value $V_{d e l, 1}$ [128].

\subsection{Wind power plant frequency control strategies}

As in the PV power plants, wind power plants can also use ESS to provide additional power boost during an imbalanced situation (i.e., frequency dips). Batteries [116], super-capacitors[118, 129] and flywheels [130] are proposed in the literature review.

Wind turbines have two possibilities to operate with the de-loading technique: $(i)$ pitch angle control and $(i i)$ overspeed control [61]. The pitch angle control consists of increasing the pitch angle from $\beta_{0}$ to $\beta_{1}$ for a constant wind speed $V_{W}$, keeping the rotor speed at the maximum power point $\Omega_{M P P}$ (Figure 16). This way, the power supplied $P_{\text {del }}$ is below the maximum available aerodynamic power $P_{M P P}$. Therefore, a certain amount of active power reserve is available to supply additional generation in case of a frequency deviation occurs $[131,132,133,134]$. The overspeed control shifts the de-loaded power $P_{\text {del }}$ towards the right of the maximum power $P_{M P P}$, maintaining the pitch angle $\beta_{0}$ for a constant wind speed $V_{W}$, see Figure 17(a). When frequency response is provided, rotor speed has to be reduced from $\Omega_{d e l, 1}$ to $\Omega_{M P P}$, releasing kinetic energy to the system $[135,136,137,138]$. As depicted in Figure $17(\mathrm{~b})$, a third possibility could be to set the turbine to operate the rotor speed below the rotor speed for MPPT operation. In that case, the rotor speed must increase from $\Omega_{d e l, 2}$ to $\Omega_{M P P}$ utilizing some power extracted from the turbine. As a consequence, the frequency response is reduced, and could even be opposite to the desired behavior during the first seconds. Because of this, it is usually considered as a 'detrimental strategy' [139, 140].

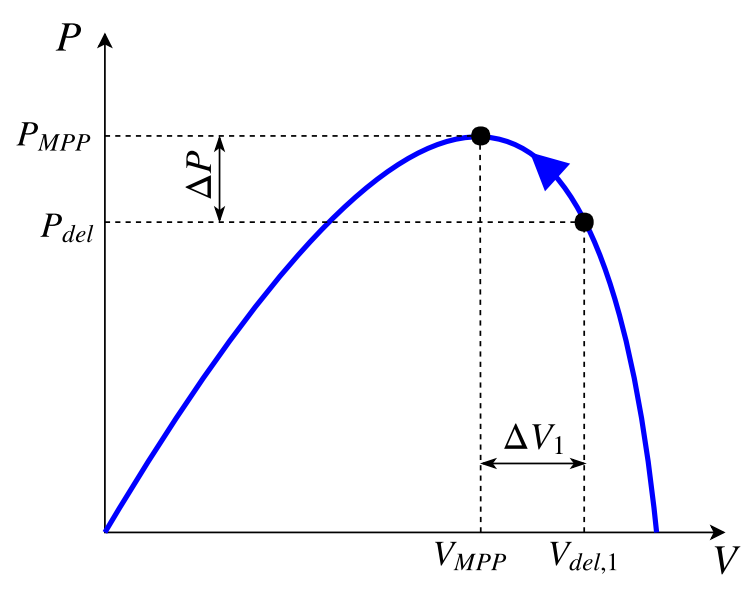

(a) $V_{d e l, 1}>V_{M P P}$

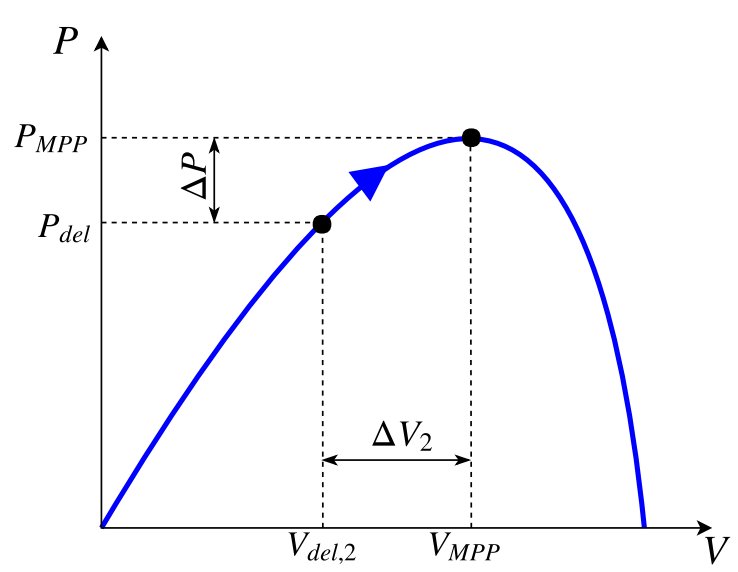

(b) $V_{\text {del, } 2}<V_{M P P}$

Figure 15: Deloading techniques for PV

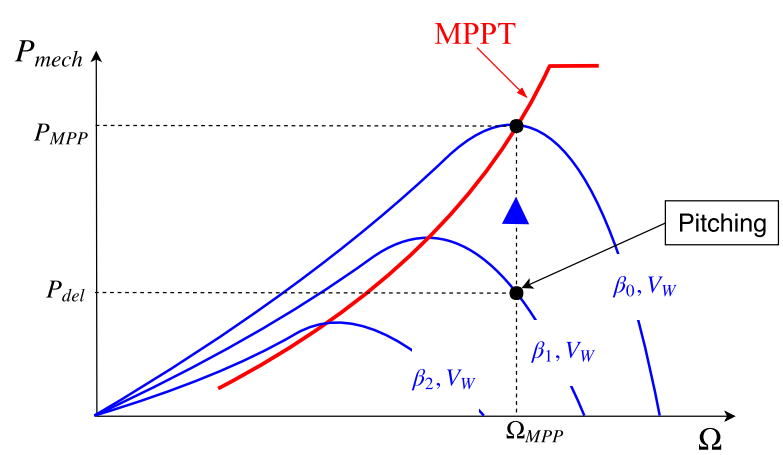

Figure 16: Pitch control 


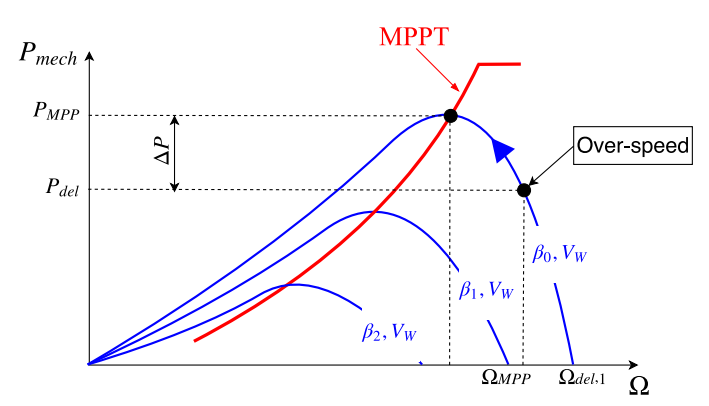

(a) Over-speed control

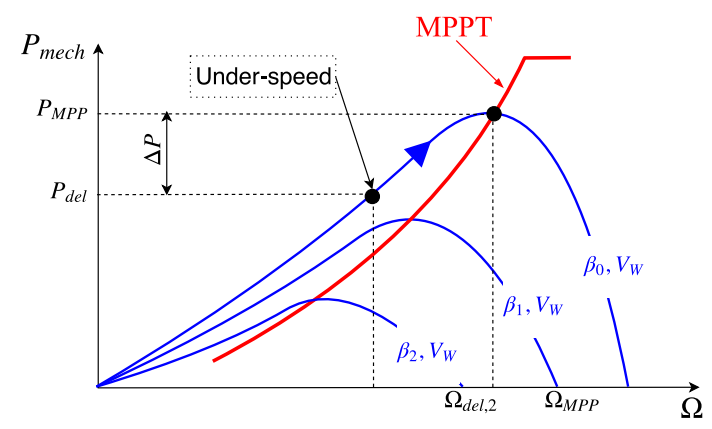

(b) Under-speed control

Figure 17: Over-speed and under-speed control

With regard to providing an inertial response from wind power plants, the main idea is to increase the output power of the VSWT for a few seconds. One or more supplementary loops are introduced into the active power control, which are only activated under frequency deviations. Both blades and rotor inertia are then used to provide primary frequency response under power imbalance situations. The kinetic energy stored in the rotating masses is supplied to the grid as an additional active power [141].

The droop control emulates the behavior of a governor in a conventional synchronous generator, responding to the changes in the system frequency. The active power supplied by the VSWTs changes proportionally to the frequency deviation $\Delta f$ as illustrated in Figure 18(a), where $R_{W T}$ is the droop control setting (speed adjustment rate). Subsequently, the variation of power is defined as Eq. (10), where $\Delta P$ is the signal given to the power converter to release the stored kinetic energy. The increase of the active power output results in a decrease in the rotor speed [142, 143, 144, 145].

$$
\Delta P=-\frac{\Delta f}{R_{W T}}
$$

Hidden inertia emulation for wind turbines is characterized by an emulation of the inertial response of a traditional synchronous generator. There are two types of hidden inertia emulation controls: $(i)$ one loop and $(i i)$ two loops. In the first case, an additional power $\Delta P$ based on the ROCOF is added to $P_{M P P}$ after a generation deficit,

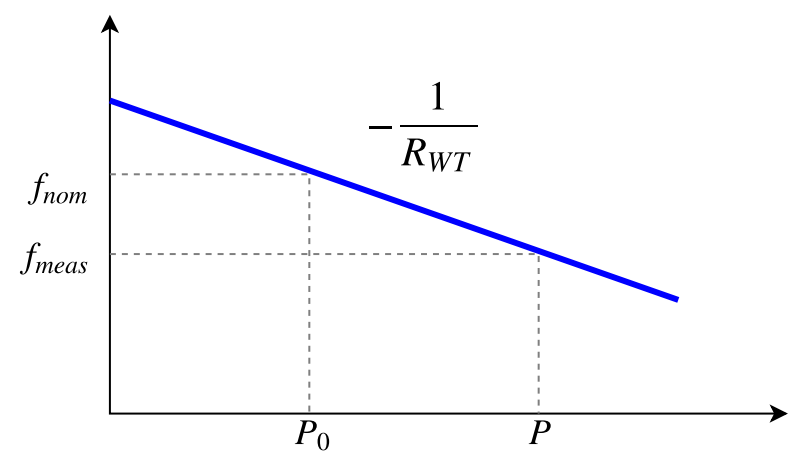

(a) Droop characteristic

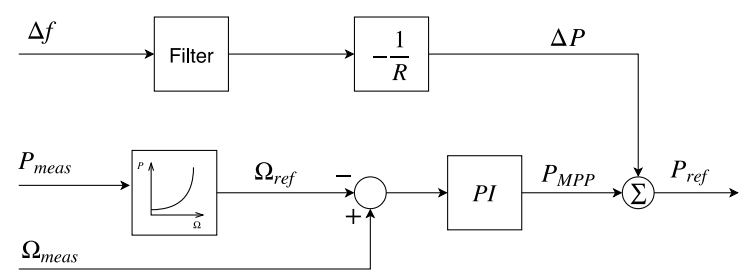

(b) Block diagram of droop control [146]

Figure 18: Droop control for VSWTs

thus, reducing the generator speed and releasing the stored kinetic energy of the rotating blades [147, 148, 149]. The drawback of this control strategy is that frequency is not restored to its nominal value [150]. An additional loop proportional to the frequency deviation $\Delta f$ is then added, as indicated in Figure 19(b). This second loop lasts until the frequency is restored to $f_{0}[78,151]$. Figure 20 compares the frequency responses by considering one or two loops controllers.

The fast power reserve technique is based on supplying the kinetic energy stored in the rotating masses of the wind turbine to the grid as additional active power. Afterward, the energy extracted is recovered through an under-production period. When the frequency deviation surpasses the predefined threshold value, the additional active power is provided, decreasing the rotational speed of the rotor. Overproduction power was initially defined as a constant value $[79,152,153,154,155,156]$. However, new approaches consider it as variable $[157,158,159]$ by considering other limits (e.g. toque limit, the current limit of the power electronic switches, etc). The recovery period is used to restore both power and rotational speed to their pre-event values. Different techniques have also been proposed in the references listed. Figure 21 shows the fast power reserve emulation control indicated in [152].

Table 4 presents an overview of the application of some of the techniques. It includes the integration of wind power plants (WPP) and the power imbalance $\Delta P$; both in the percentage of the total capacity of the system. As can be seen, some strategies are combined, in order to improve the frequency deviation after the generation-load mismatch. 


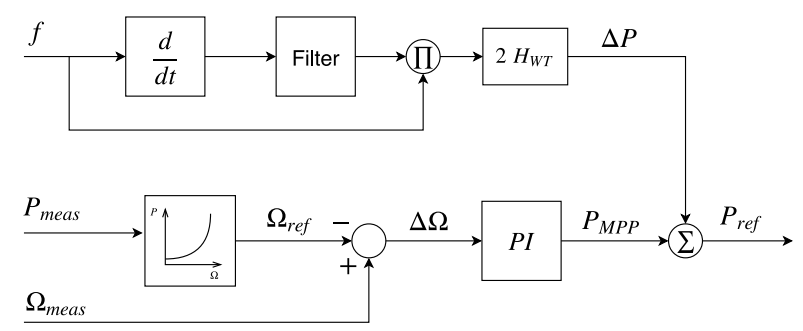

(a) One loop

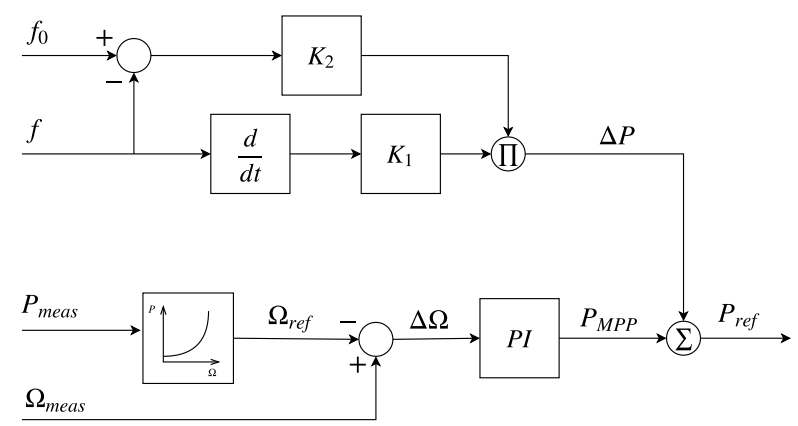

(b) Two loops

Figure 19: Hidden inertia emulation controllers

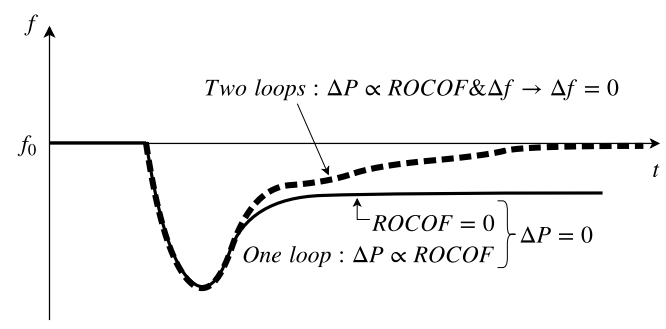

Figure 20: Frequency response of the one loop and two loops controllers

\begin{tabular}{|c|c|c|c|c|}
\hline Ref. & Type of control & WPP (\%) & $\Delta P(\%)$ & Year \\
\hline$[160]$ & Droop & 46 & 14 & 2012 \\
\hline$[160]$ & Hidden inertia $(i)$ & 46 & 14 & 2012 \\
\hline$[160]$ & Droop + Hidden inertia $(i)$ & 46 & 14 & 2012 \\
\hline$[161]$ & Variable droop & 30 & - & 2011 \\
\hline$[162]$ & De-loading by pitch & 24 & 3 & 2016 \\
\hline$[162]$ & De-loading by pitch & 50 & 4 & 2016 \\
\hline [163] & Fast power reserve & 57 & 8.5 & 2017 \\
\hline [164] & Hidden inertia $(i i)$ & 25 & 1.7 & 2012 \\
\hline$[165]$ & Dynamic droop + Hidden inertia $(i)$ & 10 & $8.5,10,11$ & 2016 \\
\hline$[166]$ & Droop + Hidden inertia $(i)$ & 15 & 2 & 2016 \\
\hline$[166]$ & Droop + Hidden inertia $(i)$ & 50 & 2 & 2016 \\
\hline$[167]$ & Fast power reserve & 12.5 & 6.25 & 2015 \\
\hline [168] & Hidden inertia $(i)$ & 20 & 8.33 & 2015 \\
\hline$[168]$ & Droop & 20 & 8.33 & 2015 \\
\hline$[168]$ & Droop & 20 & 8.33 & 2015 \\
\hline [169] & Hidden inertia $(i i)$ & 30 & 2.5 & 2013 \\
\hline$[170]$ & Hidden inertia $(i)$ & 38 & 2.3 & 2012 \\
\hline$[170]$ & De-loading by pitch + Over-speed & 38 & 2.3 & 2012 \\
\hline$[170]$ & Hidden inertia $(i)+$ Pitch + Over-speed & 38 & 2.3 & 2012 \\
\hline
\end{tabular}

Table 4: Wind turbines frequency control proposals

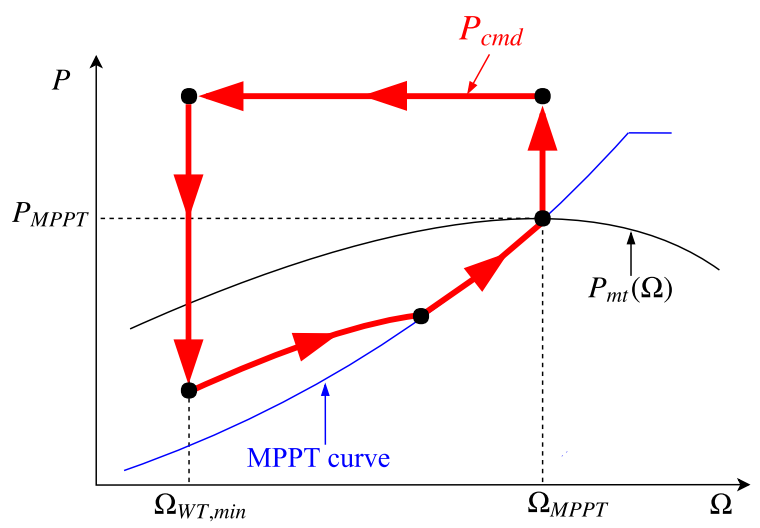

(a) $P-\Omega$ curve

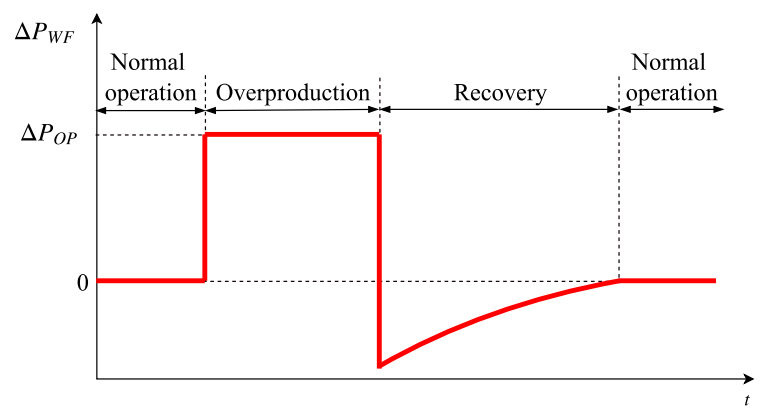

(b) Power variation

Figure 21: Fast power reserve emulation technique [152] 


\section{Conclusion}

An extensive literature review focused on inertia estimation for power systems and wind power plants is conducted by the authors. The contribution of $\mathrm{PV}$ power plants as a 'virtual inertia' is also discussed in the paper, as well as a detailed analysis of the damping factor evolution. Averaged inertia values are estimated for different regions and countries for the last two decades. Conventional generation units are considered accordingly, summarizing their inertia constant values in accordance with each type of technology and rated power. Our findings indicate that, nowadays, Europe presents a significant averaged inertia decreasing -around $20 \%$ in the last two decades-, mainly due to the renewable integration decoupled from the grid -from $14 \%$ in 1996 to $31 \%$ in $2016-$. With regard to wind turbines, they present inertia values similar to conventional generation units -between 2 and $6 \mathrm{~s}$ depending on technologies-, which is commonly considered as 'emulated hidden inertia'. The paper provides significant information for wind turbines frequency control strategies and studies of current power systems with high renewable energy source integration.

\section{Funding}

This work was supported by the Spanish Education, Culture and Sports Ministry [FPU16/04282].

\section{References}

[1] R. D'hulst, J. M. Fernandez, E. Rikos, D. Kolodziej, K. Heussen, D. Geibelk, A. Temiz, C. Caerts, Voltage and frequency control for future power systems: the ELECTRA IRP proposal, in: Smart Electric Distribution Systems and Technologies (EDST), 2015 International Symposium on, IEEE, 2015, pp. 245-250.

[2] I. Hadjipaschalis, A. Poullikkas, V. Efthimiou, Overview of current and future energy storage technologies for electric power applications, Renewable and sustainable energy reviews 13 (6-7) (2009) 1513-1522.

[3] H. Bevrani, A. Ghosh, G. Ledwich, Renewable energy sources and frequency regulation: survey and new perspectives, IET Renewable Power Generation 4 (5) (2010) 438-457.

[4] The European power sector in 2017. State of affairs and review of current developments, Tech. rep., Agora Energiewende and Sandbag (Jan. 2018).

[5] B. Zakeri, S. Syri, S. Rinne, Higher renewable energy integration into the existing energy system of Finland-is there any maximum limit?, Energy 92 (2015) 244-259.

[6] S. Weitemeyer, D. Kleinhans, T. Vogt, C. Agert, Integration of Renewable Energy Sources in future power systems: the role of storage, Renewable Energy 75 (2015) 14-20.

[7] D. Groß, F. Dörfler, On the steady-state behavior of low-inertia power systems, IFAC-PapersOnLine 50 (1) (2017) 1073510741.

[8] Technology Roadmap: Solar Photovoltaic Energy, International Energy Agency.

[9] Wind energy in Europe: Scenarios for 2030, Wind Europe.

[10] D. Ochoa, S. Martinez, Fast-frequency response provided by DFIG-wind turbines and its impact on the grid, IEEE Transactions on Power Systems 32 (5) (2017) 4002-4011. doi: 10.1109/TPWRS. 2016.2636374.
[11] R. Shah, N. Mithulananthan, R. Bansal, V. Ramachandaramurthy, A review of key power system stability challenges for large-scale PV integration, Renewable and Sustainable Energy Reviews 41 (Supplement C) (2015) 1423 - 1436. doi:https: //doi.org/10.1016/j.rser.2014.09.027.

[12] P. Tielens, D. Van Hertem, Grid inertia and frequency control in power systems with high penetration of renewables, 2012. URL \$\$Uttps://lirias.kuleuven.be/retrieve/ 182648\$\$DGrid_Inertia_and_Frequency_Control_in_ Power_Systems_with_High_Penetration_of_Renewables. pdf [freelyavailable]

[13] T. H. Mohamed, J. Morel, H. Bevrani, T. Hiyama, Model predictive based load frequency control_design concerning wind turbines, International Journal of Electrical Power \& Energy Systems 43 (1) (2012) 859-867.

[14] I. Erlich, M. Wilch, Primary frequency control by wind turbines, in: Power and Energy Society General Meeting, 2010 IEEE, IEEE, 2010, pp. 1-8.

[15] D. Gautam, L. Goel, R. Ayyanar, V. Vittal, T. Harbour, Control strategy to mitigate the impact of reduced inertia due to doubly fed induction generators on large power systems, IEEE Transactions on Power Systems 26 (1) (2011) 214-224.

[16] N. Nguyen, J. Mitra, Reliability of power system with high wind penetration under frequency stability constraint, IEEE Transactions on Power Systems 33 (1) (2018) 985-994.

[17] P. Du, J. Matevosyan, Forecast system inertia condition and its impact to integrate more renewables, IEEE Transactions on Smart Grid 9 (2) (2018) 1531-1533.

[18] G. Delille, B. Francois, G. Malarange, Dynamic frequency control support by energy storage to reduce the impact of wind and solar generation on isolated power system's inertia, IEEE Transactions on Sustainable Energy 3 (4) (2012) 931-939.

[19] P. Daly, D. Flynn, N. Cunniffe, Inertia considerations within unit commitment and economic dispatch for systems with high non-synchronous penetrations, in: PowerTech, 2015 IEEE Eindhoven, IEEE, 2015, pp. 1-6.

[20] I. Boldea, Synchronous generators, CRC Press, 2015.

[21] A. Fernández-Guillamón, A. Vigueras-Rodríguez, A. MolinaGarcía, Análisis y simulación de estrategias agregadas de control de frecuencia entre grandes parques eólicos y aprovechamientos hidroeléctricos, M.S. thesis, Universidad Politécnica de Cartagena (2017)

[22] P. M. Anderson, A. A. Fouad, Power system control and stability, John Wiley \& Sons, 2008.

[23] P. Dabur, N. K. Yadav, V. K. Tayal, Matlab design and simulation of AGC and AVR for multi-area power system and demand-side management, International Journal of Computer and Electrical Engineering 3 (2) (2011) 259.

[24] R. G. De Almeida, J. P. Lopes, Participation of doubly fed induction wind generators in system frequency regulation, IEEE transactions on power systems 22 (3) (2007) 944-950.

[25] S. Kumal, et al., Agc and avr of interconnected thermal power system while considering the effect of grcs, International Journal of Soft Computing and Engineering (IJSCE) 2.

[26] P. Kundur, N. J. Balu, M. G. Lauby, Power system stability and control, Vol. 7, McGraw-hill New York, 1994.

[27] UNED, Centrales eléctricas, el alternador, 2011.

[28] M. Shahidehpour, M. Eremia, L. Toma, Modeling the main components of the classical power plants, Handbook of Electrical Power System Dynamics: Modeling, Stability, and Control (2013) 137-178.

[29] J. J. Grainger, W. D. Stevenson, Power system analysis, McGraw-Hill, 1994

[30] E. Spahic, D. Varma, G. Beck, G. Kuhn, V. Hild, Impact of reduced system inertia on stable power system operation and an overview of possible solutions, in: Power and Energy Society General Meeting (PESGM), 2016, IEEE, 2016, pp. 1-5.

[31] E. Chiodo, D. Lauria, F. Mottola, On-line Bayes estimation of rotational inertia for power systems with high penetration of renewables. part i: Theoretical methodology, in: 2018 International Symposium on Power Electronics, Electrical Drives, 
Automation and Motion (SPEEDAM), IEEE, 2018, pp. 835840.

[32] A. Ulbig, T. S. Borsche, G. Andersson, Impact of low rotational inertia on power system stability and operation, IFAC Proceedings Volumes 47 (3) (2014) 7290-7297.

[33] H. Huang, F. Li, Sensitivity analysis of load-damping characteristic in power system frequency regulation, IEEE Transactions on Power Systems 28 (2) (2013) 1324-1335.

[34] P. Tielens, D. Van Hertem, The relevance of inertia in power systems, Renewable and Sustainable Energy Reviews 55 (2016) 999-1009.

[35] E. Ali, S. Abd-Elazim, Bacteria foraging optimization algorithm based load frequency controller for interconnected power system, International Journal of Electrical Power \& Energy Systems 33 (3) (2011) 633-638.

[36] K. Sudha, R. V. Santhi, Robust decentralized load frequency control of interconnected power system with generation rate constraint using type-2 fuzzy approach, International Journal of Electrical Power \& Energy Systems 33 (3) (2011) 699-707.

[37] L. Jiang, W. Yao, Q. Wu, J. Wen, S. Cheng, et al., Delaydependent stability for load frequency control with constant and time-varying delays, IEEE Transactions on Power systems 27 (2) (2012) 932.

[38] T. Masuta, A. Yokoyama, Supplementary load frequency control by use of a number of both electric vehicles and heat pump water heaters, IEEE Transactions on smart grid 3 (3) (2012) $1253-1262$

[39] H. Shabani, B. Vahidi, M. Ebrahimpour, A robust pid controller based on imperialist competitive algorithm for loadfrequency control of power systems, ISA transactions 52 (1) (2013) 88-95.

[40] U. K. Rout, R. K. Sahu, S. Panda, Design and analysis of differential evolution algorithm based automatic generation control for interconnected power system, Ain Shams Engineering Journal 4 (3) (2013) 409-421.

[41] R. K. Sahu, S. Panda, U. K. Rout, De optimized parallel 2dof pid controller for load frequency control of power system with governor dead-band nonlinearity, International Journal of Electrical Power \& Energy Systems 49 (2013) 19-33.

[42] M. Sathya, M. M. T. Ansari, Load frequency control using bat inspired algorithm based dual mode gain scheduling of pi controllers for interconnected power system, International Journal of Electrical Power \& Energy Systems 64 (2015) 365-374.

[43] S. Ruiz, J. Patiño, J. Espinosa, et al., Load frequency control of a multi-area power system incorporating variable-speed wind turbines.

[44] L. Dong, Y. Tang, H. He, C. Sun, An event-triggered approach for load frequency control with supplementary adp, IEEE Transactions on Power Systems 32 (1) (2017) 581-589.

[45] C. Peng, J. Zhang, H. Yan, Adaptive event-triggering $h_{\infty}$ load frequency control for network-based power systems, IEEE Transactions on Industrial Electronics 65 (2) (2018) 16851694.

[46] Y. Wu, Z. Wei, J. Weng, X. Li, R. H. Deng, Resonance attacks on load frequency control of smart grids, IEEE Transactions on Smart Grid 9 (5) (2018) 4490-4502.

[47] International Energy Agency, Total primary energy supply (tpes) by source, year and country. https://www . iea.org/statistics/?country=WORLD\& year $=2016 \&$ category $=$ Key\% 20 indicators\&indicator $=$ TPESbySource\&mode $=$ chart\&categoryBrowse $=$ false\& dataTable=ELECTRICITYANDHEAT\&showDataTable=true, accesed on 17th October 2018.

[48] S. Muyeen, R. Takahashi, T. Murata, J. Tamura, A variable speed wind turbine control strategy to meet wind farm grid code requirements, IEEE Transactions on power systems 25 (1) (2010) 331-340.

[49] J. Zhao, X. Lyu, Y. Fu, X. Hu, F. Li, Coordinated microgrid frequency regulation based on DFIG variable coefficient using virtual inertia and primary frequency control, IEEE Transactions on Energy Conversion 31 (3) (2016) 833-845.
[50] D. Groß, S. Bolognani, B. K. Poolla, F. Dörfler, Increasing the resilience of low-inertia power systems by virtual inertia and damping, in: Bulk Power Systems Dynamics and Control Symposium (IREP), 2017.

[51] T. Kerdphol, F. Rahman, Y. Mitani, K. Hongesombut, S. Küfeoğlu, Virtual inertia control-based model predictive control for microgrid frequency stabilization considering high renewable energy integration, Sustainability 9 (5) (2017) 773.

[52] F. Teng, Y. Mu, H. Jia, J. Wu, P. Zeng, G. Strbac, Challenges on primary frequency control and potential solution from EVs in the future gb electricity system, Applied energy 194 (2017) 353-362.

[53] I. Vokony, Effect of inertia deficit on power system stabilitysynthetic inertia concepts analysis, in: Energy (IYCE), 2017 6th International Youth Conference on, IEEE, 2017, pp. 1-6.

[54] J. Morren, Grid support by power electronic converters of distributed generation units, Ph.D. thesis, TU Delft (2006).

[55] H. Bevrani, T. Ise, Y. Miura, Virtual synchronous generators: A survey and new perspectives, International Journal of Electrical Power \& Energy Systems 54 (2014) 244-254.

[56] H. Gu, R. Yan, T. K. Saha, Minimum synchronous inertia requirement of renewable power systems, IEEE Transactions on Power Systems 33 (2) (2017) 1533-1543.

[57] P. Tielens, D. Van Hertem, Receding horizon control of wind power to provide frequency regulation, IEEE Transactions on Power Systems 32 (4) (2017) 2663-2672.

[58] B. Kroposki, B. Johnson, Y. Zhang, V. Gevorgian, P. Denholm, B.-M. Hodge, B. Hannegan, Achieving a 100\% renewable grid: Operating electric power systems with extremely high levels of variable renewable energy, IEEE Power and Energy Magazine 15 (2) (2017) 61-73

[59] H. Thiesen, C. Jauch, A. Gloe, Design of a system substituting today's inherent inertia in the European continental synchronous area, Energies 9 (8) (2016) 582.

[60] D. S. Simonetti, A. E. Amorim, F. D. Oliveira, Doubly fed induction generator in wind energy conversion systems, in: Advances in Renewable Energies and Power Technologies, Elsevier, 2018, pp. 461-490.

[61] X. Yingcheng, T. Nengling, Review of contribution to frequency control through variable speed wind turbine, Renewable Energy 36 (6) (2011) 1671-1677.

[62] L. Ruttledge, D. Flynn, Emulated inertial response from wind turbines: gain scheduling and resource coordination, IEEE Transactions on Power Systems 31 (5) (2015) 3747-3755.

[63] J. Van de Vyver, J. D. De Kooning, B. Meersman, L. Vandevelde, T. L. Vandoorn, Droop control as an alternative inertial response strategy for the synthetic inertia on wind turbines, IEEE Transactions on Power Systems 31 (2) (2015) 1129-1138.

[64] Y. Wang, J. Meng, X. Zhang, L. Xu, Control of pmsg-based wind turbines for system inertial response and power oscillation damping, IEEE Transactions on Sustainable Energy 6 (2) (2015) 565-574.

[65] M. Fischer, S. Engelken, N. Mihov, A. Mendonca, Operational experiences with inertial response provided by type 4 wind turbines, IET Renewable Power Generation 10 (1) (2016) 1724.

[66] A. Hosseinipour, H. Hojabri, Virtual inertia control of PV systems for dynamic performance and damping enhancement of dc microgrids with constant power loads, IET Renewable Power Generation 12 (4) (2017) 430-438.

[67] P. Tielens, Operation and control of power systems with low synchronous inertia, Ph.D. thesis, KU Leuven (2017).

[68] S. I. Nanou, A. G. Papakonstantinou, S. A. Papathanassiou, A generic model of two-stage grid-connected pv systems with primary frequency response and inertia emulation, Electric Power Systems Research 127 (2015) 186-196.

[69] J. Liu, D. Yang, W. Yao, R. Fang, H. Zhao, B. Wang, Pv-based virtual synchronous generator with variable inertia to enhance power system transient stability utilizing the energy storage system, Protection and Control of Modern Power Systems 2 (1) (2017) 39. 
[70] Z. X. Tang, Y. S. Lim, S. Morris, J. L. Yi, P. F. Lyons, P. C. Taylor, A comprehensive work package for energy storage systems as a means of frequency regulation with increased penetration of photovoltaic systems, International Journal of Electrical Power \& Energy Systems 110 (2019) 197-207.

[71] L. Yang, Z. Hu, S. Xie, S. Kong, W. Lin, Adjustable virtual inertia control of supercapacitors in pv-based ac microgrid cluster, Electric Power Systems Research 173 (2019) 71-85.

[72] A. G. Rodriguez, A. G. Rodríguez, M. B. Payán, Estimating wind turbines mechanical constants, in: Proc. Int. Conf. Renewable Energies and Power Quality (ICREPQ 07), 2007, pp. $27-30$.

[73] J. Slootweg, H. Polinder, W. Kling, Representing wind turbine electrical generating systems in fundamental frequency simulations, IEEE Transactions on energy conversion 18 (4) (2003) $516-524$.

[74] S. K. Salman, A. L. Teo, Windmill modeling consideration and factors influencing the stability of a grid-connected wind power-based embedded generator, IEEE Transactions on Power Systems 18 (2) (2003) 793-802.

[75] M. Kalantar, et al., Dynamic behavior of a stand-alone hybrid power generation system of wind turbine, microturbine, solar array and battery storage, Applied energy 87 (10) (2010) 30513064 .

[76] T. Littler, B. Fox, D. Flynn, Measurement-based estimation of wind farm inertia, in: Power Tech, 2005 IEEE Russia, IEEE, 2005, pp. 1-5.

[77] G. Lalor, A. Mullane, M. O'Malley, Frequency control and wind turbine technologies, IEEE Transactions on power systems 20 (4) (2005) 1905-1913.

[78] J. Morren, S. W. H. de Haan, W. L. Kling, J. A. Ferreira, Wind turbines emulating inertia and supporting primary frequency control, IEEE Transactions on Power Systems 21 (1) (2006) 433-434. doi:10.1109/TPWRS. 2005.861956.

[79] N. R. Ullah, T. Thiringer, D. Karlsson, Temporary primary frequency control support by variable speed wind turbinespotential and applications, IEEE Transactions on Power Systems 23 (2) (2008) 601-612.

[80] T. Ackermann, Wind power in power systems, John Wiley \& Sons, 2005

[81] J. B. Ekanayake, L. Holdsworth, X. Wu, N. Jenkins, Dynamic modeling of doubly fed induction generator wind turbines, IEEE transactions on power systems 18 (2) (2003) 803-809.

[82] R. G. de Almeida, E. D. Castronuovo, J. P. Lopes, Optimum generation control in wind parks when carrying out system operator requests, IEEE transactions on power systems 21 (2) (2006) 718-725.

[83] M. Kayikçi, J. V. Milanovic, Dynamic contribution of DFIGbased wind plants to system frequency disturbances, IEEE Transactions on Power Systems 24 (2) (2009) 859-867.

[84] L. Qu, W. Qiao, Constant power control of DFIG wind turbines with supercapacitor energy storage, IEEE Transactions on Industry Applications 47 (1) (2011) 359-367.

[85] L. Holdsworth, X. Wu, J. B. Ekanayake, N. Jenkins, Comparison of fixed speed and doubly-fed induction wind turbines during power system disturbances, IEE Proceedings-Generation, Transmission and Distribution 150 (3) (2003) 343-352.

[86] A. Perdana, O. Carlson, J. Persson, Dynamic response of gridconnected wind turbine with doubly fed induction generator during disturbances, in: Nordic workshop on power and industrial electronics, Vol. 1, Citeseer, 2004, pp. 1-7.

[87] L. Xu, L. Yao, C. Sasse, Grid integration of large DFIGbased wind farms using vsc transmission, IEEE Transactions on Power Systems 22 (3) (2007) 976-984.

[88] R. Gagnon, G. Sybille, S. Bernard, D. Paré, S. Casoria, C. Larose, Modeling and real-time simulation of a doubly-fed induction generator driven by a wind turbine, in: Intl. Conference on Power Systems Transients, Canada, 2005.

[89] M. F. M. Arani, E. F. El-Saadany, Implementing virtual inertia in DFIG-based wind power generation, IEEE Transactions on Power Systems 28 (2) (2013) 1373-1384.
[90] L. Yang, Z. Xu, J. Ostergaard, Z. Y. Dong, K. P. Wong, Advanced control strategy of DFIG wind turbines for power system fault ride through, IEEE Transactions on power systems 27 (2) (2012) 713-722.

[91] L. Xu, P. Cartwright, Direct active and reactive power control of DFIG for wind energy generation, IEEE Transactions on energy conversion 21 (3) (2006) 750-758.

[92] J. Ekanayake, L. Holdsworth, N. Jenkins, Comparison of 5th order and 3rd order machine models for doubly fed induction generator (dfig) wind turbines, Electric Power Systems Research 67 (3) (2003) 207-215.

[93] A. Westlake, J. Bumby, E. Spooner, Damping the powerangle oscillations of a permanent-magnet synchronous generator with particular reference to wind turbine applications, IEE Proceedings-Electric Power Applications 143 (3) (1996) 269280

[94] D. Rasolomampionona, A modified power system model for agc analysis, in: PowerTech, 2009 IEEE Bucharest, IEEE, 2009, pp. $1-6$.

[95] H. Bevrani, P. R. Daneshmand, Fuzzy logic-based loadfrequency control concerning high penetration of wind turbines, IEEE systems journal 6 (1) (2012) 173-180.

[96] L. L. Grigsby, Power system stability and control, CRC press, 2016.

[97] B. Ozer, O. Arikan, G. Moral, A. Altintas, Extraction of primary and secondary frequency control from active power generation data of power plants, International Journal of Electrical Power \& Energy Systems 73 (2015) 16-22.

[98] C. Zhao, E. Mallada, F. Dörfler, Distributed frequency control for stability and economic dispatch in power networks, in: 2015 American Control Conference (ACC), IEEE, 2015, pp. 23592364 .

[99] A. M. Ersdal, L. Imsland, K. Uhlen, Model predictive loadfrequency control, IEEE Transactions on Power Systems 31 (1) (2016) $777-785$

[100] C. Zhao, U. Topcu, N. Li, S. Low, Design and stability of load-side primary frequency control in power systems, IEEE Transactions on Automatic Control 59 (5) (2014) 1177-1189.

[101] S. K. Pandey, S. R. Mohanty, N. Kishor, A literature survey on load-frequency control for conventional and distribution generation power systems, Renewable and Sustainable Energy Reviews 25 (2013) 318-334.

[102] J. Li, R. Xiong, Q. Yang, F. Liang, M. Zhang, W. Yuan, Design/test of a hybrid energy storage system for primary frequency control using a dynamic droop method in an isolated microgrid power system, Applied Energy 201 (2017) 257-269.

[103] J. M. Guerrero, J. C. Vasquez, J. Matas, M. Castilla, L. G. de Vicuna, Control strategy for flexible microgrid based on parallel line-interactive ups systems, IEEE Transactions on industrial Electronics 56 (3) (2009) 726-736.

[104] Continental europe operation handbook - p1, Tech. rep., European Network of Transmission System Operators for Electricity.

[105] J. W. Simpson-Porco, Q. Shafiee, F. Dörfler, J. C. Vasquez, J. M. Guerrero, F. Bullo, Secondary frequency and voltage control of islanded microgrids via distributed averaging., IEEE Trans. Industrial Electronics 62 (11) (2015) 7025-7038.

[106] Z. Miao, L. Fan, Achieving economic operation and secondary frequency regulation simultaneously through feedback control, IEEE Transactions on Power Systems 31 (4) (2016) 3324-3325.

[107] J. Tan, Y. Zhang, I. Krad, V. Gevorgian, E. Ela, Investigating power system primary and secondary reserve interaction under high wind power penetration using frequency response model, in: Proc. Grid Future Symp., 2015, pp. 1-6.

[108] M. Perninge, R. Eriksson, Optimal tertiary frequency control in power systems with market-based regulation, IFACPapersOnLine 50 (1) (2017) 4374-4381.

[109] T. Qureshi, R. Alvi, A review on secondary and tertiary control structures for microgrid.

[110] W. Li, P. Du, N. Lu, Design of a new primary frequency control market for hosting frequency response reserve offers from both 
generators and loads, IEEE Transactions on Smart Grid.

[111] M. Nedd, C. Booth, K. Bell, Potential solutions to the challenges of low inertia power systems with a case study concerning synchronous condensers, in: Universities Power Engineering Conference (UPEC), 2017 52nd International, IEEE, 2017, pp. 1-6.

[112] A. Ulbig, T. S. Borsche, G. Andersson, Analyzing rotational inertia, grid topology and their role for power system stability, IFAC-PapersOnLine 48 (30) (2015) 541-547.

[113] A. Junyent-Ferr, Y. Pipelzadeh, T. C. Green, Blending hvdclink energy storage and offshore wind turbine inertia for fast frequency response, IEEE Transactions on sustainable energy 6 (3) (2015) 1059-1066.

[114] R. You, B. Barahona, J. Chai, N. A. Cutululis, X. Wu, Improvement of grid frequency dynamic characteristic with novel wind turbine based on electromagnetic coupler, Renewable Energy 113 (2017) 813-821.

[115] J. Marcos, O. Storkël, L. Marroyo, M. Garcia, E. Lorenzo, Storage requirements for pv power ramp-rate control, Solar Energy 99 (2014) 28-35.

[116] N. B. Salim, H. Aboelsoud, T. Tsuji, T. Oyama, K. Uchida, Load frequency control of two-area network using renewable energy resources and battery energy storage system., Journal of Electrical Systems 13 (2).

[117] Z. Zhao, H. Xiao, Y. Yang, Improved coordinated control strategy of hybrid energy storages in pv power smoothing, Energy Procedia 145 (2018) 151-156.

[118] M. Taghizadeh, M. Hoseintabar, J. Faiz, Frequency control of isolated wt/pv/sofc/uc network with new control strategy for improving sofc dynamic response, International Transactions on Electrical Energy Systems 25 (9) (2015) 1748-1770.

[119] S. You, Y. Liu, J. Tan, M. T. Gonzalez, X. Zhang, Y. Zhang, Y. Liu, Comparative assessment of tactics to improve primary frequency response without curtailing solar output in high photovoltaic interconnection grids, IEEE Transactions on Sustainable Energy.

[120] W. Ziping, G. Wenzhong, G. Tianqi, Y. Weihang, H. ZHANG, Y. Shijie, W. Xiao, State-of-the-art review on frequency response of wind power plants in power systems, Journal of Modern Power Systems and Clean Energy (2017) 1-16.

[121] H. Xin, Y. Liu, Z. Wang, D. Gan, T. Yang, A new frequency regulation strategy for photovoltaic systems without energy storage, IEEE Trans. Sustain. Energy 4 (4) (2013) 985-993.

[122] H. Alatrash, A. Mensah, E. Mark, G. Haddad, J. Enslin, Generator emulation controls for photovoltaic inverters, IEEE Transactions on Smart Grid 3 (2) (2012) 996-1011.

[123] P. Zarina, S. Mishra, P. Sekhar, Deriving inertial response from a non-inertial pv system for frequency regulation, in: Power Electronics, Drives and Energy Systems (PEDES), 2012 IEEE International Conference on, IEEE, 2012, pp. 1-5.

[124] P. Zarina, S. Mishra, P. Sekhar, Photovoltaic system based transient mitigation and frequency regulation, in: India Conference (INDICON), 2012 Annual IEEE, IEEE, 2012, pp. $1245-1249$.

[125] S. Mishra, P. Zarina, P. Sekhar, A novel controller for frequency regulation in a hybrid system with high pv penetration, in: Power and Energy Society General Meeting (PES), 2013 IEEE, IEEE, 2013, pp. 1-5.

[126] C. Rahmann, A. Castillo, Fast frequency response capability of photovoltaic power plants: The necessity of new grid requirements and definitions, Energies 7 (10) (2014) 6306-6322.

[127] P. Zarina, S. Mishra, P. Sekhar, Exploring frequency control capability of a pv system in a hybrid pv-rotating machinewithout storage system, International Journal of Electrical Power \& Energy Systems 60 (2014) 258-267.

[128] P. Moutis, A. Vassilakis, A. Sampani, N. Hatziargyriou, Dc switch driven active power output control of photovoltaic inverters for the provision of frequency regulation, IEEE Transactions on Sustainable Energy 6 (4) (2015) 1485-1493.

[129] L. Xiong, Y. Li, Y. Zhu, P. Yang, Z. Xu, Coordinated control schemes of super-capacitor and kinetic energy of DFIG for system frequency support, Energies 11 (1) (2018) 103.

[130] C. Jauch, S. Hippel, Hydraulic-pneumatic flywheel system in a wind turbine rotor for inertia control, IET Renewable Power Generation 10 (1) (2016) 33-41.

[131] P. Moutis, E. Loukarakis, S. Papathanasiou, N. D. Hatziargyriou, Primary load-frequency control from pitch-controlled wind turbines, in: PowerTech, 2009 IEEE Bucharest, IEEE, 2009, pp. 1-7.

[132] H. Ma, B. Chowdhury, Working towards frequency regulation with wind plants: combined control approaches, IET Renewable Power Generation 4 (4) (2010) 308-316.

[133] P. Moutis, S. A. Papathanassiou, N. D. Hatziargyriou, Improved load-frequency control contribution of variable speed variable pitch wind generators, Renewable Energy 48 (2012) $514-523$

[134] A. Žertek, G. Verbič, M. Pantoš, Optimised control approach for frequency-control contribution of variable speed wind turbines, IET Renewable power generation 6 (1) (2012) 17-23.

[135] L. M. Castro, C. R. Fuerte-Esquivel, J. H. Tovar-Hernández, Solution of power flow with automatic load-frequency control devices including wind farms, IEEE Transactions on power systems 27 (4) (2012) 2186-2195.

[136] K. Vidyanandan, N. Senroy, Primary frequency regulation by deloaded wind turbines using variable droop, IEEE transactions on Power Systems 28 (2) (2013) 837-846.

[137] S. Wang, K. Tomsovic, A novel active power control framework for wind turbine generators to improve frequency response, IEEE Transactions on Power Systems.

[138] X. Zhang, X. Zha, S. Yue, Y. Chen, A frequency regulation strategy for wind power based on limited over-speed de-loading curve partitioning, IEEE Access 6 (2018) 22938-22951.

[139] N. A. Janssens, G. Lambin, N. Bragard, Active power control strategies of DFIG wind turbines, in: Power Tech, 2007 IEEE Lausanne, IEEE, 2007, pp. 516-521.

[140] G. Ramtharan, N. Jenkins, J. Ekanayake, Frequency support from doubly fed induction generator wind turbines, IET Renewable Power Generation 1 (1) (2007) 3-9.

[141] A. S. Alsharafi, A. H. Besheer, H. M. Emara, Primary frequency response enhancement for future low inertia power systems using hybrid control technique, Energies 11 (4) (2018) 699

[142] M. F. Arani, Y. A. I. Mohamed, Dynamic droop control for wind turbines participating in primary frequency regulation in microgrids, IEEE Transactions on Smart Grid.

[143] P. Lertapanon, W. Wangdee, Analysis and modeling of wind turbine generators considering frequency controls, in: Electrical Engineering Congress (iEECON), 2017 International, IEEE, 2017, pp. 1-4.

[144] L. Huang, H. Xin, L. Zhang, Z. Wang, K. Wu, H. Wang, Synchronization and frequency regulation of DFIG-based wind turbine generators with synchronized control, IEEE Transactions on Energy Conversion 32 (3) (2017) 1251-1262.

[145] M. Deepak, R. J. Abraham, F. M. Gonzalez-Longatt, D. M. Greenwood, H.-S. Rajamani, A novel approach to frequency support in a wind integrated power system, Renewable Energy 108 (2017) 194-206.

[146] H. Ye, W. Pei, Z. Qi, Analytical modeling of inertial and droop responses from a wind farm for short-term frequency regulation in power systems, IEEE Transactions on Power Systems 31 (5) (2016) 3414-3423.

[147] F. Gonzalez-Longatt, E. Chikuni, W. Stemmet, K. Folly, Effects of the synthetic inertia from wind power on the total system inertia after a frequency disturbance, in: Power Engineering Society Conference and Exposition in Africa, Citeseer, 2012, pp. 9-13.

[148] A. Bonfiglio, M. Invernizzi, A. Labella, R. Procopio, Design and implementation of a variable synthetic inertia controller for wind turbine generators, IEEE Transactions on Power Systems.

[149] K. Liu, Y. Qu, H.-M. Kim, H. Song, Avoiding frequency second dip in power unreserved control during wind power rotational 
speed recovery, IEEE Transactions on Power Systems 33 (3) (2018) 3097-3106.

[150] M. Dreidy, H. Mokhlis, S. Mekhilef, Inertia response and frequency control techniques for renewable energy sources: A review, Renewable and Sustainable Energy Reviews 69 (2017) $144-155$.

[151] F. Díaz-González, M. Hau, A. Sumper, O. Gomis-Bellmunt, Participation of wind power plants in system frequency control: Review of grid code requirements and control methods, Renewable and Sustainable Energy Reviews 34 (2014) 551564.

[152] G. C. Tarnowski, P. C. Kjar, P. E. Sorensen, J. Ostergaard, Variable speed wind turbines capability for temporary overproduction, in: Power \& Energy Society General Meeting, 2009. PES'09. IEEE, IEEE, 2009, pp. 1-7.

[153] P.-K. Keung, P. Li, H. Banakar, B. T. Ooi, Kinetic energy of wind-turbine generators for system frequency support, IEEE Transactions on Power Systems 24 (1) (2009) 279-287.

[154] S. El Itani, U. D. Annakkage, G. Joos, Short-term frequency support utilizing inertial response of DFIG wind turbines, in: Power and Energy Society General Meeting, 2011 IEEE, IEEE, 2011, pp. 1-8.

[155] A. D. Hansen, M. Altin, I. D. Margaris, F. Iov, G. C. Tarnowski, Analysis of the short-term overproduction capability of variable speed wind turbines, Renewable Energy 68 (2014) 326-336.

[156] F. Hafiz, A. Abdennour, Optimal use of kinetic energy for the inertial support from variable speed wind turbines, Renewable Energy 80 (2015) 629-643.

[157] M. Kang, K. Kim, E. Muljadi, J.-W. Park, Y. C. Kang, Frequency control support of a doubly-fed induction generator based on the torque limit, IEEE Transactions on Power Systems 31 (6) (2016) 4575-4583.

[158] A. Fernández-Guillamón, J. Villena-Lapaz, A. ViguerasRodríguez, T. García-Sánchez, Á. Molina-García, An adaptive frequency strategy for variable speed wind turbines: Application to high wind integration into power systems, Energies 11 (6) (2018) 1-21.

[159] A. Fernández-Guillamón, A. Vigueras-Rodríguez, E. GómezLázaro, A. Molina-García, Fast power reserve emulation strategy for vswt supporting frequency control in multi-area power systems, Energies 11 (10). doi:10.3390/en11102775. URL http: //www.mdpi.com/1996-1073/11/10/2775

[160] I. D. Margaris, S. A. Papathanassiou, N. D. Hatziargyriou, A. D. Hansen, P. Sorensen, Frequency control in autonomous power systems with high wind power penetration, IEEE Transactions on sustainable energy 3 (2) (2012) 189-199.

[161] L.-R. Chang-Chien, W.-T. Lin, Y.-C. Yin, Enhancing frequency response control by DFIGs in the high wind penetrated power systems, IEEE transactions on power systems 26 (2) (2011) 710-718.

[162] F. Wilches-Bernal, J. H. Chow, J. J. Sanchez-Gasca, A fundamental study of applying wind turbines for power system frequency control, IEEE Transactions on Power Systems 31 (2) (2016) 1496-1505.

[163] W. Zhang, K. Fang, Controlling active power of wind farms to participate in load frequency control of power systems, IET Generation, Transmission \& Distribution 11 (9) (2017) 21942203.

[164] C. Su, Z. Chen, Influence of wind plant ancillary frequency control on system small signal stability, in: Power and Energy Society General Meeting, 2012 IEEE, IEEE, 2012, pp. 1-8.

[165] M. Hwang, E. Muljadi, J.-W. Park, P. Sørensen, Y. C. Kang, Dynamic droop-based inertial control of a doubly-fed induction generator, IEEE Transactions on Sustainable Energy 7 (3) (2016) 924-933

[166] J. Van de Vyver, J. D. De Kooning, B. Meersman, L. Vandevelde, T. L. Vandoorn, Droop control as an alternative inertial response strategy for the synthetic inertia on wind turbines, IEEE Trans. Power Syst 31 (2) (2016) 1129-1138.

[167] M. Kang, J. Lee, K. Hur, S. H. Park, Y. Choy, Y. C. Kang,
Stepwise inertial control of a doubly-fed induction generator to prevent a second frequency dip, Journal of Electrical Engineering \& Technology 10 (6) (2015) 2221-2227.

[168] R. You, B. Barahona, J. Chai, N. A. Cutululis, Frequency support capability of variable speed wind turbine based on electromagnetic coupler, Renewable Energy 74 (2015) 681-688.

[169] Z. Zhang, Y. Wang, H. Li, X. Su, Comparison of inertia control methods for DFIG-based wind turbines, in: ECCE Asia Downunder (ECCE Asia), 2013 IEEE, IEEE, 2013, pp. 960964.

[170] Z.-S. Zhang, Y.-Z. Sun, J. Lin, G.-J. Li, Coordinated frequency regulation by doubly fed induction generator-based wind power plants, IET Renewable Power Generation 6 (1) (2012) 38-47. 



\subsection{An adaptive frequency strategy for variable speed wind turbines: application to high wind integration into power systems}

This paper presents a new frequency controller for VSWTs based on the fast power reserve emulation technique. This scheme has two operation modes (overproduction and recovery), varying the active power provided by the VSWTs through the 'hidden' kinetic inertia stored in their rotating masses. In the overproduction mode, the active power provided by the wind turbines is set over the mechanical power, reducing their rotational speed. This overproduction power is estimated proportional to the frequency excursion. In the recovery mode, the active power is established under the mechanical power to recover the initial rotational speed through a smooth trajectory. The power system considered for simulation purposes includes thermal, hydro-power and wind power plants. The frequency control technique is tested within four different supply-side scenarios, increasing the wind power plants penetration from 15 to $45 \%$, at the time that thermal plants decreased from 73 to $43 \%$. In this way, it is possible to simulate the frequency response of a future power system with high integration of renewable energy sources. Simulations are carried out in Matlab/Simulink. Results show that the nadir (minimum frequency value) can be reduced a $45 \%$ if the wind power plant control strategy proposed participates in frequency control, compared to current situations in which only conventional plants provide frequency control. A secondary frequency dip is identified due to the change from overproduction to recovery periods, consequently increasing the stabilisation time. Results are also compared to a previous proposal, improving nadir, stabilisation time and especially the secondary frequency excursion.

Information of the paper:

- Journal: Energies

- DOI: 10.3390/en11061436

- Date of publication: June 2018

- Available online: https://www.mdpi.com/1996-1073/11/6/1436

- Reference: [2] 

Article

\title{
An Adaptive Frequency Strategy for Variable Speed Wind Turbines: Application to High Wind Integration Into Power Systems
}

\author{
Ana Fernández-Guillamón 1,*iD), Jorge Villena-Lapaz ${ }^{2}$, Antonio Vigueras-Rodríguez ${ }^{3}$ (D), \\ Tania García-Sánchez ${ }^{4}$ and Ángel Molina-García 1 (iD \\ 1 Department of Electrical Engineering, Universidad Politécnica de Cartagena, 30202 Cartagena, Spain; \\ angel.molina@upct.es \\ 2 Alberta Electric System Operator, Calgary, AB T2P 0L4, Canada; jorge.villena@aeso.ca \\ 3 Department of Civil Engineering, Universidad Politécnica de Cartagena, 30203 Cartagena, Spain; \\ avigueras.rodriguez@upct.es \\ 4 Department of Electrical Engineering, Universidad Politécnica de Valencia, 46022 Valencia, Spain; \\ tagarsan@die.upv.es \\ * Correspondence: ana.fernandez@upct.es; Tel.: +34-968-325357
}

Received: 10 May 2018; Accepted: 29 May 2018; Published: 4 June 2018

\begin{abstract}
This paper presents a new frequency controller for variable speed wind turbines connected to the grid under power imbalance conditions. It is based on the fast power reserve emulation technique, having two different operation modes: overproduction and recovery mode. In the first mode, the active power provided by wind turbines is set over the mechanical power, reducing their rotational speed. This overproduction power is estimated according to the frequency excursion. In the second mode, the active power is established under the mechanical power to recover the initial rotational speed through a smooth trajectory. The power system considered for simulation purposes includes thermal, hydro-power and wind-power plants. The controller proposed has been evaluated under different mix-generation scenarios implemented in Matlab/Simulink. Extensive results and comparison to previous proposals are also included in the paper.
\end{abstract}

Keywords: frequency control; wind energy; renewable energy sources integration; power system stability

\section{Introduction}

During the last decade, and due to aspects such as climate change, energy dependence, fossil resource scarcity and the increasing costs of nuclear power [1], most developed countries have promoted large-scale integration of Renewable Energy Sources (RES), mainly wind and PV power plants [2]. This relevant integration of RES has raised important concerns in terms of grid stability and reliability, mainly due to: (i) the nature of RES power variation [3] as well as the uncertainty in the privately-owned renewable generators that puts the generation-load balance at risk [4]; (ii) the reduction of the total system inertia by the decoupling between rotor mechanical speed and grid frequency [5], or even the absence of rotating machines [6]. As the system inertia decreases, an increase of primary frequency control (PFC) reserves is needed [7]. Traditionally, PFC reserves are provided by synchronous generators [8], as depicted in Figure 1a. Under power imbalance conditions, PFC reserves from conventional generation are traditionally released to compensate the disturbance and recover the rate grid frequency. If these reserves cannot compensate for the mismatch, it could cause a sharp decrease of the system frequency [9]. With the relevant penetration of wind power plants, some proportional capacity of the system reserves must be provided by them $[7,10]$ see Figure $1 \mathrm{~b}$. 
Additional reserves can be then provided by renewables, reducing the primary reserves from conventional generation units and providing enhanced solutions for weak and/or isolated power systems $[9,11]$. Under this scenario of high RES penetration, transmission system operators have required that not only conventional utilities contribute to ancillary services [12], but also renewables, especially wind power plants [13]. Indeed, [14] affirms that the participation of the wind power plants in the ancillary services such as grid frequency control becomes inevitable. For this reason, frequency control strategies are being developed to effectively integrate Variable Speed Wind Turbines (VSWTs) into the grid, in order to replace conventional power plants by maintaining a secure power system operation [15]. Most of them are based on 'hidden inertia emulation', in order to enhance the inertia response of VSWTs $[16,17]$. A classification for different control strategies based on principles for inertia emulation concept can be found in [18]. One of the possible solutions to overcome this is called fast power reserve emulation. It is based on supplying the kinetic energy stored in the rotating masses to the grid as an additional active power, being afterwards recovered through an under-production period (recovery). Overproduction is defined in the specific literature over the electrical pre-event power reference [19-24] and the overproduction power is considered as constant and independent from the frequency excursion severity [21-23]. Other proposals define the time that the wind power plant must be overproducing independently from the event [19-22] or consider that it should last until the wind turbine achieves its minimum speed limit [23]. Moreover, the transition from overproduction to recovery is defined as an abrupt drop in the active generated power by VSWTs $[21,23,24]$ or as a constant slope [19,22]. A different strategy is described in [20], where the VSWTs of the wind power plant are designed to recover at different times, avoiding 'synchronization'. Most contributions consider a low wind energy integration for simulations, between 10 and $20 \%[19,20,22]$, and only recent contributions analyze penetration level scenarios up to $40 \%$ [10]. However, the renewable share is currently over $20 \%$ in different power systems. Actually, some countries have already experienced instantaneous penetration higher than 50\% (i.e., Spain, Portugal, Ireland, Germany and Denmark) [25]. Subsequently, scenarios with a very relevant integration of wind energy should be considered and evaluated.

To overcome these drawbacks, and with the aim of improving the frequency response of power systems with massive wind energy penetration, this paper describes and evaluates an alternative fast power reserve emulation controller. The main contributions of this paper are summarized as follows:

- The active power provided by VSWTs during the overproduction operation mode is defined over the mechanical power instead of the pre-event electrical power. Such mechanical power varies with the rotational speed instead of keeping constant as the former one. Moreover, the overproduction power is estimated according to the frequency excursion, being thus an 'adaptive' overproduction strategy.

- The active power provided by VSWTs during the recovery operation mode is defined below the mechanical power to recover the rotational energy delivered in the overproduction mode. It is defined as a parabolic trajectory until the rotational speed reaches the maximum power tracking curve. Thereafter, that curve is followed. Because of that, it is considered as a 'smooth' recovery period.

- The control strategy proposed has been tested under different scenarios, considering a maximum wind energy integration of $45 \%$. In all the scenarios, the proposed solution reduces significantly the grid frequency deviations under power imbalance conditions.

The rest of the paper is organized as follows: in Section 2 the proposed frequency controller for VSWTs is described and compared to previous approaches. The power system and the different scenarios needed to assess the proposed control are discussed in Section 3. Simulation results are given in Section 4. Finally, Section 5 gives the conclusions. 


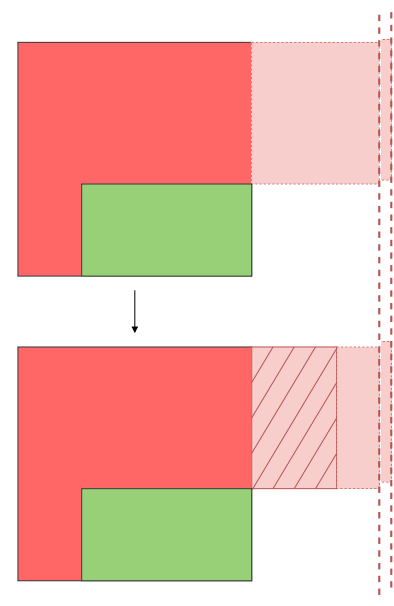

(a)

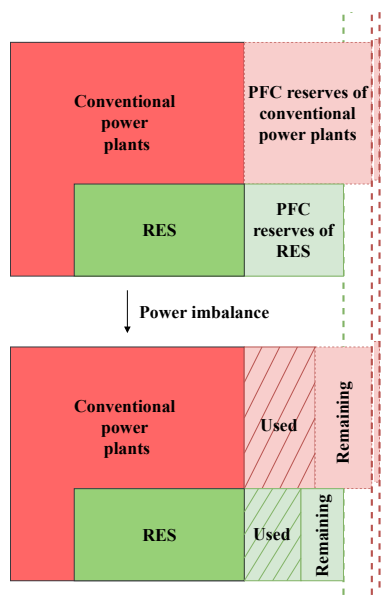

(b)

Figure 1. Change in primary frequency control (PFC) reserves from current to future power systems: (a) Current situation; (b) Future situation.

\section{Proposed Frequency Strategy for Wind Turbines}

A new frequency control strategy for VSWTs is presented in this work. It is based on supplying the kinetic energy stored in the rotating masses of the VSWT in order to enhance its inertial response. Three different operation modes are defined: normal operation, overproduction mode and recovery mode. Each mode sets a different commanded active power $P_{c m d}$ to restore the grid frequency after a power imbalance. In Figure 2, a general scheme of the proposed VSWTs frequency controller is shown.

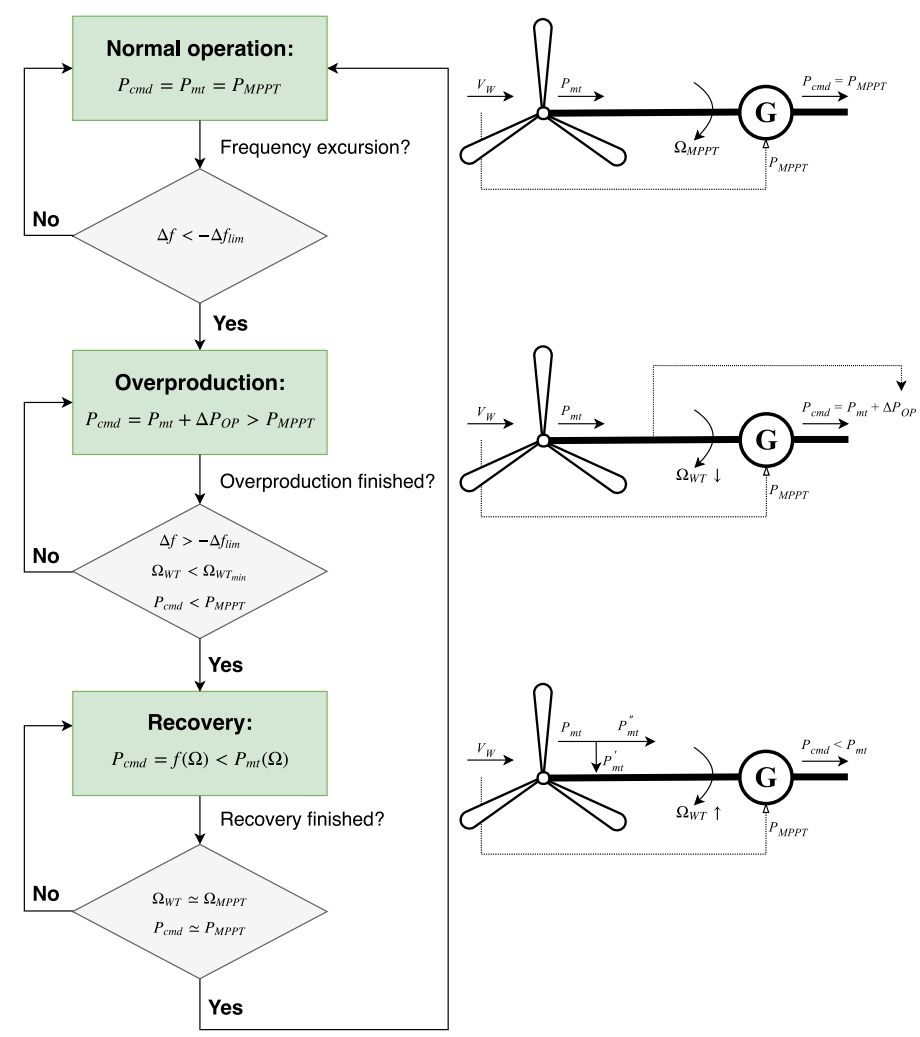

Figure 2. Scheme of the proposed Variable Speed Wind Turbines (VSWTs) frequency controller. 


\subsection{Normal Operation Mode}

The VSWTs operate at a certain point $P_{c m d}$ according to their mechanical curve $P_{m t}\left(\Omega_{W T}\right)$. The power controller compensates any change in the rotational speed $\Omega_{W T}$ or in the wind speed $V_{W}$, tracking the maximum available active power for a current wind speed $P_{M P P T}\left(V_{W}\right)$.

Under power imbalance conditions, and assuming a power supply-side decreasing, a frequency (negative) deviation $\Delta f$ is suffered by the power system. The proposed frequency controller is then initialized through an adaptive overproduction strategy:

$$
\Delta f<-\Delta f_{\text {lim }} \rightarrow \text { Overproduction. }
$$

\subsection{Overproduction Operation Mode}

The active power provided by the VSWTs, $P_{c m d}$, involves the mechanical power $P_{m t}\left(\Omega_{W T}\right)$ obtained from the wind and an additional active power $\Delta P_{O P}$ taken from the rotational speed energy stored in the rotor, $P_{c m d}=P_{m t}\left(\Omega_{W T}\right)+\Delta P_{O P}$. The proposed strategy results in a rotational speed decreasing, and subsequently a reduction of the mechanical power provided by the blades. Regarding to the additional power $\Delta P_{O P}$, it is estimated proportionally to the frequency excursion evolution, see Figure 3, which gives an adaptive response depending on the frequency excursion severity and thus emulating PFC of conventional generation units $[26,27]$. This strategy gives a more realistic scenario, a smoother response and, additionally, provides a frequency response in line with conventional primary frequency performances. Previous approaches assume the overproduction as a constant value and independent on the frequency excursion [21-23]. Moreover, the overproduction mode defined in this work considers that mechanical power $P_{m t}$ depends on the rotational speed $P_{m t}\left(\Omega_{W T}\right)$, whereas most authors assumed that mechanical power was constant when rotational speed decreased [19-24]. This overproduction strategy remains active until the frequency excursion disappears, the rotational speed reaches a minimum allowed value, or the commanded power is lower than the maximum available active power.

$$
\Delta f>-\Delta f_{\text {lim }} \text { or } \Omega_{W T}<\Omega_{W T, m i n} \text { or } P_{c m d}<P_{M P P T}\left(\Omega_{M P P T}\right) \rightarrow \text { Recovery. }
$$

In previous contributions, the minimum rotational speed was considered as a constant value; i.e., $\Omega_{W T, \min }=0.7 \mathrm{pu}$ in [23]. Under this assumption, the rotational speed deviation interval, $\Delta \Omega$ depends on the initial rotational speed value $\Omega_{M P P T}$, giving different regulation ranges. To improve this solution, the minimum rotational speed is proposed to be determined according to the initial value $\Omega_{M P P T}$, being thus $\Omega_{W T \text {,min }}=0.7 \cdot \Omega_{M P P T}$. This way, $\Omega_{W T, \min }$ is a function of $\Omega_{M P P T}$ and a $30 \%$ of rotational speed deviation is allowed. Figure 4a shows the corresponding $\Delta \Omega_{W T}=\Omega_{M P P T}-\Omega_{W T \text {,min }}$ differences depending on the wind speed values $V_{W}$ considering a fixed $\Omega_{W T \text {, min }}$. Figure $4 \mathrm{~b}$ depicts the proposed definition for $\Omega_{W T \text {, min }}$. In addition, Figure 5 compares the overproduction strategy discussed in [23] and the alternative approach proposed in this work.

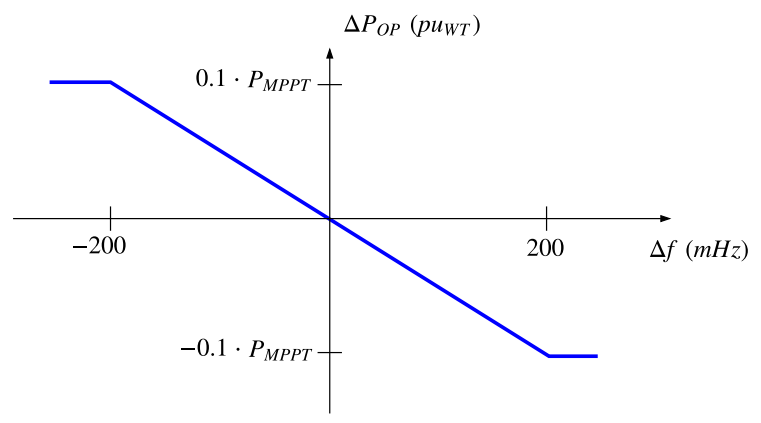

Figure 3. Proposed relationship between $\Delta P_{O P}$ and $\Delta f$ for VSWTs during overproduction. 


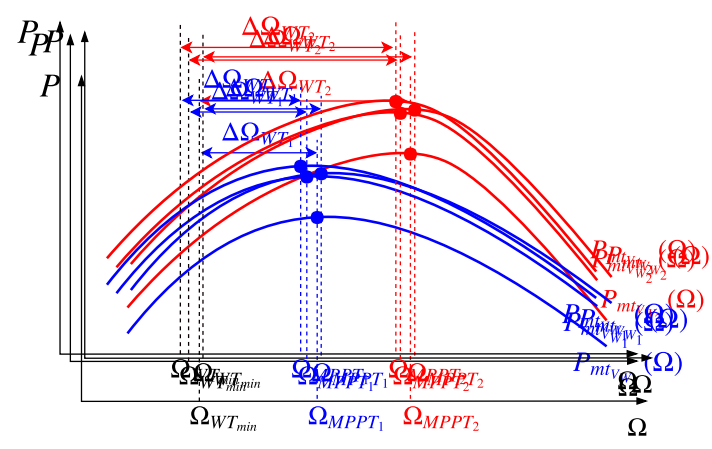

(a)

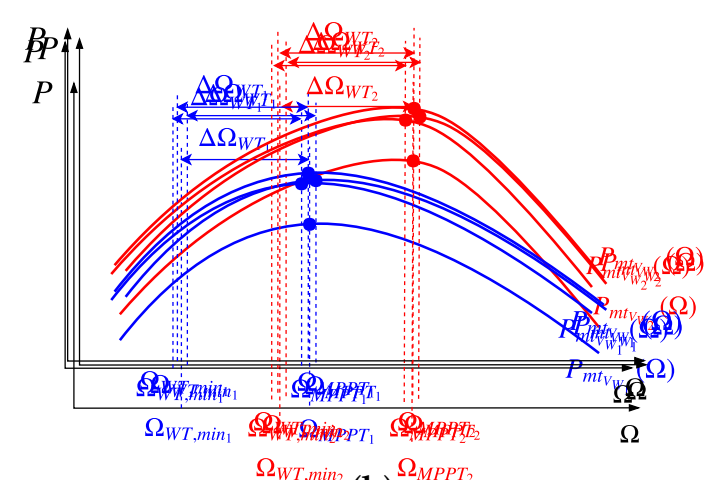

(b)

Figure 4. Comparison between overproduction operation modes. (a) $\Delta \Omega_{W T}$ for different wind speeds $V_{W}$, [23]; (b) Proposed $\Delta \Omega_{W T}$ for different wind speeds $V_{W}$.

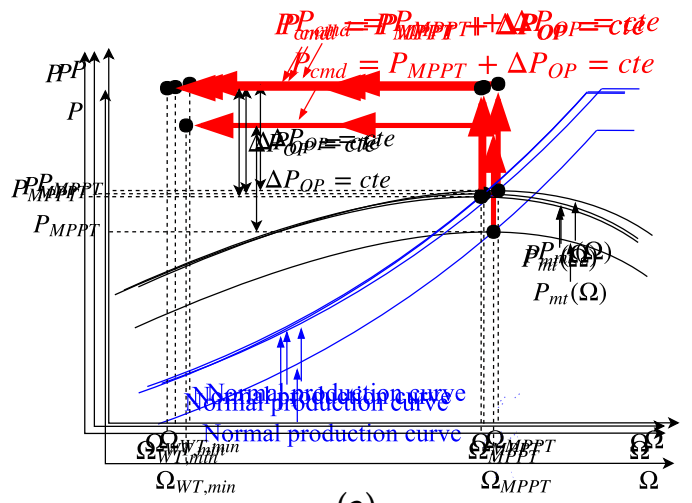

(a)

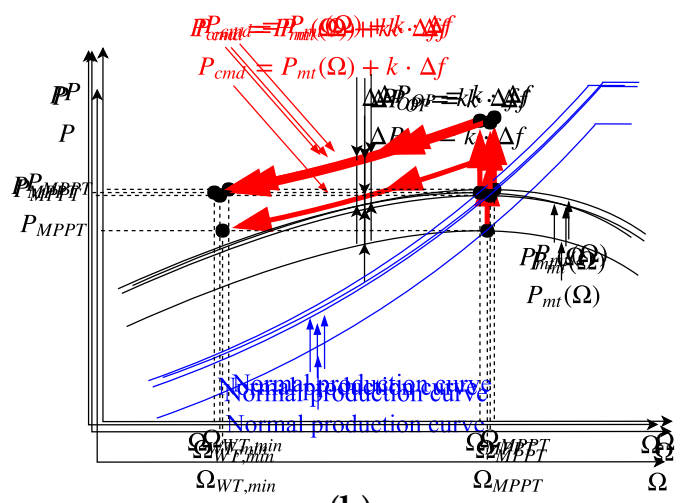

(b)

Figure 5. Comparison between overproduction operation modes; (a) Overproduction operation mode in [23]; (b) Overproduction operation mode proposed.

\subsection{Recovery Operation Mode}

After the overproduction period, a recovery operation mode is proposed to restore the rotational speed to the initial value $\Omega_{M P P T}$ and provide an optimal active power from the VSWTs. With the aim of minimizing undesirable frequency oscillations and abrupt changes from the supply-side, an alternative recovery strategy is defined and evaluated. This proposal is based on a parabolic smooth recovery strategy. Three points are considered to define this trajectory: (i) mechanical power at the minimum rotational speed achieved during the frequency excursion,

$$
P_{1}:\left(\Omega_{W T, \min }, P_{m t}\left(\Omega_{W T, \min }\right)\right) \text {. }
$$

(ii) mechanical power corresponding to the middle rotational speed deviation,

$$
P_{2}:\left(\Omega_{V}, P_{M P P T}\left(\Omega_{V}\right)\right),
$$

where $\Omega_{V}$ is $\Omega_{W T, m i n}+0.5 \cdot \Delta \Omega$, and $\Delta \Omega$ is $\Omega_{M P P T}-\Omega_{W T \text {,min }}$. (iii) maximum mechanical power available according to the wind speed,

$$
P_{3}:\left(\Omega_{M P P T}, P_{M P P T}\left(\Omega_{M P P T}\right)\right) .
$$


The commanded power before achieving $P_{2}$ is determined according to $P_{c m d}=a \cdot \Omega_{W T}^{2}+b \cdot \Omega_{W T}+c$, where $a, b$ and $c$ can be estimated by considering the three mechanical power points aforementioned. Finally, the commanded power tracks the maximum power curve available according to the power wind speed curve: $P_{c m d}=P_{M P P T}\left(\Omega_{W T}\right)$. The normal operation mode is then recovered when either $\Omega_{M P P T}$ or $P_{M P P T}\left(\Omega_{M P P T}\right)$ are respectively achieved,

$$
\Omega_{W T} \simeq \Omega_{M P P T} \text { or } \quad P_{c m d} \simeq P_{M P P T}\left(\Omega_{M P P T}\right) \rightarrow \text { Normal operation. }
$$

In [23] the recovery period is defined as $P_{c m d}=P_{m t}-P_{a c c}$, being $P_{a c c}$ a constant underproduction power value. Under this assumption, the higher $P_{a c c}$, the faster the rotational speed recovers its optimal initial value $\Omega_{M P P T}$. Despite the fact that a value of $P_{a c c}=0.02 \mathrm{pu}$ was fixed, the fast and abrupt transition from overproduction to recovery operation mode may cause an additional and severe frequency oscillation. The recovery operation mode defined in this work determines the trajectory followed by the wind farm instead of fixing a certain underproduction power, $P_{a c c}$. In Figure 6, a comparison between the recovery mode proposed in [23] and the alternative strategy described in this work is depicted. Furthermore, the recovery operation mode has been improved by modifying $P_{2}$. The power in point $P_{2}$ is then defined in accordance to the differences between $P_{M P P T}\left(\Omega_{V}\right)$ and $P_{m t}\left(\Omega_{V}\right), P_{M P P T}\left(\Omega_{V}\right)+x \cdot\left(P_{m t}\left(\Omega_{V}\right)-P_{M P P T}\left(\Omega_{V}\right)\right)$, where $x$ has been considered as $0.25,0.50$ and 0.75 . When $P_{c m d}$ achieves $P_{2 x}$, the active power is above the curve of $P_{M P P T}$ proportionally to the difference between $P_{m t}\left(\Omega_{W T}\right)$ and $P_{M P P T}\left(\Omega_{W T}\right)$, providing an adaptive and smooth recovery response. In Figure 7 , the different proposals for the recovery operation mode are compared.

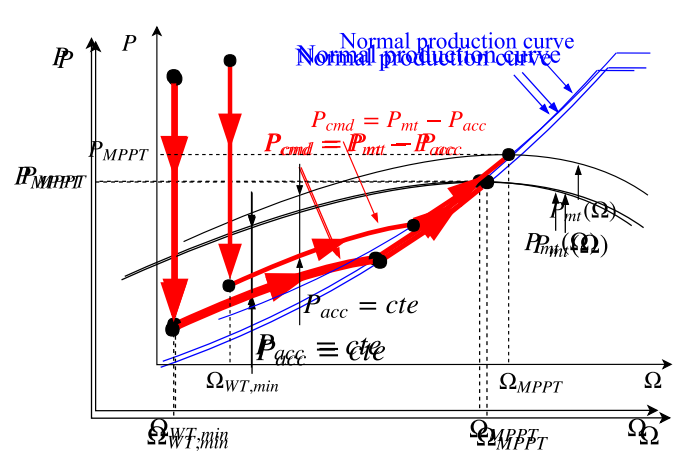

(a)

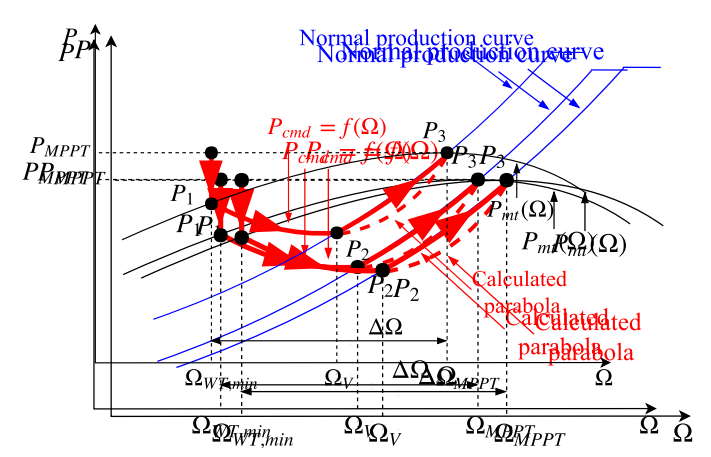

(b)

Figure 6. Comparison between recovery operation modes. (a) Recovery operation mode in [23]; (b) Recovery operation mode proposed.

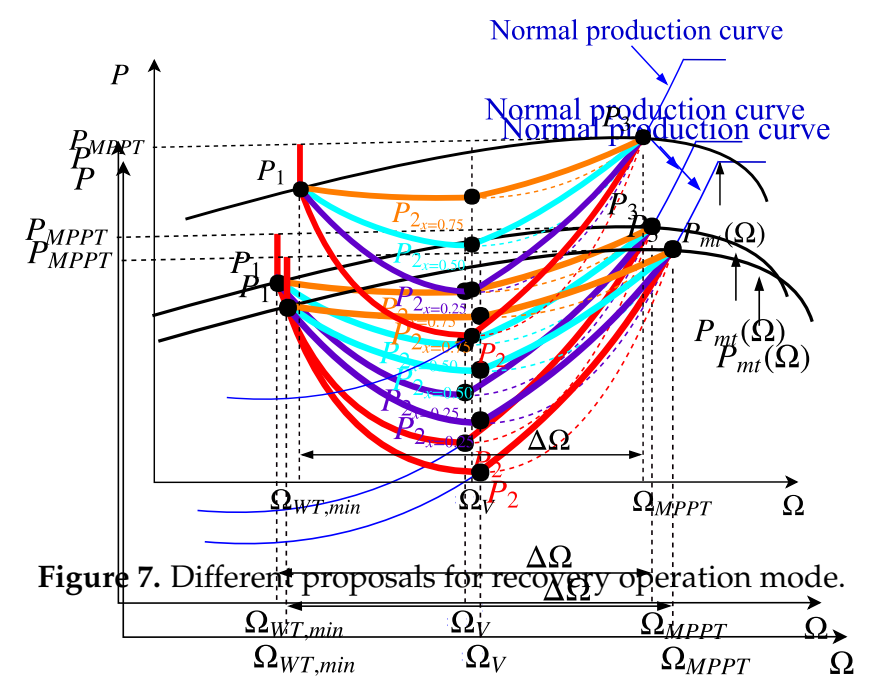




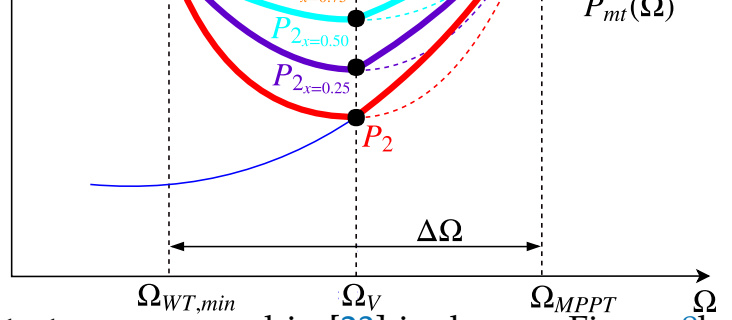

In Figure $8 \mathrm{a}$, the control strategy proposed in [23] is shown. Figure $8 \mathrm{~b}$ summarizes the new approach discussed in this work. Moreover, Figure 9 compares the VSWTs active power variations submitted to a frequency excursion, where $\Delta P_{W F}=P_{c m d}-P_{M P P T}\left(\Omega_{M P P T}\right)$. As can be seen, the proposed strategy offers a more adaptive and smoother power oscillation, which leads to reduce possible frequency oscillations due to abrupt imbalances.

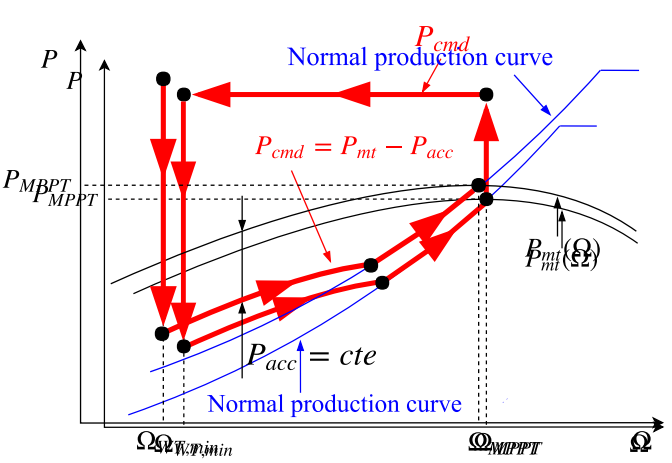

(a)

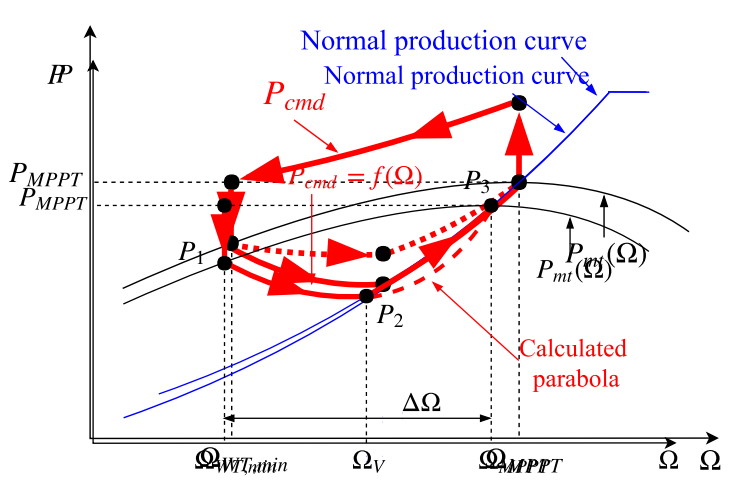

(b)

Figure 8. Comparison of frequency control strategies for VSWT. (a) Control strategy in [23]; (b) Adaptive and smooth proposed control strategy.

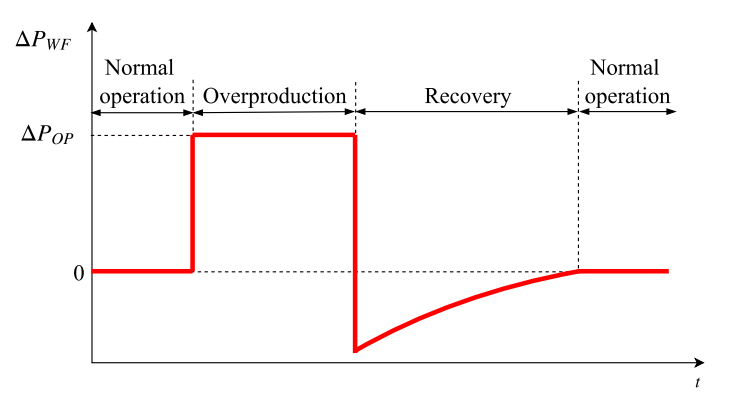

(a)

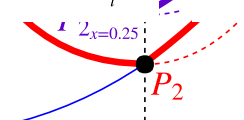

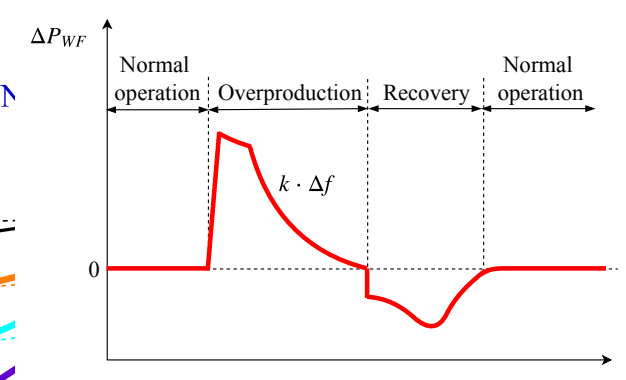

(b)

Figure 9. Additional active power of ind power plants: comparison of strategies. (a) $\Delta P_{W F}$ in [23]; (b) $\Delta P_{W F}$ proposed.

\section{Cases of Study}

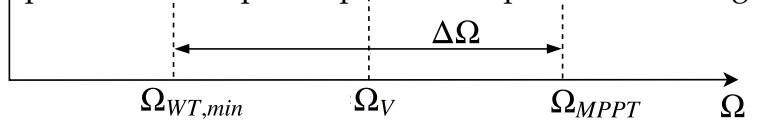

\subsection{Power System Modeling}

From the supply-side, the power system considered for simulation purposes involve conventional generating units such as thermal and hydro-power plants, and wind power plants, Simulations have been carried out in Matlab/Simulink (2016 Student Suite Version, MathWorks, Natick, MA, USA). The total capacity of the power system is $1350 \mathrm{MW}$. Simplified governor-based models have been used to simulate both thermal anddnkydro-power plants aqcording to [26], see Figure 10a,b. In Appendix A, the Pifferen values of the paraters of the block diagrams are presertedd. To simulate the power plant, an equivalent generator with n-times the n $\beta_{M P P T}$ al power of one ind turbinq is assumed [28], being $n$ the total number of turblnes [29,30]. The frequency controller introduced insection 2 is added to the wind power plant model in grder to provide frequency responseduroder powep ingsalances.

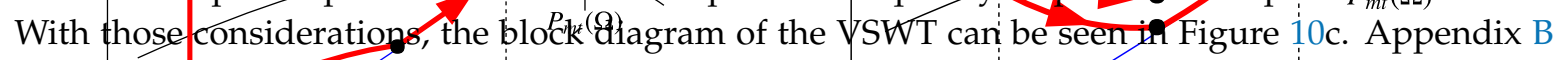
explains the different blocks of the VSWT model.
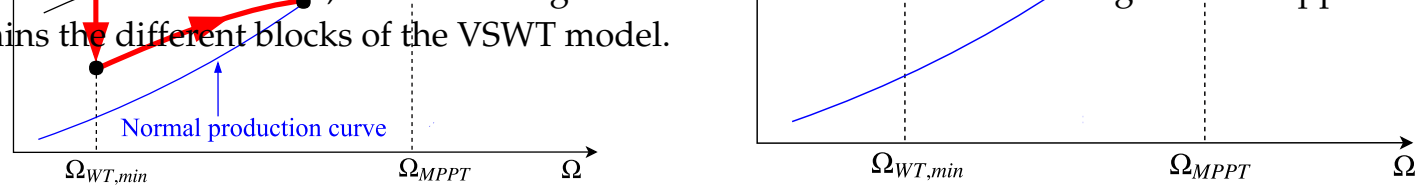


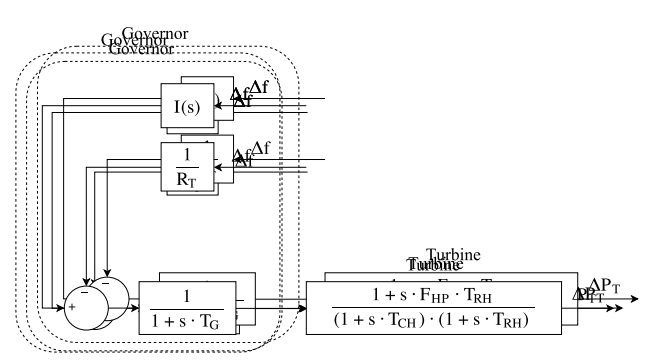

(a)

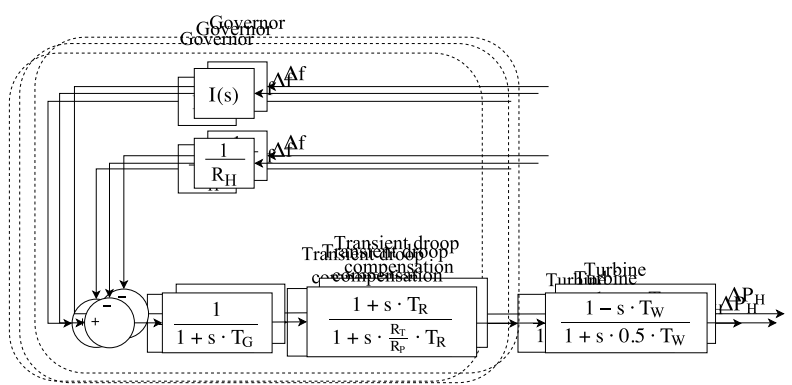

(b)

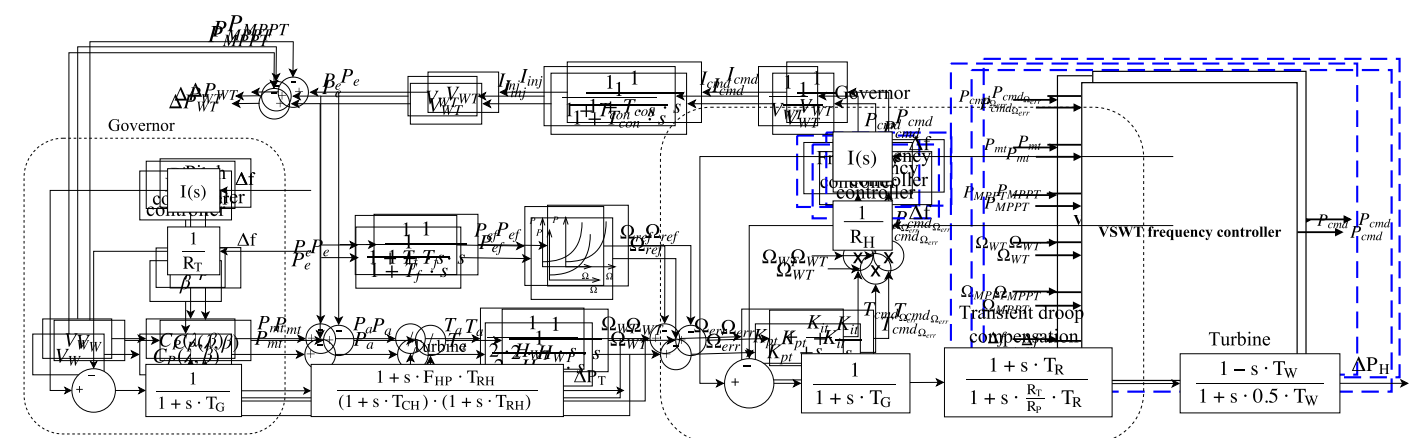

(c)

Figure 10. Powper plants models. (a) Block diagram of a thermal plant model; (b) Block diagram of a hydro-power plant model; (c) Block diagrams of a VSWT model and the proposed freatienev-controtter.

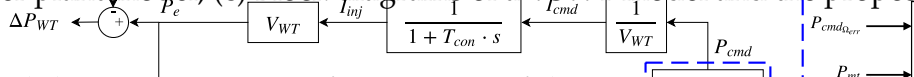

A simplifiedt diagram in terms of variations of the pow erestyste $\mathrm{m}_{1}^{\prime} \mathrm{can}^{P_{m t}} \overrightarrow{\mathrm{be}}$

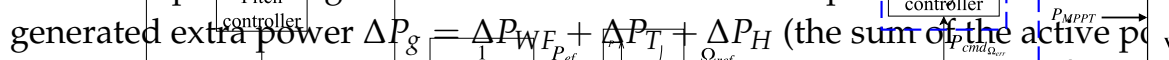

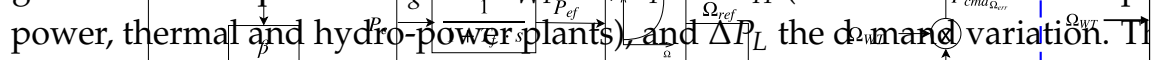
be thus estimated from the following expression,

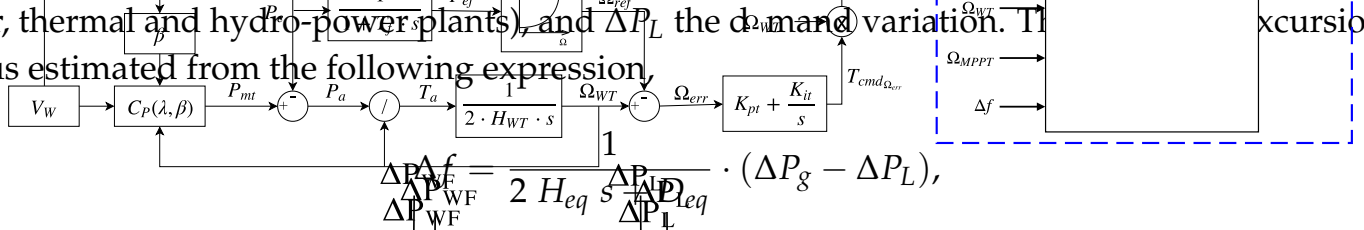

where $D_{e q}$ is the equivalent damping factor of the loads and $H_{e q}$ is the equivalent inertia constant of the system, determind $\mathrm{l}_{\mathrm{a}}$ Equ Eqution

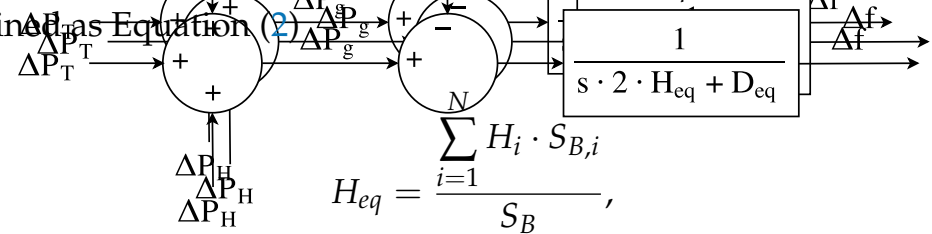

$H_{i}$ refers to the inertia constant of power plant $i, S_{B, i}$ is the rated power of power plant $i, S_{B}$ is the rated power of the power system and $N$ is the total number of conventional generators.

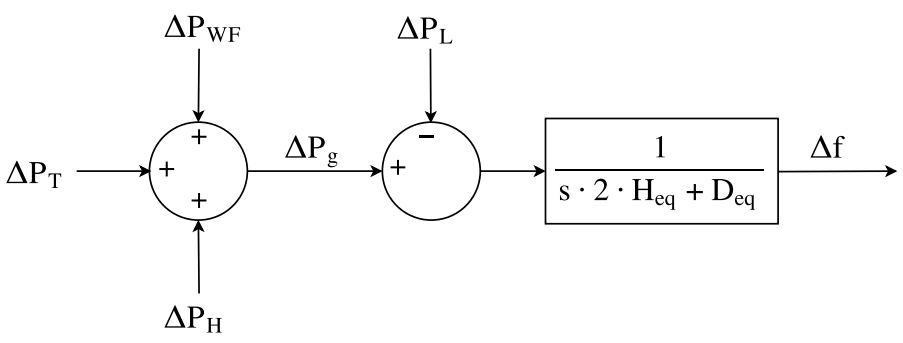

Figure 11. Simplified diagram of the modeled power system. 


\subsection{Description of the Scenarios}

Taking into account the contribution of the different sources from the supply-side in the EU-28 during 2016, see Table 1, four different scenarios have been studied. The first scenario corresponds to the current European supply-side situation, where $75 \%$ comes from thermal power plants (conventional and nuclear plants), $12 \%$ from hydro-power plants and 13\% from non-manageable sources, mainly wind, and other renewables that do not provide frequency control. According to the relevant presence of wind energy, in the rest of scenarios the non-manageable sources have been considered to be just wind power plants. Moreover, the frequency controllers indicated in Section 2 (approach of [23] and the new scheme proposed in this work) have been included in the wind power plant model, keeping constant the capacity of the hydro-power plant (12\%). Both thermal and wind capacities have changed depending on the scenarios in order to simulate a power system with high integration of RES. As a consequence, the total inertia of the power system is reduced, due to the fact that VSWTs and thus wind power plants are decoupled from the grid. The considered scenarios for simulation purposes are summarized in Table 2, where $H_{\ell q}$ has been determined according to Equation (2). To evaluate the VSWTs frequency controller, three power imbalances $\left(\Delta P_{L, 1}=0.025\right.$, $\Delta P_{L, 2}=0.050, \Delta P_{L, 3}=0.100$ ) have been considered, resulting in 12 different scenarios.

Table 1. Contribution of sources in EU-28 in 2016 [31].

\begin{tabular}{cc}
\hline Source & Contribution (\%) \\
\hline Conventional thermal & 48.6 \\
\hline Nuclear & 25.8 \\
\hline Hydro & 12.0 \\
\hline Wind & 9.7 \\
\hline Geothermal & 0.2 \\
\hline Other & 3.7 \\
\hline
\end{tabular}

Table 2. Capacity of each generating unit and total RES integration.

\begin{tabular}{ccccc}
\hline Source & Scenario 1 & Scenario 2 & Scenario 3 & Scenario 4 \\
\hline Thermal plant & $75 \%$ & $73 \%$ & $58 \%$ & $43 \%$ \\
\hline Hydro-power plant & $12 \%$ & $12 \%$ & $12 \%$ & $12 \%$ \\
\hline Wind power plant & Others & $15 \%$ & $30 \%$ & $45 \%$ \\
\hline$H_{e q}$ & $4.15 \mathrm{~s}$ & $4.05 \mathrm{~s}$ & $3.29 \mathrm{~s}$ & $2.54 \mathrm{~s}$ \\
\hline
\end{tabular}

\section{Results}

With the aim of evaluating the suitability of the proposed VSWTs frequency controller, three different strategies have been analyzed:

1. Thermal and hydro-power plants with frequency control (without frequency response from wind power plants).

2. Thermal and hydro-power plants with frequency control and wind power plants with the frequency controller of [23].

3. Thermal and hydro-power plants with frequency control and wind power plants with the proposed frequency controller.

When wind power plants are excluded from frequency control, frequency excursions by considering the different scenarios are shown in Figure 12. As wind power integration increases, without providing frequency response, the lowest point or Nadir becomes more and more significant, 
achieving $-302 \mathrm{mHz}$ in scenario 4 considering the same value of $\Delta P_{L}$, being over 1.5 times in comparison to the first one. With regard to the stabilization time (defined as the time interval taken by the frequency deviation to be within the range $|\Delta f|<10 \mathrm{mHz}$ [32]), it enhances slightly. In scenario 4, it is 1.3 times over the first one, increasing from 28 to $34 \mathrm{~s}$. The rate of change of frequency (ROCOF) also increases with the integration of wind energy without frequency response, from $83 \mathrm{mHz} / \mathrm{s}$ in scenario 1 to $132 \mathrm{mHz} / \mathrm{s}$ in scenario 4 . Therefore, the more wind power integration into grids, the more sensitive is the power system under imbalance conditions. Subsequently, a more unstable grid results from the integration of renewables without implementing any frequency response. Similar relationships are found when $\Delta P_{L}=0.050$ and $\Delta P_{L}=0.100$ (Figure 12b,c, respectively). In Figure 13, a comparison among Nadir, stabilization time and ROCOF for the different scenarios and $\Delta P_{L}=0.050$ is depicted. Results are shown in pu, considering as base the results of scenario 1 , where there are no wind power plants.

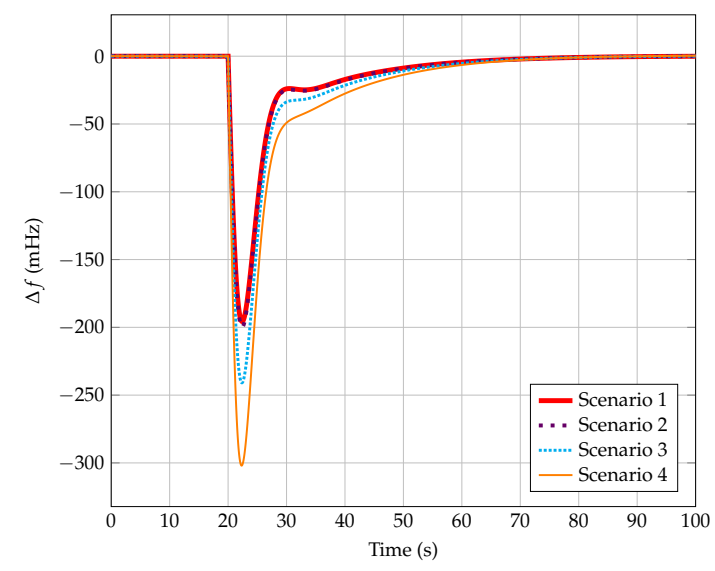

(a)

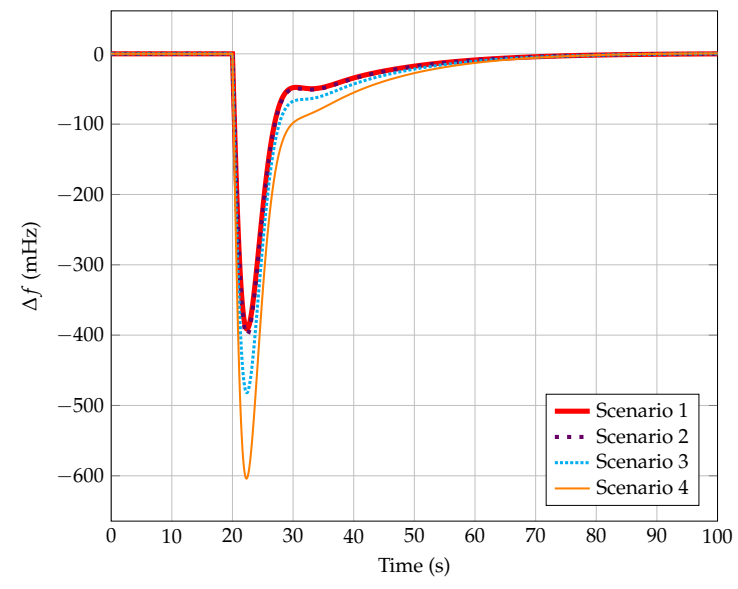

(b)

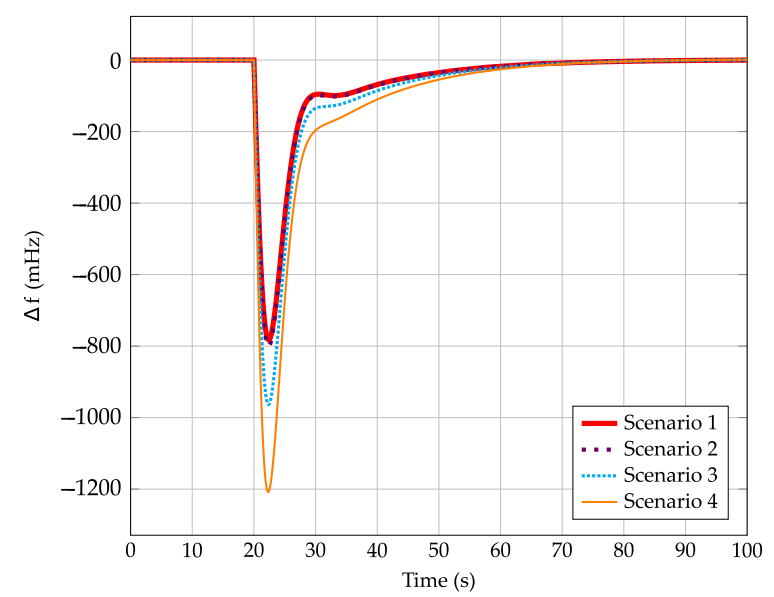

(c)

Figure 12. Frequency excursions for scenarios $1-4$ without wind power plant control. (a) Considering $\Delta P_{L}=0.025 ;(\mathbf{b})$ Considering $\Delta P_{L}=0.050 ;(\mathbf{c})$ Considering $\Delta P_{L}=0.100$.

To overcome previous frequency excursion drawbacks, and to determine the most suitable recovery strategy of the smooth controller proposed in this work, the four different recovery strategies are analyzed hereinafter. They are represented for the scenario 2, considering $\Delta P_{L}=0.050$ in Figure 14a and $\Delta P_{L}=0.100$ in Figure $14 \mathrm{~b}$. Due to the low value of the power of point $P_{2}$ (see Figure 7), the frequency deviation presents undesirable oscillations when the wind power plant is within the 
recovery operation mode. This effect is especially significant in the original proposal, and it is reduced as the power considers the difference between the actual mechanical power $P_{m t}\left(\Omega_{W T}\right)$ and the maximum mechanical power available according to the wind speed $P_{M P P T}\left(\Omega_{W T}\right)$. Actually, the best response is obtained when $P_{2}$ is defined as $P_{M P P T}\left(\Omega_{V}\right)+0.75 \cdot\left(P_{m t}\left(\Omega_{W T}\right)-P_{M P P T}\left(\Omega_{W T}\right)\right)$. Because of that, the rest of the results only consider that case $(x=0.75)$.

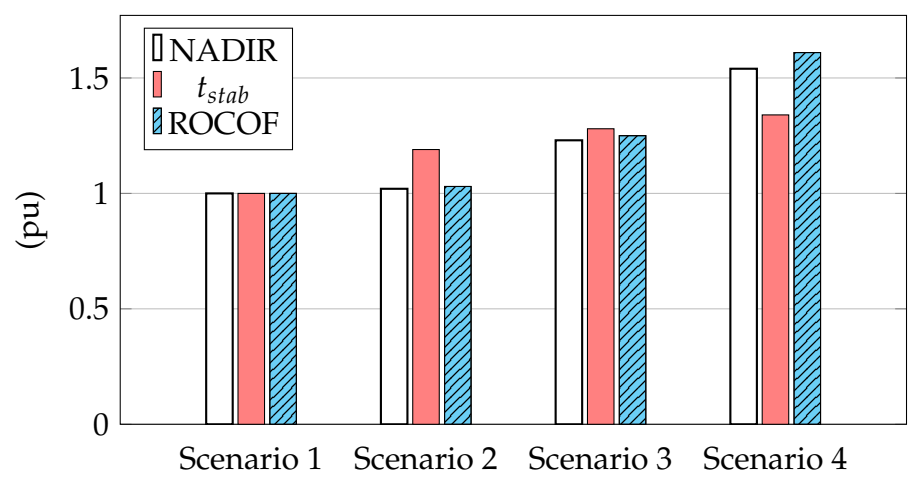

Figure 13. Nadir, stabilization time and the rate of change of frequency (ROCOF): comparison for the different scenarios without wind power plant control for $\Delta P_{L}=0.050$.

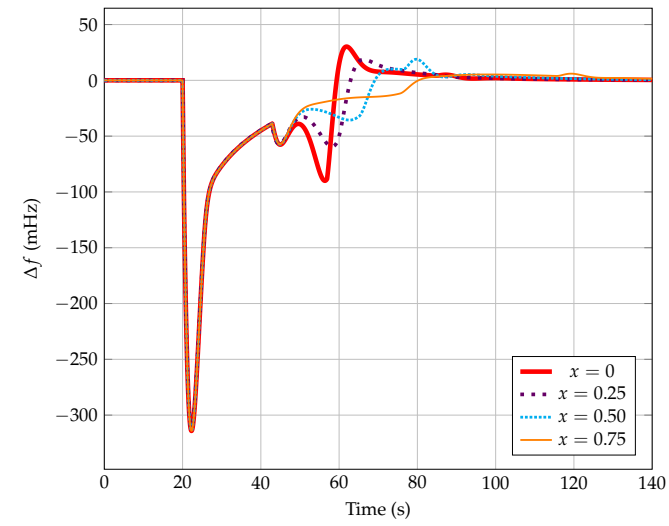

(a)

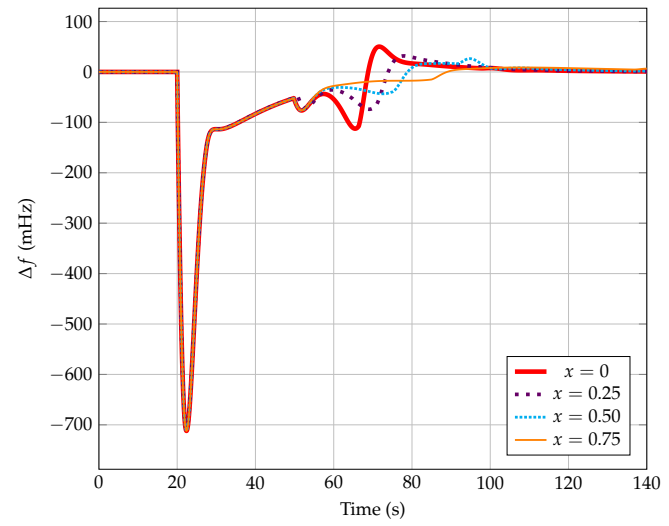

(b)

Figure 14. Frequency excursion for scenario 2. Comparison among values of $x$. (a) Considering $\Delta P_{L}=0.050 ;(\mathbf{b})$ Considering $\Delta P_{L}=0.100$.

Figures 15-17 summarize the different scenarios including frequency response from VSWTs when $\Delta P_{L}=0.025, \Delta P_{L}=0.050$ and $\Delta P_{L}=0.100$, respectively. Figures $15 \mathrm{a}, 16 \mathrm{a}$ and $17 \mathrm{a}$ refer to the controller indicated in [23]. Figures $15 \mathrm{~b}, 16 \mathrm{~b}$ and $17 \mathrm{~b}$ use the new proposal of this work, assuming $x=0.75$ in line with the previous discussion. According to the results, scenarios 2-4 present two different well-identified frequency shifts: (i) due to the power imbalance and (ii) due to the supply-side decrease as a consequence of the step from overproduction to recovery operation mode of the VSWTs frequency controller, see Figure 8. 


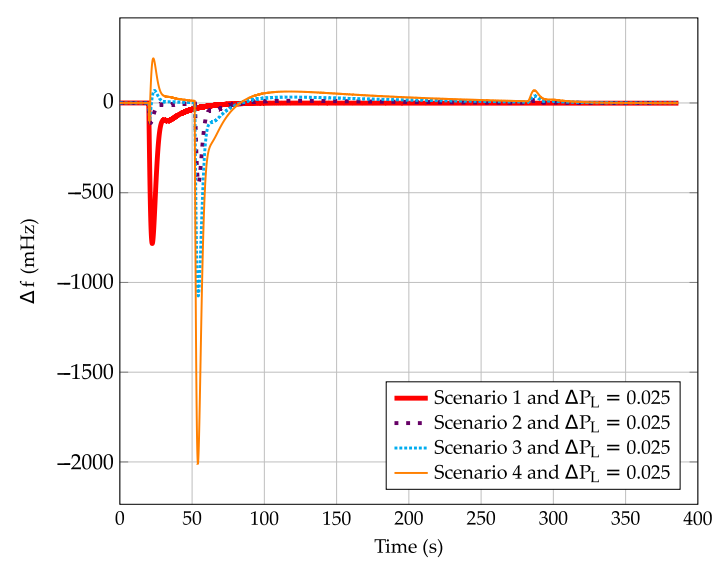

(a)

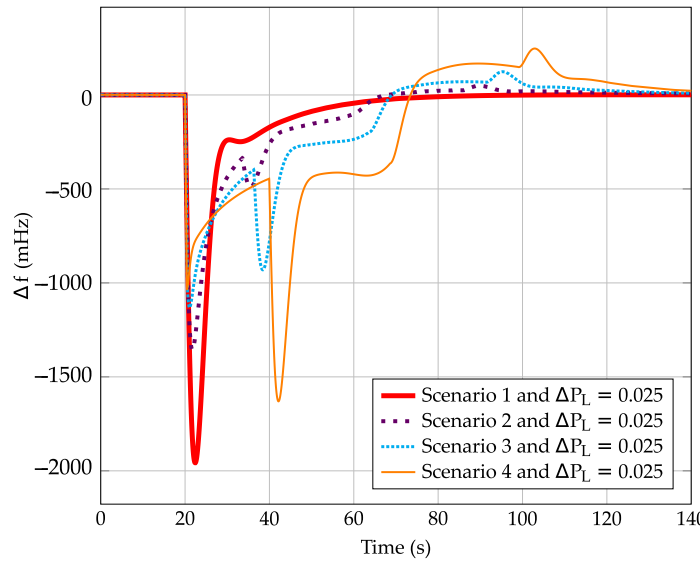

(b)

Figure 15. Comparison between frequency excursion for scenarios 1-4 including wind power plant controls and considering $\Delta P_{L}=0.025$. (a) Controller from [23]; (b) Proposed control with $x=0.75$.

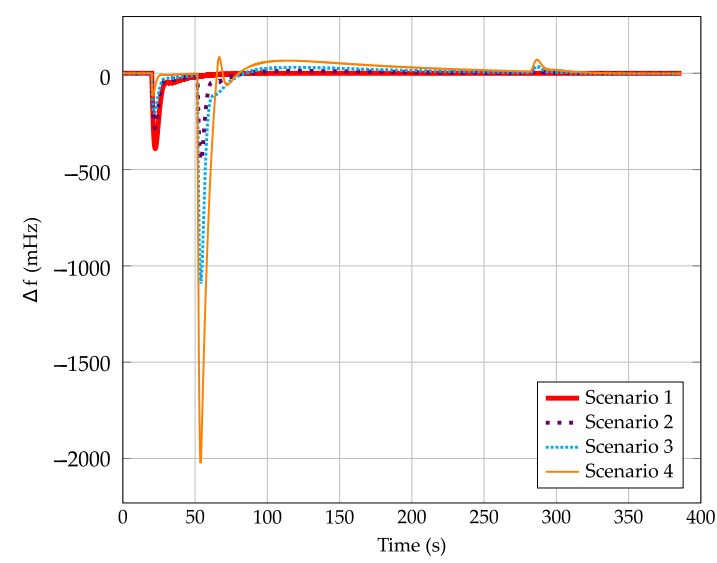

(a)

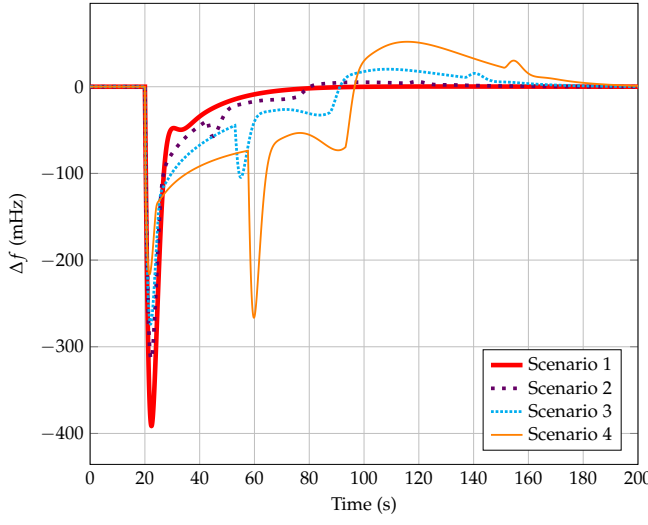

(b)

Figure 16. Comparison between frequency excursion for scenarios 1-4 including wind power plant controls and considering $\Delta P_{L}=0.050$. (a) Controller from [23]; (b) Proposed control with $x=0.75$.

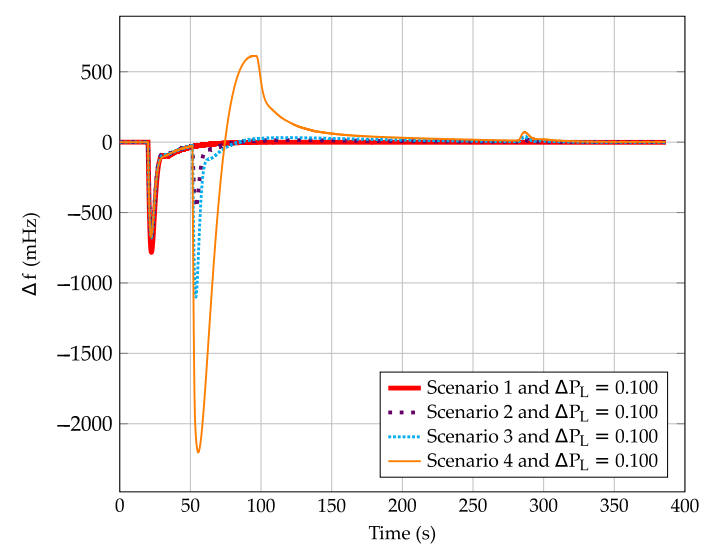

(a)

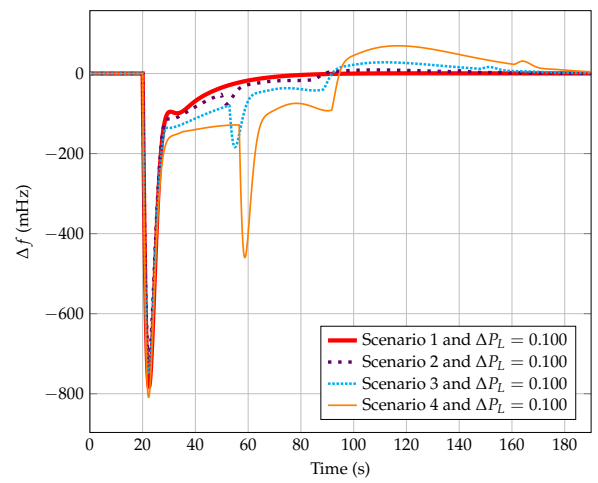

(b)

Figure 17. Comparison between frequency excursion for scenarios $1-4$ including wind power plant controls and considering $\Delta P_{L}=0.100$. (a) Controller from [23]; (b) Proposed control with $x=0.75$. 
With regard to the power imbalance condition, the frequency shift decreases as the wind energy integration increases. This reduction is due to the fast support provided by VSWTs under a generation-load mismatch. It is more noticeable when the proposal of [23] is considered, as the overproduction power is constant and independent from the frequency deviation. Actually, if the demand variation is small (i.e., $\Delta P_{L}=0.025$ ), the overproduction mode of the approach indicated in [23] may cause an overfrequency instead of an underfrequency, since the additional active power definition $\Delta P_{O P}$ (see Figure 15a, scenarios 3 and 4). This drawback does not occur if the adaptive frequency controller proposed in this work is used, as seen in Figure 15b. Considering the case in which $\Delta P_{L}=0.050$, a reduction of $70 \%$ is obtained with the approach of [23], from $391 \mathrm{mHz}$ in the first scenario to 117 in the last one. This reduction accounts for the $44 \%$, reaching $215 \mathrm{mHz}$ in scenario 4 with the new controller proposal. Finally, when $\Delta P_{L}=0.100$, both frequency controllers have similar responses during the firsts seconds, reaching a Nadir $\simeq 750 \mathrm{mHz}$.

With respect to the second frequency shift, it increases with high wind power plant integration, as it increase leads to a greater wind power generation reduction when switching from overproduction to recovery. The underfrequency value can decrease to $2 \mathrm{~Hz}$ in scenario 4 with the approach indicated in [23], due to the sudden drop of generation from VSWTs, see Figure 9. Nevertheless, this second excursion is reduced using the smooth recovery proposal of this work, decreasing up to 163, 266, $450 \mathrm{mHz}$ for scenario 4 when $\Delta P_{L}=0.025, \Delta P_{L}=0.050, \Delta P_{L}=0.100$, respectively. This fact brings out that the new proposed adaptive and smoother controller gives an improvement of the frequency response, being suitable for power systems with high wind power penetration. In Figure 18, a comparison between both frequency deviations corresponding to both frequency control strategies considering $\Delta P_{L}=0.050$ are depicted.

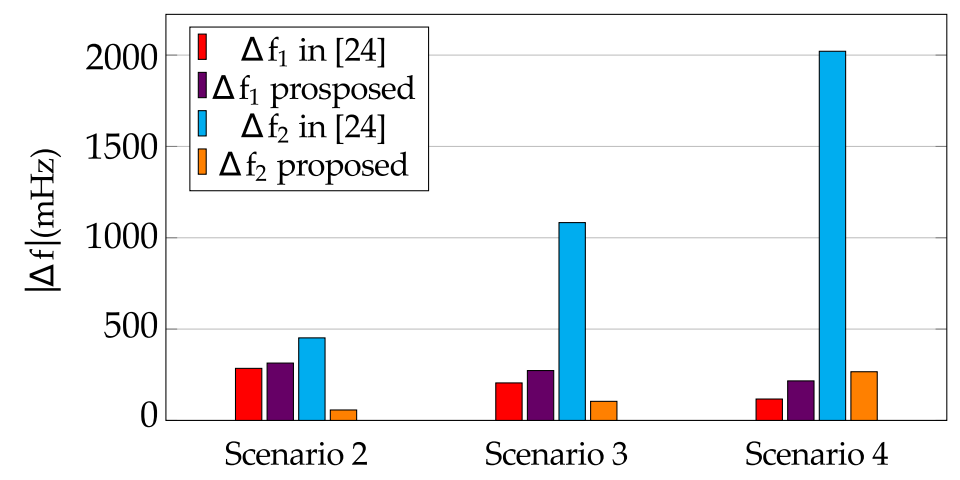

Figure 18. Comparison between $\Delta f_{1}$ and $\Delta f_{2}$ for the different scenarios depending on the wind power plant control and considering $\Delta P_{L}=0.050$.

Regarding to ROCOF, its behavior depends on the scenario and $\Delta P_{L}$. In general, it can be said that ROCOF decreases in scenarios 2 and 3 , but increases in scenario 4 . Actually, it is higher than the ROCOF of scenario 1 when the wind power plant frequency controller of [23] is analyzed. The stabilization time increases with the wind power plant integration, as a result of the second frequency dip. In the last scenario, the stabilization time is around $280 \mathrm{~s}$ for the control strategy indicated in [23] (independently from the value of $\Delta P_{L}$ ), varying between 80 and $140 \mathrm{~s}$ for the proposed approach. Figures 19 and 20 compare Nadir, stabilization time and Nadir for $\Delta P_{L}=0.050$. The increasing of the stabilization time in [23] is due to the fact that when the wind power plant changes from recovery to normal operation mode, a third frequency shift occurs. Despite it is not so noticeable compared to the second frequency excursion, see Figures 15a, 16a and 17a, it can achieve up to $70 \mathrm{mHz}$ for scenario 4 . 


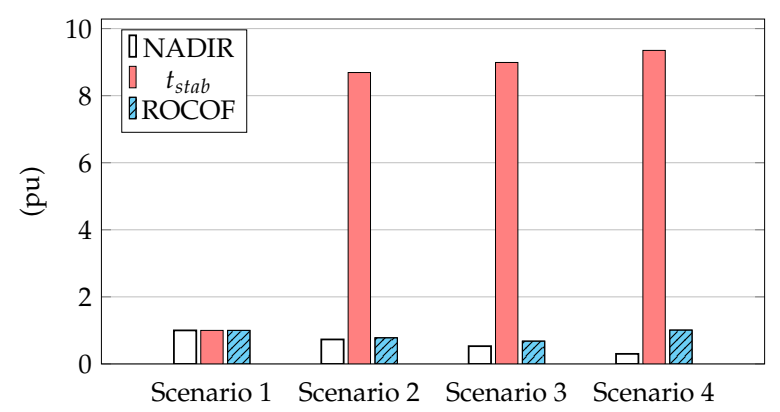

Figure 19. Nadir, stabilization time and ROCOF: comparison for the different scenarios considering $\Delta P_{L}=0.050$ and including wind power plant control from [23].

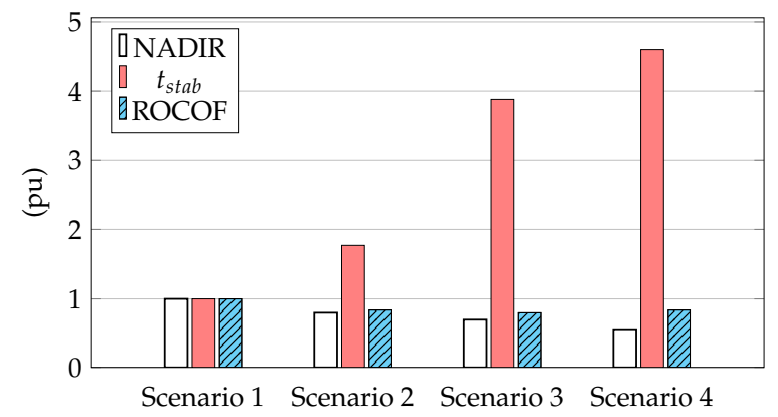

Figure 20. Nadir, stabilization time and ROCOF: comparison for the different scenarios considering $\Delta P_{L}=0.050$ and including the proposed wind power plant control.

In Figure 21 the wind power plant response of scenario 2 and $\Delta P_{L}=0.050$ with the frequency controller of [23] is depicted. Between points [1]-[2], the VSWT is working in the normal operation mode, providing its maximum power $P_{M P P T}=0.745 \mathrm{pu}$. Because of that, the variation of active power provided is 0 (see definition of $\Delta P_{W F}$ in Section 2). The rotational speed of the machine is $\Omega_{M P P T}=1.197 \mathrm{pu}$. At time $t=20 \mathrm{~s}$, the power imbalance occurs, activating the overproduction mode (points [2]-[3]). Hence, the variation of active power provided by the wind power plant is constant and equal to $\Delta P_{W F}=0.1 \mathrm{pu}$. This value corresponds to the additional active power provided by the VSWTs in this operation mode, $\Delta P_{O P}$, which is taken from the stored kinetic energy of the machine. As a consequence, the rotational speed of the VSWT decreases from $\Omega_{M P P T}=1.197$ to the minimum value $\Omega_{W T \text {, min }}=0.700 \mathrm{pu}$, corresponding to a $42 \%$ of decrease in $30 \mathrm{~s}$. When $\Omega_{W T}$ reaches its minimum value, the frequency controller changes to recovery operation mode (points [4]-[5])). The sudden drop of the variation of active power generated (points [3]-[4]) causes a second frequency departure, being this deeper than that due to the power imbalance. This power variation is $\Delta P_{W F}=P_{[4]}-P_{[3]}=-0.27-0.1=-0.37 \mathrm{pu}$. Apart from that, it is important to notice that it takes around $250 \mathrm{~s}$ to restore the rotational speed to the initial value $\Omega_{M P P T}$.

Regarding to Figure 22, the wind power plant response of scenario 2 and $\Delta P_{L}=0.050$ with the proposed controller considering $x=0.75$ is shown. In this case, the rotational speed decreases from 1.197 to $1.117 \mathrm{pu}$ in $20 \mathrm{~s}$ (points [2]-[3]). Despite it takes less time than in Figure 21, the reduction of rotational speed is also lower, only $0.07 \%$. Furthermore, the second frequency departure caused by the drop from overproduction to recovery (points [3]-[4]: $\Delta P_{W F}=P_{[4]}-P_{[3]}=-0.015-0.075=-0.090 \mathrm{pu}$ ) is negligible in comparison to the one indicated in Figure 21. The wind power plant needs only $80 \mathrm{~s}$ to restore the rotational speed to the initial value (points [4]-[5]). The equation of the parabola in this case is: $P_{c m d}=19.06 \cdot \Omega_{W T}^{2}-43.93 \cdot \Omega_{W T}+26.02$. 


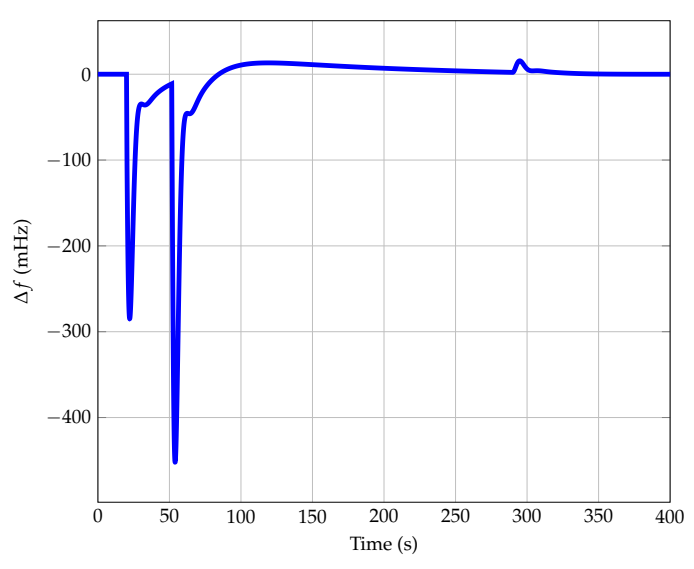

(a)

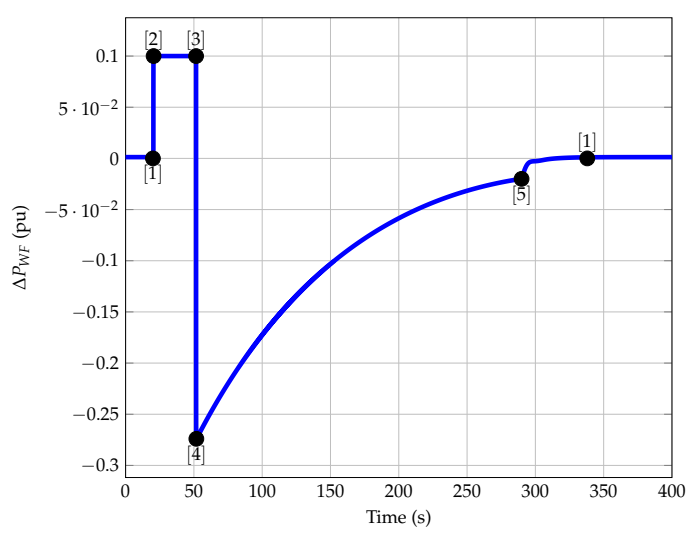

(c)

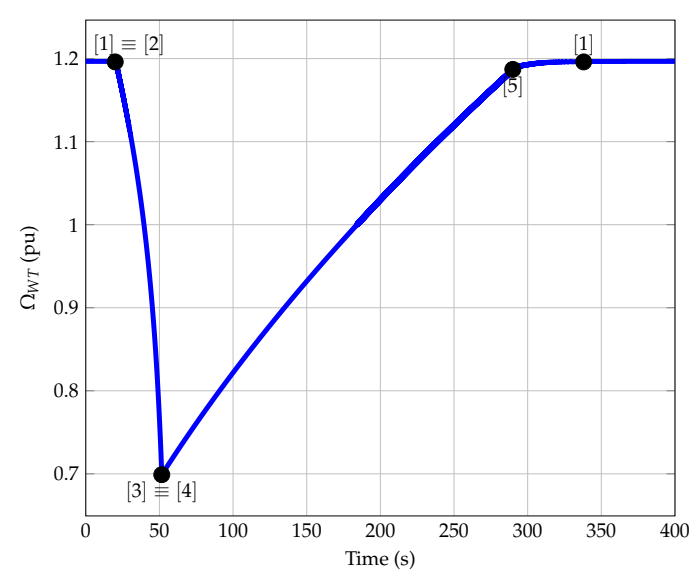

(b)

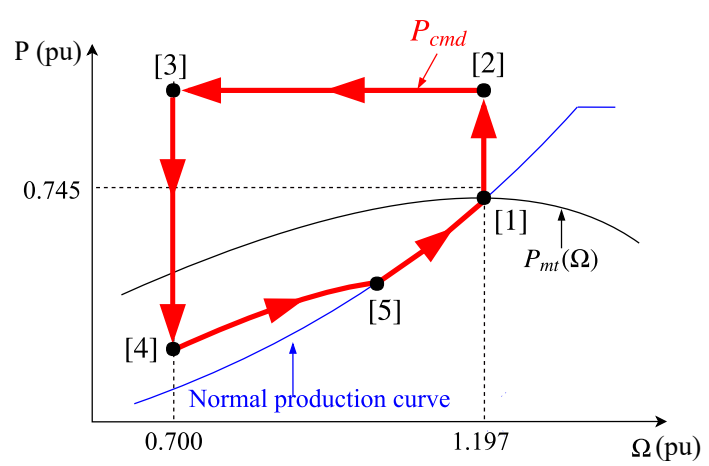

(d)

Figure 21. Wind power plant response for scenario 2 and frequency controller of [23]. (a) Frequency deviation; (b) Rotational speed; (c) Variation of wind power; (d) Frequency control strategy.

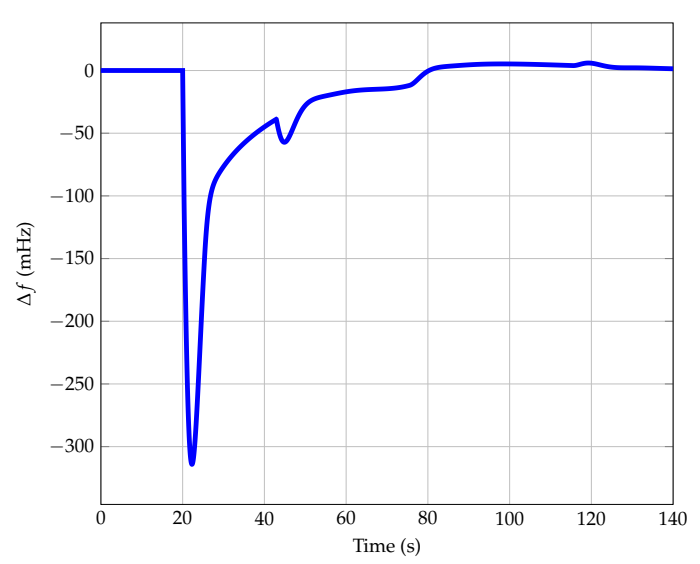

(a)

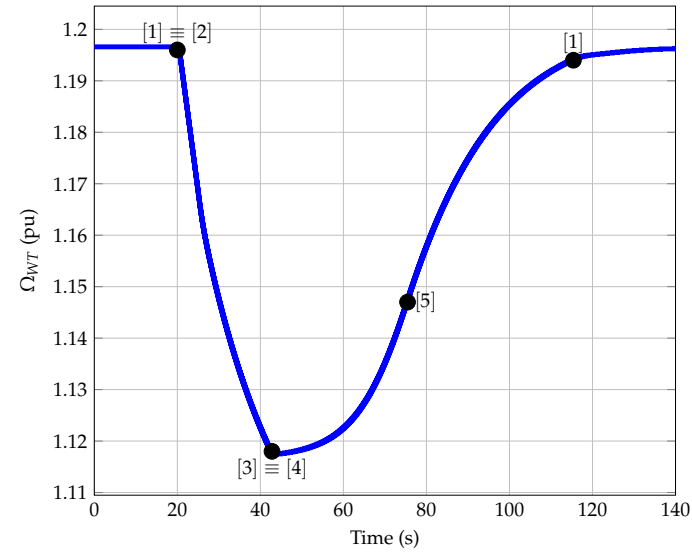

(b)

Figure 22. Cont. 


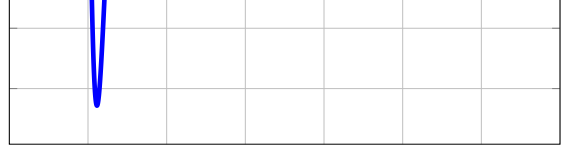

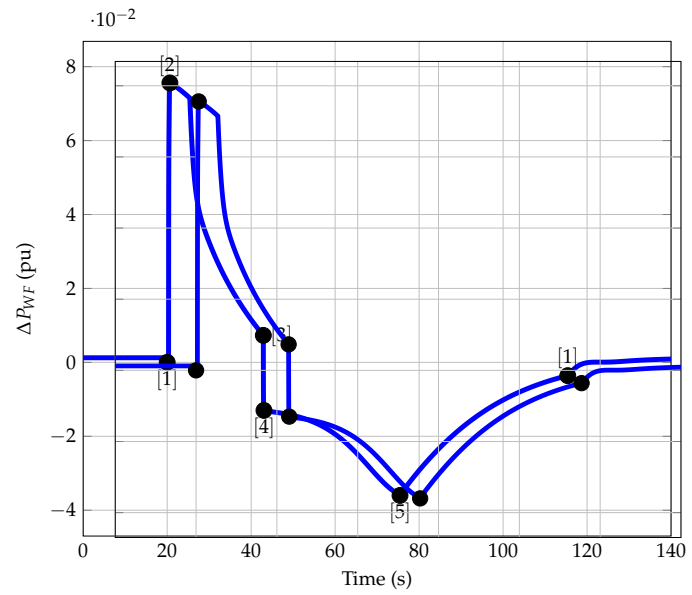

(c)

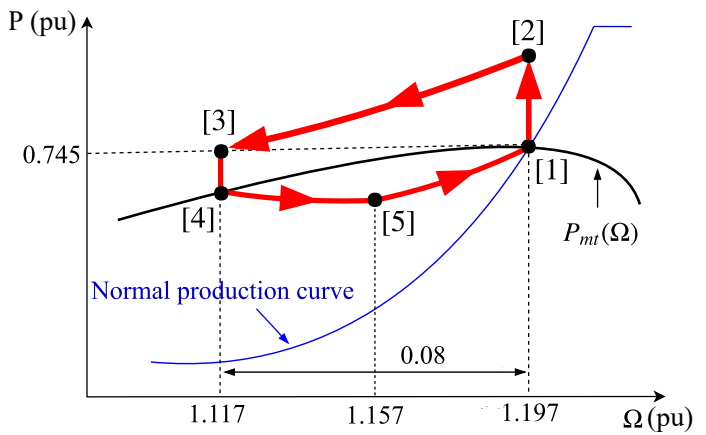

(d)

Figure 22. Wind power plant response for scenario 2 and adaptive and smoother frequency controller with $x=0.75$. (a) Frequency deviation; (b) Rotational speed; (c) Variation of wind power; (d) Frequency control strategy.

\section{Conclusions}

A new control for VSWTs has been proposed in order to allow them to participate in frequency control. It is based on two operation modes: overproduction and recovery, varying the active power provided by the VSWTs through the 'hidden' kinetic inertia stored in their rotating masses. It is tested within four different supply-side scenarios consisting of thermal, hydro-power and wind power plants. In each scenario, wind power plants have increased their capacity from 15 to $45 \%$, at the time that thermal plants have decreased from 73 to $43 \%$ in order to estimate the frequency response of a future power system with high integration of renewable energy sources.

Results show that the Nadir can be reduced a $45 \%$ if the wind power plant control proposed participates in frequency control, compared to current situations in which only conventional plants provide frequency control. A secondary frequency dip is identified due to the change from overproduction to recovery periods, consequently increasing the stabilization time. Results are also compared to a previous proposal, improving Nadir, stabilization time and especially the secondary frequency excursion. Actually, it is due to the lack of coordination between power plants, as well as the different time response of the supply-side operation units. New aggregated and coordinated strategies are being analyzed by the authors to minimize the impact of these secondary deviations.

Author Contributions: All authors contributed equally to this work.

Acknowledgments: This work was supported by "Fundación Séneca-Agencia de Ciencia y Tecnología de la Región de Murcia" (ref. 19379/PI/14) and "Ministerio de Educación, Cultura y Deporte" of Spain (ref. FPU16/04282).

Conflicts of Interest: The authors declare no conflict of interest.

\section{Abbreviations}

The following abbreviations are used in this manuscript:

a First parameter of the parabola

$b \quad$ Second parameter of the parabola

c Third parameter of the parabola

$n \quad$ Number of VSWT in the wind power plant

$C_{P} \quad$ Power coefficient

$D_{e q} \quad$ Equivalent damping factor of the power system 
$H_{e q} \quad$ Equivalent inertia constant of the power system

$H_{i} \quad$ Inertia constant of each generator unit

$P_{a c c} \quad$ Acceleration power

$P_{c m d} \quad$ Commanded power of the VSWT

$P_{e} \quad$ Active power provided by the wind power plant

$P_{e f} \quad$ Active measured power provided by the wind power plant

$P_{\text {MPPT }} \quad$ Maximum power point tracking of the VSWT

$P_{m t} \quad$ Mechanical power of the VSWT

$P_{1} \quad$ First point to calculate the parabola: $P_{1}:\left(\Omega_{W T, \min }, P_{m t}\left(\Omega_{W T, \min }\right)\right)$

$P_{2} \quad$ Second point to calculate the parabola: $P_{2}:\left(\Omega_{V}, P_{M P P T}\left(\Omega_{V}\right)\right)$

$P_{3} \quad$ Third point point to calculate the parabola: $P_{3}:\left(\Omega_{M P P T}, P_{M P P T}\left(\Omega_{M P P T}\right)\right)$

$S_{B} \quad$ Rated power of the power system

$S_{B, i} \quad$ Rated power of each power generation unit

$V_{W} \quad$ Wind speed

$\beta \quad$ Pitch angle

$\Delta f \quad$ Frequency excursion

$\Delta f_{\text {lim }} \quad$ Value at which frequency controller of the VSWT activates

$\Delta P_{g} \quad$ Variation of active power of the power system: $\Delta P_{g}=\Delta P_{W F}+\Delta P_{T}+\Delta P_{H}$

$\Delta P_{H} \quad$ Variation of active power of the hydro-power plant

$\triangle P_{L} \quad$ Variation of power demand

$\triangle P_{O P} \quad$ Additional active power in overproduction operation mode

$\triangle P_{T} \quad$ Variation of active power of the thermal plant

$\Delta P_{W F} \quad$ Variation of active power of the wind power plant

$\Delta \Omega \quad$ Rotational speed deviation: $\Delta \Omega=\Omega_{M P P T}-\Omega_{W T, \min }$

$\lambda \quad$ Tip speed ratio

$\Omega_{\text {err }} \quad$ Rotational speed error: $\Omega_{e r r}=\Omega_{W T}-\Omega_{\text {ref }}$

$\Omega_{W T} \quad$ Rotational speed of the VSWT

$\Omega_{W T, \text { min }}$ Minimum rotational speed of the VSWT

$\Omega_{M P P T} \quad$ Rotational speed at maximum power point tracking

$\Omega_{\text {ref }} \quad$ Rotational reference speed

$\Omega_{V} \quad$ Middle value between $\Omega_{W T, \min }$ and $\Omega_{M P P T}: \Omega_{V}=\Omega_{W T, \min }+0.5 \cdot \Delta \Omega$

\section{Appendix A. Parameters for Simulations}

Tables A1 and A2 summarize the thermal and hydro-power plant parameters.

Table A1. Thermal power plant parameters [26].

\begin{tabular}{ccc}
\hline Parameter & Name & Value $\left(\mathbf{p u}_{\text {thermal }}\right)$ \\
\hline$T_{G}$ & Speed relay pilot valve & 0.20 \\
\hline$F_{H P}$ & Fraction of power generated by high pressure section & 0.30 \\
\hline$T_{R H}$ & Time constant of reheater & 7.00 \\
\hline$T_{C H}$ & Time constant of main inlet volumes and steam chest & 0.30 \\
\hline$R_{T}$ & Speed droop & 0.05 \\
\hline$I(s)$ & Integral controller & 1.00 \\
\hline$H_{\text {thermal }}$ & Inertia constant & $5.00 \mathrm{~s}$ \\
\hline
\end{tabular}


Table A2. Hydro-power plant parameters [26].

\begin{tabular}{ccc}
\hline Parameter & Name & Value $\left(\mathbf{p} \mathbf{u}_{\text {hydro }}\right)$ \\
\hline$T_{G}$ & Speed relay pilot valve & 0.20 \\
\hline$T_{R}$ & Reset time & 5.00 \\
\hline$R_{T}$ & Temporary droop & 0.38 \\
\hline$R_{P}$ & Permanent droop & 0.05 \\
\hline$T_{W}$ & Water starting time & 1.00 \\
\hline$R_{H}$ & Speed droop & 0.05 \\
\hline$I(s)$ & Integral controller & 1.00 \\
\hline$H_{\text {hydro }}$ & Inertia constant & $3.00 \mathrm{~s}$ \\
\hline
\end{tabular}

\section{Appendix B. Wind Turbine Model}

The wind turbine model is based on $[29,30]$. Parameters of the wind turbine model are summarized in Table A4 The mechanical power $P_{m t}$ is obtained (in pu) from

$$
P_{m t}=\frac{0.5}{S_{n}} \cdot C_{P} \cdot \rho \cdot A_{r} \cdot V_{W}^{3},
$$

being $S_{n}$ the rated power, $\rho$ the air density, $A_{r}$ the swept area by the blades, $C_{P}$ the power coefficient and $V_{W}$ the wind speed. The power coefficient $C_{P}$ is estimated by

$$
C_{P}(\lambda, \beta)=\sum_{i=0}^{4} \sum_{j=0}^{4} \alpha_{i, j} \beta^{i} \lambda^{j} .
$$

This expression gives the mathematical representation of the $C_{P}$ curves, depending on the pitch angle $\beta$ and the tip speed ratio $\lambda$,

$$
\lambda=\frac{\Omega_{0} \cdot R \cdot \Omega_{W T}}{V_{W}}
$$

where $\Omega_{0}$ is the rotor base speed (rad/s), $\Omega_{W T}$ refers to the rotor speed (pu), $R$ is the rotor radius (m) and $V_{W}$ is the wind speed $(\mathrm{m} / \mathrm{s})$. Coefficients of $\alpha_{i, j}$ are taken from Table A3.

Table A3. Coefficients $\alpha_{i, j}$ to calculate $C_{P}(\lambda, \beta)$

\begin{tabular}{cccccc}
\hline $\mathbf{i j}$ & $\mathbf{0}$ & $\mathbf{1}$ & $\mathbf{2}$ & $\mathbf{3}$ & $\mathbf{4}$ \\
\hline $\mathbf{0}$ & $-4.19 \cdot 10^{-1}$ & $2.18 \cdot 10^{-1}$ & $-1.24 \cdot 10^{-2}$ & $-1.34 \cdot 10^{-4}$ & $1.15 \cdot 10^{-5}$ \\
\hline $\mathbf{1}$ & $-6.76 \cdot 10^{-2}$ & $6.04 \cdot 10^{-2}$ & $-1.39 \cdot 10^{-2}$ & $1.07 \cdot 10^{-3}$ & $-2.39 \cdot 10^{-5}$ \\
\hline $\mathbf{2}$ & $1.57 \cdot 10^{-2}$ & $-1.01 \cdot 10^{-2}$ & $2.15 \cdot 10^{-3}$ & $-1.49 \cdot 10^{-4}$ & $2.79 \cdot 10^{-6}$ \\
\hline $\mathbf{3}$ & $-8.60 \cdot 10^{-4}$ & $5.71 \cdot 10^{-4}$ & $-1.05 \cdot 10^{-4}$ & $5.99 \cdot 10^{-6}$ & $-8.91 \cdot 10^{-8}$ \\
\hline $\mathbf{4}$ & $1.48 \cdot 10^{-5}$ & $-9.48 \cdot 10^{-6}$ & $1.62 \cdot 10^{-6}$ & $-7.15 \cdot 10^{-8}$ & $4.97 \cdot 10^{-10}$ \\
\hline
\end{tabular}

The reference rotational speed $\Omega_{\text {ref }}$ is estimated from the maximum power tracking based on the measured active power $P_{e f}$

$$
\Omega_{r e f}=-0.67 \cdot P_{e f}^{2}+1.42 \cdot P_{e f}+0.51
$$

being $P_{e f}$ the active power generated $P_{e}$ after a delay $T_{f}$. 
The rotational speed of the wind turbine $\Omega_{W T}$ is determined from

$$
\Omega_{W T}(s)=\frac{P_{e}(s)-P_{m t}(s)}{2 H_{W T} \cdot s},
$$

being $H_{W T}$ the inertia constant of the wind turbine. The speed controller is modeled as a PI controller, based on the rotational speed error $\Omega_{\text {err }}$

$$
T_{c m d_{\Omega_{e r r}}}=\left(K_{p t}+\frac{K_{i t}}{s}\right) \Omega_{e r r}
$$

Table A4. Wind power plant parameters [29].

\begin{tabular}{ccc}
\hline Parameter & Name & Value $\left(\mathbf{p u} \mathbf{u}_{\mathbf{W F}}\right)$ \\
\hline$V_{w}$ & Wind speed & $10.000 \mathrm{~m} / \mathrm{s}$ \\
\hline$H_{W T}$ & Inertia constant & $5.190 \mathrm{~s}$ \\
\hline$\Omega_{0}$ & Base rotational speed & $1.335 \mathrm{rad} / \mathrm{s}$ \\
\hline$T_{f}$ & Time delay to measure $P_{e}$ & $5.000 \mathrm{~s}$ \\
\hline$T_{c o n}$ & Time delay to generate the current $I_{i n j}$ & $0.020 \mathrm{~s}$ \\
\hline$V_{W T}$ & Wind turbine voltage & 1.00 \\
\hline$K_{p t}$ & Proportional constant of speed controller & 3.000 \\
\hline$K_{i t}$ & Integral constant of speed controller & 0.600 \\
\hline
\end{tabular}

\section{References}

1. Huber, M.; Dimkova, D.; Hamacher, T. Integration of wind and solar power in Europe: Assessment of flexibility requirements. Energy 2014, 69, 236-246. [CrossRef]

2. Tselepis, S.; Nikoletatos, J. Renewable Energy Integration in Power Grids; The International Renewable Energy Agency: Masdar City, United Arab Emirates, 2015.

3. Bevrani, A.G.H.; Ledwich, G. Renewable energy sources and frequency regulation: Survey and new perspectives. IET Renew. Power Gener. 2010, 4, 438-457. [CrossRef]

4. Bahrami, S.; Amini, M.H. A decentralized trading algorithm for an electricity market with generation uncertainty. Appl. Energy 2018, 218, 520-532. [CrossRef]

5. Zhang, W.; Fang, K. Controlling active power of wind farms to participate in load frequency control of power systems. IET Gener. Transm. Distrib. 2017, 11, 2194-2203. [CrossRef]

6. Shah, R.; Mithulananthan, N.; Bansal, R.; Ramachandaramurthy, V. A review of key power system stability challenges for large-scale PV integration. Renew. Sustain. Energy Rev. 2015, 41, 1423-1436. [CrossRef]

7. Du, P.; Matevosyan, J. Forecast system inertia condition and its impact to integrate more renewables. IEEE Trans. Smart Grid 2018, 9, 1531-1533. [CrossRef]

8. Li, D.Y.; Li, P.; Cai, W.C.; Song, Y.D.; Chen, H.J. Adaptive Fault Tolerant Control of Wind Turbines with Guaranteed Transient Performance Considering Active Power Control of Wind Farms. IEEE Trans. Ind. Electron. 2017, 65, 3275-3285. [CrossRef]

9. Bao, Y.; Xu, J.; Liao, S.; Sun, Y.; Li, X.; Jiang, Y.; Ke, D.; Yang, J.; Peng, X. Field Verification of Frequency Control by Energy-Intensive Loads for Isolated Power Systems with High Penetration of Wind Power. IEEE Trans. Power Syst. 2018, 1. [CrossRef]

10. Toulabi, M.; Bahrami, S.; Ranjbar, A.M. An Input-to-State Stability Approach to Inertial Frequency Response Analysis of Doubly-Fed Induction Generator-Based Wind Turbines. IEEE Trans. Energy Convers. 2017, 32, 1418-1431. [CrossRef] 
11. Ochoa, D.; Martinez, S. Proposals for Enhancing Frequency Control in Weak and Isolated Power Systems: Application to the Wind-Diesel Power System of San Cristobal Island-Ecuador. Energies 2018, 11, 910. [CrossRef]

12. Aho, J.; Buckspan, A.; Laks, J.; Fleming, P.; Jeong, Y.; Dunne, F.; Churchfield, M.; Pao, L.; Johnson, K. A tutorial of wind turbine control for supporting grid frequency through active power control. In Proceedings of the 2012 American Control Conference (ACC), Montreal, QC, Canada, 27-29 June 2012; pp. 3120-3131. [CrossRef]

13. Kayikçi, M.; Milanovic, J.V. Dynamic contribution of DFIG-based wind plants to system frequency disturbances. IEEE Trans. Power Syst. 2009, 24, 859-867. [CrossRef]

14. Toulabi, M.; Bahrami, S.; Ranjbar, A.M. Application of Edge theorem for robust stability analysis of a power system with participating wind power plants in automatic generation control task. IET Renew. Power Gener. 2017, 11, 1049-1057. [CrossRef]

15. Yingcheng, X.; Nengling, T. Review of contribution to frequency control through variable speed wind turbine. Renew. Energy 2011, 36, 1671-1677. [CrossRef]

16. Sun, D.; Sun, L.; Wu, F.; Zu, G. Frequency Inertia Response Control of SCESS-DFIG under Fluctuating Wind Speeds Based on Extended State Observers. Energies 2018, 11, 830. [CrossRef]

17. Tavakoli, M.; Pouresmaeil, E.; Adabi, J.; Godina, R.; Catalao, J.P. Load-frequency control in a multi-source power system connected to wind farms through multi terminal HVDC systems. Comput. Oper. Res. 2018, 96, 305-315. [CrossRef]

18. Alsharafi, A.S.; Besheer, A.H.; Emara, H.M. Primary Frequency Response Enhancement for Future Low Inertia Power Systems Using Hybrid Control Technique. Energies 2018, 11, 699. [CrossRef]

19. El Itani, S.; Annakkage, U.D.; Joos, G. Short-term frequency support utilizing inertial response of DFIG wind turbines. In Proceedings of the 2011 IEEE Power and Energy Society General Meeting, San Diego, CA, USA, 24-29 July 2011; pp. 1-8.

20. Keung, P.K.; Li, P.; Banakar, H.; Ooi, B.T. Kinetic energy of wind-turbine generators for system frequency support. IEEE Trans. Power Syst. 2009, 24, 279-287. [CrossRef]

21. Hansen, A.D.; Altin, M.; Margaris, I.D.; Iov, F.; Tarnowski, G.C. Analysis of the short-term overproduction capability of variable speed wind turbines. Renew. Energy 2014, 68, 326-336. [CrossRef]

22. Hafiz, F.; Abdennour, A. Optimal use of kinetic energy for the inertial support from variable speed wind turbines. Renew. Energy 2015, 80, 629-643. [CrossRef]

23. Tarnowski, G.C.; Kjar, P.C.; Sorensen, P.E.; Ostergaard, J. Variable speed wind turbines capability for temporary over-production. In Proceedings of the 2009 IEEE Power \& Energy Society General Meeting, Calgary, AB, Canada, 26-30 July 2009; pp. 1-7.

24. Kang, M.; Kim, K.; Muljadi, E.; Park, J.W.; Kang, Y.C. Frequency control support of a doubly-fed induction generator based on the torque limit. IEEE Trans. Power Syst. 2016, 31, 4575-4583. [CrossRef]

25. Tielens, P.; Hertem, D.V. Receding Horizon Control of Wind Power to Provide Frequency Regulation. IEEE Trans. Power Syst. 2017, 32, 2663-2672. [CrossRef]

26. Kundur, P.; Balu, N.J.; Lauby, M.G. Power System Stability and Control; McGraw-hill: New York, NY, USA, 1994; Volume 7.

27. Margaris, I.D.; Papathanassiou, S.A.; Hatziargyriou, N.D.; Hansen, A.D.; Sorensen, P. Frequency control in autonomous power systems with high wind power penetration. IEEE Trans. Sustain. Energy 2012, 3, 189-199. [CrossRef]

28. Pyller, M.; Achilles, S. Aggregated Wind Park Models for Analyzing Power System Dynamics. In Proceedings of the 4th International Workshop on Large-Scale Integration of Wind Power and Transmission Networks for Offshore Wind Farms, Billund, Denmark, 20-21 October 2003.

29. Ullah, N.R.; Thiringer, T.; Karlsson, D. Temporary primary frequency control support by variable speed wind turbines-Potential and applications. IEEE Trans. Power Syst. 2008, 23, 601-612. [CrossRef]

30. Miller, N.W.; Sanchez-Gasca, J.J.; Price, W.W.; Delmerico, R.W. Dynamic modeling of GE 1.5 and 3.6 MW wind turbine-generators for stability simulations. In Proceedings of the 2003 IEEE Power Engineering Society General Meeting (IEEE Cat. No.03CH37491), Toronto, ON, Canada, 13-17 July 2003; Volume 3, pp. 1977-1983. 
31. Electricity Statistics 2016 (in GWh). 2017. Available online: http://ec.europa.eu/eurostat/statisticsexplained/index.php/File:Electricity_Statistics_2016_(in_GWh)-T1.png (accessed on 1 June 2018).

32. ENTSOE. Network Code on Load-Frequency Control and Reserves. 2013. Available online: https:/ / www.entsoe.eu/ (accessed on 1 June 2018).

(C) 2018 by the authors. Licensee MDPI, Basel, Switzerland. This article is an open access article distributed under the terms and conditions of the Creative Commons Attribution (CC BY) license (http:// creativecommons.org/licenses/by/4.0/). 



\subsection{Fast power reserve emulation strategy for VSWT supporting frequency control in multi-area power systems}

The integration of renewable sources into power systems involves significant targets and new scenarios with an important role for these alternative resources, mainly wind and PV power plants. Among the different objectives, frequency control strategies and new reserve analysis are currently considered as a major concern in power system stability and reliability studies. This paper aims to provide an analysis of multi-area power systems submitted to power imbalances, considering a high wind power penetration (between $25 \%$ and $40 \%$ ). From the supply-side, conventional and renewable resources are considered, including thermal, hydro-power, wind, and PV power plants. Tie-line power is limited to a maximum value of $10 \%$, in line with recent EU directives. Frequency control from wind power plants is considered, comparing among different strategies depending on the area in which the imbalance occurs. According to the results, the nadir reductions are maximised when only wind power plants within the area submitted to imbalances are considered. In this case, the nadir is reduced between $40 \%$ and $50 \%$ in the area where the power mismatch occurs, in comparison to conventional generation unit scenarios. Moreover, these nadir values are also reduced in the other areas between $20 \%$ and $30 \%$. When wind power responses of all areas are considered, higher frequency oscillations and lower nadir reductions are reached. Stabilisation time remains almost constant under different situations, and very similar to simulations where only conventional units respond under frequency excursions. Subsequently, the authors suggest including only wind power plant frequency response within the area submitted to imbalances, avoiding additional frequency oscillations coming from wind power plants located in the other areas.

Information of the paper:

- Journal: Energies

- DOI: 10.3390/en11102775

- Date of publication: October 2018

- Available online: https://www.mdpi.com/1996-1073/11/10/2775

- Reference: [3] 

Article

\title{
Fast Power Reserve Emulation Strategy for VSWT Supporting Frequency Control in Multi-Area Power Systems
}

\author{
Ana Fernández-Guillamón ${ }^{1} * \mathbb{D}$, Antonio Vigueras-Rodríguez ${ }^{2}$ (D) Emilio Gómez-Lázaro ${ }^{3}$ (D) \\ and Ángel Molina-García ${ }^{1}$ (D) \\ 1 Department of Electrical Engineering, Universidad Politécnica de Cartagena, 30202 Cartagena, Spain; \\ angel.molina@upct.es \\ 2 Department of Civil Engineering, Universidad Politécnica de Cartagena, 30203 Cartagena, Spain; \\ avigueras.rodriguez@upct.es \\ 3 Renewable Energy Research Institute and DIEEAC-EDII-AB, Universidad de Castilla-La Mancha, \\ 02071 Albacete, Spain; emilio.gomez@uclm.es \\ * Correspondence: ana.fernandez@upct.es; Tel.: +34-968-325357
}

Received: 2 October 2018; Accepted: 11 October 2018; Published: 16 October 2018

\begin{abstract}
The integration of renewables into power systems involves significant targets and new scenarios with an important role for these alternative resources, mainly wind and PV power plants. Among the different objectives, frequency control strategies and new reserve analysis are currently considered as a major concern in power system stability and reliability studies. This paper aims to provide an analysis of multi-area power systems submitted to power imbalances, considering a high wind power penetration in line with certain European energy road-maps. Frequency control strategies applied to wind power plants from different areas are studied and compared for simulation purposes, including conventional generation units. Different parameters, such as nadir values, stabilization time intervals and tie-line active power exchanges are also analyzed. Detailed generation unit models are included in the paper. The results provide relevant information on the influence of multi-area scenarios on the global frequency response, including participation of wind power plants in system frequency control.
\end{abstract}

Keywords: frequency control; wind power integration; power system stability

\section{Introduction}

Traditionally, synchronous generators have provided frequency control reserves, which are released under power imbalance conditions to recover grid frequency [1]. In fact, any generationdemand imbalance leads the grid frequency to deviate from its nominal value, which can cause serious scale stability problems [2]. With the significant penetration of renewables, mainly wind power plants, a proportional capacity of the system reserves must be provided by these new resources [3]. In this way, reference [4] considers that wind power plant participation in grid frequency control is imminent. However, wind turbines usually include back-to-back converters, and they are electrically decoupled from the grid through power electronic converters [5]. Consequently, with the significant integration of wind power into power systems, grid frequency tends to degrade progressively due to the reduction of the grid inertial responses [6]. Therefore, this new scenario presents a preliminary reduction of reserves from conventional generation units, mainly in weak and/or isolated power systems with high renewable resource penetration [7,8]. Moreover, these problems would be exacerbated in micro-grids, with a high share of power-electronically interfaced and thus a low grid inertia $[9,10]$. Under this framework, frequency control strategies must be included in wind power plants to provide additional 
active power under disturbances [11]. These new strategies would allow us to integrate Variable Speed Wind Turbines (VSWTs) into these services, replacing conventional power plants by renewables [12] and maintaining a reliable power system operation [13]. Most of the proposed strategies for VSWTs are based on 'hidden inertia emulation', enhancing their inertia response [14-16]. According to the specific literature, 'Fast power reserve emulation' has been proposed as a suitable solution. It is based on supplying the kinetic energy stored in the rotating masses to the grid as an additional active power, being subsequently recovered through an under-production period (recovery) [17-19]. Different studies can be found to discuss the definition of overproduction period and the transition from overproduction to recovery period [20-25]. These studies are mainly focused on analyzing the inertia reduction problem on isolated power systems [20,21,23-27]. However, there is a lack of contributions focused on large interconnected power systems with high wind power penetration [28]. These new scenarios are in line with current wind generation units, covering more than $20 \%$ in different power systems. Moreover, renewables have accounted for more than $50 \%$ at different times in some European countries such as Spain, Portugal, Ireland, Germany or Denmark [29].

In general, synchronous generators inherently release or absorb kinetic energy as an inertial response to imbalance situations [24]. However, to recover the grid frequency at the nominal value, an additional control system is needed as well [30]. Automatic Generation Control (AGC) is thus considered as one of the most important ancillary services in power systems. AGC is used to match the total generation with the total demand, including power system losses [31]. Over the last decade, different authors have proposed several control strategies and optimization techniques. A modified AGC for an interconnected power system in a deregulated environment is described in [32]. A similar contribution can be found in [33], where an energy storage system is added to a multi-area power system, and the $I$ controller gains are optimized by using the Opposition-based Harmony Search algorithm. A teaching-learning process based on an optimization algorithm to tune both I and PID controller parameters in single and multi-area power systems is described in [34]. In [35], a hybrid fuzzy PI controller is proposed for AGC of multi-area systems, yielding significant improvements compared to previous approaches. In [36], the gray wolf optimization method is proposed to tune the controller gains of an interconnected power system. This solution presented a more suitable tuning capability than other population-based optimization techniques. An optics inspired optimization algorithm is proposed in [37] and compared to other optimization algorithms, reaching a better performance for maximum overshoot and settling time values. However, in these contributions, only thermal, gas and hydro-power plants are considered from the supply side [32-36]. Therefore, multi-area power system modeling by including wind power plants are required to simulate frequency excursions under power imbalance conditions. Consequently, and by considering previous contributions, this paper analyzes different power imbalance situations and the corresponding frequency deviations in a multi-area interconnected power system with high wind power penetration. The main contributions of the paper are summarized as follows:

- Different multi-area power systems are analyzed with significant wind power integration, in line with current shares of renewables accounting for between $25 \%$ and $40 \%$. Most previous studies on multi-area power systems only consider conventional generating units, such as thermal, gas and hydro-power [38-41].

- Wind power plants include a fast power reserve emulation control strategy in order to provide frequency response under power imbalances. Indeed, there is a lack of contributions describing frequency control response in wind power plants without energy storage solutions under multi-area power systems [42-45].

- The total power exchanged between areas is in line with the recent EU-wide targets, assuming a power interconnection share of $10 \%$ [46].

- The impact of wind power plants located in different areas on the frequency evolution is included in our model and dicussed in detail. 
The rest of the paper is organized as follows: Section 2 presents the frequency control strategy for VSWTs. The implemented multi-area interconnected power system is described in Section 3. The results are provided and widely discussed in Section 4. Finally, the conclusions are presented in Section 5.

\section{Improving Frequency Control Strategy of Wind Turbines}

According to the specific literature, different methods for VSWTs have been proposed to provide frequency control. Figure 1 summarizes the corresponding solutions to be implemented in wind power plants: (i) de-loading, (ii) droop control and (iii) inertial response [47]. With regard to de-loading control methods, they are based on operating VSWTs below their optimal generation point. A certain amount of active power reserve is thus available to supply additional generation under a contingency [48]. It can be implemented by regulating the pitch angle from $\beta_{\text {min }}$ to a maximum value or by increasing the rotational speed above the Maximum Power Point Tracking (MPPT) speed (over-speeding) [49]. An extension of de-loading strategy applied to Photovoltaic system (PV) taking into account a percentage of the PV power production for back-up reserve can be found in [50]. Secondly, droop control solutions have a significant influence on the frequency minimum value (nadir) and the frequency recovery [51]. The controller is based on considering the torque/power-set point as a function of the frequency excursion $(\Delta f)$ and the rate of change of frequency (ROCOF) [52-56]. Finally, 'hidden inertia' controllers introduce a supplementary loop into the active power control. This additional loop control is only added under frequency deviations. Both blades and rotor inertia are then used to provide primary frequency response. Different approaches can be found in the specific literature. One solution is based on emulating similar inertia response to conventional generation units, shifting the torque/power reference proportionally to the ROCOF [51,57-60]. Another study uses the fast power reserve emulation. Constant overproduction power is released from the kinetic energy stored in the rotating mass of the wind turbine, with the rotational speed being recovered later through an underproduction period $[17,20,21,25,47,61]$.

$$
\text { Frequency control strategies }\left\{\begin{array}{l}
\text { De-loading }\left\{\begin{array}{l}
\text { Over speed } \\
\text { Pitch angle }
\end{array}\right. \\
\text { Droop control } \\
\text { Inertia response }\left\{\begin{array}{l}
\text { Hidden inertia emulation } \\
\text { Fast power reserves }
\end{array}\right.
\end{array}\right.
$$

Figure 1. Wind power plant frequency control: general overview [28,47].

In line with previous contributions, the frequency control strategy for VSWTs implemented in this work is based on the fast power reserve emulation technique developed by the authors in [25]. This approach improves an initial proposal described in [61], by minimizing frequency oscillations and smoothing the wind power plant frequency response. Three operation modes are considered: normal operation mode, overproduction mode and recovery mode, see Figure 2. Different active power $\left(P_{c m d}\right)$ values are determined aiming to restore the grid frequency under power imbalance conditions. Figure $2 \mathrm{~b}$ depicts the VSWTs active power variations $\left(\Delta P_{W F}\right)$ submitted to an under-frequency excursion, being $\Delta P_{W F}=P_{c m d}-P_{M P P T}\left(\Omega_{M P P T}\right)$. 


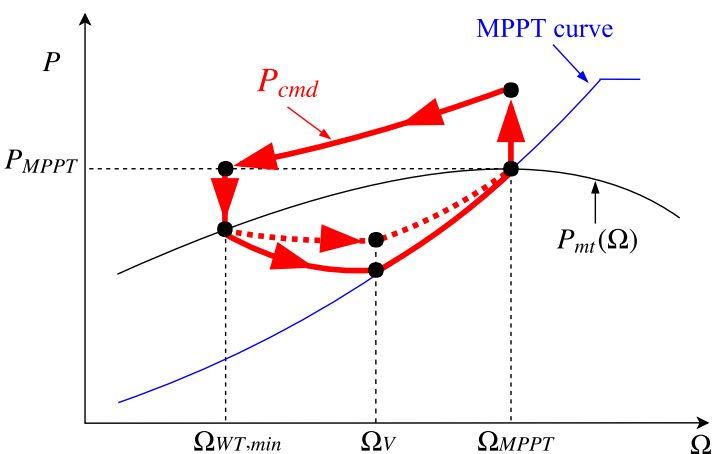

(a)

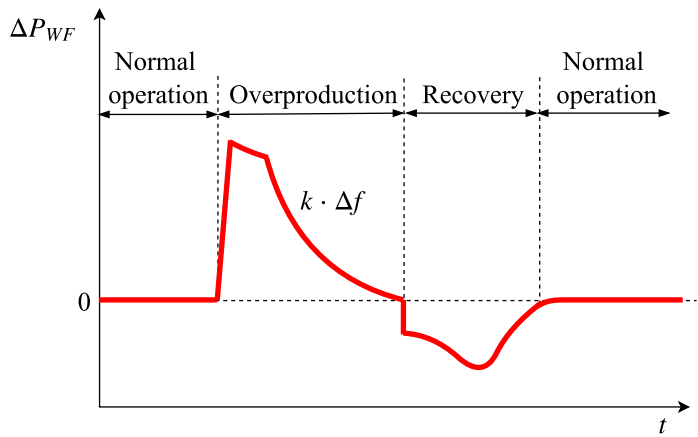

(b)

Figure 2. Wind frequency control strategy and VSWTs' active power variation $\left(\Delta P_{W F}\right)$ [25]; (a) frequency control strategy used for VSWTs; (b) $\Delta P_{W F}$ with frequency control strategy.

1. Normal operation mode. The VSWTs operate at a certain active power value $\left(P_{c m d}\right)$, according to the available mechanical power for a specific wind speed, $P_{m t}\left(\Omega_{W T}\right)$. It matches the maximum available active power for this current wind speed $P_{M P P T}\left(V_{W}\right)$; see Figure 2a,

$$
P_{c m d}=P_{m t}\left(\Omega_{W T}\right)=P_{M P P T}\left(V_{W}\right) .
$$

Under power imbalance conditions, and assuming an under-frequency deviation, the frequency controller strategy changes to the overproduction mode and, subsequently, $\Delta f<-\Delta f_{\text {lim }} \rightarrow$ Overproduction.

2. Overproduction mode. The active power supplied by the VSWTs involves (i) mechanical power $P_{m t}$ available from the $P_{m t}\left(\Omega_{W T}\right)$ curve and (ii) additional active power $\Delta P_{O P}$ provided by the kinetic energy stored in the rotational masses,

$$
P_{c m d}=P_{m t}\left(\Omega_{W T}\right)+\Delta P_{O P}(\Delta f) .
$$

$\Delta P_{O P}$ is estimated proportionally to the evolution of frequency excursion in order to emulate primary frequency control of conventional generation units [26,62]. Most previous approaches assume $\Delta P_{O P}$ as a constant value independent of the frequency excursion [22,23,61]. Moreover, the mechanical power $P_{m t}$ is also considered as constant by most authors, even when rotational speed decreased [20-24,61]. This overproduction strategy remains active until one of the following conditions is met: the frequency excursion disappears, the rotational speed reaches a minimum allowed value, or the commanded power is lower than the maximum available active power,

$$
\left.\begin{array}{ll}
\Delta f & >-\Delta f_{\text {lim }} \\
\Omega_{W T} & <\Omega_{W T, \min } \\
P_{c m d} & <P_{M P P T}\left(\Omega_{M P P T}\right)
\end{array}\right\} \rightarrow \text { Recovery. }
$$

3. Recovery mode. With the aim of minimizing frequency oscillations, wind power plants have to move from overproduction mode to recovery mode as smoothly as possible, avoiding abrupt power changes and, subsequently, undesirable secondary frequency shifts $[20,22,24,61]$. With this aim, the authors' solution described in [25] follows the mechanical power curve $P_{m t}\left(\Omega_{W T}\right)$ according to the wind speed instead of the maximum power curve $P_{M P P T}\left(\Omega_{W T}\right)$ [22]. The power provided by the VSWTs in this mode is based on two periods according to [25]: (i) a parabolic trajectory and (ii) following the $P_{M P P T}$ curve proportional to the difference between $P_{m t}\left(\Omega_{W T}\right)$ and $P_{M P P T}\left(\Omega_{W T}\right)$. The normal operation mode then can be recovered when either $\Omega_{M P P T}$ or $P_{M P P T}\left(\Omega_{M P P T}\right)$ are respectively reached by the wind turbine. 
This strategy was evaluated in [25] and compared to [61] for single-are power system modeling, providing an improved frequency response under power imbalance conditions. This approach is considered in the present paper and extended to a multi-area power system with significant wind power integration into different areas.

\section{Power System Modeling}

\subsection{General Overview}

Traditional power system modeling for frequency deviation analysis under imbalance conditions is usually based on the following expression [63],

$$
\Delta f=\frac{1}{2 H_{e q} s+D_{e q}} \cdot\left(\Delta P_{g}-\Delta P_{L}\right),
$$

where $\Delta f$ is the frequency variation from nominal system frequency, $H_{e q}$ is the equivalent inertia constant of the system, $D_{e q}$ is the equivalent damping factor of the loads, and $\Delta P_{g}-\Delta P_{L}$ is the power imbalance. $H_{e q}$ is estimated from Equation (5), $H_{m}$ is the inertia constant of $m$-power plant, $S_{B, m}$ is the rated power of the $m$-generating unit, $C G$ is the total number of conventional synchronous generators and $S_{B}$ is the base power system:

$$
H_{e q}=\frac{\sum_{m=1}^{C G} H_{m} \cdot S_{B, m}}{S_{B}} .
$$

Transmission level voltage is usually considered for multi-area interconnection purposes through tie-lines. Frequency and tie-line power exchange can vary according to variations in power load demand [64-68]. The total tie-line power exchange between two areas is determined by

$$
\Delta P_{t i e_{i, j}}=\frac{2 \cdot \pi \cdot T_{i, j}}{s} \cdot\left(\Delta f_{i}-\Delta f_{j}\right)
$$

where $T_{i, j}$ is the synchronizing moment coefficient of the tie-line between $i$ and $j$ areas.

When a frequency deviation is detected, the balance between an interconnected power system is determined by generating the Area Control Error signal $(A C E)$, expressed as a linear combination of the tie-line power exchange and the frequency deviation [69]

$$
A C E_{i}=B_{i} \cdot \Delta f_{i}+\sum_{\substack{j=1 \\ j \neq i}}^{N} \Delta P_{t i i_{i, j}}
$$

where $i, j$ refers to $i$ and $j$ areas, respectively, $B$ is the bias-factor, $\Delta P_{\text {tie }}$ is the variation in the exchanged tie-line power and $N$ is the total number of interconnected areas. Figure 3 schematically shows these power exchanges for a three-area power system example. Recent contributions focused on a new control logic of the Balancing Authority Area Control Error Limit (BAAL) Standard adopted in the North American power grid can be found in [70]. 


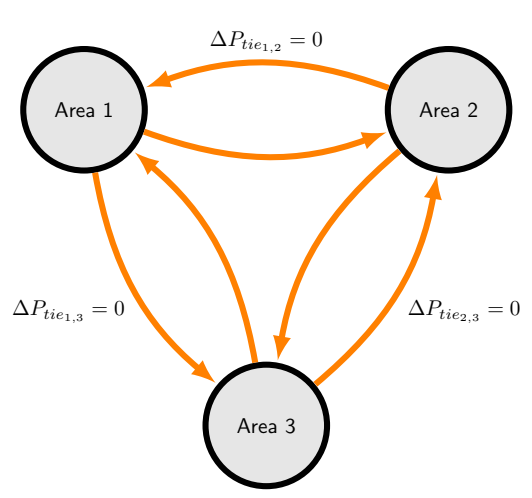

(a)

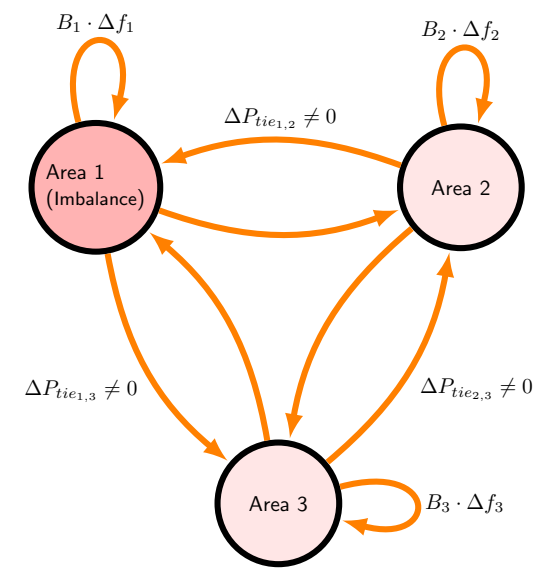

(b)

Figure 3. Multi-area power system. (a) balanced situation; (b) imbalanced situation in Area 1.

\subsection{Supply-Side Modeling}

From the supply-side, the power systems considered for simulation purposes involve conventional generating units (such as non-reheat thermal and hydro-power) and renewable energy sources (wind and PV power plants). One equivalent generator is used for each type of production to model the supply-side. This assumption is in line with previous contributions focused on frequency strategy control analysis.

The conventional generating unit models considered for simulations can be seen in Figure 4. Taking into account the specific literature, they are modeled according to the simplified governor-based models widely used and proposed in [62]. Parameters are provided in Tables 1 and 2, respectively. The different transfer functions of governor and turbine are indicated in Figure 4.

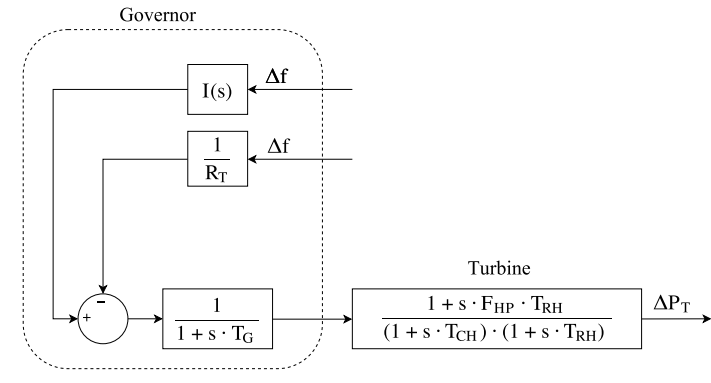

(a)

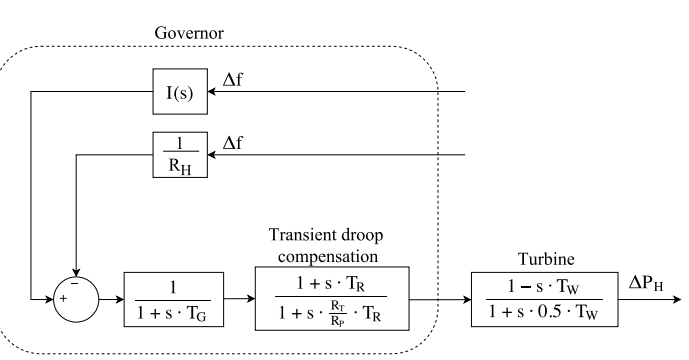

(b)

Figure 4. Conventional generation modeling. (a) thermal plant model; (b) hydro-power plant model.

Table 1. Thermal power plant parameters [62].

\begin{tabular}{ccc}
\hline Parameter & Name & Value $\left(\mathbf{p u}_{\text {thermal }}\right)$ \\
\hline$T_{G}$ & Speed relay pilot valve & 0.20 \\
$F_{H P}$ & Fraction of power generated by high pressure section & 0.30 \\
$T_{R H}$ & Time constant of reheater & 7.00 \\
$T_{C H}$ & Time constant of main inlet volumes and steam chest & 0.30 \\
$R_{T}$ & Speed droop & 0.05 \\
$I(s)$ & Integral controller & 1.00 \\
$H_{\text {thermal }}$ & Inertia constant & $5.00 \mathrm{~s}$ \\
\hline
\end{tabular}


Table 2. Hydro-power plant parameters [62].

\begin{tabular}{ccc}
\hline Parameter & Name & Value $\left(\mathbf{p u} \mathbf{u}_{\text {hydro }}\right)$ \\
\hline$T_{G}$ & Speed relay pilot valve & 0.20 \\
$T_{R}$ & Reset time & 5.00 \\
$R_{T}$ & Temporary droop & 0.38 \\
$R_{P}$ & Permanent droop & 0.05 \\
$T_{W}$ & Water starting time & 1.00 \\
$R_{H}$ & Speed droop & 0.05 \\
$I(s)$ & Integral controller & 1.00 \\
$H_{\text {hydro }}$ & Inertia constant & $3.00 \mathrm{~s}$ \\
\hline
\end{tabular}

Wind power plants are able to provide frequency response according to the strategy discussed in Section 2. An aggregated model for wind power plants is considered for the simulation purposes. They are represented by one equivalent generator, which is generally accepted in the specific literature for frequency response simulations (Figure 5). The equivalent wind turbine has $n$-times the size of each individual wind turbine, with $n$ being the number of wind turbines [71,72]. The equivalent wind turbine model is based on [73,74], which have been widely used in recent publications [22,23,25,75-77]. Parameters are shown in Table 3. The remaining renewable generation is modeled through an equivalent $\mathrm{PV}$ power plant connected to the grid. It represents a renewable non-dispatchable energy source, following recent contributions [78]. Due to the short period of simulated time (under $5 \mathrm{~min}$ ), a constant active power provided by this non-dispatchable resource is considered for our analysis.

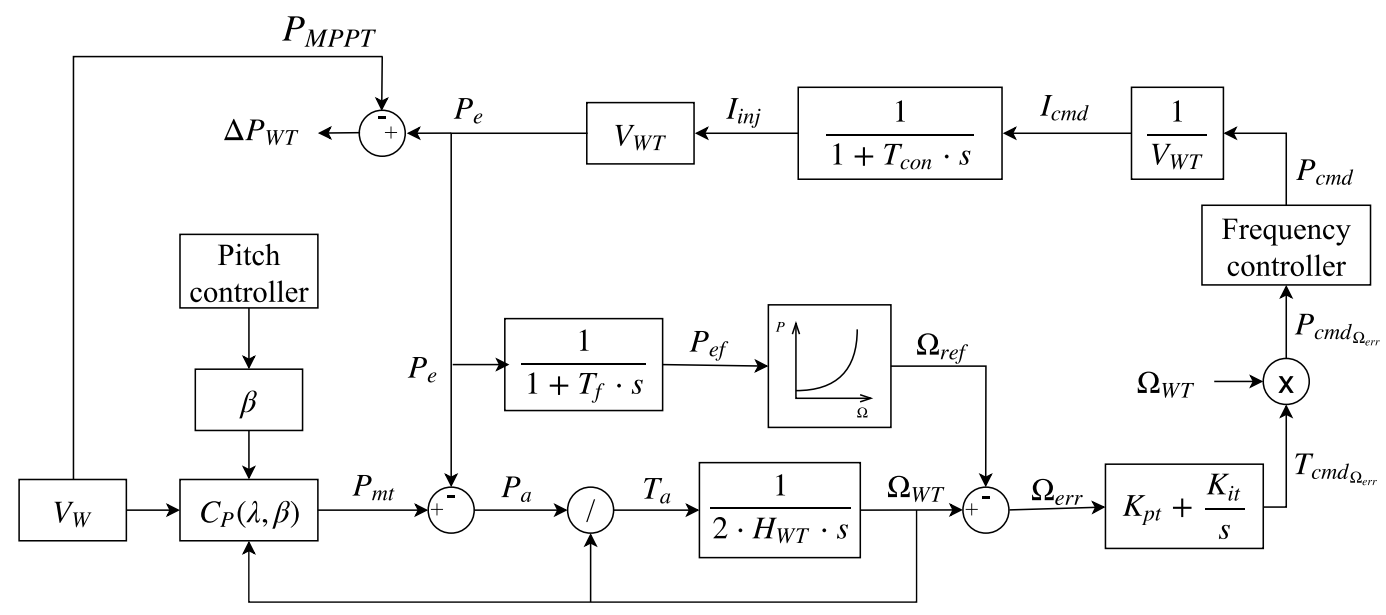

Figure 5. Aggregated wind power plant model with frequency controller.

Table 3. Wind turbine parameters [74].

\begin{tabular}{ccc}
\hline Parameter & Name & Value \\
\hline$V_{w}$ & Wind speed & $10 \mathrm{~m} / \mathrm{s}$ \\
$S_{n}$ & Rated power & $3.6 \mathrm{MW}$ \\
$H_{W T}$ & Inertia constant & $5.19 \mathrm{~s}$ \\
$\Omega_{0}$ & Base rotational speed & $1.335 \mathrm{rad} / \mathrm{s}$ \\
$T_{f}$ & Time delay to measure electric power & $5 \mathrm{~s}$ \\
$T_{c o n}$ & Time delay to generate the injected current $I_{i n j}$ & $0.020 \mathrm{~s}$ \\
$V_{W T}$ & Wind turbine voltage & $1 \mathrm{pu} \mathbf{W T}_{\mathrm{WT}}$ \\
$K_{p t}$ & Proportional constant of speed controller & $3 \mathrm{pu}_{\mathrm{WT}}$ \\
$K_{i t}$ & Integral constant of speed controller & $0.6 \mathrm{pu}_{\mathrm{WT}}$ \\
\hline
\end{tabular}




\subsection{Area Descriptions}

Figure 6 summarizes the percentages for the different generating units of each area. Previous studies address the problem of multi-area power systems considering only conventional power plants (mainly thermal, hydro-power and gas) and assuming two or three areas [32-36,38-41]. In this work, two different interconnected multi-source power systems are analyzed: (i) a two-area power system (considering only Areas 1 and 2) and (ii) a three-area power system. Both systems allow us to study in detail the relationships between the number of areas and the exchanged power between them when a significant number of renewable energies are considered from the supply-side. A base power of $2000 \mathrm{MW}$ per area is assumed that corresponds to the capacity of each area. In Europe, it is expected that wind and PV will cover up to $30 \%$ and $18 \%$ of the demand respectively by $2030[79,80]$. Therefore, the integration of these sources in the areas considered in this paper are in line with current European road-maps, having a RES/non-dispatchable integration lying between $25 \%$ to $50 \%$. In addition, $\Delta P_{t i i_{i, j}}$ is limited to a maximum value of $10 \%$. This limit agrees with recent EU-wide targets, which expect to have an interconnection power of $10 \%$ in the year 2020 [46]. Most contributions found in the literature review either do not limit the maximum tie-line power, or it is not indicated [81-84].

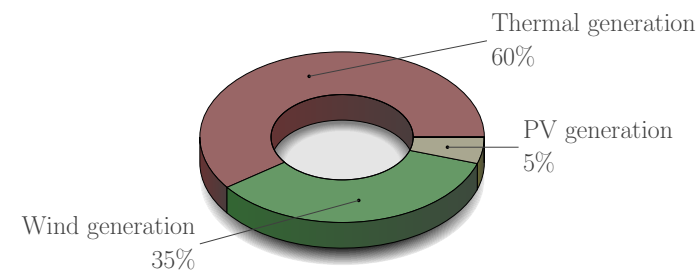

(a)

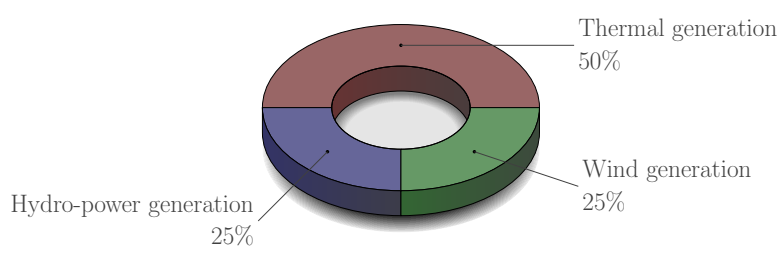

(b)

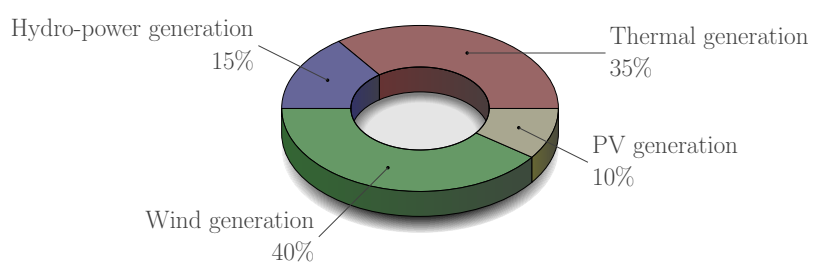

(c)

Figure 6. Generation contribution per area. (a) Area 1; (b) Area 2; (c) Area 3.

$T_{i, j}$ and $B$ values are provided in Table 4 for the two-interconnected areas $[30,35]$ and in Table 5 for three-interconnected areas [30]. The equivalent inertia $H_{\text {eq }}$ of each area is calculated according to Equation (5), and taking into account the inertia constants of thermal and hydro-power plants indicated in Section 3.2. With regard to the damping factor, the impact of an inaccurate value is relatively small if the power system is stable [85]. Moreover, it is expected to decrease accordingly to the use of variable frequency drives [86]. Table 6 summarizes different values proposed for the damping factor in the literature over recent decades. A value of $D_{e q}=1$ is considered for simulation purposes, which is in line with recent contributions and is lower than values corresponding to previous works. A general overview of a two-area power system can be seen in Figure 7.

Table 4. Interconnected two-area power system parameters [30,35].

\begin{tabular}{ccc}
\hline Parameter & Name & Value \\
\hline$B_{1}$ & Bias factor of Area 1 & 0.425 \\
$B_{2}$ & Bias factor of Area 2 & 0.425 \\
$T_{1,2}$ & Synchronizing moment coefficient between Areas 1 and 2 & 0.545 \\
$H_{e q, 1}$ & Equivalent inertia constant of Area 1 & $2.997 \mathrm{~s}$ \\
$H_{e q, 2}$ & Equivalent inertia constant of Area 2 & $3.324 \mathrm{~s}$ \\
\hline
\end{tabular}


Table 5. Interconnected three-area power system parameters [30].

\begin{tabular}{ccc}
\hline Parameter & Name & Value \\
\hline$B_{1}$ & Bias factor of Area 1 & 0.3483 \\
$B_{2}$ & Bias factor of Area 2 & 0.3827 \\
$B_{3}$ & Bias factor of Area 3 & 0.3629 \\
$T_{1,2}$ & Synchronizing moment coefficient between Areas 1 and 2 & 0.2 \\
$T_{2,3}$ & Synchronizing moment coefficient between Areas 2 and 3 & 0.12 \\
$T_{3,1}$ & Synchronizing moment coefficient between Areas 3 and 1 & 0.25 \\
$H_{e q, 1}$ & Equivalent inertia constant of Area 1 & $2.997 \mathrm{~s}$ \\
$H_{e q, 2}$ & Equivalent inertia constant of Area 2 & $3.324 \mathrm{~s}$ \\
$H_{e q, 3}$ & Equivalent inertia constant of Area 3 & $2.246 \mathrm{~s}$ \\
\hline
\end{tabular}

Table 6. Damping factor values.

\begin{tabular}{cccc}
\hline Ref. & Value $\mathbf{( p u / H z )}$ & Analysis & Year \\
\hline$[62]$ & $1-2$ & Power system stability & 1994 \\
{$[87]$} & 0.83 & Two areas with non-reheat thermal units & 2011 \\
{$[88]$} & 1.66 & Two areas with thermal units & 2011 \\
{$[89]$} & $1-1.8$ & Three areas with non-reheat thermal units & 2012 \\
{$[90]$} & 2 & One area with nuclear, thermal, wind and PV & 2012 \\
{$[91]$} & $0.5-0.9$ & Three areas with nonlinear thermal units & 2013 \\
{$[92]$} & 0.83 & Two areas non-reheat thermal units & 2013 \\
{$[93]$} & 0.83 & Two areas with thermal units & 2013 \\
{$[67]$} & 0.83 & Two areas with reheat units & 2015 \\
{$[94]$} & 0.8 & IEEE 9 bus system with hydro-power, gas and wind turbines & 2016 \\
{$[95]$} & $1-1.8$ & One and three areas with non-reheat thermal units & 2017 \\
{$[96]$} & $1-1.8$ & Three areas with non-reheat thermal units & 2018 \\
{$[97]$} & 1 & Two areas with non-reheat thermal units & 2018 \\
\hline
\end{tabular}

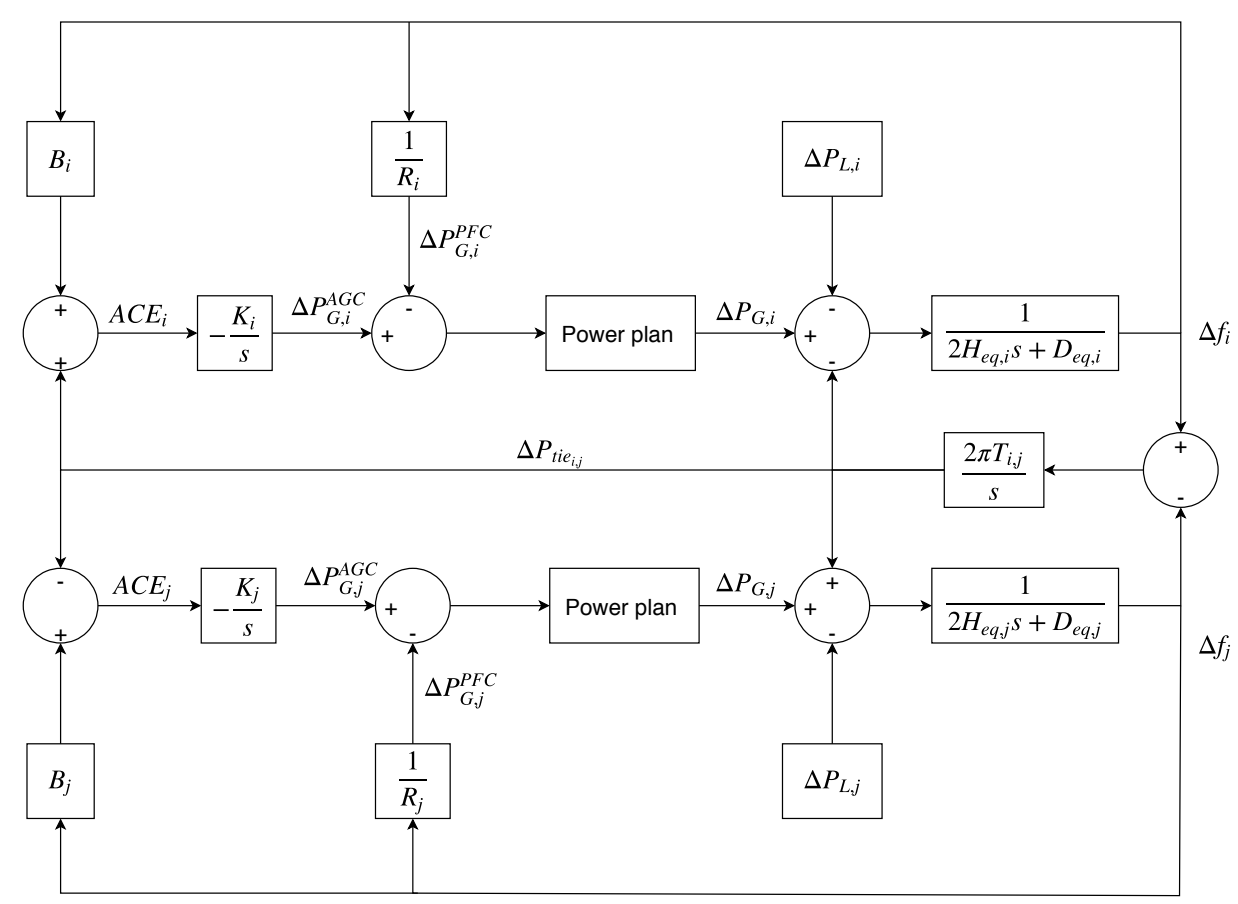

Figure 7. Two-area power system modeling for frequency control.

\section{Results}

As was discussed in Section 3, and with the aim of evaluating frequency oscillations and power system performances under imbalance conditions with different number of areas, two different 
multi-area power systems were simulated: (i) a two-area power system and (ii) a three-area power system. Both power systems were implemented in Matlab/Simulink ( ) (2016, MathWorks, Natick, MA, USA). Source codes are available under request.

\subsection{Two-Area Interconnected Power System}

Firstly, and in order to evaluate the sensitivity of frequency excursions in a multi-area power system, two different imbalance conditions were simulated. In both cases, one area is submitted to imbalances while the other area maintains a balanced condition. A $5 \%$ increase in demand of the base power is assumed in all simulations as imbalance power $\left(\Delta P_{L, 1}=\Delta P_{L, 2}=100 \mathrm{MW}\right)$. Under these scenarios, with an active-power deficit, different frequency control strategies are addressed by the simulations depending on the generation units involved in the frequency response: case (1) whole conventional generation units of the multi-area power system; case (2) whole conventional generation units and only wind power plants within the area submitted to imbalances; and case (3) whole conventional generation units and wind power plants.

Figure $8 \mathrm{a}, \mathrm{b}$ shows the frequency oscillations in both areas when a power imbalance is applied to Area $1\left(\Delta P_{L, 1}\right)$. As can be seen, the maximum nadir is achieved in both areas when case (1) is conducted. The nadir values are improved when wind power plants are considered for frequency control: cases (2) and (3). Indeed, case (2) offers a smoother and less oscillatory response than case (3), yielding a stabilization time interval very similar to case (1). Moreover, case (3) causes three different well-identified frequency shifts: the first one is due to the power imbalance; the second one occurs due to the lack of coordination between power plants as well as the different time response of the supply-side operation units (see Figure 9); and the last one depends on the transition from overproduction mode to recovery mode of the wind power plant located in Area 2 (see Figure $2 \mathrm{~b}$ and the active power decrease in WPP2 Figure 9).

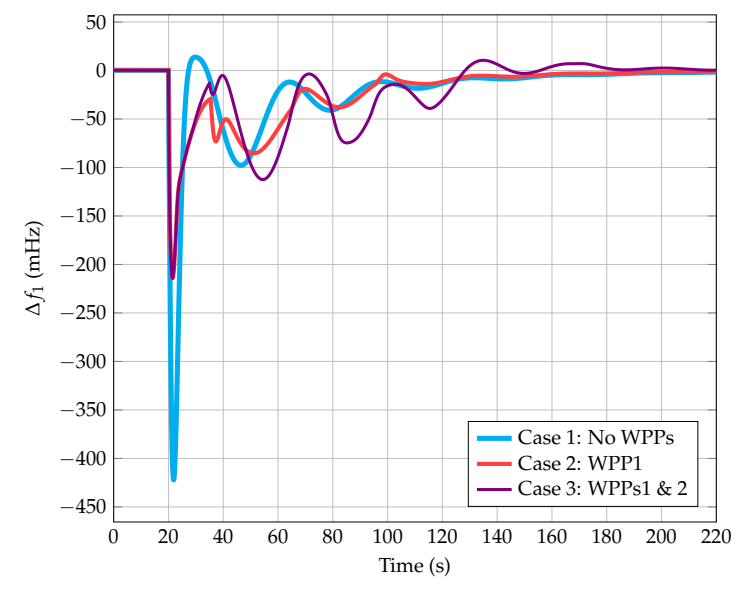

(a)

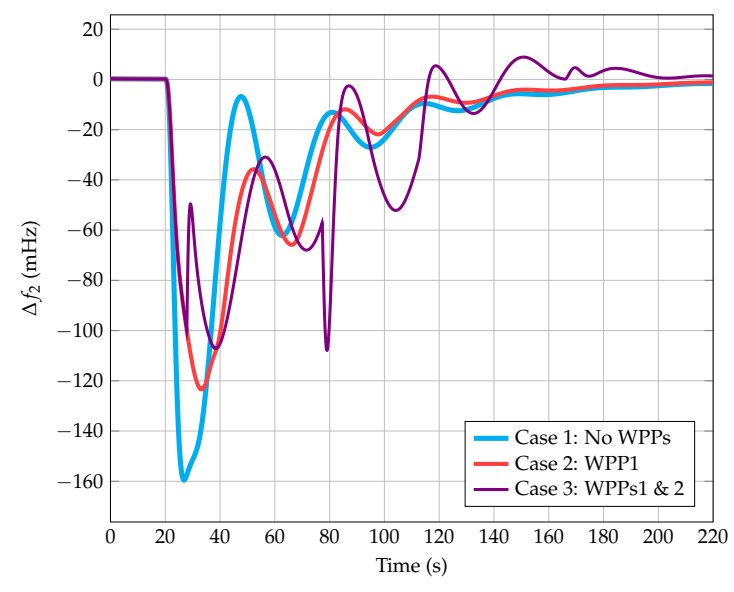

(b)

Figure 8. Area 1 under power imbalance $\left(\Delta P_{L, 1}\right)$; (a) frequency oscillations in Area 1 ; (b) frequency oscillations in Area 2. 


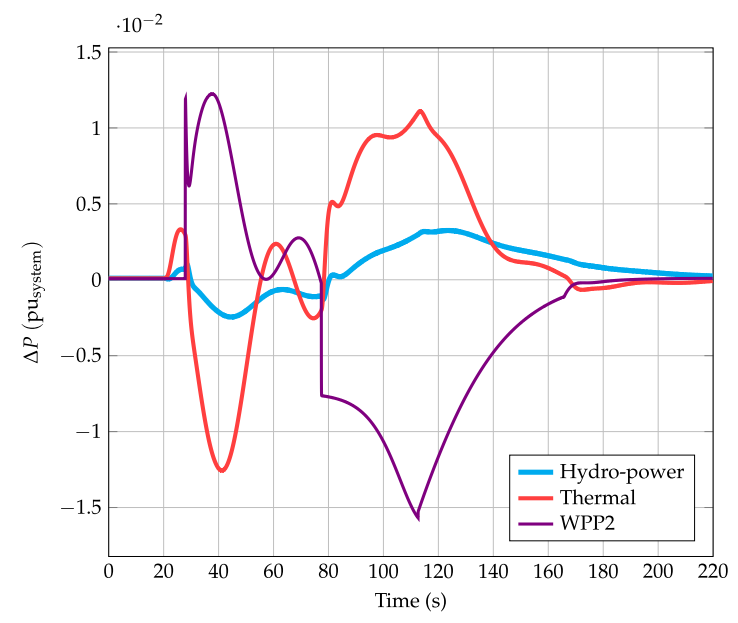

Figure 9. Area 1 under power imbalance $\left(\Delta P_{L, 1}\right)$ : generation deviations in Area 2.

A similar study can be carried out by considering power imbalance conditions in Area $2\left(\Delta P_{L, 2}\right)$. Figure 10 compares the results in terms of nadir for both scenarios $\left(\Delta P_{L, 1}\right.$ and $\left.\Delta P_{L, 2}\right)$ and considering the different frequency control strategies. As can be seen, minor differences are found in both analyses. In addition, Figure 11 compares the tie-line power evolution under both imbalance conditions, $\Delta P_{L, 1}$ and $\Delta P_{L, 2}$ accordingly, and peak-to-peak tie-line power exchange. Subsequently, and according to the generation mix considered in each area, frequency oscillations and active tie-line power results present similar values regardless of the area submitted to imbalances. Based on these results, and taking into account the different frequency control strategies implemented and simulated, lower frequency oscillations are obtained when only wind power plants within the area submitted to imbalance conditions are considered. Therefore, the contribution of wind power plants from other areas under frequency excursions would provide additional oscillation responses.

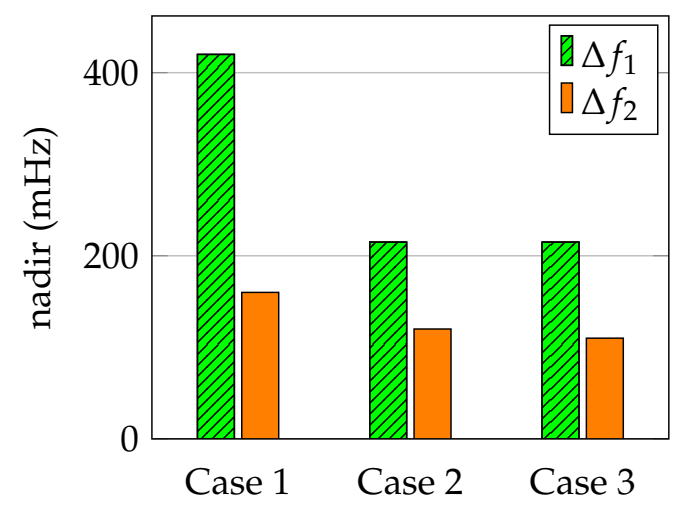

(a)

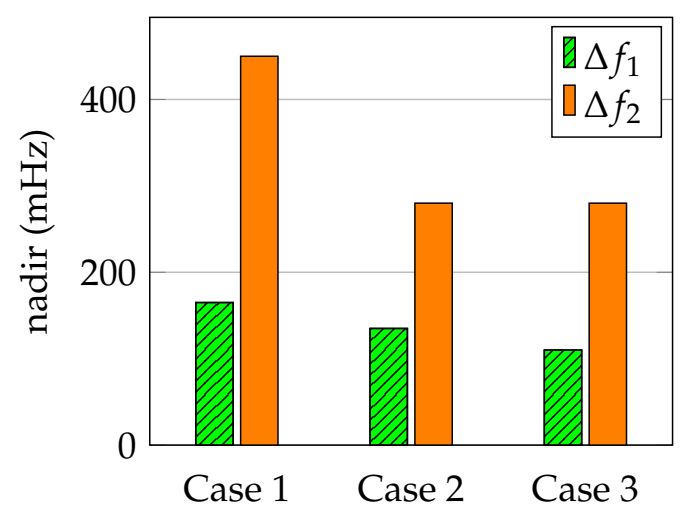

(b)

Figure 10. Nadir: Comparison of $\Delta P_{L, 1}$ and $\Delta P_{L, 2}$ scenarios. (a) Area 1 submitted to imbalance $\left(\Delta P_{L, 1}\right)$; (b) Area 2 submitted to imbalance $\left(\Delta P_{L, 2}\right)$. 


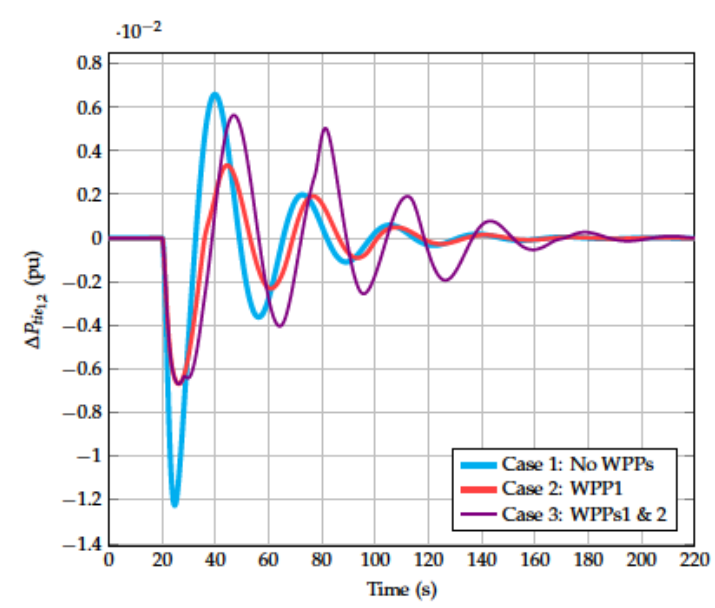

(a)

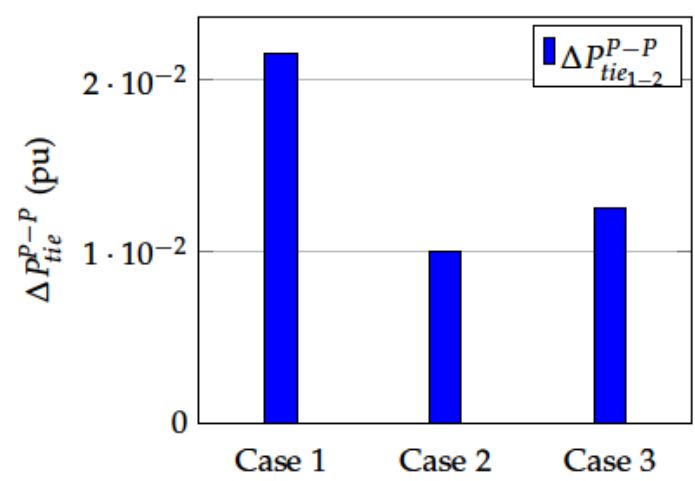

(c)

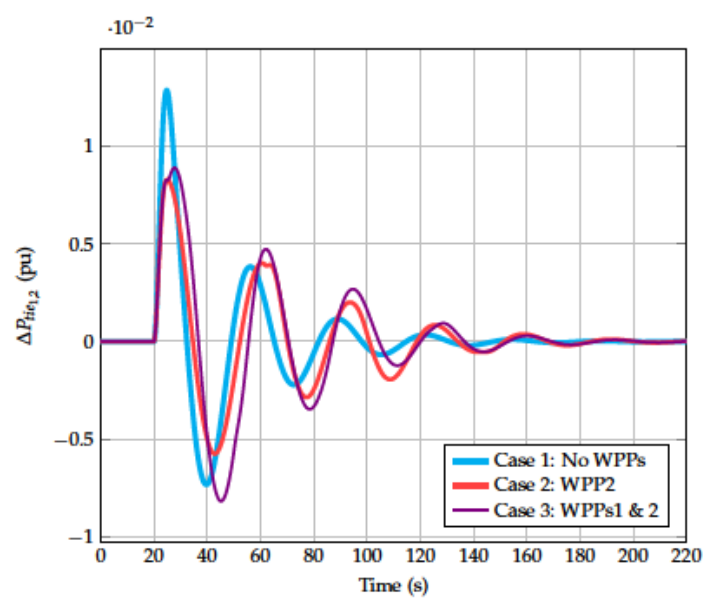

(b)

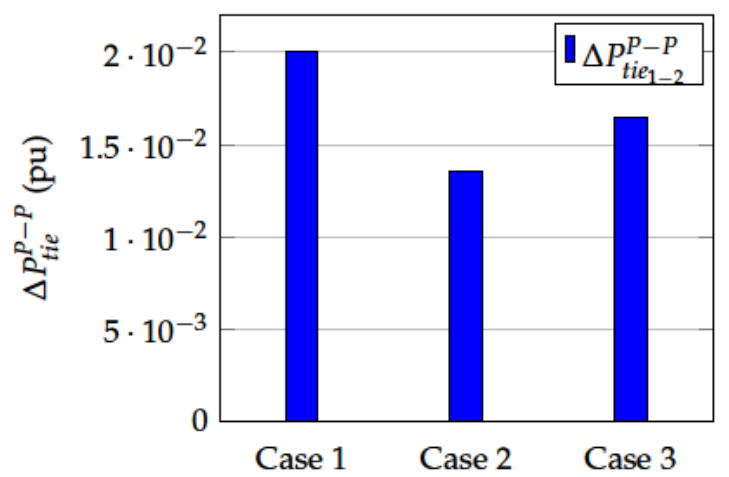

(d)

Figure 11. Active tie-line power evolution: comparison of $\Delta P_{L, 1}$ and $\Delta P_{L, 2}$ scenarios. (a) Area 1 submitted to power imbalance $\left(\Delta P_{L, 1}\right)$; (b) Area 2 submitted to power imbalance $\left(\Delta P_{L, 2}\right)$; (c) Area 1 submitted to imbalance $\left(\Delta P_{L, 1}\right)$; (d) Area 2 submitted to imbalance $\left(\Delta P_{L, 2}\right)$.

\subsection{Three-Area Interconnected Power System}

Considering the preliminary conclusion given in Section 4.1, where similar results are obtained independently of the area submitted to imbalances, the authors reduce the number of simulations in this three-area interconnected power system, assuming only that one area is submitted to imbalance conditions. Different frequency control strategies are then simulated by including an active-power deficit applied to Area $1, \Delta P_{L, 1}$. It is also defined as a step of $5 \%$ with respect to the base power $\left(\Delta P_{L, 1}=100 \mathrm{MW}\right)$.

Figure 12 depicts the frequency deviation of each area and the nadir comparison according to the different frequency control strategies. As can be seen, the results are in line with those obtained previously, when a two-area power system was considered. Therefore, the maximum nadir values are obtained in all areas when wind power plants are not included for frequency control. When wind power plants provide frequency response, the nadir values of all areas are considerably improved. Regarding case (2) and case (3), nadir values give similar results. However, larger frequency oscillations are identified when case (3) is conducted, especially in Area 2 and area 3. This behavior is a consequence of the wind power variations due to the different operation modes of each frequency controller, increasing the tie-line power exchanged between these two areas. Stabilization time presents similar values $\left(t_{\text {stab }} \simeq 100 \mathrm{~s}\right)$ in all cases and areas. 


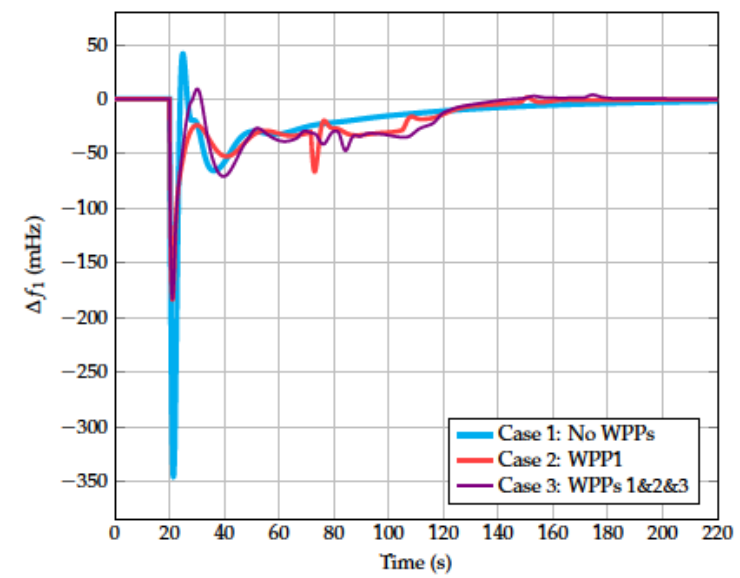

(a)

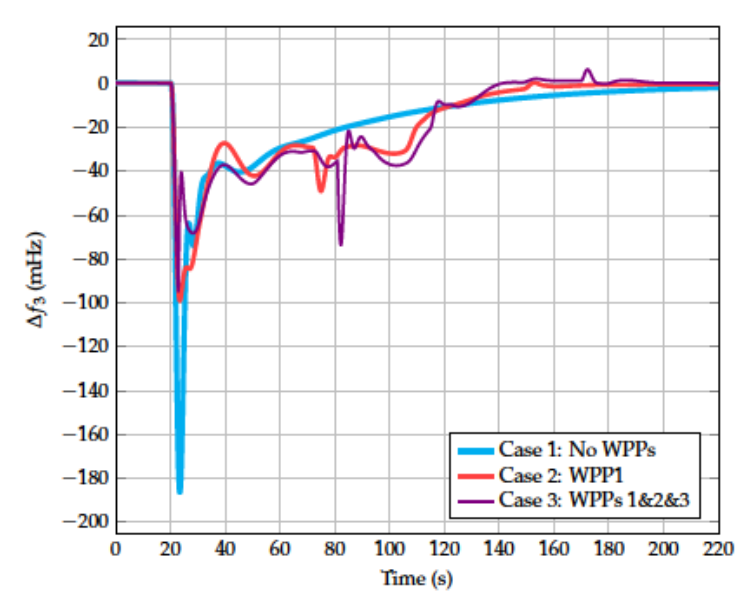

(c)

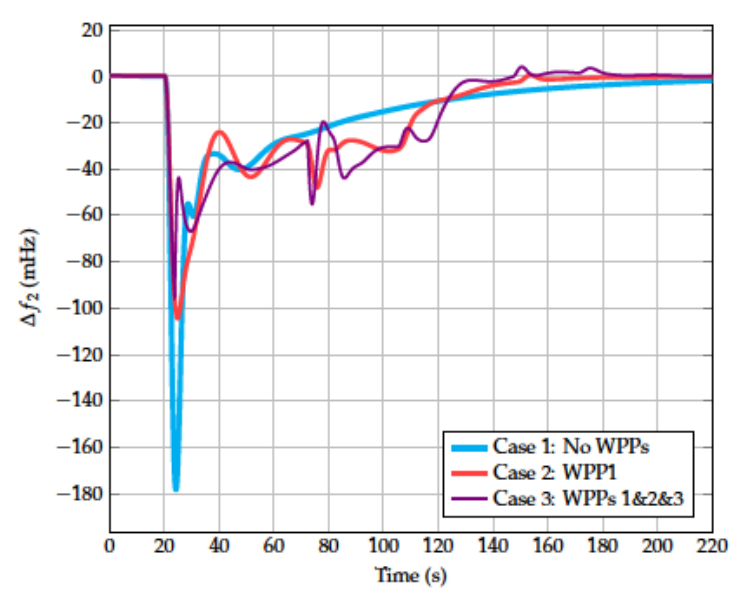

(b)

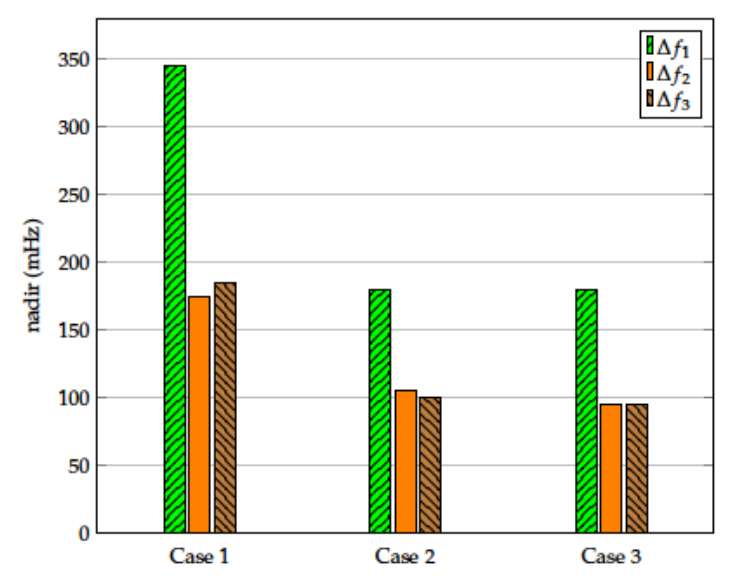

(d)

Figure 12. Frequency oscillations: Area 1 under power imbalance $\left(\Delta P_{L, 1}\right)$; (a) frequency oscillations in Area $1\left(\Delta f_{1}\right)$; (b) frequency oscillations in Area $2\left(\Delta f_{2}\right)$; (c) frequency oscillations in Area $3\left(\Delta f_{3}\right)$; (d) nadir values: case comparison.

Figure 13 shows and compares the tie-line power variation and its peak-to-peak value. As can be seen, tie-line power exchange does not overcome the maximum restriction of $10 \%$ under any circumstances. Power exchanged between areas $2-3$ is practically negligible regardless of the frequency control strategy, as the frequency deviations in these areas are a consequence of imbalances subsequently induced by Area 1 (see Section 3.1). As was previously mentioned, with the use of the wind power plants in all the areas $\Delta P_{t i e_{2,3}}$ increases due to the wind power plants variations. Actually, $\Delta P_{t i e_{2,3}}$ case (3) doubles the value of case (2), subsequently producing more oscillations in frequency deviations in those areas, as depicted in Figure 12. Therefore, case (2) is suggested by the authors under imbalance conditions to reduce frequency oscillations and power flow between areas. 


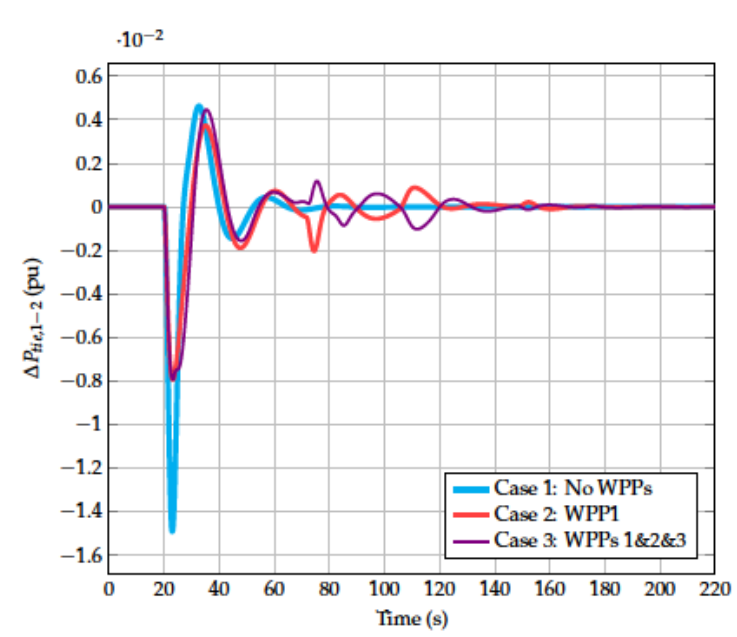

(a)

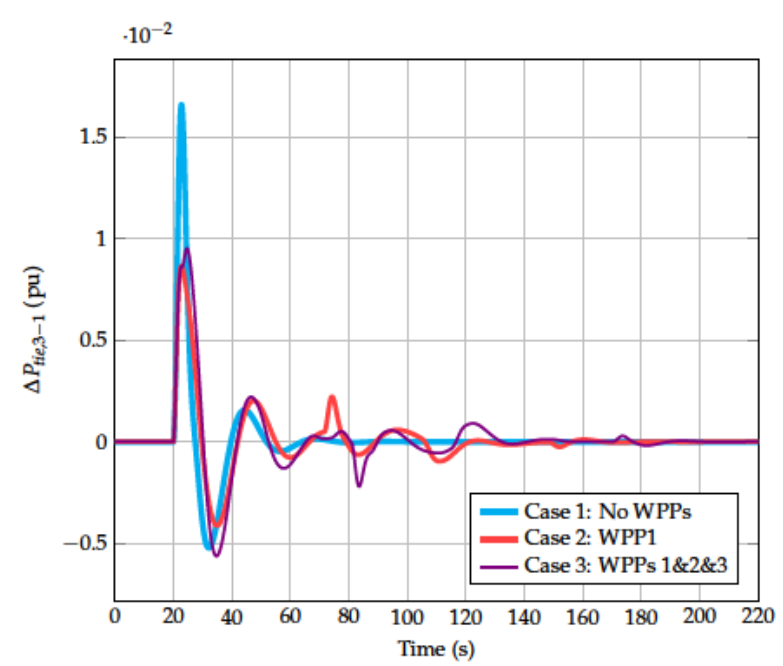

(c)

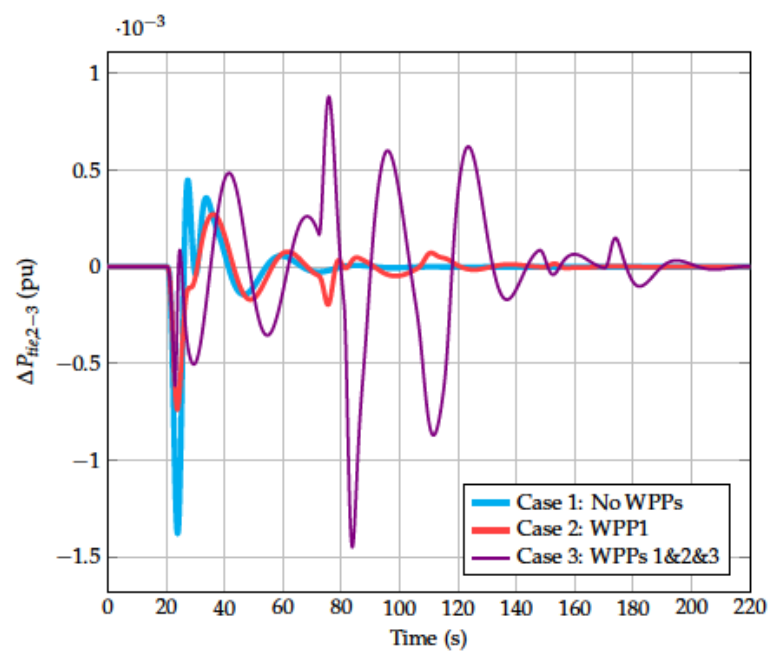

(b)

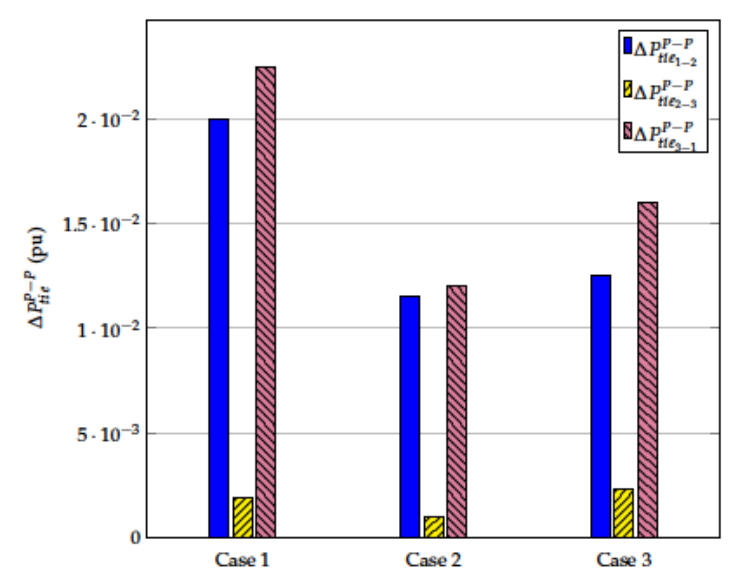

(d)

Figure 13. Area 1 under power imbalance $\left(\Delta P_{L, 1}\right)$ : tie-line power comparison; (a) tie-line power variation between Areas 1 and 2; (b) tie-line power variation between Areas 2 and 3; (c) tie-line power variation between Areas 3 and 1; (d) comparison among peak-to-peak tie-line power variation exchange.

\section{Conclusions}

Multi-areas interconnected power systems are analyzed under power imbalance conditions and with high wind energy integration. From the supply-side, conventional and renewable resources are considered, including thermal, hydro-power, wind and PV power plants. Wind power integration accounts for between $25 \%$ and $40 \%$, corresponding to current percentages in some European countries. Tie-line power is limited to a maximum value of $10 \%$, in line with recent EU directives. Different cases are compared and analyzed, depending on frequency control strategies applied by wind power plants. According to the results, frequency responses are improved by including wind power plants in frequency control, in comparison with simulations where this task is only performed by conventional generation units. Of the different cases, the nadir reductions are maximized when only wind power plants within the area submitted to imbalances are considered. In this case, the nadir is reduced between $40 \%$ and $50 \%$ in the area submitted to imbalanced areas in comparison to conventional generational unit scenarios. Moreover, these nadir values are also reduced in the other areas between $20 \%$ and $30 \%$. When wind power responses of all areas are considered, higher frequency oscillations and lower nadir reductions can be reached in comparison with only conventional generation unit 
scenarios. Stabilization time remains almost constant under different situations, and very similar to simulations where only conventional units respond under frequency excursions. Subsequently, the authors suggest including only wind power plant frequency response within the area submitted to imbalances, avoiding additional frequency oscillations coming from wind power plants located in the other areas.

Author Contributions: Data curation, A.F.-G.; formal analysis, A.F.-G.; methodology, A.F.-G., A.V.-R. and A.M.-G.; software, A.F.-G.; supervision, A.V.-R. and E.G.-L.; visualization, A.M.-G.; writing—original draft, A.M.-G.; writing-review \& editing, E.G.-L.

Funding: This work was supported by 'Ministerio de Educación, Cultura y Deporte' of Spain (ref. FPU16/04282). The authors are grateful for the financial support from the Spanish Ministry of the Economy and Competitiveness and the European Union -ENE2016-78214-C2-2-R.

Conflicts of Interest: The authors declare no conflict of interest.

\section{Abbreviations}

The following abbreviations are used in this manuscript:

$\begin{array}{ll}A C E & \text { Area Control Error } \\ A G C & \text { Automatic Generation Control } \\ C G & \text { Total number of conventional synchronous generators } \\ R O C O F & \text { Rate of Change of Frequency } \\ V S W T s & \text { Variable Speed Wind Turbines } \\ W P P & \text { Wind Power Plant } \\ n a d i r & \text { Minimum value of the frequency excursion } \\ n & \text { Number of VSWT in the wind power plant } \\ t_{s t a b} & \text { Stabilization time } \\ B & \text { Bias factor } \\ D_{e q} & \text { Equivalent damping factor of the power system } \\ H_{e q} & \text { Equivalent inertia constant of the power system } \\ H_{m} & \text { Inertia constant of generating unit } m \\ N & \text { Number of interconnected areas } \\ P_{c m d} & \text { Commanded power of the VSWT } \\ P_{M P P T} & \text { Maximum power point tracking of the VSWT } \\ P_{m t} & \text { Mechanical power of the VSWT } \\ S_{B} & \text { Rated power of the power system } \\ S_{B, m} & \text { Rated power of generating unit } m \\ S_{n} & \text { Rated power of a VSWT } \\ T_{i, j} & \text { synchronizing moment coefficient of a tie-line between areas } i \text { and } j \\ V_{W} & \text { Wind speed } \\ \beta & \text { Pitch angle } \\ \Delta f & \text { Frequency excursion } \\ \Delta f_{l i m} & \text { Value at which frequency controller of the VSWT activates } \\ \Delta P_{g} & \text { Variation of active power of the power system } \\ \Delta P_{L} & \text { Variation of power demand } \\ \Delta P_{O P} & \text { Additional active power in overproduction operation mode } \\ \Delta P_{t i e_{i, j}} & \text { Tie-line power changed between areas } i \text { and } j \\ \Delta P_{t i e_{i, j}}^{P} & \text { Peak-to-peak tie-line power changed between areas } i \text { and } j \\ \Delta P_{W F} & \text { Variation of active power of the wind power plant } \\ \Omega_{W T} & \text { Rotational speed of the VSWT } \\ \Omega_{W T, m i n} & \text { Minimum rotational speed of the VSWT } \\ \Omega_{M P P T} & \text { Rotational speed at maximum power point tracking } \\ & \end{array}$




\section{References}

1. Li, D.Y.; Li, P.; Cai, W.C.; Song, Y.D.; Chen, H.J. Adaptive Fault Tolerant Control of Wind Turbines with Guaranteed Transient Performance Considering Active Power Control of Wind Farms. IEEE Trans. Ind. Electron. 2017, 65, 3275-3285. [CrossRef]

2. Rasolomampionona, D. A modified power system model for AGC analysis. In Proceedings of the 2009 IEEE Bucharest PowerTech, Bucharest, Romania, 28 June-2 July 2009; pp. 1-6.

3. Du, P.; Matevosyan, J. Forecast system inertia condition and its impact to integrate more renewables. IEEE Trans. Smart Grid 2018, 9, 1531-1533. [CrossRef]

4. Toulabi, M.; Bahrami, S.; Ranjbar, A.M. Application of Edge theorem for robust stability analysis of a power system with participating wind power plants in automatic generation control task. IET Renew. Power Gener. 2017, 11, 1049-1057. [CrossRef]

5. Toulabi, M.; Bahrami, S.; Ranjbar, A.M. An Input-to-State Stability Approach to Inertial Frequency Response Analysis of Doubly-Fed Induction Generator-Based Wind Turbines. IEEE Trans. Energy Convers. 2017, 32, 1418-1431. [CrossRef]

6. Ochoa, D.; Martinez, S. Frequency dependent strategy for mitigating wind power fluctuations of a doubly-fed induction generator wind turbine based on virtual inertia control and blade pitch angle regulation. Renew. Energy 2018, 128, 108-124. [CrossRef]

7. Ochoa, D.; Martinez, S. Proposals for Enhancing Frequency Control in Weak and Isolated Power Systems: Application to the Wind-Diesel Power System of San Cristobal Island-Ecuador. Energies 2018, 11, 910.10.3390/en11040910. [CrossRef]

8. Bao, Y.; Xu, J.; Liao, S.; Sun, Y.; Li, X.; Jiang, Y.; Ke, D.; Yang, J.; Peng, X. Field Verification of Frequency Control by Energy-Intensive Loads for Isolated Power Systems with High Penetration of Wind Power. IEEE Trans. Power Syst. 2018, in press. [CrossRef]

9. Fini, M.H.; Golshan, M.E.H. Determining optimal virtual inertia and frequency control parameters to preserve the frequency stability in islanded microgrids with high penetration of renewables. Electr. Power Syst. Res. 2018, 154, 13-22. [CrossRef]

10. Li, H.; Wang, X.; Xiao, J. Differential Evolution-Based Load Frequency Robust Control for Micro-Grids with Energy Storage Systems. Energies 2018, 11, 686. [CrossRef]

11. Huang, L.; Xin, H.; Zhang, L.; Wang, Z.; Wu, K.; Wang, H. Synchronization and Frequency Regulation of DFIG-Based Wind Turbine Generators With Synchronized Control. IEEE Trans. Energy Convers. 2017, 32, 1251-1262. [CrossRef]

12. Luo, X.; Wang, J.; Dooner, M.; Clarke, J. Overview of current development in electrical energy storage technologies and the application potential in power system operation. Appl. Energy 2015, 137, 511-536. [CrossRef]

13. Xue, Y.; Tai, N. Review of contribution to frequency control through variable speed wind turbine. Renew. Energy 2011, 36, 1671-1677.

14. Sun, D.; Sun, L.; Wu, F.; Zu, G. Frequency Inertia Response Control of SCESS-DFIG under Fluctuating Wind Speeds Based on Extended State Observers. Energies 2018, 11, 830. [CrossRef]

15. Tavakoli, M.; Pouresmaeil, E.; Adabi, J.; Godina, R.; Catalao, J.P. Load-frequency control in a multi-source power system connected to wind farms through multi terminal HVDC systems. Comput. Oper. Res. 2018, 96, 305-315. [CrossRef]

16. Saeed Uz Zaman, M.; Bukhari, S.B.A.; Hazazi, K.M.; Haider, Z.M.; Haider, R.; Kim, C.H. Frequency Response Analysis of a Single-Area Power System with a Modified LFC Model Considering Demand Response and Virtual Inertia. Energies 2018, 11, 787. [CrossRef]

17. Sun, Y.; Zhang, Z.; Li, G.; Lin, J. Review on frequency control of power systems with wind power penetration. In Proceedings of the 2010 IEEE International Conference on Power System Technology (POWERCON), Hangzhou, China, 24-28 October 2010; pp. 1-8.

18. Gonzalez-Longatt, F.M.; Bonfiglio, A.; Procopio, R.; Verduci, B. Evaluation of inertial response controllers for full-rated power converter wind turbine (Type 4). In Proceedings of the 2016 IEEE Power and Energy Society General Meeting (PESGM), Boston, MA, USA, 17-21 July 2016; pp. 1-5.

19. Wu, Z.; Gao, W.; Gao, T.; Yan, W.; Zhang, H.; Yan, S.; Wang, X. State-of-the-art review on frequency response of wind power plants in power systems. J. Modern Power Syst. Clean Energy 2018, 6, 1-16. [CrossRef] 
20. Keung, P.K.; Li, P.; Banakar, H.; Ooi, B.T. Kinetic energy of wind-turbine generators for system frequency support. IEEE Trans. Power Syst. 2009, 24, 279-287. [CrossRef]

21. El Itani, S.; Annakkage, U.D.; Joos, G. Short-term frequency support utilizing inertial response of DFIG wind turbines. In Proceedings of the 2011 IEEE Power and Energy Society General Meeting, Detroit, MI, USA, 24-28 July 2011; pp. 1-8.

22. Hansen, A.D.; Altin, M.; Margaris, I.D.; Iov, F.; Tarnowski, G.C. Analysis of the short-term overproduction capability of variable speed wind turbines. Renew. Energy 2014, 68, 326-336. [CrossRef]

23. Hafiz, F.; Abdennour, A. Optimal use of kinetic energy for the inertial support from variable speed wind turbines. Renew. Energy 2015, 80, 629-643. [CrossRef]

24. Kang, M.; Kim, K.; Muljadi, E.; Park, J.W.; Kang, Y.C. Frequency control support of a doubly-fed induction generator based on the torque limit. IEEE Trans. Power Syst. 2016, 31, 4575-4583. [CrossRef]

25. Fernández-Guillamón, A.; Villena-Lapaz, J.; Vigueras-Rodríguez, A.; García-Sánchez, T.; Molina-García, Á. An Adaptive Frequency Strategy for Variable Speed Wind Turbines: Application to High Wind Integration into Power Systems. Energies 2018, 11, 1436. [CrossRef]

26. Margaris, I.D.; Papathanassiou, S.A.; Hatziargyriou, N.D.; Hansen, A.D.; Sorensen, P. Frequency control in autonomous power systems with high wind power penetration. IEEE Trans. Sustain. Energy 2012, 3, 189-199. [CrossRef]

27. Vidyanandan, K.; Senroy, N. Primary frequency regulation by deloaded wind turbines using variable droop. IEEE Trans. Power Syst. 2013, 28, 837-846. [CrossRef]

28. Alsharafi, A.S.; Besheer, A.H.; Emara, H.M. Primary Frequency Response Enhancement for Future Low Inertia Power Systems Using Hybrid Control Technique. Energies 2018, 11, 699. [CrossRef]

29. Tielens, P.; Van Hertem, D. Receding horizon control of wind power to provide frequency regulation. IEEE Trans. Power Syst. 2017, 32, 2663-2672. [CrossRef]

30. Sahu, R.K.; Gorripotu, T.S.; Panda, S. Automatic generation control of multi-area power systems with diverse energy sources using teaching learning based optimization algorithm. Eng. Sci. Technol. Int. J. 2016, 19, 113-134. [CrossRef]

31. Shayeghi, H.; Shayanfar, H.; Jalili, A. Load frequency control strategies: A state-of-the-art survey for the researcher. Energy Convers. Manag. 2009, 50, 344-353. [CrossRef]

32. Parmar, K.S.; Majhi, S.; Kothari, D. LFC of an interconnected power system with multi-source power generation in deregulated power environment. Int. J. Electr. Power Energy Syst. 2014, 57, 277-286. [CrossRef]

33. Shankar, R.; Chatterjee, K.; Bhushan, R. Impact of energy storage system on load frequency control for diverse sources of interconnected power system in deregulated power environment. Int. J. Electr. Power Energy Syst. 2016, 79, 11-26. [CrossRef]

34. Barisal, A. Comparative performance analysis of teaching learning based optimization for automatic load frequency control of multi-source power systems. Int. J. Electr. Power Energy Syst. 2015, 66, 67-77. [CrossRef]

35. Sahu, R.K.; Panda, S.; Sekhar, G.C. A novel hybrid PSO-PS optimized fuzzy PI controller for AGC in multi area interconnected power systems. Int. J. Electr. Power Energy Syst. 2015, 64, 880-893. [CrossRef]

36. Guha, D.; Roy, P.K.; Banerjee, S. Load frequency control of interconnected power system using grey wolf optimization. Swarm Evol. Comput. 2016, 27, 97-115. [CrossRef]

37. Ozdemir, M.T.; Ozturk, D. Comparative Performance Analysis of Optimal PID Parameters Tuning Based on the Optics Inspired Optimization Methods for Automatic Generation Control. Energies 2017, 10, 2134. [CrossRef]

38. Mohanty, B.; Panda, S.; Hota, P. Controller parameters tuning of differential evolution algorithm and its application to load frequency control of multi-source power system. Int. J. Electr. Power Energy Syst. 2014, 54, 77-85. [CrossRef]

39. Zare, K.; Hagh, M.T.; Morsali, J. Effective oscillation damping of an interconnected multi-source power system with automatic generation control and TCSC. Int. J. Electr. Power Energy Syst. 2015, 65, 220-230. [CrossRef]

40. Gorripotu, T.S.; Sahu, R.K.; Panda, S. AGC of a multi-area power system under deregulated environment using redox flow batteries and interline power flow controller. Eng. Sci. Technol. Int. J. 2015, 18, 555-578. [CrossRef]

41. Hota, P.; Mohanty, B. Automatic generation control of multi source power generation under deregulated environment. Int. J. Electr. Power Energy Syst. 2016, 75, 205-214. [CrossRef] 
42. Ketabi, A.; Fini, M.H. An underfrequency load shedding scheme for hybrid and multiarea power systems. IEEE Trans. Smart Grid 2015, 6, 82-91. [CrossRef]

43. Mi, Y.; Fu, Y.; Li, D.; Wang, C.; Loh, P.C.; Wang, P. The sliding mode load frequency control for hybrid power system based on disturbance observer. Int. J. Electr. Power Energy Syst. 2016, 74, 446-452. [CrossRef]

44. Kerdphol, T.; Rahman, F.S.; Mitani, Y. Virtual Inertia Control Application to Enhance Frequency Stability of Interconnected Power Systems with High Renewable Energy Penetration. Energies 2018, 11, 981. [CrossRef]

45. Babahajiani, P.; Shafiee, Q.; Bevrani, H. Intelligent demand response contribution in frequency control of multi-area power systems. IEEE Trans. Smart Grid 2018, 9, 1282-1291. [CrossRef]

46. 2030 Energy Strategy. Available online: https://ec.europa.eu/energy/en/topics/energy-strategy-andenergy-union/2030-energy-strategy (accessed on 15 August 2018).

47. Dreidy, M.; Mokhlis, H.; Mekhilef, S. Inertia response and frequency control techniques for renewable energy sources: A review. Renew. Sustain. Energy Rev. 2017, 69, 144-155. [CrossRef]

48. Wang, H.; Yang, J.; Chen, Z.; Ge, W.; Hu, S.; Ma, Y.; Li, Y.; Zhang, G.; Yang, L. Gain Scheduled Torque Compensation of PMSG-Based Wind Turbine for Frequency Regulation in an Isolated Grid. Energies 2018, 11, 1623. [CrossRef]

49. Jallad, J.; Mekhilef, S.; Mokhlis, H. Frequency Regulation Strategies in Grid Integrated Offshore Wind Turbines via VSC-HVDC Technology: A Review. Energies 2017, 10, 1244. [CrossRef]

50. Tavakkoli, M.; Adabi, J.; Zabihi, S.; Godina, R.; Pouresmaeil, E. Reserve Allocation of Photovoltaic Systems to Improve Frequency Stability in Hybrid Power Systems. Energies 2018, 11, 583. [CrossRef]

51. Kayikçi, M.; Milanovic, J.V. Dynamic contribution of DFIG-based wind plants to system frequency disturbances. IEEE Trans. Power Syst. 2009, 24, 859-867. [CrossRef]

52. Morren, J.; de Haan, S.W.H.; Kling, W.L.; Ferreira, J.A. Wind turbines emulating inertia and supporting primary frequency control. IEEE Trans. Power Syst. 2006, 21, 433-434. [CrossRef]

53. Ramtharan, G.; Jenkins, N.; Ekanayake, J. Frequency support from doubly fed induction generator wind turbines. IET Renew. Power Gener. 2007, 1, 3-9. [CrossRef]

54. Chowdhury, B.H.; Ma, H.T. Frequency regulation with wind power plants. In Proceedings of the 2008 IEEE Power and Energy Society General Meeting-Conversion and Delivery of Electrical Energy in the 21st Century, 20-24 July 2008; pp. 1-5.

55. Conroy, J.F.; Watson, R. Frequency response capability of full converter wind turbine generators in comparison to conventional generation. IEEE Trans. Power Syst. 2008, 23, 649-656. [CrossRef]

56. Mauricio, J.M.; Marano, A.; Gómez-Expósito, A.; Ramos, J.L.M. Frequency regulation contribution through variable-speed wind energy conversion systems. IEEE Trans. Power Syst. 2009, 24, 173-180. [CrossRef]

57. Bassi, F.; Caciolli, L.; Giannuzzi, G.; Corsi, N.; Giorgi, A. Use of hidden inertia from wind generation for frequency support in power grids. In Proceedings of the 2016 IEEE AEIT International Annual Conference (AEIT), Capri, Italy, 5-7 October 2016; pp. 1-6.

58. Gonzalez-Longatt, F.M. Impact of emulated inertia from wind power on under-frequency protection schemes of future power systems. J. Modern Power Syst. Clean Energy 2016, 4, 211-218. [CrossRef]

59. Hu, J.; Sun, L.; Yuan, X.; Wang, S.; Chi, Y. Modeling of type 3 wind turbines with df/dt inertia control for system frequency response study. IEEE Trans. Power Syst. 2017, 32, 2799-2809. [CrossRef]

60. Bonfiglio, A.; Invernizzi, M.; Labella, A.; Procopio, R. Design and Implementation of a Variable Synthetic Inertia Controller for Wind Generating Units. IEEE Trans. Power Syst. 2018, in press.

61. Tarnowski, G.C.; Kjar, P.C.; Sorensen, P.E.; Ostergaard, J. Variable speed wind turbines capability for temporary over-production. In Proceedings of the 2009 IEEE Power \& Energy Society General Meeting (PES'09), Calgary, AB, Canada, 26-30 July 2009; pp. 1-7.

62. Kundur, P.; Balu, N.J.; Lauby, M.G. Power System Stability and Control; McGraw-Hill: New York, NY, USA, 1994; Volume 7.

63. Tan, W. Load frequency control: Problems and solutions. In Proceedings of the 2011 IEEE 30th Chinese Control Conference (CCC), Yantai, China, 22-24 July 2011; pp. 6281-6286.

64. Ma, M.; Chen, H.; Liu, X.; Allgöwer, F. Distributed model predictive load frequency control of multi-area interconnected power system. Int. J. Electr. Power Energy Syst. 2014, 62, 289-298. [CrossRef]

65. Yousef, H.A.; Khalfan, A.K.; Albadi, M.H.; Hosseinzadeh, N. Load frequency control of a multi-area power system: An adaptive fuzzy logic approach. IEEE Trans. Power Syst. 2014, 29, 1822-1830. [CrossRef] 
66. Pan, I.; Das, S. Fractional-order load-frequency control of interconnected power systems using chaotic multi-objective optimization. Appl. Soft Comput. 2015, 29, 328-344. [CrossRef]

67. Sathya, M.; Ansari, M.M.T. Load frequency control using Bat inspired algorithm based dual mode gain scheduling of PI controllers for interconnected power system. Int. J. Electr. Power Energy Syst. 2015, 64, 365-374. [CrossRef]

68. Abdelaziz, A.; Ali, E. Cuckoo search algorithm based load frequency controller design for nonlinear interconnected power system. Int. J. Electr. Power Energy Syst. 2015, 73, 632-643. [CrossRef]

69. Padhan, D.G.; Majhi, S. A new control scheme for PID load frequency controller of single-area and multi-area power systems. ISA Trans. 2013, 52, 242-251. [CrossRef] [PubMed]

70. Chang, Y.; Liu, R.; Ba, Y.; Li, W. A New Control Logic for a Wind-Area on the Balancing Authority Area Control Error Limit Standard for Load Frequency Control. Energies 2018, 11, 121. [CrossRef]

71. Pyller, M.; Achilles, S. Aggregated wind park models for analyzing power system dynamics. In Proceedings of the 4th International Workshop Large-Scale Integration of Wind Power and Transmission Networks, Billund, Denmark, 20-21 October 2003.

72. Mokhtari, M.; Aminifar, F. Toward wide-area oscillation control through doubly-fed induction generator wind farms. IEEE Trans. Power Syst. 2014, 29, 2985-2992. [CrossRef]

73. Miller, N.W.; Sanchez-Gasca, J.J.; Price, W.W.; Delmerico, R.W. Dynamic modeling of GE 1.5 and 3.6 MW wind turbine-generators for stability simulations. In Proceedings of the 2003 IEEE Power Engineering Society General Meeting, Toronto, ON, Canada, 13-17 July 2003; Volume 3, pp. 1977-1983.

74. Ullah, N.R.; Thiringer, T.; Karlsson, D. Temporary primary frequency control support by variable speed wind turbines-Potential and applications. IEEE Trans. Power Syst. 2008, 23, 601-612. [CrossRef]

75. Baccino, F.; Conte, F.; Grillo, S.; Massucco, S.; Silvestro, F. An optimal model-based control technique to improve wind farm participation to frequency regulation. IEEE Trans. Sustain. Energy 2015, 6, $993-1003$. [CrossRef]

76. Zhao, J.; Lyu, X.; Fu, Y.; Hu, X.; Li, F. Coordinated microgrid frequency regulation based on DFIG variable coefficient using virtual inertia and primary frequency control. IEEE Trans. Energy Convers. 2016, 31, 833-845. [CrossRef]

77. Martínez-Lucas, G.; Sarasúa, J.I.; Sánchez-Fernández, J.Á. Frequency Regulation of a Hybrid Wind-Hydro Power Plant in an Isolated Power System. Energies 2018, 11, 239. [CrossRef]

78. Perera, A.T.D.; Nik, V.M.; Mauree, D.; Scartezzini, J.L. Electrical hubs: An effective way to integrate non-dispatchable renewable energy sources with minimum impact to the grid. Appl. Energy 2017, 190, 232-248. [CrossRef]

79. Wind energy in Europe: Scenarios for 2030. Wind Eur. 2017. Available online: https://windeurope.org/wpcontent/uploads/files/about-wind/reports/Wind-energy-in-Europe-Scenarios-for-2030.pdf (accessed on 10 August 2018).

80. Technology Roadmap: Solar Photovoltaic Energy. Int. Energy Agency 2014. Available online: https:// www.iea.org/publications/freepublications / publication/TechnologyRoadmapSolarPhotovoltaicEnergy_ 2014edition.pdf (accessed on 10 August 2018).

81. Huang, C.; Yue, D.; Xie, X.; Xie, J. Anti-windup load frequency controller design for multi-area power system with generation rate constraint. Energies 2016, 9, 330. [CrossRef]

82. Zeng, G.Q.; Xie, X.Q.; Chen, M.R. An Adaptive Model Predictive Load Frequency Control Method for Multi-Area Interconnected Power Systems with Photovoltaic Generations. Energies 2017, 10, 1840. [CrossRef]

83. Yang, L.; Liu, T.; Hill, D.J. Decentralized periodic event-triggered frequency regulation for multi-area power systems. In Proceedings of the 2018 IEEE Power Systems Computation Conference (PSCC), Dublin, Ireland, 11-15 June 2017; pp. 1-7.

84. Lu, K.; Zhou, W.; Zeng, G.; Zheng, Y. Constrained population extremal optimization-based robust load frequency control of multi-area interconnected power system. Int. J. Electr. Power Energy Syst. 2019, 105, 249-271. [CrossRef]

85. Huang, H.; Li, F. Sensitivity analysis of load-damping characteristic in power system frequency regulation. IEEE Trans. Power Syst. 2013, 28, 1324-1335. [CrossRef]

86. Tielens, P.; Van Hertem, D. The relevance of inertia in power systems. Renew. Sustain. Energy Rev. 2016, 55, 999-1009. [CrossRef] 
87. Ali, E.; Abd-Elazim, S. Bacteria foraging optimization algorithm based load frequency controller for interconnected power system. Int. J. Electr. Power Energy Syst. 2011, 33, 633-638. [CrossRef]

88. Sudha, K.; Santhi, R.V. Robust decentralized load frequency control of interconnected power system with generation rate constraint using type-2 fuzzy approach. Int. J. Electr. Power Energy Syst. 2011, 33, 699-707. [CrossRef]

89. Jiang, L.; Yao, W.; Wu, Q.; Wen, J.; Cheng, S.; others. Delay-dependent stability for load frequency control with constant and time-varying delays. IEEE Trans. Power Syst. 2012, 27, 932. [CrossRef]

90. Masuta, T.; Yokoyama, A. Supplementary load frequency control by use of a number of both electric vehicles and heat pump water heaters. IEEE Trans. Smart Grid 2012, 3, 1253-1262. [CrossRef]

91. Shabani, H.; Vahidi, B.; Ebrahimpour, M. A robust PID controller based on imperialist competitive algorithm for load-frequency control of power systems. ISA Trans. 2013, 52, 88-95. [CrossRef] [PubMed]

92. Rout, U.K.; Sahu, R.K.; Panda, S. Design and analysis of differential evolution algorithm based automatic generation control for interconnected power system. Ain Shams Eng. J. 2013, 4, 409-421. [CrossRef]

93. Sahu, R.K.; Panda, S.; Rout, U.K. DE optimized parallel 2-DOF PID controller for load frequency control of power system with governor dead-band nonlinearity. Int. J. Electr. Power Energy Syst. 2013, 49, 19-33. [CrossRef]

94. Ruiz, S.; Patiño, J.; Espinosa, J. Load Frequency Control of a Multi-area Power System Incorporating Variable-speed Wind Turbines. 2016, in press.

95. Dong, L.; Tang, Y.; He, H.; Sun, C. An event-triggered approach for load frequency control with supplementary ADP. IEEE Trans. Power Syst. 2017, 32, 581-589. [CrossRef]

96. Peng, C.; Zhang, J.; Yan, H. Adaptive Event-Triggering $H_{\infty}$ Load Frequency Control for Network-Based Power Systems. IEEE Trans. Ind. Electr. 2018, 65, 1685-1694. [CrossRef]

97. Wu, Y.; Wei, Z.; Weng, J.; Li, X.; Deng, R.H. Resonance attacks on load frequency control of smart grids. IEEE Trans. Smart Grid 2018, 9, 4490-4502. [CrossRef]

(C) 2018 by the authors. Licensee MDPI, Basel, Switzerland. This article is an open access article distributed under the terms and conditions of the Creative Commons Attribution (CC BY) license (http:// creativecommons.org/licenses/by/4.0/). 


\subsection{Frequency control analysis based on unit commitment schemes with high wind power integration: A Spanish isolated power system case study}

Most contributions regarding wind turbines participation into frequency control discuss power imbalances under arbitrary power imbalance conditions, usually ranged between 5\% and 20\%, and assuming averaged energy schedule scenarios. In this paper, the Gran Canaria Island's isolated power system (Spain) is used as case study. Frequency excursions are analysed by considering the loss of the largest conventional generation group, including a wind frequency control strategy, a load shedding program and realistic energy scenarios obtained by a unit commitment model. With regard to the frequency analysis, by including wind power generation into frequency control, nadir and $\mathrm{RoCoF}$ are reduced in most of energy scenarios considered (110 $\mathrm{mHz}$ and $185 \mathrm{mHz} / \mathrm{s}$ in average, respectively), subsequently reducing the load shedding in 11 out of the 30 power imbalance cases analysed. This improvement is more significant in high wind power integration scenarios (regardless of the power demand), and for high power demands (regardless of the wind power integration). Therefore, wind frequency control can be considered a remarkable solution to reduce load shedding in isolated power systems with high wind power integration. Moreover, there is no homogeneity in the frequency response results, providing a clear dependence on the dispatch of the conventional rotational generation units, their participation in the global energy scenario and the inertia changes addressed by the generation unit tripping. Subsequently, the participation of wind power plants into frequency control should be analysed by considering not only the wind power integration level, but also other variables, such as the energy scenario, the rate power of the different generation units, as well as the reserves provided by conventional generation units and thus, the equivalent rotational inertia given by them. Indeed, nadir and RoCoF values give almost homogeneous values when such aspects are not included in the simulations. Whereas our findings are derived based on an specific power system case study, our results are useful and significant based on the relevance of our realistic case study coupled with the number of different energy scenarios and wind power integration ranges.

Information of the paper:

- Journal: International Journal of Electrical Power \& Energy Systems

- DOI: 10.1016/j.ijepes.2020.106044

- Date of publication: January 2020

- Available online: https://arxiv.org/pdf/2004.09604.pdf

- Reference: [4] 



\title{
Frequency Control Analysis based on Unit Commitment Schemes with High Wind Power Integration: a Spanish Isolated Power System Case Study
}

\author{
Ana Fernández-Guillamón ${ }^{\mathrm{a}}$, José Ignacio Sarasúa ${ }^{\mathrm{b}}$, Manuel Chazarra $^{\mathrm{b}}$, Antonio Vigueras-Rodríguez ${ }^{\mathrm{c}}$, Daniel \\ Fernández-Muñoz ${ }^{\mathrm{b}}$, Ángel Molina-García ${ }^{\mathrm{a}, *}$ \\ ${ }^{a}$ Dept. of Electrical Engineering, Universidad Politécnica de Cartagena, 30202 Cartagena, Spain \\ ${ }^{b}$ Dept. of Hydraulic, Energy and Environmental Engineering, Universidad Politécnica de Madrid, 28040, Spain \\ ${ }^{c}$ Dept. of Civil Engineering, Universidad Politécnica de Cartagena, 30202 Cartagena, Spain
}

\section{Abstract}

The relevant integration of wind power into the grid has involved a remarkable impact on power system operation, mainly in terms of security and reliability due to the inherent loss of the rotational inertia as a consequence of such new generation units decoupled from the grid. In these weak scenarios, the contribution of wind turbines to frequency control is considered as a suitable solution to improve system stability. With regard to frequency response analysis and grid stability, most contributions introduce wind control discuss generation tripping for isolated power systems under arbitrary power imbalance conditions. Frequency response is then analyzed for hypothetical imbalances usually ranged between $5 \%$ and 20\%, and assuming averaged energy schedule scenarios. In this paper, a more realistic framework is proposed to evaluate frequency deviations by including high wind power integration. With this aim, unit commitment schemes and frequency load shedding are considered in this work for frequency response analysis under high wind power penetration. The Gran Canaria Island's isolated power system (Spain) is used for evaluation purposes. Results provide a variety of influences from wind frequency control depending not only on the wind power integration, but also the generation units under operation, the rotational inertia reductions as well as the available reserves from each resource, aspects that have not been addressed previously in the specific literature to evaluate frequency excursions under high wind power integration.

Keywords: Power system stability, Wind energy integration, Wind frequency control, Unit commitment

\section{Nomenclature}

cc Combined cycle (subscript)

$d s \quad$ Diesel (subscript)

$D \quad$ Load-frequency sensitivity parameter (damping factor)

$f \quad$ Frequency

$g \quad$ Gas (subscript)

$K \quad$ Participation factor

$H_{i} \quad$ Rotational inertia of synchronous generator $i$

$h_{W T} \quad$ Number of wind turbines

$P_{i} \quad$ Power supplied by generation units $i$

$P_{d} \quad$ Power demand

$P_{J} \quad$ Power of Jinámar power plant

$P_{M P P T} \quad$ Maximum power point of wind turbines

$P_{s p} \quad$ Set-point active power of wind turbines

$P_{T} \quad$ Power of Barranco de Tirijana power plant

$P_{w} \quad$ Power of wind power plants

$R R \quad$ Regulation effort

\footnotetext{
* Corresponding author

Email addresses: ana.fernandez@upct.es (Ana

Fernández-Guillamón), joseignacio.sarasua@upm.es (José Ignacio Sarasúa), manuel.chazarra@upm.es (Manuel Chazarra), avigueras.rodriguez@upct.es (Antonio Vigueras-Rodríguez), daniel.fernandezm@upm.es (Daniel Fernández-Muñoz), angel.molina@upct.es (Ángel Molina-García)
}

\begin{tabular}{ll}
$s$ & Steam (subscript) \\
$T_{m}(t)$ & Inertia of the power system \\
$T_{u, t h}$ & Secondary response time constant \\
$v_{w}$ & Wind speed \\
\hline AGC & Automatic generation control \\
RES & Renewable energy sources \\
MILP & Mixed integer linear programming \\
RoCoF & Rate of change of frequency \\
TSO & Transmission system operator \\
UC & Unit commitment \\
VSWT & Variable speed wint turbines
\end{tabular}

\section{Introduction}

Conventional power plants with synchronous generators have traditionally determined the inertia of power systems [1]. However, during the last decades, most countries have promoted large-scale integration of Renewable Energy Sources (RES) [2, 3]. RES are usually not connected to the grid through synchronous machines, but through power electronic converters electrically decoupled from the grid $[4,5]$. As a consequence, by increasing the amount of RES and replacing synchronous conventional units, the effective rotational inertia of power systems can be significantly reduced [6-8]. Actually, Albadi et al. consider 
that the impact of RES on power systems mainly depends on the RES integration and the system inertia [9], being the RES negative effects more severe in isolated power systems [10]. Among the different RES, wind power is the most developed and relatively mature technology [11], especially variable speed wind turbines (VSWT) [12-16]. Indeed, Toulabi et al. affirm that the participation of wind power into frequency control services becomes inevitable due to the relevant integration of such resource [17].

Power imbalances between generation and demand can occur, among others, due to the loss of power generators [18]. Actually, this loss of power generators can be the most severe contingency in case it is the largest one [19]. These imbalances cause frequency fluctuations, and subsequently the grid becomes unstable, even leading to blackouts [20, 21]. Hence, the frequency control services are playing an essential role for secure and reliable power systems [22]. Moreover, frequency stability is the most critical issue in isolated power systems due to their low rotational inertia [23-25]. Frequency control has a hierarchical structure, and in Europe is usually organized up to five layers: $(i)$ frequency containment, (ii) imbalance netting, $($ iii, $i v)$ frequency restoration (automatic and/or manual) and $(v)$ replacement, from fast to slow timescales [26].

According to the specific literature, several studies have proposed wind frequency control approaches. However, authors notice that in those contributions: $(i)$ energy schedule scenarios considered are usually arbitrary and unrealistic, without considering a unit commitment (UC) scheme and individual generation units [27-31]; (ii) the power imbalance is usually taken as a fixed random value (between 3 and 20\%), excluding the $N-1$ criterion [3235]; (iii) load shedding is not taken into account in the frequency response analysis [36-38]; and (iv) only a few wind power integration scenarios are commonly analyzed to evaluate the wind frequency controller - usually one or two different scenarios- [39-42]. As a consequence, simulations can address unrealistic and inaccurate results. For instance, recent studies considering two wind integration share rates provide different - and even opposite- conclusions regarding frequency nadir and RoCoF (Rate of Change of Frequency): some authors conclude that these parameters can improve $[33,43]$, others that they could get worse $[31,44]$ or even be similar $[34]$ as wind penetration increases.

By considering previous contributions, the aim of this paper is to analyze the frequency response of an isolated power system with high integration of wind power generation including wind frequency control and load shedding. These energy schedule scenarios are determined by a UC model, taking into account some technical and economical constraints [45] and guaranteeing the frequency system recovery after the largest power plant outage $(N-1$ criterion) [46]. A realistic load shedding program is also included, as well as wind frequency control. With this aim, our study is carried out in Gran Canaria Island power system, in the Canary island archipelago (Spain), where the wind power integration has increased from 90 to $180 \mathrm{MW}$ in the last two years. Moreover, in the Canary island archipelago, more than 200 loss of generation events per year were registered between 2005 and 2010. In fact, the number of this kind of incidents even surpassed 300 per year, subsequently suffering from the activation of the load shedding programs [47]. This analysis can be extended to other isolated power systems with relevant wind energy potential, such as Madagascar [48] or Japan [49]. The main contributions of this paper can be thus summarized as follows:

- Evaluation of wind frequency control responses, including load shedding and rotational inertia changes from realistic operation conditions under generation unit tripping.

- Analysis of frequency deviations (nadir, RoCoF) in isolated power systems with high penetration of wind power, using energy schedules and unit comments obtained from an optimization model.

The rest of the paper is organized as follows: Section 2 describes the Gran Canaria power system and the generation scheduling process. The power system model, including both optimization and dynamic models, are described in Section 3. Simulation results are analyzed and discussed in Section 4. Finally, Section 5 outlines the main conclusions of the paper.

\section{Power System and Generation Scheduling Pro- cess}

\subsection{Preliminaries}

Different frequency analysis studies have been carried out by authors based on specific power systems. For instance, Zerket et al. . considered a modified Nordic 32-bus test system [50]; in [51], the power system of Flores Island, and the electric power system of Sao Miguel Island were used; Moghadam et al. . focused on the power system of Ireland [52]; in [53], the Singapore power system was used; Pradhan et al. tested the three-area New England system [54]; and [55] considered the Spanish isolated power system located in El Hierro Island. In this paper, authors have focused on Gran Canaria Island (Spain), where the wind power integration has increased from 90 to $180 \mathrm{MW}$ in the last two years.

Gran Canaria Island belongs to Canarian archipelago, one of the outermost regions of the European Union. Canarian archipelago is located in the north-west of the African Continent. From the energy point of view, Gran Canaria Island is an isolated power system. Traditionally, Gran Canaria Island's generation has been exclusively associated with fossil fuels: diesel, steam, gas and combined cycle units from two different power plants: Jinámar power plant and Barranco de Tirijana power plant. However, this fossil fuel dependence has involved an important economic and environmental drawback. To overcome theses 
problems, the Canary Government promoted the installation of wind power plants in the 90's, accounting for $70 \mathrm{MW}$ in 2002. In the following decade, the installation of wind power plants stopped around $95 \mathrm{MW}$ and, since 2015, wind power capacity has been doubled, nearly reaching $180 \mathrm{MW}$.

Regarding the wind power generation and system demand in Gran Canaria Island along 2018, both are shown in Fig. 1. The system demand is discretized for six different intervals, considering the lowest and highest demand of Gran Canaria Island. Wind power generation is discretized for five intervals. According to the ranges in the system demand and the wind power generation shown in Fig. 1, thirty energy scenarios are proposed to analyse the frequency response of the system including wind frequency control. Each energy scenario is based on a pair demandwind power generation as it is further described in Section 4 .

\subsection{Generation Scheduling Process}

The generation scheduling of the Gran Canaria Island power system is ruled in $[57,58]$. It is carried out by the Spanish Transmission System Operator (TSO) according to the economic criterion of variable costs of each power plant. The schedules are obtained according to different time horizons: weekly or daily. Each energy schedule depends on the previous time horizon and, subsequently, weekly and daily schedules are required to determine the hourly generation scheduling, which is used in the present paper. An overview of these schedules is summarized in Fig. 2.

1. Weekly scheduling: Estimation of the hourly start-up and shut-down decisions from each Saturday (00:00 h) to the following Friday $(23: 59 \mathrm{~h})$. This initial generation schedule is determined following two steps: $(i)$ an economic dispatch is carried out to minimize the total variable costs to meet the net power system demand (i.e., the power system demand minus the renewable generation). The result of such economic dispatch includes both the hourly energy and the reserve schedules (labeled as Schedule-A). (ii) an economic and security dispatch is determined taking into account the transmission lines and minimizing the total variable costs to support the net power system demand and a certain level of power quality. The result of this economic and security dispatch is also a hourly energy and reserve schedule (labeled as Schedule-B).

2. Daily scheduling: Updates the Schedule-B of a certain day $D$ from the updated available information of the power system: generation from suppliers, demand from consumers and the state of the transmission lines. The result of the daily scheduling in the day $D$ is a new hourly energy and reserve schedule (labeled as Schedule-C). It is obtained before 14:00 h of the day $D-1$. This Schedule-C is determined following a similar process as in the weekly scheduling: $(i)$ an economic dispatch is firstly carried out and (ii) an economic and security dispatch is then calculated. The daily scheduling processes aims to minimize the total variable costs to meet the net power system demand with a minimum certain level of power quality.

\section{Methodology: Unit Commitment and Fre- quency Model}

Frequency deviations are analyzed according to possible generation tripping and power system reserves by considering explicitly individual generation units and technologies. With this aim, a series of energy scenarios for each scenario of system demand and wind power generation based on a real isolated power system (the Gran Canaria Island) are estimated and evaluated accordingly, considering current wind power integration percentages and load shedding programs. Fig. 3 shows the proposed methodology, highlighting the novelties and differences presented in this paper compared to other approaches focused on frequency analysis (i.e., carry out a UC to determine the energy scenarios, consider the loss of the largest power plant as imbalance, and include load shedding with and without wind frequency control). The following subsections describe respectively the unit commitment model and frequency models used in this work. Fig. 4 shows a simplified scheme of the modelled Gran Canaria Island power system, where conventional and wind power plants are depicted.

\subsection{Unit commitment model: creation of scenarios}

In order to analyze frequency deviations in the Gran Canaria power system, a UC model is required to estimate the number of thermal units connected to the grid for each generation mix scenario. These thermal units remain unchanged during the subsequent frequency control analysis. The UC model used in this paper has been recently proposed by the authors in [59], based on [60], which is a deterministic thermal model based on mixed integer linear programming (MILP). Other contributions focused on probabilistic unit commitment can be also found in the specific literature. In this way, [61] proposes an optimal allocation of up/down spinning reserves under high integration of wind power. The planning horizon of our model is adapted to 24 hours with a time resolution of one hour consistent with the approach used by the TSO for the next-day generation scheduling [62]; and the hydropower technology is excluded from the model formulation in order to be consistent with the generation mix of the Gran Canaria power system. The model formulation is partially based on [63] which is, to the author's knowledge, the most computationally efficient formulation available in the literature when considering different types of start-up costs of thermal units.

The Gran Canaria power system is operated in a centralized manner by the TSO in order to minimize the total 


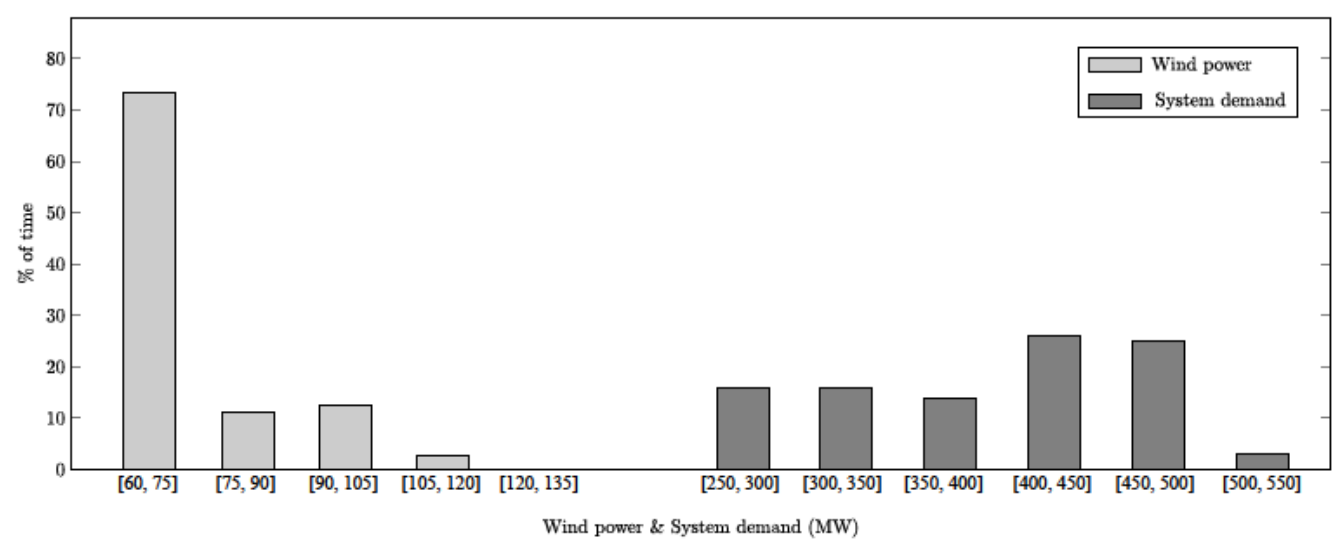

Figure 1: Wind power generation and system demand distribution in Gran Canaria Island power system along 2018 [56].

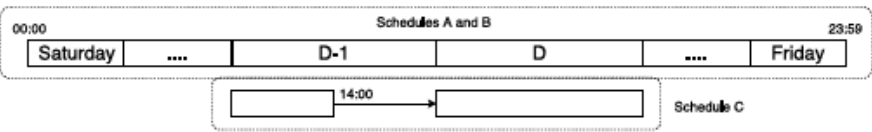

(a) Weekly and daily scheduling

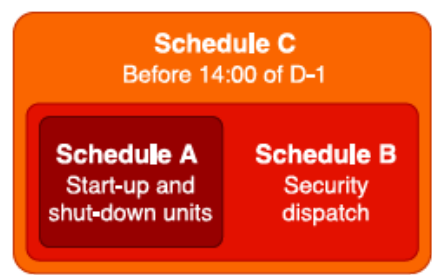

(b) Schedules A-C

Figure 2: Generation scheduling of Gran Canaria Island power system

system costs, according to [58]. Therefore, the objective function of the UC model here used consists in minimizing the start-up cost, the fuel cost, the operation and maintenance cost and the wear and tear cost of all thermal units. The optimal solution of the UC model is formed by the hourly energy schedule of each thermal unit of the system, taking into account their minimum on-line and off-line times. Among others, the energy schedule is restricted by the following constraints. The production-cost curve of each thermal unit is modeled as a piece-wise linear function discretized by ten pieces. The number of pieces is determined as a trade-off between the accuracy of the solution and the computation time cost limits. In addition, the system demand and the spinning reserve requirements must be fulfilled in each hour. According to the P.O. SEIE 1 in [57], the hourly spinning reserve must be higher or equal to the maximum of the following three values: $(i)$ the expected inter-hourly increase in the system demand between two consecutive hours; (ii) the most likely wind power loss calculated by the TSO from historical data; (iii) the loss of the largest spinning generating unit in each hour. It is important to bear in mind that there are two conceptual differences between the formulation presented in [63] and the one used here:

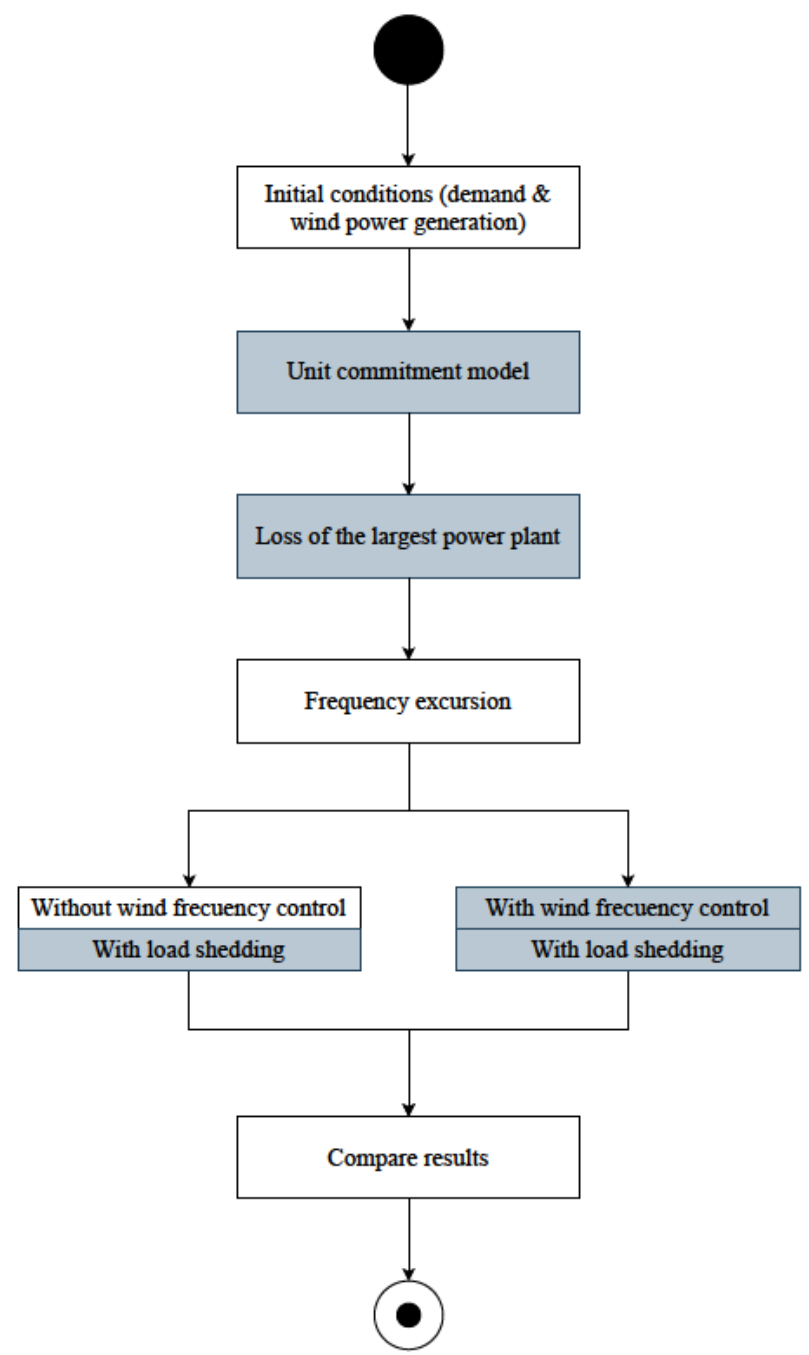

Figure 3: Flow chart of the methodology used 


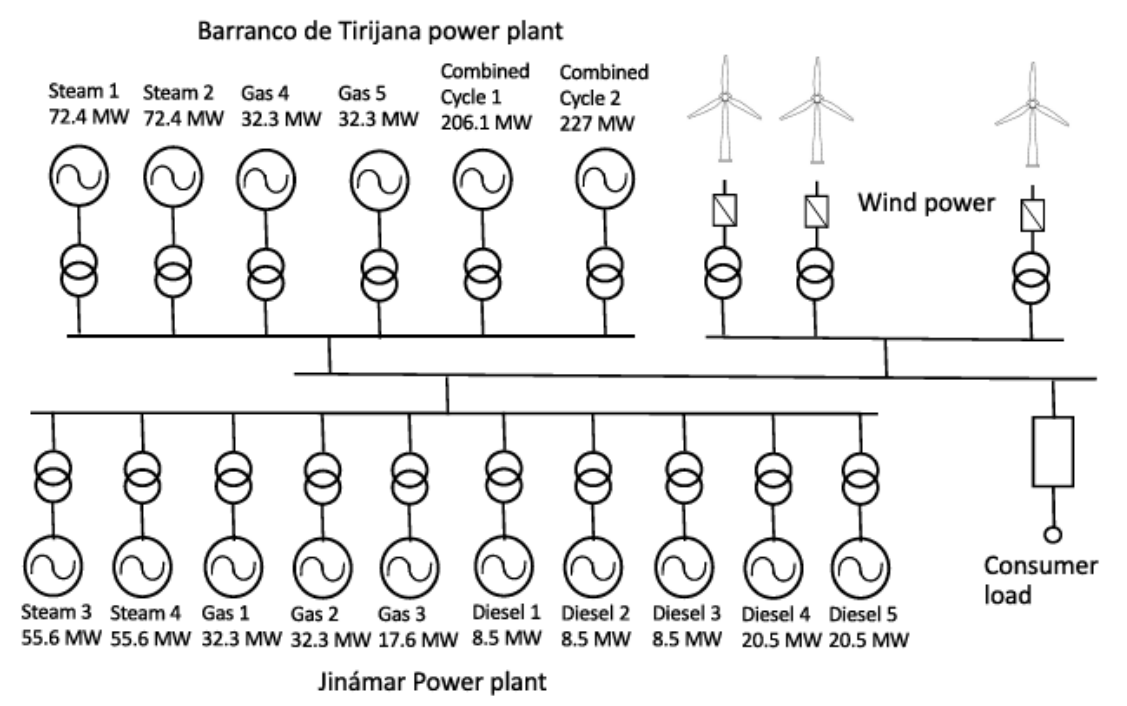

Figure 4: Gran Canaria Island power system, simplified one-line diagram

- The meaning of each start-up type of each thermal unit is different. In [63], each start-up type corresponds to a different power trajectory of the thermal unit whereas the approach of the model here used is the following: each start-up type refers to the startup cost as a function of the time that the unit has remained off-line since the previous shut-down. The start-up cost calculation and the involved parameters of the thermal units are defined in [58].

- For those thermal units that have a start-up process longer than one hour, a single output power trajectory ranging from zero to the unit's minimum output power is considered.

Further details of the UC model formulation can be found in [59].

\subsection{Frequency analysis model}

\subsubsection{General overview}

Frequency deviations in power systems are usually modeled by means of an aggregated inertial model. This assumption has been successfully applied to isolated power systems, as the Irish power system [64]. In this paper, frequency system variations are the result of an imbalance between the supply-side (Barranco de Tirijana power plant $P_{T}$, Jinámar power plant $P_{J}$ and wind power plants $P_{w}$, which are explicitly considered for simulations) and the demand-side $P_{d}$. A load frequency sensitivity parameter $D$ is also included to model the load sensitivity under frequency excursions [65],

$$
f \frac{d f}{d t}=\frac{1}{T_{m}(t)}\left(P_{T}+P_{J}+P_{w}-P_{d}-D \cdot \Delta f\right),
$$

being $T_{m}(t)$ the total inertia of the power system, which corresponds to the equivalent addition of the rotational inertia of all synchronous generators under operation conditions, in terms of the system base,

$T_{m}(t)=\sum_{m=1}^{4} 2 H_{s, m}+\sum_{q=1}^{5} 2 H_{g, q}+\sum_{k=1}^{5} 2 H_{d s, k}+\sum_{l=1}^{2} 2 H_{c c, l}$.

Frequency and power variables also depend on time, but it is not explicitly included to simplify the expressions. Fig. 5 shows the general block diagram of the proposed simulation model. It has been developed in Matlab/Simulink. The block 'Power system' in Fig. 5 contains eq. (1), modeled with the corresponding block diagram. The power provided by the power plants, $P_{T}$ and $P_{J}$ respectively, are the addition of the power supplied by each thermal generation unit (steam $s$, gas $g$, combined cycle $c c$ and diesel $d s$ ) under operating conditions, expressed as follows:

$$
\begin{aligned}
& P_{T}=\sum_{m=1}^{2} P_{s, m}+\sum_{q=4}^{5} P_{g, q}+\sum_{l=1}^{2} P_{c c, l}, \\
& P_{J}=\sum_{m=3}^{4} P_{s, m}+\sum_{q=1}^{3} P_{g, i}+\sum_{k=1}^{5} P_{d s, k} .
\end{aligned}
$$

The $k, l, m$ and $q$ indexes refer to the number of diesel, combined cycle, steam and gas units of each power plant, respectively. The proposed dynamic model depicted in Fig. 5 is thus composed by the different thermal units belonging to Barranco de Tirijana and Jinámar power plants - explicitly considered in the model- , as well as the wind power plants, the power system and the power load of consumers. This load consumer block includes the load shedding program, activated when the grid frequency exceed certain thresholds. The dynamic response of each generation unit is simulated according to the transfer functions discussed in Section 3.2.2. 


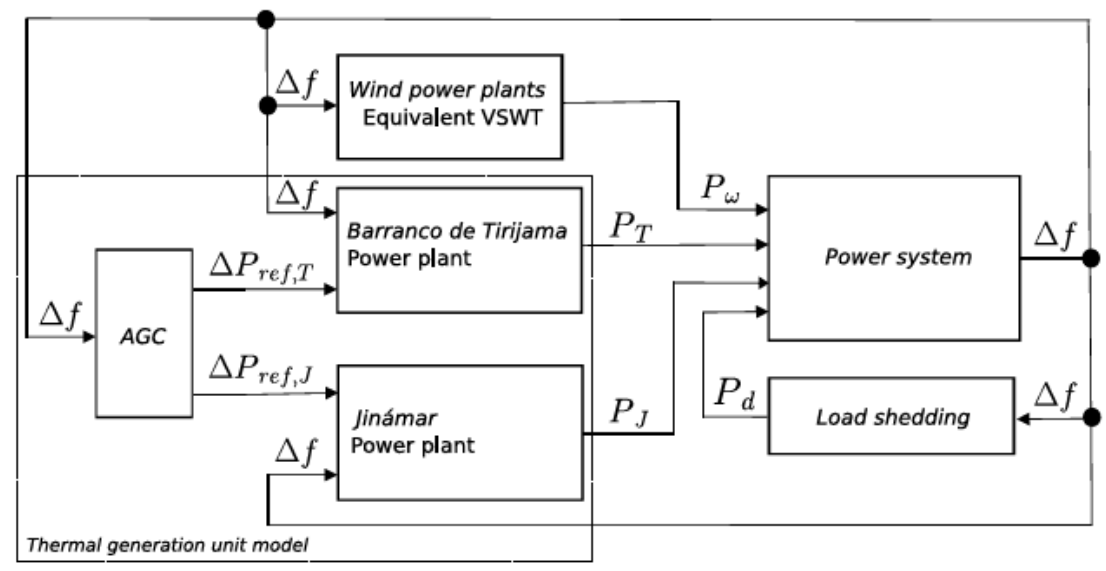

Figure 5: Frequency analysis model. Block diagram.

Table 1: Block diagram parameters of thermal units models $[66,67]$

\begin{tabular}{lccccc}
\hline \multicolumn{2}{c}{ Gas and combined cycle units } & \multicolumn{2}{c}{ Diesel units } & \multicolumn{2}{c}{ Steam units } \\
\hline$T R_{g}$ & $0.05 \mathrm{~s}$ & $T 1_{d}$ & $0.01 \mathrm{~s}$ & $T R_{s}$ & $0.2 \mathrm{~s}$ \\
$T 1_{g}$ & $0.6 \mathrm{~s}$ & $T 2_{d}$ & $0.0 \mathrm{~s}$ & $T S M_{s}$ & $0.1 \mathrm{~s}$ \\
$T 2_{g}$ & $0.5 \mathrm{~s}$ & $T 3_{d}$ & $2.0 \mathrm{~s}$ & $T C H_{s}$ & $0.3 \mathrm{~s}$ \\
$T 3_{g}$ & $0.01 \mathrm{~s}$ & $T 4_{d}$ & $0.1 \mathrm{~s}$ & $R_{s}$ & $0.05 \mathrm{pu}$ \\
$T 4_{g}$ & $0.24 \mathrm{~s}$ & $T 5_{d}$ & $0.1 \mathrm{~s}$ & $H_{s}$ & $5 \mathrm{~s}$ \\
$T D_{g}$ & $0.2 \mathrm{~s}$ & $T 6_{d}$ & $0.1 \mathrm{~s}$ & & \\
$R_{g}$ & $0.05 \mathrm{pu}$ & $K_{d}$ & 3 & & \\
$R_{c c}$ & $0.05 \mathrm{pu}$ & $R_{d}$ & $0.05 \mathrm{pu}$ & & \\
$H_{g}$ & $5 \mathrm{~s}$ & $H_{d}$ & $2.45 \mathrm{~s}$ & & \\
$H_{c c}$ & $5 \mathrm{~s}$ & & & & \\
\hline
\end{tabular}

\subsubsection{Thermal generation units}

The frequency response of the thermal generation units has been modeled through the transfer functions proposed in $[66,67]$. Parameters have been selected from typical values, see Table 1 . The combined cycle generation unit frequency behavior is supposed similar to the gas generation units, see Fig. 6. The two inputs for these three frequency models are $(i)$ frequency deviations -including constraints provided by the frequency containment-, and (ii) AGC conditions for the frequency restoration in isolated power systems. Both inputs are linked by the corresponding droop.

According to the Spanish insular power system requirements, the AGC system is in charge of removing the steady-state frequency error after the frequency containment control. This is usually known as 'frequency restoration', and modeled in a similar way to [68]. The equivalent regulation effort $\Delta R R$ is then estimated as:

$$
\Delta R R=-K_{f} \cdot \Delta f
$$

This expression is included in the block diagram shown Fig. 5, in block 'AGC'. $K_{f}$ is determined following the ENTSO-E recommendations [69]. This regulation effort is conducted by all thermal generation units and distributed depending on the participation factors $K_{u, i}$, assuming that: $(i)$ all thermal generation units connected to the power system equally participate in secondary regulation control and ( $i i)$ the participation factors are obtained as
Table 2: Load shedding scheme.

\begin{tabular}{ccccc}
\hline \multirow{2}{*}{ Step } & Threshold (Hz) & \multirow{2}{*}{ Delay (s) } & \multicolumn{2}{c}{ Load shedding (MW) } \\
& & & Peak demand & Valley demand \\
\hline 1 & 48.9 & 0.1 & 14.6 & 5.8 \\
2 & 48.9 & 0.2 & 16.2 & 7.0 \\
3 & 48.8 & 0.4 & 17.1 & 8.6 \\
4 & 48.8 & 0.6 & 41.1 & 18.8 \\
5 & 48.5 & 0.1 & 8.0 & 4.1 \\
6 & 48.5 & 0.2 & 27.3 & 11.8 \\
7 & 48.4 & 0.4 & 17.5 & 7.7 \\
8 & 48.1 & 0.1 & 17.9 & 9.7 \\
\hline
\end{tabular}

a function of the speed droop of each unit. The participation factors $K_{u, i}$ of thermal generation units disconnected from the grid are considered as zero [70]:

$$
\begin{aligned}
\Delta P_{r e f, t h} & =\frac{1}{T_{u, t h}} \int \Delta R R \cdot K_{u, t h} d t= \\
& =\frac{-1}{T_{u, t h}} \cdot K_{u, t h} \cdot K_{f} \int \Delta f d t . \\
\sum K_{u, t h} & =\sum_{m=1}^{4} K_{u, s, m}+\sum_{q=1}^{5} K_{u, g, q}+ \\
& +\sum_{k=1}^{5} K_{u, d, k}+\sum_{l=1}^{2} K_{u, c c, l}=1
\end{aligned}
$$

\subsubsection{Load shedding}

A realistic load shedding scheme is considered in the proposed model by means of sudden load disconnections when frequency excursions are higher than certain thresholds. Table 2 summarizes these frequency thresholds, time delay and load shedding values for different scenarios. This load shedding scheme depends on the islanding power system operation conditions required by the Spanish TSO and thus, the responses are in line with certain frequency excursion thresholds. When the scenario corresponds to an intermediate load case, the load shedding value is interpolated from the corresponding steps. 


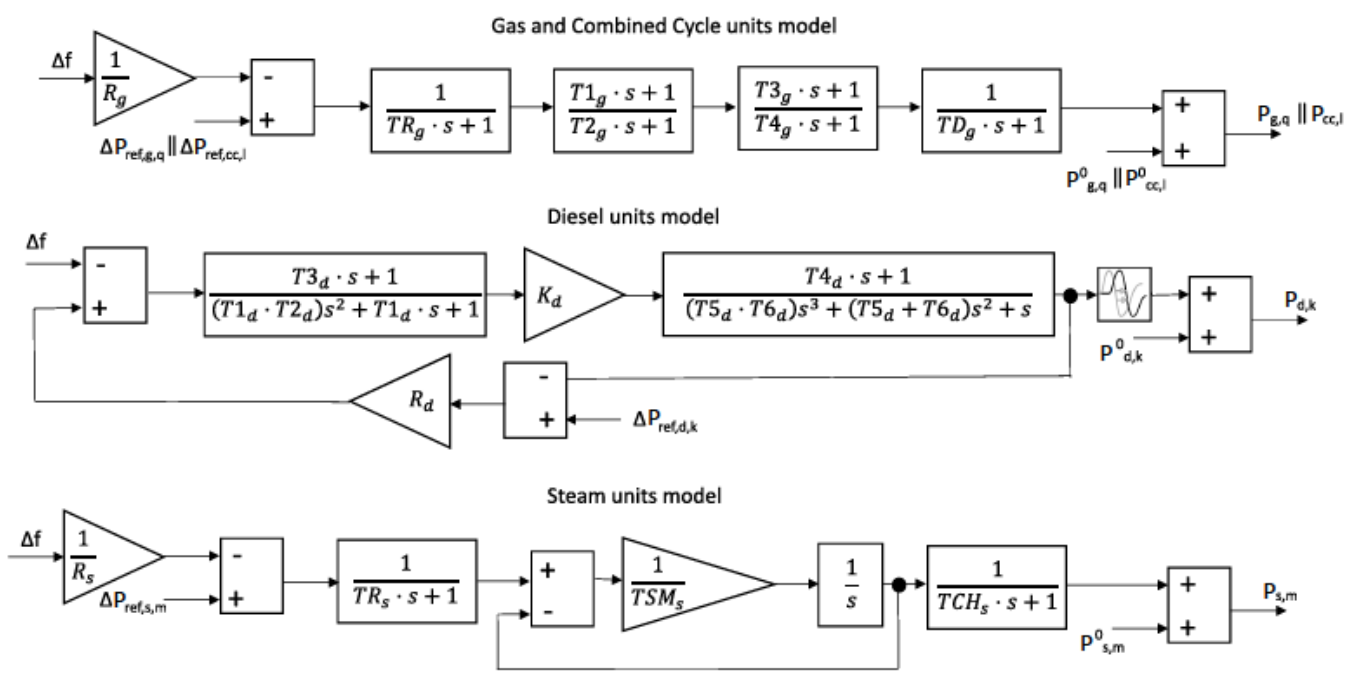

Figure 6: Block diagrams of thermal units models.

\subsubsection{Wind power plants}

One equivalent VSWT with $n_{W T}$-times the size of each one model the wind power penetration - being $n_{W T}$ the number of wind turbines [71, 72]-, is proposed as aggregated model for wind power plants. An equivalent averaged wind speed $\left(v_{w}=10.25 \mathrm{~m} / \mathrm{s}\right)$ is assumed for the simulations. This wind speed is considered as constant, which has been previously used in the specific literature for short-time period frequency analysis including wind power plants $[50,73-76]$. With this wind speed, the wind generation accounts for $80 \%$ of the installed wind power capacity.

Wind turbines are modeled according to the turbine control model, mechanical two-mass model and wind power model described in [77, 78]. The two-mass model assumes the rotor and blades as a single mass, and the generator as another mass $[79,80]$. Huerta et al. consider that the two-mass model is the most suitable to evaluate the grid stability [81]. Wind turbines also include a frequency control response. The strategy for VSWTs implemented in this paper is based on the technique described in [82, 83], see Fig. 7a. It was evaluated in [82] for isolated power systems with up to a $45 \%$ of wind power integration and compared to the approach of [84], providing a more appropriate frequency response under power imbalance conditions. In [83], the proposed frequency control strategy was studied for multi-area power systems. Three operation modes are considered: $(i)$ normal operation mode, (ii) overproduction mode and (iii) recovery mode. Different set-point active power $P_{s p}$ values are then determined aiming to restore the grid frequency under power imbalance conditions. Fig. 7b depicts the VSWTs active power variations $\Delta P_{W F}$ submitted to an under-frequency excursion, being $\Delta P_{w}=P_{s p}-P_{M P P T}\left(\Omega_{M P P T}\right)$.

With the aim of reducing load shedding contributions under high wind power integration scenarios, two modifications are carried out to the preliminary frequency con- troller, both in overproduction and recovery periods. According to [82], the overproduction power $\Delta P_{O P}$ is estimated proportionally to the frequency excursion evolution, with a maximum value of $10 \%$. In this paper, the maximum $\Delta P_{O P}$ is increased to $15 \%$, in order to provide more power after the imbalance and minimizing load shedding situations. In the recovery mode, the power of point $P_{2}$ is defined as $P_{M P P T}\left(\Omega_{V}\right)+x \cdot\left(P_{m t}\left(\Omega_{V}\right)-P_{M P P T}\left(\Omega_{V}\right)\right)$ see Fig. $7 \mathrm{a}-$, being $x$ an scale factor considered as 0.75 in the original approach [82]. However, in this case, the recovery time period of the wind turbines is faster than the AGC action of the frequency restoration control, and subsequently obtaining an undesirable frequency evolution, see Fig. 9. As a consequence, $x$ has been increased to 0.95 , smoothing and slowing down the recovery period of the wind frequency controller. This alternative frequency controller is included in the VSWT model as seen in Fig. 8.

\section{Results}

\subsection{Scenarios under consideration}

According to the demand distribution in Gran Canaria Island along 2018 previously discussed in Section 2.1, six different power demand conditions are considered for the study. Each system demand is analyzed under different wind power generation percentages following Fig. 1. Thus, thirty different energy scenarios are under study, which is significantly higher than other contributions focused on frequency control under contingencies including wind power plants $[85,86]$. To determine the energy schedule of each supply-demand scenario, the Unit Commitment model described in Section 3.1 is run with GAMS software and Cplex 12.2 solver, which uses a branch and cut algorithm to solve MILP problems. Fig. 10 depicts the energy schedule of each scenario aggregated by generation technology. From the $N-1$ criterion, the largest generation unit is suddenly disconnected under a contingency. 


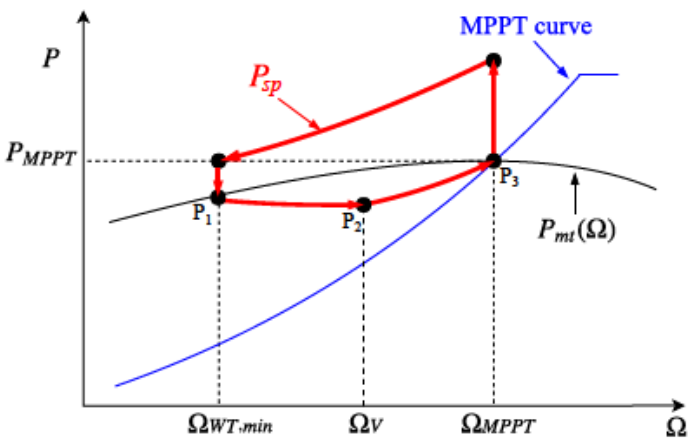

(a) Frequency control strategy

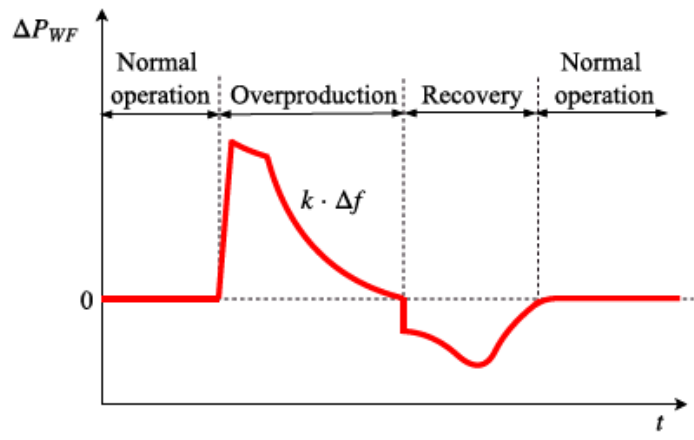

(b) $\triangle P_{W F}$ with frequency control strategy

Figure 7: Wind frequency control strategy and VSWTs active power variation [82].

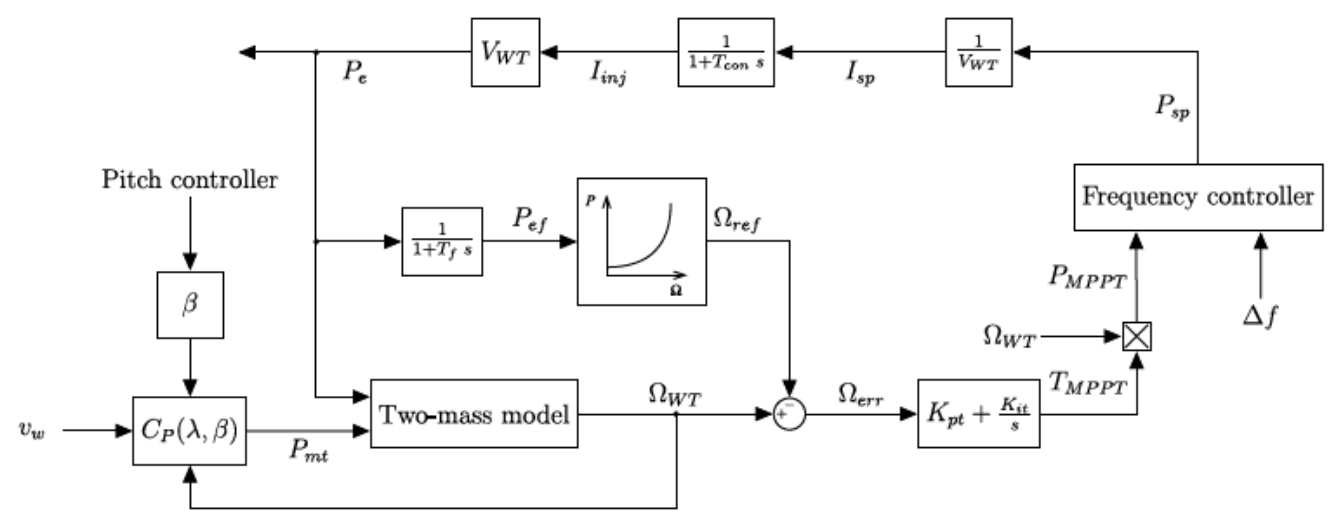

Figure 8: Variable speed wind turbine model with frequency controller

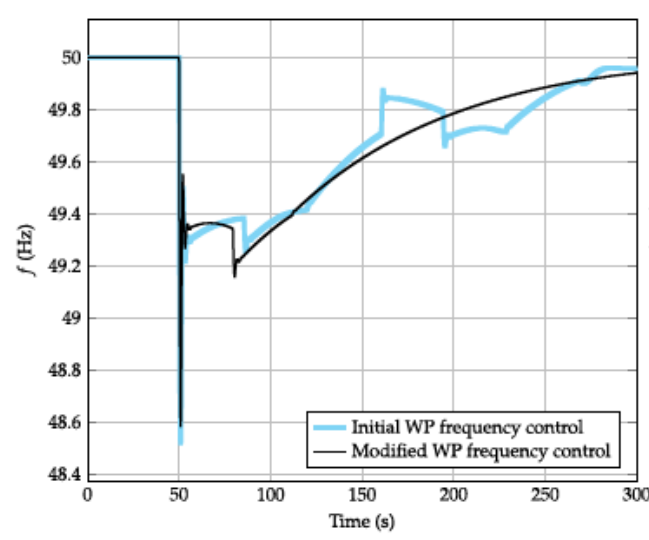

(a) Frequency evolution

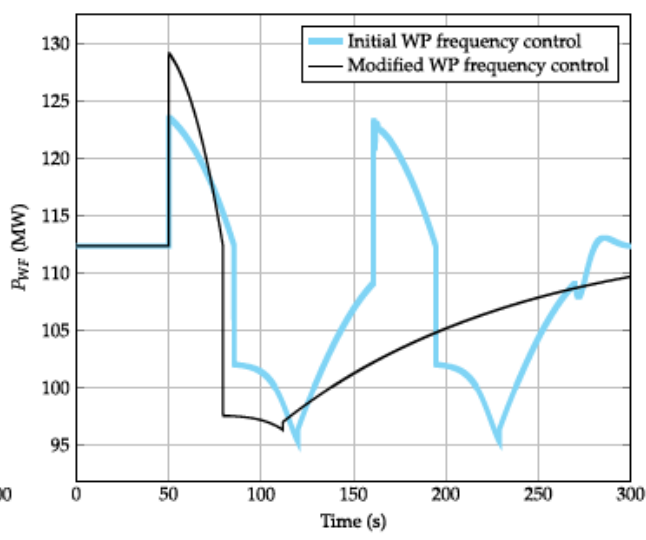

(b) Wind power generation

Figure 9: Frequency deviation and wind power generation when using the original wind frequency controller 


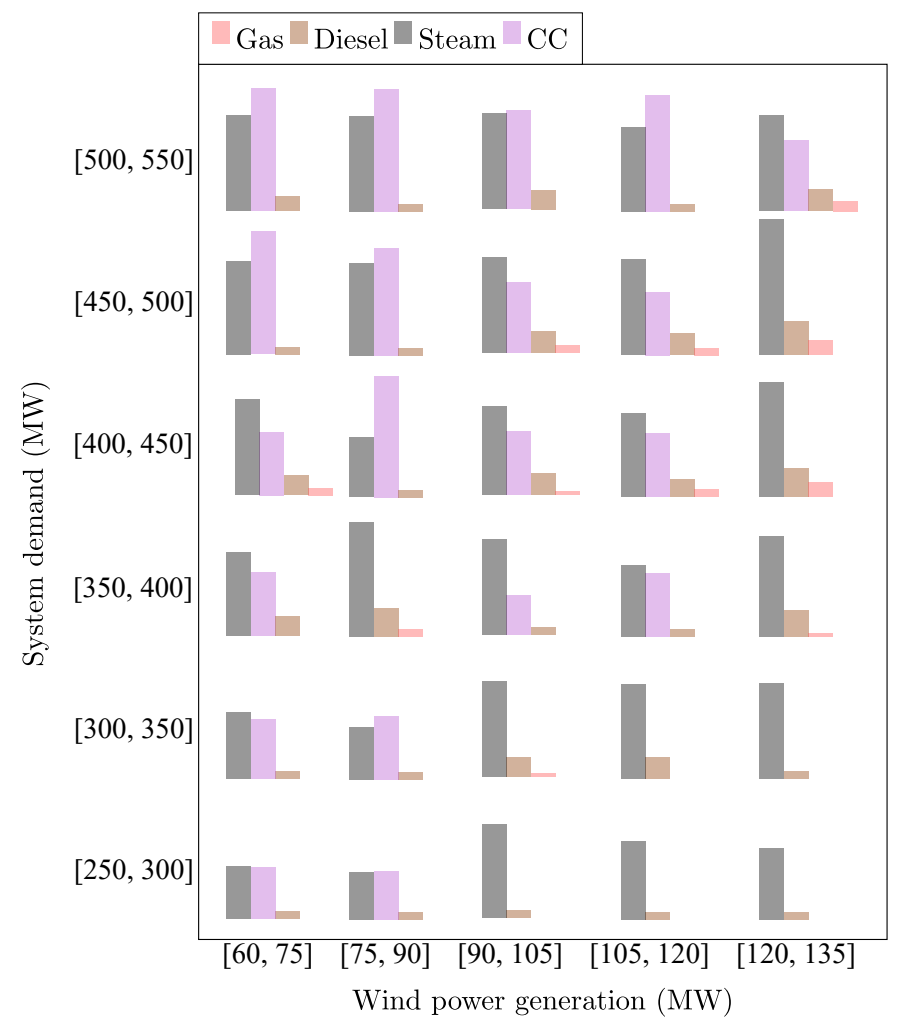

Figure 10: Scenarios under study

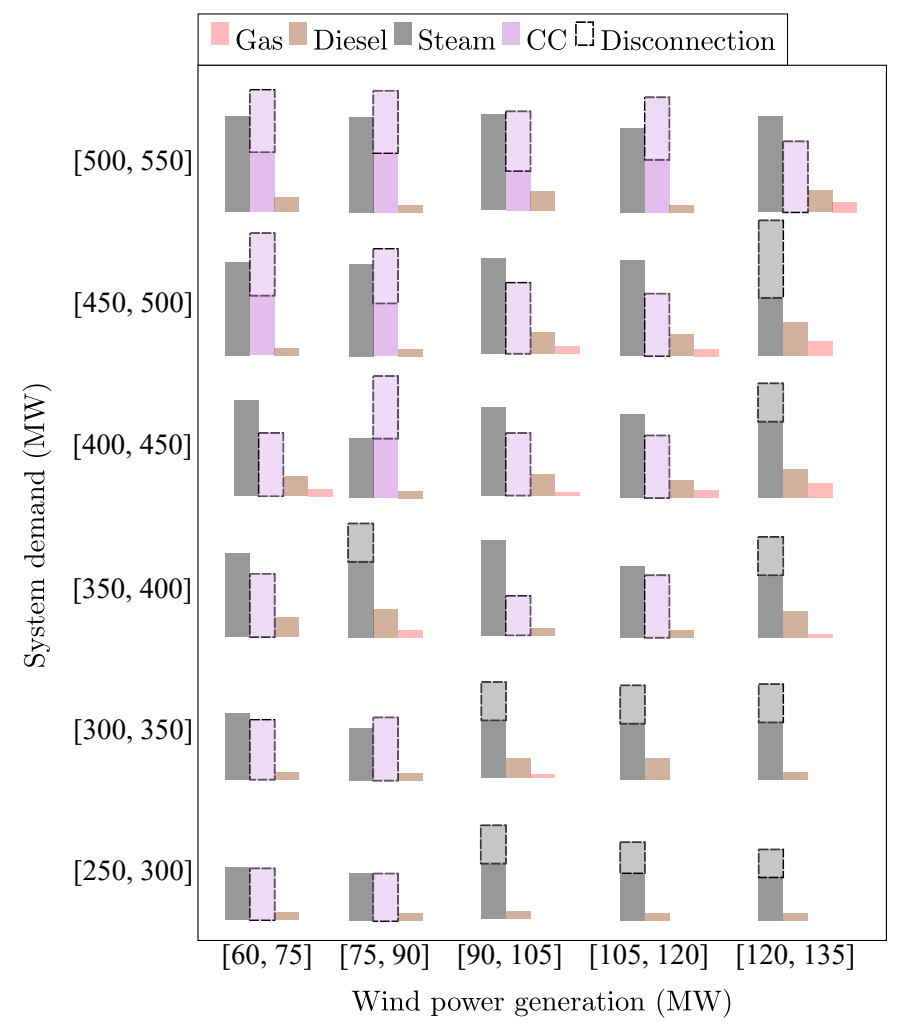

Figure 11: Generation mix after disconnections
As a consequence, a different generation group is disconnected in each scenario, depending on the energy schedule obtained by the UC model and subsequently addressed a variety of power imbalance situations. Fig. 11 summarizes the energy schedule of each scenario after these disconnections, pointed out the technology and generation unit tripping under such circumstances. Due to these sudden disconnections, the equivalent rotational inertia of the power system is reduced according to eq. (2).

\subsection{Frequency response analysis}

With the aim of evaluating frequency deviation and power system performance under the sudden generation disconnection established with the $N-1$ criterion, grid frequency response is analyzed $(i)$ excluding wind frequency control and only considering conventional units; and (ii) including conventional units and wind frequency control strategy. Firstly, nadir and RoCoF results for the 30 simulated scenarios according to the generation unit tripping obtained for the UC model and depicted in Fig. 11 are compared to results obtained following methodologies of previous contributions $[27,28,31,32]$. They usually assume a constant $10 \%$ imbalance, neglect any inertia power system modification and do not include load shedding scheme in their frequency analysis models. With this aim, Fig.s 12 and 13 summarize nadir and RoCoF respectively, including (or not) wind frequency response. RoCoF is calculated between 0.3 and $0.5 \mathrm{~s}$ after the sudden disconnection of the largest conventional generation unit for each energy scenario. As can be seen, clear differences are identified between both approaches. In fact, most obvious results are determined with a constant power imbalance, as was to be expected, see Fig. 12b and 12d for nadir comparison values. If a simplified power system modeling is considered for frequency control analysis, with typical $10 \%$ power imbalance conditions - usually assumed in previous contributions as was previously discussed- $49.4 \mathrm{~Hz}$ nadir and $0.5 \mathrm{~Hz} / \mathrm{s}$ RoCoF values are obtained for all cases, which provides significant discrepancies with our proposal, see Fig. 12 and 13 respectively. Indeed, nadir lies in between 48.54 and $49.15 \mathrm{~Hz}$ when wind power plants are excluded from frequency control, depending on each scenario - see Fig. 12a-. In fact, these values were even worse if the load shedding program was not considered, as it is activated in 21 of the 30 scenarios analyzed. However, a larger wind power integration without frequency control - see Fig. 12a - doesn't imply a worse nadir response, which could be deduced a priori, due to the loss of the larger power plant (which is different, depending on the scenario). When wind frequency control is considered for simulations, the minimum frequency is increased $110 \mathrm{mHz}$ in average for all cases. Moreover, the more wind power integration providing frequency control, the lower nadir is obtained. For instance, for wind power integration over $50 \%$, the minimum frequency is reduced around $200 \mathrm{mHz}$. It can't be then deduced an homogeneous response of the considered power system submitted to realistic generation unit tripping. In this way, and based on the proposed 
nadir $(\mathrm{Hz})$

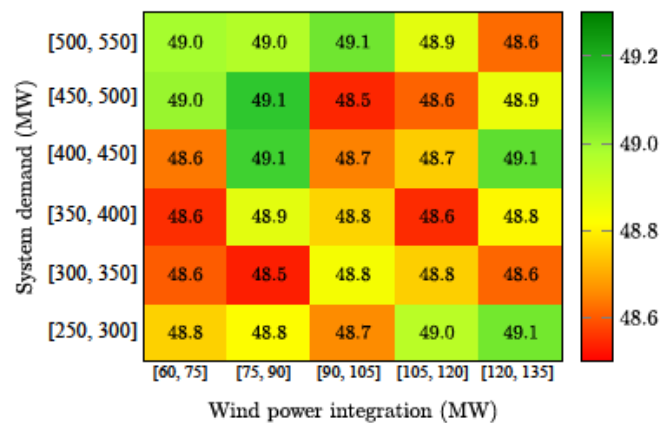

(a) Without wind frequency response

nadir $(\mathrm{Hz})$

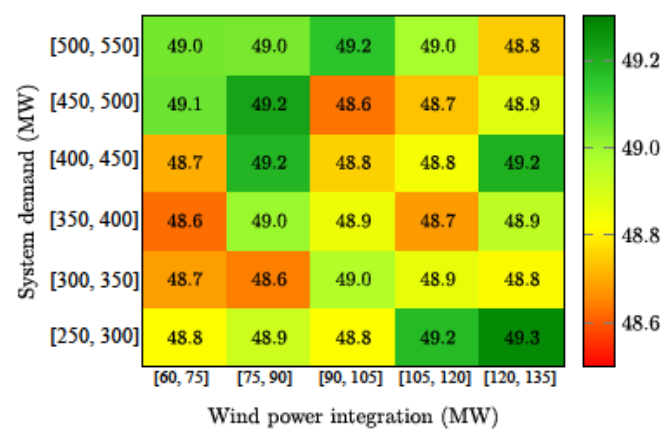

(c) With wind frequency response

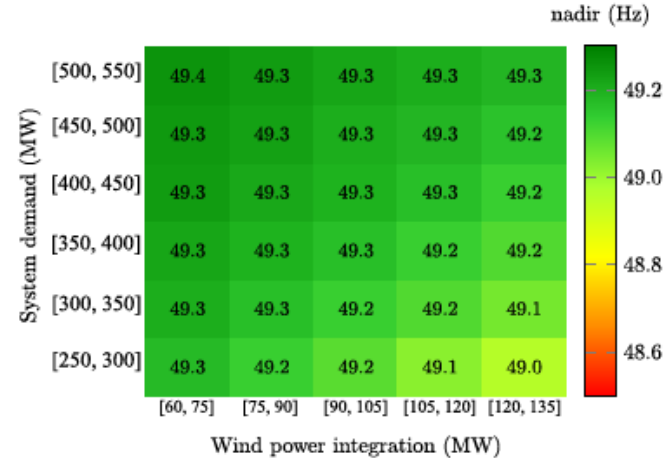

(b) Without wind frequency response and $\Delta P=$ $10 \%$

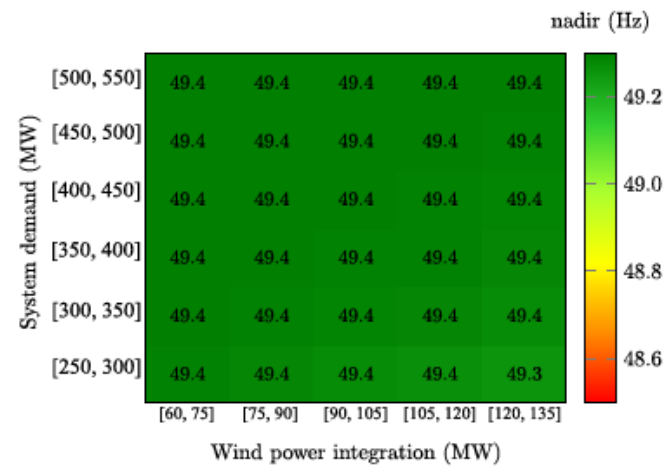

(d) With wind frequency response and $\Delta P=10 \%$

Figure 12: Nadir estimation: power demand and wind power integration in Gran Canaria

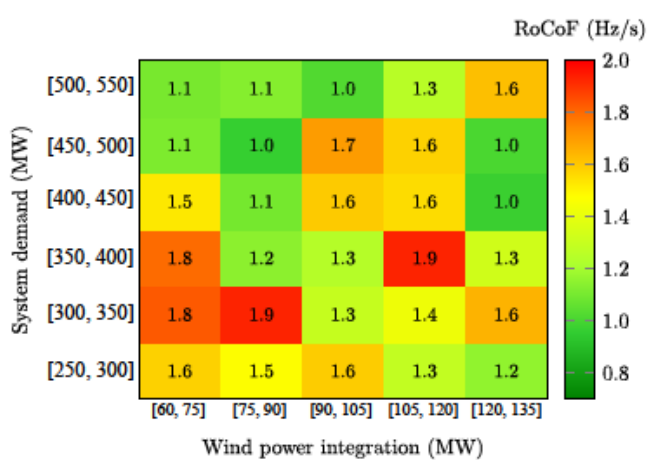

(a) Without wind frequency response

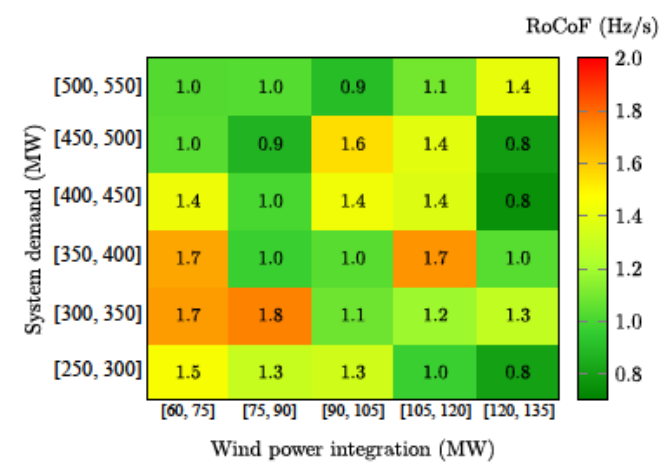

(c) With wind frequency response

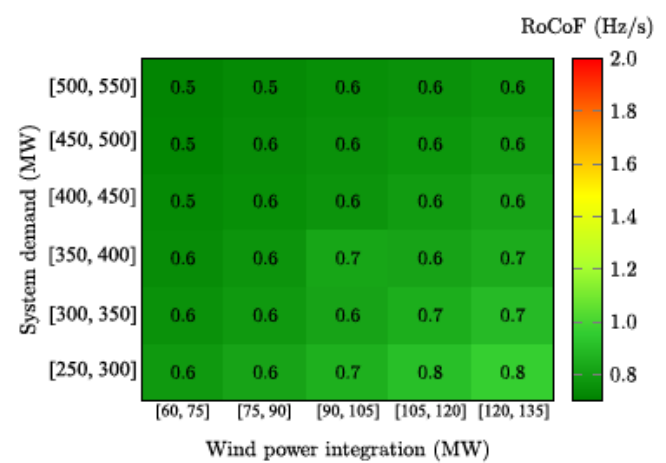

(b) Without wind frequency response and $\Delta P=$ $10 \%$

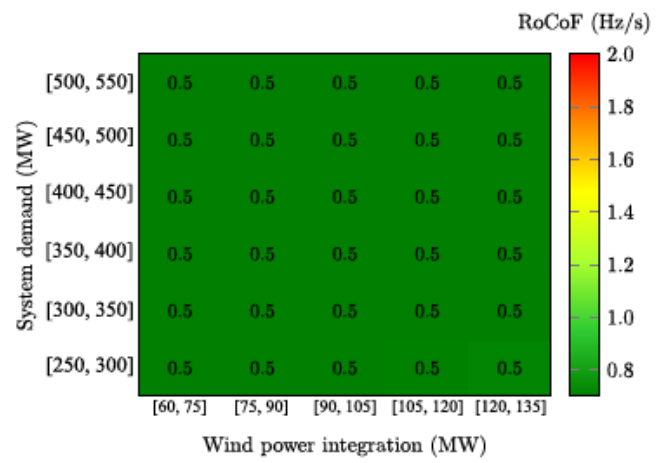

(d) With wind frequency response and $\Delta P=10 \%$

Figure 13: RoCoF estimation: power demand and wind power integration in Gran Canaria 
Load shedding (MW)

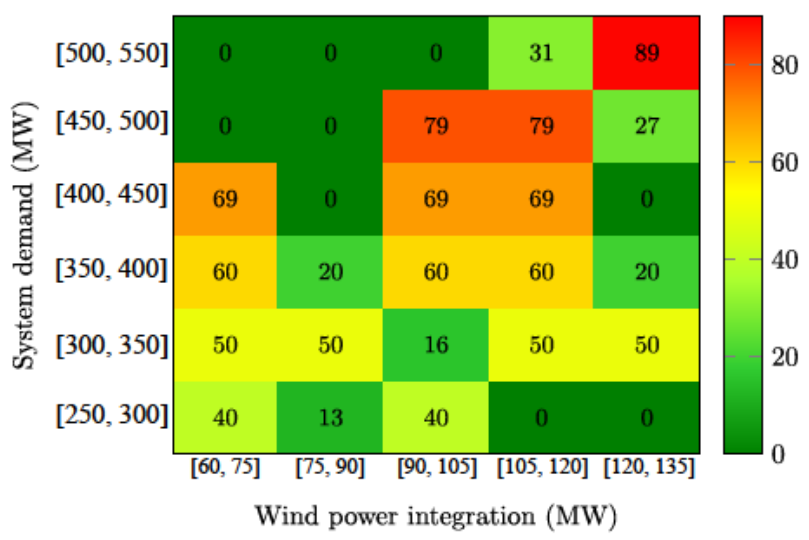

(a) Load shedding without wind power frequency response

Load shedding (MW)

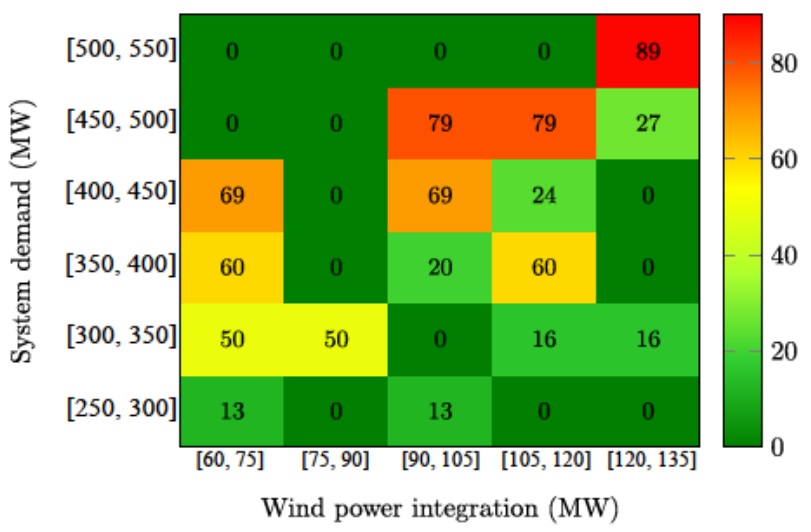

(b) Load shedding with wind power frequency response

Figure 14: Load shedding: power demand and wind power integration in Gran Canaria

methodology and modeling, it is important to point out that higher wind power integration excluding frequency control does not always imply a worse frequency response, see Fig. 12a. With regard to RoCoF, it varies between 0.97 and $1.93 \mathrm{~Hz} / \mathrm{s}$ initially, see Fig. 13a, but slighted $185 \mathrm{mHz} / \mathrm{s}$ in average by including wind frequency control, Fig. 13c. These results are substantially different from those obtained in the simplified power system analysis (where RoCoF was around $0.5 \mathrm{~Hz} / \mathrm{s}$ ); this is mainly due to the inertia change considered in this study and neglected in the previous one, as low inertia is related to a faster ROCOF [87]. Therefore, including wind power frequency control can lead to lower frequency deviations under imbalances, as was expected.

The proposed wind frequency response analysis allows us to evaluate the wind frequency control impact on load shedding actions in islanding power systems under different imbalances. Fig. 14 summarizes the load shedding for the 30 simulated scenarios and considering the generation unit tripping obtained for the UC model, see Fig. 11. In this way, Fig. 14a and Fig. 14b shows the corresponding load shedding responses by including or not wind fre- quency control for the considered energy scenarios. Both nadir and RoCoF improvements lead to a load shedding reduction in 11 scenarios. Moreover, in these 11 scenarios, the average load shedding reduction is $80 \%$, getting up to a $100 \%$ reduction in 5 scenarios - for example, compare 30.80 MW load shedding under the range $[500,550]$ MW power demand and $[105,120]$ MW wind power generation, Fig. 14a, to $0 \mathrm{MW}$ load shedding under the same demand and wind power values when wind frequency control is included, Fig. 14b-.

Table 3 shows a comparison of results between the proposed analysis described in this paper and conventional methodologies previously considered where a constant imbalance is assumed, inertia of the power system is kept constant during the imbalance and load shedding is not included for simulations. In the table, the average $\mu$ and variance $\sigma^{2}$ of nadir, RoCoF inertia change and load shedding values for the 30 different generation mix and imbalance scenarios are shown with and without wind frequency control.

\section{Conclusion}

Frequency excursions are analyzed in an isolated power system by considering the loss of the largest conventional generation group, including wind frequency control strategy, load shedding and energy scenarios obtained by a UC model. The case study is focused on the real isolated power system located in the Gran Canaria Island (Spain), which has doubled its wind power capacity in the last two years. With regard to the frequency analysis, by including wind power generation into frequency control, nadir and $\mathrm{RoCoF}$ are reduced in most of energy scenarios considered $(110 \mathrm{mHz}$ and $185 \mathrm{mHz} / \mathrm{s}$ in average, respectively). Regarding load shedding, it is reduced in 11 out of the 30 power imbalance analyzed. This improvement is more significant in high wind power integration scenarios (regardless of the power demand), and for high power demands (regardless of the wind power integration). Therefore, wind frequency control can be considered a remarkable solution to reduce load shedding in islanding power systems with high wind power integration.

It can be affirmed that there is no homogeneity in the frequency response results, providing a clear dependence on the dispatch of the conventional rotational generation units, their participation in the global energy scenario and the inertia changes addressed by the generation unit tripping - for example $\mu(\Delta f)=1.2 \mathrm{~Hz}$ and $\sigma^{2}(\Delta f)=0.036$ for the nadir results. Subsequently, the participation of wind power plants into frequency control should be analyzed by considering not only the wind power integration level, but also other variables, such as the energy scenario, the rate power of the different generation units, as well as the reserves provided by conventional generation units and thus, the equivalent rotational inertia given by them; aspects that have not explicitly taken into account in previous works. Indeed, nadir and RoCoF values give almost 
Table 3: Comparison of results: nadir, RoCoF, inertia change and load shedding

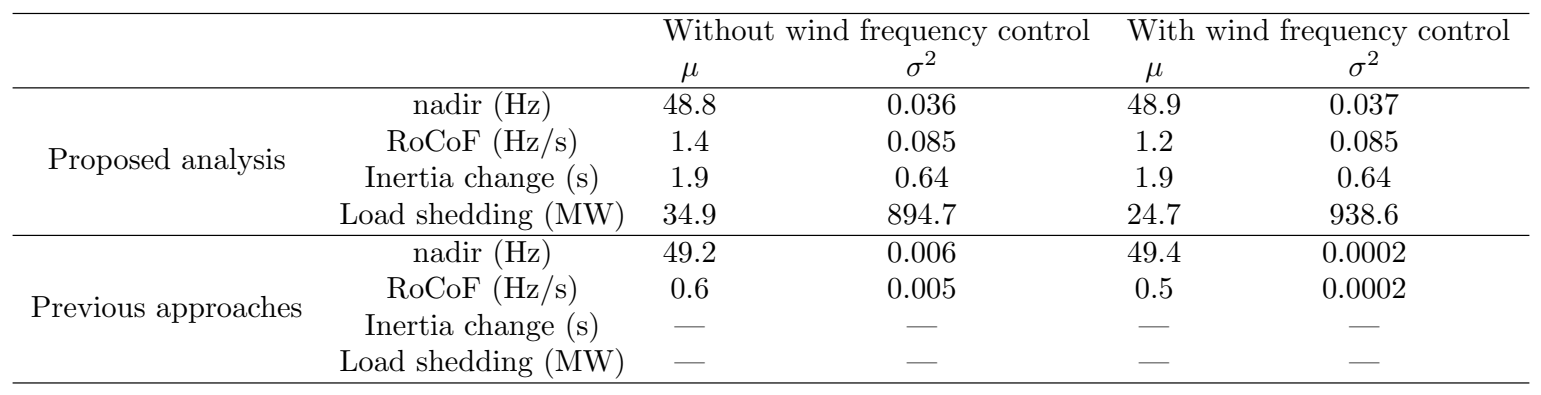

homogeneous values when such aspects are not included in the simulations, with a typical deviation near zero. In addition, and according to the remarkable frequency excursion dependence on different parameters such as on power system rotational inertia, generation unit technologies and rate power of the tripping-generation unit; controller parameters should dynamically vary in line with those power system variables and at the same time keeping frequency requirements. These aspects are currently under analysis by the authors for further contributions. Whereas our findings are derived based on a single-islanding power system case study, our results are useful and significant based on the relevance of our realistic case study coupled with the number of different energy scenarios and wind power integration ranges.

\section{Acknowledgment}

Authors thank Ignacio Ares for the preliminary analyses that he did as part of his final master project.

\section{Funding}

This work has been partially supported the Spanish Ministry of Economy and Competitiveness under the project 'Value of pumped-hydro energy storage in isolated power systems with high wind power penetration' of the National Plan for Scientific and Technical Research and Innovation 2013-2016 (Ref. ENE2016-77951-R) and by the Spanish Education, Culture and Sports Ministry (Ref. FPU16/04282).

\section{References}

[1] P. Tielens, D. Van Hertem, The relevance of inertia in power systems, Renewable and Sustainable Energy Reviews 55 (2016) 999-1009.

[2] W. Zhang, K. Fang, Controlling active power of wind farms to participate in load frequency control of power systems, IET Generation, Transmission \& Distribution 11 (9) (2017) 21942203.

[3] A. Fernández-Guillamón, E. Gómez-Lázaro, E. Muljadi, Á. Molina-García, Power systems with high renewable energy sources: A review of inertia and frequency control strategies over time, Renewable and Sustainable Energy Reviews 115 (2019) 109369.
[4] A. Junyent-Ferr, Y. Pipelzadeh, T. C. Green, Blending HVDClink energy storage and offshore wind turbine inertia for fast frequency response, IEEE Transactions on sustainable energy 6 (3) (2015) 1059-1066.

[5] P. Tian, X. Xiao, K. Wang, R. Ding, A hierarchical energy management system based on hierarchical optimization for microgrid community economic operation, IEEE Transactions on Smart Grid 7 (5) (2016) 2230-2241.

[6] Z. Akhtar, B. Chaudhuri, S. Y. R. Hui, Primary frequency control contribution from smart loads using reactive compensation, IEEE Transactions on Smart Grid 6 (5) (2015) 2356-2365.

[7] S. Yang, J. Fang, Y. Tang, H. Qiu, C. Dong, P. Wang, Syntheticinertia-based modular multilevel converter frequency control for improved micro-grid frequency regulation, in: 2018 IEEE Energy Conversion Congress and Exposition (ECCE), IEEE, 2018, pp. $5177-5184$.

[8] A. Fernandez-Guillamon, A. Vigueras-Rodriguez, A. Garcia, Analysis of power system inertia estimation in high wind power plant integration scenarios, IET Renewable Power Generation.

[9] M. Albadi, E. El-Saadany, Overview of wind power intermittency impacts on power systems, Electric power systems research 80 (6) (2010) 627-632.

[10] G. Martínez-Lucas, J. I. Sarasúa, J. Á. Sánchez-Fernández, Frequency regulation of a hybrid wind-hydro power plant in an isolated power system, Energies 11 (1) (2018) 239.

[11] P. Breeze, Chapter 11 — wind power, in: P. Breeze (Ed.), Power Generation Technologies (Second Edition), second edition Edition, Newnes, Boston, 2014, pp. 223 - 242. doi: 10.1016/B978-0-08-098330-1.00011-9.

[12] M. Edrah, K. L. Lo, O. Anaya-Lara, Impacts of high penetration of DFIG wind turbines on rotor angle stability of power systems, IEEE Transactions on Sustainable Energy 6 (3) (2015) 759-766.

[13] R. Syahputra, I. Soesanti, DFIG control scheme of wind power using anfis method in electrical power grid system.

[14] E. Artigao, A. Honrubia-Escribano, E. Gomez-Lazaro, Current signature analysis to monitor DFIG wind turbine generators: A case study, Renewable Energy 116 (2018) 5-14.

[15] C. Cardozo, W. van Ackooij, L. Capely, Cutting plane approaches for frequency constrained economic dispatch problems, Electric Power Systems Research 156 (2018) 54-63.

[16] P. Li, Y. Liu, H. Xin, X. Jiang, A robust distributed economic dispatch strategy of virtual power plant under cyber-attacks, IEEE Transactions on Industrial Informatics 14 (10) (2018) 4343-4352.

[17] M. Toulabi, S. Bahrami, A. M. Ranjbar, An input-to-state stability approach to inertial frequency response analysis of doublyfed induction generator-based wind turbines, IEEE Transactions on Energy Conversion 32 (4) (2017) 1418-1431.

[18] L. E. Sokoler, P. Vinter, R. Baerentsen, K. Edlund, J. B. Jorgensen, Contingency-constrained unit commitment in meshed isolated power systems, IEEE Transactions on Power Systems 31 (5) (2016) 3516-3526.

[19] G. Zhang, E. Ela, Q. Wang, Market scheduling and pricing for primary and secondary frequency reserve, IEEE Transactions on Power Systems.

[20] M. R. Khalghani, M. H. Khooban, E. Mahboubi-Moghaddam, 
N. Vafamand, M. Goodarzi, A self-tuning load frequency control strategy for microgrids: Human brain emotional learning, International Journal of Electrical Power \& Energy Systems 75 (2016) 311-319.

[21] M. Marzband, M. M. Moghaddam, M. F. Akorede, G. Khomeyrani, Adaptive load shedding scheme for frequency stability enhancement in microgrids, Electric Power Systems Research 140 (2016) 78-86.

[22] B. Ozer, O. Arikan, G. Moral, A. Altintas, Extraction of primary and secondary frequency control from active power generation data of power plants, International Journal of Electrical Power \& Energy Systems 73 (2015) 16-22.

[23] M. R. Aghamohammadi, H. Abdolahinia, A new approach for optimal sizing of battery energy storage system for primary frequency control of islanded microgrid, International Journal of Electrical Power \& Energy Systems 54 (2014) 325-333.

[24] H. Jiang, J. Lin, Y. Song, D. J. Hill, MPC-based frequency control with demand-side participation: A case study in an isolated wind-aluminum power system, IEEE Transactions on Power Systems 30 (6) (2015) 3327-3337.

[25] H. Jiang, J. Lin, Y. Song, S. You, Y. Zong, Explicit model predictive control applications in power systems: an agc study for an isolated industrial system, IET Generation, Transmission \& Distribution 10 (4) (2016) 964-971.

[26] ENTSO-E, Electricity balancing in Europe, https: //docstore.entsoe.eu/Documents/Network\%20codes\% 20documents/NC\%20EB/entso-e_balancing_in\%20_europe_ report_Nov2018_web.pdf.

[27] P.-K. Keung, P. Li, H. Banakar, B. T. Ooi, Kinetic energy of wind-turbine generators for system frequency support, IEEE Transactions on Power Systems 24 (1) (2009) 279-287.

[28] S. El Itani, U. D. Annakkage, G. Joos, Short-term frequency support utilizing inertial response of dfig wind turbines, in: Power and Energy Society General Meeting, 2011 IEEE, IEEE, 2011, pp. 1-8.

[29] T. Mahto, V. Mukherjee, A novel scaling factor based fuzzy logic controller for frequency control of an isolated hybrid power system, Energy 130 (2017) 339-350.

[30] A. Abazari, M. G. Dozein, H. Monsef, An optimal fuzzy-logic based frequency control strategy in a high wind penetrated power system, Journal of the Franklin Institute 355 (14) (2018) $6262-6285$.

[31] A. Alsharafi, A. Besheer, H. Emara, Primary frequency response enhancement for future low inertia power systems using hybrid control technique, Energies 11 (4) (2018) 699

[32] H. Ma, B. Chowdhury, Working towards frequency regulation with wind plants: combined control approaches, IET Renewable Power Generation 4 (4) (2010) 308-316.

[33] M. Wang-Hansen, R. Josefsson, H. Mehmedovic, Frequency controlling wind power modeling of control strategies, IEEE transactions on sustainable energy 4 (4) (2013) 954-959.

[34] M. Kang, K. Kim, E. Muljadi, J.-W. Park, Y. C. Kang, Frequency control support of a doubly-fed induction generator based on the torque limit, IEEE Transactions on Power Systems 31 (6) (2016) 4575-4583.

[35] D. Ochoa, S. Martinez, Frequency dependent strategy for mitigating wind power fluctuations of a doubly-fed induction generator wind turbine based on virtual inertia control and blade pitch angle regulation, Renewable energy 128 (2018) 108-124.

[36] H. Bevrani, P. R. Daneshmand, Fuzzy logic-based loadfrequency control concerning high penetration of wind turbines, IEEE systems journal 6 (1) (2011) 173-180.

[37] S. Ma, H. Geng, G. Yang, B. C. Pal, Clustering-based coordinated control of large-scale wind farm for power system frequency support, IEEE Transactions on Sustainable Energy 9 (4) (2018) 1555-1564.

[38] L. Badesa, F. Teng, G. Strbac, Simultaneous scheduling of multiple frequency services in stochastic unit commitment, IEEE Transactions on Power Systems 34 (5) (2019) 3858-3868. doi : 10.1109/TPWRS. 2019.2905037.

[39] Z.-S. Zhang, Y.-Z. Sun, J. Lin, G.-J. Li, Coordinated frequency regulation by doubly fed induction generator-based wind power plants, IET Renewable Power Generation 6 (1) (2012) 38-47.

[40] Y. Mi, Y. Fu, D. Li, C. Wang, P. C. Loh, P. Wang, The sliding mode load frequency control for hybrid power system based on disturbance observer, International Journal of Electrical Power \& Energy Systems 74 (2016) 446-452.

[41] Y. Bao, J. Xu, S. Liao, Y. Sun, X. Li, Y. Jiang, D. Ke, J. Yang, X. Peng, Field verification of frequency control by energy-intensive loads for isolated power systems with high penetration of wind power, IEEE Transactions on Power Systems 33 (6) (2018) 6098-6108.

[42] K. Chen, P. Peng, H. Li, T. Xu, C. Li, Dfig primary frequency regulation strategy with optimal dynamic droop control under variable wind speeds, in: IOP Conference Series: Earth and Environmental Science, Vol. 188, IOP Publishing, 2018, p. 012087.

[43] F. Wilches-Bernal, J. H. Chow, J. J. Sanchez-Gasca, A fundamental study of applying wind turbines for power system frequency control, IEEE Transactions on Power Systems 31 (2) (2015) 1496-1505.

[44] A. Aziz, A. T. Oo, A. Stojcevski, Analysis of frequency sensitive wind plant penetration effect on load frequency control of hybrid power system, International Journal of Electrical Power \& Energy Systems 99 (2018) 603-617.

[45] M. Farrokhabadi, C. A. Cañizares, K. Bhattacharya, Unit commitment for isolated microgrids considering frequency control, IEEE Transactions on Smart Grid 9 (4) (2018) 3270-3280.

[46] F. Teng, V. Trovato, G. Strbac, Stochastic scheduling with inertia-dependent fast frequency response requirements, IEEE Transactions on Power Systems 31 (2) (2016) 1557-1566.

[47] S. Padrón, M. Hernández, A. Falcón, Reducing under-frequency load shedding in isolated power systems using neural networks. gran canaria: a case study, IEEE Transactions on Power Systems 31 (1) (2015) 63-71.

[48] J. P. Praene, M. H. Radanielina, V. R. Rakotoson, A. L. Andriamamonjy, F. Sinama, D. Morau, H. T. Rakotondramiarana, Electricity generation from renewables in madagascar: Opportunities and projections, Renewable and Sustainable Energy Reviews 76 (2017) 1066-1079.

[49] METI, Japan's energy plan, Tech. rep. (2015).

URL https://www.enecho.meti.go.jp/en/category/ brochures/pdf/energy_plan_2015.pdf

[50] A. Zertek, G. Verbic, M. Pantos, A novel strategy for variablespeed wind turbines' participation in primary frequency control, IEEE Transactions on sustainable energy 3 (4) (2012) 791-799.

[51] M. H. Nazari, Z. Costello, M. J. Feizollahi, S. Grijalva, M. Egerstedt, Distributed frequency control of prosumer-based electric energy systems, IEEE Transactions on Power Systems 29 (6) (2014) 2934-2942

[52] M. R. V. Moghadam, R. T. Ma, R. Zhang, Distributed frequency control in smart grids via randomized demand response, IEEE Transactions on Smart Grid 5 (6) (2014) 2798-2809.

[53] Y. Wang, H. Li, Y. Xu, Y. Tang, System frequency regulation in singapore using distributed energy storage systems, in: 2017 Asian Conference on Energy, Power and Transportation Electrification (ACEPT), IEEE, 2017, pp. 1-6.

[54] C. Pradhan, C. N. Bhende, Online load frequency control in wind integrated power systems using modified jaya optimization, Engineering Applications of Artificial Intelligence 77 (2019) 212-228

[55] J. I. Sarasúa, G. Martínez-Lucas, M. Lafoz, Analysis of alternative frequency control schemes for increasing renewable energy penetration in el hierro island power system, International Journal of Electrical Power \& Energy Systems 113 (2019) 807-823.

[56] Red Eléctrica de España, n.d., Gran canaria — seguimiento de la demanda de energía eléctrica, https://demanda.ree.es/ visiona/canarias/gcanaria/.

[57] Ministerio de Industria, Energía y Turismo, Procedimientos de operación de los Sistemas eléctricos Insulares y Extrapeninsulares: P.O. 3.1; 3.2; 9; SEIE-1; SEIE-2.2; SEIE-2.3; SEIE-3.1; SEIE-7.1; SEIE-7.2; SEIE-8.2; SEIE-9, Boletín Oficial del Estado Edition (2012). 
[58] Ministerio de Industria Energía y Turismo, Real Decreto $738 / 2015$, de 31 de julio, por el que se regula la actividad de producción de energía eléctrica y el procedimiento de despacho en los sistemas eléctricos de los territorios no peninsulares, Boletín Oficial del Estado Edition (2015).

[59] D. Fernández-Muñoz, J. Pérez-Díaz, Contribution of nonconventional pumped-storage hydropower plant configurations in an isolated power system with an increasing share of renewable energy, IET Renewable Power Generationdoi:10.1049/ iet-rpg. 2019.0874.

[60] D. Fernández-Muñoz, J. I. Pérez-Díaz, M. Chazarra, A twostage stochastic optimisation model for the water value calculation in a hybrid diesel/wind/pumped-storage power system, IET Renewable Power Generation 13 (12) (2019) 2156-2165.

[61] R. Azizipanah-Abarghooee, F. Golestaneh, H. B. Gooi, J. Lin, F. Bavafa, V. Terzija, Corrective economic dispatch and operational cycles for probabilistic unit commitment with demand response and high wind power, Applied Energy 182 (2016) $634-$ 651. doi:https://doi.org/10.1016/j.apenergy.2016.07.117.

[62] M. Pezic, V. M. Cedrés, Unit commitment in fully renewable, hydro-wind energy systems, in: 2013 10th International Conference on the European Energy Market (EEM), IEEE, 2013, pp. $1-8$.

[63] G. Morales-España, J. M. Latorre, A. Ramos, Tight and compact milp formulation of start-up and shut-down ramping in unit commitment, IEEE Transactions on Power Systems 28 (2) (2013) 1288-1296.

[64] S. Mansoor, D. Jones, D. A. Bradley, F. Aris, G. Jones, Reproducing oscillatory behaviour of a hydroelectric power station by computer simulation, Control Engineering Practice 8 (11) (2000) 1261-1272.

[65] J. O'Sullivan, A. Rogers, D. Flynn, P. Smith, A. Mullane, M. O'Malley, Studying the maximum instantaneous nonsynchronous generation in an island system - frequency stability challenges in ireland, IEEE Transactions on Power Systems 29 (6) (2014) 2943-2951.

[66] P. Kundur, N. J. Balu, M. G. Lauby, Power system stability and control, Vol. 7, McGraw-hill New York, 1994.

[67] NEPLAN AG, Turbine-governor models, standard dynamic turbine-governor systems, https://www.neplan.ch/ wp-content/uploads/2015/08/Nep_TURBINES_GOV.pdf (2016).

[68] J. I. Perez-Diaz, J. I. Sarasua, J. R. Wilhelmi, Contribution of a hydraulic short-circuit pumped-storage power plant to the loadfrequency regulation of an isolated power system, International Journal of Electrical Power \& Energy Systems 62 (2014) 199211.

[69] ENTSO-E, Continental Europe Operation Handbook, https://docstore.entsoe.eu/publications/ system-operations-reports/operation-handbook/Pages/ default.aspx.

[70] A. J. Wood, B. F. Wollenberg, Power generation, operation, and control, John Wiley \& Sons, 2012.

[71] M. Pyller, S. Achilles, Aggregated wind park models for analyzing power system dynamics.

[72] M. Mokhtari, F. Aminifar, Toward wide-area oscillation control through doubly-fed induction generator wind farms, IEEE Transactions on Power Systems 29 (6) (2014) 2985-2992.

[73] L.-R. Chang-Chien, W.-T. Lin, Y.-C. Yin, Enhancing frequency response control by DFIGs in the high wind penetrated power systems, IEEE transactions on power systems 26 (2) (2010) 710718.

[74] I. Erlich, M. Wilch, Primary frequency control by wind turbines, in: IEEE PES general meeting, IEEE, 2010, pp. 1-8.

[75] I. D. Margaris, S. A. Papathanassiou, N. D. Hatziargyriou, A. D. Hansen, P. Sorensen, Frequency control in autonomous power systems with high wind power penetration, IEEE Transactions on Sustainable Energy 3 (2) (2012) 189-199.

[76] A. Žertek, G. Verbič, M. Pantoš, Optimised control approach for frequency-control contribution of variable speed wind turbines, IET Renewable power generation 6 (1) (2012) 17-23.

[77] N. R. Ullah, T. Thiringer, D. Karlsson, Temporary primary fre- quency control support by variable speed wind turbines - potential and applications, IEEE Transactions on Power Systems 23 (2) (2008) 601-612.

[78] K. Clark, N. W. Miller, J. J. Sanchez-Gasca, Modeling of GE wind turbine-generators for grid studies, GE Energy 4 (2010) 0885-8950.

[79] A. Jafari, G. Shahgholian, Analysis and simulation of a sliding mode controller for mechanical part of a doubly-fed induction generator-based wind turbine, IET Generation, Transmission \& Distribution 11 (10) (2017) 2677-2688.

[80] J. Liu, Y. Gao, S. Geng, L. Wu, Nonlinear control of variable speed wind turbines via fuzzy techniques, IEEE Access 5 (2017) $27-34$.

[81] F. Huerta, R. L. Tello, M. Prodanovic, Real-time powerhardware-in-the-loop implementation of variable-speed wind turbines, IEEE Transactions on Industrial Electronics 64 (3) (2017) 1893-1904.

[82] A. Fernández-Guillamón, J. Villena-Lapaz, A. ViguerasRodríguez, T. García-Sánchez, Á. Molina-García, An adaptive frequency strategy for variable speed wind turbines: Application to high wind integration into power systems, Energies 11 (6) (2018) 1436.

[83] A. Fernández-Guillamón, A. Vigueras-Rodríguez, E. GómezLázaro, Á. Molina-García, Fast power reserve emulation strategy for vswt supporting frequency control in multi-area power systems, Energies 11 (10) (2018) 2775.

[84] G. C. Tarnowski, P. C. Kjar, P. E. Sorensen, J. Ostergaard, Variable speed wind turbines capability for temporary overproduction, in: Power \& Energy Society General Meeting, 2009. PES'09. IEEE, IEEE, 2009, pp. 1-7.

[85] G. Lalor, A. Mullane, M. O'Malley, Frequency control and wind turbine technologies, IEEE Transactions on power systems 20 (4) (2005) 1905-1913.

[86] L. Sigrist, I. Egido, E. F. Sanchez-Ubeda, L. Rouco, Representative operating and contingency scenarios for the design of ufls schemes, IEEE Transactions on Power Systems 25 (2) (2009) 906-913.

[87] P. Daly, D. Flynn, N. Cunniffe, Inertia considerations within unit commitment and economic dispatch for systems with high non-synchronous penetrations, in: PowerTech, 2015 IEEE Eindhoven, IEEE, 2015, pp. 1-6. 


\subsection{Analysis of power system inertia estimation in high wind power plant integration scenarios}

Nowadays, power system inertia is reducing as a consequence of replacing conventional units by vRES, mainly VSWT and PV power plants. This reduction affects significantly the grid frequency response under contingencies. As a result, new frequency control strategies for vRES are being currently developed to emulate the behaviour of conventional power plants under such power imbalances. These approaches are usually called 'virtual inertia emulation techniques'. In this study, an analysis, comparison and discussion of the inertia estimation methodologies previously proposed have been carried out by considering the new supply-side scenarios. The power system under study involves conventional units (i.e., thermal and hydro-power), and wind power plants, which are considered to have the ability to participate in frequency control. Four different generation mix cases are considered. In this way, wind power plants are increasing their generation capacity from 15 to $45 \%$, reducing the thermal plants capacity accordingly, in line with current and future generation mix road-maps. Under this considerations, results show that all methodologies considered give an accurate result to estimate the equivalent inertia when wind power is not participating in frequency control (inertia was only provided by conventional power plants). In fact, the deviation error is lower than a $10 \%$ with respect to the global rotational generation units directly connected to grid. However, when wind power plants participate in frequency control, most inertia estimation strategies gave a similar value to the one estimated when wind frequency response was disabled. Only one methodology was able to estimate the new equivalent inertia as a combination of rotational and virtual inertias. In fact, the virtual inertia constant of VSWT estimated with this methodology has a value of $H_{V, W T}=3.57 \mathrm{~s}$, in line with the typical inertia constants of conventional power plants. Moreover, the estimation of equivalent inertia values is highly dependent on the wind power plant frequency control strategy, and then, different results would be obtained if derivative frequency dependence is (or not) included in the frequency strategy. Alternative methodologies and processes should be thus proposed to provide suitable results regarding equivalent inertia estimation in power systems with high renewable penetration including frequency control.

Information of the paper:

- Journal: IET Renewable Power Generation

- DOI: 10.1049/iet-rpg.2019.0220

- Date of publication: August 2019

- Available online: https://arxiv.org/pdf/2005.02091.pdf

- Reference: [5] 



\title{
Analysis of power system inertia estimation in high wind power plant integration scenarios
}

\author{
Ana Fernández-Guillamón ${ }^{1}$, Antonio Vigueras-Rodríguez ${ }^{2}$, Ángel Molina-García ${ }^{*}$ \\ ${ }^{1}$ Department of Automatics, Electrical Eng. and Electronic Technology, Universidad Politecnica de Cartagena, 30202 Cartagena, Spain \\ ${ }^{2}$ Department of Civil Engineering, Universidad Politecnica de Cartagena, 30203 Cartagena, Spain \\ *E-mail: angel.molina@upct.es
}

\begin{abstract}
Nowadays, power system inertia is changing as a consequence of replacing conventional units by renewable energy sources, mainly wind and PV power plants. This fact affects significantly the grid frequency response under power imbalances. As a result, new frequency control strategies for renewable plants are being developed to emulate the behaviour of conventional power plants under such contingencies. These approaches are usually called 'virtual inertia emulation techniques'. In this paper, an analysis of power system inertia estimation from frequency excursions is carried out by considering different inertia estimation methodologies, discussing the applicability and coherence of these methodologies under the new supply-side circumstances. The modelled power system involves conventional units and wind power plants, including wind frequency control strategies in line with current mix generation scenarios. Results show that all methodologies considered provide an accurate result to estimate the equivalent inertia based on rotational generation units directly connected to the grid. However, significant discrepancies are found when frequency control strategies are included in wind power plants decoupled from the grid. In this way, authors consider that it is necessary to define alternative inertia estimation methodologies by including virtual inertia emulation. Extensive discussion and results are also provided in this study.
\end{abstract}

\section{Introduction}

Frequency of a power system deviates from its nominal value after a severe power imbalance between generation and consumption [1]. Due to the increasing penetration of renewable energy sources (RES), mainly wind and PV, electrical grids can suffer more frequency stability challenges [2]. RES are intermittent and uncertain because they depend on weather conditions [3]. This fact makes them hard to integrate into power systems [4], as they pose stress on their operation [5]: Transmission System Operators (TSOs) have to deal with not only the uncontrollable demand but also uncontrollable generation [6].

Moreover, renewable power plants are not connected to the grid through synchronous machines, but through electronic converters [7]. Thus, by increasing the amount of renewable sources and replacing synchronous conventional units, the effective rotational inertia of the system can be significantly reduced $[8,9]$. The rotational inertia is important to limit the rate of change of frequency (ROCOF) right after a power imbalance [10]. Therefore, power systems with lower equivalent inertia are initially more sensitive to frequency deviations [11, 12]. As a result, frequency control strategies have been developed to effectively integrate RES into the grid [13]. Such methods are commonly referred to as synthetic, artificial, emulated or virtual inertia [14].

The aim of this paper is to estimate and compare the equivalent inertia constant of a power system with high RES integration from the frequency deviations suffered after an imbalance. Several methodologies have been proposed during the last decades in the specific literature [15-21]. The power system considered in this paper is in line with current grids, involving conventional and wind power plants. Moreover, wind plants include frequency control according to a recent approach [22]. The rest of the paper is organized as follows: the theoretical background of the problem is covered in Section 2. Section 3 reviews and explains the different strategies to estimate the inertia constant of a power system after an imbalance. In Section 4, the power system and different scenarios considered in this paper are detailed. Results are discussed in Section 5. Conclusions are given in Section 6.

\section{Theoretical background}

\subsection{Inertia constant $H$}

From a traditional point of view, after a power imbalance, the kinetic energy stored in the rotating masses of a generator is released following expression (1) [23]:

$$
E_{k i n}=\frac{1}{2} J\left(2 \cdot \pi \cdot f_{m}\right)^{2},
$$

where $J$ is the moment of inertia and $f_{m}$ is the rated rotational frequency of the machine. The inertia constant $H$ of a generator is defined as the ratio between the stored kinetic energy $E_{k i n}$ and its rated power $S_{r}$ [24]. $H$ determines the time interval during which an electrical generator can supply its rated power only by using the kinetic energy stored in its rotating masses [25]:

$$
H=\frac{E_{k i n}}{S_{r}}=\frac{J\left(2 \cdot \pi \cdot f_{m}\right)^{2}}{2 \cdot S_{r}} .
$$

Depending on the type of conventional units (i.e., steam, combined cycle, hydroelectric, etc.), typical inertia constants are in the range of $2-10 \mathrm{~s}$, as indicated in Table 1.

\subsection{Swing equation of a power system. Equivalent rotational system inertia}

Power systems include several synchronous generators. Thus, it is possible to estimate the equivalent rotational system inertia $\left(H_{e q}\right)$ by using [34]:

$$
H_{e q}=\frac{\sum_{i=1}^{C P} H_{i} \cdot S_{B, i}}{S_{B}},
$$

$H_{i}$ refers to the inertia constant of power plant $i, S_{B, i}$ is the rated power of power plant $i, S_{B}$ is the rated power of the power system and $C P$ is the total number of conventional plants. 
Table $1 H$ according to generation type, rated power and reference

\begin{tabular}{lllll}
\hline Type of power plant & Rated power $(\mathbf{M W})$ & $H(\mathbf{s})$ & Ref. & Year \\
\hline Thermal (2 poles) & Not indicated & $2.5-6$ & {$[26]$} & 1994 \\
Thermal (4 poles) & Not indicated & $4-10$ & {$[26]$} & 1994 \\
Thermal & 10 & 4 & {$[27]$} & 2007 \\
Thermal & $500-1500$ & $2.3-2$ & {$[28]$} & 2008 \\
Thermal & 1000 & $4-5$ & {$[29]$} & 2011 \\
Thermal & Not indicated & $4-5$ & {$[30]$} & 2012 \\
Thermal (steam) & 130 & 4 & {$[31]$} & 2012 \\
Thermal (steam) & 60 & 3.3 & {$[31]$} & 2012 \\
Thermal (combined cycle) & 115 & 4.3 & {$[31]$} & 2012 \\
Thermal (gas) & $90-120$ & 5 & {$[31]$} & 2012 \\
Thermal (nuclear) & $100-1400$ & 4 & {$[25]$} & 2016 \\
Thermal (fossil) & $0-1000$ & $5-3$ & {$[25]$} & 2016 \\
\hline Hydroelectric & Not indicated & $2-4$ & {$[26]$} & 1994 \\
Hydroelectric $n<200 \mathrm{rpm}$ & Not indicated & $2-3$ & {$[32]$} & 1994 \\
Hydroelectric $n>200 \mathrm{rpm}$ & Not indicated & $2-4$ & {$[32]$} & 1994 \\
Hydroelectric $450<\mathrm{n}<514 \mathrm{rpm}$ & $10-65$ & $2-4.3$ & {$[28]$} & 2008 \\
Hydroelectric $200<\mathrm{n}<400 \mathrm{rpm}$ & $10-75$ & $2-4$ & {$[28]$} & 2008 \\
Hydroelectric $138<\mathrm{n}<180 \mathrm{rpm}$ & $10-90$ & $2-3.3$ & {$[28]$} & 2008 \\
Hydroelectric $80<\mathrm{n}<120 \mathrm{rpm}$ & $10-85$ & $1.75-3$ & {$[28]$} & 2008 \\
Hydroelectric & Not indicated & 4.75 & {$[33]$} & 2013 \\
\hline
\end{tabular}

The swing equation of a power system is used to analyse transient stability problems, as well as frequency control design and regulation [35]. Moreover, it relates frequency excursions with the power imbalance [36]:

$$
\frac{d \Delta f}{d t}=\frac{1}{2 H_{e q}}\left(\Delta P_{m}-\Delta P_{e}\right),
$$

where $\Delta f$ is the deviation of the grid frequency, $H_{e q}$ is the equivalent inertia constant for the power system determined by (3), $\Delta P_{m}$ is the mechanical power change supplied by generator and $\Delta P_{e}$ is the electrical power demand variation.

Some electrical loads are frequency dependent (such as rotating machines). Consequently, $\Delta P_{e}$ is expressed as [37]:

$$
\Delta P_{e}=\Delta P_{L}+D \cdot \Delta f,
$$

being $\Delta P_{L}$ the power change of frequency independent loads and $D$ the damping factor (load-frequency response constant). Combining (4) and (5), the swing equation of a power system is obtained [38].

$$
\frac{d \Delta f}{d t}=\frac{1}{2 H_{e q}}\left(\Delta P_{m}-\Delta P_{L}-D \Delta f\right) .
$$

\subsection{Future definition of inertia constant of a power system}

By considering policies to promote the integration of renewables, RES have replaced conventional power plants and, subsequently, synchronous generators [39]. Among the different renewable sources available, PV and wind (especially doubly fed induction generators, DFIG [40]) are the two most promising resources for generating electrical energy [41]. Both wind and PV power plants are controlled by power converters according to the maximum power point tracking (MPPT) control [42, 43]. This technique prevents both sources to directly contribute to the inertia of the system [44-46], which is considered as one of the main drawbacks to integrate large amounts of RES into the grid [47]. In fact, modern wind turbines have rotational inertia constants comparable to those of conventional generators, provided by their blades, drive train and electrical generator. However, this inertia is hidden from the power system point of view due to the converter [48]. Moreover, ROCOF depends on the available inertia [49]. As a result, larger frequency deviations are achieved after an imbalance between supply-side and demand when RES replace conventional units without providing frequency response [50].

Therefore, it is necessary that RES become an active agent in grid frequency regulation [51]. Actually, several TSOs are requiring that
RES contribute to ancillary services as well [52], especially wind power plants [53]. Toulabi et al. affirm that the participation of wind turbines in frequency control is necessary [54]. Under these requirements, different solutions providing inertia and frequency control from RES have been under study during the last decades. These technologies are usually known as 'virtual inertia techniques' [55] and are explained in [55-59].

If RES providing frequency response were considered, the equivalent inertia of the power system would have two different components: $(i)$ synchronous rotational inertia due to conventional generators $H_{R, e q}$, calculated with eq. (3), and (ii) virtual inertia corresponding to RES, $H_{V, e q}$, as indicated in eq. (7) [60, 61]. In this way, $H_{V, j}$ refers to the emulated inertia constant of power plant $j, S_{B, j}$ is the rated power of power plant $j$ and $V G$ is the total number of virtual generators included in the power system under consideration. The rest of the parameters are the same as (3).

$$
H_{e q}=\frac{\overbrace{\sum_{i=1}^{C P} H_{i} \cdot S_{B, i}}^{H_{R}, e q}+\overbrace{\sum_{j=1}^{V G} H_{V, j} \cdot S_{B, j}}^{H_{V, e q}}}{S_{B}}
$$

However, the values of $H_{V, j}$ are not normally known and can be time dependent. Thus, it is difficult to apply eq. (7).

\section{Inertia estimation strategies. Methodology}

Different inertia estimation strategies have been proposed during the last decades [15-21]. Damping factor is neglected in most approaches as its effects are small on the firsts moments of the imbalance $\Delta P$.

Inoue et al. propose a procedure for estimating the inertia constant of a power system using transients of the frequency measured at an imbalance [15]. At the onset of an imbalance $\left(t=0^{+}\right)$, the frequency deviation is $\Delta f=0$. Assuming that the imbalance $\Delta P=$ $\Delta P_{m}-\Delta P_{L}$ is known, and by estimating the ROCOF $(d f / d t)$ at $t=0^{+}$, the inertia constant can be calculated with

$$
H_{e q}=\frac{-\Delta P}{\left.\frac{2 d\left(\Delta f / f_{0}\right)}{d t}\right|_{t=0^{+}}} .
$$

To calculate the ROCOF, a $5^{\text {th }}$ degree polynomial approximation of $\Delta f / f_{0}$ with respect to time is fitted. The time interval is about 15 to $20 \mathrm{~s}$ after the imbalance

$$
\Delta f / f_{0}=A_{5} \cdot t^{5}+A_{4} \cdot t^{4}+A_{3} \cdot t^{3}+A_{2} \cdot t^{2}+A_{1} \cdot t,
$$

where $t$ is the time. By estimating the coefficients $A_{1}$ to $A_{5}$, the equivalent inertia constant $H_{e q}$ is obtained by using eq. (11), as $A_{1}$ is approximately equal to the ROCOF at $t_{0}^{+}$

$$
\begin{gathered}
A_{1}=\left.f^{\prime}\left(t=0^{+}\right) \approx \frac{\Delta f / f_{0}}{d t}\right|_{t=0} \\
H_{e q}=\frac{-\Delta P}{2 \cdot A_{1}} .
\end{gathered}
$$

Chassin et al [16] frequency and power values from the Western Electricity Coordination Council were collected. In this case, ROCOF is estimated by removing noise from the frequency data recorded and applying the first derivative. The equation to estimate $H_{e q}$ is as below

$$
H_{e q}=\frac{-\Delta P}{2 \frac{d f}{d t}} .
$$

Wall et al. present a robust estimation method for the inertia available in the system $[17,18]$. It uses as input data the active power $P$ 


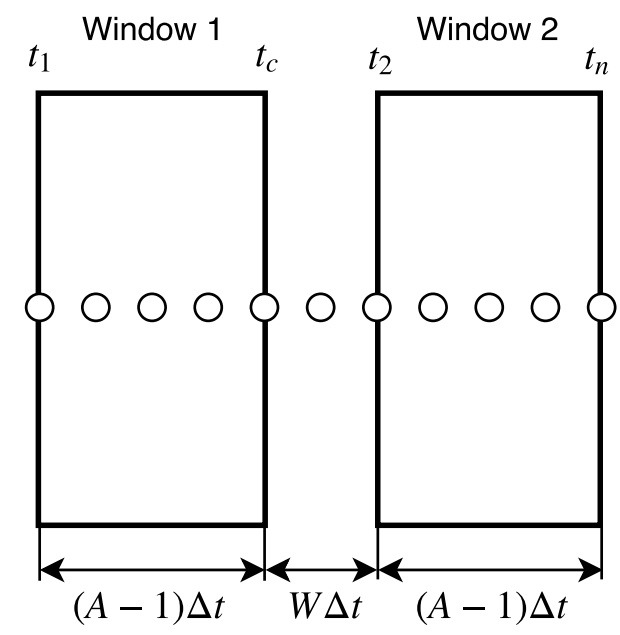

Fig. 1: Sample of windows. In this case, $A=5$ and $W=2$

and the derivative of frequency $d f(t) / d t$, measured from a single location. The proposed algorithm consists of a set of four filters (two for the total active power $-P_{1}$ and $P_{2}-$ and two for the ROCOF $-R_{1}$ and $R_{2}-$ ) applied as sliding windows, see Figure 1 . Windows have a width of $A$ data points and they are separated by a width $W$.

$H_{e q}$ is estimated by the following expression:

$$
H_{e q}=\frac{1}{2} \frac{P_{1}-P_{2}}{R_{2}-R_{1}}
$$

where $P_{1}, P_{2}, R_{1}$ and $R_{2}$ are calculated with (14):

$$
\begin{gathered}
P_{1}\left(t_{n}\right)=\frac{1}{A} \sum_{t=t_{1}}^{t_{c}} P(t), \\
P_{2}\left(t_{n}\right)=\frac{1}{A} \sum_{t=t_{2}}^{t_{n}} P(t), \\
R_{1}\left(t_{n}\right)=\frac{1}{A} \sum_{t=t_{1}}^{t_{c}} \frac{d f(t)}{d t}, \\
R_{2}\left(t_{n}\right)=\frac{1}{A} \sum_{t=t_{2}}^{t_{n}} \frac{d f(t)}{d t} .
\end{gathered}
$$

The result of applying eq. (13) is only $H_{e q}$ during the time in which the power imbalance has occurred $\left(t_{\text {dist }}\right)$ [18].

Zografos and Ghandhari [19] consider an aggregated load model to represent the behaviour of the average system load. The load power change is expressed by

$$
\Delta P_{L}(t)=P_{\text {prod }} \cdot\left(V_{s}(t)-1\right)
$$

where $P_{\text {prod }}$ is the total power production before the disturbance and $V_{s}(t)$ is the system's overall voltage profile, approximated by the voltage of the generator buses according to

$$
V_{s}(t)=\frac{\sum_{i=1}^{n}\left(\frac{V_{G, i}(t)}{V_{G 0, i}}\right)}{n}
$$

being $V_{G, i}(t)$ the voltage at the bus of generator $i$ at time $t, V_{G 0, i}$ the voltage before the disturbance at the bus of generator $i$ and $n$ the number of connected generators. By combining (6) and (15), the inertia constant of the system is calculated from (17), where $\Delta P_{\text {dist }}$ is the size of the disturbance at the moment of the disturbance

$$
H_{\text {est }}=\frac{\Delta P(t)}{2 \cdot \frac{d f}{d t}}=\frac{\Delta P_{L}(t)+\Delta P_{\text {dist }}}{2 \cdot \frac{d f}{d t}} .
$$

Tuttelberg et al. [20] simplify the dynamic response to a reduced order system with the generic form of (18)

$$
H(s)=\frac{b_{n-1} s^{n-1}+b_{n-2} s^{n-2}+\ldots+b_{0}}{a_{n} s^{n}+a_{n-1} s^{n-1}+\ldots+a_{0}} .
$$

The inertia of a power system $H_{e q}$ can be determined by the value of its unit impulse response at $t=0$. For a transfer function like the one presented in (18), the first value of the impulse response can be evaluated in Matlab with: (i) the impulse function, $(i i)$ the gain value of the zero-pole model from $t f 2 \mathrm{zpk}$ or $(\mathrm{iii})$ as the ratio of $a_{n}$ to $-b_{n-1}$.

Zografos et al. [21] introduce two approaches to express the power change due to the frequency and voltage dynamics $(R$ and $V$ approaches, respectively)

$$
\Delta P(t)=h_{1}(f(t))+h_{2}(V(t))-\Delta P_{\text {dist }},
$$

where $P_{\text {dist }}$ is the size of the disturbance, and $h_{1}(f(t))$ and $h_{2}(V(t))$ deal with the power change due to the frequency and the voltage dynamics, respectively.

In the $R$ approach, it is considered that $\Delta P(t)=h_{1}(f(t))-$ $\Delta P_{\text {dist }}$. To obtain $h_{1}(f(t))$, the governor's behavior is analysed. $h_{1}(f(t))$ relates the mechanical power change and the frequency deviation. It is considered that

$$
\Delta P_{m}(t)=-R(t) \cdot \Delta f(t)
$$

being $\Delta P_{m}$ the mechanical power change and $R(t)$ an unknown time varying function that accommodates the dynamic response of the system related to $\Delta f(t)$. Then eq. (6) is converted into

$$
2 \cdot H_{e q} \frac{d f}{d t}=h_{1}(f(t))-\Delta P_{d i s t}=R(t) \cdot \Delta f(t)-\Delta P_{d i s t}
$$

where $H_{e q}$ is the estimated inertia constant to be found. However, as previously said, $R(t)$ is also unknown. To compute $R(t)$, a specific selected time $t_{s r}$ is considered. $t_{s r}$ is recommended to be the first local extreme of the ROCOF curve after the moment of the disturbance. Moreover, eq. (21) is considered for $N$ discrete points equally distributed around $t_{s r} . R(t)$ can thus be approximated by the average of the values of $R(t)$ of the $N$ neighbouring points to $t_{s r}$. Therefore, a system with $N+1$ linear equations and $N+1$ unknowns is obtained (22). By solving it, $R\left(t_{s r}\right)$ is obtained

$$
\begin{gathered}
2 \cdot H_{e q} \frac{d f\left(t_{s r}+i\right)}{d t}=R\left(t_{s r}+i\right) \cdot \Delta f\left(t_{s r}+i\right)-\Delta P_{d i s t} \\
R\left(t_{s r}\right)=\frac{\sum_{i=-N / 2}^{N / 2} R\left(t_{s r}+i\right)}{N} \\
\forall i \in \mathbb{Z}:-N / 2 \leq i \leq N / 2: i \neq 0
\end{gathered}
$$

In the $V$ approach, it is considered that $\Delta P(t)=h_{2}(V(t))-$ $\Delta P_{\text {dist }}$. To obtain $h_{2}(V(t))$, the load power change due to voltage dependency is analysed

$$
\Delta P_{L V}(t)=P_{\text {prod }}\left(k_{z}\left(V_{s}(t)\right)\right)^{2}+k_{i}\left(V_{s}(t)+k_{p}\right)-P_{\text {prod }},
$$

where $P_{\text {prod }}$ is the total power production before the disturbance, $k_{z}, k_{i}$ and $k_{p}$ define the fraction of each component, and $V_{s}(t)$ is 
Table 2 Summary of inertia estimation methodologies

\begin{tabular}{lll}
\hline Ref. & Methodology based on & Year \\
\hline$[15]$ & Power imbalance and ROCOF & 1997 \\
{$[16]$} & Power imbalance and ROCOF & 2005 \\
{$[17]$} & Total power supplied and ROCOF & 2012 \\
{$[18]$} & Total power supplied and ROCOF & 2014 \\
{$[19]$} & Power imbalance and ROCOF & 2017 \\
{$[20]$} & Impulse function & 2018 \\
{$[21]$} & Power imbalance and ROCOF & 2018 \\
\hline
\end{tabular}

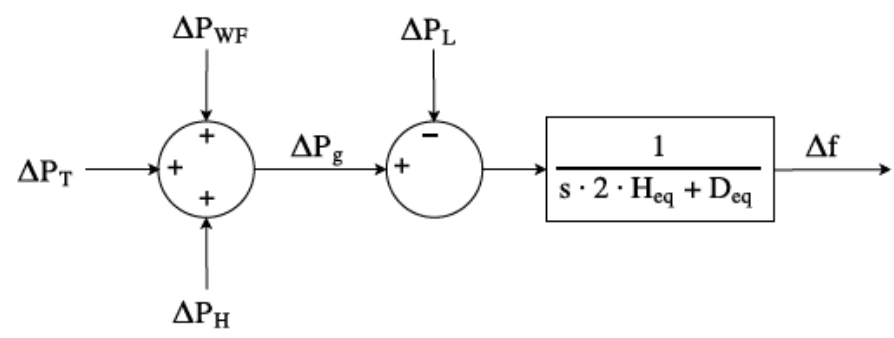

Fig. 2: Simplified diagram of the electrical power system used for simulations [62]

the loads' aggregated voltage profile, calculated with (16). Then

$$
2 \cdot H_{e q} \frac{d f}{d t}=h_{2}(V(t))-\Delta P_{d i s t}=-\Delta P_{L V}(t)-\Delta P_{d i s t} .
$$

The application range $t_{s v}$ of this strategy should be selected before $500 \mathrm{~ms}$, and as soon as possible after the disturbance to avoid the governor frequency response.

The estimated equivalent inertia is calculated with (25), where $t_{s}$ is recommended to be the $t_{s r}$ estimated with (22)

$$
H_{e q}=\frac{R\left(t_{s}\right) \Delta f\left(t_{s}\right)-\Delta P_{L V}\left(t_{s}\right)-\Delta P_{d i s t}}{2 \frac{d f\left(t_{s}\right)}{d t}}
$$

Finally, Table 2 summarizes the different inertia estimation methodologies discussed in this work. As can be seen, most of them are based on the power imbalance and ROCOF, in line with the swing equation and the frequency control of conventional generation units.

\section{System identification}

\subsection{Power system modelling}

From the supply-side, the power system considered for simulation purposes involve conventional generating units (thermal and hydropower plants) and wind power plants. A simplified diagram of the power system can be seen in Figure 2, being the variation of the generated power $\Delta P_{g}=\Delta P_{W F}+\Delta P_{T}+\Delta P_{H}$, and $\Delta P_{L}$ the power imbalance. A base power of $1350 \mathrm{MW}$ is assumed, corresponding to the capacity of the power system. It is considered that the active power of loads is independent on voltage, and as a consequence, the term $\Delta P_{L}(t)$ of eq. (17) [19] is not considered, and the $V$ approach of Zografos et al. [21] is not taken into account. The equivalent damping factor of loads is $D_{e q}=1 \mathrm{pu}_{M W} / \mathrm{pu}_{H z}$ [26]. Simulations have been carried out in Matlab/Simulink.

Conventional units are modelled according to the simplified governor-based models widely used and proposed in [26], see Figure 3. The inertia constant for these power plants are $H_{\text {thermal }}=5 \mathrm{~s}$ and $H_{\text {hydro }}=3.3 \mathrm{~s}$. Wind power plants are modelled according to an equivalent wind turbine, with the mechanical single-mass and turbine control models presented in [63-65]. The frequency controller is included in the wind turbine model as can be seen in Figure 4. Parameters of both conventional and wind power plants are summarized in the Appendix.

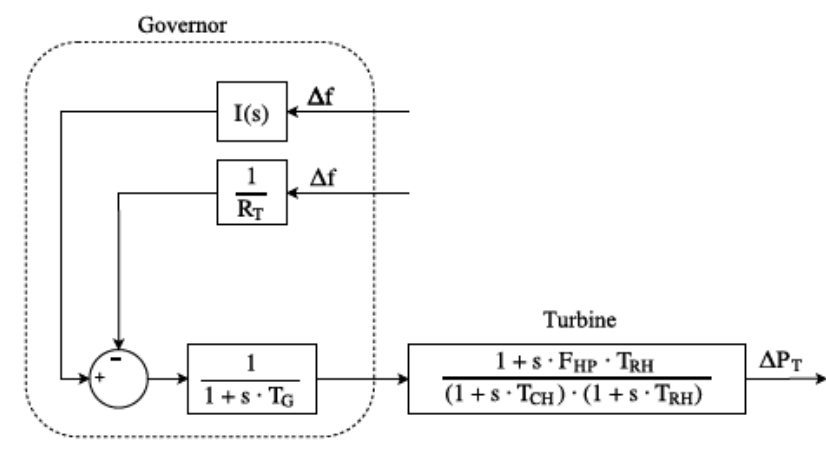

(a)

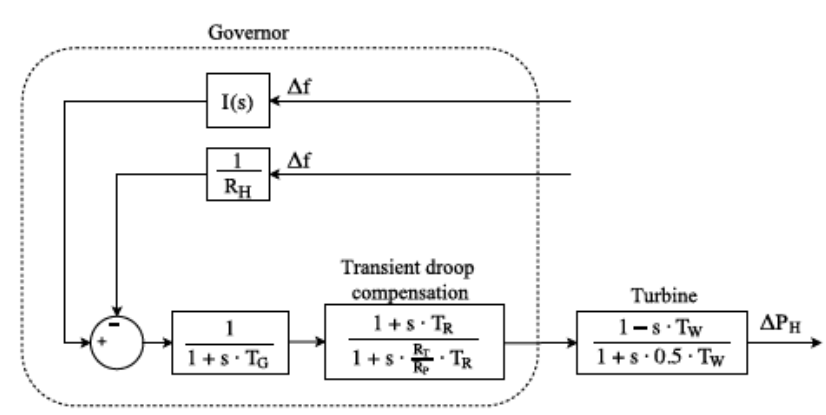

(b)

Fig. 3: Thermal and hydro-power plant models [26] (a) Reheat thermal power plant (b) Hydro-power

\subsection{Frequency control strategies}

Under power imbalance conditions, the governor control mechanisms of conventional units modify their active power supply to recover system power balance and, thus, remove the frequency deviation [66]. Grid frequency deviation $\Delta f$ is subsequently used as an input signal for primary and secondary frequency controls [67]. Primary frequency control is performed locally at the generator, being the active power increment/decrement proportional to $\Delta f$ through the speed regulation parameter $R$ [68]. Secondary frequency control involves an integral controller that modifies the turbine set-point of each generation unit [69].

Wind turbines can also include frequency control strategies. Different solutions have been proposed in the last decade. These strategies are usually classified as indicated in Figure 5 [70], excluding the use of energy storage systems. According to the specific literature, examples of these strategies are summarized in Table 3.

Moreover, some approaches can be combined, in order to improve the frequency deviation after the power imbalance [71-77]. As can be seen, an alternative classification can be then proposed: (i) not-including derivative frequency dependence and (ii) including derivative frequency dependence. An additional active power $\Delta P$ is added to the pre-event power supplied by the wind power plant $P_{0}$ in all the cases except de-loading technique. In the fast power reserve, $\Delta P$ can be defined: $(i)$ as a constant, $(i i)$ proportional to the rotational speed of the turbine or (iii) proportional to the frequency excursion, depending on the reference. The hidden inertia emulation uses a proportional derivative controller, being $K_{d}$ and $K_{p}$ the derivative and proportional constants of the controller, respectively. With regard to the droop control, $\Delta P$ is proportional to the frequency deviation $\Delta f$ by the droop constant $R$. As discussed in Section 5 , this frequency controllers modify considerably the estimated inertia values and addresses significant discrepancies among methodologies.

The strategy for VSWTs implemented in this paper is based on the fast power reserve technique presented in [22] for for isolated power systems and assessed in [94] for multi-area power 


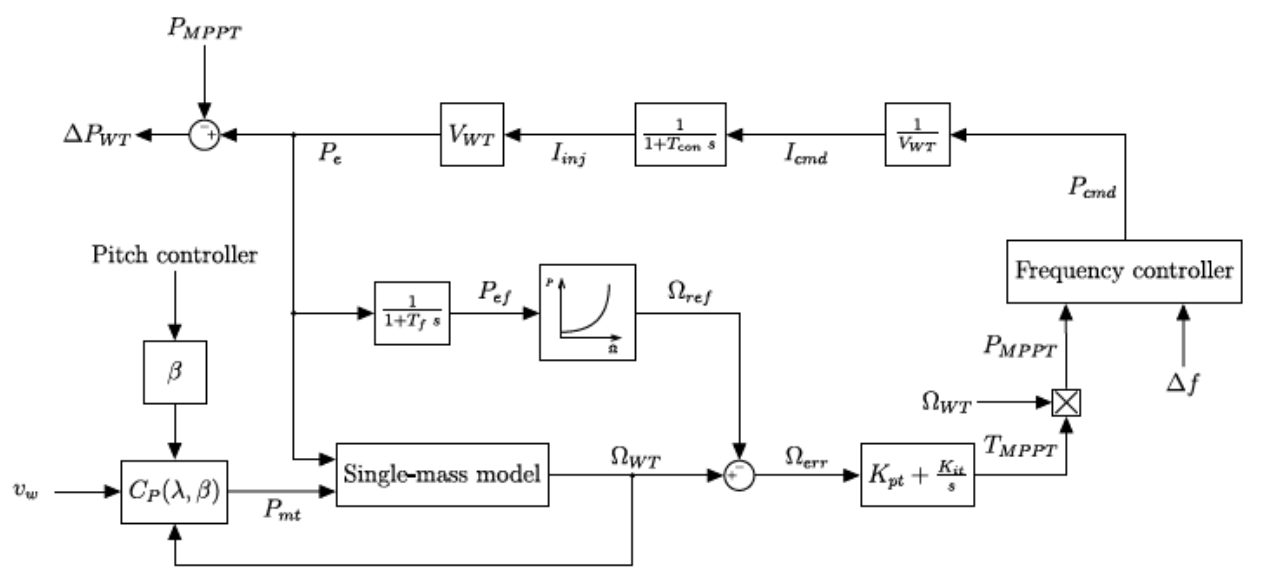

Fig. 4: Variable speed wind turbine model with frequency controller

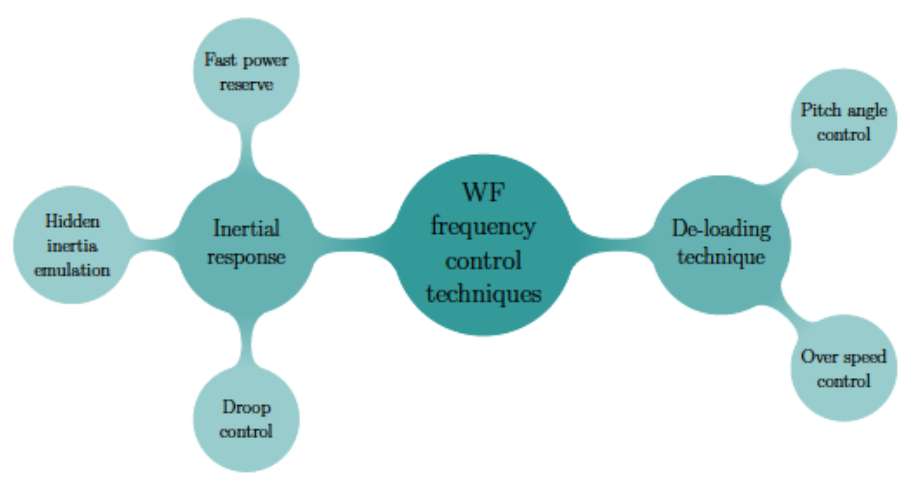

Fig. 5: Frequency control techniques for wind power plants

Table 3 Wind turbines frequency control proposals

\begin{tabular}{|c|c|c|c|}
\hline Ref. & Type of control & Definition & Year \\
\hline [78] & Fast power reserve & $P_{0}+\Delta P, \Delta P=c t e$ & 2009 \\
\hline [79] & Fast power reserve & $P_{0}+\Delta P, \Delta P=$ cte & 2009 \\
\hline [80] & Fast power reserve & $P_{0}+\Delta P, \Delta P \propto \Omega$ & 2011 \\
\hline [81] & Fast power reserve & $P_{0}+\Delta P, \Delta P=c t e$ & 2011 \\
\hline [82] & Fast power reserve & $P_{0}+\Delta P, \Delta P=c t e$ & 2014 \\
\hline [83] & Fast power reserve & $P_{0}+\Delta P, \Delta P=c t e$ & 2015 \\
\hline [84] & Fast power reserve & $P_{0}+\Delta P, \Delta P=$ cte & 2015 \\
\hline [85] & Fast power reserve & $P_{0}+\Delta P, \Delta P \propto \Omega$ & 2016 \\
\hline [22] & Fast power reserve & $P_{0}+\Delta P, \Delta P \propto \Delta f$ & 2018 \\
\hline [86] & Hidden inertia emulation & $P_{0}+K_{d} d f / d t+K_{p} \Delta f$ & 2012 \\
\hline [72] & Hidden inertia emulation & $P_{0}+K_{d} d f / d t+K_{p} \Delta f$ & 2012 \\
\hline [87] & Hidden inertia emulation & $P_{0}+K_{d} d f / d t+K_{p} \Delta f$ & 2013 \\
\hline [88] & Hidden inertia emulation & $P_{0}+K_{d} d f / d t+K_{p} \Delta f$ & 2015 \\
\hline [75] & Hidden inertia emulation & $P_{0}+K_{d} d f / d t+K_{p} \Delta f$ & 2016 \\
\hline [89] & Droop & $P_{0}+R \Delta f$ & 2016 \\
\hline [90] & Droop & $P_{0}+R \Delta f$ & 2016 \\
\hline [91] & Droop & $P_{0}+R \Delta f$ & 2017 \\
\hline [92] & Droop & $P_{0}+R \Delta f$ & 2019 \\
\hline [93] & Pitch angle deloading & - & 2016 \\
\hline
\end{tabular}

systems. As indicated in Figure 6, under power imbalance conditions three operation modes are considered: $(i)$ normal operation mode, $($ ii) overproduction mode and (iii) recovery mode. Different commanded active power $\left(P_{c m d}\right)$ values are determined aiming to restore the grid frequency. Figure 6a depicts the trajectory of $P_{c m d}$ in a $\Omega_{W T}-P$ plot, indicating the three different operation modes. In Figure $6 \mathrm{~b}$, the VSWTs active power variations $\left(\Delta P_{W F}\right)$ submitted to an under-frequency excursion can be seen, being $\Delta P_{W F}=$ $P_{c m d}-P_{M P P T}\left(\Omega_{M P P T}\right)$.

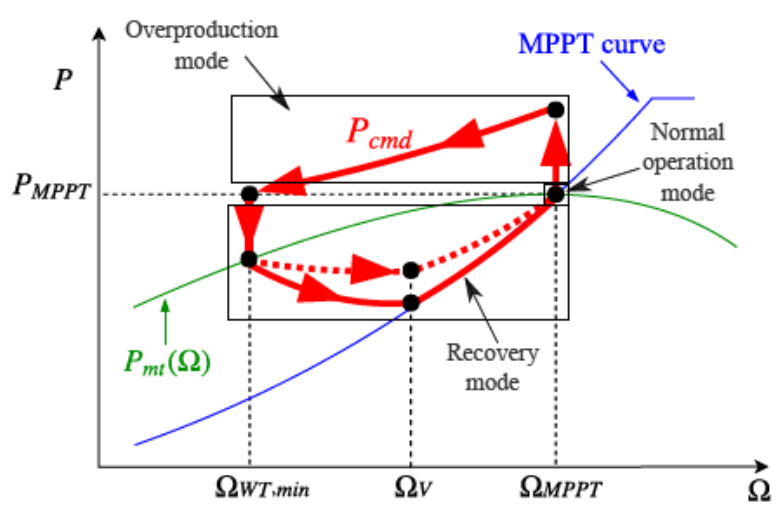

(a)

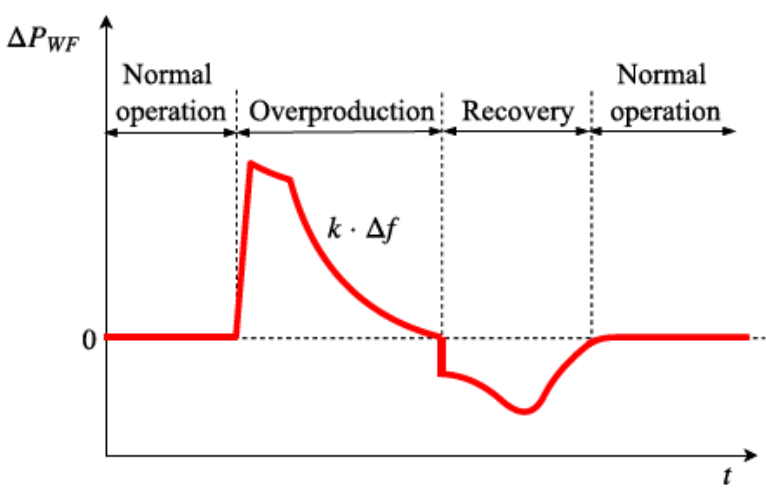

(b)

Fig. 6: Wind frequency control strategy and VSWTs active power variation [22].

(a) Frequency control strategy

(b) $\Delta P_{W F}$ with frequency control strategy

i. In the normal operation mode, the VSWTs operate at the maximum available active power for the current wind speed $P_{M P P T}\left(v_{w}\right)$ and the available mechanical power $\left(P_{m t}\left(\Omega_{W T}\right)\right)$.

$$
P_{c m d}=P_{m t}\left(\Omega_{W T}\right)=P_{M P P T}\left(v_{w}\right) .
$$

When a generation-load mismatch occurs, the frequency controller strategy switches to the overproduction mode, 
Table 4 Capacity of generating units

\begin{tabular}{lllll}
\hline Source & Scenario 1 & Scenario 2 & Scenario 3 & Scenario 4 \\
\hline Thermal & $88 \%$ & $73 \%$ & $58 \%$ & $43 \%$ \\
Hydro-power & $12 \%$ & $12 \%$ & $12 \%$ & $12 \%$ \\
Wind & $0 \%$ & $15 \%$ & $30 \%$ & $45 \%$ \\
$H_{\text {eq }}$ based on (3) & $4.80 \mathrm{~s}$ & $4.05 \mathrm{~s}$ & $3.30 \mathrm{~s}$ & $2.55 \mathrm{~s}$ \\
\hline
\end{tabular}

$$
|\Delta f|>\Delta f_{\text {lim }} \rightarrow \text { Overproduction. }
$$

ii. In the overproduction mode, the active power supplied by the VSWTs $\left(P_{c m d}\right)$ is over the available mechanical power $P_{m t}\left(\Omega_{W T}\right)$ curve. The additional active power $\Delta P_{O P}$ is provided by the kinetic energy stored in the rotational masses, and is proportional to $\Delta f$ to emulate primary frequency control of conventional generation units [71].

$$
P_{c m d}=P_{m t}\left(\Omega_{W T}\right)+\Delta P_{O P}(\Delta f) .
$$

Overproduction mode remains active until: either the rotational speed reaches a minimum allowed value $\Omega_{W T, \min }$ or the commanded power $P_{c m d}$ is lower than the maximum available active power $P_{M P P T}\left(\Omega_{M P P T}\right)$,

$$
\left.\begin{array}{ll}
\Omega_{W T} & <\Omega_{W T, \min } \\
P_{c m d} & <P_{M P P T}\left(\Omega_{M P P T}\right)
\end{array}\right\} \rightarrow \text { recovery. }
$$

iii. In the recovery mode, the power supplied by the VSWTs $\left(P_{c m d}\right)$ is based on two periods: following a parabolic trajectory until the middle of the rotational speed deviation $\left(\Omega_{V}\right.$ in Figure 6a) and through an estimated curve proportional to the difference between $P_{m t}\left(\Omega_{W T}\right)$ and $P_{M P P T}\left(\Omega_{W T}\right)$, being $x$ the proportionality constant.

$$
\begin{array}{ll}
P_{c m d}=a \cdot \Omega_{W T}^{2}+b \cdot \Omega_{W T}+c \cdot \Omega_{W T} & \Omega_{W T} \leq \Omega_{V} \\
P_{c m d}=P_{M P P T}+x \cdot\left(P_{m t}-P_{M P P T}\right) & \Omega_{W T}>\Omega_{V}
\end{array}
$$

The normal operation mode is recovered when either $\Omega_{M P P T}$ or $P_{M P P T}\left(\Omega_{M P P T}\right)$ are reached by the VSWTs.

$$
\left.\begin{array}{l}
\Omega_{W T} \approx \Omega_{M P P T} \\
P_{c m d} \approx P_{M P P T}\left(\Omega_{M P P T}\right)
\end{array}\right\} \rightarrow \text { normal operation. }
$$

\subsection{Scenarios}

Four different scenarios have been considered for simulations. The first scenario includes only conventional generation units: $88 \%$ comes from thermal power plants and $12 \%$ from hydro-power plants. Hydro-power capacity remains constant in all the scenarios (12\%). However, thermal and wind capacities change depending on the scenario to be simulated by giving a power system with high integration of RES, see Table 4. The equivalent inertia constant $H_{e q}$ determined by (3) is also indicated in Table 4 . The power imbalance considered is $\Delta P_{L}=0.05 \mathrm{pu}$ in all simulations.

\section{Results}

According to the different methodologies discussed in Section 3, the equivalent inertia constant $H_{e q}$ is estimated from the frequency deviations after a power imbalance. Two different approaches are considered and compared in this work:

i. Wind power plants without participation in frequency control.

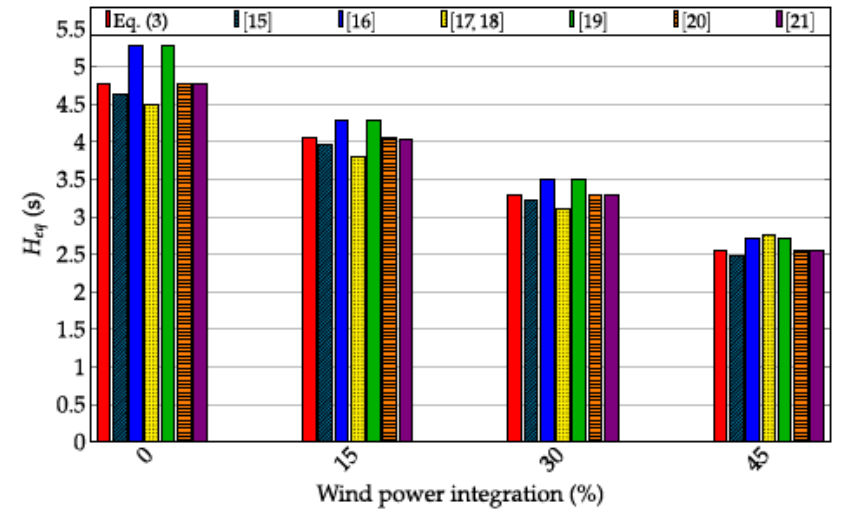

(a)

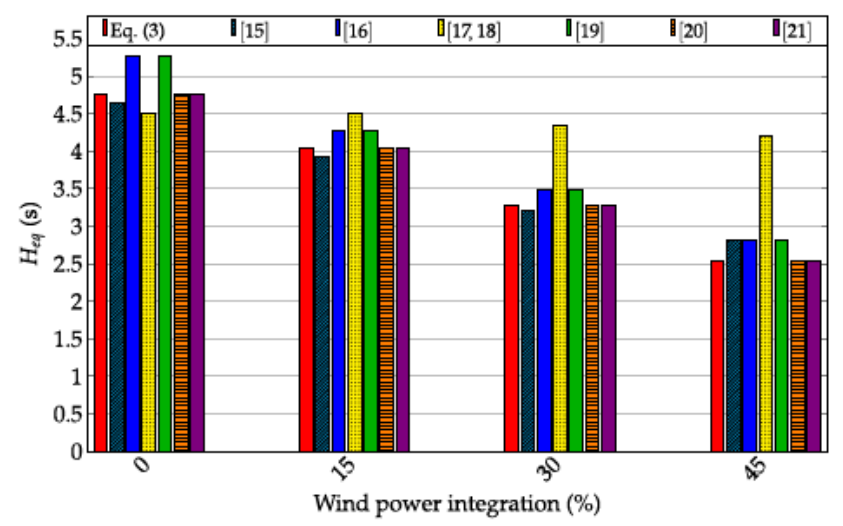

(b)

Fig. 7: Comparison of equivalent inertia depending on the participation of wind power plants into frequency control

(a) Estimated $H_{e q}$ when wind power plants do not participate in frequency control

(b) Estimated $H_{e q}$ when wind power plants participate in frequency control

ii. Wind power plants with participation in frequency control.

Figure 7a depicts the estimated $H_{e q}$ according to the different methodologies without considering wind power plant participation in frequency control. In this case, $H_{R, e q}=H_{e q}$. The different approaches of inertia estimation provide an accurate approximation of the directly connected rotational inertia calculated with eq. (3). The deviation from the estimated inertia value is lower that a $10 \%$ error.

In addition, Figure 7b summarizes the estimated $H_{e q}$ from the different methodologies when wind power plants participate in frequency control. In this case, it is expected that the estimated $H_{e q}$ values from $\Delta f$ include the virtual inertia $H_{V, e q}$ referred to eq. (7). However, as can be seen, most methodologies only provide the rotational inertia $H_{R, e q}$ directly connected to the grid [15, 16, 19-21], neglecting the 'virtual inertia' emulated and provided by the wind power plants. With these methodologies, the estimation of $H_{e q}$ is again accurate to the value calculated by eq. (3), having a deviation lower that a $10 \%$ error.

The frequency controller applied on the equivalent wind turbine doesn't include a derivative dependence control, see Section 4.2. As a consequence, the ROCOF is hardly modified in comparison to scenarios where wind power plants are excluded from the frequency control. At the beginning of the frequency oscillations, $\Delta f$ values don't change significantly - see Fig. 8-, regardless of the integration and participation of wind power plants into the frequency control. Table 5 summarizes these ROCOF values $(\mathrm{mHz} / \mathrm{s})$ depending on the participation of wind power plants into frequency control. 


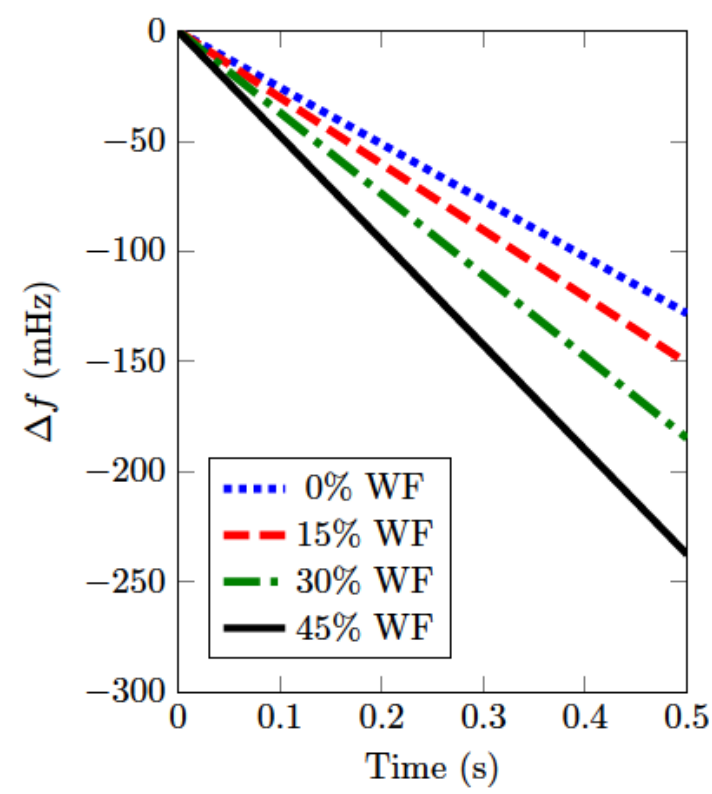

(a)

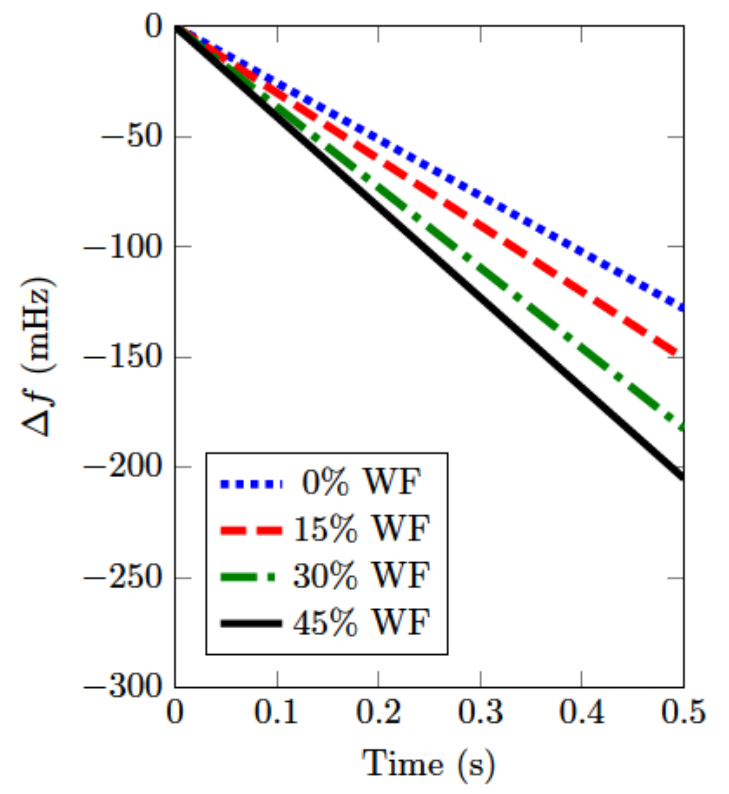

(b)

Fig. 8: Comparison of ROCOF depending on the participation of wind power plants into frequency control

(a) Wind power plants do not participate in frequency control

(b) Wind power plants participate in frequency control

Table 5 ROCOF values $(\mathrm{mHz} / \mathrm{s})$ depending on the participation of wind power plants into frequency control

\begin{tabular}{lllll}
\hline & \multicolumn{4}{c}{ Wind power integration } \\
& $0 \%$ & $15 \%$ & $30 \%$ & $45 \%$ \\
\hline Without control & -256.06 & -301.08 & -369.20 & -474.70 \\
With control & -256.06 & -298.45 & -364.90 & -410.10 \\
\hline
\end{tabular}

Methodologies $[15,16,19,21]$ estimate $H_{e q}$ based on the power imbalance $\Delta P$ and the ROCOF. $\Delta P$ is the same in all the scenarios $(\Delta P=0.05 \mathrm{pu})$, and the ROCOF values are similar regardless of the participation of wind power plants into frequency control as aforementioned. As a result, the estimated $H_{e q}$ barely changes despite of including wind power plants into frequency control. Tuttelberg et al. apply an impulse function to the dynamic response, estimating $H_{e q}$ by its value at $t=0$ [20]. Only [17, 18], by considering the total active power supplied and the ROCOF - referred to eq. (13)-, estimates the equivalent inertia as a combination of rotational $H_{R, e q}$ and virtual $H_{V, e q}$ inertias as were expressed in (7).

Figure 9 compares the equivalent inertia with and without frequency control from wind power plants in Scenario 4. This inertia is estimated according to $[17,18]$. Total power variation and ROCOF are also depicted for the sake of clarity. The disturbance time is $t_{\text {dist }}=50 \mathrm{~s}$. As indicated in $[17,18]$ (and previously mentioned in Section 3), Figure 9a is only the equivalent inertia around $t_{\text {dist }}$, as squared in the figure. Moreover, when wind power plants don't participate in frequency control, the equivalent inertia obtained is similar to the value calculated with eq. (3), as already mentioned in Figure 7a. However, a significant difference exists in the estimated equivalent inertia when wind power plants include frequency control. This increasing is due to the 'virtual inertia' provided by the wind frequency control. This virtual inertia thus depends on how relevant is the wind integration into the generation mix. Moreover, a linear relationship has been found between the wind power integration and the virtual inertia with $R^{2} \approx 1$. The linear relationship can be determined as

$$
H_{V, e q}=0.0357 \cdot W P I,
$$

being $W P I$ the wind power integration into the grid (in \%). Considering eq. (7), (32) and the base power $S_{B}=1350 \mathrm{MW}$, it is obtained that the virtual inertia constant coming from wind turbines is $H_{V, W T}=3.57 \mathrm{~s}$, in line with the typical rotational inertia constants of conventional plants (refer to Section 2.1) and the wind turbines inertia values proposed by some authors during the last decade $[25,31,95,96]$.

Finally, Figure 10 summarizes the simulated scenarios in terms of the estimated $H_{e q}$ from the different methodologies when frequency control is also provided by wind power plants. As can be seen, and depending on the methodology, these approaches address significant discrepancies on the equivalent inertia values. Actually, some of them include some virtual inertia from the wind turbine frequency control of [22], whereas the others consider their effects barely significant regarding to the equivalent system inertia. Therefore, both wind power plant frequency control strategies and equivalent inertia estimation methodologies must be revised in detail to give suitable results and avoid significant discrepancies among the different proposals in the new mix generation scenarios.

\section{Conclusion}

In this paper, an analysis and comparison of power system inertia estimation methodologies has been carried out. Different approaches proposed in the literature have been implemented and tested under four different supply-side scenarios including thermal, hydro-power and wind power plants from the supply-side, according to current mix generation road-maps. In this way, wind power plants are increasing their generation capacity from 15 to $45 \%$, reducing the thermal plants capacity accordingly. Furthermore, wind power plants include a virtual inertia frequency control strategy to support frequency excursions under imbalance conditions. The inertia estimation methodologies give an accurate value of the equivalent inertia when wind power plants do not participate in frequency control, with a deviation error lower than a $10 \%$ with respect to the global rotational generation units directly connected to grid. By including wind power plants into frequency control, most methodologies estimate the equivalent rotational inertia principally provided by conventional units, maintaining a deviation error lower than $10 \%$ in comparison with this value. One methodology estimates the equivalent inertia as a combination of rotational and virtual inertias. The virtual inertia constant estimated with this methodology has a value of $H_{V, W T}=3.57 \mathrm{~s}$, in line with the typical inertia constants of conventional plants. Therefore, wind power plant frequency control strategies and equivalent inertia estimation methodologies must be 


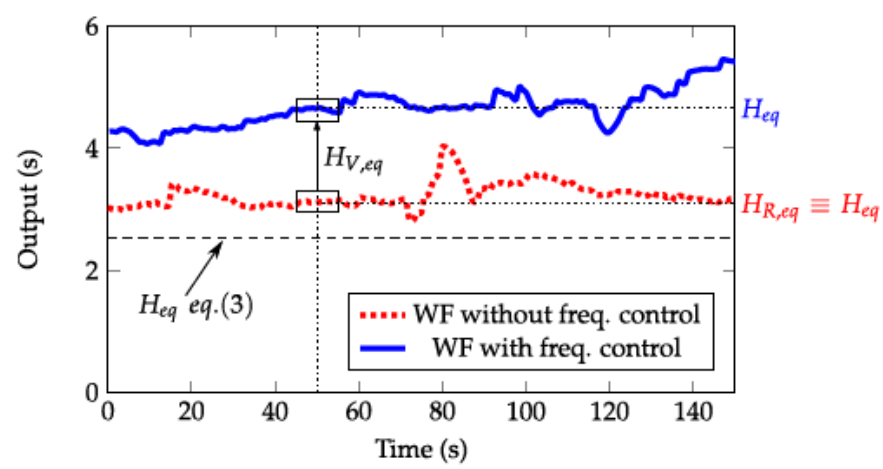

(a)

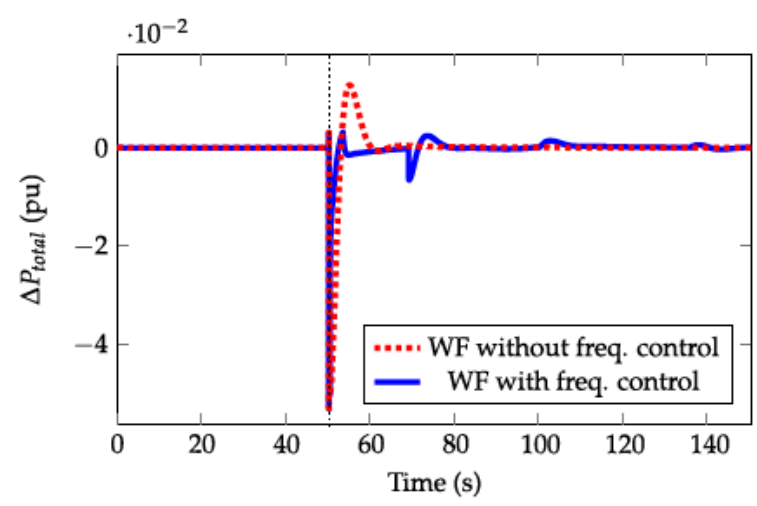

(b)

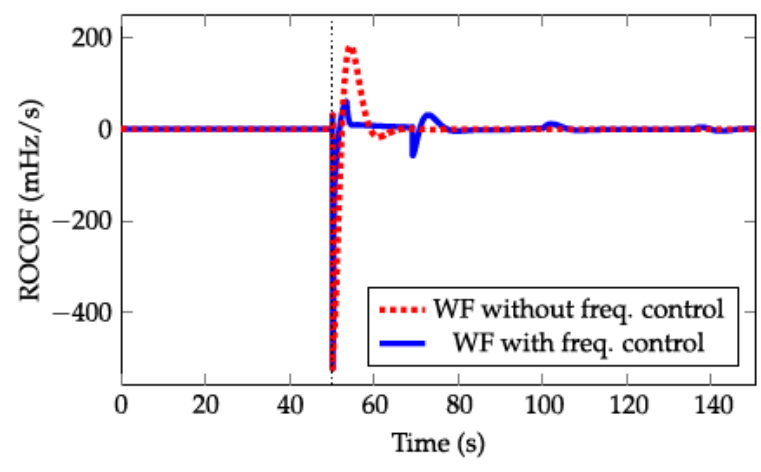

(c)

Fig. 9: Estimated equivalent inertia according to [17, 18], total power variation and ROCOF in scenario 4

(a) Estimated equivalent inertia (s)

(b) Total power variation (pu)

(c) $\operatorname{ROCOF}(\mathrm{mHz} / \mathrm{s})$

revised to provide consistent results and avoid significant discrepancies among the different alternatives. Moreover, the estimation of equivalent inertia values is highly dependent on the wind power plant frequency control strategies, and then, different results are determined when derivative frequency dependence is (or not) included in the frequency strategy. Alternative methodologies and processes should be thus proposed by the sector to provide suitable results regarding equivalent inertia estimations in power systems with high renewable penetration.

\section{Acknowledgments}

This work is supported by the Spanish Ministry of Education, Culture and Sport -FPU16/04282-.
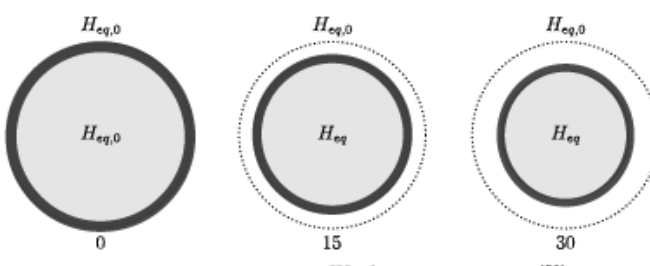

30

Wind power integration (\%)

(a)
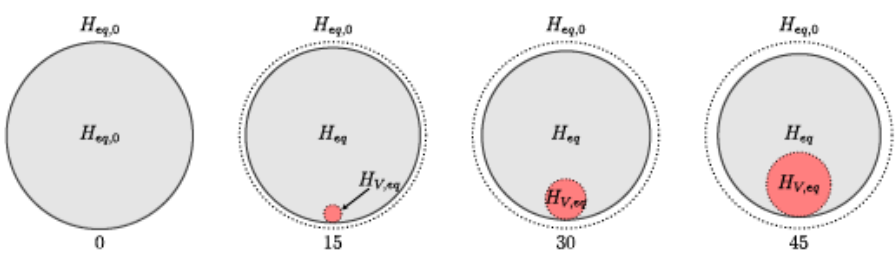

Wind power integration (\%)

(b)

Fig. 10: Comparison of inertia estimation including wind power plants into frequency control

$$
\begin{aligned}
& \text { (a) } H_{e q} \text { according to }[15,16,19-21] \\
& \text { (b) } H_{e q} \text { according to }[17,18]
\end{aligned}
$$

\section{Appendix}

\subsection{Parameters for thermal and hydro-power plants}

Table 6 and 7 summarize the thermal and hydro-power plant parameters used in the simulations.

Table 6 Thermal power plant parameters [26]

\begin{tabular}{llll}
\hline Parameter & Description & Value & Units \\
\hline$T_{G}$ & Speed relay pilot valve & 0.20 & - \\
$F_{H P}$ & Fraction of power of high pressure section & 0.30 & - \\
$T_{R H}$ & Time constant of reheater & 7.00 & $\mathrm{~s}$ \\
$T_{C H}$ & Time constant (inlet volumes and steam chest) & 0.30 & $\mathrm{~s}$ \\
$R_{T}$ & Speed droop & 0.05 & $\mathrm{pu}$ \\
$I(s)$ & Integral controller & 1.00 & - \\
$H_{\text {thermal }}$ & Inertia constant & 5.00 & $\mathrm{~s}$ \\
\hline
\end{tabular}

Table 7 Hydro-power plant parameters [26]

\begin{tabular}{llll}
\hline Parameter & Description & Value & Units \\
\hline$T_{G}$ & Speed relay pilot valve & 0.20 & $\mathrm{~s}$ \\
$T_{R}$ & Reset time & 5.00 & $\mathrm{~s}$ \\
$R_{T}$ & Temporary droop & 0.38 & - \\
$R_{P}$ & Permanent droop & 0.05 & - \\
$T_{W}$ & Water starting time & 1.00 & $\mathrm{~s}$ \\
$R_{H}$ & Speed droop & 0.05 & $\mathrm{pu}$ \\
$I(s)$ & Integral controller & 1.00 & - \\
$H_{\text {hydro }}$ & Inertia constant & 3.00 & $\mathrm{~s}$ \\
\hline
\end{tabular}

\subsection{Wind turbine model}

The wind turbine model is based on $[63,64]$. Parameters of the wind turbine model are summarized in Table 8.

\section{References}

1 Babahajiani, P., Shafiee, Q., Bevrani, H.: 'Intelligent demand response contribution in frequency control of multi-area power systems', IEEE Transactions on Smar Grid, 2018, 9, (2), pp. 1282-1291 
Table 8 Equivalent wind turbine parameters[63, 64]

\begin{tabular}{llll}
\hline Parameter & Description & Value & Units \\
\hline$v_{w}$ & Wind speed & 10.00 & $\mathrm{~m} / \mathrm{s}$ \\
$K_{p t}$ & Proportional constant of speed controller & 3.00 & - \\
$K_{i t}$ & Integral constant of speed controller & 0.60 & - \\
$V_{W T}$ & Voltage of the wind turbine & 1.00 & $\mathrm{pu}$ \\
$T_{c o n}$ & Time delay to generate the current $I_{i n j}$ & 0.02 & $\mathrm{~s}$ \\
$T_{f}$ & Time delay to measure the active power $P_{e}$ & 5.00 & $\mathrm{~s}$ \\
\hline
\end{tabular}

2 Cvetković, M., Pan, K., López, C.D., Bhandia, R., Palensky, P. 'Co-simulation aspects for energy systems with high penetration of distributed energy resources'. In: AEIT International Annual Conference, 2017. (IEEE, 2017. pp. 1-6

3 Wang, X., Palazoglu, A., El.Farra, N.H.: 'Operational optimization and demand response of hybrid renewable energy systems', Applied Energy, 2015, 143, pp. 324-335

4 Teng, F., Mu, Y., Jia, H., Wu, J., Zeng, P., Strbac, G.: 'Challenges on primary frequency control and potential solution from evs in the future gb electricity system', Applied energy, 2017, 194, pp. 353-362

5 Rodriguez, R.A., Becker, S., Andresen, G.B., Heide, D., Greiner, M.: 'Transmission needs across a fully renewable european power system', Renewable Energy, 2014, 63, pp. 467-476

6 Zhang, W., Fang, K.: 'Controlling active power of wind farms to participate in load frequency control of power systems', IET Generation, Transmission \& Distribution, 2017, 11, (9), pp. 2194-2203

7 Junyent.Ferr, A., Pipelzadeh, Y., Green, T.C.: 'Blending hvdc-link energy storage and offshore wind turbine inertia for fast frequency response', IEEE Transactions on sustainable energy, 2015, 6, (3), pp. 1059-1066

8 Akhtar, Z., Chaudhuri, B., Hui, S.Y.R.: 'Primary frequency control contribution from smart loads using reactive compensation', IEEE Transactions on Smart Grid, 2015, 6, (5), pp. 2356-2365

9 Yang, S., Fang, J., Tang, Y., Qiu, H., Dong, C., Wang, P. 'Synthetic-inertia-based modular multilevel converter frequency control for improved micro-grid frequency regulation'. In: 2018 IEEE Energy Conversion Congress and Exposition (ECCE). (IEEE, 2018. pp. 5177-5184

10 Dehghanpour, K., Afsharnia, S.: 'Electrical demand side contribution to frequency control in power systems: a review on technical aspects', Renewable and Sustainable Energy Reviews, 2015, 41, pp. 1267-1276

11 Kim, Y.S., Kim, E.S., Moon, S.I.: 'Frequency and voltage control strategy of standalone microgrids with high penetration of intermittent renewable generation systems', IEEE Transactions on Power systems, 2016, 31, (1), pp. 718-728

12 Nguyen, H.T., Yang, G., Nielsen, A.H., Jensen, P.H.: 'Combination of synchronous condenser and synthetic inertia for frequency stability enhancement in low inertia systems', IEEE Transactions on Sustainable Energy, 2018,

13 Groß, D., Bolognani, S., Poolla, B.K., Dörfler, F. 'Increasing the resilience of lowinertia power systems by virtual inertia and damping'. In: Bulk Power Systems Dynamics and Control Symposium (IREP). (, 2017.

14 Vokony, I. 'Effect of inertia deficit on power system stability-synthetic inertia concepts analysis'. In: Energy (IYCE), 2017 6th International Youth Conference on. (IEEE, 2017. pp. 1-6

15 Inoue, T., Taniguchi, H., Ikeguchi, Y., Yoshida, K.: 'Estimation of power system inertia constant and capacity of spinning-reserve support generators using measured frequency transients', IEEE Transactions on Power Systems, 1997, 12, (1), pp. 136-143

16 Chassin, D.P., Huang, Z., Donnelly, M.K., Hassler, C., Ramirez, E., Ray, C.: 'Estimation of wecc system inertia using observed frequency transients', IEEE Transactions on Power Systems, 2005, 20, (2), pp. 1190-1192

17 Wall, P., Gonzalez.Longatt, F., Terzija, V. 'Estimation of generator inertia available during a disturbance'. In: Power and Energy Society General Meeting, 2012 IEEE. (Citeseer, 2012. pp. 1-8

18 Wall, P., Terzija, V.: 'Simultaneous estimation of the time of disturbance and inertia in power systems', IEEE Trans Power Del, 2014, 29, (4), pp. 2018-2031

19 Zografos, D., Ghandhari, M. 'Power system inertia estimation by approaching load power change after a disturbance'. In: Power \& Energy Society General Meeting, 2017 IEEE. (IEEE, 2017. pp. 1-5

20 Tuttelberg, K., Kilter, J., Wilson, D.H., Uhlen, K.: 'Estimation of power system inertia from ambient wide area measurements', IEEE Transactions on Power Systems, 2018,

21 Zografos, D., Ghandhari, M., Eriksson, R.: 'Power system inertia estimation: Utilization of frequency and voltage response after a disturbance', Electric Power Systems Research, 2018, 161, pp. 52-60

22 Fernández.Guillamón, A., Villena.Lapaz, J., Vigueras.Rodríguez, A., García.Sánchez, T., Molina.García, Á.: 'An adaptive frequency strategy for variable speed wind turbines: Application to high wind integration into power systems', Energies, 2018, 11, (6), pp. 1-21

23 Ulbig, A., Borsche, T.S., Andersson, G.: 'Impact of low rotational inertia on power system stability and operation', IFAC Proceedings Volumes, 2014, 47, (3), pp. 7290-7297

24 Uriarte, F.M., Smith, C., VanBroekhoven, S., Hebner, R.E.: 'Microgrid ramp rates and the inertial stability margin', IEEE Transactions on Power Systems, 2015, 30, (6), pp. 3209-3216

25 Tielens, P., Van.Hertem, D.: 'The relevance of inertia in power systems', Renewable and Sustainable Energy Reviews, 2016, 55, pp. 999-1009

26 Kundur, P., Balu, N.J., Lauby, M.G.: 'Power system stability and control'. vol. 7. (McGraw-hill New York, 1994)
27 De.Almeida, R.G., Lopes, J.P.: 'Participation of doubly fed induction wind generators in system frequency regulation', IEEE transactions on power systems, 2007, 22, (3), pp. 944-950

28 Anderson, P.M., Fouad, A.A.: 'Power system control and stability'. (John Wiley \& Sons, 2008)

29 Dabur, P., Yadav, N.K., Tayal, V.K.: 'Matlab design and simulation of AGC and AVR for multi area power system and demand side management', International Journal of Computer and Electrical Engineering, 2011, 3, (2), pp. 259

30 Kumal, S., et al.: 'Agc and avr of interconnected thermal power system while considering the effect of grcâĂŹs', International Journal of Soft Computing and Engineering (IJSCE), 2012, 2

31 Tielens, P., Van.Hertem, D. 'Grid inertia and frequency control in power systems with high penetration of renewables'. (, 2012.

32 Grainger, J.J., Stevenson, W.D.: 'Power system analysis'. (McGraw-Hill, 1994)

33 Shahidehpour, M., Eremia, M., Toma, L.: 'Modeling the main components of the classical power plants', Handbook of Electrical Power System Dynamics. Modeling, Stability, and Control, 2013, pp. 137-178

34 Spahic, E., Varma, D., Beck, G., Kuhn, G., Hild, V. 'Impact of reduced system inertia on stable power system operation and an overview of possible solutions'. In: Power and Energy Society General Meeting (PESGM), 2016. (IEEE, 2016. pp. $1-5$

35 Raisz, D., Musa, A., Ponci, F., Monti, A. 'Linear and uniform system dynamics of future converter-based power systems'. In: 2018 IEEE Power \& Energy Society General Meeting (PESGM). (IEEE, 2018. pp. 1-5

36 Tofis, Y., Timotheou, S., Kyriakides, E.: 'Minimal load shedding using the swing equation', IEEE Transactions on Power Systems, 2017, 32, (3), pp. 2466-2467

37 Suh, J., Yoon, D.H., Cho, Y.S., Jang, G.: 'Flexible frequency operation strategy of power system with high renewable penetration', IEEE Transactions on Sustainable Energy, 2017, 8, (1), pp. 192-199

38 Yazdi, S.S.H., Milimonfared, J., Fathi, S.H., Rouzbehi, K., Rakhshani, E.: 'Analytical modeling and inertia estimation of vsg-controlled type 4 wtgs: Power system frequency response investigation', International Journal of Electrical Power \& Energy Systems, 2019, 107, pp. 446-461

$39 \mathrm{Li}, \mathrm{W} ., \mathrm{Du}, \mathrm{P} ., \mathrm{Lu}, \mathrm{N} .:$ 'Design of a new primary frequency control market for hosting frequency response reserve offers from both generators and loads', IEEE Transactions on Smart Grid, 2017.

40 Ochoa, D., Martinez, S.: 'Fast-frequency response provided by dfig-wind turbines and its impact on the grid', IEEE Transactions on Power Systems, 2017, 32, (5), pp. 4002-4011

41 Shah, R., Mithulananthan, N., Bansal, R.C., Ramachandaramurthy, V.K.: 'A review of key power system stability challenges for large-scale pv integration', Renewable and Sustainable Energy Reviews, 2015, 41, (Supplement C), pp. 1423 - 1436

42 Muyeen, S., Takahashi, R., Murata, T., Tamura, J.: 'A variable speed wind turbine control strategy to meet wind farm grid code requirements', IEEE Transactions on power systems, 2010, 25, (1), pp. 331-340

43 Mohamed, T.H., Morel, J., Bevrani, H., Hiyama, T.: 'Model predictive based load frequency control_design concerning wind turbines', International Journal of Electrical Power \& Energy Systems, 2012, 43, (1), pp. 859-867

44 Zhao, J., Lyu, X., Fu, Y., Hu, X., Li, F.: 'Coordinated microgrid frequency regulation based on dfig variable coefficient using virtual inertia and primary frequency control', IEEE Transactions on Energy Conversion, 2016, 31, (3), pp. 833-845

45 Hosseinipour, A., Hojabri, H.: 'Virtual inertia control of pv systems for dynamic performance and damping enhancement of dc microgrids with constant power loads', IET Renewable Power Generation, 2017, 12, (4), pp. 430-438

46 Tielens, P. 'Operation and control of power systems with low synchronous inertia'. KU Leuven, 2017

47 Du, P., Matevosyan, J.: 'Forecast system inertia condition and its impact to integrate more renewables', IEEE Transactions on Smart Grid, 2018, 9, (2), pp. $1531-1533$

48 Yingcheng, X., Nengling, T.: 'Review of contribution to frequency control through variable speed wind turbine', Renewable energy, 2011, 36, (6), pp. 1671-1677

49 Ulbig, A., Borsche, T.S., Andersson, G.: 'Analyzing rotational inertia, grid topology and their role for power system stability', IFAC-PapersOnLine, 2015, 48, (30), pp. $541-547$

50 Nedd, M., Booth, C., Bell, K. 'Potential solutions to the challenges of low inertia power systems with a case study concerning synchronous condensers'. In: Universities Power Engineering Conference (UPEC), 2017 52nd International. (IEEE 2017. pp. 1-6

51 You, R., Barahona, B., Chai, J., Cutululis, N.A., Wu, X.: 'Improvement of grid frequency dynamic characteristic with novel wind turbine based on electromagnetic coupler', Renewable Energy, 2017, 113, pp. 813-821

52 Aho, J., Buckspan, A., Laks, J., Fleming, P., Jeong, Y., Dunne, F., et al. 'A tutorial of wind turbine control for supporting grid frequency through active power control'. In: 2012 American Control Conference (ACC). (, 2012. pp. 3120-3131

53 Kayikçi, M., Milanovic, J.V.: 'Dynamic contribution of dfig-based wind plants to system frequency disturbances', IEEE Transactions on Power Systems, 2009, 24 (2), pp. 859-867

54 Toulabi, M., Bahrami, S., Ranjbar, A M.: 'An input-to-state stability approach to inertial frequency response analysis of doubly-fed induction generator-based wind turbines', IEEE Transactions on Energy Conversion, 2017, 32, (4), pp. 1418-1431

55 Tamrakar, U., Shrestha, D., Maharjan, M., Bhattarai, B., Hansen, T., Tonkoski, R. 'Virtual inertia: Current trends and future directions', Applied Sciences, 2017, 7 , (7), pp. 654

56 Sun, Y.z., Zhang, Z.s., Li, G.j., Lin, J. 'Review on frequency control of power systems with wind power penetration'. In: Power System Technology (POWERCON), 2010 International Conference on. (IEEE, 2010. pp. 1-8

57 Attya, A., Dominguez.Garcia, J., Anaya.Lara, O.: 'A review on frequency support provision by wind power plants: Current and future challenges', Renewable and Sustainable Energy Reviews, 2018, 81, pp. 2071-2087 
58 Wang, D., Gao, X., Meng, K., Qiu, J., Lai, L.L., Gao, S.: 'Utilisation of kinetic energy from wind turbine for grid connections: a review paper', IET Renewable Power Generation, 2018, 12, (6), pp. 615-624

59 Ziping, W., Wenzhong, G., Tianqi, G., Weihang, Y., Zhang, H., Shijie, Y., et al.: 'State-of-the-art review on frequency response of wind power plants in power systems', Journal of Modern Power Systems and Clean Energy, 2018, 6, (1), pp. $1-16$

60 Morren, J. 'Grid support by power electronic converters of distributed generation units'. TU Delft, 2006

61 Tielens, P., Van.Hertem, D.: 'Receding horizon control of wind power to provide frequency regulation', IEEE Transactions on Power Systems, 2017, 32, (4), pp. 2663-2672

62 Muñoz Benavente, I., Hansen, A.D., Gómez.Lázaro, E., García.Sánchez, T., Fernández.Guillamán, A., Molina.García, A.: 'Impact of combined demand-response and wind power plant participation in frequency control for multi-area power systems', Energies, 2019, 12, (9)

63 Miller, N.W., Sanchez Gasca, J.J., Price, W.W., Delmerico, R.W. 'Dynamic modeling of ge 1.5 and $3.6 \mathrm{mw}$ wind turbine-generators for stability simulations'. In: Power Engineering Society General Meeting, 2003, IEEE. vol. 3. (IEEE, 2003. pp. 1977-1983

64 Ullah, N.R., Thiringer, T., Karlsson, D.: 'Temporary primary frequency control support by variable speed wind turbines - potential and applications', IEEE Transactions on Power Systems, 2008, 23, (2), pp. 601-612

65 Clark, K., Miller, N.W., Sanchez.Gasca, J.J.: 'Modeling of ge wind turbinegenerators for grid studies', GE Energy, 2010, 4, pp. 0885-8950

66 Díaz.González, F., Hau, M., Sumper, A., Gomis.Bellmunt, O.: 'Participation of wind power plants in system frequency control: Review of grid code requirements and control methods', Renewable and Sustainable Energy Reviews, 2014, 34, pp. 551-564

67 Alomoush, M.I.: 'Load frequency control and automatic generation control using fractional-order controllers', Electrical Engineering, 2010, 91, (7), pp. 357-368

68 Dai, J., Phulpin, Y., Sarlette, A., Ernst, D.: 'Coordinated primary frequency control among non-synchronous systems connected by a multi-terminal high-voltage direct current grid', IET generation, transmission \& distribution, 2012, 6, (2), pp. $99-108$

69 Simpson. Porco, J.W., Shafiee, Q., Dörfler, F., Vasquez, J.C., Guerrero, J.M., Bullo, F.: 'Secondary frequency and voltage control of islanded microgrids via distributed averaging.', IEEE Trans Industrial Electronics, 2015, 62, (11), pp. 7025-7038

70 Dreidy, M., Mokhlis, H., Mekhilef, S.: 'Inertia response and frequency control techniques for renewable energy sources: A review', Renewable and Sustainable Energy Reviews, 2017, 69, pp. 144-155

71 Margaris, I.D., Papathanassiou, S.A., Hatziargyriou, N.D., Hansen, A.D., Sorensen, P.: 'Frequency control in autonomous power systems with high wind power penetration', IEEE Transactions on Sustainable Energy, 2012, 3, (2), pp. 189-199

72 Zhang, Z.S., Sun, Y.Z., Lin, J., Li, G.J.: 'Coordinated frequency regulation by doubly fed induction generator-based wind power plants', IET Renewable Power Generation, 2012, 6, (1), pp. 38-47

73 Ye, H., Pei, W., Qi, Z.: 'Analytical modeling of inertial and droop responses from a wind farm for short-term frequency regulation in power systems', IEEE Transactions on Power Systems, 2015, 31, (5), pp. 3414-3423

74 Abo.Al.Ez, K M., Tzoneva, R. 'Active power control (apc) of pmsg wind farm using emulated inertia and droop control'. In: 2016 International Conference on the Industrial and Commercial Use of Energy (ICUE). (IEEE, 2016. pp. 140-147

75 Hwang, M., Muljadi, E., Park, J.W., Sørensen, P., Kang, Y.C. 'Dynamic droopbased inertial control of a doubly-fed induction generator', IEEE Transactions on Sustainable Energy, 2016, 7, (3), pp. 924-933

76 Van de Vyver, J., De.Kooning, J.D., Meersman, B., Vandevelde, L., Vandoorn, T.L.: 'Droop control as an alternative inertial response strategy for the synthetic inertia on wind turbines', IEEE Trans Power Syst, 2016, 31, (2), pp. 1129-1138

77 Liu, T., Pan, W., Quan, R., Liu, M.: 'A variable droop frequency control strategy for wind farms that considers optimal rotor kinetic energy', IEEE Access, 2019,

78 Tarnowski, G.C., Kjar, P.C., Sorensen, P.E., Ostergaard, J. 'Variable speed wind turbines capability for temporary over-production'. In: Power \& Energy Society General Meeting, 2009. PES'09. IEEE. (IEEE, 2009. pp. 1-7

79 Keung, P., Li, P., Banakar, H., Ooi, B.T.: 'Kinetic energy of wind-turbine generators for system frequency support', IEEE Transactions on Power Systems, 2009, 24, (1), pp. 279-287

80 Chang Chien, L.R., Lin, W.T., Yin, Y.C. 'Enhancing frequency response control by dfigs in the high wind penetrated power systems', IEEE transactions on power systems, 2011, 26, (2), pp. 710-718

81 Itani, S.E., Annakkage, U.D., Joos, G. 'Short-term frequency support utilizing inertial response of dfig wind turbines'. In: 2011 IEEE Power and Energy Society General Meeting. (, 2011. pp. 1-8

82 Hansen, A.D., Altin, M., Margaris, I.D., Iov, F., Tarnowski, G.C.: 'Analysis of the short-term overproduction capability of variable speed wind turbines', Renewable Energy, 2014, 68, pp. $326-336$

83 Kang, M., Lee, J., Hur, K., Park, S.H., Choy, Y., Kang, Y.C.: 'Stepwise inertial control of a doubly-fed induction generator to prevent a second frequency dip', Journal of Electrical Engineering \& Technology, 2015, 10, (6), pp. 2221-2227

84 Hafiz, F., Abdennour, A.: 'Optimal use of kinetic energy for the inertial support from variable speed wind turbines', Renewable Energy, 2015, 80, pp. 629-643

85 Kang, M., Kim, K., Muljadi, E., Park, J., Kang, Y.C.: 'Frequency control support of a doubly-fed induction generator based on the torque limit', IEEE Transactions on Power Systems, 2016, 31, (6), pp. 4575-4583

$86 \mathrm{Su}, \mathrm{C}$., Chen, Z. 'Influence of wind plant ancillary frequency control on system small signal stability'. In: Power and Energy Society General Meeting, 2012 IEEE. (IEEE, 2012. pp. 1-8
87 Zhang, Z., Wang, Y., Li, H., Su, X. 'Comparison of inertia control methods for dfig-based wind turbines'. In: ECCE Asia Downunder (ECCE Asia), 2013 IEEE. (IEEE, 2013. pp. 960-964

88 You, R., Barahona, B., Chai, J., Cutululis, N.A.: 'Frequency support capability of variable speed wind turbine based on electromagnetic coupler', Renewable Energy, 2015, 74, pp. 681-688

89 Bonfiglio, A., Gonzalez.Longatt, F., Procopio, R.: 'Integrated inertial and droop frequency controller for variable speed wind generators', WSEAS Transactions on Environment and Development, 2016, 12, (18), pp. 167-177

90 Persson, M., Chen, P.: 'Frequency control by variable speed wind turbines in islanded power systems with various generation mix', IET Renewable Power Generation, 2016, 11, (8), pp. 1101-1109

91 Ye, H., Liu, Y., Pei, W., Kong, L. 'Efficient droop-based primary frequency control from variable-speed wind turbines and energy storage systems'. In: 2017 IEEE Transportation Electrification Conference and Expo, Asia-Pacific (ITEC Asia-Pacific). (IEEE, 2017. pp. 1-5

92 Jahan, E., Hazari, M.R., Muyeen, S., Umemura, A., Takahashi, R., Tamura, J. 'Primary frequency regulation of the hybrid power system by deloaded pmsgbased offshore wind farm using centralised droop controller', The Journal of Engineering, 2019

93 Wilches.Bernal, F., Chow, J.H., Sanchez.Gasca, J.J.: 'A fundamental study of applying wind turbines for power system frequency control', IEEE Transactions on Power Systems, 2016, 31, (2), pp. 1496-1505

94 Fernández.Guillamón, A., Vigueras.Rodríguez, A., Gómez.Lázaro, E. Molina.García, Á.: 'Fast power reserve emulation strategy for vswt supporting frequency control in multi-area power systems', Energies, 2018, 11, (10), pp. 2775

95 Yang, L., Xu, Z., Ostergaard, J., Dong, Z.Y., Wong, K.P.: 'Advanced control strat egy of dfig wind turbines for power system fault ride through', IEEE Transactions on power systems, 2012, 27, (2), pp. 713-722

96 Arani, M.F.M., El.Saadany, E.F.: 'Implementing virtual inertia in dfig-based win power generation', IEEE Transactions on Power Systems, 2013, 28, (2), pp. 1373 1384 


\subsection{An adaptive control scheme for variable speed wind turbines providing frequency regulation in isolated power systems with thermal generation}

The contribution of VSWTs to frequency regulation involves several drawbacks related to their efficiency and equipment wear due to electrical power requirements, rotational speed changes, and subsequently, shaft torque oscillations. As a result, wind energy producers are not usually willing to offer such frequency regulation. This paper proposed a new control technique to optimise the frequency response of wind power plants after a power imbalance situation. The proposed frequency controller depends on different parameters of the grid (RoCoF, synchronous inertia, and assigned power of thermal units before the incident) through a linear regression. Based on such regression, the contribution of VSWTs is determined for each imbalanced condition. Consequently, VSWTs frequency contribution is estimated to minimise their mechanical and electrical efforts, thus reducing their equipment wear. The proposed adaptive controller is compared to a conventional fast power reserve strategy. Results show that the new adaptive control reduces significantly the VSWTs maximum torque variations (23\%), and slightly the speed variations $(5 \%)$ in comparison to previous frequency control strategies, while maintaining similar values for the power shed with the load shedding program. Moreover, transitions between overproduction and recovery periods are considerably smoother, and thus, electrical and mechanical VSWT efforts are reduced. In addition, VSWTs are not required to react to frequency deviations in $56 \%$ of the imbalance scenarios under consideration, maintaining the frequency excursions within acceptable ranges. As a result, a longer life span is expected for the VSWTs electrical and mechanical components.

Information of the paper:

- Journal: Energies

- DOI: $10.3390 /$ en13133369

- Date of publication: July 2020

- Available online: https://www.mdpi.com/1996-1073/13/13/3369

- Reference: [6] 



\title{
An Adaptive Control Scheme for Variable Speed Wind Turbines Providing Frequency Regulation in Isolated Power Systems with Thermal Generation
}

\author{
Ana Fernández-Guillamón 1,+ ${ }^{D}$, Guillermo Martínez-Lucas ${ }^{2, *,+}$ (D) and Ángel Molina-García 1,+ \\ and Jose Ignacio Sarasua $2,+$ (b) \\ 1 Department of Automatics, Electrical Engineering and Electronic Technology, Universidad Politécnica \\ de Cartagena, 30202 Cartagena, Spain; ana.fernandez@upct.es (A.F.-G.); angel.molina@upct.es (Á.M.-G.) \\ 2 Department of Hydraulic, Energy and Environmental Engineering, Universidad Politécnica de Madrid, \\ 28040 Madrid, Spain; joseignacio.sarasua@upm.es \\ * Correspondence: guillermo.martinez@upm.es; Tel.: +34-91-067-43-33 \\ + These authors contributed equally to this work.
}

Received: 27 May 2020; Accepted: 28 June 2020; Published: 1 July 2020

\begin{abstract}
The lack of synchronous inertia, associated with the relevant penetration of variable speed wind turbines (VSWTs) into isolated power systems, has increased their vulnerability to strong frequency deviations. In fact, the activation of load shedding schemes is a common practice when an incident occurs, i.e., the outage of a conventional unit. Under this framework, wind power plants should actively contribute to frequency stability and grid reliability. However, the contribution of VSWTs to frequency regulation involves several drawbacks related to their efficiency and equipment wear due to electrical power requirements, rotational speed changes, and subsequently, shaft torque oscillations. As a result, wind energy producers are not usually willing to offer such frequency regulation. In this paper, a new control technique is proposed to optimize the frequency response of wind power plants after a power imbalanced situation. The proposed frequency controller depends on different power system parameters through a linear regression to determine the contribution of wind power plants for each imbalance condition. As a consequence, VSWTs frequency contribution is estimated to minimize their mechanical and electrical efforts, thus reducing their equipment wear. A group of sixty supply-side and imbalance scenarios are simulated and analyzed. Results of the case study are compared to previous proposals. The proposed adaptive control reduces the maximum torque and rotational speed variations while at the same time maintaining similar values of the load shedding program. Extensive results and discussion are included in the paper.
\end{abstract}

Keywords: frequency control; isolated system; linear regression; power system stability; wind turbines

\section{Introduction}

The different services carried out by the transmission system operators (TSO) for a reliable and secure power system are known as ancillary services [1]. Among them, load-frequency control focuses on mitigating the effects of unpredictable changes both in the demand and in the generation units that can address frequency deviations [2]. In fact, power imbalances between generation and consumption cause frequency variations [3]. In Europe, frequency control has a hierarchical structure, usually organized in up to five layers (from fast to slow timescales): (i) frequency containment (also known as primary frequency control); (ii) imbalance netting; (iii) automatic and/or manual frequency restoration (also known as secondary frequency control), and (iv) replacement [4]. If the different reserves of such frequency control layers are consumed or unable to keep frequency within an acceptable range, a variety of strategies called special protection systems are then used. Load shedding 
is included in those special protection systems. Moreover, it is considered as the last option to prevent frequency instability [5]. Despite load shedding being an effective solution to prevent a power system collapse after a major imbalance, it is considered as an undesirable situation and it is important to reduce it as much as possible [6-8].

Traditionally, power systems have been based on conventional power plants with synchronous generators directly connected to the grid, automatically providing their stored kinetic energy after a generation-load mismatch [9]. However, in recent decades, power systems have been suffering a slow change from conventional synchronous power plants to inverter-interfaced renewable energy sources (II-RES), i.e., wind power plants based on variable speed wind turbines (VSWTs) and/or solar photovoltaic (PV) [10]. Among them, VSWTs are considered as the most efficient, developed, and installed renewable resource, and currently they account for more than $650 \mathrm{GW}$ of installed capacity around the world [11,12]. This remarkable integration of wind power plants requires an important reformulation of their contribution to ancillary services [13]. Moreover, as they are connected to the grid through power inverters, the synchronous inertia of the power system decreases when such renewable source replaces conventional power plants [14]. Indeed, faster rate of change of frequency $(\mathrm{RoCoF})$ and larger frequency deviations are related to low synchronous system inertia values [15]. These effects are even more critical in isolated power systems [16,17]. As a result, Toulabi et al. consider that, due to the massive integration of VSWTs, their participation into frequency control is necessary [18]. With this aim, different frequency control approaches can be found in the specific literature to effectively replace conventional power plants by VSWTs and maintain a reliable power system operation [19]. These strategies are summarized in Figure 1 according to the different approaches [20,21].

$$
\text { VSWTs frequency control strategies }\left\{\begin{array}{l}
\text { De-loading }\left\{\begin{array}{l}
\text { Over-speed } \\
\text { Pitch angle }
\end{array}\right. \\
\text { Inertia response }\left\{\begin{array}{l}
\text { Droop } \\
\text { Hidden inertia emulation } \\
\text { Fast power reserve }
\end{array}\right.
\end{array}\right.
$$

Figure 1. General classification for Variable Speed Wind Turbines (VSWTs) frequency control techniques.

VSWTs are designed to work in their maximum power point (MPP) according to the available wind speed $s_{w}: p_{M P P}\left(s_{w}\right)$ [22]. As a consequence, the first approach (deloading technique) consists of operating the VSWTs in a suboptimal power point $p_{d e l}$, below $p_{M P P}\left(s_{w}\right)$. Therefore, a certain amount of power $\Delta p_{d}$ can be supplied in case of a power imbalance [23,24]. Two different possibilities are identified [25]: (i) the pitch-angle control and (ii) over-speed control. In the first one, the pitch angle is increased from $\beta_{0}$ to $\beta_{1}$ for a constant $s_{w}$. Subsequently, the generated power $p_{d e l}$ is below the maximum power $p_{M P P}$ [26-29]. When the additional power $\Delta p_{d}$ is supplied, the pitch angle reduces to $\beta_{0}$. The over-speed control increases the rotational speed of the rotor, shifting the supplied power $p_{\text {del }}$ towards the right of the maximum power $p_{M P P}$ [30-32]. When the additional power $\Delta p_{d}$ is supplied, the rotor speed has to be reduced to $\omega_{M P P}$, releasing kinetic energy [33]. However, despite the fact that this technique can improve the long term frequency regulation, it is not an economically viable solution for wind power plants' operators due to loss of profits [34].

Due to the power inverter, VSWTs cannot naturally provide the kinetic energy stored in their rotor and generator. To overcome this, one or more additional control loops must be included in the power inverter. Three different possibilities can be found in the specific literature: (i) the droop control, (ii) the hidden inertia emulation control, and (iii) the fast power reserve approach. The droop control provides an additional active power $\Delta p$ proportional to the frequency deviation $\Delta f$, following $\Delta p=-\frac{\Delta f}{R_{W T}}$, where $R_{W T}$ is the droop control setting of the VSWT [35-39]. This definition of $\Delta p$ gives an adaptive response depending on the frequency excursion severity and thus emulating primary 
frequency control of conventional generation units [40]. The hidden inertia emulation control usually includes two different loops: one considering the RoCoF and the other considering the frequency excursion $(\Delta p \propto \operatorname{RoCoF} \& \Delta f)$ [41-43]. However, there are also proposals to use only one additional loop, being $\Delta p \propto \operatorname{RoCoF}$ [44-46]. Even though these methods improved the nadir frequency (minimum value), a little frequency dip was observed in later stages. This was due to a small reduction in the generated power compared to the prefault active power (thus, not operating in the MPP) [47]. The fast power reserve approach defines the overproduction power $\Delta p$ as a constant value independent of the power system configuration and frequency deviation [48-51] or as a variable value depending on the frequency deviation or minimum rotor speed limits [52-54]. With these three techniques, as the additional power $\Delta p$ is provided, the rotor and generator rotational speeds decrease (subsequently, modifying their torques). Rotor speed variations cause large amplitude edgewise vibrations for the blades [55], affecting the productivity and reducing the efficiency [56]. Large torque increases can address severe mechanical loads on the turbine, even causing critical situations under high mechanical stress conditions [57]. Moreover, consecutive torque increments is related to random load cycles, with important influences on fatigue loads [58].

In this work, a new fast power reserve controller for frequency regulation is proposed for isolated power systems including conventional generation (thermal units) and wind power plants (VSWTs). The proposed adaptive frequency controller is based on a linear regression from different power system parameters (i.e., RoCoF, active power supplied by each synchronous group, and synchronous inertia) to estimate the additional power provided by the wind power plants by maintaining certain frequency thresholds. This way mechanical stress is reduced without excessively prejudicing power system. Subsequently, VSWTs do not always participate in the frequency control but only when they are required according to both the monitored variables. VSWTs frequency control contributions are thus optimized, improving the grid frequency response and providing similar or lower load shedding actions in line with previous frequency control strategies. This proposed VSWT controller approach is tested in the Gran Canaria Island (Canarian archipelago, Spain), an isolated power system where the wind power capacity has doubled since 2017 (from 90 to 180 MW) [59]. Moreover, from 2005 to 2010, more than 200 trips of generators were registered per year in the Canarian archipelago, hence activating the corresponding load shedding programs [60].

The rest of the paper is organized as follows: Section 2 describes the mathematical model used to simulate the power system under consideration; the new frequency control approach proposed in this work is explained in Section 3; cases of study and simulation results are provided in Section 4; Finally, Section 5 gives the conclusions.

\section{Power System Modeling}

A mathematical model has been designed to analyze the proposed VSWT adaptive frequency control in an isolated power system. A generic wind-thermal isolated system is considered in this study (refer to Figure 2), including steam, diesel, gas, and combined cycle units, as well as wind power plants. Consequently, the model developed in Matlab/Simulink (2016) includes these thermal units, one equivalent VSWT acting as the wind power plants, the automatic generation control (AGC), the power system, and the power demand (including a load shedding scheme). The electromagnetic transients are supposed to be much faster than the other components of the model, and their influence in the system's dynamics is omitted [61]. In Figure 3, the block diagram of the power system under study can be seen. 


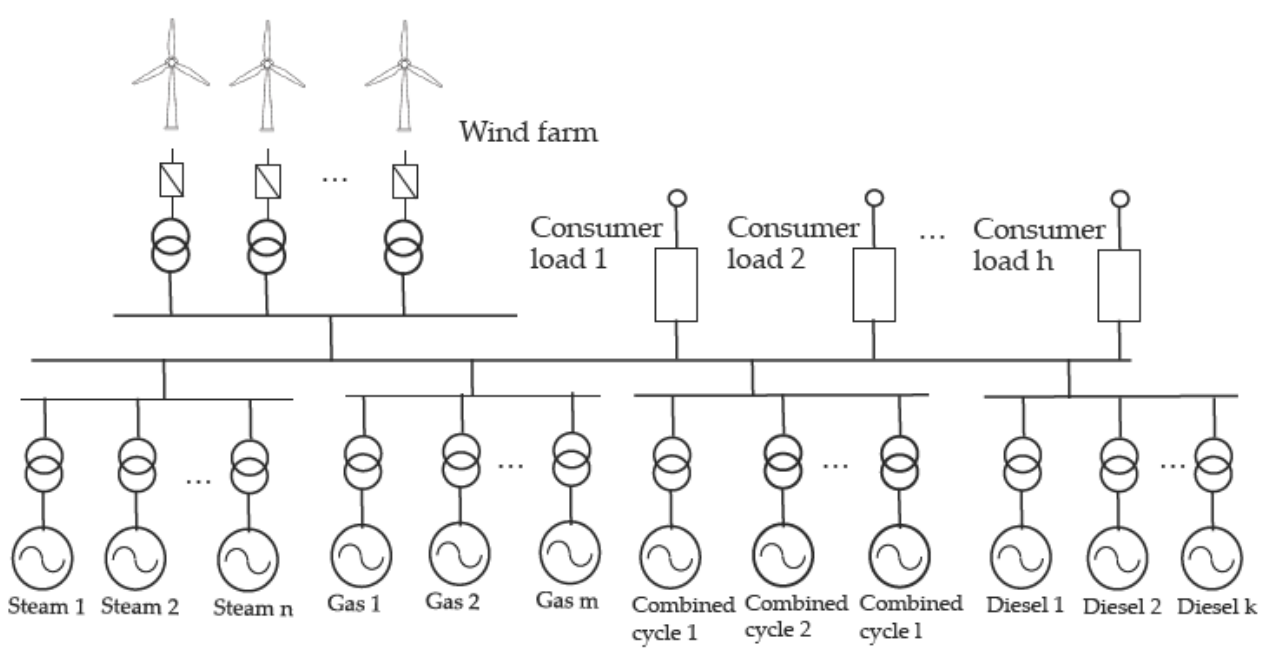

Figure 2. Simplified one-line diagram of the generic isolated power system.

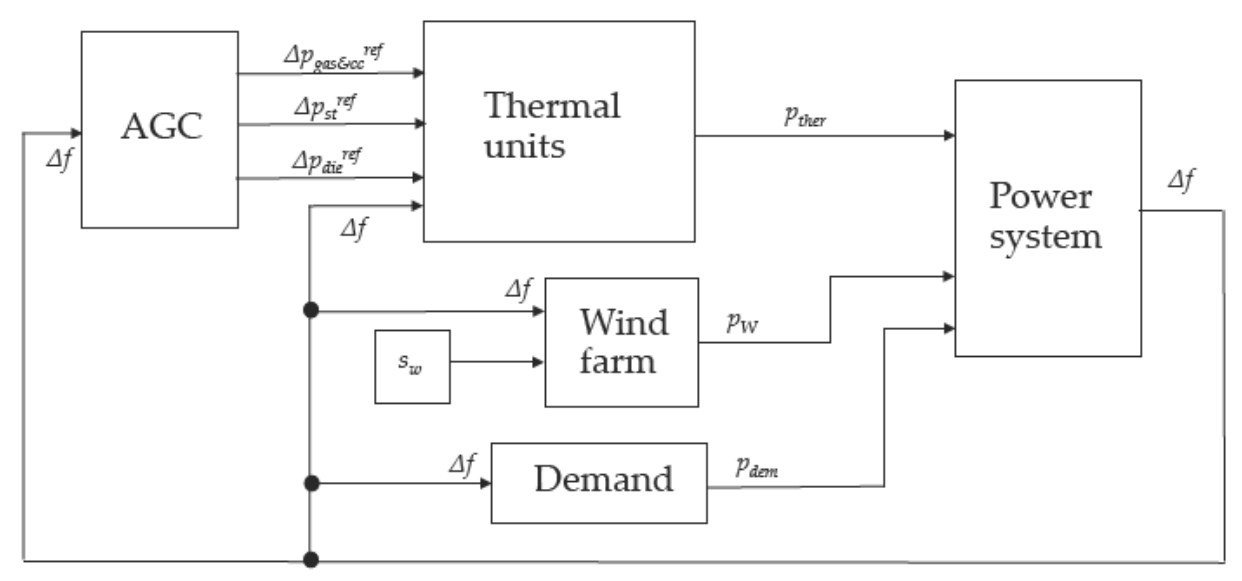

Figure 3. Block diagram of the frequency analysis model.

\subsection{Power System}

Frequency regulation based on droop speed control can be divided into two consecutive control actions: frequency containment and frequency restoration. On the one hand, frequency containment (or primary frequency regulation), which is based on the governor control, adjusts the active power of the generation units to correct frequency variations. In fact, the frequency nadir is directly related with the generator's droop characteristic. In Spanish electric power system, primary regulation services act up to $30 \mathrm{~s}$ after a frequency disturbance [62]. On the other hand, frequency restoration (or secondary frequency regulation) refers to the AGC, adjusting the active power output of generation units to bring system frequency back to its rated value after the governor-based primary response.

An aggregated inertial model is commonly used to analyze frequency deviations in isolated power systems [63]. This modeling approach has been previously applied in El Hierro isolated power system (another isle of the Canarian archipelago) in [64]. Therefore, frequency deviations are the result of the imbalance between the power supplied by the generation units and the power demand:

$$
f \frac{d f}{d t}=\frac{1}{T_{m, \text { ther }}(t)}\left(p_{\text {ther }}+p_{w}-p_{\text {dem }}-D_{\text {net }} \Delta f\right),
$$

where $T_{m \text {,ther }}(t)$ corresponds to the total mechanical inertia of thermal units depending on the number of generation operating units at each moment. Note that only thermal units provide inertia to the power system, since VSWTs are decoupled from the grid through power inverters. 
When frequency disturbances are higher than certain limits, an under frequency load shedding scheme is activated to recover the grid frequency and fulfill certain frequency range requirements. In this work, a realistic load shedding scheme is included, consisting of the sequential and sudden disconnection of certain amount of load as established frequency thresholds are exceeded. The load shedding program can be found in [59].

\subsection{Thermal Power Plants}

The different thermal generation technologies (i.e., steam, diesel, gas, and combined cycle) included in the isolated power system are modeled by different transfer functions proposed in $[59,65]$. These transfer functions supply the power variation of each thermal technology from the frequency deviation and power reference provided by the AGC. Both the model and the parameters can be found in [59]. Since fast response of combined cycle power plants is in charge of the gas turbines, frequency response of combined cycle and gas units is assumed to be equal. The total thermal generation is then the sum of each thermal unit power supplied.

\subsection{Variable Speed Wind Turbines}

One equivalent VSWT model aggregating all the VSWTs is used $[59,66]$. The proposed VSWT equivalent model includes the wind power model and both pitch and torque maximum power point tracking control. Further information can be found in [67]. The one-mass rotor mechanical model is used for simulations, which is detailed enough according to [68] for power converters decoupling the generator from the grid. The VSWT diagram is represented in Figure 4. This wind turbine model has been previously used in [69] for short-time period frequency analysis. The equivalent aggregated wind turbine modeling also includes the frequency control response strategy, described in Section 3.

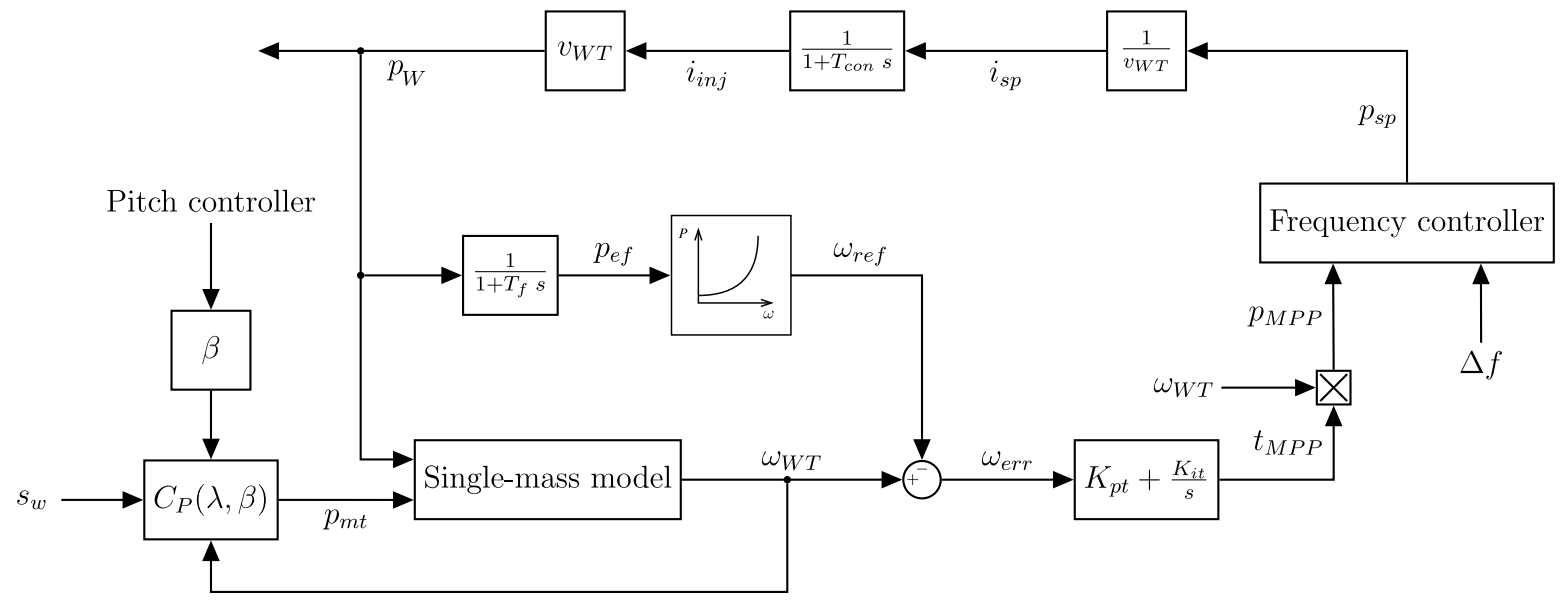

Figure 4. Block diagram of VSWT.

\subsection{Automatic Generation Control (AGC)}

The secondary control action removes the steady-state frequency error after the primary frequency control. It is modeled similar to [70]. The total secondary regulation effort $(\Delta R R)$ is obtained from:

$$
\Delta R R=-\Delta f K_{f}
$$

being $K_{f}$ determined according to the European Network of Transmission System Operators for Electricity (ENTSO-E) recommendations [71]. This regulation effort is distributed among each $i$ synchronized thermal unit as a function of their participation factors $\left(K_{u, i}\right)$, which are related to the speed droop of each unit [72]. Subsequently, the result of adding all $K_{u, i}$ must be one: 


$$
\Delta p_{i}^{r e f}=\frac{1}{T_{u, i}} \int \Delta R R K_{u, i} d t=\frac{-1}{T_{u, i}} \int K_{u, i} K_{f} d t
$$

where $i$ represents $g a s, c c$, die, and st respectively. All thermal units connected to the grid participate in secondary control, whereas the participation factors of those units not connected are considered as zero, $K_{u, i}=0$.

\section{Adaptive Frequency Control Strategy-Methodology}

The adaptive control approach proposed in this work tries to minimize the effort of VSWTs when providing frequency response. The proposed approach is based on the fast power reserve technique. This control strategy distinguishes two different periods after a sudden power imbalance: (i) overproduction and (ii) recovery. During overproduction, the stored kinetic energy in the rotating masses of the VSWTs is supplied to the grid as an additional active power $\Delta p$ during a few seconds, being thus $p_{w}$ over $p_{M P P}\left(s_{w}\right)$. Subsequently, the rotational speed $\omega$ is reduced. Different definitions of this $\Delta p$ have been proposed. In fact, some authors consider $\Delta p$ as a fixed constant value [48-51], whereas others propose to estimate $\Delta p$ as dependent on the torque limit [52] or proportional to the frequency excursion [53]. The recovery period aims to restore $\omega$ to the prefault rotational speed value $\omega_{0}$. To overcome this, $p_{w}$ should be reduced below $p_{\text {mech }}(\omega)$. Previous proposals specified an underproduction power $p_{U P}$ by different ways, being thus the supplied power of each VSWTs: $p_{W}=p_{\text {mech }}-p_{\text {UP }}$.

In the proposed adaptive frequency control strategy, the initial value of $\Delta p$ for the overproduction period is related to the power system conditions. The authors propose a new frequency control approach based on the methodology followed in [73]. This reference estimates the exact and minimum amount of load needed to be shed after an imbalance depending on the RoCoF. In fact, a decision table that links the RoCoF with the strict amount of load shedding is developed based on presimulations. Then, the corresponding load shedding is activated after a contingency, tripping some amount of load demand immediately [74]. In this case, the proposed adaptive controller is based on a decision table that estimates the accurate value of $\Delta p$ for the VSWT overproduction.

The first step to formulate the decision table consists of defining several simulation scenarios that reflect the variability of the demand, the scheduling units, and/or the wind power penetration. To estimate the overproduction power $\Delta p$ after the outage of a thermal group, an iterative process is proposed for each scenario (see Figure 5). The condition considered to calculate such $\Delta p$ is that frequency $f$ should not be below a certain limit $f_{\text {lim }}$ for longer than a preset time limit $t_{\text {lim }}$. Both values $f_{l i m}$ and $t_{\text {lim }}$ are related to the load shedding program of the power system. A counter is thus triggered when $f$ is below $f_{\text {lim }}$, computing the time that frequency is under that $f_{\text {lim }}$. Initially, the $i$-scenario is simulated assuming that the overproduction power in the first iteration $j$ is equal to $0\left(\Delta p_{j}=0\right)$. If $f$ is below $f_{\text {lim }}$ for longer than $t_{\text {lim }}, \Delta p_{j}$ is increased by a fixed value $\Delta p_{\text {inc }}$ with respect to the previous iteration $\left(\Delta p_{j}=\Delta p_{j-1}+\Delta p_{i n c}\right)$ and the same $i$-scenario is simulated again with the new value of $\Delta p_{j}$. When the condition is satisfied (i.e., $f$ is below $f_{\text {lim }}$ less time that $t_{\text {lim }}$ ), the minimum $\Delta p$ for the $i$-scenario $\left(\Delta p_{i}\right)$ that VSWTs should provide has been determined $\left(\Delta p_{i}=\Delta p_{j}\right)$. Note that the overproduction power $\Delta p$ is supplied with a delay of $200 \mathrm{~ms}$, in order to have the measure of the RoCoF and in line with the delay time-interval in between 50 and $500 \mathrm{~ms}$ suggested in [75]. Once all the $\Delta p$ values have been determined from the simulations, a mathematical relationship between such $\Delta p$ and other variables of the power system need to be found. The obtained expression will be the decision table for the adaptive controller. 


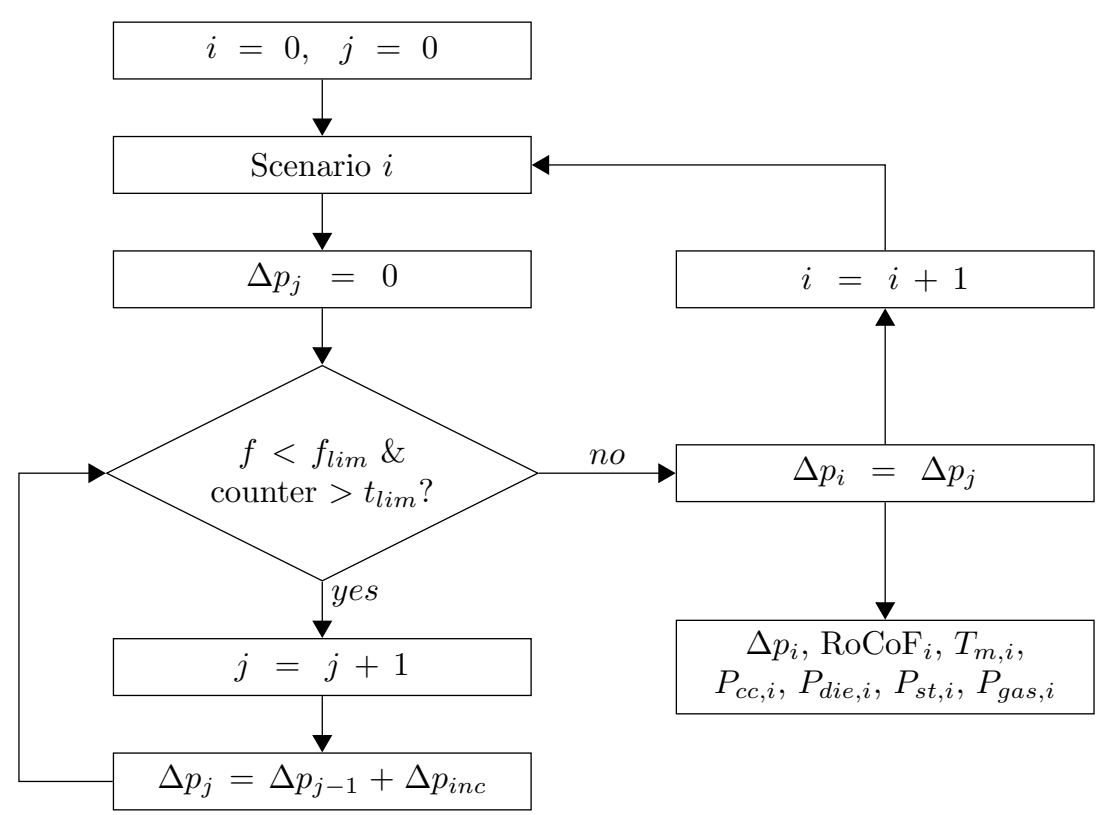

Figure 5. Flow-chart to estimate the overproduction of VSWTs.

When a power imbalance occurs, the VSWTs' controller determines the overproduction power $\Delta p$ according to the previous decision table. This situation causes a sudden $p_{w}$ increase and, after that, the supplied power starts to decrease. In this approach, instead of "forcing" the recovery period, the transition to recovery is carried out by the rotor speed PI controller in the converter, which slowly reduces the active power to achieve again $p_{M P P}\left(s_{w}\right)$. In order to avoid a fast power change, that could cause a secondary frequency dip, $K_{p t}$ and $K_{i t}$ (proportional and integral constants of the converter, refer to Figure 4) must be conveniently tuned. As a consequence, instead of fixing a $p_{U P}$ or defining an underproduction trajectory, the converter should adapt both the electrical power and the rotational speed to make them return to their pre-event values. Figure 6 presents the evolution of $P_{W}$ and $\omega$ under an imbalanced situation with the proposed approach, pointing out the overproduction and recovery periods.

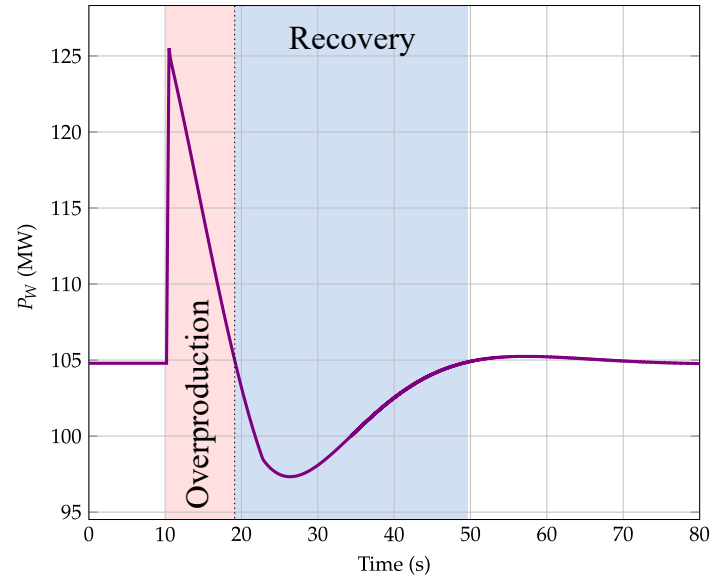

(a)

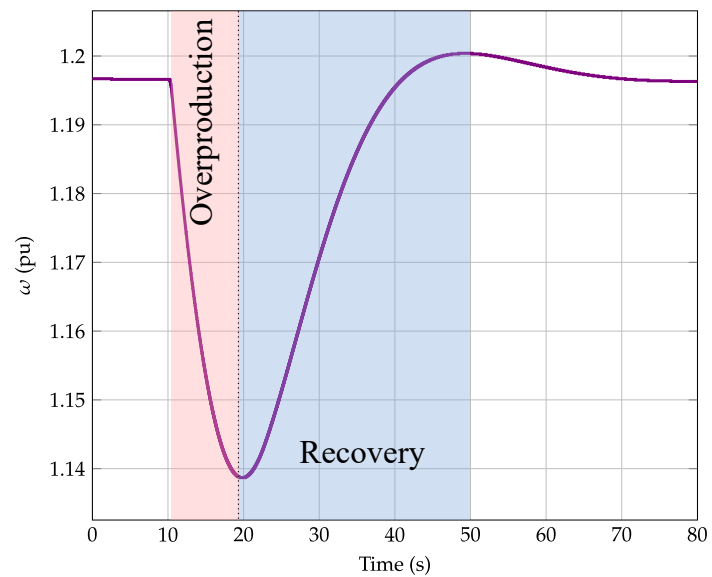

(b)

Figure 6. Example of overproduction and recovery periods. (a) Electrical power (MW); (b) Rotational speed (pu). 


\section{Case Study-Results}

The VSWT adaptive control strategy proposed in this study is applied to the Gran Canaria power system. Gran Canaria Island belongs to Spanish Canarian archipelago, being thus an isolated power system. Its electrical generation has always been based on fossil fuels from two power plants: Jinámar and Barranco de Tirijana power plants. These power plants included diesel, steam, gas, and combined cycle units. However, in recent decades, the government started to promote wind power plants' installation, doubling its capacity up to $180 \mathrm{MW}$ since 2017. Table 1 lists each thermal unit capacity of the Gran Canaria power system.

Table 1. Gran Canaria thermal units power.

\begin{tabular}{cccccccc}
\hline \multicolumn{2}{c}{ Steam } & \multicolumn{2}{c}{ Gas } & \multicolumn{2}{c}{ Combined Cycle } & \multicolumn{2}{c}{ Diesel } \\
\hline$P_{s t, 1}$ & $72.4 \mathrm{MW}$ & $P_{\text {gas }, 1}$ & $32.3 \mathrm{MW}$ & $P_{c c, 1}$ & $206.1 \mathrm{MW}$ & $P_{d i e, 1}$ & $8.5 \mathrm{MW}$ \\
$P_{s t, 2}$ & $72.4 \mathrm{MW}$ & $P_{\text {gas }, 2}$ & $32.3 \mathrm{MW}$ & $P_{c c, 2}$ & $227.0 \mathrm{MW}$ & $P_{d i e, 2}$ & $8.5 \mathrm{MW}$ \\
$P_{s t, 3}$ & $55.6 \mathrm{MW}$ & $P_{\text {gas }, 3}$ & $17.3 \mathrm{MW}$ & & & $P_{d i e, 3}$ & $8.5 \mathrm{MW}$ \\
$P_{s t, 4}$ & $55.6 \mathrm{MW}$ & $P_{\text {gas }, 4}$ & $32.3 \mathrm{MW}$ & & & $P_{d i e, 4}$ & $20.5 \mathrm{MW}$ \\
& & $P_{g a s, 5}$ & $32.3 \mathrm{MW}$ & & & $P_{d i e, 5}$ & $20.5 \mathrm{MW}$ \\
\hline
\end{tabular}

\subsection{Scenarios under Consideration}

Thirty different generation mixes of supply-side programs are under study for different demands and wind power generation. The generation mix scenarios are taken from [59], where a unit commitment model was also included. Figure 7 presents the different supply-side energy schedule of each program. From these generation mix scenarios, two different imbalance conditions are defined: (i) the loss of the largest power plant and (ii) the loss of the second largest power plant. In this way, a total of sixty different scenarios are analyzed. Figure 8 summarizes the supply-side after the disconnection of the largest and second largest units. In addition, it also points out the percentage that represents the loss of each unit over the total system demand.

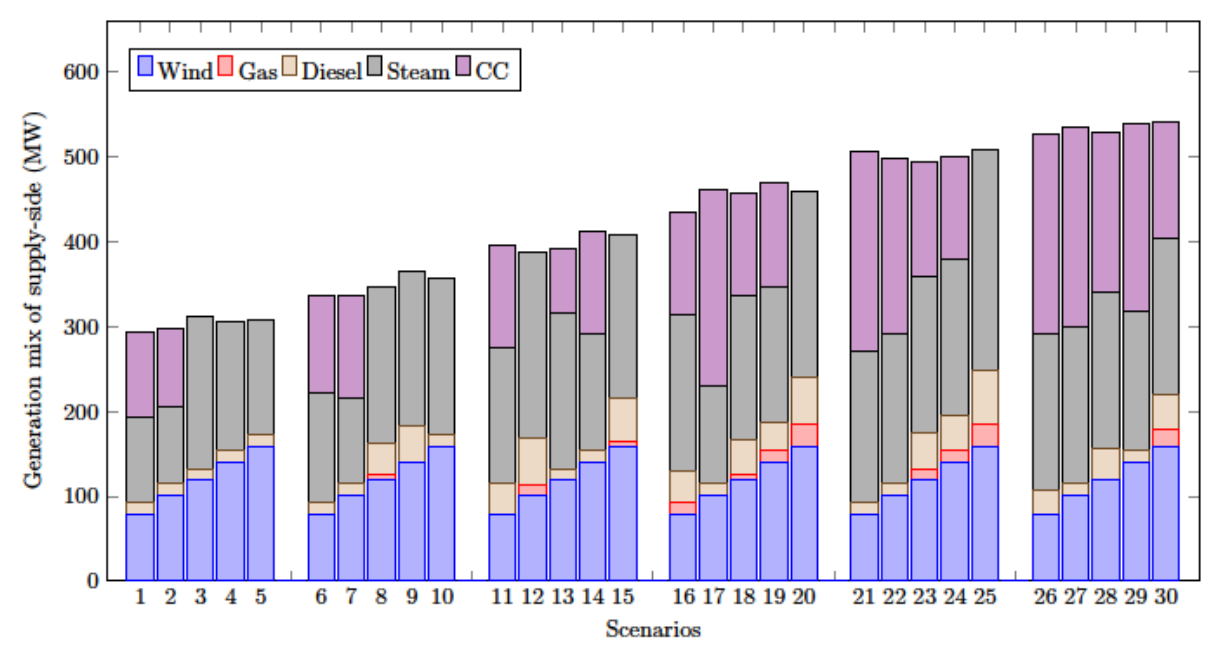

Figure 7. Generation mix scenarios under consideration. 


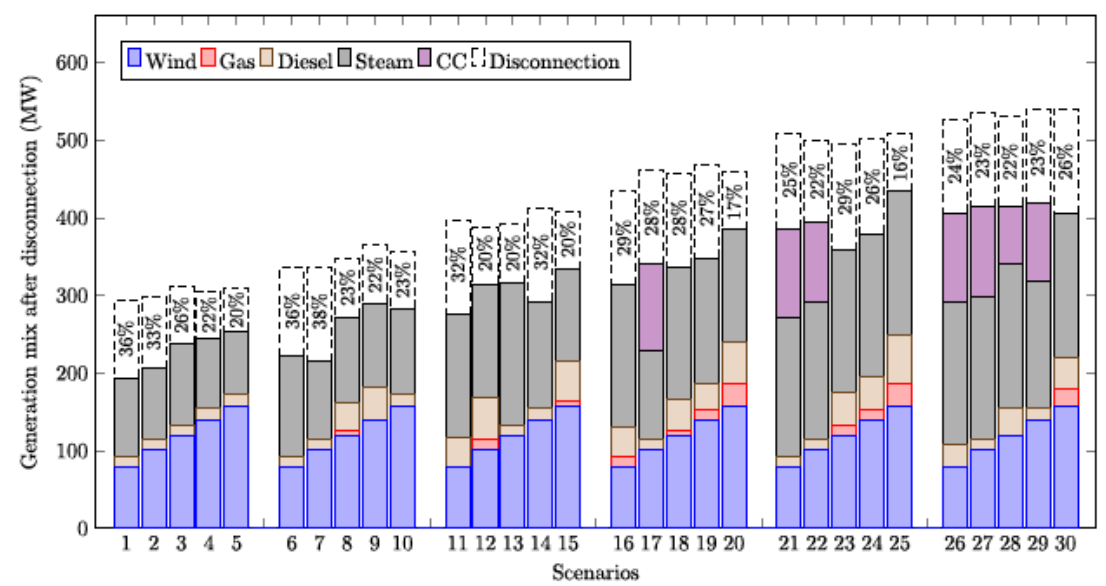

(a)

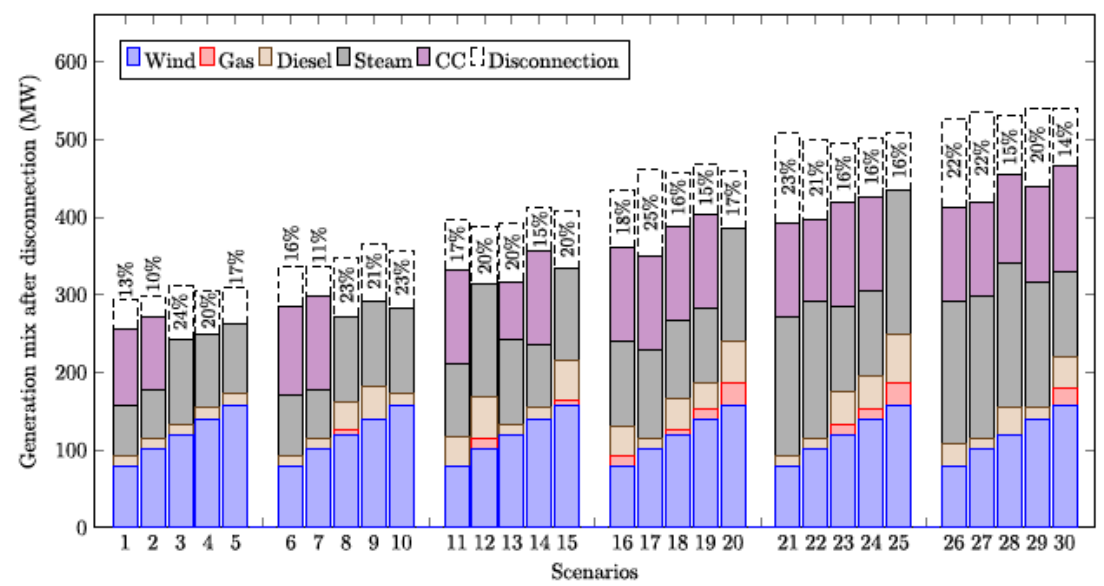

(b)

Figure 8. Generation mix after disconnection (a) Largest power plant disconnection. (b) Second largest power plant disconnection.

\subsection{Decision Table Definition: Regression Analysis}

From the sixty scenarios presented in Section 4.1, the corresponding $\Delta p$ values are determined following Section 3. In this work, and according to the load shedding scheme presented in [59], $f_{\text {lim }}=49 \mathrm{~Hz}, t_{\text {lim }}=1 \mathrm{~s}$ and $\Delta p_{\text {inc }}=0.01 \mathrm{pu}$ for the Gran Canaria island power system. A mathematical relationship between such $\Delta p$ and other variables of the power system need to be found. As aforementioned, [73] proposed to relate the power to be shed with the RoCoF by a linear and quadratic regression, with $R^{2}=0.951$ and $R^{2}=0.969$, respectively. However, both the linear regression and the quadratic regression of $\Delta P$ and RoCoF for this case study accounted for low values of $R^{2}: R^{2}=0.433$ for linear regression and $R^{2}=0.512$ for quadratic regression. As a consequence, other variables are introduced in the proposed mathematical lineal regression. By also considering the electrical power of each thermal technology assigned in the scheduled program, the system synchronous inertia before the incident, and neglecting all those cases in which the estimated $\Delta p$ was $\Delta p=0$, the coefficient of determination increased to $R^{2}=0.801$ following Equation (4):

$$
\Delta P=-386.15+108.63 \cdot \operatorname{RoCoF}-1.32 \cdot P_{\text {gas }}+0.26 \cdot P_{\text {die }}+0.65 \cdot P_{s t}-0.42 \cdot P_{c c}+32.92 \cdot T_{m},
$$

being $\Delta P$ in MW, RoCoF in $\mathrm{Hz} / \mathrm{s}, P_{i}$ in MW ( $i$ stands for $g a s, c c$, die and $\left.s t\right)$, and $T_{m}$ in s.

Comparing the results of $\Delta P$ obtained from the simulations and those estimated with Equation (4), two additional conditions were included: 
1. If the power supplied by the combined cycle power plants before the imbalance was over $180 \mathrm{MW}$ $\left(P_{c c, 0}>180 \mathrm{MW}\right), \Delta P=0$

2. If the estimated $\Delta P$ with the regression is negative $(\Delta P<0), \Delta P=0$

Moreover, the maximum overproduction power $\Delta P$ of the wind power plant was considered as $20 \%$ over the installed capacity of the wind power plant, $\Delta P_{\max }=0.2 \cdot P_{w}$.

\subsection{Results}

Apart from the adaptive control approach, other frequency strategies have been simulated and compared for the sixty scenarios under consideration:

1. Frequency control only provided by thermal power plants (referred to as without VSWTs).

2. Frequency control provided by thermal power plants and VSWTs. The overproduction is defined as proportional to $\Delta f$; change from overproduction to recovery period occurs when $\omega / \omega_{0}<0.9$, and $p_{U P}=0.05 \mathrm{pu}$ (fast power reserve technique). It is triggered when $\Delta f \geq 100 \mathrm{mHz}$ and the maximum $\Delta p=0.15 \cdot p_{\text {mech }}(\omega)$ (referred to as previous approach).

3. Frequency control provided by thermal power plants and VSWTs using the proposed control approach (referred to as adaptive approach).

As was discussed in Section 4.1, sixty different scenarios are considered to evaluate the new frequency control approach for VSWTs. Results are focused on four different aspects for each scenario: (i) the minimum rotational speed $\omega_{\text {min }}$; (ii) the maximum torque $T_{\max }$; (iii) the power shed due to the corresponding load shedding programs; (iv) number of cases in which VSWTs do not participate in frequency control with the adaptive proposed approach. Both $\omega_{\min }$ and $T_{\max }$ are expressed in \% with regard to the pre-event values, which is equal to their values when they do not participate in frequency control.

Figure 9 depicts the range values of the rotational speed in \% compared to the pre-event value. When VSWTs do not participate in frequency control, its $\omega$ variation is null, as they are providing $p_{M P P}\left(s_{w}\right)$. According to these results, and depending on the frequency control strategy, important differences can be identified. With regard to the frequency control referred to as previous approach, and considering that the change from overproduction to recovery period is always with $\omega / \omega_{0}<0.9$, all scenarios then give the same minimum $\omega$, which represents more than a $7 \%$ variation. Based on the adaptive approach, $\omega_{\min }$ variations range in between 0 (for those cases in which the frequency control is not activated) and $6.62 \%$. In fact, the average $\omega_{\min }$ variation with the proposed strategy is $2.15 \%$. As a consequence, the new frequency control strategy technique does not only optimize those imbalances where VSWTs frequency control participation is required but also reduces the averaged variation of $\omega$ to more than half of the previous frequency control approaches.

Figure 10 compares the maximum torque during the VWST frequency response to the corresponding pre-event value. These results are in line with the previous rotational speed comparison, see Figure 9. The torque does not vary when VSWTs do not participate in frequency control, as both $\omega$ and $p_{e}$ remain constant. With the previous approach for VSWT frequency control, the maximum torque variation is always the same. Moreover, this variation is over a $30 \%$ increase-in comparison to the pre-event value, which can address relevant mechanical loads on the turbine shaft. In contrast, with the proposed adaptive approach, the maximum $T_{\max }$ variation is $26.5 \%$ (only 9 out of 60 scenarios), with an average $T_{\max }$ of $9.7 \%$. It can be then deduced that the new frequency control approach does not only avoid the activation of the frequency control of VSWTs in most of imbalance scenarios but also that both $\omega$ and $T_{\max }$ ranges are reduced significantly compared to previous approaches. 


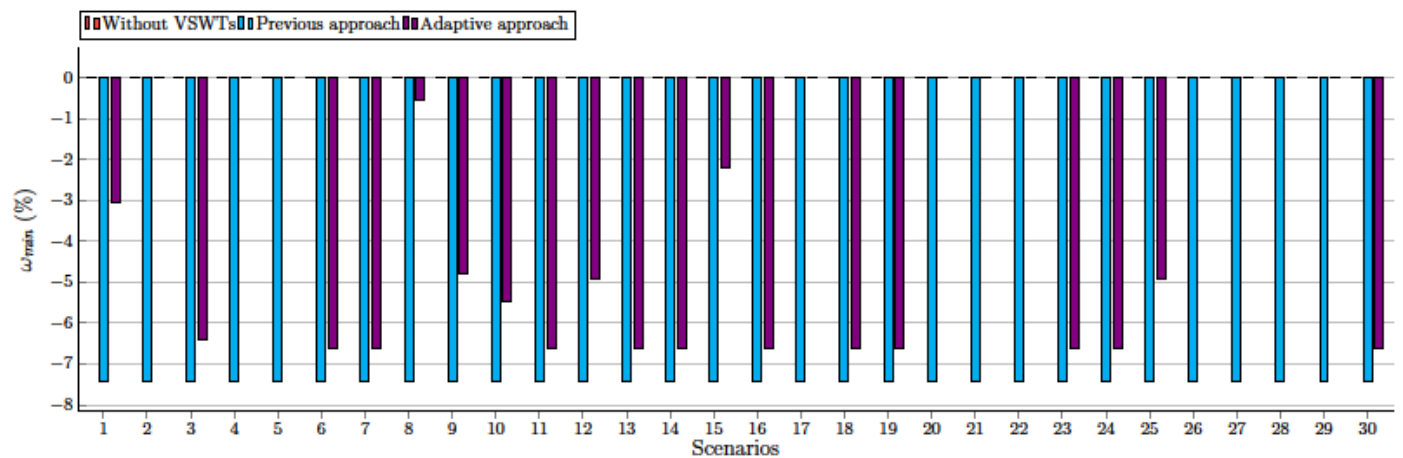

(a)

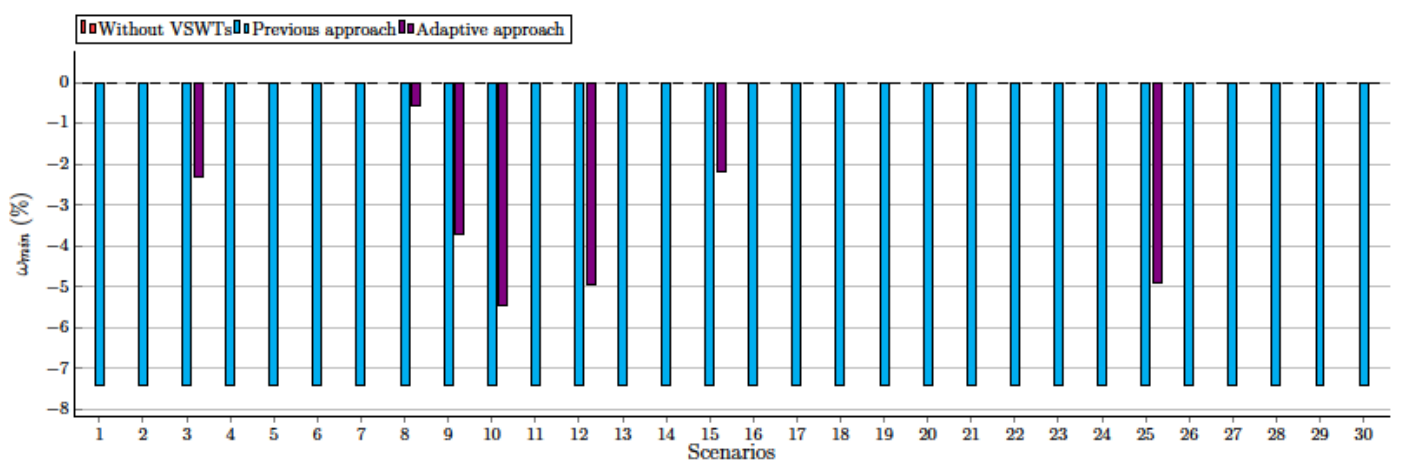

(b)

Figure 9. Minimum rotational speed (a) Largest power plant disconnection; (b) Second largest power plant disconnection.

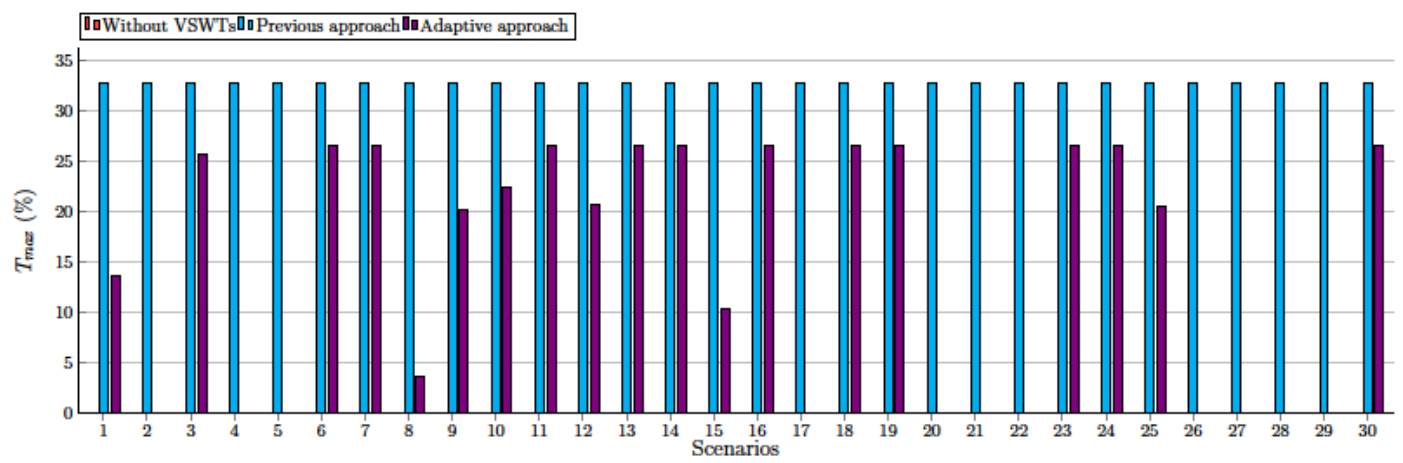

(a)

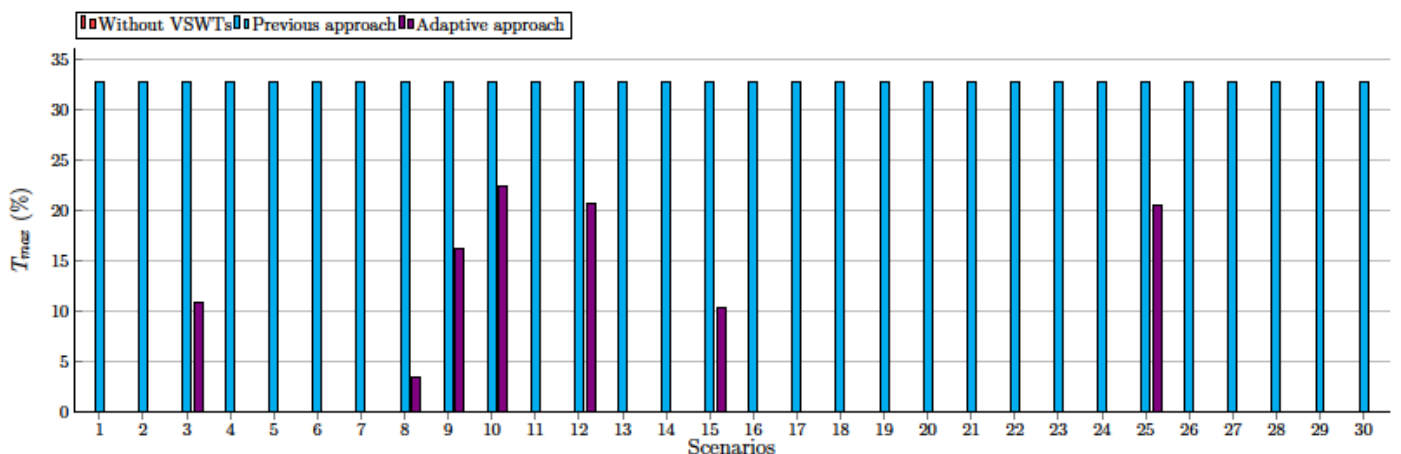

(b)

Figure 10. Maximum torque variation (a) Largest power plant disconnection; (b) Second largest power plant disconnection. 
Figure 11 shows the power shed by the load shedding program. As can be seen, it is reduced when wind power plants participate in frequency control, compared to the current case in which only thermal power plants are providing such ancillary service. Comparing the two different frequency control approaches analyzed, small differences are found. The previous approach gets better results in 4 out of 60 scenarios under study, whereas the adaptive approach obtained lower load shedding values in 2 out of 60 scenarios. In the other cases, both frequency controllers obtain the same load shedding.

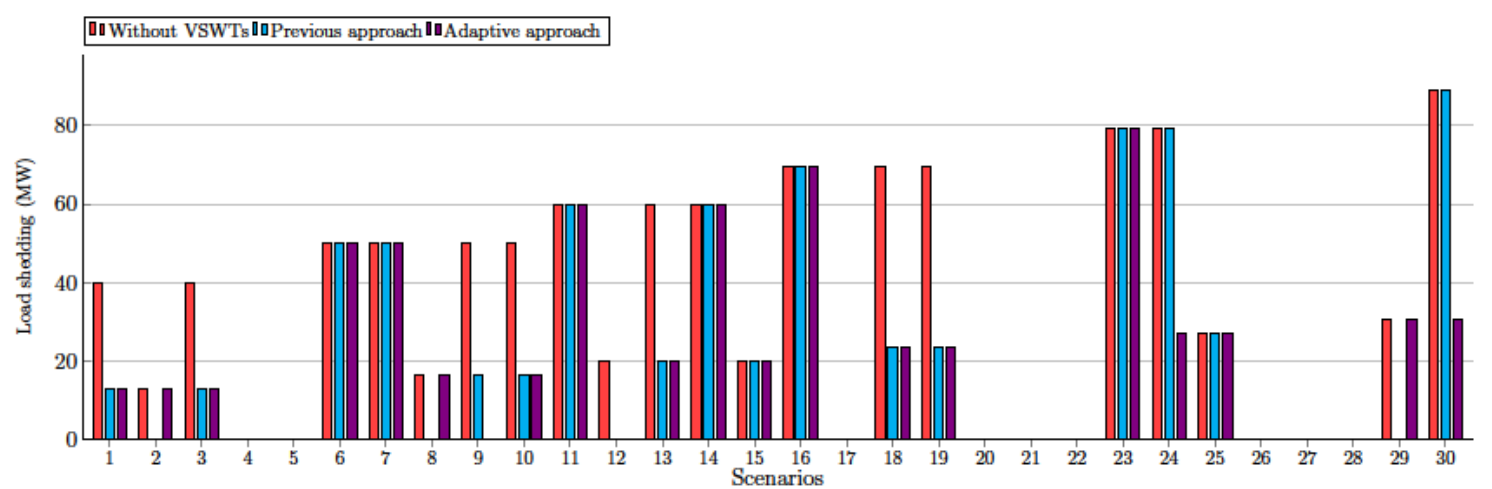

(a)

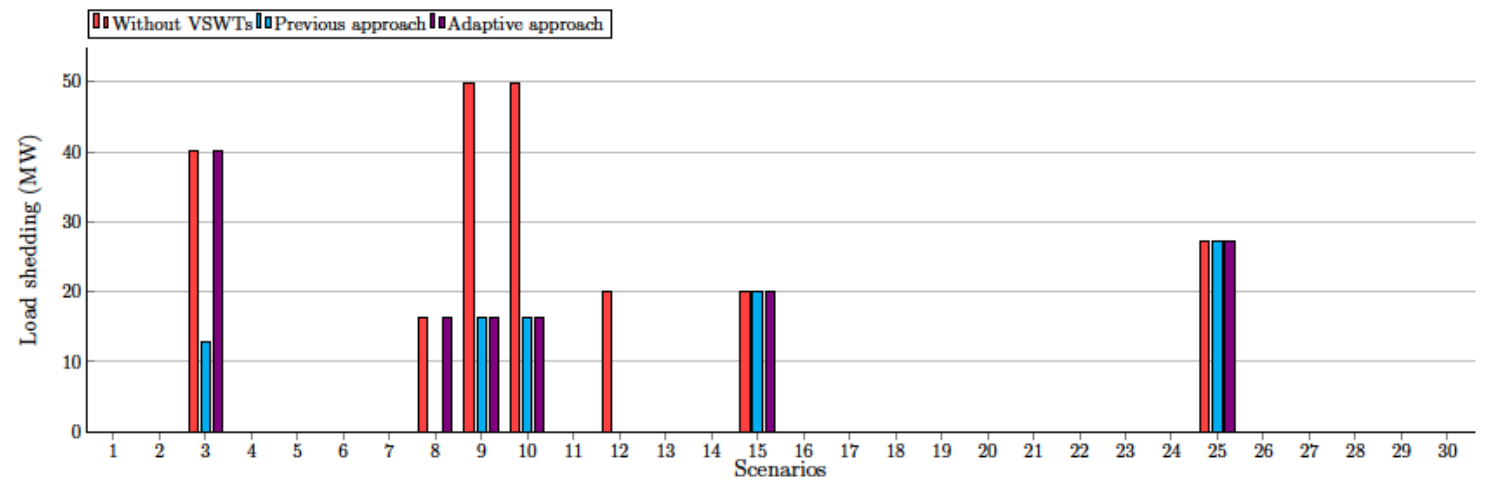

(b)

Figure 11. Load shedding (a) Largest power plant disconnection; (b) Second largest power plant disconnection.

Finally, $57 \%$ of imbalances without any VSWTs frequency response participation have been identified. These results reduce significantly the mechanical and electrical VSWT efforts under imbalances, maintaining similar frequency excursions to the previous control strategies. More specifically, the VSWT frequency participation is not required to provide additional power in 11 out of 30 for the largest power plant loss and 23 out of 30 for the second largest power plant loss. These 34 scenarios where the adaptive frequency control is not triggered can be seen in Figures 9 and 10: imbalance scenarios will null variation of $\omega_{\min }$ and $T_{\max }$ for the proposed control strategy. Therefore, $p_{e}$ and $\omega$ values keep as constant during the imbalance and, subsequently, also maintain the torque. In addition, authors have checked that in $94 \%$ of the cases in which VSWTs are not participating in frequency control with the adaptive approach, the power shed was initially null, pointing out that their participation was not required within acceptable frequency excursion ranges.

As an additional result, Figures 12-14 depict the frequency evolution, load shedding, wind power, and rotational speed for scenarios 9, 16, and 27, respectively, for the loss of the largest power plant. Together with the aforementioned advantages of the new approach, authors also point out that the rotational speed of VSWTs is recovered in a lower time interval than with the previous frequency control approach. Moreover, the transition from overproduction to recovery period is also smoother, avoiding undesirable secondary frequency dips (refer to Figure 12). 


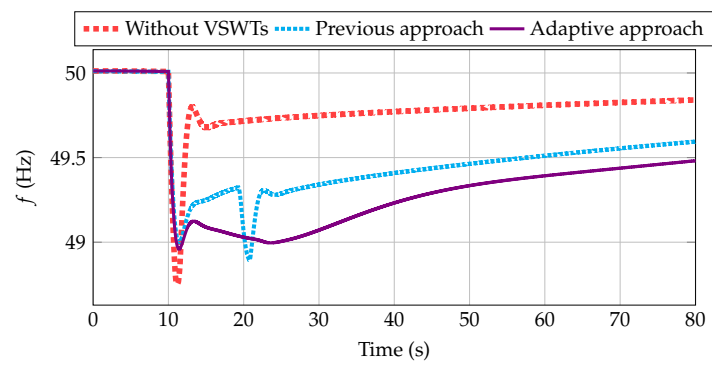

(a)

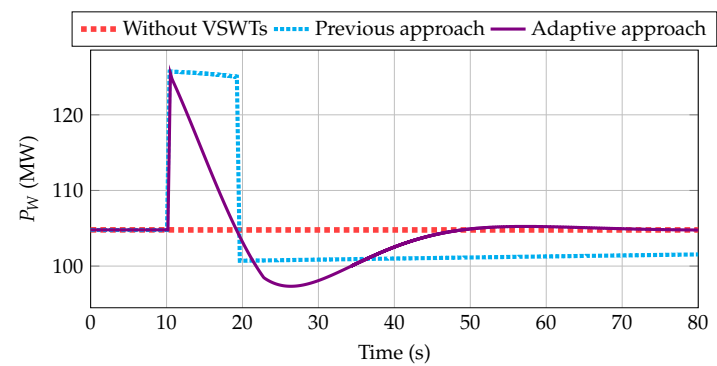

(c)

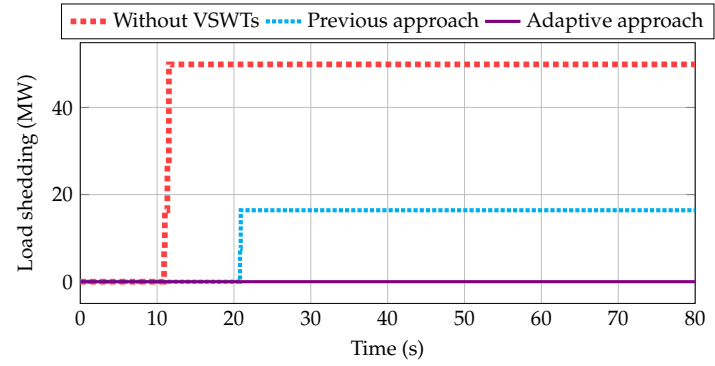

(b)

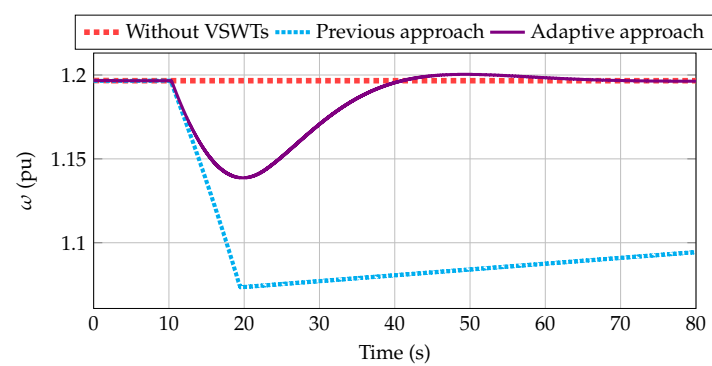

(d)

Figure 12. Results for scenario 9 (a) Frequency (Hz). (b) Load shedding (MW) (c) Wind power (MW) (d) VSWTs rotational speed (pu).

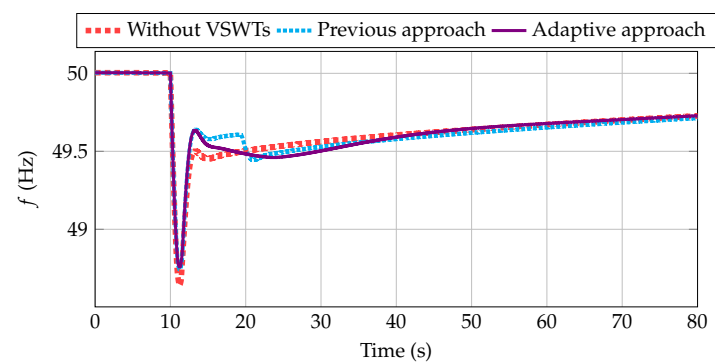

(a)

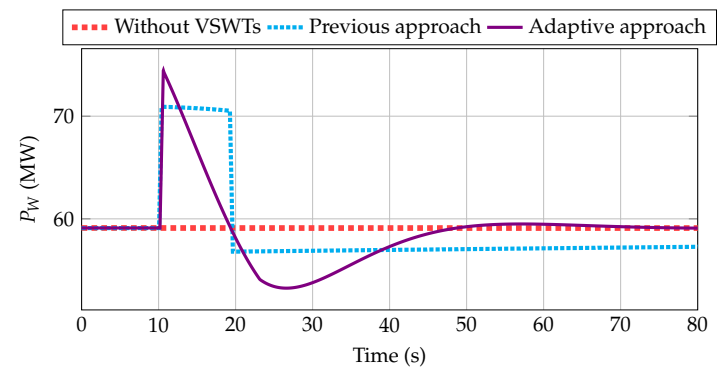

(c)

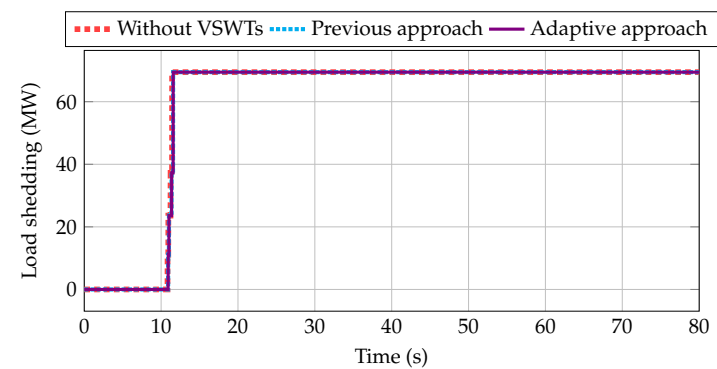

(b)

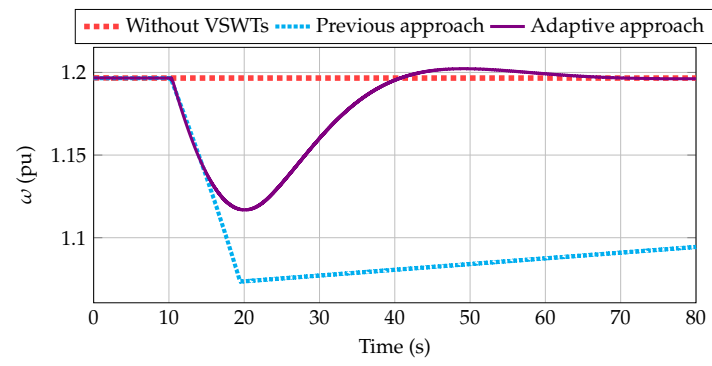

(d)

Figure 13. Results for scenario 16 (a) Frequency (Hz); (b) Load shedding (MW); (c) Wind power (MW); (d) VSWTs rotational speed $(\mathrm{pu})$. 


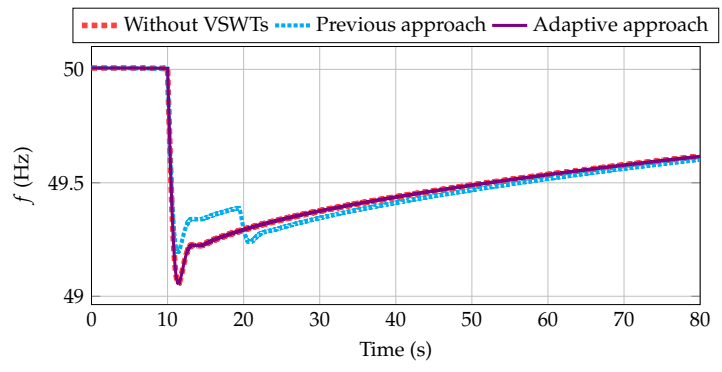

(a)

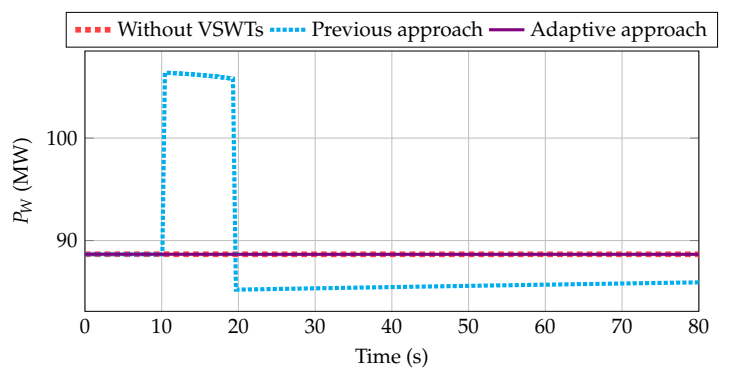

(c)

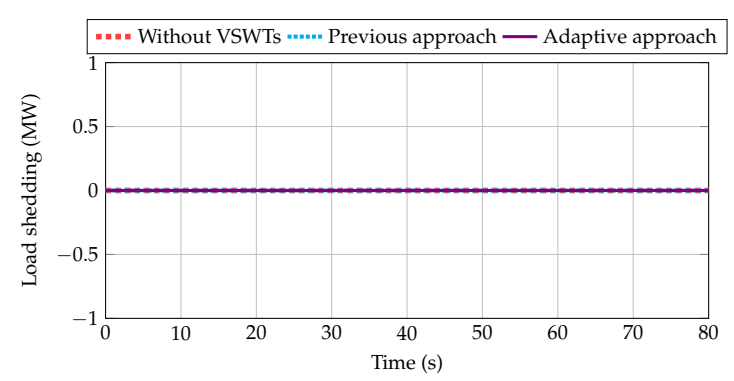

(b)

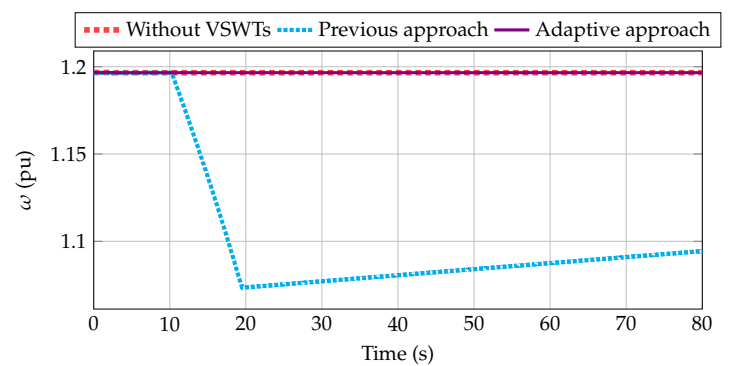

(d)

Figure 14. Results for scenario 27 (a) Frequency (Hz); (b) Load shedding (MW); (c) Wind power (MW); (d) VSWTs rotational speed $(\mathrm{pu})$.

\section{Conclusions}

Due to the massive penetration of VSWTs, their contribution to frequency regulation has become a need. As isolated power systems have low synchronous inertia, VSWTs frequency control is even more required. Even though different control strategies for VSWTs have been proposed in the last decade, they usually imply important drawbacks in terms of efficiency, economic profits, and/or equipment wear. As a result, with the aim of reducing the mechanical stress of VSWTs providing frequency response, an adaptive control strategy is proposed in this work. Our approach is based on estimating the minimum overproduction power provided by VSWTs following a linear regression estimation. In this way, such overproduction power depends on some grid parameters (i.e., RoCoF, synchronous inertia, and assigned power of thermal units before the incident). The proposed controller is compared to a conventional fast power reserve strategy. The Gran Canaria isolated power system (Spain) is considered as case study, analyzing sixty representative imbalance scenarios. Results show that similar values for the power shed with the load shedding program are obtained with the two approaches. However, the new adaptive control reduces the VSWTs maximum torque variations and the speed variations ( $23 \%$ and $5 \%$ on average, respectively), in comparison to the conventional VSWTs frequency control strategy. This is due to the smoother transition from overproduction to recovery periods, which reduces the electrical and mechanical VSWT efforts. In addition, in $57 \%$ of the imbalance scenarios under consideration, VSWTs are not required to participate in frequency response. Thus, both electrical power and rotational speed are kept as constants (subsequently maintaining the torque). As a result, a longer life span is expected for the VSWTs electrical and mechanical components.

Author Contributions: Conceptualization, J.I.S.; Data curation, A.F.-G.; Formal analysis, G.M.-L.; Investigation, A.F.-G.; Methodology, J.I.S.; Resources, A.F.-G. and G.M.-L.; Software, A.F.-G.; Supervision, Á.M.-G. and J.I.S.; Validation, G.M.-L. and J.I.S.; Visualization, Á.M.-G.; Writing—original draft, A.F.-G. and G.M.-L.; Writing一review and editing, A.M.-G. and J.I.S. All authors have read and agreed to the published version of the manuscript. 
Funding: This work was partially supported by 'Ministerio de Educación, Cultura y Deporte' of Spain (ref. FPU16/04282) and by 'Ministerio de Economía y Competitividad', under the project "Value of pumped-hydro energy storage in isolated power systems with high wind power penetration" of the National Plan for Scientific and Technical Research and Innovation 2013-2016, grant number ENE2016-77951-R.

Conflicts of Interest: The authors declare no conflict of interest.

\section{Abbreviations}

The following abbreviations are used in this manuscript:

$\beta \quad$ Pitch angle (grades)

$\omega \quad$ Rotational speed (p.u.)

$\triangle P \quad$ Overproduction power of VSWT (MW)

$\triangle R R \quad$ Total secondary regulation effort

$f \quad$ Frequency $(\mathrm{Hz})$

$p \quad$ Active power (p.u.)

$s_{w} \quad$ Wind speed (m/s)

$D_{\text {net }} \quad$ Damping factor of loads

$K_{u} \quad$ Participation factor in secondary control

$P \quad$ Active power (MW)

$T_{m} \quad$ Inertia constant (s)

$0 \quad$ Pre-event value (subscript)

$c c \quad$ Combined cycle (subscript)

dem Demand (subscript)

die Diesel (subscript)

gas Gas (subscript)

$\max$ Maximum value (subscript)

mech Mechanical (subscript)

min Minimum value (subscript)

st Steam (subscript)

ther Thermal (subscript)

$w \quad$ Wind (subscript)

UP Underproduction (subscript)

AGC Automatic Generation Control

II-RES Inverter Interfaced Renewable Energy Sources

MPP Maximum Power Point

PV Photovoltaic

RoCoF Rate of Change of Frequency

TSO Transmission System Operator

VSWT Variable Speed Wind Turbine

\section{References}

1. Kaushal, A.; Van Hertem, D. An Overview of Ancillary Services and HVDC Systems in European Context. Energies 2019, 12, 3481. [CrossRef]

2. Martínez-Lucas, G.; Sarasúa, J.I.; Wilhelmi, J.R.; ángel Sánchez, J. Contribution to load-frequency regulation of a hydropower plant with long tail-race tunnel. In Proceedings of the 15th International Conference on Environment and Electrical Engineering (EEEIC), Rome, Italy, 10-13 June 2015; pp. 1886-1891.

3. Qi, Y.; Wang, D.; Wang, X.; Jia, H.; Pu, T.; Chen, N.; Liu, K. Frequency control ancillary service provided by efficient power plants integrated in Queuing-Controlled domestic water heaters. Energies 2017, 10, 559. [CrossRef]

4. ENTSO-E. Electricity Balancing in Europe. Available online: https://docstore.entsoe.eu/ (accessed on 15 April 2020).

5. Das, K.; Nitsas, A.; Altin, M.; Hansen, A.D.; Sørensen, P.E. Improved load-shedding scheme considering distributed generation. IEEE Trans. Power Deliv. 2016, 32, 515-524. [CrossRef] 
6. Tofis, Y.; Timotheou, S.; Kyriakides, E. Minimal load shedding using the swing equation. IEEE Trans. Power Syst. 2016, 32, 2466-2467. [CrossRef]

7. Costa, M.H.; Ravetti, M.G.; Saldanha, R.R.; Carrano, E.G. Minimizing undesirable load shedding through robust coordination of directional overcurrent relays. Int. J. Electr. Power Energy Syst. 2019, 113, 748-757. [CrossRef]

8. Rudez, U.; Mihalic, R. RoCoF-based improvement of conventional under-frequency load Shedding. In Proceedings of the 2019 IEEE Milan PowerTech, Milan, Italy, 23-27 June 2019; pp. 1-5.

9. Fernández-Guillamón, A.; Molina-García, A.; Vigueras-Rodríguez, A.; Gómez-Lázaro, E. Frequency response and inertia analysis in power systems with high wind energy integration. In Proceedings of the 2019 International Conference on Clean Electrical Power (ICCEP), Otranto, Italy, 2-4 July 2019; pp. 388-393.

10. Fernández-Guillamón, A.; Vigueras-Rodríguez, A.; Molina-García, Á. Analysis of power system inertia estimation in high wind power plant integration scenarios. IET Renew. Power Gener. 2019, 13, 2807-2816. [CrossRef]

11. Molina-García, A.; Fernández-Guillamón, A.; Gómez-Lázaro, E.; Honrubia-Escribano, A.; Bueso, M.C. Vertical Wind Profile Characterization and Identification of Patterns Based on a Shape Clustering Algorithm. IEEE Access 2019, 7, 30890-30904. [CrossRef]

12. Available online: https://gwec.net/global-wind-report-2019/ (accessed on 29 April 2020).

13. Muñoz-Benavente, I.; Hansen, A.D.; Gómez-Lázaro, E.; García-Sánchez, T.; Fernández-Guillamón, A.; Molina-García, Á. Impact of combined demand-response and wind power plant participation in frequency control for multi-area power systems. Energies 2019, 12, 1687. [CrossRef]

14. Tielens, P.; Van Hertem, D. The relevance of inertia in power systems. Renew. Sustain. Energy Rev. 2016, 55, 999-1009. [CrossRef]

15. Daly, P.; Flynn, D.; Cunniffe, N. Inertia considerations within unit commitment and economic dispatch for systems with high non-synchronous penetrations. In Proceedings of the 2015 IEEE Eindhoven PowerTech, Eindhoven, The Netherlands, 29 June-2 July 2015; pp. 1-6.

16. Martínez-Lucas, G.; Sarasúa, J.I.; Sánchez-Fernández, J.Á.; Wilhelmi, J.R. Power-frequency control of hydropower plants with long penstocks in isolated systems with wind generation. Renew. Energy 2015, 83, 245-255. [CrossRef]

17. Martinez-Lucas, G.; Sarasúa, J.I.; Sánchez-Fernández, J.Á.; Wilhelmi, J.R. Frequency control support of a wind-solar isolated system by a hydropower plant with long tail-race tunnel. Renew. Energy 2016, 90, 362-376. [CrossRef]

18. Toulabi, M.; Bahrami, S.; Ranjbar, A.M. An input-to-state stability approach to inertial frequency response analysis of doubly-fed induction generator-based wind turbines. IEEE Trans. Energy Convers. 2017, 32, 1418-1431. [CrossRef]

19. Fernández-Guillamón, A.; Gómez-Lázaro, E.; Muljadi, E.; Molina-García, Á. Power systems with high renewable energy sources: A review of inertia and frequency control strategies over time. Renew. Sustain. Energy Rev. 2019, 115, 109369. [CrossRef]

20. Alsharafi, A.S.; Besheer, A.H.; Emara, H.M. Primary Frequency Response Enhancement for Future Low Inertia Power Systems Using Hybrid Control Technique. Energies 2018, 11, 699. [CrossRef]

21. Fernández-Guillamón, A.; Vigueras-Rodríguez, A.; Gómez-Lázaro, E.; Molina-García, Á. Fast power reserve emulation strategy for VSWT supporting frequency control in multi-area power systems. Energies 2018, 11, 2775. [CrossRef]

22. Chen, Z.; Yin, M.; Zou, Y.; Meng, K.; Dong, Z. Maximum wind energy extraction for variable speed wind turbines with slow dynamic behavior. IEEE Trans. Power Syst. 2016, 32, 3321-3322. [CrossRef]

23. Ziping, W.; Wenzhong, G.; Tianqi, G.; Weihang, Y.; ZHANG, H.; Shijie, Y.; Xiao, W. State-of-the-art review on frequency response of wind power plants in power systems. J. Mod. Power Syst. Clean Energy 2017, 6, 1-16.

24. Fernández-Guillamón, A.; Gómez-Lázaro, E.; Muljadi, E.; Molina-Garcia, Á. A Review of Virtual Inertia Techniques for Renewable Energy-Based Generators. In Power Systems; IntechOpen: London, UK, 2020.

25. Yingcheng, X.; Nengling, T. Review of contribution to frequency control through variable speed wind turbine. Renew. Energy 2011, 36, 1671-1677. [CrossRef]

26. Ma, H.; Chowdhury, B. Working towards frequency regulation with wind plants: Combined control approaches. IET Renew. Power Gener. 2010, 4, 308-316. [CrossRef] 
27. Moutis, P.; Papathanassiou, S.A.; Hatziargyriou, N.D. Improved load-frequency control contribution of variable speed variable pitch wind generators. Renew. Energy 2012, 48, 514-523. [CrossRef]

28. Žertek, A.; Verbič, G.; Pantoš, M. Optimised control approach for frequency-control contribution of variable speed wind turbines. IET Renew. Power Gener. 2012, 6, 17-23. [CrossRef]

29. Martínez-Lucas, G.; Sarasúa, J.I.; Pérez-Díaz, J.I.; Martínez, S.; Ochoa, D. Analysis of the Implementation of the Primary and/or Inertial Frequency Control in Variable Speed Wind Turbines in an Isolated Power System with High Renewable Penetration. Case Study: El Hierro Power System. Electronics 2020, 9, 901. [CrossRef]

30. Castro, L.M.; Fuerte-Esquivel, C.R.; Tovar-Hernández, J.H. Solution of power flow with automatic load-frequency control devices including wind farms. IEEE Trans. Power Syst. 2012, 27, 2186-2195. [CrossRef]

31. Vidyanandan, K.; Senroy, N. Primary frequency regulation by deloaded wind turbines using variable droop. IEEE Trans. Power Syst. 2013, 28, 837-846. [CrossRef]

32. Zhang, X.; Zha, X.; Yue, S.; Chen, Y. A Frequency Regulation Strategy for Wind Power Based on Limited Over-Speed De-Loading Curve Partitioning. IEEE Access 2018, 6, 22938-22951. [CrossRef]

33. Wang, S.; Tomsovic, K. A Novel Active Power Control Framework for Wind Turbine Generators to Improve Frequency Response. IEEE Trans. Power Syst. 2018, 33, 6579-6589. [CrossRef]

34. Fang, X.; Krishnan, V.; Hodge, B.M. Strategic offering for wind power producers considering energy and flexible ramping products. Energies 2018, 11, 1239. [CrossRef]

35. Ye, H.; Pei, W.; Qi, Z. Analytical modeling of inertial and droop responses from a wind farm for short-term frequency regulation in power systems. IEEE Trans. Power Syst. 2016, 31, 3414-3423. [CrossRef]

36. Arani, M.F.; Mohamed, Y.A.I. Dynamic Droop Control for Wind Turbines Participating in Primary Frequency Regulation in Microgrids. IEEE Trans. Smart Grid 2017, 9, 5742-5751. [CrossRef]

37. Lertapanon, P.; Wangdee, W. Analysis and modeling of wind turbine generators considering frequency controls. In Proceedings of the Electrical Engineering Congress (iEECON), Pattaya, Thailand, 8-10 March 2017; pp. 1-4.

38. Huang, L.; Xin, H.; Zhang, L.; Wang, Z.; Wu, K.; Wang, H. Synchronization and Frequency Regulation of DFIG-Based Wind Turbine Generators With Synchronized Control. IEEE Trans. Energy Convers. 2017, 32, 1251-1262. [CrossRef]

39. Deepak, M.; Abraham, R.J.; Gonzalez-Longatt, F.M.; Greenwood, D.M.; Rajamani, H.S. A novel approach to frequency support in a wind integrated power system. Renew. Energy 2017, 108, 194-206. [CrossRef]

40. Margaris, I.D.; Papathanassiou, S.A.; Hatziargyriou, N.D.; Hansen, A.D.; Sorensen, P. Frequency control in autonomous power systems with high wind power penetration. IEEE Trans. Sustain. Energy 2012, 3, 189-199. [CrossRef]

41. Morren, J.; de Haan, S.W.H.; Kling, W.L.; Ferreira, J.A. Wind turbines emulating inertia and supporting primary frequency control. IEEE Trans. Power Syst. 2006, 21, 433-434. [CrossRef]

42. Díaz-González, F.; Hau, M.; Sumper, A.; Gomis-Bellmunt, O. Participation of wind power plants in system frequency control: Review of grid code requirements and control methods. Renew. Sustain. Energy Rev. 2014, 34, 551-564. [CrossRef]

43. Dreidy, M.; Mokhlis, H.; Mekhilef, S. Inertia response and frequency control techniques for renewable energy sources: A review. Renew. Sustain. Energy Rev. 2017, 69, 144-155. [CrossRef]

44. Ekanayake, J.; Jenkins, N. Comparison of the response of doubly fed and fixed-speed induction generator wind turbines to changes in network frequency. IEEE Trans. Energy Convers. 2004, 19, 800-802. [CrossRef]

45. Gonzalez-Longatt, F.; Chikuni, E.; Stemmet, W.; Folly, K. Effects of the synthetic inertia from wind power on the total system inertia after a frequency disturbance. In Proceedings of the Power Engineering Society Conference and Exposition in Africa, Johannesburg, South Africa, 9-13 July 2012; pp. 9-13.

46. Bonfiglio, A.; Invernizzi, M.; Labella, A.; Procopio, R. Design and Implementation of a Variable Synthetic Inertia Controller for Wind Turbine Generators. IEEE Trans. Power Syst. 2018, 34, 754-764. [CrossRef]

47. Singarao, V.Y.; Rao, V.; Harral, M.A. Review on engineering and regulatory aspects associated with frequency control capabilities of wind power plants. In Proceedings of the 2013 IEEE Energytech, Cleveland, OH, USA, 21-23 May 2013; pp. 1-6.

48. Tarnowski, G.C.; Kjar, P.C.; Sorensen, P.E.; Ostergaard, J. Variable speed wind turbines capability for temporary over-production. In Proceedings of the Power \& Energy Society General Meeting, Calgary, AB, Canada, 26-30 July 2009; pp. 1-7. 
49. Keung, P.K.; Li, P.; Banakar, H.; Ooi, B.T. Kinetic energy of wind-turbine generators for system frequency support. IEEE Trans. Power Syst. 2009, 24, 279-287. [CrossRef]

50. El Itani, S.; Annakkage, U.D.; Joos, G. Short-term frequency support utilizing inertial response of DFIG wind turbines. In Proceedings of the Power and Energy Society General Meeting, Detroit, MI, USA, 24-28 July 2011; pp. 1-8.

51. Hafiz, F.; Abdennour, A. Optimal use of kinetic energy for the inertial support from variable speed wind turbines. Renew. Energy 2015, 80, 629-643. [CrossRef]

52. Kang, M.; Kim, K.; Muljadi, E.; Park, J.W.; Kang, Y.C. Frequency control support of a doubly-fed induction generator based on the torque limit. IEEE Trans. Power Syst. 2016, 31, 4575-4583. [CrossRef]

53. Fernández-Guillamón, A.; Villena-Lapaz, J.; Vigueras-Rodríguez, A.; García-Sánchez, T.; Molina-García, Á. An Adaptive Frequency Strategy for Variable Speed Wind Turbines: Application to High Wind Integration Into Power Systems. Energies 2018, 11, 1436. [CrossRef]

54. Liu, K.; Qu, Y.; Kim, H.M.; Song, H. Avoiding Frequency Second Dip in Power Unreserved Control During Wind Power Rotational Speed Recovery. IEEE Trans. Power Syst. 2018, 33, 3097-3106. [CrossRef]

55. Staino, A.; Basu, B. Dynamics and control of vibrations in wind turbines with variable rotor speed. Eng. Struct. 2013, 56, 58-67. [CrossRef]

56. Rahman, M.; Ong, Z.C.; Chong, W.T.; Julai, S.; Khoo, S.Y. Performance enhancement of wind turbine systems with vibration control: A review. Renew. Sustain. Energy Rev. 2015, 51, 43-54. [CrossRef]

57. Hansen, A.D.; Altin, M.; Margaris, I.D.; Iov, F.; Tarnowski, G.C. Analysis of the short-term overproduction capability of variable speed wind turbines. Renew. Energy 2014, 68, 326-336. [CrossRef]

58. Lind, P.G.; Herráez, I.; Wächter, M.; Peinke, J. Fatigue load estimation through a simple stochastic model. Energies 2014, 7, 8279-8293. [CrossRef]

59. Fernández-Guillamón, A.; Sarasúa, J.I.; Chazarra, M.; Vigueras-Rodríguez, A.; Fernández-Muñoz, D.; Molina-García, Á. Frequency control analysis based on unit commitment schemes with high wind power integration: A Spanish isolated power system case study. Int. J. Electr. Power Energy Syst. 2020, 121, 106044. [CrossRef]

60. Padrón, S.; Hernández, M.; Falcón, A. Reducing under-frequency load shedding in isolated power systems using neural networks. Gran Canaria: A case study. IEEE Trans. Power Syst. 2015, 31, 63-71. [CrossRef]

61. Martínez-Lucas, G.; Sarasúa, J.I.; Sánchez-Fernández, J.Á. Frequency regulation of a hybrid wind-hydro power plant in an isolated power system. Energies 2018, 11, 239. [CrossRef]

62. Aziz, A.; Oo, A.T.; Stojcevski, A. Frequency regulation capabilities in wind power plant. Sustain. Energy Technol. Assess. 2018, 26, 47-76. [CrossRef]

63. Mansoor, S.; Jones, D.; Bradley, D.A.; Aris, F.; Jones, G. Reproducing oscillatory behaviour of a hydroelectric power station by computer simulation. Control Eng. Pract. 2000, 8, 1261-1272. [CrossRef]

64. Sarasúa, J.I.; Martínez-Lucas, G.; Lafoz, M. Analysis of alternative frequency control schemes for increasing renewable energy penetration in El Hierro Island power system. Int. J. Electr. Power Energy Syst. 2019, 113, 807-823. [CrossRef]

65. Kundur, P.; Balu, N.J.; Lauby, M.G. Power System Stability and Control; McGraw-Hill: New York, NY, USA, 1994; Volume 7.

66. Pöller, M.; Achilles, S. Aggregated wind park models for analyzing power system dynamics. In Proceedings of the 4th International Workshop on Large-Scale Integration of Wind Power and Transmission Networks for Offshore Wind Farms, Billund, Denmark, 20-21 October 2003.

67. Clark, K.; Miller, N.W.; Sanchez-Gasca, J.J. Modeling of GE wind turbine-generators for grid studies. GE Energy 2010, 4, 0885-8950.

68. Zhao, S.; Nair, N.K. Assessment of wind farm models from a transmission system operator perspective using field measurements. IET Renew. Power Gener. 2011, 5, 455-464. [CrossRef]

69. Martínez-Lucas, G.; Sarasúa, J.I.; Sánchez-Fernández, J.Á. Eigen analysis of wind-hydro joint frequency regulation in an isolated power system. Int. J. Electr. Power Energy Syst. 2018, 103, 511-524. [CrossRef]

70. Perez-Diaz, J.I.; Sarasua, J.I.; Wilhelmi, J.R. Contribution of a hydraulic short-circuit pumped-storage power plant to the load-frequency regulation of an isolated power system. Int. J. Electr. Power Energy Syst. 2014, 62, 199-211. [CrossRef] 
71. UCTE (Union for the Co-ordination of Transmission of Electricity). Operation Handbook. 2004. Available online: https: / / www.entsoe.eu/publications/system-operations-reports/operation-handbook (accessed on 4 May 2020).

72. Wood, A.J.; Wollenberg, B.F.; Sheblé, G.B. Power Generation, Operation, and Control; John Wiley \& Sons: Hoboken, NJ, USA, 2013.

73. Sigrist, L. A UFLS scheme for small isolated power systems using rate-of-change of frequency. IEEE Trans. Power Syst. 2014, 30, 2192-2193. [CrossRef]

74. Dai, Y.; Xu, Y.; Dong, Z.; Wong, K.; Zhuang, L. Real-time prediction of event-driven load shedding for frequency stability enhancement of power systems. IET Gener. Transm. Distrib. 2012, 6, 914-921. [CrossRef]

75. Arani, M.F.M.; Mohamed, Y.A.R.I. Analysis and mitigation of undesirable impacts of implementing frequency support controllers in wind power generation. IEEE Trans. Energy Convers. 2015, 31, 174-186. [CrossRef]

(C) (9)

(C) 2020 by the authors. Licensee MDPI, Basel, Switzerland. This article is an open access article distributed under the terms and conditions of the Creative Commons Attribution (CC BY) license (http://creativecommons.org/licenses/by/4.0/). 



\subsection{Hybrid wind-PV frequency control strategy under variable weather conditions in isolated power systems}

As variable speed wind turbines (VSWTs) and photovoltaic (PV) power plants are connected to the grid through power converters, they are electrically decoupled from the grid. Moreover, the variable and stochastic nature of wind speed and solar irradiation may lead to large frequency deviations, especially in isolated power systems. This paper proposes a hybrid wind-PV frequency control approach for isolated power systems with high VSWTs and PV power plants integration under variable weather conditions. The proposed controller consists on VSWTs including a hidden-inertia emulation technique and PV power plants working with a de-load power of $10 \%$. The input of the PV frequency control is the rotational speed deviation of VSWTs, in contrast to previous studies where the frequency deviation was the input of the de-load PV controller. In this way, the PV power plants modify their generated power by following the rotational speed deviation of VSWTs. The proposed hybrid frequency approach is compared to three different frequency strategies: $(i)$ conventional power plants; $(i i)$ conventional power plants and wind power plants; and (iii) conventional power plants, wind power plants, and PV power plants with grid frequency as input. Results show that frequency oscillations are drastically reduced by including the proposed hybrid controller. In fact, the mean squared error of frequency variations is reduced up to a $95 \%$ comparing to the case in which only conventional power plants are controlling the frequency excursions. Severe reductions are also found when comparing the hybrid wind-PV strategy to the other two strategies in which VSWTs and PV were also participating in frequency control (between 20-65\%). The rotational speed deviation of the VSWTs also reduces with the hybrid wind-PV frequency approach, even getting the same mean squared error as when VSWTs do not participate in frequency control. However, the generated energy by the PV power plants decreases between $20-30 \%$ by using the proposed approach, and should be subsequently analysed by the transmission/distribution operators to guarantee some additional benefits for the owners of such generation units. Due to the interesting results here obtained, authors believe that new hybrid frequency control strategies in line with this work should be proposed and analysed to minimise frequency excursions linked to a massive RES integration.

Information of the paper:

- Journal: Sustainability

- DOI: $10.3390 /$ su12187750

- Date of publication: September 2020

- Available online: https://www.mdpi.com/2071-1050/12/18/7750

- Reference: [7] 

Article

\title{
Hybrid Wind-PV Frequency Control Strategy under Variable Weather Conditions in Isolated Power Systems
}

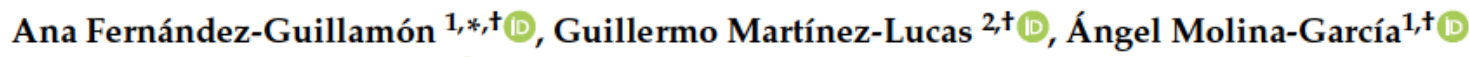 \\ and Jose-Ignacio Sarasua $2,+(\mathbb{D}$ \\ 1 Department of Automatics, Electrical Engineering and Electronic Technology, Universidad Politécnica de \\ Cartagena, 30202 Cartagena, Spain; angel.molina@upct.es \\ 2 Department of Hydraulic, Energy and Environmental Engineering, Universidad Politécnica de Madrid, \\ 28040 Madrid, Spain; guillermo.martinez@upm.es (G.M.-L.); joseignacio.sarasua@upm.es (J.-I.S.) \\ * Correspondence: ana.fernandez@upct.es; Tel.: +34-968-325-357 \\ + These authors contributed equally to this work.
}

Received: 7 August 2020; Accepted: 15 September 2020; Published: 19 September 2020

\begin{abstract}
Over the last two decades, variable renewable energy technologies (i.e., variable-speed wind turbines (VSWTs) and photovoltaic (PV) power plants) have gradually replaced conventional generation units. However, these renewable generators are connected to the grid through power converters decoupled from the grid and do not provide any rotational inertia, subsequently decreasing the overall power system's inertia. Moreover, the variable and stochastic nature of wind speed and solar irradiation may lead to large frequency deviations, especially in isolated power systems. This paper proposes a hybrid wind-PV frequency control strategy for isolated power systems with high renewable energy source integration under variable weather conditions. A new PV controller monitoring the VSWTs' rotational speed deviation is presented in order to modify the PV-generated power accordingly and improve the rotational speed deviations of VSWTs. The power systems modeled include thermal, hydro-power, VSWT, and PV power plants, with generation mixes in line with future European scenarios. The hybrid wind-PV strategy is compared to three other frequency strategies already presented in the specific literature, and gets better results in terms of frequency deviation (reducing the mean squared error between $20 \%$ and $95 \%$ ). Additionally, the rotational speed deviation of VSWTs is also reduced with the proposed approach, providing the same mean squared error as the case in which VSWTs do not participate in frequency control. However, this hybrid strategy requires up to a $30 \%$ reduction in the PV-generated energy. Extensive detailing of results and discussion can be also found in the paper.
\end{abstract}

Keywords: frequency control; power system stability; variable renewable energy sources; wind power plants; photovoltaic power plants

\section{Introduction}

Over the last two decades, power systems' generation has slowly been changing, replacing conventional generation units (mainly based on the fossil and nuclear fuels) with variable renewable energy sources (vRESs) [1]. This transition has been supported by several aspects, including environmental concern (especially greenhouse gas emissions) and the aim of decreasing the energy dependence of third countries [2-4]. vRES refers to variable-speed wind turbines (VSWTs) and photovoltaic (PV) power plants, which have a stochastic behavior due to their dependence on weather conditions [5]. Together with this point, vRESs are connected to the grid through power inverters decoupled from the grid and, hence, do not inherently provide any inertial or frequency response 
under power imbalances [6]. Consequently, the high penetration levels of vRESs will substantially challenge the supply security and reliability of future power systems, thus requiring more flexibility to maintain the balance between generation and demand [7-9]. Moreover, this real-time power balance is required for a stable grid frequency [10].

As an attempt to improve the frequency response of power systems with high vRES integration, several frequency control techniques have been proposed for such generation units in the specific literature [11,12]. In fact, they are usually classified as depicted in Figure 1. Together with these strategies, energy storage systems (i.e., batteries, flywheels, and supercapacitors) have also been considered as suitable options to maintain grid stability $[13,14]$. With regard to PV power plants, as they are static elements without any rotating parts, they do not have any stored kinetic energy [15]. Therefore, their synchronous inertia constant is nearly zero $\left(H_{P V} \approx 0\right)$ [16]. Consequently, they can only provide frequency response based on de-loading strategies. The de-loading technique implies the reduction of the supplied active power under normal operation conditions, going towards the right part of the P-V curve (refer to Figure 2). In this way, when grid frequency is lower than its nominal value, the PV installations can slightly decrease their voltage (from $V_{\text {del }}$ to $V_{M P P}$, see Figure 2) and subsequently increase the corresponding generated power [17]. The $\Delta V$ decrease is usually estimated based on the grid frequency deviation $\Delta f$ through a proportional or proportional-integral controller. Similarly to PV power plants, VSWTs can also provide frequency response using the de-loading technique. In this case, it is performed by pitching the blades or over-speeding the rotor [18]. De-loading strategies imply a reduction of the electrical power generated (both for PV and VSWTs) and, subsequently, a considerable decrease in the benefits for their owners [19]. As VSWTs have some stored kinetic energy due to their blades, drive train, and the electrical generator, some authors affirm that VSWTs' inertia constant $H_{W T}$ is in line with those of conventional power plants, but it is hidden from the power system point of view due to the power converter $[20,21]$. Consequently, together with the de-loading approach, VSWTs can provide such rotational inertia to the grid through different inertial response strategies. These strategies require at least one supplementary control loop to be included in the power controller [22]. Under frequency deviation conditions, the frequency control loop(s) will provide an additional input to the VSWTs, aiming to temporarily increase their active power generation. With this type of controller, VSWTs can always generate their maximum active power according to each wind speed value, in contrast to the de-loading technique, in which they slightly curtailed certain amounts of power. As a result, inertial response approaches are preferable to the de-loading technique, since the wind resource is better used [23]. However, inertial response approaches are limited by the VSWTs' speed governor, which prevents the rotational speed of the VSWTs from decreasing below the minimum allowed value [24]. Tables 1 and 2 summarize different vRES frequency control strategies proposed in the specific literature over the last years, including the type of control, PV/VSWT integration level, and the power imbalance $(\Delta P)$ that causes the frequency deviation. As can be seen in Tables 1 and 2, these frequency control strategies are usually analyzed under severe power imbalances (up to 50\%). However, in isolated power systems with high wind-PV integration, the variability of wind speed and solar irradiation commonly causes large deviations in the system frequency [25]. Indeed, these fluctuations pose stress on the power system operation, as transmission and distribution system operators (TSOs/DSOs) deal with not only unmanageable demand, but also uncontrollable generation [26]. Consequently, there is an acute need to improve the frequency response of isolated power systems with high vRES integration, especially under typical variable meteorological changes. In fact, over the last decade, some studies have already focused on this topic. However, most of the works proposed are based on including energy storage systems [27-34], demand response [35], and electric vehicles [36], or using independent frequency controllers for VSWT and PV power plants [37-39]. 
vRES frequency control strategies $\left\{\begin{array}{l}\operatorname{PV}\{\text { De-loading } \\ \text { VSWT }\left\{\begin{array}{l}\text { De-loading }\left\{\begin{array}{l}\text { Pitch } \\ \text { Over-speed }\end{array}\right. \\ \text { Inertial response }\left\{\begin{array}{l}\text { Droop } \\ \text { Hidden-inertia } \\ \text { Fast power reserve }\end{array}\right.\end{array}\right.\end{array}\right.$

Figure 1. Frequency control strategies for variable renewable energy sources (vRESs).

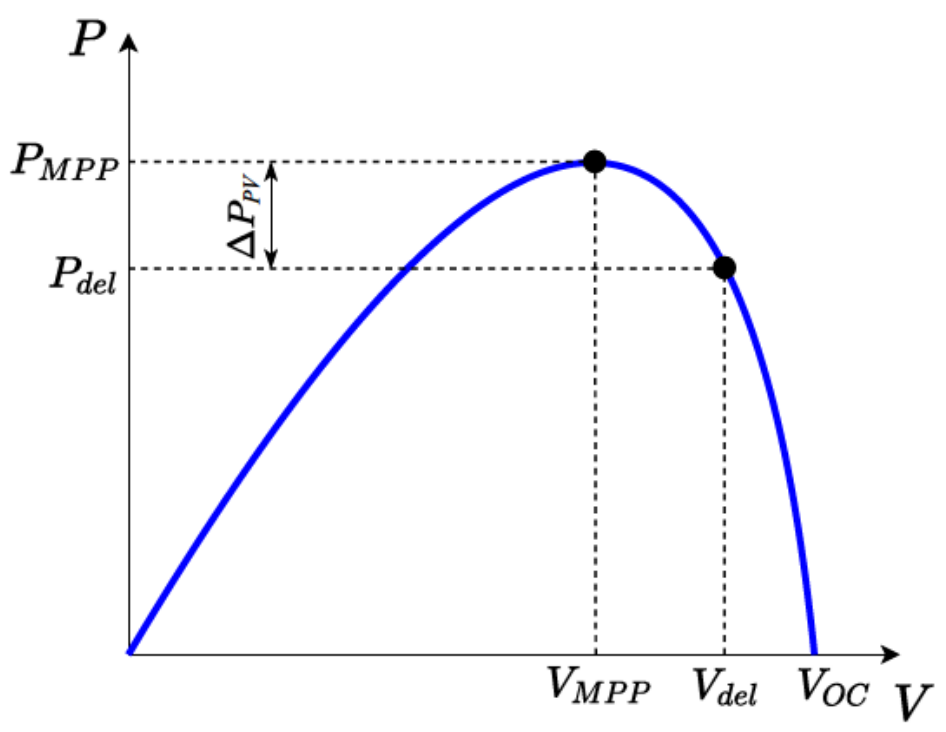

Figure 2. De-loading technique of photovoltaic (PV) power plants.

Table 1. PV frequency control proposals.

\begin{tabular}{ccccc}
\hline Ref. & Type of Control & PV Integration (\%) & $\boldsymbol{\Delta P}(\%)$ & Year \\
\hline$[40]$ & De-loading & 9 & 5 & 2012 \\
{$[41]$} & De-loading & 9 & 5 & 2012 \\
{$[42]$} & De-loading & 16 & - & 2013 \\
{$[43]$} & De-loading & 22 & 8.1 & 2014 \\
{$[44]$} & De-loading & $23-48$ & 50 & 2017 \\
{$[45]$} & De-loading & $10-20-30$ & 10 & 2019 \\
{$[46]$} & De-loading & 10 & 10 & 2019 \\
\hline
\end{tabular}

Table 2. Variable-speed wind turbine (VSWT) frequency control proposals.

\begin{tabular}{lcccc}
\hline Ref. & Type of Control & VSWT Integration (\%) & $\Delta \boldsymbol{P ( \% )}$ & Year \\
\hline$[47]$ & De-loading (pitch) & - & - & 2016 \\
\hline$[48]$ & Droop & $11,29.5$ & 15 & 2013 \\
\hline$[49]$ & Hidden-inertia emulation & 20 & 8.3 & 2015 \\
{$[50]$} & Hidden-inertia emulation & - & 10 & 2016 \\
{$[51]$} & Hidden-inertia emulation & - & 10 & 2019 \\
\hline$[52]$ & Fast power reserve & 20 & 10 & 2015 \\
{$[53]$} & Fast power reserve & $16.7-33$ & 16.7 & 2016 \\
{$[54]$} & Fast power reserve & $5-45$ & $2.5-10$ & 2018 \\
\hline
\end{tabular}


In contrast to the previous studies, this paper proposes a hybrid wind-PV frequency control strategy in which the VSWTs' rotational speed deviation is the proportional-integral (PI) controller input of the PV frequency response strategy. Similar approaches have been previously proposed by the authors, but by linking the rotational speed deviation of VSWTs to hydro-power plants instead of PV power plants [55]. The main contributions of this paper can be summarized as:

- A new hybrid wind-PV frequency control strategy is proposed. VSWTs include the hidden-inertia emulation technique, whereas PV power plants use the de-loading approach. The novelty of the hybrid control is that the PV frequency controller receives the VSWTs' rotational speed deviation as an input instead of the grid frequency deviation.

- The proposed controller is tested on an isolated power system consisting of thermal, hydro-power, VSWT, and PV power plants under six different scenarios. Frequency deviations are the result of the variability of both wind speed and solar irradiation, synthetically estimated (wind speed) and based on real measured values (solar irradiation).

- The frequency response is compared to three different frequency strategies: $(i)$ conventional power plants; (ii) conventional power plants and wind power plants; and (iii) conventional power plants, wind power plants, and PV power plants with frequency deviation as input. Minor frequency oscillations were obtained with the hybrid wind-PV frequency strategy in terms of minimum and maximum frequency deviations and mean squared error (MSE) of frequency, as well as in terms of minimum and maximum rotational speed of the VSWTs and MSE of their rotational speed deviation.

The rest of the paper is organized as follows: The models used for the simulations are described in Section 2; the methodology followed to carry out this study is presented in Section 3; in Section 4, the results of the study are shown and analyzed; finally, Section 5 presents the main conclusions of the paper.

\section{Proposed System Modeling}

A mathematical simulation model is used to analyze the proposed hybrid wind-PV frequency controller. This power system and, consequently, the model implemented in Matlab/Simulink includes conventional generators (hydro-power and thermal power plants), PV power plants, and VSWTs as well as the power demand, as shown in Figure 3. The frequency control is in line with current European requirements (primary and secondary controls), as will be presented in Section 3. In the following subsections, the main components of the proposed model are described in detail.

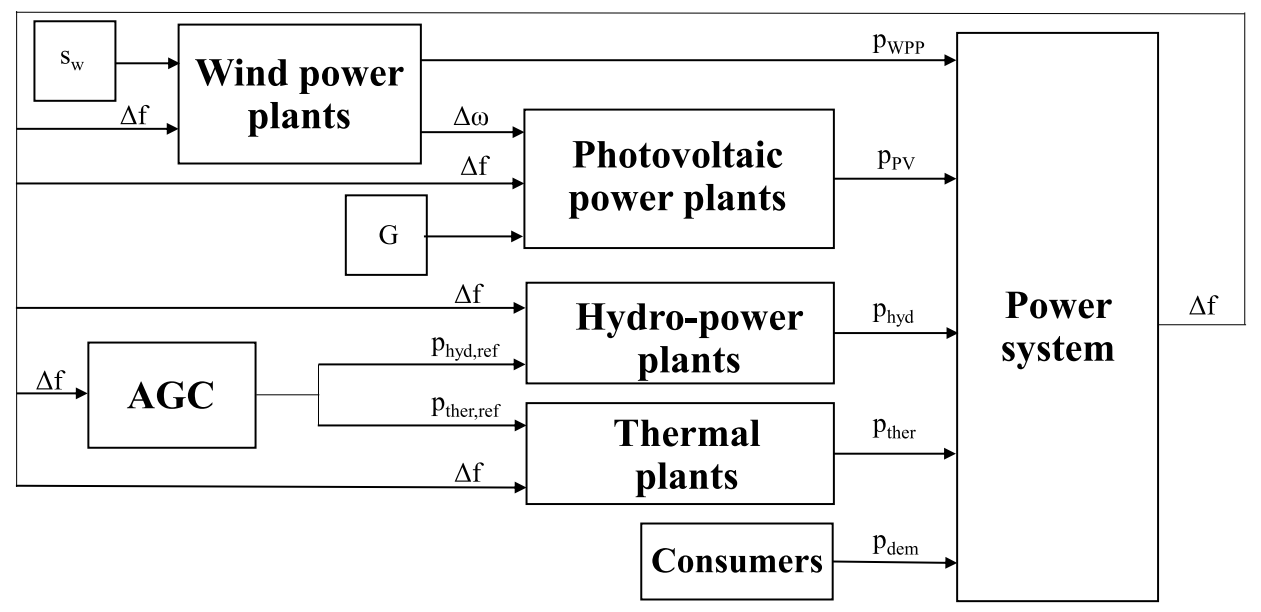

Figure 3. Block diagram of the model. 


\subsection{Power System and System Inertia}

The power system is modeled considering an aggregated inertial model as proposed in [56]. This formulation has been previously used to model the Irish isolated power system [57] and El Hierro isolated power system [58], among others. Grid frequency variations are the result of the imbalance between the power generation and the corresponding demand (see Equation (1)):

$$
f \frac{d f}{d t}=\frac{1}{2 H_{e q}}\left(p_{w}+p_{P V}+p_{\text {hyd }}+p_{\text {ther }}-p_{\text {dem }}-D_{\text {net }} \Delta f\right),
$$

where $p_{w}, p_{P V}, p_{h y d}$, and $p_{\text {ther }}$ represent the power supplied by VSWT, PV, hydro-power, and thermal power plants, respectively; $p_{d e m}$ is the total power demand; and $D_{n e t}$ is the consumer load sensitivity factor to frequency variations. System inertia $\left(H_{e q}\right)$ is estimated as [59]:

$$
H_{e q}=H_{h y d}+H_{\text {ther }}
$$

where $H_{\text {hyd }}$ and $H_{\text {ther }}$ are the hydro-power and thermal power plants' inertia constants, respectively. The VSWT and PV power plants are connected to the grid through power converters and, therefore, do not inherently provide synchronous inertia to the grid, as already discussed in Section 1.

\subsection{Conventional Power Plants}

The conventional power plants (CPPs) considered in this paper are reheat thermal and hydro-power plants. Both of them are modeled following the transfer functions proposed in [60]. Thermal power plants' transfer function, shown in Figure 4a, provides the power variations of these power plants from the frequency deviation $(\Delta f)$ and the automatic generation control (AGC) power reference $\left(p_{\text {ther, ref }}\right)$. Figure $4 \mathrm{~b}$ shows the transfer function to model the hydro-power plant, including the conduits' dynamics. The generated power $p_{\text {hyd }}$ also depends on the frequency deviation $\Delta f$ and the power reference signal provided by the AGC ( $\left.p_{h y d r, r e f}\right)$. The parameters for both models in Figure 4 are listed in Table 3.

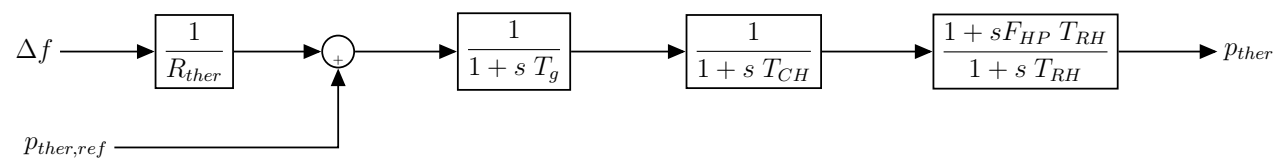

(a)

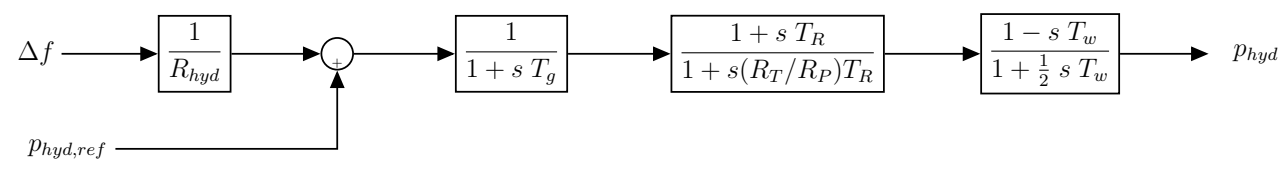

(b)

Figure 4. Block diagram of conventional power plants: (a) thermal power plants' transfer function and (b) hydro-power plants' transfer function.

\subsection{Wind Power Plants}

Four different wind power plants (WPPs) are considered by modeling each WPP with an aggregated wind turbine. Therefore, one equivalent wind turbine is then simulated by multiplying the corresponding generated power by the number of VSWTs of such a WPP [61]. The VSWT model includes the wind power model, which determines the power extracted from the wind speed; the blade pitch control to regulate the wind input torque; the torque maximum power point (MPP) tracking control, which restores the optimal rotor speed after a rotational speed deviation; and the frequency 
controller, which is discussed in Section 3.2. Further information with regard to the VSWT model can be found in [62]. The one-mass rotor mechanical model is used for simulations, and is acceptable when the voltage is assumed to be constant $[63,64]$ :

$$
\omega_{W T}=\frac{p_{m t}-p_{W}}{2 H_{W T} s} .
$$

The reference rotational speed $\omega_{\text {ref }}$ is determined from the measured power $p_{e f}$, which is the active generated power $p_{W}$ after a delay $T_{f}$ :

$$
\omega_{r e f}=-0.67 \times p_{e f}^{2}+1.42 \times p_{e f}+0.51 .
$$

The VSWT model is represented in Figure 5. The values of the different parameters are listed in Table 3.

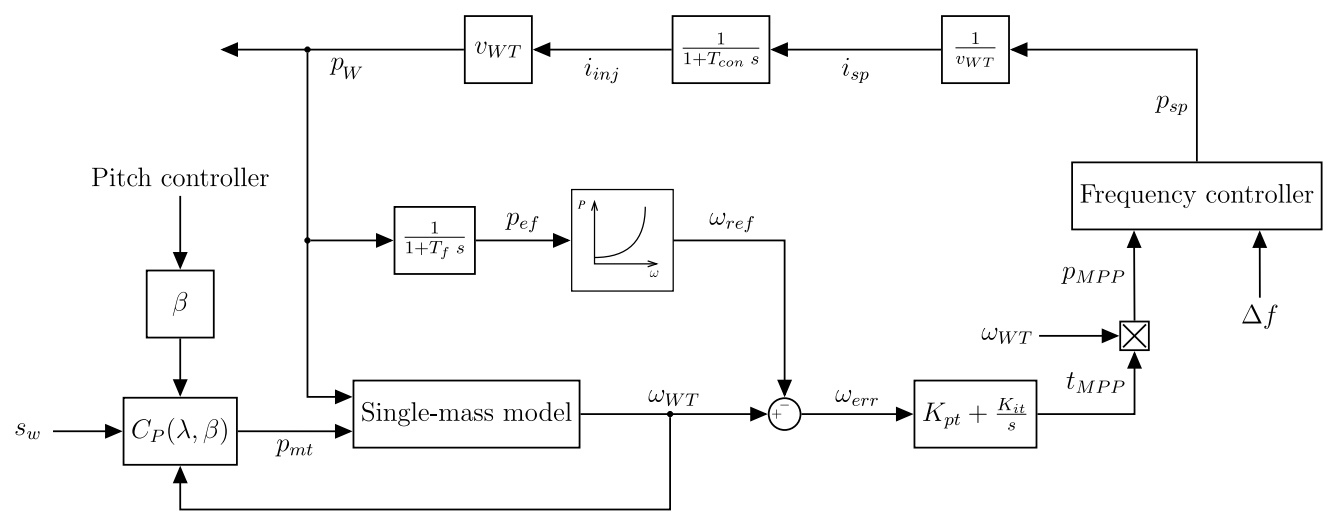

Figure 5. Block diagram of a VSWT.

\subsection{PV Power Plant}

Four different PV power plants are also considered. They are modeled following the diode equation, where the output current $I_{P V}$ is given by $[65,66]$ :

$$
I_{P V}=N_{P} \times I_{p h}-N_{P} \times I_{r s} \times\left[\exp \left(\frac{q}{k_{B} \times T_{C} \times A} \times \frac{V_{P V}}{N_{s}}\right)-1\right] .
$$

$N_{s}$ is the number of cells in series, $N_{P}$ is the number of strings in parallel, $I_{p h}$ is the photo-current, $q$ is the electron charge, $k_{B}$ is Boltzmann's constant, $T_{C}$ is the temperature of the cell, $A$ is the diode ideality factor, and $V_{P V}$ is the PV voltage. The photo-current $I_{p h}$ is calculated by:

$$
I_{p h}=\left[I_{s C}+k_{I}\left(T_{C}-T_{S T C}\right)\right] \times G,
$$

where $I_{s c}$ is the PV cell's short-circuit current, $k_{I}$ is the short-circuit current temperature coefficient of the PV cell, $T_{S T C}$ is the temperature under Standard Test Conditions (STC), and G is the solar irradiation. The PV cell's reverse saturation current $I_{r s}$ follows Equation (7), where $I_{r, \text { ref }}$ is the reverse saturation current at $T_{S T C}$, and $E_{G}$ is the band-gap energy of the PV cell's material:

$$
I_{r s}=I_{r, r e f} \times\left(\frac{T_{C}}{T_{S T C}}\right)^{3} \times \exp \left[\frac{q \times E_{G}}{k_{B} \times A} \times\left(\frac{1}{T_{S T C}}-\frac{1}{T_{C}}\right)\right] .
$$

The voltage at the MPP $\left(V_{M P P}\right)$ for a given irradiation $G$ and cell temperature $T_{C}$ is estimated depending on its value at STC and a correction factor $\alpha_{V}$ :

$$
V_{M P P}=V_{M P P, S T C} \times\left(\frac{\ln (G)}{\ln (1000)}\right) \times\left(1+\alpha_{V} \times\left(T_{C}-T_{S T C}\right)\right) .
$$


By multiplying the PV voltage $V_{P V}$ by the output PV current $I_{P V}$, the active power of the PV generator is then estimated. In the case that the PV voltage corresponds to the MPP voltage $V_{M P P}$, the output power of the PV power plants would be the maximum available active power under such $G$ and $T_{C}$ conditions. The values of the different parameters considered are listed in Table 3.

Table 3. Power plant parameters $[60,62,66]$.

\begin{tabular}{cccccccc}
\hline \multicolumn{2}{c}{ Thermal } & \multicolumn{2}{c}{ Hydro-Power } & \multicolumn{2}{c}{ VSWTs } & \multicolumn{2}{c}{ PV } \\
\hline Parameter & Value & Parameter & Value & Parameter & Value & Parameter & Value \\
\hline$R_{\text {ther }}$ & 0.05 & $R_{\text {hyd }}$ & 0.05 & $T_{f}$ & 5 & $k_{I}$ & 0.0017 \\
$T_{g}$ & 0.2 & $T_{g}$ & 0.2 & $T_{\text {con }}$ & 0.02 & $I_{r, r e f}$ & $1.2 \times 10^{-7}$ \\
$T_{C H}$ & 0.3 & $T_{R}$ & 5 & $v_{W T}$ & 1 & $\alpha_{v}$ & $-5.53 \times 10^{-3}$ \\
$F_{H P}$ & 0.3 & $R_{T}$ & 0.38 & $K_{p t}$ & 1 & $q$ & $1.602 \times 10^{-19}$ \\
$T_{R H}$ & 7 & $R_{P}$ & 0.05 & $K_{i t}$ & 0.2 & $k_{B}$ & $1.38 \times 10^{-23}$ \\
$H_{\text {ther }}$ & 5 & $T_{w}$ & 1 & & & $A$ & 1.92 \\
& & $H_{\text {hydro }}$ & 3.3 & & & $I_{s c}$ & 8.03 \\
& & & & & & $E_{g}$ & 1.12 \\
\hline
\end{tabular}

\section{Methodology}

Frequency control strategies focus on minimizing grid frequency variations due to generation-demand mismatches [67]. With this aim, generation units must increase/decrease their generation to equal the total power demand (plus the power system losses) [68]. In the following subsections, frequency controls for CPPs, VSWTs, and PV power plants are described.

\subsection{Frequency Control in Conventional Power Plants}

CPPs based on synchronous generators inherently release or absorb kinetic energy as a natural inertial response to frequency deviations. In Europe, frequency control with CPPs has a hierarchical structure, usually organized in primary control (frequency containment reserves), secondary control (frequency restoration reserves), and tertiary control (replacement reserves) [69]. Primary frequency control (PFC) is automatically activated by the generator units some seconds after the power imbalance. The CPP power response is proportional to the frequency deviation $\Delta f$, following Equation (9), in which $R$ is the droop characteristic [70,71]:

$$
\Delta p=-\frac{\Delta f}{R} .
$$

According to the European network of transmission system operators for electricity (ENTSO-E), $R$ should range between $2 \%$ and $12 \%$, with a dead-band between 10 and $30 \mathrm{mHz}$ in which the PFC is not activated [72]. For this work, $R$ is considered as $5 \%$ for both thermal and hydro-power plants, and the dead-band is established at $30 \mathrm{mHz}$. Subsequent to the PFC action, there is still some remaining frequency deviation due to the power imbalance. The secondary frequency control is then required to completely remove this frequency deviation $[73,74]$. In fact, this secondary frequency control is in charge of modifying the power generation set-point accordingly [75]. The AGC coordinates the effort's dispatch among the different CPPs of the secondary frequency control. In this paper, the equivalent total secondary regulation effort $(\triangle R R)$ is determined by:

$$
\Delta R R=-\Delta f \times K_{f},
$$


where $K_{f}$ is estimated following the ENTSO-E's recommendations [76]. This $\Delta R R$ is distributed between the thermal and hydro-power plants depending on their participation factors $\left(K_{u, i}\right)$, determined according to the droop of each power plant [77]:

$$
\Delta p_{i, r e f}=\frac{1}{T_{u, i}} \int \Delta R R \times K_{u, i} d t=\frac{-1}{T_{u, i}} \times K_{u, i} \times K_{f} \times \int \Delta f d t
$$

where $i$ represents hyd or ther, and $K_{u, h y d}+K_{u, t h e r}=1$.

\subsection{VSWT Frequency Control Strategy}

Among the three different inertial response strategies for VSWTs (refer to Figure 1), the hidden-inertia emulation technique is selected for this work. The hidden-inertia emulation technique is based on a proportional-derivative $(P D)$ control loop, with $\Delta f$ as input. This $P D$ controller provides an additional power proportional to the frequency deviation and its derivative value:

$$
\Delta p_{F C}=K_{d} \times \frac{d \Delta f}{d t}+K_{p} \times \Delta f
$$

The derivative part represents the inertial control loop (emulating the hidden-inertia of the VSWTs). These inertial (derivative) and proportional control loops allow that some of the kinetic energy stored in the rotating masses of the VSWTs (i.e., rotor, drive train, and electrical generator) is released to provide a fast frequency response from the power converter's capability. This $\Delta p_{F C}$ signal is added to the power reference output depending on the wind speed.

\subsection{PV Frequency Control Strategy}

The de-loading technique is used for PV frequency control. This strategy curtails a certain amount of active power, working the PV power plant on a de-loaded voltage value $\left(V_{d e l}\right)$ on the right side of the MPP voltage $\left(V_{M P P}\right)$, as shown in Figure 2. Note that $V_{\text {del }}>V_{M P P}$. In the following subsections, the traditional de-loading strategy and the proposed hybrid wind-PV frequency control approach are analyzed.

\subsubsection{Conventional De-Loaded PV Frequency Control Strategy}

To provide frequency response, the PV power plant usually works at the de-loaded voltage $V_{d e l}$. In the case of frequency reduction, the PV voltage should be also reduced, moving towards $V_{M P P}$ to increase its generated active power. The strategies previously proposed in the specific literature include a proportional $(P)$ or proportional-integral $(P I)$ controller, with the frequency deviation $(\Delta f)$ as an input of such a controller [40-43]. Frequency deviation $(\Delta f)$ passes through the corresponding control loop (P or $P I)$, giving an additional voltage $\Delta V$ (refer to Figure 6). The modified PV voltage is then determined as:

$$
V_{P V}=V_{d e l}-\Delta V
$$

This $V_{P V}$ is used in Equation (5) to determine the PV current, $I_{P V}$, which is the corresponding PV active power:

$$
P_{P V}=I_{P V} \times V_{P V} .
$$




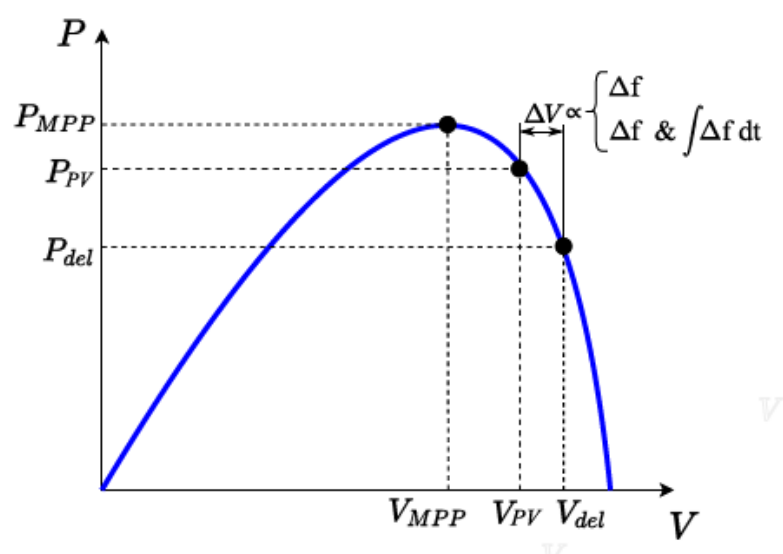

Figure 6. Conventional de-loaded PV frequency control.

\subsubsection{Hybrid Wind-PV Frequency Control}

In this work, and in contrast to previous studies, the authors propose the use of the VSWT rotational speed deviation $\Delta \omega$ as an input for the de-loaded PV frequency controller. Due to the VSWTs' hidden-inertia frequency controller, the rotational speed $\omega_{j}$ of each WPP deviates from the reference value $\omega_{r e f, j}$, following Equation (15):

$$
\Delta \omega_{j}=\omega_{j}-\omega_{r e f, j}
$$

where $\omega_{r e f, j}$ is calculated from Equation (4). The global $\Delta \omega$ sent to the PV power plants is the sum of the $\Delta \omega_{j}$ of each WPP:

$$
\Delta \omega=\sum_{j=1}^{4} \Delta \omega_{j} .
$$

This global $\Delta \omega$ will pass through the PI controller, obtaining the value of $\Delta V$ of Equation (13). An overview of the hybrid wind-PV frequency control approach is shown in Figure 7. By using $\Delta \omega$ as an input, PV power plants modify their generated power according to this rotational speed deviation, improving the VSWTs' rotational speed control and subsequently increasing the inertial control performance of the VSWTs.

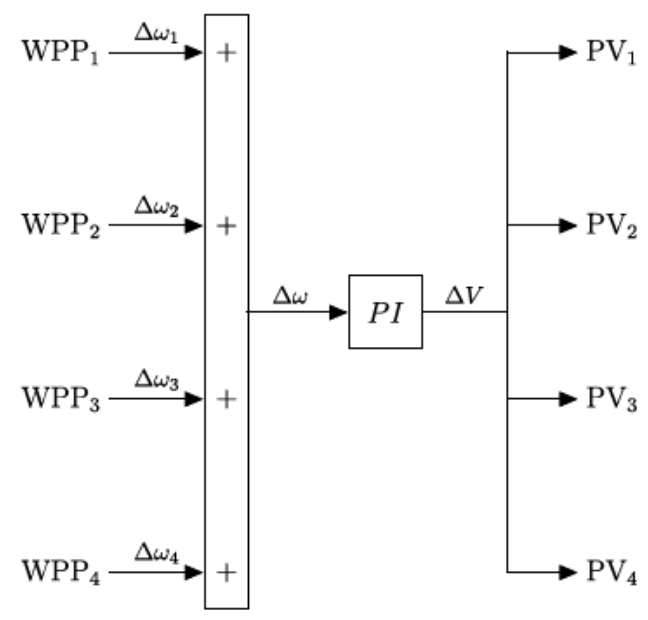

Figure 7. Hybrid wind-PV frequency control approach. 


\section{Results}

\subsection{Scenarios under Consideration}

The Ten-Year Network Development Plan (TYNDP) 2020 Scenario Report is used to propose the generation mix under consideration [78]. National trend scenarios are taken into account by the authors, which account for both the supply and demand data collected from the European electricity TSOs. Figure 8 shows the generation mix considered in this paper following [78] for the years 2025 and 2040.

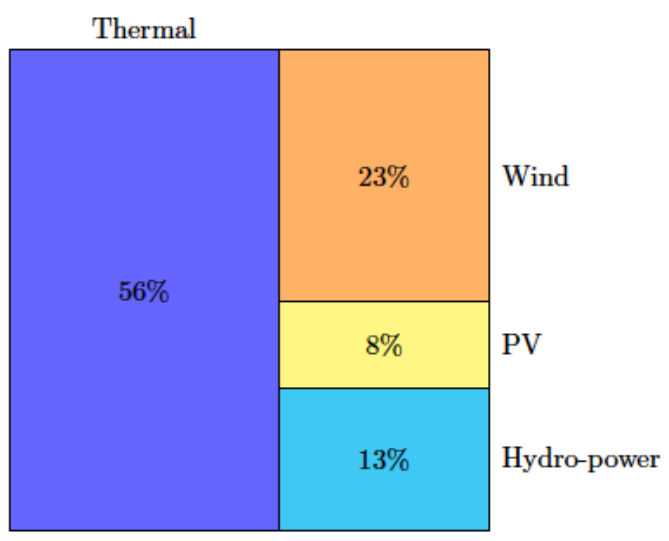

(a)

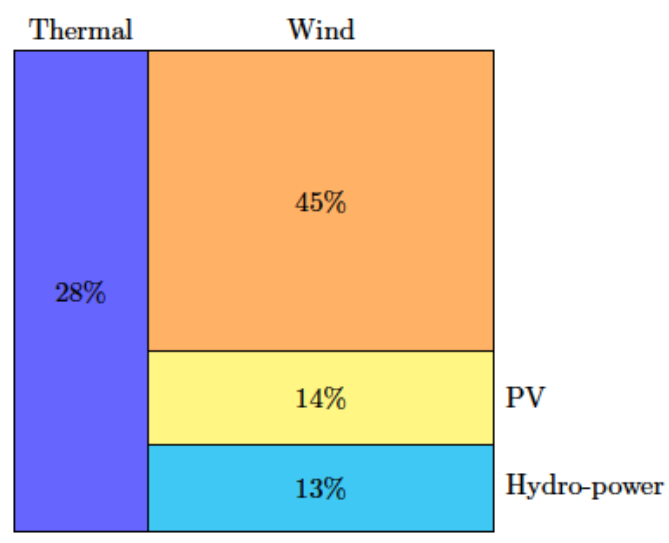

(b)

Figure 8. Generation mix following the national trends of TYNDP in (a) year 2025 and (b) year 2040.

Three different electricity demand values (i.e., valley, mean, and peak periods) are also studied based on the Gran Canaria isolated power system (Spain). This power system has been extensively described in [79]. Consequently, by combining the two generation mixes and the three different demand values, six scenarios are under analysis. Power demand is assumed as constant during the simulations, as the timeframe under analysis is $5 \mathrm{~min}(300 \mathrm{~s})$. As presented in Table 4, this assumption is in line with most TSOs.

Table 4. Time interval where demand is considered as constant for different transmission system operators (TSOs).

\begin{tabular}{cccc}
\hline TSO & Location & Time (min) & Website \\
\hline ENMAX & Canada & 15 & {$[80]$} \\
ERGON & Australia & 15 & {$[81]$} \\
RTE & France & 15 & {$[82]$} \\
REE & Spain & 10 & {$[83]$} \\
IESO & Canada & 5 & {$[84]$} \\
CAISO & California & 5 & {$[85]$} \\
TEPCO & Japan & 5 & {$[86]$} \\
TRANSPOWER & New Zealand & 5 & {$[87]$} \\
\hline
\end{tabular}

Wind speed and solar irradiation present some oscillations during the simulation time intervals. These variations cause certain frequency deviations from the nominal value $(50 \mathrm{~Hz})$. Real measured values of solar irradiation from a PV power plant in Albacete (Spain) are used for simulation purposes. In addition, synthetic wind speeds estimated from the methodology detailed in [88] are also included in the scenarios. Such synthetic wind speeds have been statistically compared to real measured wind speed series, obtaining similar values. 
As mentioned in Section 2, four different WPPs and PV power plants are considered:

$$
\begin{gathered}
p_{W P P}=\sum_{j=1}^{4} p_{W P P, j}, \\
p_{P V}=\sum_{k=1}^{4} p_{P V, k} .
\end{gathered}
$$

A heterogeneous distribution of wind- and PV-generated power is estimated to give more realistic simulations, considering that $\mathrm{WPP}_{1}$ and $\mathrm{PV}_{1}$ account for $50 \%$ of the total $p_{W P P}$ and $p_{P V} ; \mathrm{WPP}_{2}$ and $\mathrm{PV}_{2}$ are $25 \%$ of the total $p_{W P P}$ and $p_{P V}$; and $\mathrm{WPP}_{3}=\mathrm{WPP}_{4}$ and $\mathrm{PV}_{3}=\mathrm{PV}_{4}$ are $12.5 \%$ of the total $p_{W P P}$ and $p_{P V}$, respectively. The wind speed values $s_{w}$ and solar irradiation $G$ for each WPP and PV power plant are depicted in Figures 9 and 10.

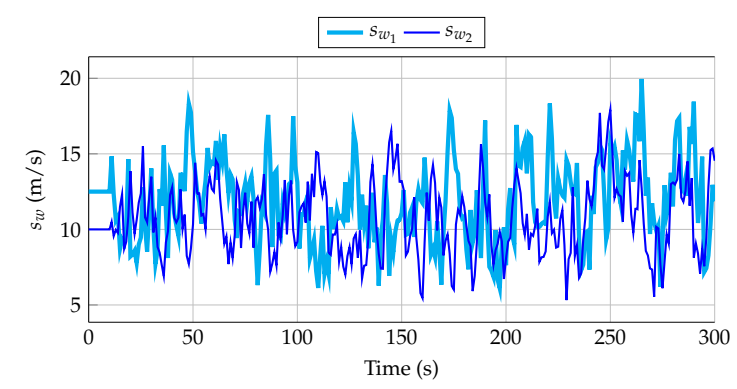

(a)

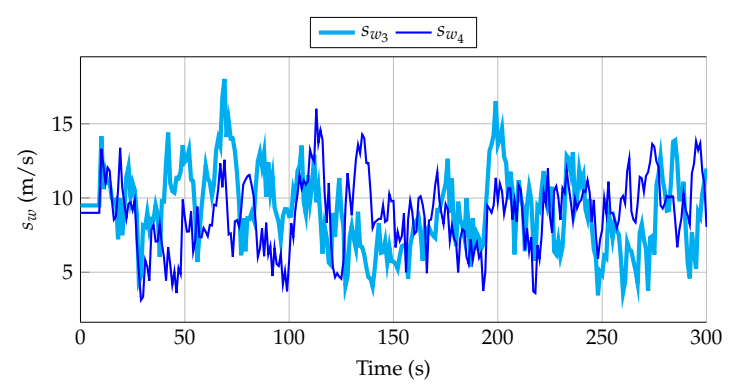

(b)

Figure 9. Wind speeds considered for the wind power plants (WPPs): (a) $\mathrm{WPP}_{1}$ and $\mathrm{WPP}_{2}$ as well as (b) $\mathrm{WPP}_{3}$ and $\mathrm{WPP}_{4}$.

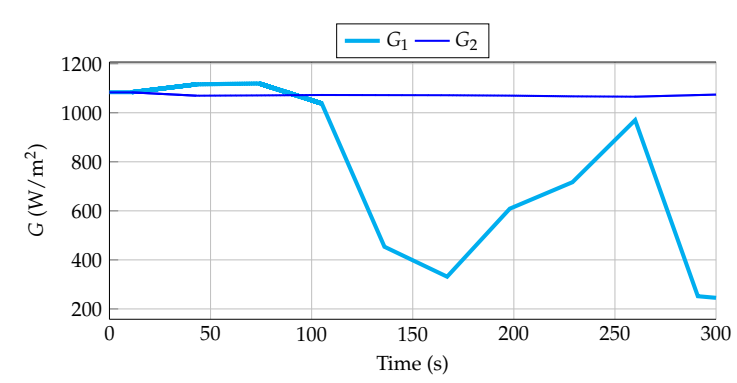

(a)

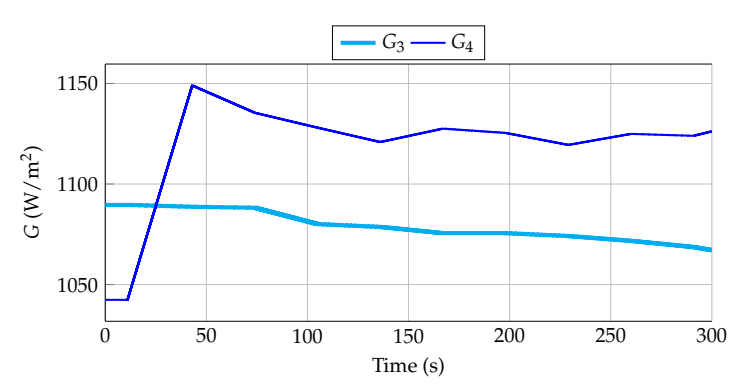

(b)

Figure 10. Solar irradiations considered for (a) $\mathrm{PV}_{1}$ and $\mathrm{PV}_{2}$ as well as (b) $\mathrm{PV}_{3}$ and $\mathrm{PV}_{4}$.

\subsection{Simulation Results}

The six scenarios presented in Section 4.1 were simulated in a Matlab/Simulink environment. A fixed step with the ode3 (Bogcki-Shampine) solver and a step size of $10^{-2} \mathrm{~s}$ was used. The Matlab version was r2016a. Four different frequency control strategies were compared:

1. Frequency control is only provided by conventional power plants (referred to as $C P P$ ).

2. Frequency control is provided by conventional power plants and WPPs with a hidden-inertia emulation technique (referred to as WPP).

3. Frequency control is provided by conventional power plants, WPPs with a hidden-inertia emulation technique, and PV power plants with $10 \%$ de-loading and a $P$ controller with $\Delta f$ as input (referred to as $P V(f))$. 
4. Frequency control is provided by conventional power plants, WPPs with a hidden-inertia emulation technique, and PV power plants with $10 \%$ de-loading and a PI controller with $\Delta \omega$ of the VSWTs as input (referred to as $P V(\omega)$ ), which is the hybrid wind-PV frequency strategy proposed in this paper.

In each simulation, the authors considered different criteria to compare the frequency control strategies under consideration. Specifically, the parameters taken into account are the following: the minimum and maximum frequency values, the MSE of the grid frequency, the PV-generated energy, the MSE of the thermal and hydro-power plants with respect to their initial assigned power, the minimum and maximum values of the rotational speed of each WPP, and the MSE of the rotational speed of each WPP with respect to their reference value $\left(\omega_{\text {ref }}\right)$ for each wind speed. Tables $5-9$ show the results of the parameters for the six scenarios simulated under the different frequency control strategies. The PV-generated energy is determined by multiplying the active power $P_{P V}$ by the time interval under analysis (5 $\mathrm{min})$.

Table 5. Simulation results: frequency, PV electrical energy, and the conventional power plants' mean square error (MSE).

\begin{tabular}{|c|c|c|c|c|c|c|c|}
\hline \multirow{2}{*}{ Scenario } & \multirow{2}{*}{$\begin{array}{c}\text { Load (MW) } \\
\text { Year }\end{array}$} & \multicolumn{2}{|c|}{250} & \multicolumn{2}{|c|}{400} & \multicolumn{2}{|c|}{550} \\
\hline & & 2025 & 2040 & 2025 & 2040 & 2025 & 2040 \\
\hline \multirow{4}{*}{$f_{\min }(\mathrm{Hz})$} & $\mathrm{CPP}$ & 49.28 & 44.89 & 49.31 & 46.24 & 49.34 & 45.74 \\
\hline & WPP & 49.54 & 48.49 & 49.55 & 48.59 & 49.57 & 48.63 \\
\hline & $\operatorname{PV}(f)$ & 49.58 & 48.88 & 49.61 & 48.85 & 49.60 & 49.00 \\
\hline & $\mathrm{PV}(\omega)$ & 49.58 & 48.94 & 49.61 & 48.87 & 49.61 & 49.20 \\
\hline \multirow{4}{*}{$f_{\max }(\mathrm{Hz})$} & CPP & 50.85 & 54.30 & 50.84 & 54.16 & 50.78 & 54.08 \\
\hline & WPP & 50.47 & 50.74 & 50.47 & 50.71 & 50.45 & 50.72 \\
\hline & $\operatorname{PV}(f)$ & 50.26 & 50.41 & 50.29 & 50.48 & 50.32 & 50.48 \\
\hline & $\operatorname{PV}(\omega)$ & 50.23 & 50.25 & 50.18 & 50.23 & 50.17 & 50.54 \\
\hline \multirow{4}{*}{$M S E_{f}\left(\mathrm{~Hz}^{2}\right)$} & CPP & 0.072 & 1.481 & 0.069 & 1.123 & 0.063 & 1.154 \\
\hline & WPP & 0.035 & 0.243 & 0.034 & 0.216 & 0.032 & 0.203 \\
\hline & $\operatorname{PV}(f)$ & 0.019 & 0.108 & 0.021 & 0.111 & 0.023 & 0.104 \\
\hline & $\operatorname{PV}(\omega)$ & 0.015 & 0.087 & 0.014 & 0.082 & 0.015 & 0.085 \\
\hline \multirow{4}{*}{$E_{P V}(\mathrm{MWh})$} & $\mathrm{CPP}$ & 1.536 & 2.878 & 2.636 & 4.645 & 3.424 & 5.955 \\
\hline & WPP & 1.536 & 2.878 & 2.636 & 4.645 & 3.424 & 5.955 \\
\hline & $\operatorname{PV}(f)$ & 1.269 & 2.391 & 2.251 & 3.930 & 3.096 & 5.010 \\
\hline & $\operatorname{PV}(\omega)$ & 1.072 & 2.186 & 1.962 & 3.610 & 2.740 & 4.091 \\
\hline \multirow{4}{*}{$M S E_{P_{\text {ther }}}\left(\mathrm{MW}^{2}\right)$} & CPP & 105.4 & 198.7 & 258.1 & 515.6 & 442.0 & 932.0 \\
\hline & WPP & 83.40 & 171.8 & 206.3 & 442.2 & 370.9 & 795.8 \\
\hline & $\operatorname{PV}(f)$ & 56.98 & 128.2 & 143.9 & 320.5 & 290.7 & 555.3 \\
\hline & $\operatorname{PV}(\omega)$ & 73.62 & 150.3 & 170.5 & 359.4 & 328.7 & 773.7 \\
\hline \multirow{4}{*}{$M S E_{P_{h y d}}\left(\mathrm{MW}^{2}\right)$} & CPP & 2.931 & 41.51 & 7.272 & 97.38 & 12.51 & 177.1 \\
\hline & WPP & 2.579 & 31.51 & 6.426 & 74.60 & 11.69 & 130.8 \\
\hline & $\mathrm{PV}(f)$ & 2.029 & 20.28 & 4.939 & 49.68 & 9.798 & 81.92 \\
\hline & $\operatorname{PV}(\omega)$ & 3.021 & 26.07 & 7.021 & 61.54 & 13.19 & 127.3 \\
\hline
\end{tabular}

With respect to the frequency deviations, the proposed hybrid wind-PV technique results in the maximum $f_{\min }$ and the minimum $f_{\max }$ values. This means that smaller frequency deviations are obtained, which is also shown in the MSE. In fact:

- A reduction of the MSE between $75 \%$ and $95 \%$ is obtained when the proposed hybrid wind-PV frequency strategy is used, in contrast to the CPP approach.

- A reduction of the MSE between 50\% and $65 \%$ is obtained when the proposed hybrid wind-PV frequency strategy is used, in contrast to the WPP approach.

- A reduction of the MSE between $20 \%$ and $35 \%$ is obtained when the proposed hybrid wind-PV frequency strategy is used, in contrast to the $\operatorname{PV}(f)$ approach. 
Moreover, the authors would like to highlight that similar results are obtained for the three different power demand scenarios in terms of minimum and maximum frequency deviations, together with the MSE of frequency. Consequently, it can be affirmed that this study is scalable to other isolated power systems, and similar results will be obtained independently of the demand as long as the generation mixes are similar to those considered here, which are in line with future European renewable energy integration roadmaps. It is important to remark that, for the 2025 scenario, frequency deviations are nearly within the acceptable range proposed by the ENTSO-E, i.e., $\pm 800 \mathrm{mHz}$ [89], even if the vRESs do not participate in frequency control. However, as vRESs massively replace CPPs, frequency response will be substantially deteriorated. In fact, minimum and maximum frequency values under $45 \mathrm{~Hz}$ and over $54 \mathrm{~Hz}$, respectively, are obtained if only CPPs are considered for frequency control response for year 2040. This means that, in the medium term, it is a crucial need that vRESs participate in frequency control to avoid such negative effects due to important (and negative) frequency oscillations.

Focusing on the PV-generated energy, the hybrid wind-PV technique gets the minimum values, mainly due to the initial $10 \%$ power de-loading and the action based on the $\Delta \omega$ that comes from VSWTs. Specifically:

- Considering the CPP and WPP strategies, the PV power plants work on their MPP and, subsequently, their generated energy is the maximum among the four strategies (and the same for both cases).

- Considering the PV $(f)$ strategy, the PV power plants are de-loaded by $10 \%$. A reduction between $10 \%$ and $20 \%$ of the PV-generated energy is then obtained in comparison to the CPP and WPP strategies.

- A reduction between $20 \%$ and $30 \%$ of the PV-generated energy is obtained by using the proposed hybrid wind-PV control compared to the CPP and WPP strategies.

Therefore, the hybrid wind-PV strategy implies an additional PV energy reduction of up to $10 \%$ in comparison to a conventional PV frequency control strategy. This aspect should be subsequently evaluated by the PV installation operators. Indeed, their benefits should be partially reduced if TSOs/DSOs do not reward them for providing frequency control services.

With regard to the conventional power plants, including any frequency strategy of vRESs reduces the contribution of thermal and hydro-power to the frequency response. The MSE between the power generated by them and their initial assigned value is thus reduced:

- Comparing the CPP and WPP strategies, the use of VSWTs for frequency control reduces the MSE of thermal power plants by between $14 \%-20 \%$, with a reduction between $12 \%-24 \%$ for hydro-power plants.

- Comparing the CPP and PV $(f)$ strategies, including a conventional de-loading frequency control strategy for PV power plants reduces the MSE of thermal power plants by between $35 \%-46 \%$, with a reduction between $31 \%-51 \%$ for hydro-power plants.

- Comparing the CPP and PV $(\omega)$ strategies, using the hybrid wind-PV control approach reduces the MSE of thermal power plants between $24 \%-30 \%$, with a reduction between $5 \%-35 \%$ for hydro-power plants. Moreover, there are some cases in which the MSE of the hydro-power plant is slightly increased.

The $P V(f)$ strategy is then the best technique from the point of view of the MSE of conventional power plants.

Finally, focusing on the rotational speed of WPPs (Tables 6-9):

- The CPP strategy has the smallest variations of rotational speeds. This is due to the fact that such rotational speed variations are only the result of wind speed changes.

- The WPP strategy has the largest variations of rotational speed values. In fact, both the minimum/maximum values of $\omega_{j}$ are obtained with this technique, even though they are small 
variations of around 5\%-10\%. Consequently, the maximum MSE is obtained with the WPP strategy. In some cases, the MSE result is three times higher than the value obtained with the CPP approach. Naturally, the speed deviations with this strategy are the result of both the wind speed changes and the hidden-inertia frequency control approach.

- The $P V(f)$ technique slightly improves the minimum/maximum rotational speed values and the MSE (if comparing to the WPP strategy). However, these values are still worse than with the CPP approach.

- The PV $(\omega)$ strategy reduces the minimum and maximum values of the rotational speed even more, and, consequently, reduces the MSE (if comparing to the WPP and PV $(f)$ strategies). In fact, there are some cases in which the MSE is quite similar for both the CPP and $\operatorname{PV}(\omega)$ techniques.

It can be affirmed that the $\operatorname{PV}(\omega)$ technique is the best overall frequency control strategy, as frequency deviations are reduced and the rotational speed variations of the WPPs are closer to their reference values. Nevertheless, this frequency control solution implies certain reductions in PV-generated energy that should be analyzed by the PV installation operators to compensate for possible decreases in benefits. In Figure 11, the frequency evolution, active power of the four generation units, and $\Delta \omega$ input for the PI controller of PV power plants for the hybrid wind-PV strategy are presented for the $550 \mathrm{MW}$ load and 2025 year scenario. As can be seen, when CPPs are only considered for frequency control, there are severe frequency oscillations, which are reduced by including vRESs into the frequency control. As was discussed, among the three different vRES frequency control strategies, the proposed hybrid wind-PV technique reduces frequency oscillations, together with lower fluctuations in both thermal and hydro-power generation units. Even though CPPs oscillate less than with the other approaches, they are working further than their initially assigned values, as demonstrated with the MSE of Table 5. Similar output wind power values are determined for the three vRES strategies, as the same $P D$ constants are assumed. This response is also less oscillatory than the case in which only CPPs are responding under imbalance conditions. Finally, the PV output power is equal if only the CPP or WPP strategies are considered, as PV active power only changes due to the variations in the solar irradiation $G$. When the de-loading technique is implemented, the PV power plants include a curtailed 10\% active power (from 50 to $45 \mathrm{MW}$, approximately). Moreover, note that considering the $\Delta \omega$ as input significantly reduces the PV-generated power and, consequently, the generated energy (refer to Table 5), but the frequency deviations are also reduced in comparison to the PV $(f)$ strategy. In Figures 12 and 13, the active power of the four WPP and PV power plants are shown, respectively.

Table 6. Simulation results: rotational speed of $\mathrm{WPP}_{1}$.

\begin{tabular}{cccccccc}
\hline \multirow{2}{*}{ Scenario } & Load (MW) & \multicolumn{2}{c}{$\mathbf{2 5 0}$} & \multicolumn{2}{c}{$\mathbf{4 0 0}$} & \multicolumn{2}{c}{$\mathbf{5 5 0}$} \\
\cline { 2 - 8 } & Year & $\mathbf{2 0 2 5}$ & $\mathbf{2 0 4 0}$ & $\mathbf{2 0 2 5}$ & $\mathbf{2 0 4 0}$ & $\mathbf{2 0 2 5}$ & $\mathbf{2 0 4 0}$ \\
\hline \multirow{3}{*}{$\omega_{1, \min }(\mathrm{pu})$} & $\mathrm{CPP}$ & 1.067 & 1.067 & 1.067 & 1.067 & 1.067 & 1.067 \\
& $\mathrm{WPP}$ & 1.000 & 0.971 & 1.003 & 0.983 & 1.005 & 0.976 \\
& $\mathrm{PV}(f)$ & 1.024 & 1.000 & 1.019 & 1.001 & 1.016 & 0.995 \\
& $\mathrm{PV}(\omega)$ & 1.030 & 1.000 & 1.033 & 1.026 & 1.030 & 0.995 \\
\hline \multirow{3}{*}{$\omega_{1, \max }(\mathrm{pu})$} & $\mathrm{CPP}$ & 1.359 & 1.359 & 1.359 & 1.359 & 1.359 & 1.359 \\
& $\mathrm{WPP}$ & 1.394 & 1.405 & 1.391 & 1.409 & 1.389 & 1.408 \\
& $\mathrm{PV}(f)$ & 1.381 & 1.399 & 1.385 & 1.405 & 1.385 & 1.403 \\
& $\mathrm{PV}(\omega)$ & 1.372 & 1.370 & 1.377 & 1.376 & 1.379 & 1.403 \\
\hline \multirow{3}{*}{$M_{S E_{\omega_{1}}, \times 10^{-3}}\left(\mathrm{pu}^{2}\right)$} & $\mathrm{CPP}$ & 3.631 & 2.649 & 2.649 & 2.649 & 2.479 & 2.649 \\
& $\mathrm{WPP}$ & 4.406 & 6.485 & 4.081 & 5.582 & 4.098 & 5.966 \\
& $\mathrm{PV}(f)$ & 3.738 & 4.956 & 3.613 & 4.517 & 3.770 & 4.892 \\
& $\mathrm{PV}(\omega)$ & 3.631 & 4.551 & 3.497 & 3.985 & 3.589 & 5.075 \\
\hline
\end{tabular}


Table 7. Simulation results: rotational speed of $\mathrm{WPP}_{2}$.

\begin{tabular}{cccccccc}
\hline \multirow{2}{*}{ Scenario } & Load (MW) & \multicolumn{2}{c}{$\mathbf{2 5 0}$} & \multicolumn{2}{c}{$\mathbf{4 0 0}$} & \multicolumn{2}{c}{$\mathbf{5 5 0}$} \\
\cline { 2 - 7 } & Year & $\mathbf{2 0 2 5}$ & $\mathbf{2 0 4 0}$ & $\mathbf{2 0 2 5}$ & $\mathbf{2 0 4 0}$ & $\mathbf{2 0 2 5}$ & $\mathbf{2 0 4 0}$ \\
\hline \multirow{3}{*}{$\omega_{2, \min }(\mathrm{pu})$} & $\mathrm{CPP}$ & 1.052 & 1.052 & 1.052 & 1.052 & 1.038 & 1.052 \\
& $\mathrm{WPP}$ & 1.011 & 0.885 & 1.014 & 0.945 & 1.015 & 0.919 \\
& $\mathrm{PV}(f)$ & 1.037 & 0.906 & 1.032 & 0.966 & 1.027 & 0.938 \\
& $\mathrm{PV}(\omega)$ & 1.043 & 0.891 & 1.041 & 0.945 & 1.040 & 0.926 \\
\hline \multirow{3}{*}{$\omega_{2, \max }(\mathrm{pu})$} & $\mathrm{CPP}$ & 1.327 & 1.327 & 1.327 & 1.327 & 1.327 & 1.327 \\
& $\mathrm{WPP}$ & 1.407 & 1.385 & 1.406 & 1.389 & 1.404 & 1.389 \\
& $\mathrm{PV}(f)$ & 1.393 & 1.393 & 1.396 & 1.390 & 1.399 & 1.391 \\
& $\mathrm{PV}(\omega)$ & 1.348 & 1.373 & 1.355 & 1.376 & 1.360 & 1.403 \\
\hline \multirow{3}{*}{$\mathrm{MSE}_{\omega_{2}, \times 10^{-3}\left(\mathrm{pu}^{2}\right)}$} & $\mathrm{CPP}$ & 3.037 & 3.037 & 3.037 & 3.037 & 3.517 & 3.037 \\
& $\mathrm{WPP}$ & 5.455 & 9.638 & 5.470 & 8.692 & 5.268 & 8.902 \\
& $\mathrm{PV}(f)$ & 4.485 & 7.363 & 4.663 & 7.191 & 4.718 & 7.317 \\
& $\mathrm{PV}(\omega)$ & 3.765 & 6.432 & 3.948 & 6.138 & 4.031 & 7.117 \\
\hline
\end{tabular}

Table 8. Simulation results: rotational speed of $\mathrm{WPP}_{3}$.

\begin{tabular}{cccccccc}
\hline \multirow{2}{*}{ Scenario } & Load (MW) & \multicolumn{2}{c}{$\mathbf{2 5 0}$} & \multicolumn{2}{c}{$\mathbf{4 0 0}$} & \multicolumn{2}{c}{$\mathbf{5 5 0}$} \\
\cline { 2 - 8 } & Year & $\mathbf{2 0 2 5}$ & $\mathbf{2 0 4 0}$ & $\mathbf{2 0 2 5}$ & $\mathbf{2 0 4 0}$ & $\mathbf{2 0 2 5}$ & $\mathbf{2 0 4 0}$ \\
\hline \multirow{3}{*}{$\omega_{3, \min }(\mathrm{pu})$} & $\mathrm{CPP}$ & 0.917 & 0.917 & 0.917 & 0.917 & 0.766 & 0.917 \\
& WPP & 0.915 & 0.885 & 0.912 & 0.894 & 0.914 & 0.891 \\
& $\mathrm{PV}(f)$ & 0.917 & 0.902 & 0.914 & 0.917 & 0.915 & 0.912 \\
& $\mathrm{PV}(\omega)$ & 0.922 & 0.917 & 0.919 & 0.925 & 0.919 & 0.916 \\
\hline \multirow{3}{*}{$\omega_{3, \max }(\mathrm{pu})$} & $\mathrm{CPP}$ & 1.345 & 1.345 & 1.345 & 1.345 & 1.366 & 1.345 \\
& $\mathrm{WPP}$ & 1.410 & 1.410 & 1.408 & 1.413 & 1.406 & 1.412 \\
& $\mathrm{PV}(f)$ & 1.386 & 1.414 & 1.390 & 1.410 & 1.395 & 1.414 \\
& $\mathrm{PV}(\omega)$ & 1.352 & 1.383 & 1.367 & 1.380 & 1.369 & 1.401 \\
\hline \multirow{3}{*}{$M_{S E_{\omega_{3},} \times 10^{-3}\left(\mathrm{pu}^{2}\right)}$} & $\mathrm{CPP}$ & 11.778 & 11.778 & 11.778 & 11.778 & 24.351 & 11.778 \\
& $\mathrm{WPP}$ & 13.636 & 15.890 & 13.653 & 15.304 & 13.572 & 15.314 \\
& $\mathrm{PV}(f)$ & 12.912 & 14.462 & 13.120 & 14.287 & 13.230 & 14.492 \\
& $\mathrm{PV}(\omega)$ & 11.394 & 12.575 & 11.650 & 12.774 & 11.803 & 13.708 \\
\hline
\end{tabular}

Table 9. Simulation results: rotational speed of $\mathrm{WPP}_{4}$.

\begin{tabular}{cccccccc}
\hline \multirow{2}{*}{ Scenario } & Load (MW) & \multicolumn{2}{c}{$\mathbf{2 5 0}$} & \multicolumn{2}{c}{$\mathbf{4 0 0}$} & \multicolumn{2}{c}{$\mathbf{5 5 0}$} \\
\cline { 2 - 8 } & Year & $\mathbf{2 0 2 5}$ & $\mathbf{2 0 4 0}$ & $\mathbf{2 0 2 5}$ & $\mathbf{2 0 4 0}$ & $\mathbf{2 0 2 5}$ & $\mathbf{2 0 4 0}$ \\
\hline \multirow{3}{*}{$\omega_{4, \min }(\mathrm{pu})$} & $\mathrm{CPP}$ & 0.925 & 0.925 & 0.925 & 0.925 & 0.925 & 0.925 \\
& $\mathrm{WPP}$ & 0.946 & 0.817 & 0.947 & 0.865 & 0.945 & 0.848 \\
& $\mathrm{PV}(f)$ & 0.933 & 0.847 & 0.936 & 0.871 & 0.938 & 0.874 \\
& $\mathrm{PV}(\omega)$ & 0.924 & 0.866 & 0.925 & 0.879 & 0.926 & 0.895 \\
\hline \multirow{3}{*}{$\omega_{4, \max }(\mathrm{pu})$} & $\mathrm{CPP}$ & 1.332 & 1.332 & 1.332 & 1.332 & 1.323 & 1.332 \\
& $\mathrm{WPP}$ & 1.376 & 1.455 & 1.377 & 1.431 & 1.373 & 1.443 \\
& $\mathrm{PV}(f)$ & 1.366 & 1.438 & 1.370 & 1.437 & 1.368 & 1.433 \\
& $\mathrm{PV}(\omega)$ & 1.356 & 1.440 & 1.361 & 1.436 & 1.361 & 1.427 \\
\hline \multirow{3}{*}{$\mathrm{MSE}_{\omega_{4}, \times 10^{-3}}\left(\mathrm{pu}^{2}\right)$} & $\mathrm{CPP}$ & 8.601 & 8.601 & 8.601 & 8.601 & 11.235 & 8.601 \\
& $\mathrm{WPP}$ & 9.380 & 13.266 & 9.593 & 12.791 & 9.485 & 12.584 \\
& $\mathrm{PV}(f)$ & 9.113 & 11.317 & 9.300 & 11.347 & 9.276 & 11.096 \\
& $\mathrm{PV}(\omega)$ & 8.820 & 10.696 & 8.846 & 10.446 & 8.854 & 11.237 \\
\hline
\end{tabular}




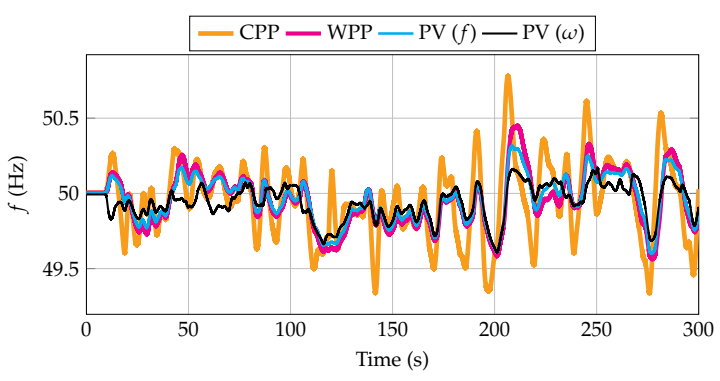

(a)

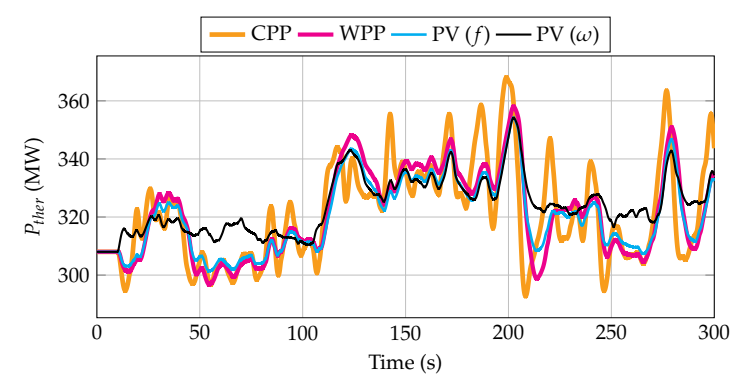

(c)

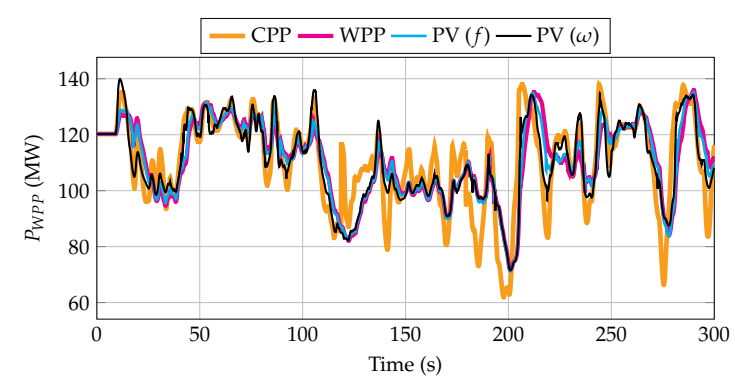

(e)

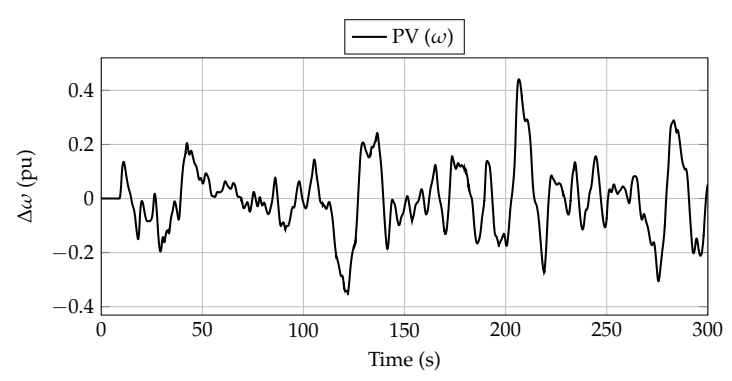

(b)

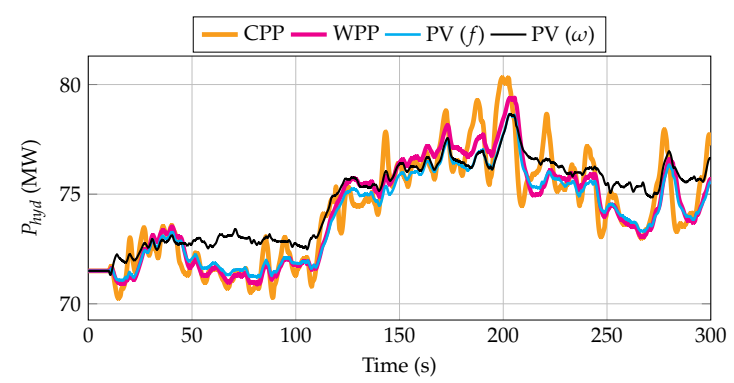

(d)

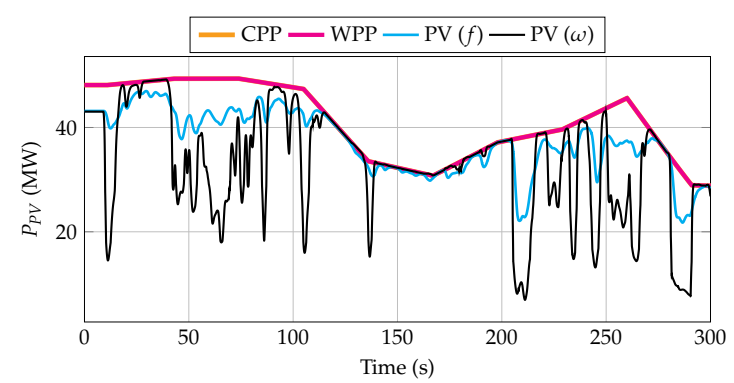

(f)

Figure 11. Simulation results for $550 \mathrm{MW}$ demand and year 2025: (a) frequency evolution, (b) rotational speed deviation, (c) thermal power, (d) hydro-power, (e) VSWT power, and (f) PV power. 


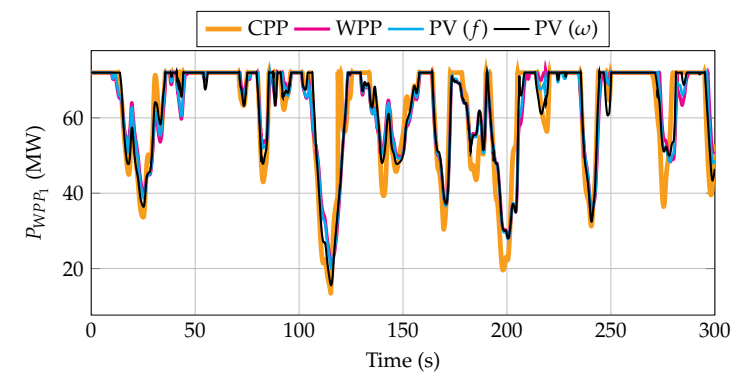

(a)

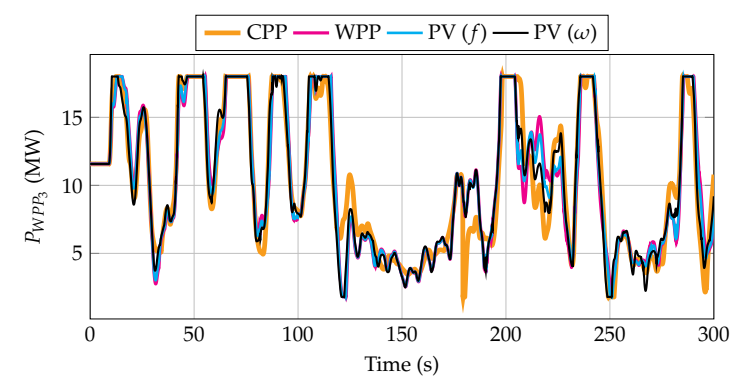

(c)

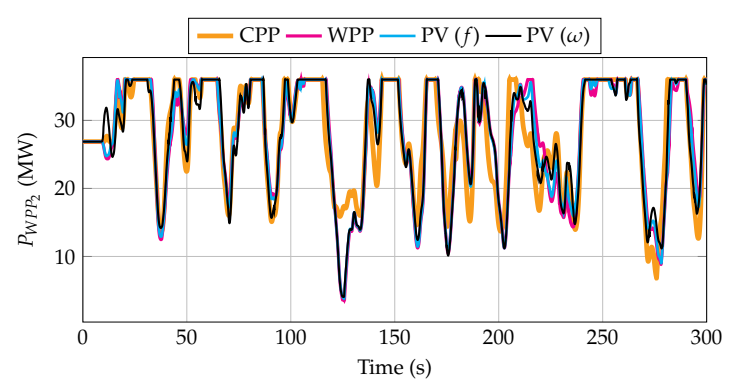

(b)

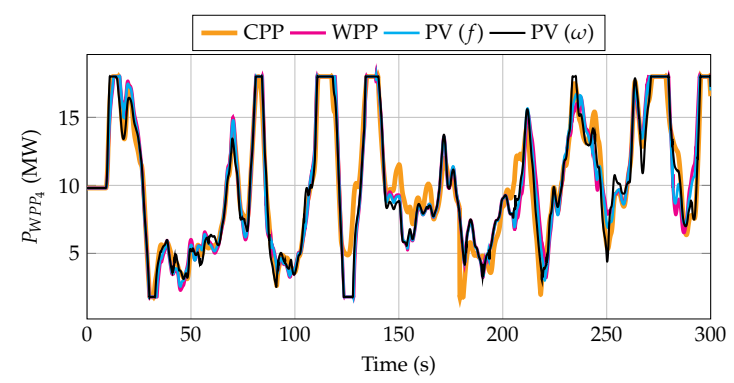

(d)

Figure 12. WPP power for $550 \mathrm{MW}$ demand and year 2025: (a) $\mathrm{WPP}_{1}$, (b) $\mathrm{WPP}_{2}$, (c) $\mathrm{WPP}_{3}$, and (d) $\mathrm{WPP}_{4}$.

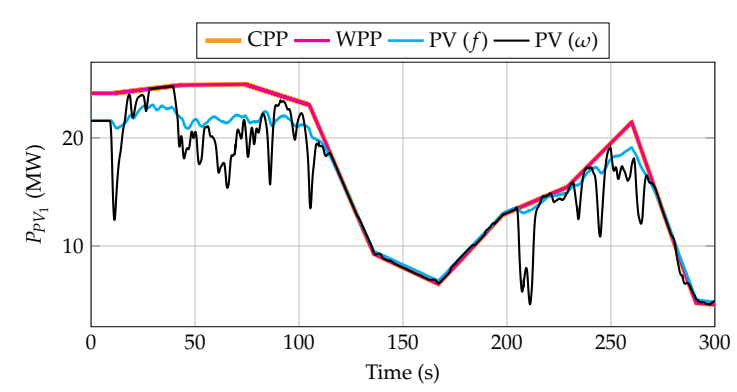

(a)

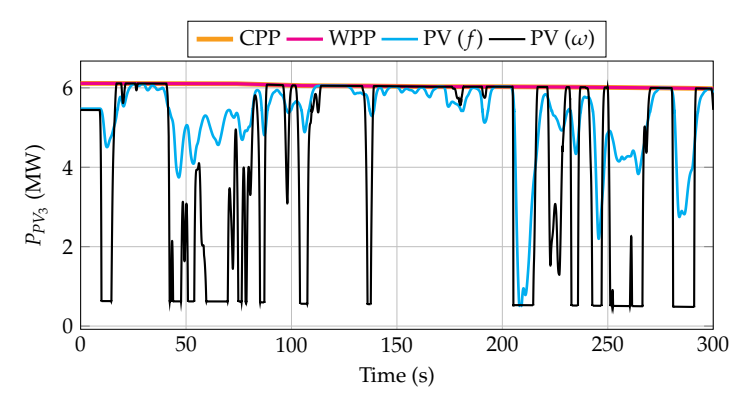

(c)

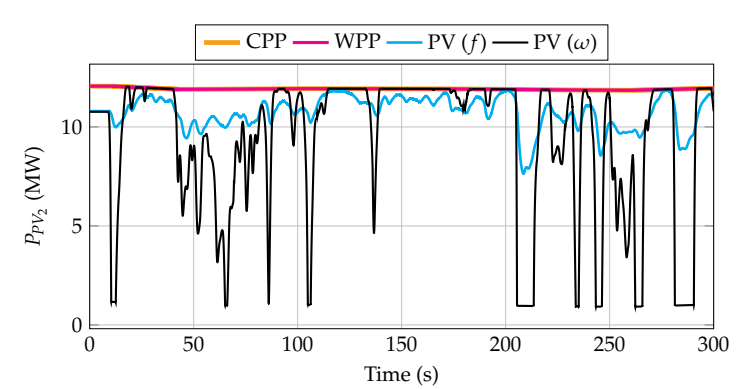

(b)

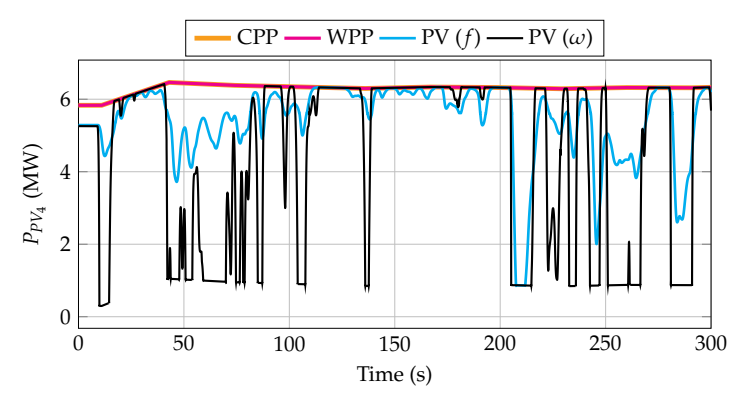

(d)

Figure 13. $\mathrm{PV}$ power for $550 \mathrm{MW}$ demand and year 2025: (a) $\mathrm{PV}_{1}$, (b) $\mathrm{PV}_{2}$, (c) $\mathrm{PV}_{3}$, and (d) $\mathrm{PV}_{4}$. 
Figure 14 depicts the frequency evolution, active power of the four generation units, and $\Delta \omega$ input for the PI controller of PV power plants for the hybrid wind-PV strategy, corresponding to the $250 \mathrm{MW}$ demand and year 2040 scenario. These results are similar to the previous simulations depicted in Figure 11. In this case, when only CPPs participate in frequency control, the frequency oscillations are higher due to the reduced synchronous inertia of the power system. Grid frequency oscillations are drastically reduced by including vRESs into the frequency response, especially with the proposed hybrid wind-PV solution. Similar active wind power is obtained if they also participate in frequency regulation, providing lower oscillations than the case in which only CPPs are considered. When PV power plants include the de-loading technique, a 10\% power reduction is required (from 38 to $34 \mathrm{MW}$, approximately). When the PV installations receive the $\Delta \omega$ as an input, their active power is reduced accordingly, in line with the generated energy shown in Table 5.

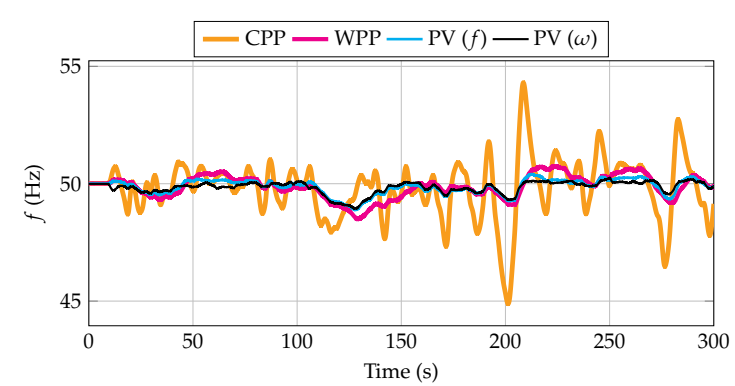

(a)

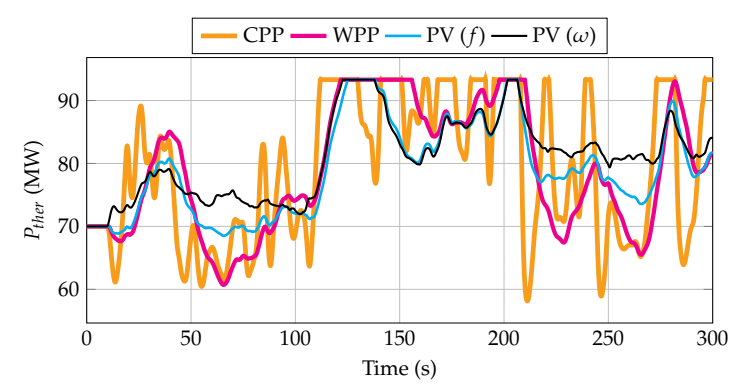

(c)

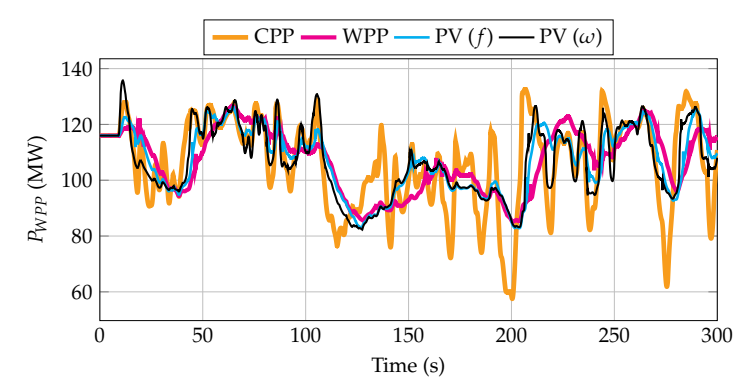

(e)

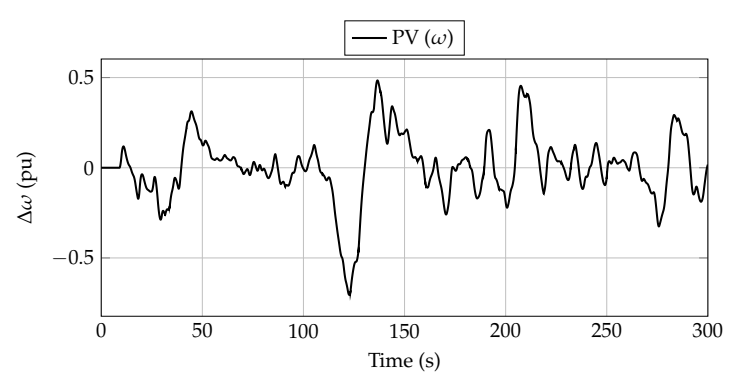

(b)

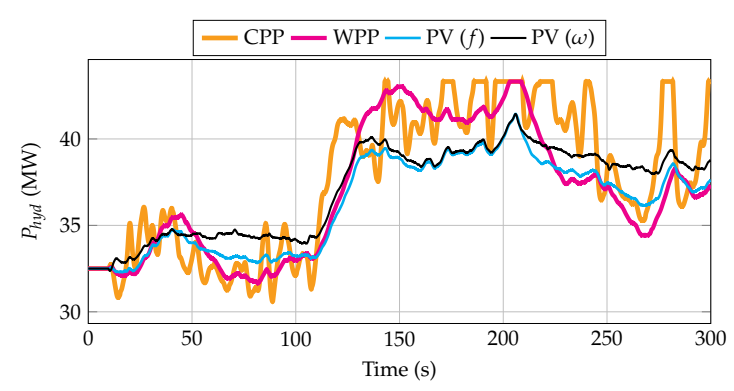

(d)

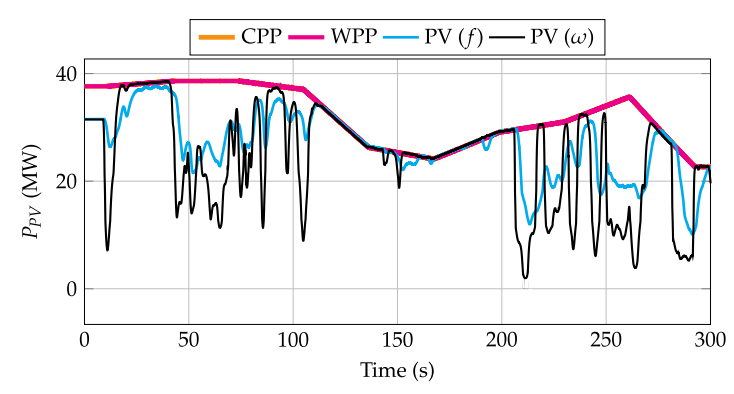

$(\mathbf{f})$

Figure 14. Simulation results for $250 \mathrm{MW}$ demand and year 2040: (a) frequency evolution, (b) rotational speed deviation, (c) thermal power, (d) hydro-power, (e) VSWT power, and (f) PV power. 


\subsection{Limitations and Further Work}

This paper tests the benefits of introducing a hybrid wind-PV frequency controller that is able to monitor not only frequency deviations, but also VSWTs' rotational speed deviations from their optimal reference values. This generalization allows conclusions to be drawn in a high casuistry of scenarios, but it makes it necessary to neglect or simplify some aspects without losing accuracy. These simplifications are:

- Thermal units are supposed to work at the same operating point, considering a single equivalent turbine. In addition, only one thermal power plant technology is assumed (reheat thermal). Hydro-power plants are modeled analogously (including only one kind of hydro turbine). Finally, each wind power plant is modeled as one equivalent VSWT.

- The initial assigned power (generation programming) of each one of the generation units was not obtained with technical-economic criteria (unit commitment), nor were their PFC reserves and secondary control action. Once each generation unit is individually modeled, it is reasonable to assign an initial power to each unit according to both technical and economic criteria.

- To obtain each vRES penetration level, the ENTSO-E recommendations for interconnected power systems were followed by the authors. However, isolated power systems can have different vRES integration levels. However, this hypothesis is assumed to give generality to the present study.

- As described in Section 2, power line dynamics are neglected, as well as the communication lines between the wind and PV power plants for the proposed hybrid wind-PV controller set-up.

As the results and conclusions of this study can be considered as positive, the next step proposed by the authors is to analyze the impact of establishment in some specific isolated power systems, such as one of the existing ones in the Canary archipelago, in the Aegean islands, or in the Azores archipelago. Since those power systems are well known, it is reasonable to individually introduce each generation unit into the dynamic model. Additionally, current and future renewable energy penetration as well as real wind speed and irradiation data can be used for future simulations. Once the locations of both wind and PV power plants are known, the influence of the communication time on the control actions can be also analyzed. The corresponding time delays with the measurement of errors and the transmission of control signals between wind and PV power plants would then be included in the model. Likewise, this proposal will be able to optimize the power system's operation by associating the control of some specific wind power plants to certain geographically neighboring PV power plants.

\section{Conclusions}

This paper proposes a hybrid wind-PV frequency control approach for isolated power systems with high vRES integration under variable weather conditions. The proposed controller consists of VSWTs that include a hidden-inertia emulation technique and PV power plants working with a de-load power of $10 \%$. The input of the PV frequency control is the rotational speed deviation of the VSWTs, in contrast to previous studies where the frequency deviation is the input of the de-loaded PV controller. In this way, the PV power plants modify their generated power by following the rotational speed deviation of the VSWTs, reducing the deviation of such rotational speeds, and, consequently, minimizing the frequency deviations under power imbalances. The proposed hybrid frequency approach is compared to three different frequency strategies: $(i)$ conventional power plants, (ii) conventional power plants and wind power plants, and (iii) conventional power plants, wind power plants, and PV power plants with grid frequency as input. The results show that frequency oscillations are drastically reduced by including the proposed hybrid controller. In fact, the mean squared error of frequency variations is reduced by up to $95 \%$ in comparison to the case in which only conventional power plants are controlling the frequency variations. Severe reductions are also found when comparing the hybrid wind-PV strategy to the other two strategies in which vRESs participate in frequency control (between $20 \%$ and $65 \%$ ). The rotational speed deviation of the VSWTs 
also decreases with the hybrid wind-PV frequency approach, even getting the same mean squared error as when VSWTs do not participate in frequency control. However, the energy generated by the PV power plants decreases by between $20 \%$ and $30 \%$ when using the proposed approach, and should be subsequently analyzed by the transmission/distribution operators to guarantee some additional benefits for the owners of such generation units. Based on the results, the authors also wish to remark on the importance of vRESs participating in frequency control in the near future in order to avoid significant frequency deviations that will occur if these sources keep replacing conventional power plants without providing any frequency response. Consequently, hybrid frequency control strategies in line with this work should be proposed and analyzed to minimize frequency variations linked to a massive vRES integration.

Author Contributions: Conceptualization, A.F.-G. and J.-I.S.; methodology, A.F.-G.; software, A.F.-G. and G.M.-L.; validation, G.M.-L. and J.-I.S.; formal analysis, J.-I.S.; investigation, Á.M.-G. and J.-I.S.; resources, A.F.-G.; data curation, A.F.-G. and J.-I.S.; writing-original draft preparation, A.F.-G. and G.M.-L.; writing-review and editing, J.-I.S. and Á.M.-G.; visualization, Â.M.-G.; supervision, J.-I.S.; project administration, A.F.-G.; funding acquisition, A.F.-G., Á.M.G, J.-I.S., and G.M.-L. All authors have read and agreed to the published version of the manuscript.

Funding: This work was partially supported by 'Ministerio de Educación, Cultura y Deporte' of Spain (ref. FPU16/04282) and by 'Ministerio de Economía y Competitividad' under the project 'Value of pumped-hydro energy storage in isolated power systems with high wind power penetration' of the National Plan for Scientific and Technical Research and Innovation 2013-2016, grant number ENE2016-77951-R.

Conflicts of Interest: The authors declare no conflict of interest.

\section{Abbreviations}

The following abbreviations and nomenclature are used in this manuscript:

$\alpha_{V} \quad$ Correction factor depending on the cell's temperature

$\Delta \omega \quad$ Rotational speed deviation of VSWT

$\Delta f \quad$ Frequency deviation

$\triangle P \quad$ Power imbalance

$\triangle R R$ Total secondary regulation effort

$\Delta V \quad$ Additional voltage for PV frequency control

$f \quad$ Grid frequency

$k_{B} \quad$ Boltzmann's constant

$k_{I} \quad$ Short-circuit current temperature coefficient

$p \quad$ Active power (pu)

$q \quad$ Electron charge

$s_{w} \quad$ Wind speed

A Diode ideality factor

$D_{\text {net }} \quad$ Consumer loads' sensitivity to frequency deviations

$E_{G} \quad$ Band-gap energy

G Sun irradiation

$H \quad$ Inertia constant

I Current

$I_{p h} \quad$ Photo-current

$I_{r, \text { ref }} \quad$ Reverse saturation current at $T_{S T C}$

$I_{r s} \quad$ Reverse saturation current

$I_{S C} \quad$ Short-circuit current

$K_{u} \quad$ Participation factor on AGC

$N_{P} \quad$ Number of PV strings in parallel

$N_{S} \quad$ Number of PV cells in series

$P \quad$ Active power (MW)

$R \quad$ Droop characteristic

$S_{B} \quad$ Base power

$T \quad$ Temperature

$T_{C} \quad$ Temperature of the PV cell

$V \quad$ Voltage 


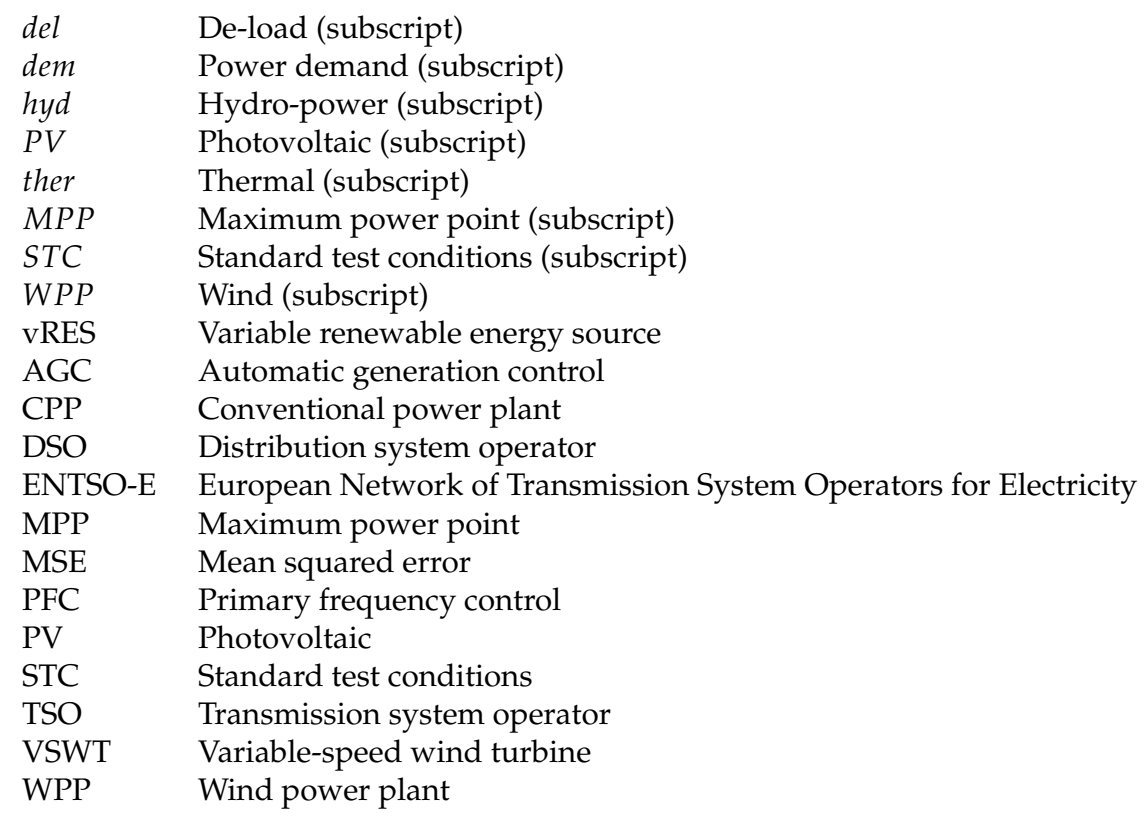

\section{References}

1. Aquila, G.; de Oliveira Pamplona, E.; de Queiroz, A.R.; Junior, P.R.; Fonseca, M.N. An overview of incentive policies for the expansion of renewable energy generation in electricity power systems and the Brazilian experience. Renew. Sustain. Energy Rev. 2017, 70, 1090-1098.

2. Bjelic, I.B.; Ciric, R.M. Optimal distributed generation planning at a local level-A review of Serbian renewable energy development. Renew. Sustain. Energy Rev. 2014, 39, 79-86.

3. Zappa, W.; Van Den Broek, M. Analysing the potential of integrating wind and solar power in Europe using spatial optimisation under various scenarios. Renew. Sustain. Energy Rev. 2018, 94, 1192-1216.

4. Fernández-Guillamón, A.; Das, K.; Cutululis, N.A.; Molina-García, Á. Offshore wind power integration into future power systems: Overview and trends. J. Mar. Sci. Eng. 2019, 7, 399.

5. Beaudin, M.; Zareipour, H.; Schellenberglabe, A.; Rosehart, W. Energy storage for mitigating the variability of renewable electricity sources: An updated review. Energy Sustain. Dev. 2010, 14, 302-314.

6. Ulbig, A.; Borsche, T.S.; Andersson, G. Impact of low rotational inertia on power system stability and operation. IFAC Proc. Vol. 2014, 47, 7290-7297.

7. Bouffard, F.; Ortega-Vazquez, M. The value of operational flexibility in power systems with significant wind power generation. In Proceedings of the 2011 IEEE Power and Energy Society General Meeting, Detroit, MI, USA, 24-28 July 2011; pp. 1-5.

8. Schaber, K.; Steinke, F.; Mühlich, P.; Hamacher, T. Parametric study of variable renewable energy integration in Europe: Advantages and costs of transmission grid extensions. Energy Policy 2012, 42, 498-508.

9. Osorio, S.; van Ackere, A. From nuclear phase-out to renewable energies in the Swiss electricity market. Energy Policy 2016, 93, 8-22.

10. Van Stiphout, A.; Poncelet, K.; De Vos, K.; Deconinck, G. The impact of operating reserves in generation expansion planning with high shares of renewable energy sources. In Proceedings of the IAEE European Energy Conference, Sustainable Energy Policy and Strategies for Europe, Rome, Italy, 28-31 October 2014; pp. 1-15.

11. Rakhshani, E.; Rodriguez, P. Active power and frequency control considering large-scale RES. In Large Scale Renewable Power Generation; Springer: 2014; pp. 233-271.

12. Fernández-Guillamón, A.; Gómez-Lázaro, E.; Muljadi, E.; Molina-Garcia, Á. A Review of Virtual Inertia Techniques for Renewable Energy-Based Generators. In Power Systems; IntechOpen: 2020.

13. Serban, I.; Teodorescu, R.; Marinescu, C. Energy storage systems impact on the short-term frequency stability of distributed autonomous microgrids, an analysis using aggregate models. IET Renew. Power Gener. 2013, 7, 531-539. 
14. Adrees, A.; Milanovic, J.V. Study of frequency response in power system with renewable generation and energy storage. In Proceedings of the 2016 Power Systems Computation Conference (PSCC), Genoa, Italy, 20-24 June 2016; pp. 1-7.

15. Hosseinipour, A.; Hojabri, H. Virtual inertia control of PV systems for dynamic performance and damping enhancement of DC microgrids with constant power loads. IET Renew. Power Gener. 2017, 12, 430-438.

16. Fernández-Guillamón, A.; Gómez-Lázaro, E.; Muljadi, E.; Molina-García, Á. Power systems with high renewable energy sources: A review of inertia and frequency control strategies over time. Renew. Sustain. Energy Rev. 2019, 115, 109369.

17. Alatrash, H.; Mensah, A.; Mark, E.; Haddad, G.; Enslin, J. Generator emulation controls for photovoltaic inverters. IEEE Trans. Smart Grid 2012, 3, 996-1011.

18. Zhang, X.; Chen, Y.; Wang, Y.; Zha, X.; Yue, S.; Cheng, X.; Gao, L. Deloading power coordinated distribution method for frequency regulation by wind farms considering wind speed differences. IEEE Access 2019, 7, 122573-122582.

19. Fang, X.; Krishnan, V.; Hodge, B.M. Strategic offering for wind power producers considering energy and flexible ramping products. Energies 2018, 11, 1239.

20. Yingcheng, X.; Nengling, T. Review of contribution to frequency control through variable speed wind turbine. Renew. Energy 2011, 36, 1671-1677.

21. Fernández-Guillamón, A.; Vigueras-Rodríguez, A.; Molina-García, Á. Analysis of power system inertia estimation in high wind power plant integration scenarios. IET Renew. Power Gener. 2019, 13, 2807-2816.

22. Martínez-Lucas, G.; Sarasúa, J.I.; Sánchez-Fernández, J.Á. Eigen analysis of wind-hydro joint frequency regulation in an isolated power system. Int. J. Electr. Power Energy Syst. 2018, 103, 511-524.

23. Martínez-Lucas, G.; Sarasúa, J.I.; Sánchez-Fernández, J.Á. Frequency regulation of a hybrid wind-hydro power plant in an isolated power system. Energies 2018, 11, 239.

24. Ullah, N.R.; Thiringer, T.; Karlsson, D. Temporary primary frequency control support by variable speed wind turbines-Potential and applications. IEEE Trans. Power Syst. 2008, 23, 601-612.

25. Pandey, S.K.; Mohanty, S.R.; Kishor, N. A literature survey on load-frequency control for conventional and distribution generation power systems. Renew. Sustain. Energy Rev. 2013, 25, 318-334.

26. Fernández-Guillamón, A.; Molina-García, A.; Vigueras-Rodríguez, A.; GÓmez-Lázaro, E. Frequency Response and Inertia Analysis in Power Systems with High Wind Energy Integration. In Proceedings of the 2019 International Conference on Clean Electrical Power (ICCEP), Otranto, Italy, 2-4 July 2019; pp. 388-393.

27. Li, X.; Li, Y.; Han, X.; Hui, D. Application of fuzzy wavelet transform to smooth wind/PV hybrid power system output with battery energy storage system. Energy Procedia 2011, 12, 994-1001.

28. Nayeripour, M.; Hoseintabar, M.; Niknam, T. Frequency deviation control by coordination control of FC and double-layer capacitor in an autonomous hybrid renewable energy power generation system. Renew. Energy 2011, 36, 1741-1746.

29. Li, X.; Hui, D.; Lai, X. Battery energy storage station (BESS)-based smoothing control of photovoltaic (PV) and wind power generation fluctuations. IEEE Trans. Sustain. Energy 2013, 4, 464-473.

30. Ma, Y.; Yang, P.; Wang, Y.; Zhou, S.; He, P. Frequency control of islanded microgrid based on wind-PV-diesel-battery hybrid energy sources. In Proceedings of the 2014 17th International Conference on Electrical Machines and Systems (ICEMS), Hangzhou, China, 22-25 October 2014; pp. 290-294.

31. Gatta, F.M.; Geri, A.; Lamedica, R.; Lauria, S.; Maccioni, M.; Palone, F.; Rebolini, M.; Ruvio, A. Application of a LiFePO4 battery energy storage system to primary frequency control: Simulations and experimental results. Energies 2016, 9, 887.

32. Krishnan, M.S.; Ramkumar, M.S.; Amudha, A. Frequency Deviation Control In Hybrid Renewable Energy System Using Fc-Uc. Int. J. Control Theory Appl. 2017, 10, 333-344.

33. Salama, H.S.; Aly, M.M.; Vokony, I. Voltage/Frequency control of isolated unbalanced radial distribution system fed from intermittent wind/PV power using fuzzy logic controlled-SMES. In Proceedings of the 2019 International Conference on Innovative Trends in Computer Engineering (ITCE), Hangzhou, China, 22-25 October 2019; pp. 414-419.

34. Das, S.; Akella, A. A fuzzy logic-based frequency control scheme for an isolated AC coupled PV-wind-battery hybrid system. Int. J. Model. Simul. 2020, 40, 308-320. 
35. Marchese, K.; Pourmousavi, S.; Nehrir, M. The application of demand response for frequency regulation in an islanded microgrid with high penetration of renewable generation. In Proceedings of the 2013 North American Power Symposium (NAPS), Manhattan, KS, USA, 22-24 September 2013; pp. 1-6.

36. Vahedipour-Dahraie, M.; Rashidizaheh-Kermani, H.; Najafi, H.R.; Anvari-Moghaddam, A.; Guerrero, J.M. Coordination of EVs participation for load frequency control in isolated microgrids. Appl. Sci. 2017, 7, 539.

37. Almi, M.; Arrouf, M.; Belmili, H.; Boulouma, S.; Bendib, B. Energy management of wind/PV and battery hybrid system. Int. J. New Comput. Archit. Appl. (IJNCAA) 2014, 4, 30-38.

38. Liu, Y.; You, S.; Liu, Y. Study of wind and PV frequency control in US power grids-EI and TI case studies. IEEE Power Energy Technol. Syst. J. 2017, 4, 65-73.

39. Vattigunta, R.R.; Rather, Z.H.; Gokaraju, R. Fast frequency support from hybrid solar PV and wind power plant. In Proceedings of the 2018 IEEE International Conference on Power Electronics, Drives and Energy Systems (PEDES), Chennai, India, 18-21 December 2018; pp. 1-6.

40. Zarina, P.; Mishra, S.; Sekhar, P. Deriving inertial response from a non-inertial PV system for frequency regulation. In Proceedings of the 2012 IEEE International Conference on Power Electronics, Drives and Energy Systems (PEDES), Bengaluru, India, 16-19 December 2012; pp. 1-5.

41. Zarina, P.; Mishra, S.; Sekhar, P. Photovoltaic system based transient mitigation and frequency regulation. In Proceedings of the 2012 Annual IEEE India Conference (INDICON), Kochi, India, 7-9 December 2012; pp. 1245-1249.

42. Mishra, S.; Zarina, P.; Sekhar, P. A novel controller for frequency regulation in a hybrid system with high PV penetration. In Proceedings of the 2013 IEEE Power \& Energy Society General Meeting, Vancouver, BC, Canada, 21-25 July 2013; pp. 1-5.

43. Rahmann, C.; Castillo, A. Fast frequency response capability of photovoltaic power plants: The necessity of new grid requirements and definitions. Energies 2014, 7, 6306-6322.

44. Jietan, Z.; Linan, Q.; Pestana, R.; Fengkui, L.; Libin, Y. Dynamic frequency support by photovoltaic generation with "synthetic" inertia and frequency droop control. In Proceedings of the 2017 IEEE Conference on Energy Internet and Energy System Integration (EI2), Beijing, China, 26-28 November 2017; pp. 1-6.

45. Jibji-Bukar, F.; Anaya-Lara, O. Frequency support from photovoltaic power plants using offline maximum power point tracking and variable droop control. IET Renew. Power Gener. 2019, 13, 2278-2286.

46. Li, Q.; Baran, M.E. A Novel Frequency Support Control Method for PV Plants using Tracking LQR. IEEE Trans. Sustain. Energy 2019, doi:10.1109/TSTE.2019.2953684.

47. Wilches-Bernal, F.; Chow, J.H.; Sanchez-Gasca, J.J. A fundamental study of applying wind turbines for power system frequency control. IEEE Trans. Power Syst. 2016, 31, 1496-1505.

48. Wang, Y.; Delille, G.; Bayem, H.; Guillaud, X.; Francois, B. High wind power penetration in isolated power systems-Assessment of wind inertial and primary frequency responses. IEEE Trans. Power Syst. 2013, $28,2412-2420$.

49. You, R.; Barahona, B.; Chai, J.; Cutululis, N.A. Frequency support capability of variable speed wind turbine based on electromagnetic coupler. Renew. Energy 2015, 74, 681-688.

50. Hafiz, F.; Abdennour, A. An adaptive neuro-fuzzy inertia controller for variable-speed wind turbines. Renew. Energy 2016, 92, 136-146.

51. Magnus, D.; Pfitscher, L.; Scharlau, C. A Synergy Analysis of Synthetic Inertia and Speed Controllers on Variable Speed Wind Turbines. In Proceedings of the 2019 IEEE PES Innovative Smart Grid Technologies Conference-Latin America (ISGT Latin America), Gramado, Brazil, 15-18 September 2019; pp. 1-6.

52. Hafiz, F.; Abdennour, A. Optimal use of kinetic energy for the inertial support from variable speed wind turbines. Renew. Energy 2015, 80, 629-643.

53. Kang, M.; Kim, K.; Muljadi, E.; Park, J.; Kang, Y.C. Frequency Control Support of a Doubly-Fed Induction Generator Based on the Torque Limit. IEEE Trans. Power Syst. 2016, 31, 4575-4583, doi:10.1109/TPWRS.2015.2514240.

54. Fernández-Guillamón, A.; Villena-Lapaz, J.; Vigueras-Rodríguez, A.; García-Sánchez, T.; Molina-García, Á. An Adaptive Frequency Strategy for Variable Speed Wind Turbines: Application to High Wind Integration Into Power Systems. Energies 2018, 11, 1436.

55. Fernández Guillamón, A. Análisis y Simulación de Estrategias Agregadas de Control de Frecuencia Entre Grandes Parques Eólicos y Aprovechamientos Hidroeléctricos. 2017. Available online: https: / / repositorio. upct.es/handle/10317/6222 (accessed on 10 July 2020). 
56. Mansoor, S.; Jones, D.; Bradley, D.A.; Aris, F.; Jones, G. Reproducing oscillatory behaviour of a hydroelectric power station by computer simulation. Control Eng. Pract. 2000, 8, 1261-1272.

57. O'Sullivan, J.; Rogers, A.; Flynn, D.; Smith, P.; Mullane, A.; O'Malley, M. Studying the maximum instantaneous non-synchronous generation in an island system-Frequency stability challenges in Ireland. IEEE Trans. Power Syst. 2014, 29, 2943-2951.

58. Sarasúa, J.I.; Martínez-Lucas, G.; Lafoz, M. Analysis of alternative frequency control schemes for increasing renewable energy penetration in El Hierro Island power system. Int. J. Electr. Power Energy Syst. 2019, 113, 807-823.

59. Fernández-Guillamón, A.; Vigueras-Rodríguez, A.; Gómez-Lázaro, E.; Molina-García, Á. Fast power reserve emulation strategy for VSWT supporting frequency control in multi-area power systems. Energies 2018, $11,2775$.

60. Kundur, P.; Balu, N.J.; Lauby, M.G. Power System Stability and Control; McGraw-Hill: New York, NY, USA, 1994; Volume 7,

61. Pöller, M.; Achilles, S. Aggregated wind park models for analyzing power system dynamics. In Proceedings of the 4th International Workshop on Large-Scale Integration of Wind Power and Transmission Networks for Offshore Wind Farms, Billund, Denmark, Billund, Denmark, 20-21 October 2003.

62. Clark, K.; Miller, N.W.; Sanchez-Gasca, J.J. Modeling of GE wind turbine-generators for grid studies. GE Energy 2010, 4, 0885-8950.

63. Zhao, S.; Nair, N.K. Assessment of wind farm models from a transmission system operator perspective using field measurements. IET Renew. Power Gener. 2011, 5, 455-464.

64. Fortmann, J. Modeling of Wind Turbines With Doubly Fed Generator System; Springer: 2014.

65. Zarina, P.; Mishra, S.; Sekhar, P. Exploring frequency control capability of a PV system in a hybrid PV-rotating machine-without storage system. Int. J. Electr. Power Energy Syst. 2014, 60, 258-267.

66. Sekhar, P.; Mishra, S. Storage free smart energy management for frequency control in a diesel-PV-fuel cell-based hybrid AC microgrid. IEEE Trans. Neural Netw. Learn. Syst. 2015, 27, 1657-1671.

67. Martínez-Lucas, G.; Sarasúa, J.I.; Sánchez-Fernández, J.Á.; Wilhelmi, J.R. Power-frequency control of hydropower plants with long penstocks in isolated systems with wind generation. Renew. Energy 2015, 83, 245-255.

68. Mancarella, P.; Chicco, G.; Capuder, T. Arbitrage opportunities for distributed multi-energy systems in providing power system ancillary services. Energy 2018, 161, 381-395.

69. ENTSO-E. Electricity Balancing in Europe. Available online https://docstore.entsoe.eu/ (accessed on 15 July 2020).

70. Díaz-González, F.; Hau, M.; Sumper, A.; Gomis-Bellmunt, O. Participation of wind power plants in system frequency control: Review of grid code requirements and control methods. Renew. Sustain. Energy Rev. 2014, 34, 551-564.

71. Ersdal, A.M.; Imsland, L.; Uhlen, K. Model predictive load-frequency control. IEEE Trans. Power Syst. 2015, 31, 777-785.

72. ENTSO-E. ENTSO-E Network Code for Requirements for Grid Connection Applicable to all Generators. June 2011. Available online: https:/ / consultations.entsoe.eu/ (accessed on 20 July 2020)

73. Guo, F.; Wen, C.; Mao, J.; Song, Y.D. Distributed secondary voltage and frequency restoration control of droop-controlled inverter-based microgrids. IEEE Trans. Ind. Electron. 2014, 62, 4355-4364.

74. Zhao, C.; Mallada, E.; Low, S.H. Distributed generator and load-side secondary frequency control in power networks. In Proceedings of the 2015 49th Annual Conference on Information Sciences and Systems (CISS), Baltimore, MD, USA, 18-20 March 2015; pp. 1-6.

75. Zhao, C.; Mallada, E.; Low, S.; Bialek, J. A unified framework for frequency control and congestion management. In Proceedings of the 2016 Power Systems Computation Conference (PSCC), Genoa, Italy, 20-24 June 2016; pp. 1-7.

76. UCTE (Union for the Co-ordination of Transmission of Electricity). Operation Handbook. 2004. Available online: https://www.entsoe.eu/publications/system-operations-reports/operation-handbook (accessed on 17 July 2020)

77. Wood, A.J.; Wollenberg, B.F.; Sheblé, G.B. Power Generation, Operation, and Control; John Wiley \& Sons: Hoboken, NJ, USA, 2013. 
78. ENTSO-E. TYNDP 2020-Scenario Report; 2020. Available online: https://www.entsos-tyndp2020scenarios.eu/wp-content/uploads/2020/06/TYNDP_2020_Joint_ScenarioReport_final.pdf (accessed on 1 July 2020).

79. Fernández-Guillamón, A.; Sarasúa, J.I.; Chazarra, M.; Vigueras-Rodríguez, A.; Fernández-Muñoz, D.; Molina-García, A. Frequency control analysis based on unit commitment schemes with high wind power integration: A Spanish isolated power system case study. Int. J. Electr. Power Energy Syst. 2020, 121, 106044.

80. ENMAX. Available online: https://www.enmax.com/generation-wires/real-time-system-demand (accessed on 6 July 2020).

81. ERGON. Available online: www.ergon.com.au/network/manage-your-energy/home-energy-tips/peakdemand-at-home/network-demand (accessed on 6 July 2020).

82. RTE. Available online: https://www.rte-france.com/en/eco2mix/eco2mix-consommation-en (accessed on 6 July 2020).

83. REE. Available online: https://demanda.ree.es/visiona/peninsula/demanda/tablas/2020-07-04/1 (accessed on 6 July 2020).

84. IESO. Available online: http:/ / www.ieso.ca/power-data (accessed on 6 July 2020).

85. CAISO. Available online: http://www.caiso.com/TodaysOutlook/Pages/default.aspx (accessed on 6 July 2020).

86. TEPCO. Available online: https://www4.tepco.co.jp/en/forecast/html/index-e.html (accessed on 6 July 2020).

87. TRANSPOWER. Available online: https://www.transpower.co.nz/power-system-live-data (accessed on 6 July 2020).

88. Martínez-Lucas, G.; Sarasúa, J.I.; Pérez-Díaz, J.I.; Martínez, S.; Ochoa, D. Analysis of the Implementation of the Primary and/or Inertial Frequency Control in Variable Speed Wind Turbines in an Isolated Power System with High Renewable Penetration. Case Study: El Hierro Power System. Electronics 2020, 9, 901.

89. ENTSO-E. Frequency Stability Evaluation Criteria for the Synchronous Zone of Continental Europe; ENTSO-E: Brussels, Belgium, 2016.

(C) 2020 by the authors. Licensee MDPI, Basel, Switzerland. This article is an open access article distributed under the terms and conditions of the Creative Commons Attribution (CC BY) license (http:/ / creativecommons.org/licenses/by/4.0/). 



\subsection{Extensive frequency response and inertia analysis under high RES integration scenarios: application to the European interconnected power system}

Traditionally, power system's inertia has been estimated according to the rotating masses directly connected to the grid. However, a new generation mix scenario is currently identified, where conventional supply-side is gradually replaced by renewable sources decoupled from the grid by electronic converters (i.e., wind and photovoltaic power plants). Due to the significant penetration of such renewable generation units, the conventional grid inertia is decreasing, subsequently affecting both reliability analysis and grid stability. Under this new framework, an algorithm to estimate the minimum inertia needed to fulfil the ENTSO-E requirements for the interconnected European power system for ROCOF values is proposed and assessed under a relevant variety of imbalanced conditions. The additional active power needed to be within the frequency dynamic range is also estimated and determined. Both inertia and additional active power can come from different sources, such as storage solutions, renewable sources decoupled from the grid including some frequency control strategies, interconnections with other grids, increasing the primary frequency reserves, or a combination of them. The power system under consideration includes thermal, hydro-power plants, and renewable generation units, in line with most current and future European supply-side power systems. More than 700 generation mix scenarios are identified and simulated, varying the renewable integration, the power imbalance, and the inertia constant of conventional power plants. The results show that an additional power between 0 and $0.32 \mathrm{pu}$ is enough to avoid any frequency excursion lower than $49.2 \mathrm{~Hz}$, even if RES generation is over $50 \%$ and the power imbalance is $40 \%$. Authors assume a maximum virtual inertia of $15 \mathrm{~s}$. Under this assumption, the ROCOF values following the ENTSO-E requirements are fulfilled for $85 \%$ of the simulated scenarios. From our analysis, it can be deduced that the additional power and virtual inertia to support frequency deviations after power imbalances can be provided independently and from different resources. Even though this analysis is carried out considering the interconnected European power system, it can be applied to any other power system with high penetration of renewable sources, considering the specific recommendations of such grid.

Information of the paper:

- Journal: IET Renewable Power Generation

- DOI: 10.1049/iet-rpg.2020.0045

- Accepted, pending publication

- Available online: https://arxiv.org/pdf/2011.01749.pdf

- Reference: [8] 



\title{
Extensive frequency response and inertia analysis under high renewable energy source integration scenarios: application to the European interconnected power system
}

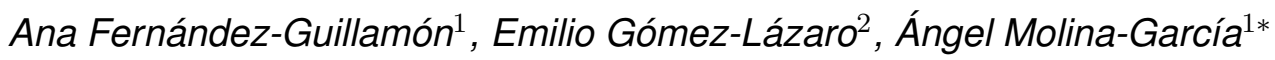 \\ ${ }^{1}$ Automatics, Electrical Eng., and Electronic Tech. Dept., Universidad Politecnica de Cartagena, Cartagena, Spain \\ ${ }^{2}$ Renewable Energy Research Institute and DIEEAC-EDII-AB, Universidad de Castilla-La Mancha, Albacete, Spain \\ *E-mail: angel.molina@upct.es
}

\begin{abstract}
Traditionally, power system's inertia has been estimated according to the rotating masses directly connected to the grid. However, a new generation mix scenario is currently identified, where conventional supply-side is gradually replaced by renewable sources decoupled from the grid by electronic converters (i.e., wind and photovoltaic power plants). Due to the significant penetration of such renewable generation units, the conventional grid inertia is decreasing, subsequently affecting both reliability analysis and grid stability. As a result, concepts such as 'synthetic inertia', 'hidden inertia' or 'virtual inertia', together with alternative spinning reserves, are currently under discussion to ensure power system stability and reliability. Under this new framework, an algorithm to estimate the minimum inertia needed to fulfil the ENTSO-E requirements for ROCOF values is proposed and assessed under a relevant variety of imbalanced conditions. The additional active power needed to be within the frequency dynamic range is also estimated and determined. Both inertia and additional active power can come from different sources, such as storage solutions, renewable sources decoupled from the grid including some frequency control strategies, interconnections with other grids, or a combination of them. The power system under consideration includes thermal, hydro-power plants, and renewable generation units, in line with most current and future European supply-side power systems. More than 700 generation mix scenarios are identified and simulated, varying the renewable integration, the power imbalance, and the inertia constant of conventional power plants. In fact, the solutions studied here provide important information to ease the massive integration of renewable resources, without reducing the capacity of the grid in terms of stability and response to contingencies.
\end{abstract}

\section{Nomenclature}

The following nomenclature has been used:

\begin{tabular}{ll}
$\Delta f$ & Frequency variation \\
$\Delta P_{a d d}$ & Additional power \\
$\Delta P_{g}$ & Variation of the supply-side active power \\
$\Delta P_{\text {load }}$ & Variation of the demand-side active power \\
$\Delta P_{L}$ & Power imbalance \\
$D_{e q}$ & Equivalent damping factor of loads \\
$f$ & Frequency \\
$H$ & Inertia constant \\
$H_{e q}$ & Equivalent inertia constant \\
$H_{R E S}$ & Virtual inertia constant \\
$H_{S}$ & Synchronous inertia constant \\
$S_{B}$ & Rated power of power plant/power system \\
\hline aFR & Automatic frequency restoration \\
DSO & Distribution system operators \\
ENTSO-E & European network of transmission system operators for electricity \\
EU & European Union \\
FC & Frequency containment \\
IN & Imbalance netting \\
mFR & Manual frequency restoration \\
PFR & Primary frequency reserves \\
PV & Photovoltaic \\
RES & Renewable energy sources \\
ROCOF & Rate of change of frequency \\
TSO & Transmission system operators \\
VSWT & Variable speed wind turbines \\
& \\
\hline
\end{tabular}

\section{Introduction}

Power system stability analysis currently relies on synchronous machines with rotational masses connected to the grid. These generation units store kinetic energy, which is automatically extracted in response to a sudden loss of generation, slowing down the machine and reducing the grid frequency [1]. However, power systems are gradually changing [2]. Fossil fuel problems, such as resource scarcity, increasing prices and geopolitical risks related to import dependency [3-5], have encouraged most developed countries to promote Renewable Energy Sources (RES) large-scale integration [6]. In Europe, wind, solar and biomass overtook coal power for the first time in 2017 [7]. According the current road-maps, $323 \mathrm{GW}$ and $192 \mathrm{GW}$ of wind and photovoltaic (PV) power plants are expected to be installed in Europe by 2030, covering up to $30 \%$ and $18 \%$ of the European Union (EU) demand respectively $[8,9]$. Some authors affirm that with current technologies, only $50 \%$ of the overall electricity demand can be given by RES [10]. By 2030, the EU will be close to achieving this theoretical limit. As a result, under this European roadmap, it is desirable to analyse the theoretical renewable threshold by considering the international frequency control requirements for a reliable and secure interconnection frequency response.

Among the different RES, PV and wind resources —especially variable speed wind turbines, VSWT [11] — are considered as the two most promising resources for power generation [12]. However, their intermittent behaviour makes them difficult to integrate into current power systems. In fact, Transmission and Distribution System Operators (TSO/DSO) deal with not only uncontrollable demand, but also oscillated generation [12-15]. Additionally, these resources do not contribute directly to inertia and power system reserves [16], as they are electrically decoupled from the grid through power converters [17]. It significantly reduces the grid effective inertia [18], compromising power system stability and 
modifying their transient response [19]. Moreover, low system inertia is related to $(i)$ a faster rate of change of frequency (ROCOF) and (ii) larger frequency deviations (larger nadir) within a shorter time frame [20]. Therefore, inertia reduction is considered as a relevant problem to the large integration of RES into power systems [21]. Subsequently, [22] considers that there is an acute need to study how inertia reduction impacts system dynamic performances. Some contributions can be found in the specific literature focused on such inertia reduction impacts. The application of probabilistic and risk-based assessment techniques for operation planning in power systems with high wind power generation has attracted high interest from electrical power industry [23].

Different wind turbine controllers with virtual inertia are proposed in the specific literature, mostly evaluated under simplified power system modelling and usually including a few imbalance situations. Fu et al [24] includes only a sudden load decrease and a sudden decrease as experimental test. Another examples of such test conditions with a sudden load increase/decrease can be found in [11, 25-27]. Six case studies are considered in [28], with hypothetical load step rise events. The loss of the largest power plant of thirty energy schedules were simulated in [29] under different wind power integration levels. Wang et al [30] performs statistical analysis of dynamic frequency stability studies, but considering only the current reference incident (a loss of $3 \mathrm{GW}$ ). This reference incident -also known as worst contingency - is simulated both in over and under frequency to study the impact of synchronous compensators and battery energy storage systems in order to maintain the stability of the power system adding real or virtual inertia [31]. Also the impact of large-scale PV power plants have been also analysed. A review focused on power stability challenges can be found in [12]. As an example, Bueno et al [32] defines six scenarios for stability purposes in transmission systems with large PV power plant integration.

However, it is noted that all these studies focus on providing a specific technique for VSWT/PV power plants to participate in frequency control, evaluating the proposal under a reduced number of scenarios from the supply-side and the imbalance conditions. Even though these approaches can be acceptable to improve the frequency response of power systems, authors propose a more general but detailed and precise frequency analysis in terms of nadir and ROCOF. As a result, this papers focuses on estimating and determining the minimum inertia and additional active power to be provided after an imbalance, following the European Network of Transmission System Operators for Electricity (ENTSO-E) recommendations for nadir and ROCOF values. Such virtual inertia and additional power can be provided by a variety of complementary solutions/resources, which can be combined in an optimised power system environment. A similar but simpler studied was performed in [33] for the Australian power system. Primary frequency reserves (PFR) requirements were estimated as a function of the system inertia and the maximum power imbalance; following some predefined frequency constraints such as ROCOF and frequency nadir. The power system under analysis includes thermal, hydro-power plants, and different RES integration levels, in line with current and future European generation mix scenarios. Moreover, different inertia constant values for the conventional power plants (i.e., thermal and hydro-power) are considered for the analysis. Preliminary results and a simplified previous analysis was addressed by the authors in [34]. The contributions of the paper are then summarised as follows:

- A relevant variety of scenarios are considered for simulation. In total, 720 different scenarios are analysed, resulting from the combination of 5 RES penetration levels (up to $60 \%$ ), 16 power imbalance conditions (up to $40 \%$ in line with ENTSO-E recommendations), 3 thermal inertia constant values, and 3 hydro-power inertia constant values (both inertia constants of conventional power plants are usually considered as constant in most of previous works).

- An algorithm to estimate the minimum inertia and the additional power to fulfil the ROCOF and nadir values recommended by ENTSO-E is proposed. These inertia and additional power can come from different sources, such as storage solutions (flywheels, batteries, super-capacitors), participation of RES into frequency control, interconnection with other power systems, increased primary frequency control reserves of conventional units, or a combination of them.

- This study gives extensive results regarding the massive integration of RES and current power system characteristics, maintaining the frequency stability of the grid. Subsequently, it would be then possible to gradually replace conventional power plants providing the same reliability. The proposed analysis can be extended to other international requirements and rules.

The rest of the paper is organised as follows: Section 2 discusses the importance of inertia in power system stability and summarises the recommendations regarding nadir and ROCOF developed by ENTSO-E. The methodology is presented in Section 3, describing the power system modelling and the different scenarios to be simulated. Results are described in Section 4. Finally, Section 5 presents the conclusions.

\section{Inertia for power system stability. ENTSO-E recommendations}

\subsection{Preliminaries}

Let us consider turbine-synchronous generators submitted to small variations around their steady-state conditions. The mechanical and electrical power of a generation unit can be then related as follows [35]:

$$
\Delta \omega_{r}=\frac{\Delta P_{m}-\Delta P_{e}}{2 H s+D},
$$

where $\omega_{r}$ is the rotational pulsation of the generator, $P_{m}$ is the mechanical power, $P_{e}$ represents the electrical power, $H$ is the inertia constant, and $D$ is the damping factor of the loads. $H$ is defined in the specific literature as the time interval (in seconds) during which the generator can supply its rated power from the stored kinetic energy. This time interval usually lies between 2 and $10 \mathrm{~s}$ for conventional generators [36, 37]. Regarding eq. (1), certain simplifications are usually considered to apply such expression to power systems with conventional generation: $(i)$ loads are reduced to an aggregated load with an equivalent damping factor $D_{e q}$ [38]; (ii) the synchronous generators are reduced to an equivalent rotating mass $H_{e q}$ :

$$
H_{e q}=\frac{\sum_{i=1}^{C G} H_{i} \cdot S_{B, i}}{S_{B}},
$$

where $H_{i}$ is the inertia constant of the $i$-power plant, $S_{B, i}$ is the rated power of the $i$-power plant, $S_{B}$ is the rated power of the power system, and $C G$ is the total number of conventional generators.

Conventional power plants have been replaced by RES over the last ten years, mainly in response to different policies focused on promoting their integration. These actions have subsequently generated a decline in system inertia [39]. Consequently, larger frequency deviations can be suffered after a supply-side and demand imbalance [40]; being ROCOF also depending on the available inertia [41]. In consequence, TSO and DSO require that RES also contribute to ancillary services [42], especially wind turbines [43]. Indeed, [44] affirms that the wind turbine participation in frequency control is inevitable. By considering these requirements, different alternatives providing additional inertia and frequency control from RES can be found in the recent specific literature. These solutions are commonly known as 'hidden', 'synthetic', or 'virtual' inertial techniques [45-47]. The equivalent inertia of power systems can be then divided into two different components: $(i)$ synchronous inertia provided by conventional generators $H_{S}$ and (ii) virtual inertia 
Table 1 European frequency control structure

\begin{tabular}{lll}
\hline Type & Activation & Timescale \\
\hline FC & Automatic activation & $0-30 \mathrm{~s}$ \\
aFR & Automatic activation & $30 \mathrm{~s}-15 \mathrm{~min}$ \\
mFR & Semi-automatic or manual activation & 15 min maximum \\
R & Semi-automatic or manual activation & 15 min minimum \\
\hline
\end{tabular}

provided by RES electrically decoupled from the grid, $H_{R E S}$,

$$
H_{e q}=\frac{\overbrace{\sum_{i=1}^{C G} H_{i} \cdot S_{B, i}}^{H_{S}}+\overbrace{\sum_{j=1}^{V P P} H_{R E S, j} \cdot S_{B, j}}^{H_{R E S}},}{S_{B}},
$$

where $H_{R E S, j}$ is the emulated inertia constant corresponding to the $j$-renewable power plant, and $V P P$ the total number of renewable virtual power plants included in the grid under study. Further information about this equivalent inertia definition can be found in $[48-50]$.

\subsection{ENTSO-E recommendations}

ENTSO-E has already focused on the high RES integration-low synchronous inertia problem. In fact, several reports have been published for the EU [51-58]. In Europe, frequency control has a hierarchical structure, usually organised in a maximum of five layers (from fast to slow timescales): (i) frequency containment (FC); (ii) imbalance netting (IN); (iii, iv) frequency restoration (automatic (aFR) and/or manual (mFR)) and $(v)$ replacement $(\mathrm{R})$ [51]. Table 1 presents an overview of each layer. IN reduces the simultaneous activation of aFR from different areas and thus, is not included in the table. The increase in RES and loads connected through power electronics is currently a major issue, as several problems are involved, including frequency stability, voltage stability, and power quality [52]. In this paper, the authors focus on frequency stability problems due to the reduction of the power systems' inertia. According to [52], the minimum inertia of a power system should range between 2-3 s, which is lower than conventional power plants, as discussed in Section 2. Solutions to avoid a huge decrease of system inertia include [52]: $(i)$ real-time restriction of the maximum penetration of RES connected through power electronics; $(i i)$ inclusion of synchronous compensators or flywheels; and (iii) addition of virtual inertia from power electronic interfaced sources.

According to the ENTSO-E recommendations, if the integration of generation units and loads connected to the grid through power electronics is higher than $65 \%$, the grid may suffer from severe problems in terms of frequency deviation [52]. Current power systems should be robust enough to support a load imbalance of $40 \%$ [53]. Consequently, virtual inertia is proposed for small/isolated power systems/areas (such as Ireland and Great Britain) with a high integration of non-synchronous elements [53]. In terms of nadir and ROCOF requirements, the main challenges that face these grids after an imbalance are [53]:

- High initial ROCOF. The grid inertia value determines the initial ROCOF after an imbalance. To reduce this initial ROCOF when some synchronous generators have been replaced by RES, the electronic interfaced sources (such as PV and VSWT) should deliver virtual inertia without any delay.

- Low nadir (minimum frequency). It is important to increase nadir frequency in order to avoid a load shedding program. The frequency control response of conventional power plants can be too slow for this target. However, generation units including power electronics or other storage solutions can be highly effective for this aim, due to power electronic flexibility and control.

By considering both challenges, high initial ROCOF is assumed to be more critical than low nadir, as nadir takes some seconds to reach the minimum frequency value [53] and initial ROCOF is reached practically instantaneously. Indeed, a high ROCOF can endanger the secure system operation of a grid due to [54]: $(i)$ mechanical limitations of synchronous machines; ( $i i)$ failure of protection systems; or (iii) load shedding programs. The ROCOF limits defined by ENTSO-E depend on the sliding time-window, considering three different limits [54]:

- $\pm 2 \mathrm{~Hz} / \mathrm{s}$ for a sliding time-window of $0.5 \mathrm{~s}$

- $\pm 1.5 \mathrm{~Hz} / \mathrm{s}$ for a sliding time-window of $1 \mathrm{~s}$

- $\pm 1.25 \mathrm{~Hz} / \mathrm{s}$ for a sliding time-window of $2 \mathrm{~s}$

With regard to supply-side generators, they can only be disconnected $(i)$ if any of such ROCOF limits is achieved or $(i i)$ if the frequency deviation is below $47.5 \mathrm{~Hz}$ or above $51.5 \mathrm{~Hz}$ [54]. Nevertheless, under such large frequency deviations, it is difficult to avoid a power system blackout [55]. The dynamic range allowed for frequency deviations is currently $\pm 800 \mathrm{mHz}$. However, and according to [55], future power systems should handle $2 \mathrm{~Hz} / \mathrm{s}$ ROCOF and $40 \%$ power imbalance. Under these circumstances, the considered scenarios cover a variety of imbalances (up to $40 \%$ ) in line with these recommendations, see Section 4.

\section{Methodology}

\subsection{Power system modelling}

With the aim of analysing the influence on the frequency response of high integration of generation units connected to the grid through power electronics, an equivalent power system with a total capacity of $1000 \mathrm{MW}$ is first proposed for simulations. The supply-side mix is in line with most current European power systems, where conventional and renewable units can be considered as an averaged common generation scenario. The system consists of conventional power plants (reheat thermal and hydro-power) and non-dispatchable RES (VSWT and/or PV power plants). Both thermal and hydro-power plants are modelled by using simplified governor-based models, derived from speed-governing systems widely used and described in [59], see Figure 1. Different inertia constants for thermal and hydro-power plants $\left(H_{T}\right.$ and $H_{H}$ respectively) considered following the review [47].

The power system model for frequency deviation analysis is based on the swing equation, see Section 2,

$$
\Delta f=\frac{1}{2 H_{e q} s+D_{e q}} \cdot\left(\Delta P_{g}-\Delta P_{l o a d}\right),
$$

where $\Delta P_{g}=\Delta P_{R E S}+\Delta P_{T}+\Delta P_{H}$ is the active power variation from supply-side and $\Delta P_{\text {load }}$ is the demand-side variation. $H_{e q}$ is the equivalent inertia of the power system according to eq. (3) and $D_{e q}$ is the damping factor, considered as constant $D_{e q}=2 \% / \mathrm{Hz}$ following the ENTSO-E recommendations [55]. The power imbalance $\Delta P_{L}$ is simulated as a sudden step. Most frequency deviation analysis only consider a reduced number of such sudden imbalances, as was discussed in Section 1. To overcome this drawback, $\Delta P_{L}$ varies from $2.5 \%$ to $40 \%$ (2.5\% steps) following the ENTSO-E recommendations previously discussed in Section 2.2 .

\subsection{Virtual inertia and additional power estimation}

Following the case studies explained in Section 3.1, the equivalent synchronous inertia of each simulated scenario is determined by eq. (2). This equivalent inertia lies between $8.71 \mathrm{~s}$ (5\% RES, $H_{T}=10 \mathrm{~s}$ and $\left.H_{H}=4.75 \mathrm{~s}\right)$ and $0.76 \mathrm{~s}\left(60 \%\right.$ RES, $H_{T}=2 \mathrm{~s}$ and $\left.H_{H}=1.75 \mathrm{~s}\right)$. Authors analyse such $H_{e q}$ variations to emphasise the relevance of such conventional power plant inertia constants. Indeed, small $H$ variations can drastically affect the whole inertia power system $H_{e q}$, and subsequently, the minimum additional virtual inertia to be provided by the other sources. As will be discussed in Section 4, only by considering the synchronous inertia, the ROCOF limits would be violated (especially for imbalances $\Delta P_{L} \geq$ 


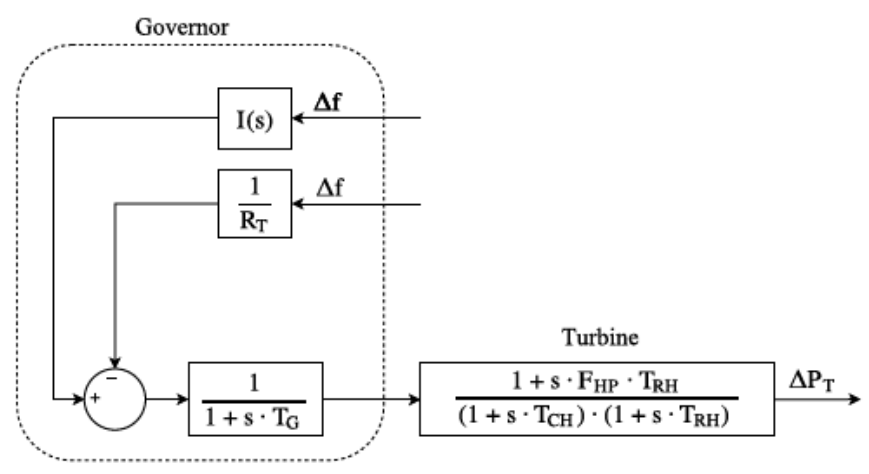

(a) Thermal power plant

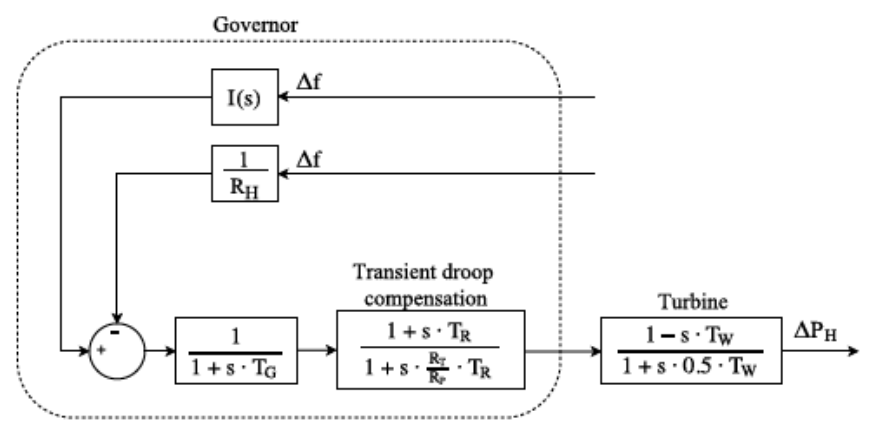

(b) Hydro-power plant

Fig. 1: Conventional power plant models.

$20 \%$ ) and the nadir frequency would be lower than $49.2 \mathrm{~Hz}$ in most cases. Consequently, the virtual additional inertia that should be provided $H_{R E S}$ to fulfil the ROCOF limits established by ENTSO-E, as well as the additional power $\Delta P_{a d d}$ to be within the allowable dynamical variation of frequency, are estimated. Both virtual inertia and additional supply-side power can be provided by a variety of different, complementary solutions/resources, which can be combined in an optimised power system source environment.

3.2.1 Estimation of minimum $H_{R E S}$ : From the ROCOF limits presented in Section 2.2, the minimum system inertia can be obtained as

$$
H_{\text {eq }, \min }=\frac{\Delta P_{L}}{P_{\text {load }}} \cdot \frac{f_{0}}{R O C O F_{l i m}},
$$

where $\Delta P_{L}$ is the power imbalance, $P_{\text {load }}$ is the total load of the power system, $f_{0}$ is the nominal frequency and $R O C O F_{l i m}$ is the maximum limit ROCOF allowed [55]. Combining eqs. (3) and (5), it is possible to obtain the minimum $H_{R E S}$ required to fulfil the ROCOF limits:

$$
H_{R E S}=\frac{H_{e q, \min } \cdot S_{B}-H_{T} \cdot S_{B, T}-H_{H} \cdot S_{B, H}}{S_{B, R E S}} .
$$

In consequence, an algorithm to estimate the minimum RES inertia constant $H_{R E S}$ is proposed, see Figure 2,

i. Simulate the $i$-scenario, depending on the RES percentage, conventional generation units' inertia $\left(H_{T}\right.$ and $H_{H}$, respectively), and power imbalance $\Delta P_{L}$.

ii. Determine each $\operatorname{ROCOF}_{j}$ (being $j=0.5,1$ and 2) with eq. (7)(9), where $t_{0}$ is the imbalance time instant (in $s$ ):

$$
\begin{aligned}
R O C O F_{0.5} & =\frac{\Delta f_{t_{0}+0.5}-\Delta f_{t_{0}}}{0.5}, \\
R O C O F_{1} & =\frac{\Delta f_{t_{0}+1}-\Delta f_{t_{0}}}{1},
\end{aligned}
$$

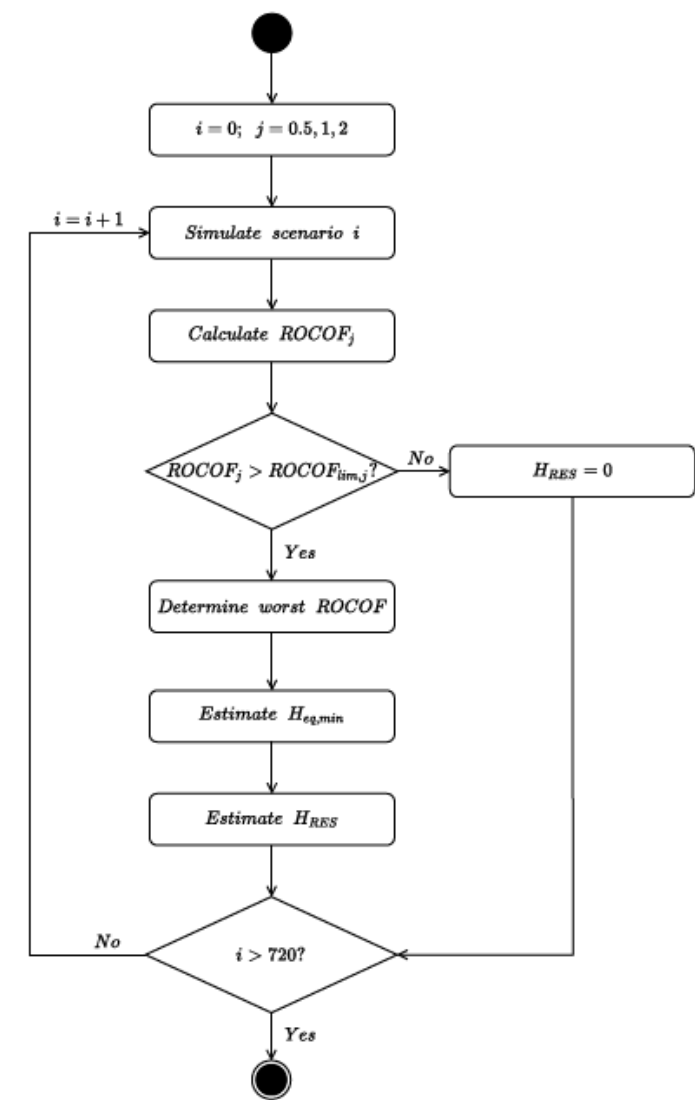

Fig. 2: Graphic description to estimate minimum $H_{R E S}$ according to the ENTSO-E recommendations.

$$
R O C O F_{2}=\frac{\Delta f_{t_{0}+2}-\Delta f_{t_{0}}}{2} .
$$

iii. Check whether any of the previously determined $\mathrm{ROCOF}_{j}$ is over their limit: $\mathrm{ROCOF}_{0.5}>2 \mathrm{~Hz} / \mathrm{s}, \mathrm{ROCOF}_{1}>1.5 \mathrm{~Hz} / \mathrm{s}$, and/or $\mathrm{ROCOF}_{2}>1.25 \mathrm{~Hz} / \mathrm{s}$.

(a)If no $\mathrm{ROCOF}_{j}$ exceeds the corresponding limit, non-additional inertia is required $\left(H_{R E S}=0\right)$, and the following scenario is then simulated $(i=i+1)$.

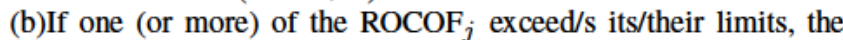
algorithm proceeds to the next step.

iv. Determine the worst ROCOF $_{j}$ value. This is performed by calculating the relative differences between each $\mathrm{ROCOF}_{j}$ exceeding the limits and the corresponding $\mathrm{ROCOF}_{l i m, j}$ (in \%). The maximum value of such relative differences is then considered for the next step.

v. Estimate the minimum equivalent inertia $H_{e q, \min }$ (eq. (5)) for the worst ROCOF previously determined, considering $\mathrm{ROCOF}_{l i m}$ as $2,1.5$ or $1.25 \mathrm{~Hz} / \mathrm{s}$ depending on $\operatorname{ROCOF}_{j}(0.5$, 1 or 2 ), respectively.

vi. Calculate the additional RES inertia constant $H_{R E S}$ from eq. (6).

vii. Simulate the following $(i=i+1)$ scenario, finishing the algorithm when all scenarios under consideration are simulated $(i>720)$.

3.2.2 Estimation of minimum $\Delta P_{\text {add }}$ : According to ENTSO$\mathrm{E}$, the maximum dynamic variation of frequency is $f_{0} \pm 800 \mathrm{mHz}$. Moreover, if $f \leq 47.5 \mathrm{~Hz}$, it is difficult to avoid a power system blackout [55]. These frequency limits are exceeded in most of the supply-side scenarios currently under analysis. Consequently, some additional power $\Delta P_{a d d}$ should be provided to be within the dynamic range of such frequency variations. The estimated $\Delta P_{a d d}$ can be provided by: $(i)$ additional power from RES (by including frequency control strategies), (ii) energy storage solutions, (iii) increasing the PFR of conventional power plants, (iv) other 


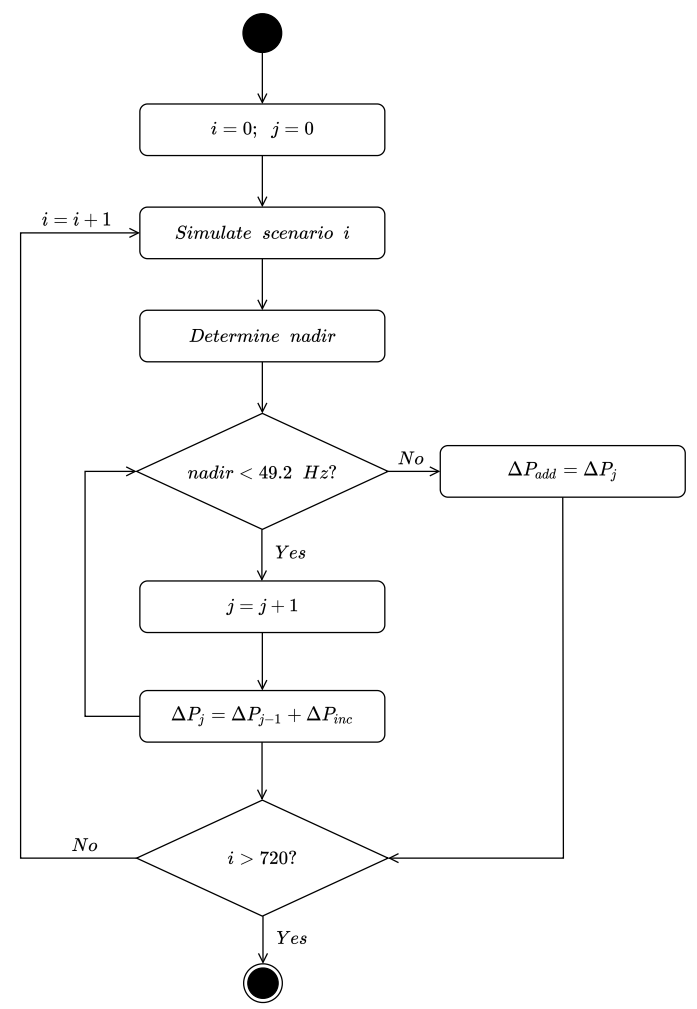

Fig. 3: Graphic description to estimate minimum $\Delta P_{a d d}$ according to the ENTSO-E recommendations.

power systems from interconnections, or $(v)$ a combination of them. Taking into account the power system discussed in Section 3.1, the corresponding additional active power $\Delta P_{a d d}$ is then estimated as follows, see Figure 3:

i. Simulate the $i$-scenario, which depends on the RES integration, conventional generation units' inertia $\left(H_{T}\right.$ and $H_{H}$, respectively) and power imbalance $\Delta P_{L}$.

ii. Determine the nadir (minimum value of the frequency deviation).

iii. Check if the nadir value is below $49.2 \mathrm{~Hz}$ ( $800 \mathrm{mHz}$ deviation) as recommended by ENTSO-E.

(a)If nadir is $f \geq 49.2 \mathrm{~Hz}$, no additional power is needed $\left(\Delta P_{a d d}=0\right)$, and a new scenario is simulated $(i=i+1)$, going back to the first step of the algorithm.

(b)If nadir is below $49.2 \mathrm{~Hz}$, the algorithm proceeds to the next step.

iv. Increase the additional power $\Delta P_{j}$ by a predefined value $\Delta P_{\text {inc }}$. In this case, $\Delta P_{i n c}=0.01 \mathrm{pu}$. This step is repeated until the nadir value is over $49.2 \mathrm{~Hz}$.

v. Simulate the following $(i=i+1)$ scenario, finishing the algorithm when all scenarios under consideration are simulated $(i>720)$

\section{$4 \quad$ Results}

\subsection{Case study discussion}

Considering the recommendations of ENTSO-E previously discussed in Section 2.2 as well as current RES integration and roadmaps cited in Section 3.1, 5 different RES integration levels and 16 different power imbalances are identified for simulation and analysis purposes. Although the existing studies offer no guidance for the maximum RES limit integration, the percentage to maintain the system frequency response within the permissible bounds is estimated to be around 50\% [60], or even higher by other authors with the installation of small, but highly efficient storage devices [61]. Hydro-power capacity remains constant in all cases. Thermal
Table 2 Generation by source

\begin{tabular}{llllll}
\hline Supply-side resource & \multicolumn{5}{c}{ Mix generation (\%) } \\
\hline Thermal power plant & 80 & 70 & 55 & 40 & 25 \\
Hydro-power plant & 15 & 15 & 15 & 15 & 15 \\
Renewable power plant & 5 & 15 & 30 & 45 & 60 \\
\hline
\end{tabular}

Table 3 Synchronous equivalent inertia $\left(H_{e q}\right)$. Example of results

\begin{tabular}{lccccc}
\hline & $\mathbf{5}$ & $\mathbf{1 5}$ & $\mathbf{3 0}$ & $\mathbf{4 5}$ & $\mathbf{6 0}$ \\
\hline $\begin{array}{c}H_{T}=10 \\
H_{H}=4.75\end{array}$ & 8.71 & 7.71 & 6.21 & 4.71 & 3.21 \\
\hline $\begin{array}{c}H_{T}=6 \\
H_{H}=3.25\end{array}$ & 5.29 & 4.69 & 3.79 & 2.89 & 1.99 \\
\hline $\begin{array}{c}H_{T}=2 \\
H_{H}=1.75\end{array}$ & 1.86 & 1.66 & 1.36 & 1.06 & 0.76 \\
\hline
\end{tabular}

capacity decreases proportionately as RES capacity increases. The five generation mix cases are summarised in Table 2. These generation mix cases are in line with those proposed by the 10-year network development plan for the EU [62]. The power imbalance $\Delta P_{L}$ increases from $2.5 \%$ up to $40 \%$ in $2.5 \%$ steps.

Most of previous contributions discussed in Section 1 assume a supply-side modelling without any parameter diversity in their equivalent generation units. Following the recent review by [47], three different values for the inertia constant of the thermal $H_{T}$ and hydro-power $H_{H}$ plants are considered for simulations. The minimum, mean and maximum value of such inertia constants are then taken into account: $H_{T}=\{2,6,10\}, H_{H}=\{1.75,3.25,4.75\}$. Therefore, by combining the different $\Delta P_{L}$ (16), RES integration (5), $H_{T}$ (3) and $H_{H}$ (3), 720 scenarios are identified and simulated. The equivalent synchronous inertia corresponding to the conventional generation units (i.e., thermal and hydro-power) is then determined from eq. (2), which also depends on the RES integration. All of the simulations are carried out under a Matlab/Simulink environment.

\subsection{Results}

Figures 4-6 depict 240 cases out of the 720 under consideration. In each figure, 80 scenarios are summarised (combination of the 16 power imbalances and the 5 generation mix). Both the nadir frequency and the three ROCOF values for three different combinations of $H_{T}$ and $H_{H}$ are depicted, being significant the diversity of results under a variety of such parameters, commonly assumed as constant in most of previous contributions as was discussed in Section 1. The equivalent synchronous inertia of the system for each figure is detailed in Table 3, depending on the RES integration.

With regard to nadir frequency, values over $f \geq 49.2 \mathrm{~Hz}$ are dynamically accepted by ENTSO-E. As a consequence, they are coloured in green. If the nadir decreases under $f<49.2 \mathrm{~Hz}$ (but is still over $f \geq 47.5 \mathrm{~Hz}$ ), it is coloured in yellow and orange, as they are outside the dynamic range allowed by ENTSO-E. When nadir is under $f<47.5 \mathrm{~Hz}$, a possible blackout may occur in the grid, subsequently being coloured in red. Two different planes are included in Figures 4-6 determining such limits. As can be seen, most of the scenarios under consideration are outside the dynamically accepted range, especially if both the RES integration and the power imbalance are high. Even though the equivalent synchronous inertia is significantly reduced depending on the $H_{T}$ and $H_{H}$ values (for instance, $H_{e q}=8.71 \mathrm{~s}, H_{e q}=5.29 \mathrm{~s}$ or $H_{e q}=1.86 \mathrm{~s}$ for $5 \%$ RES integration, refer to Table 3), the nadir frequency does not decrease drastically for the same generation mix. In fact, if comparing the 5\% RES integration energy mix, and the imbalance $\Delta P_{L}=2.5 \%$, the 


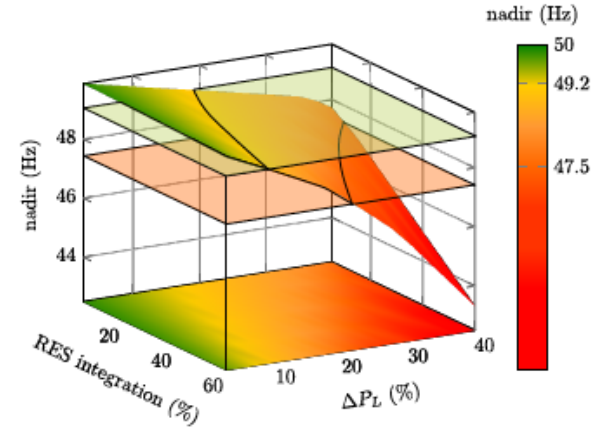

(a) Nadir frequency

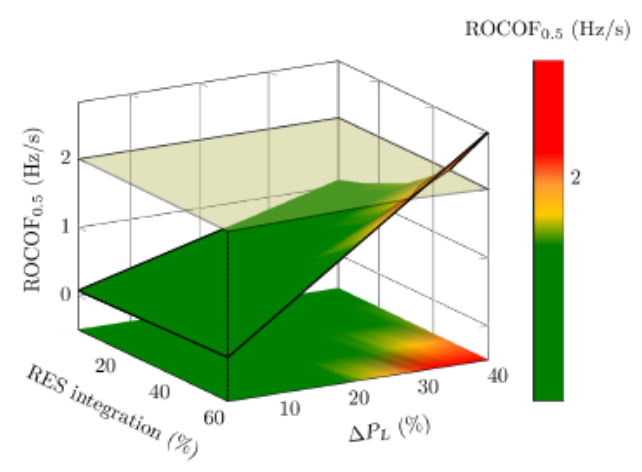

(b) $\mathrm{ROCOF}_{0.5}$ overview

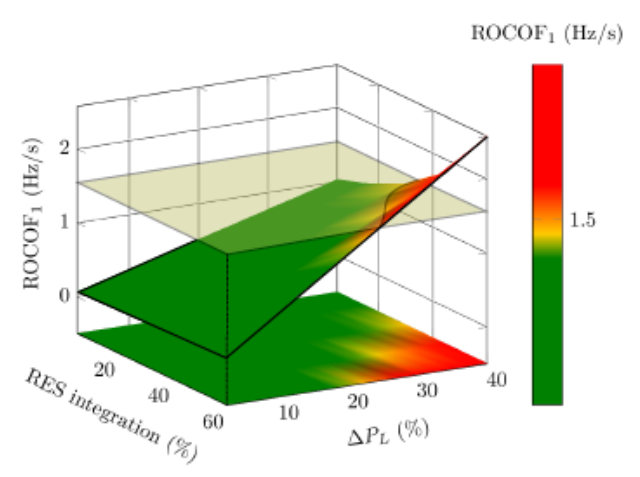

(c) ROCOF$_{1}$ overview

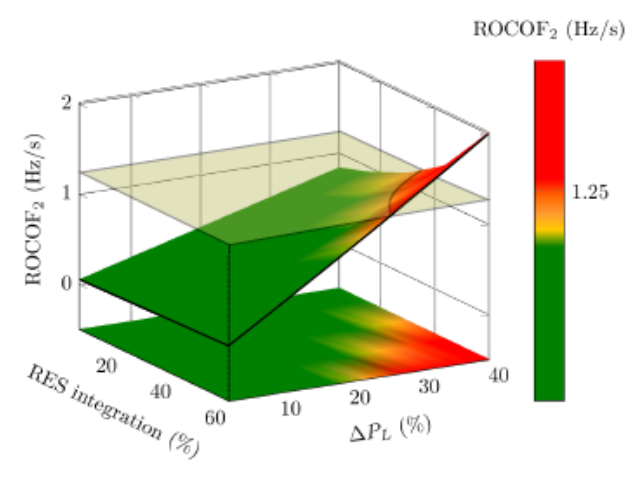

(d) $\mathrm{ROCOF}_{2}$ overview

Fig. 4: Overview of nadir frequency and ROCOFs when $H_{T}=10 \mathrm{~s}$ and $H_{H}=4.75 \mathrm{~s}$

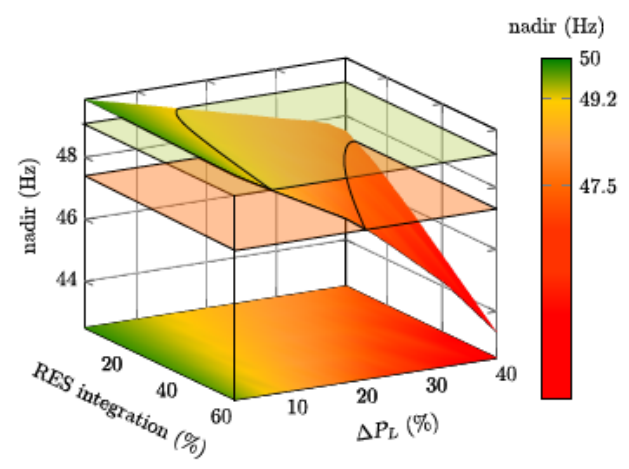

(a) Nadir frequency

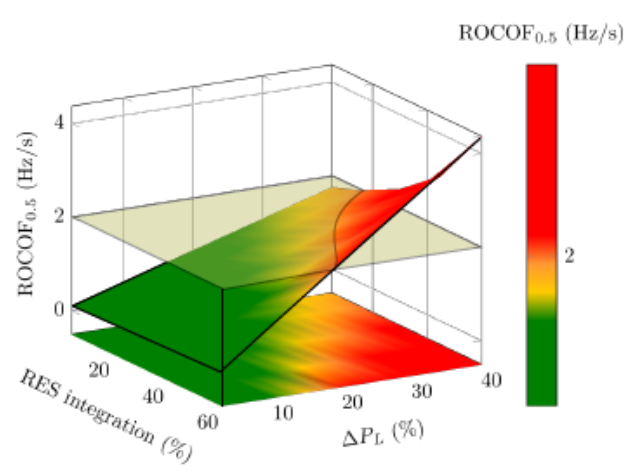

(b) $\mathrm{ROCOF}_{0.5}$ overview

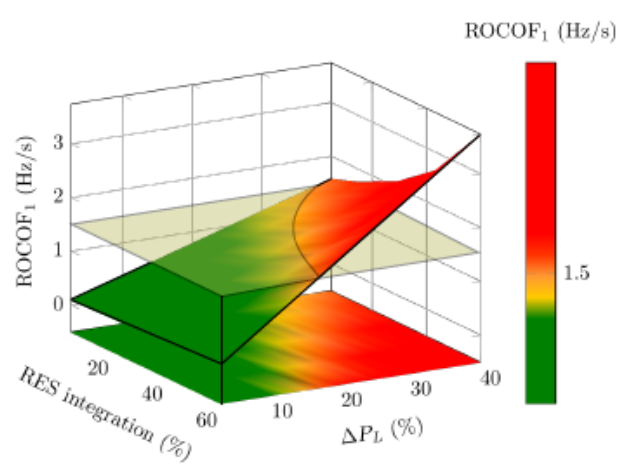

(c) ROCOF $_{1}$ overview

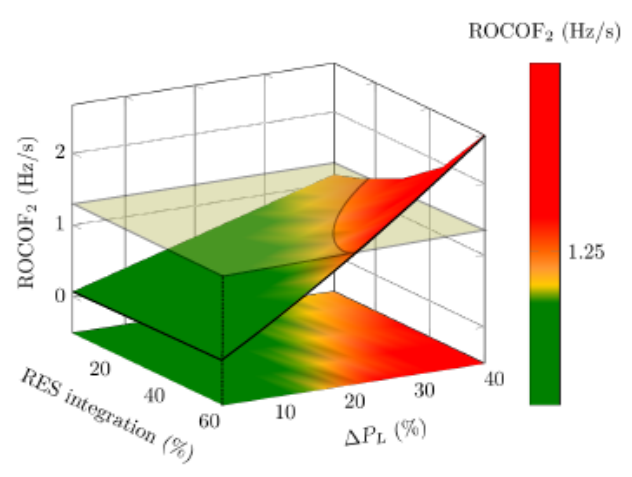

(d) $\mathrm{ROCOF}_{2}$ overview

Fig. 5: Overview of nadir frequency and ROCOFs when $H_{T}=6 \mathrm{~s}$ and $H_{H}=3.25 \mathrm{~s}$ 
nadir $(\mathrm{Hz})$

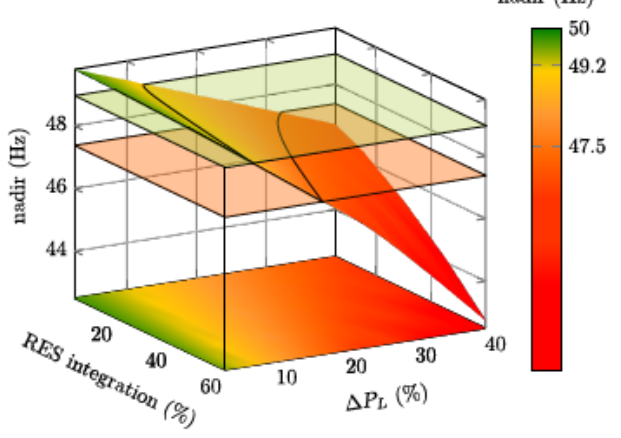

(a) Nadir frequency

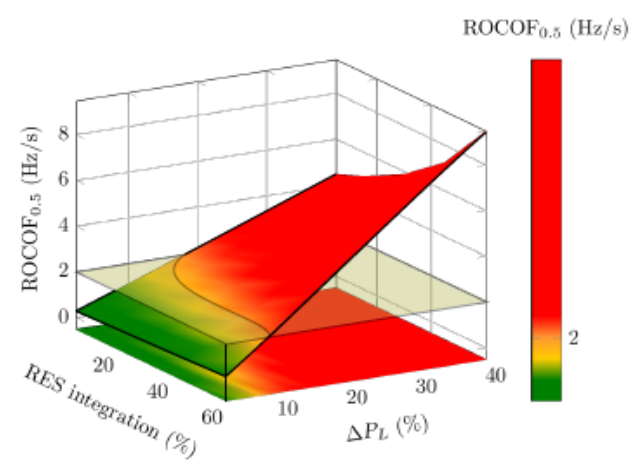

(b) $\mathrm{ROCOF}_{0.5}$ overview

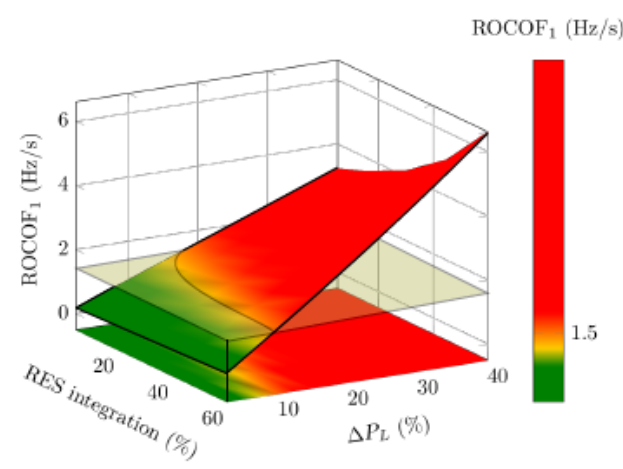

(c) ROCOF$_{1}$ overview

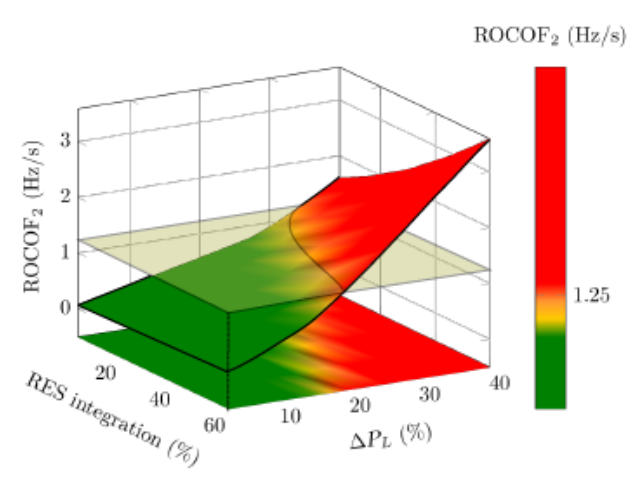

(d) $\mathrm{ROCOF}_{2}$ overview

Fig. 6: Overview of nadir frequency and ROCOFs when $H_{T}=6 \mathrm{~s}$ and $H_{H}=3.25 \mathrm{~s}$

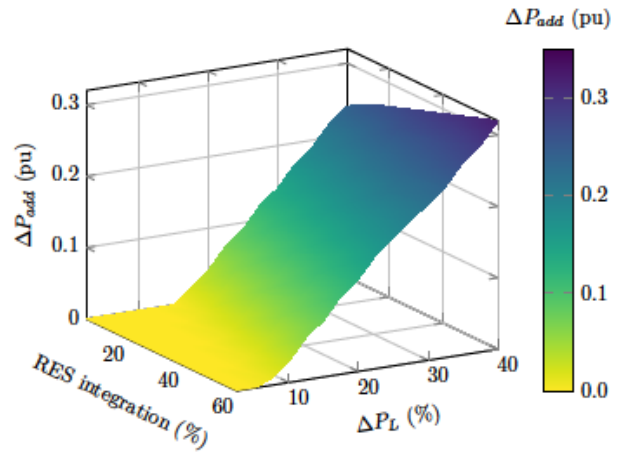

(a) $\Delta P_{a d d}$ to fulfil nadir frequency limit

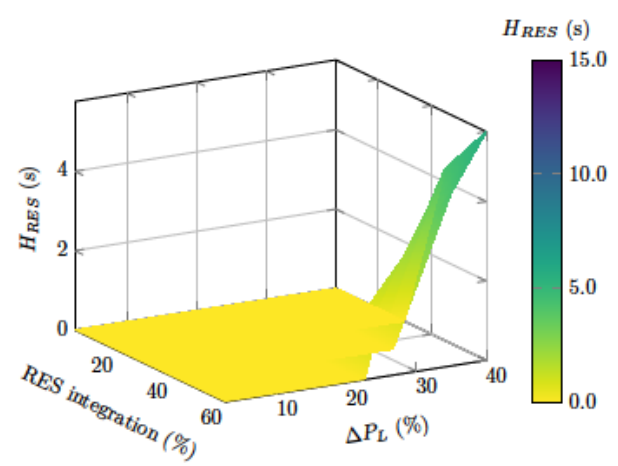

(b) $H_{R E S}$ to fulfil ROCOFs limits

Fig. 7: $H_{R E S}$ and $\Delta P_{a d d}$ estimation $\left(H_{T}=10 \mathrm{~s}, H_{H}=4.75 \mathrm{~s}\right)$.

nadir frequencies are $49.88,49.86$ and $49.80 \mathrm{~Hz}$, from the highest to the lowest combination values of $H_{T}$ and $H_{H}$. Similar results are obtained for the worst scenario (i.e., $60 \%$ RES integration energy mix and the imbalance $\Delta P_{L}=40 \%$ ), where the nadir frequencies are $43.33,43.33$ and $42.75 \mathrm{~Hz}$, respectively.

By considering the three ROCOF values, the limits established by ENTSO-E are ROCOF $0.5 \leq 2 \mathrm{~Hz} / \mathrm{s}, \mathrm{ROCOF}_{1} \leq 1.5 \mathrm{~Hz} / \mathrm{s}$ and $\mathrm{ROCOF}_{2} \leq 1.25 \mathrm{~Hz} / \mathrm{s}$ for the $0.5,1$ and $2 \mathrm{~s}$ time-window, respectively. ROCOF values are coloured in accordance to their limits, in line with the nadir frequency.Most scenarios under consideration are outside the limits determined, especially if both the RES integration and the power imbalance $\Delta P_{L}$ are high values. In contrast to nadir values, ROCOFs are really dependent on the synchronous equivalent inertia. Indeed, the lower the $H_{e q}$, the higher the ROCOFs values (compare, for instance, the ROCOFs of Figure 4 to those values of Figure 6).

\section{3 $H_{R E S}$ and $\Delta P_{a d d}$ estimation}

Following the methodology described in Section 3.2, the virtual inertia $H_{R E S}$ to fulfil the ROCOF limits, and the additional active power $\Delta P_{a d d}$ needed to be within the dynamic range of frequency variations are estimated. The results shown in Figures 7-9 correspond to the 240 cases presented in Figures 4-6.

The additional power $\Delta P_{\text {add }}$ to be provided in order to avoid the nadir frequency under $f<49.2 \mathrm{~Hz}$ takes a maximum value of $0.32 \mathrm{pu}$. This $\Delta P_{a d d}$ can be given by different resources (such as including RES in frequency control, storage solutions, increasing the PFR of conventional power plants, interconnections, or a combination of some of these). As can be seen in Figures 7-9, the higher the RES integration and $\Delta P_{L}$, the higher the additional power $\Delta P_{a d d}$ required. In fact, a lineal regression with $R^{2}=0.96$ depending on the RES integration and the $\Delta P_{L}$ can be deduced. 


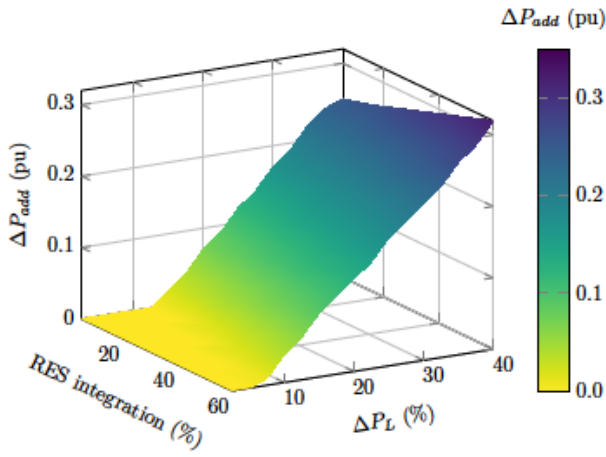

(a) $\Delta P_{\text {add }}$ to fulfil nadir frequency limit

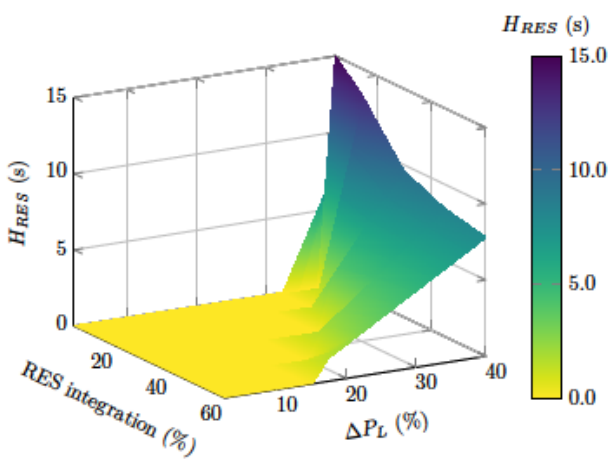

(b) $H_{R E S}$ to fulfil ROCOFs limits

Fig. 8: $H_{R E S}$ and $\Delta P_{a d d}$ estimation $\left(H_{T}=6 \mathrm{~s}, H_{H}=3.25 \mathrm{~s}\right)$.

With regard to $H_{R E S}$, some of the estimated results may lead to unrealistic solutions. Indeed, a maximum value of $H_{R E S}=96 \mathrm{~s}$ was obtained. This $H_{R E S}$ could also come from different resources. Moreover, the RES virtual inertia constant does not have any physical meaning (and an arbitrary value could be set). According to $[63,64]$, the most appropriate value for VSWT is $1.85 \cdot H_{W T}$ (being $H_{W T}$ the inertia constant of the wind turbine) to avoid the stalling of the turbine. As a result, a maximum $H_{R E S}$ of $15 \mathrm{~s}$ is considered in Figures 7-9, which is slightly over inertia constants of conventional power plants (2-10 s) [47, 50]. By considering this maximum limit, ROCOF is within the limits of the ENTSO-E recommendations for $85 \%$ of the analysed cases (612 scenarios).

\subsection{Discussion}

The recommended inertia constant of future power systems, according to ENTSO-E, ranges in between 2-3 s [52], whereas in conventional power plants it used to be 5-6 s [53]. In this study, authors have considered cases in which $H_{e q}$ is lower and higher than such recommended values, corresponding to a wide range of RES. In fact, under the same RES integration percentage, a relevant variety of $H_{e q}$ is obtained, highly depending on the $H_{T}$ and $H_{H}$, refer to Table 3 . As a result, the different values of $H$ for conventional power plants is identified as a major importance to properly carry out frequency deviation studies for future scenarios.

As was mentioned in Section 1, PV and wind resources are considered as the most promising RES technologies. The absence of rotational parts in PV power plants implies an inertia constant $H \approx 0$ [65]. The stored kinetic energy and, subsequently, deployable inertia of VSWTs is not directly available due to the power inverter [66]. As a consequence, the more the RES penetration into a power system, the weaker it will be in terms of frequency stability due to the reduction of $H_{e q}[67,68]$. Consequently, the maximum penetration

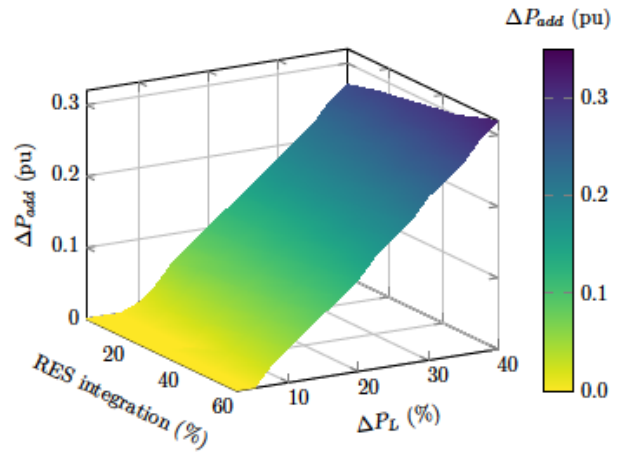

(a) $\Delta P_{\text {add }}$ to fulfil nadir frequency limit

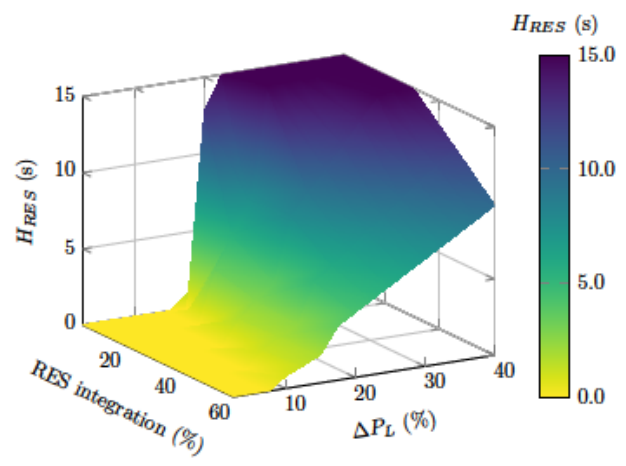

(b) $H_{R E S}$ to fulfil ROCOFs limits

Fig. 9: $H_{R E S}$ and $\Delta P_{a d d}$ estimation $\left(H_{T}=2 \mathrm{~s}, H_{H}=1.75 \mathrm{~s}\right)$.

of RES for this $H_{e q, \min }$ of 2-3 s is between 50-70\%. In fact, some authors affirm that with current RES technologies, only $50 \%$ of the overall electricity demand can be provided by them [10,61]. This RES integration discussion should also include an extensive frequency response analysis, which is the aim of this work. The 720 scenarios previously analysed have been then simulated by including the results of $H_{R E S}$ and $\Delta P_{a d d}$ estimated in Section 4.3. In this way, it is then possible to verify that $H_{R E S}$ and $\Delta P_{a d d}$ values are suitable to fulfil the ENTSO-E recommendations. Figure 10 summarises in a box-and-whisker plot the virtual inertia values for all thermal and hydro inertia constant scenarios depending on the RES integration and the power imbalance. A maximum $15 \mathrm{~s}$ for virtual inertia is assumed by the authors to achieve such requirements. Additionally, Figure 11 depicts the corresponding $\Delta P_{\text {add }}$ values in a box-and-whisker plot.

Finally, and as examples of these frequency excursion analysis, some scenarios are depicted in Figures 12-13, including the frequency evolution and the three ROCOF values considering in the ENTSO-E requirements. Different inertia values for $H_{T}$ and $H_{H}$, together with several imbalances $\Delta P_{L}$ and RES integration levels are shown. As can be seen, all nadirs are $f \geq 49.2 \mathrm{~Hz}$, thus staying in the dynamic accepted range of frequency variations. Moreover, the three ROCOF values are lower than their recommended limit values. As a consequence, the proposed methodology is suitable to estimate $\Delta P_{a d d}$ and $H_{R E S}$ values, and it can be apply to other international power system requirements.

\section{Conclusion}

This paper presents a detailed analysis of nadir and ROCOFs values following ENTSO-E recommendations for the interconnected European power system. A total of 720 generation mix scenarios are simulated, considering different RES integration (between 5\% 


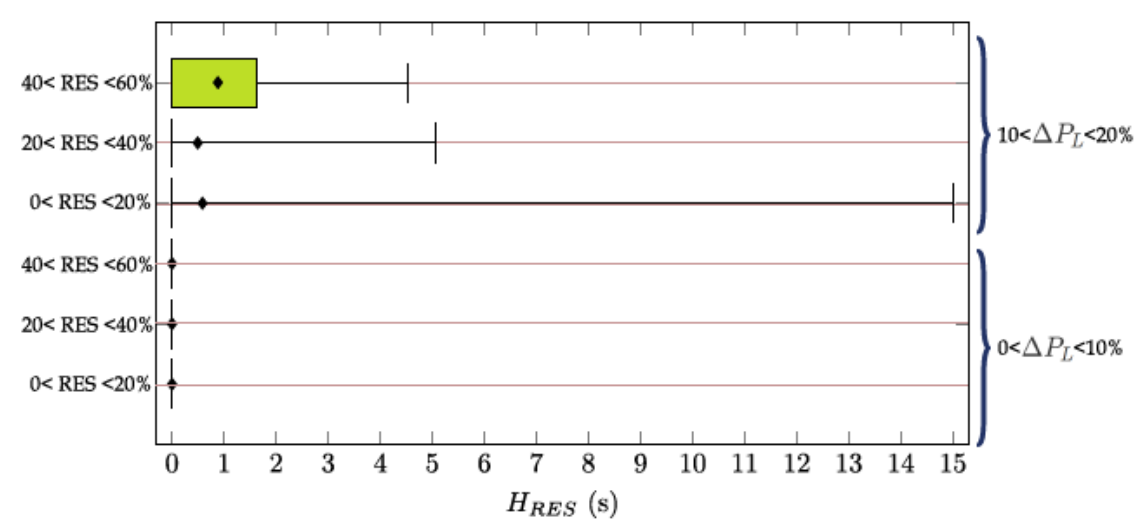

(a) Thermal and hydro inertia constant scenarios for $0<\Delta P_{L}<20$.

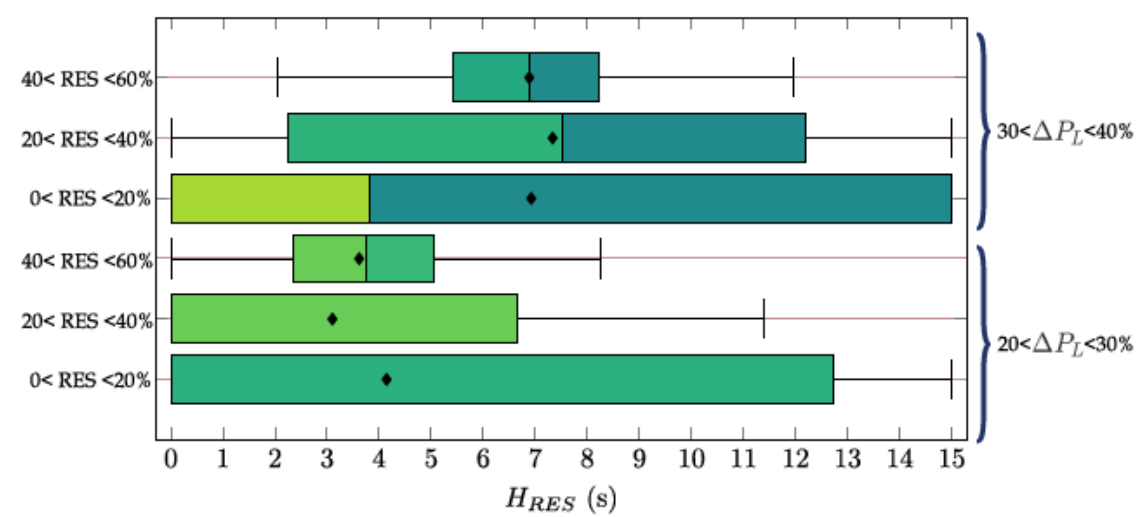

(b) Thermal and hydro inertia constant scenarios for $20<\Delta P_{L}<40$.

Fig. 10: $H_{R E S}$ to fulfil ROCOFs limits: summary of virtual inertia values.

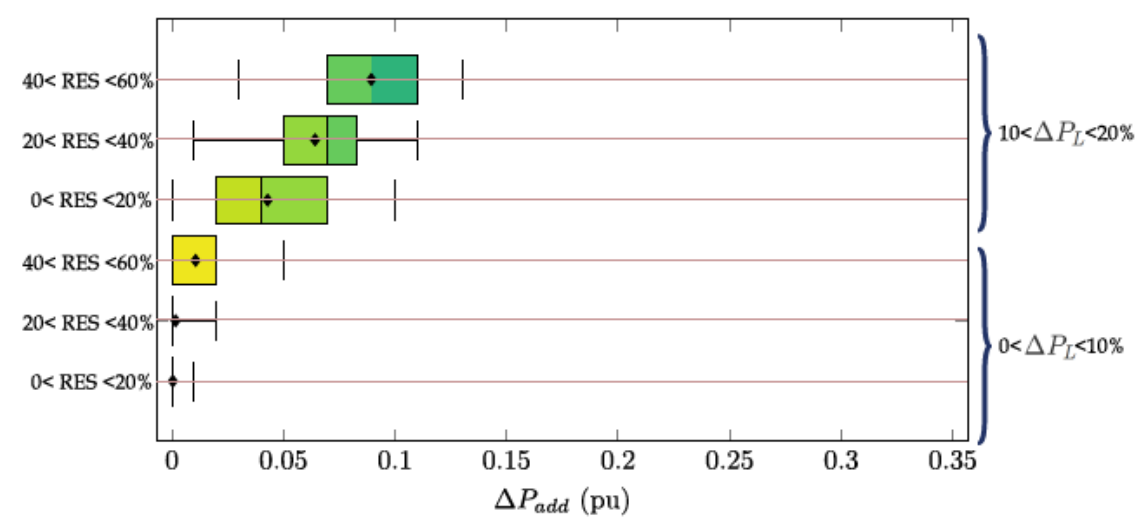

(a) Thermal and hydro inertia constant scenarios for $0<\Delta P_{L}<20$.

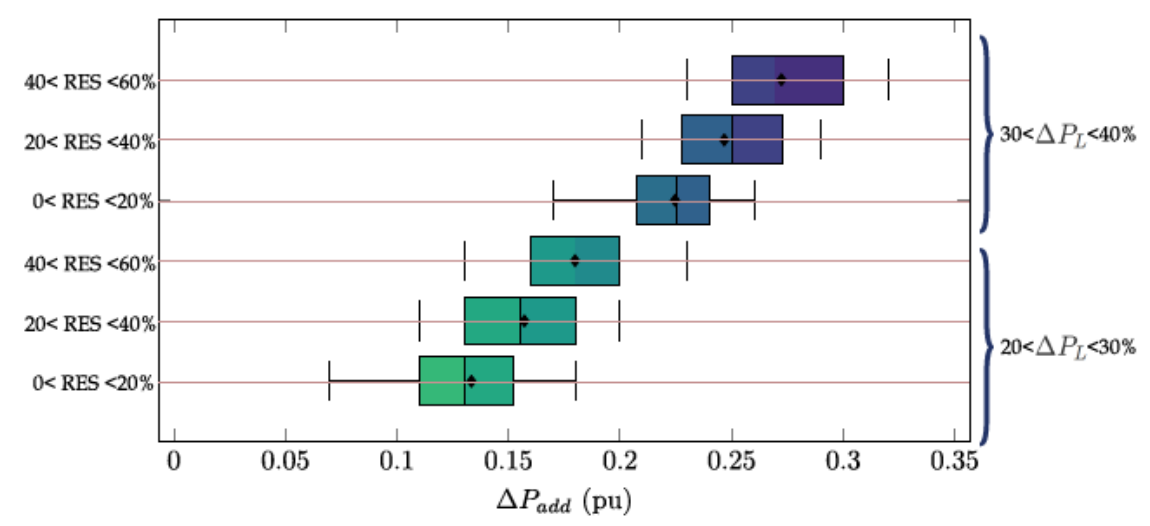

(b) Thermal and hydro inertia constant scenarios for $20<\Delta P_{L}<40$.

Fig. 11: $\Delta P_{a d d}$ to fulfil nadir frequency limit: summary of values. 


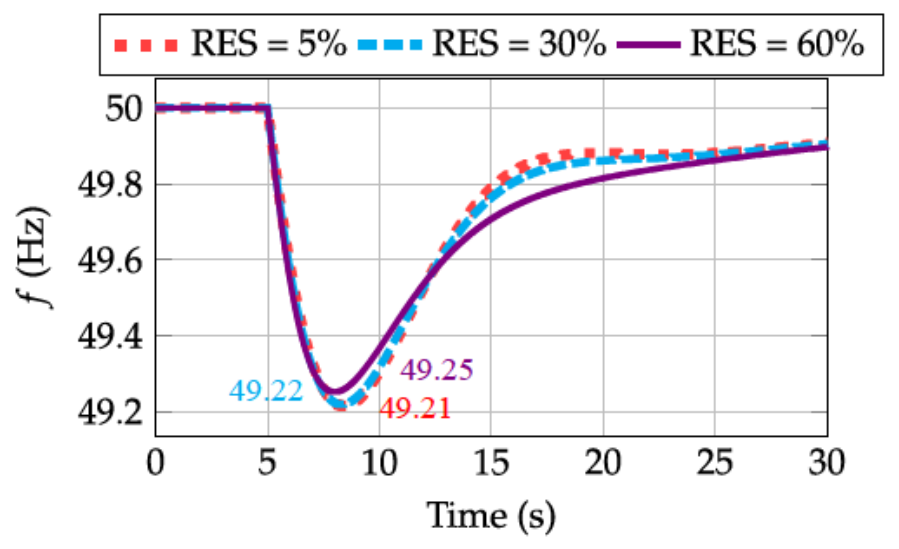

(a) Frequency evolution for $\Delta P_{L}=20 \%$

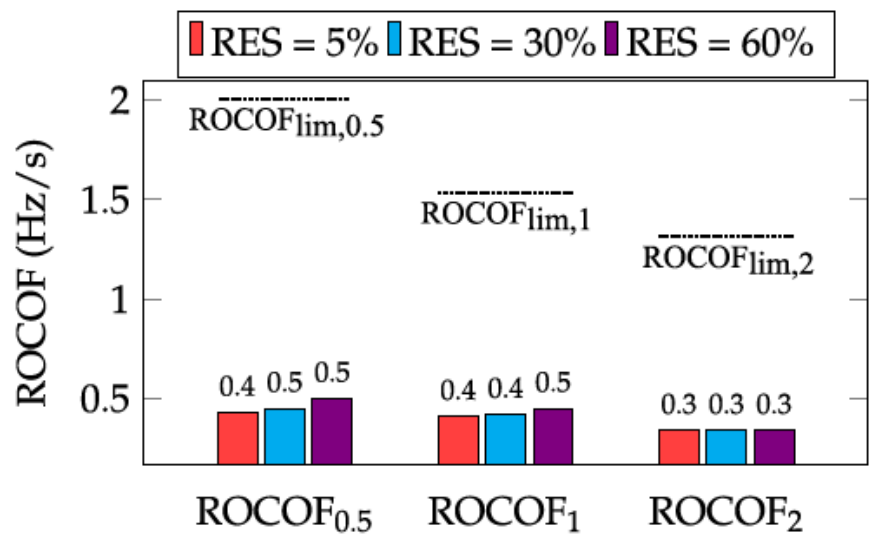

(b) ROCOF values for $\Delta P_{L}=20 \%$

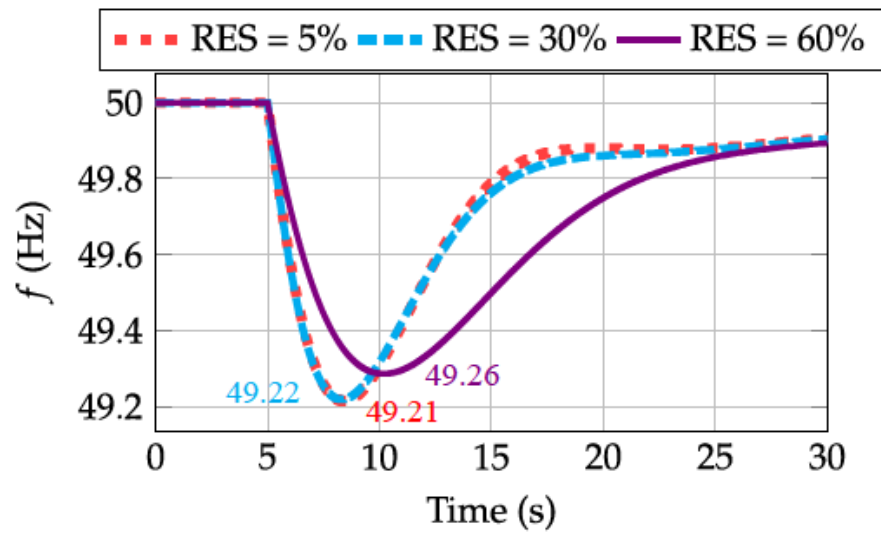

(c) $\Delta P_{L}=40 \%$

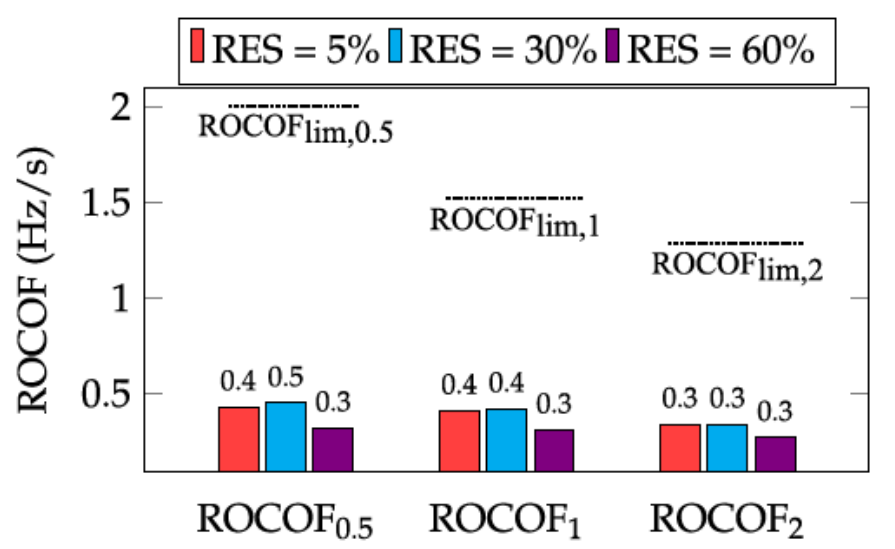

(d) ROCOF values for $\Delta P_{L}=40 \%$

Fig. 12: Frequency evolution and ROCOF values $\left(H_{T}=10 \mathrm{~s}\right.$, $\left.H_{H}=4.75 \mathrm{~s}\right)$.

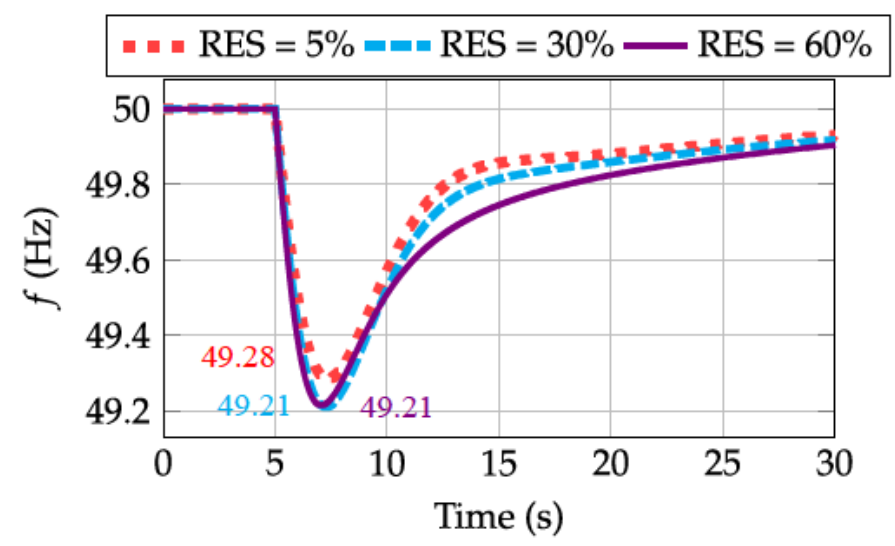

(a) Frequency evolution for $\Delta P_{L}=12.5 \%$

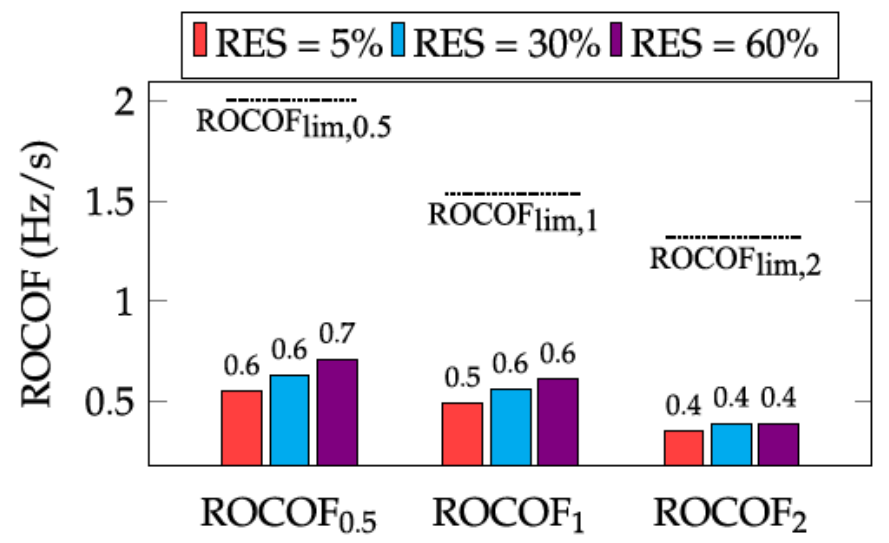

(b) ROCOF values for $\Delta P_{L}=12.5 \%$

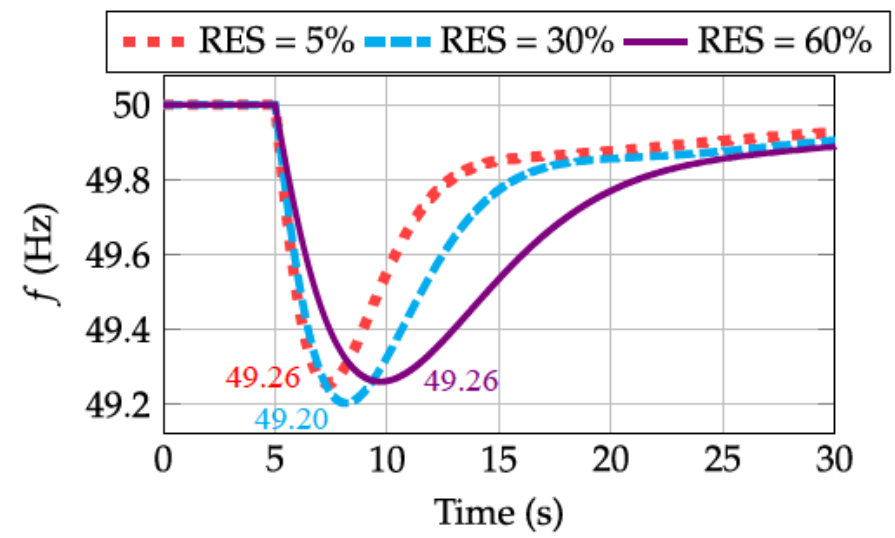

(c) $\Delta P_{L}=35 \%$

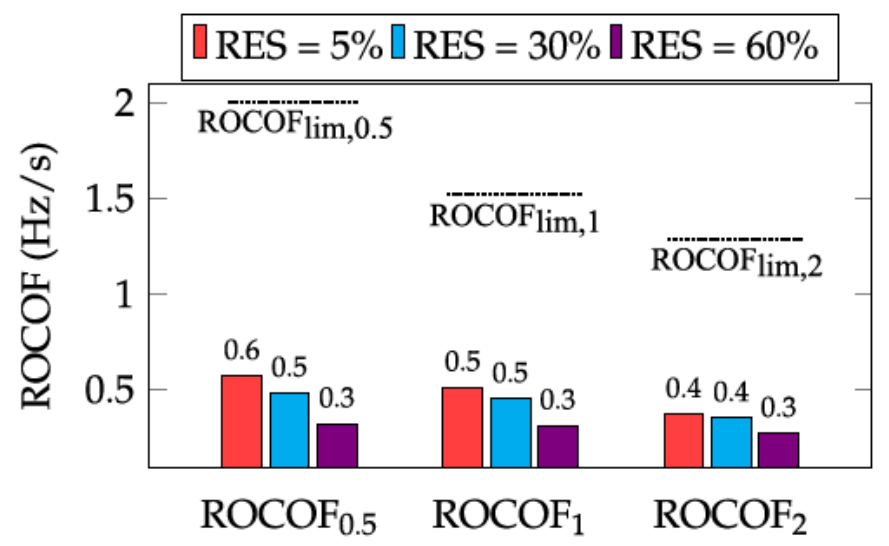

(d) ROCOF values for $\Delta P_{L}=35 \%$

Fig. 13: Frequency evolution and ROCOF values $\left(H_{T}=6 \mathrm{~s}\right.$, $H_{H}=3.25 \mathrm{~s}$ ). 
and 60\%), power imbalance and inertia constants of conventional power plants (thermal and hydro-power). The minimum additional power and virtual inertia required to fulfil the nadir and ROCOF limits established by ENTSO-E are estimated for each scenario. The results show that an additional power between 0 and $0.32 \mathrm{pu}$ is enough to avoid any frequency excursion lower than $49.2 \mathrm{~Hz}$, even if RES generation is over $50 \%$ and the power imbalance is $40 \%$. This additional power can be provided by a sort of sources, such as RES (through frequency control techniques), increasing the primary frequency reserves of conventional power plants, storage systems, provided by a different power system through interconnections, or a combination of some of them. Authors assume a maximum virtual inertia lower than $15 \mathrm{~s}$. Under this assumption, the ROCOF values following the ENTSO-E requirements are fulfilled for $85 \%$ of the simulated scenarios. From our analysis, it can be deduced that the additional power and virtual inertia to support frequency deviations after power imbalances can be provided independently and from different resources. This is due to the fact that ROCOF is directly related to inertia, but nadir is not so affected by such parameter. This analysis is carried out considering the interconnected European power system. Nevertheless, it can be applied to any other power system with high penetration of renewable sources, considering the specific recommendations of such grid.

\section{Acknowledgements}

This work is supported by the Spanish Ministry of Education, Culture and Sport -FPU16/04282 - and by the Spanish Ministry of Economy and Competitiveness and the European Union - FEDER Funds, ENE2016-78214-C2-1-R-.

\section{References}

1 D'hulst, R., Fernandez, J.M., Rikos, E., Kolodziej, D., Heussen, K., Geibelk, D., et al. 'Voltage and frequency control for future power systems: the electra irp proposal'. In: Smart Electric Distribution Systems and Technologies (EDST), 2015 International Symposium on. (IEEE, 2015. pp. 245-250

2 Hadjipaschalis, I., Poullikkas, A., Efthimiou, V.: 'Overview of current and future energy storage technologies for electric power applications', Renewable and sustainable energy reviews, 2009, 13, (6-7), pp. 1513-1522

3 Zervos, A., Lins, C., Muth, J.: 'RE-thinking 2050: a 100\% renewable energy vision for the European Union'. (Erec, 2010)

4 Liu, G., Tomsovic, K.: 'Quantifying spinning reserve in systems with significant wind power penetration', IEEE Transactions on Power Systems, 2012, 27, (4), pp. 2385-2393

5 Huber, M., Dimkova, D., Hamacher, T.: 'Integration of wind and solar power in europe: Assessment of flexibility requirements', Energy, 2014, 69, (Supplement C), pp. $236-246$

6 Tselepis, S., Nikoletatos, J.: 'Renewable energy integration in power grids', , 2015,

7 'The european power sector in 2017. state of affairs and review of current developments'. (Agora Energiewende and Sandbag, 2018.

8 Europe, W.: 'Wind energy in europe: Scenarios for 2030', Wind Europe: Brussels, Belgium, 2017,

9 Energy, S.P.: 'Technology roadmap', , 2014,

10 Zakeri, B., Syri, S., Rinne, S.: 'Higher renewable energy integration into the existing energy system of finland-is there any maximum limit?', Energy, 2015, 92, pp. 244-259

11 Ochoa.Correa, D., Martinez, S.: 'Fast-frequency response provided by dfig-wind turbines and its impact on the grid', IEEE Transactions on Power Systems, 2017, 32, pp. 4002-4011

12 Shah, R., Mithulananthan, N., Bansal, R.C., Ramachandaramurthy, V.K.: 'A review of key power system stability challenges for large-scale PV integration', Renewable and Sustainable Energy Reviews, 2015, 41, pp. 1423 - 1436

13 Green, R., Vasilakos, N.: 'Market behaviour with large amounts of intermittent generation', Energy Policy, 2010, 38, (7), pp. 3211-3220

14 Rodriguez, R.A., Becker, S., Andresen, G.B., Heide, D., Greiner, M.: 'Transmission needs across a fully renewable european power system', Renewable Energy, 2014, 63, pp. 467-476

15 Zhang, W., Fang, K.: 'Controlling active power of wind farms to participate in load frequency control of power systems', IET Generation, Transmission \& Distribution, 2017, 11, pp. 2194-2203(9)

16 Tielens, P., Van.Hertem, D.: 'Grid inertia and frequency control in power systems with high penetration of renewables', , 2012,

17 Spahic, E., Varma, D., Beck, G., Kuhn, G., Hild, V. 'Impact of reduced system inertia on stable power system operation and an overview of possible solutions'. In: Power and Energy Society General Meeting (PESGM), 2016. (IEEE, 2016. pp. $1-5$

18 Gautam, D., Goel, L., Ayyanar, R., Vittal, V., Harbour, T.: 'Control strategy to mitigate the impact of reduced inertia due to doubly fed induction generators on large power systems', IEEE Transactions on Power Systems, 2011, 26, (1), pp. 214-224
19 Delille, G., Francois, B., Malarange, G.: 'Dynamic frequency control support by energy storage to reduce the impact of wind and solar generation on isolated power system's inertia', IEEE Transactions on Sustainable Energy, 2012, 3, (4), pp. 931939

20 Daly, P., Flynn, D., Cunniffe, N. 'Inertia considerations within unit commitment and economic dispatch for systems with high non-synchronous penetrations'. In: PowerTech, 2015 IEEE Eindhoven. (IEEE, 2015. pp. 1-6

$21 \mathrm{Du}$, P., Matevosyan, J.: 'Forecast system inertia condition and its impact to integrate more renewables', IEEE Transactions on Smart Grid, 2018, 9, (2), pp. 1531-1533

$22 \mathrm{Xu}, \mathrm{T} ., \mathrm{Liu}, \mathrm{Y} ., \mathrm{Overbye}, \mathrm{T} . J$. 'Metric development for evaluating inertia's locational impacts on system primary frequency response'. In: Texas Power and Energy Conference (TPEC), 2018 IEEE. (IEEE, 2018. pp. 1-6

23 Negnevitsky, M., Nguyen, D.H., Piekutowski, M.: 'Risk assessment for power system operation planning with high wind power penetration', IEEE Transactions on Power Systems, 2015, 30, (3), pp. 1359-1368

24 Fu, Y., Wang, Y., Zhang, X.: 'Integrated wind turbine controller with virtual inertia and primary frequency responses for grid dynamic frequency support', IET Renewable Power Generation, 2017, 11, (8), pp. 1129-1137

25 Nguyen, H.T., Yang, G., Nielsen, A.H., Jensen, P.H. 'Frequency stability improvement of low inertia systems using synchronous condensers'. In: 2016 IEEE International Conference on Smart Grid Communications (SmartGridComm). (, 2016. pp. 650-655

26 Kerdphol, T., Rahman, F.S., Mitani, Y.: 'Virtual inertia control application to enhance frequency stability of interconnected power systems with high renewable energy penetration', Energies, 2018, 11, (4)

27 Canevese, S., Iaria, A., Rapizza, M. 'Impact of fast primary regulation and synthetic inertia on grid frequency control'. In: 2017 IEEE PES Innovative Smart Grid Technologies Conference Europe (ISGT-Europe). (, 2017. pp. 1-6

28 Attya, A.B.T., Hartkopf, T.: 'Control and quantification of kinetic energy released by wind farms during power system frequency drops', IET Renewable Power Generation, 2013, 7, (3), pp. 210-224

29 Fernández.Guillamón, A., Sarasúa, J.I., Chazarra, M., Vigueras.Rodríguez, A., Fernández.Muñoz, D., Molina.García, Á.: 'Frequency control analysis based on unit commitment schemes with high wind power integration: A spanish isolated power system case study', International Journal of Electrical Power \& Energy Systems, 2020, 121, pp. 106044

30 Wang, Y., Silva, V., Lopez-Botet-Zulueta, M.: 'Impact of high penetration of variable renewable generation on frequency dynamics in the continental europe interconnected system', IET Renewable Power Generation, 2016, 10, (1), pp. 1016

31 Mosca, C., Arrigo, F., Mazza, A., Bompard, E., Carpaneto, E., Chicco, G., et al.: 'Mitigation of frequency stability issues in low inertia power systems using synchronous compensators and battery energy storage systems', IET Generation, Transmission Distribution, 2019, 13, (17), pp. 3951-3959

32 Bueno, P.G., Hernández, J.C., Ruiz-Rodriguez, F.J.: 'Stability assessment for transmission systems with large utility-scale photovoltaic units', IET Renewable Power Generation, 2016, 10, (5), pp. 584-597

33 P ̈̈sschel.LØvengreen, S., Mancarella, P. 'Frequency response constrained economic dispatch with consideration of generation contingency size'. In: 2018 Power Systems Computation Conference (PSCC). (IEEE, 2018. pp. 1-7

34 Fenández.Guillamón, A., Molina.Garcia, A., Vigueras.Rodríguez, A., Gómez.Lázaro, E. 'Frequency response and inertia analysis in power systems with high wind energy integration'. In: International Conference on Clean Electrical Power - ICCEP, Italy. (IEEE, 2019. pp. 1-6

35 Boldea, I.: 'Synchronous generators'. (CRC Press, 2015)

36 Tielens, P., Van.Hertem, D.: 'The relevance of inertia in power systems', Renew able and Sustainable Energy Reviews, 2016, 55, pp. 999-1009

37 Fernández.Guillamón, A., Vigueras.Rodríguez, A., Molina.García, A. 'Análisis y simulación de estrategias agregadas de control de frecuencia entre grandes parques eólicos y aprovechamientos hidroeléctricos' [M.S. thesis]. Universidad Politécnica de Cartagena, 2017

38 Chiodo, E., Lauria, D., Mottola, F. 'On-line bayes estimation of rotational inertia for power systems with high penetration of renewables. part i: Theoretical methodology'. In: 2018 International Symposium on Power Electronics, Electrical Drives, Automation and Motion (SPEEDAM). (IEEE, 2018. pp. 835-840

$39 \mathrm{Li}, \mathrm{W} ., \mathrm{Du}, \mathrm{P} ., \mathrm{Lu}, \mathrm{N} .:$ 'Design of a new primary frequency control market for hosting frequency response reserve offers from both generators and loads', IEEE Transactions on Smart Grid, 2017

40 Nedd, M., Booth, C., Bell, K. 'Potential solutions to the challenges of low inertia power systems with a case study concerning synchronous condensers'. In: Universities Power Engineering Conference (UPEC), 2017 52nd International. (IEEE 2017. pp. $1-6$

41 Ulbig, A., Borsche, T.S., Andersson, G.: 'Analyzing rotational inertia, grid topology and their role for power system stability', IFAC-PapersOnLine, 2015, 48, (30), pp. 541-547

42 Aho, J., Buckspan, A., Laks, J., Fleming, P., Jeong, Y., Dunne, F., et al. 'A tutorial of wind turbine control for supporting grid frequency through active power control' In: 2012 American Control Conference (ACC). (2012 pp. 3120-3131

43 Kayikçi, M., Milanovic, J.V.: 'Dynamic contribution of dfig-based wind plants to system frequency disturbances', IEEE Transactions on Power Systems, 2009, 24 (2), pp. 859-867

44 Toulabi, M., Bahrami, S., Ranjbar, A M.: 'An input-to-state stability approach to inertial frequency response analysis of doubly-fed induction generator-based wind turbines', IEEE Transactions on Energy Conversion, 2017, 32, (4), pp. 1418-1431

45 Sun, Y.z., Zhang, Z.s., Li, G.j., Lin, J. 'Review on frequency control of power systems with wind power penetration'. In: Power System Technology (POWERCON), 2010 International Conference on. (IEEE, 2010. pp. 1-8 
Dreidy, M., Mokhlis, H., Mekhilef, S.: 'Inertia response and frequency control techniques for renewable energy sources: A review', Renewable and Sustainable Energy Reviews, 2017, 69, pp. 144-155

47 Fernández.Guillamón, A., Gómez.Lázaro, E., Muljadi, E., Molina.García, Á.: 'Power systems with high renewable energy sources: A review of inertia and frequency control strategies over time', Renewable and Sustainable Energy Reviews, 2019, 115, pp. 109369

48 Morren, J.. 'PhD Grid support by power electronic converters of distributed generation units (TU Delft)'. (, 2006

49 Tielens, P., Van.Hertem, D.: 'Receding horizon control of wind power to provide frequency regulation', IEEE Transactions on Power Systems, 2017, 32, (4), pp. 2663-2672

50 Fernández.Guillamón, A., Vigueras.Rodríguez, A., Molina.García, Á.: 'Analysis of power system inertia estimation in high wind power plant integration scenarios', IET Renewable Power Generation, 2019, 13, (15), pp. 2807-2816

51 ENTSO-E. 'Electricity balancing in Europe'. (, . Available from: https: // docstore.entsoe.eu/

52 ENTSO-E. 'High Penetration of Power Electronic Interfaced Power Sources (HPoPEIPS)'. (, . Available from: https: //consultations.ent soe.eu/ 53 ENTSO-E. 'Need for synthetic inertia (SI) for frequency regulation'. (, 2017.11. Available from: https://consultations.entsoe.eu/

54 ENTSO-E. 'Rate of Change of Frequency (RoCoF) withstand capability'. (, . Available from: https://docstore.entsoe.eu/

55 ENTSO-E. 'Frequency Stability Evaluation Criteria for the Synchronous Zone of Continental Europe'. (, . Available from: https://docstore.entsoe.eu/

56 ENTSO-E. 'Explanatory note for the FCR dimensioning rules proposal'. (, . Available from: https://consultations.ent soe.eu/

57 ENTSO.E. 'Nc load frequency control \& reserve: Overview last developments'. (, 2012. Available from: https://www. ent soe.eu/

58 ENTSO-E. 'Explanatory document for the Nordic synchronous area Proposal for the dimensioning rules for FCR in accordance with Article 153 of the Commission Regulation (EU) 2017/1485 of 2 August 2017 establishing a guideline on electricity transmission system operation'. (, Available from: https: //consultations.entsoe.eu/

59 Kundur, P., Balu, N.J., Lauby, M.G.: 'Power system stability and control'. vol. 7. (McGraw-hill New York, 1994)

60 Ahmadyar, A.S., Riaz, S., Verbič, G., Chapman, A., Hill, D.J.: 'A framework for assessing renewable integration limits with respect to frequency performance', IEEE Transactions on Power Systems, 2018, 33, (4), pp. 4444-4453

61 Weitemeyer, S., Kleinhans, D., Vogt, T., Agert, C.: 'Integration of renewable energy sources in future power systems: The role of storage', Renewable Energy, 2015, 75, pp. $14-20$

62 ENTSO-E: 'Ten-Year Network Development Plan (TYNDP) 2020 - Scenario Report', 2020, Available from: https://tyndp.entsoe.eu/ scenarios/

63 Zhang, Z.S., Sun, Y.Z., Lin, J., Li, G.J.: 'Coordinated frequency regulation by doubly fed induction generator-based wind power plants', IET Renewable Power Generation, 2012, 6, (1), pp. 38-47

64 Krpan, M., Kuzle, I.: 'Inertial and primary frequency response model of variablespeed wind turbines', The Journal of Engineering, 2017, 2017, (13), pp. 844-848

65 Tielens, P.. 'PhD Operation and control of power systems with low synchronous inertia (KU Leuven)'. (, 2017. Available from: https://core.ac.uk/ download/pdf/95687043.pdf

66 Gonzalez.Longatt, F. 'Frequency control and inertial response schemes for the future power networks'. In: Large Scale Renewable Power Generation. (Springer, 2014. pp. $193-231$

67 Pulgar.Painemal, H., Wang, Y., Silva.Saravia, H.: 'On inertia distribution, interarea oscillations and location of electronically-interfaced resources', IEEE Transactions on Power Systems, 2017, 33, (1), pp. 995-1003

68 Fang, J., Lin, P., Li, H., Yang, Y., Tang, Y: 'An improved virtual inertia control for three-phase voltage source converters connected to a weak grid', IEEE Transactions on Power Electronics, 2018, 34, (9), pp. 8660-8670 


\section{Conclusions}

The electrical energy transition suffered in most countries over the recent decades implies several drawbacks in terms of the frequency regulation that should be assessed and analysed before proceeding to a massive vRES integration. These two main concerns regarding VSWTs and PV installations involve the fast power fluctuations due to the variable and stochastic behaviour of wind speed and solar irradiation, and the reduction of the synchronous inertia of the grid. Consequently, frequency control (one of the most important ancillary services) should also start to be provided by vRES. Consequently, new solutions and schemes should be developed to ease the integration of vRES into the grid, without reducing its stability and reliability. In fact, from the different papers previously presented, it is concluded that it is a crucial need that vRES start to participate into frequency control, as it is the only way to promote the massive integration of such sources.

To evaluate the possible solutions to provide inertial response and frequency control from vRES, the contribution of VSWTs and PV power plants in terms of hidden/virtual/emulated inertia and the current different frequency control approaches proposed were discussed. Moreover, an extensive review of inertia constants of conventional and wind power plants, and damping factors was carried out. Also the averaged inertia constants of different regions were estimated based on the electrical generation of the conventional power plants. It was shown that in Europe, the inertia constant has nearly reduced by $20 \%$ in the last twenty years, in line with the vRES integration of such region in the same period.

A new fast power reserve emulation technique was proposed, especially focused on reducing the secondary frequency deviations due to the transition from overproduction to recovery. To overcome this, a smooth trajectory was defined. This approach was initially tested on isolated and compared to a previous technique, substantially reducing the secondary frequency deviation and also improving nadir and stabilisation time. Such strategy was also tested on multi-area power systems, giving better results in terms of frequency excursions if only the VSWTs of the area submitted to imbalance provided frequency response. In fact, nadir was reduced between 40 and $50 \%$ in the area where the power imbalance occurs, and also between $20 \%$ and $30 \%$ in the other areas.

A real power system located in Spain (the Gran Canaria isolated power system) was also analysed. Frequency deviations were considered under realistic energy schedules based on a unit commitment model. The loss of the largest conventional generation group was studied, including the VSWTs frequency scheme previously mentioned and a load shedding programme. It was seen that frequency response results strongly depend on the dispatch of conventional generation units, their frequency reserves and the inertia change addressed by the grid. Subsequently, 
controller parameters of VSWTs should dynamically vary in line with those power system variables.

The virtual inertia constant of VSWTs with the fast power reserve emulate technique was estimated with a value of $H_{V, W T}=3.57 \mathrm{~s}$, which is in line with conventional power plants' inertia constants. However, it should be kept in mind that the estimation of the equivalent inertia constant values depends on the wind frequency strategy, and different results would be obtained if also a derivative frequency dependence is included in the VSWT frequency control technique. New methods to estimate the inertia constant's of the power system based on previous frequency deviations should be proposed to be able to effectively determine the virtual/hidden inertia provided by VSWTs/PV when they participate in frequency control.

Furthermore, there are some cases in which VSWTs frequency control is not needed (for instance, if load shedding is not going to be activated). Subsequently, another fast power reserve technique was proposed, based on estimating the minimum overproduction power provided by VSWTs following a linear regression estimation. This regression depends on the ROCOF, synchronous inertia, and assigned power of thermal units before the incident. In this way, in 57\% of the imbalance scenarios under consideration, VSWTs are not required to participate in frequency response. Moreover, maximum torque variations and the speed variations were substantially reduced ( $23 \%$ and $5 \%$ on average, respectively), in comparison to a conventional VSWTs fast power reserve strategy, while maintaining similar values for the power shed with the load shedding program.

By considering the future European scenarios, a hybrid wind-PV frequency control strategy was tested in an isolated power system with variable weather conditions. In this case, VSWTs included a hidden-inertia emulation technique, and PV power plants were $10 \%$ de-loaded. However, the input of the PV controller was the rotational speed deviation of VSWTs, instead of the frequency excursion, as previously proposed in the specific literature. Consequently, the PV power plants modify their active power to reduce the deviation of such rotational speeds, improving them and, as a consequence, the frequency of the grid. Comparing to previous strategies, frequency oscillations were substantially reduced, together with the rotational speed of VSWTs. However, this hybrid strategy requires up to a $30 \%$ reduction in the PV generated energy, and should be considered by the TSOs/DSOs to guarantee some additional benefits for the owner of these generation units.

Finally, the minimum additional power and inertia that should be included to fulfil the ENTSO-E recommendations for nadir and ROCOF was determined and estimated. For this aim, more than 700 generation mix scenarios following the interconnected European power system were analysed. Both inertia and additional 
power can naturally come from different sources (i.e., storage solutions, frequency control with vRES, increasing primary frequency reserves of conventional units, interconnections with other grids, or a combination of some of them). The results show that an additional power up to $0.32 \mathrm{pu}$ was enough to avoid that frequency decayed under $49.2 \mathrm{~Hz}$; and considering a maximum virtual inertia of $15 \mathrm{~s}, 85 \%$ of the scenarios fulfilled the ROCOF requirements of ENTSO-E. 



\section{References}

[1] A. Fernández-Guillamón, E. Gómez-Lázaro, E. Muljadi, and Á. MolinaGarcía, "Power systems with high renewable energy sources: A review of inertia and frequency control strategies over time," Renewable and Sustainable Energy Reviews, vol. 115, p. 109369, 2019.

[2] A. Fernández-Guillamón, J. Villena-Lapaz, A. Vigueras-Rodríguez, T. GarcíaSánchez, and Á. Molina-García, "An adaptive frequency strategy for variable speed wind turbines: application to high wind integration into power systems," Energies, vol. 11, no. 6, p. 1436, 2018.

[3] A. Fernández-Guillamón, A. Vigueras-Rodríguez, E. Gómez-Lázaro, and Á. Molina-García, "Fast power reserve emulation strategy for vswt supporting frequency control in multi-area power systems," Energies, vol. 11, no. 10, p. $2775,2018$.

[4] A. Fernández-Guillamón, J. I. Sarasúa, M. Chazarra, A. Vigueras-Rodríguez, D. Fernández-Muñoz, and Á. Molina-García, "Frequency control analysis based on unit commitment schemes with high wind power integration: A spanish isolated power system case study," International Journal of Electrical Power \& Energy Systems, vol. 121, p. 106044, 2020.

[5] A. Fernández-Guillamón, A. Vigueras-Rodríguez, and Á. Molina-García, "Analysis of power system inertia estimation in high wind power plant integration scenarios," IET Renewable Power Generation, vol. 13, no. 15, pp. 2807-2816, 2019.

[6] A. Fernández-Guillamón, G. Martínez-Lucas, Á. Molina-García, and J. I. Sarasua, "An adaptive control scheme for variable speed wind turbines providing frequency regulation in isolated power systems with thermal generation," Energies, vol. 13, no. 13, p. 3369, 2020.

[7] A. Fernández-Guillamón, G. Martínez-Lucas, Á. Molina-García, and J.-I. Sarasua, "Hybrid wind-pv frequency control strategy under variable weather conditions in isolated power systems," Sustainability, vol. 12, no. 18, p. 7750, 2020 .

[8] A. Fernández-Guillamón, E. Gǿmez-Lázaro, and Á. Molina-García, "Extensive frequency response and inertia analysis under high renewable energy source integration scenarios: application to the european interconnected power system," IET Renewable Power Generation, 2020. 
[9] I. Muñoz-Benavente, A. D. Hansen, E. Gómez-Lázaro, T. García-Sánchez, A. Fernández-Guillamón, and Á. Molina-García, "Impact of combined demand-response and wind power plant participation in frequency control for multi-area power systems," Energies, vol. 12, no. 9, p. 1687, 2019.

[10] A. Molina-García, A. Fernández-Guillamón, E. Gómez-Lázaro, A. HonrubiaEscribano, and M. C. Bueso, "Vertical wind profile characterization and identification of patterns based on a shape clustering algorithm," IEEE Access, vol. 7, pp. 30890-30904, 2019.

[11] I. C. Gil-García, M. S. García-Cascales, A. Fernández-Guillamón, and A. Molina-García, "Categorization and analysis of relevant factors for optimal locations in onshore and offshore wind power plants: A taxonomic review," Journal of Marine Science and Engineering, vol. 7, no. 11, p. 391, 2019.

[12] A. Fernández-Guillamón, K. Das, N. A. Cutululis, and Á. Molina-García, "Offshore wind power integration into future power systems: Overview and trends," Journal of Marine Science and Engineering, vol. 7, no. 11, p. 399, 2019.

[13] T. García-Sánchez, I. Muñoz-Benavente, E. Gómez-Lázaro, and A. Fernández-Guillamón, "Modelling types 1 and 2 wind turbines based on iec 61400-27-1: Transient response under voltage dips," Energies, vol. 13, no. 16, p. 4078, 2020.

[14] T. García-Sánchez, A. K. Mishra, E. Hurtado-Pérez, R. Puché-Panadero, and A. Fernández-Guillamón, "A controller for optimum electrical power extraction from a small grid-interconnected wind turbine," Energies, vol. 13, no. 21,2020 .

[15] P. Tafarte, S. Das, M. Eichhorn, and D. Thrän, "Small adaptations, big impacts: Options for an optimized mix of variable renewable energy sources," Energy, vol. 72, pp. 80-92, 2014.

[16] M. Ram, D. Bogdanov, A. Aghahosseini, S. Oyewo, A. Gulagi, M. Child, H.-J. Fell, and C. Breyer, "Global energy system based on $100 \%$ renewable energy-power sector," Lappeenranta University of Technology and Energy Watch Group: Lappeenranta, Finland, 2017.

[17] E. IRENA, "Renewable energy prospects for the european union," International Renewable Energy Agency (IRENA), European Commission (EC), Abu Dhabi, 2018.

[18] ENTSO-E, “TYNDP 2020 - Scenario Report,” 2020. 
[19] IEA, "Data \& Statistics." https://Www.iea.org/ data and statistics.

[20] J. Woo, H. Choi, and J. Ahn, "Well-to-wheel analysis of greenhouse gas emissions for electric vehicles based on electricity generation mix: A global perspective," Transportation Research Part D: Transport and Environment, vol. 51, pp. 340-350, 2017.

[21] G. Janssens-Maenhout, M. Crippa, D. Guizzardi, M. Muntean, E. Schaaf, J. G. Olivier, J. Peters, and K. M. Schure, Fossil CO2 \& GHG emissions of all world countries, vol. 107877. Publications Office of the European Union Luxembourg, 2017.

[22] J. Rogelj, M. Den Elzen, N. Höhne, T. Fransen, H. Fekete, H. Winkler, R. Schaeffer, F. Sha, K. Riahi, and M. Meinshausen, "Paris agreement climate proposals need a boost to keep warming well below 2 c," Nature, vol. 534, no. 7609, pp. 631-639, 2016.

[23] F. Creutzig, P. Agoston, J. C. Goldschmidt, G. Luderer, G. Nemet, and R. C. Pietzcker, "The underestimated potential of solar energy to mitigate climate change," Nature Energy, vol. 2, no. 9, p. 17140, 2017.

[24] M. Pacesila, S. G. Burcea, and S. E. Colesca, "Analysis of renewable energies in european union," Renewable and Sustainable Energy Reviews, vol. 56, pp. 156-170, 2016.

[25] P. E. Gasser, Quantifying Electricity Supply Resilience of Countries with Multi-Criteria Decision Analysis. PhD thesis, ETH Zurich, 2019.

[26] K. J. Chalvatzis and A. Ioannidis, "Energy supply security in the eu: Benchmarking diversity and dependence of primary energy," Applied Energy, vol. 207, pp. 465-476, 2017.

[27] R. C. da Silva, I. de Marchi Neto, and S. S. Seifert, "Electricity supply security and the future role of renewable energy sources in brazil," Renewable and Sustainable Energy Reviews, vol. 59, pp. 328-341, 2016.

[28] M. Cvetković, K. Pan, C. D. López, R. Bhandia, and P. Palensky, "Cosimulation aspects for energy systems with high penetration of distributed energy resources," in AEIT International Annual Conference, 2017, pp. 1-6, IEEE, 2017.

[29] Y. Wang, J. Meng, X. Zhang, and L. Xu, "Control of pmsg-based wind turbines for system inertial response and power oscillation damping," IEEE Transactions on Sustainable Energy, vol. 6, no. 2, pp. 565-574, 2015. 
[30] D. E. M. Bondy, A. Thavlov, J. B. M. Tougaard, and K. Heussen, "Performance requirements modeling and assessment for active power ancillary services," in 2017 IEEE Manchester PowerTech, pp. 1-6, IEEE, 2017.

[31] M. K. Hossain and M. H. Ali, "Transient stability augmentation of pv/dfig/sgbased hybrid power system by parallel-resonance bridge fault current limiter," Electric Power Systems Research, vol. 130, pp. 89-102, 2016.

[32] R. A. Rodriguez, S. Becker, G. B. Andresen, D. Heide, and M. Greiner, "Transmission needs across a fully renewable european power system," Renewable Energy, vol. 63, pp. 467-476, 2014.

[33] F. Teng, Y. Mu, H. Jia, J. Wu, P. Zeng, and G. Strbac, "Challenges on primary frequency control and potential solution from evs in the future gb electricity system," Applied energy, vol. 194, pp. 353-362, 2017.

[34] P. Wang, Z. Gao, and L. Bertling, "Operational adequacy studies of power systems with wind farms and energy storages," IEEE Transactions on Power Systems, vol. 27, no. 4, pp. 2377-2384, 2012.

[35] A. M. Quevedo, E. J. M. Domínguez, J. M. de León Izquier, R. C. de León, P. S. Arozarena, J. G. Moreno, A. C. Quintero, and J. G. Hernández, "Gorona del viento wind-hydro power plant," 2018.

[36] W. Zhang and K. Fang, "Controlling active power of wind farms to participate in load frequency control of power systems," IET Generation, Transmission \& Distribution, vol. 11, no. 9, pp. 2194-2203, 2017.

[37] A. Junyent-Ferr, Y. Pipelzadeh, and T. C. Green, "Blending hvdc-link energy storage and offshore wind turbine inertia for fast frequency response," IEEE Transactions on sustainable energy, vol. 6, no. 3, pp. 1059-1066, 2015.

[38] S. Yang, J. Fang, Y. Tang, H. Qiu, C. Dong, and P. Wang, "Synthetic-inertiabased modular multilevel converter frequency control for improved microgrid frequency regulation," in 2018 IEEE Energy Conversion Congress and Exposition (ECCE), pp. 5177-5184, IEEE, 2018.

[39] H. Thiesen, C. Jauch, and A. Gloe, "Design of a system substituting today's inherent inertia in the european continental synchronous area," Energies, vol. 9, no. 8, p. 582, 2016.

[40] A. Hosseinipour and H. Hojabri, "Virtual inertia control of pv systems for dynamic performance and damping enhancement of $\mathrm{dc}$ microgrids with 
constant power loads," IET Renewable Power Generation, vol. 12, no. 4, pp. 430-438, 2017.

[41] G. Delille, B. Francois, and G. Malarange, "Dynamic frequency control support by energy storage to reduce the impact of wind and solar generation on isolated power system's inertia," IEEE Transactions on Sustainable Energy, vol. 3, no. 4, pp. 931-939, 2012.

[42] A. Muzhikyan, T. Mezher, and A. M. Farid, "Power system enterprise control with inertial response procurement," IEEE Transactions on Power Systems, vol. 33, no. 4, pp. 3735-3744, 2017.

[43] F. Milano, F. Dörfler, G. Hug, D. J. Hill, and G. Verbič, "Foundations and challenges of low-inertia systems," in 2018 Power Systems Computation Conference (PSCC), pp. 1-25, IEEE, 2018.

[44] T. Borsche, A. Ulbig, and G. Andersson, "A new frequency control reserve framework based on energy-constrained units," in 2014 Power Systems Computation Conference, pp. 1-7, IEEE, 2014.

[45] S. Padrón, M. Hernández, and A. Falcón, "Reducing under-frequency load shedding in isolated power systems using neural networks. gran canaria: a case study," IEEE Transactions on Power Systems, vol. 31, no. 1, pp. 63-71, 2015.

[46] Y. P. Verma and A. Kumar, "Load frequency control in deregulated power system with wind integrated system using fuzzy controller," Frontiers in Energy, vol. 7, no. 2, pp. 245-254, 2013.

[47] "EN 50160: Voltage Characteristics in Public Distribution Systems," standard, Mar. 2011.

[48] H. Shayeghi, H. Shayanfar, and A. Jalili, "Load frequency control strategies: A state-of-the-art survey for the researcher," Energy Conversion and management, vol. 50, no. 2, pp. 344-353, 2009.

[49] R. Chilipi, N. Al Sayari, K. Al Hosani, and A. R. Beig, "Control scheme for grid-tied distributed generation inverter under unbalanced and distorted utility conditions with power quality ancillary services," IET Renewable Power Generation, vol. 10, no. 2, pp. 140-149, 2016.

[50] A. Iovine, M. J. Carrizosa, G. Damm, and P. Alou, "Nonlinear control for dc microgrids enabling efficient renewable power integration and ancillary services for ac grids," IEEE Transactions on Power Systems, vol. 34, no. 6, pp. 5136-5146, 2018. 
[51] A. Kaushal and D. Van Hertem, "An overview of ancillary services and hvdc systems in european context," Energies, vol. 12, no. 18, p. 3481, 2019.

[52] G. Martínez-Lucas, J. I. Sarasúa, J. R. Wilhelmi, and J. ángel Sánchez, "Contribution to load-frequency regulation of a hydropower plant with long tail-race tunnel," in 2015 IEEE 15th International Conference on Environment and Electrical Engineering (EEEIC), pp. 1886-1891, IEEE, 2015.

[53] P. Mancarella, G. Chicco, and T. Capuder, "Arbitrage opportunities for distributed multi-energy systems in providing power system ancillary services," Energy, vol. 161, pp. 381-395, 2018.

[54] ENTSO-E, "Electricity balancing in Europe." https://docstore. entsoe.eu/.

[55] V. Knap, S. K. Chaudhary, D.-I. Stroe, M. Swierczynski, B.-I. Craciun, and R. Teodorescu, "Sizing of an energy storage system for grid inertial response and primary frequency reserve," IEEE Transactions on Power Systems, vol. 31, no. 5, pp. 3447-3456, 2015.

[56] M. Kang, K. Kim, E. Muljadi, J.-W. Park, and Y. C. Kang, "Frequency control support of a doubly-fed induction generator based on the torque limit," IEEE Transactions on Power Systems, vol. 31, no. 6, pp. 4575-4583, 2016.

[57] P. Tielens and D. Van Hertem, "The relevance of inertia in power systems," Renewable and Sustainable Energy Reviews, vol. 55, pp. 999-1009, 2016.

[58] F. M. Uriarte, C. Smith, S. VanBroekhoven, and R. E. Hebner, "Microgrid ramp rates and the inertial stability margin," IEEE Transactions on Power Systems, vol. 30, no. 6, pp. 3209-3216, 2015.

[59] A. Ulbig, T. Rinke, S. Chatzivasileiadis, and G. Andersson, "Predictive control for real-time frequency regulation and rotational inertia provision in power systems," in 52nd IEEE Conference on Decision and Control, pp. 2946-2953, IEEE, 2013.

[60] J. Dai, Y. Phulpin, A. Sarlette, and D. Ernst, "Coordinated primary frequency control among non-synchronous systems connected by a multi-terminal highvoltage direct current grid," IET generation, transmission \& distribution, vol. 6, no. 2, pp. 99-108, 2012.

[61] T. Borsche, A. Ulbig, M. Koller, and G. Andersson, "Power and energy capacity requirements of storages providing frequency control reserves," in 2013 IEEE Power \& Energy Society General Meeting, pp. 1-5, IEEE, 2013. 
[62] F. Díaz-González, M. Hau, A. Sumper, and O. Gomis-Bellmunt, "Participation of wind power plants in system frequency control: Review of grid code requirements and control methods," Renewable and Sustainable Energy Reviews, vol. 34, pp. 551-564, 2014.

[63] A. M. Ersdal, L. Imsland, and K. Uhlen, "Model predictive load-frequency control," IEEE Transactions on Power Systems, vol. 31, no. 1, pp. 777-785, 2015 .

[64] ENTSO-E, "ENTSO-E Network Code for Requirements for Grid Connection Applicable to all Generators." https://consultations.entsoe.eu/, 2011.06.

[65] F. Guo, C. Wen, J. Mao, and Y.-D. Song, "Distributed secondary voltage and frequency restoration control of droop-controlled inverter-based microgrids," IEEE Transactions on industrial Electronics, vol. 62, no. 7, pp. 4355-4364, 2014.

[66] C. Zhao, E. Mallada, and S. H. Low, "Distributed generator and loadside secondary frequency control in power networks," in 2015 49th Annual Conference on Information Sciences and Systems (CISS), pp. 1-6, IEEE, 2015.

[67] C. Zhao, E. Mallada, S. Low, and J. Bialek, "A unified framework for frequency control and congestion management," in 2016 Power Systems Computation Conference (PSCC), pp. 1-7, IEEE, 2016.

[68] F. D. Mohammadi, H. K. Vanashi, and A. Feliachi, "State-space modeling, analysis, and distributed secondary frequency control of isolated microgrids," IEEE Transactions on Energy Conversion, vol. 33, no. 1, pp. 155-165, 2017.

[69] A. Ulbig, M. D. Galus, S. Chatzivasileiadis, and G. Andersson, "General frequency control with aggregated control reserve capacity from time-varying sources: The case of phevs," in 2010 IREP Symposium Bulk Power System Dynamics and Control-VIII (IREP), pp. 1-14, IEEE, 2010.

[70] E. Lobato, I. Egido, and L. Rouco, "Monitoring frequency control in the turkish power system," Electric power systems research, vol. 84, no. 1, pp. 144-151, 2012.

[71] A. Adrees and J. V. Milanovic, "Study of frequency response in power system with renewable generation and energy storage," in 2016 Power Systems Computation Conference (PSCC), pp. 1-7, IEEE, 2016.

[72] H. H. Alhelou and M. Golshan, "Hierarchical plug-in ev control based on primary frequency response in interconnected smart grid," in 2016 24th 
Iranian Conference on Electrical Engineering (ICEE), pp. 561-566, IEEE, 2016.

[73] M. Perninge and R. Eriksson, "Optimal tertiary frequency control in power systems with market-based regulation," IFAC-PapersOnLine, vol. 50, no. 1, pp. 4374-4381, 2017.

[74] J. J. Grainger and W. D. Stevenson, Power system analysis. McGraw-Hill, 1994.

[75] P. Kundur, N. J. Balu, and M. G. Lauby, Power system stability and control, vol. 7. McGraw-hill New York, 1994.

[76] A. Fernández Guillamón et al., "Análisis y simulación de estrategias agregadas de control de frecuencia entre grandes parques eólicos y aprovechamientos hidroeléctricos," 2017.

[77] Y. Tofis, S. Timotheou, and E. Kyriakides, "Minimal load shedding using the swing equation," IEEE Transactions on Power Systems, vol. 32, no. 3, pp. 2466-2467, 2016.

[78] H. A. Yousef, A.-K. Khalfan, M. H. Albadi, and N. Hosseinzadeh, "Load frequency control of a multi-area power system: An adaptive fuzzy logic approach," IEEE transactions on power systems, vol. 29, no. 4, pp. 1822 $1830,2014$.

[79] M. T. Ozdemir and D. Ozturk, "Comparative performance analysis of optimal pid parameters tuning based on the optics inspired optimization methods for automatic generation control," Energies, vol. 10, no. 12, p. 2134, 2017.

[80] P. Tielens, Operation and control of power systems with low synchronous inertia. PhD thesis, KU Leuven, 2017.

[81] F. Gonzalez-Longatt, "Frequency control and inertial response schemes for the future power networks," in Large Scale Renewable Power Generation, pp. 193-231, Springer, 2014.

[82] H. Pulgar-Painemal, Y. Wang, and H. Silva-Saravia, "On inertia distribution, inter-area oscillations and location of electronically-interfaced resources," IEEE Transactions on Power Systems, vol. 33, no. 1, pp. 995-1003, 2017.

[83] J. Fang, P. Lin, H. Li, Y. Yang, and Y. Tang, "An improved virtual inertia control for three-phase voltage source converters connected to a weak grid," IEEE Transactions on Power Electronics, vol. 34, no. 9, pp. 8660-8670, 2018. 
[84] ENTSO-E, "Need for synthetic inertia (SI) for frequency regulation." https://consultations.entsoe.eu/, 2017.11.

[85] ENTSO-E, "High Penetration of Power Electronic Interfaced Power Sources (HPoPEIPS).” https://consultations.entsoe.eu/.

[86] B. Zakeri, S. Syri, and S. Rinne, "Higher renewable energy integration into the existing energy system of finland-is there any maximum limit?," Energy, vol. 92, pp. 244-259, 2015.

[87] S. Weitemeyer, D. Kleinhans, T. Vogt, and C. Agert, "Integration of renewable energy sources in future power systems: The role of storage," Renewable Energy, vol. 75, pp. 14 - 20, 2015.

[88] A. Ulbig, T. S. Borsche, and G. Andersson, "Impact of low rotational inertia on power system stability and operation," IFAC Proceedings Volumes, vol. 47, no. 3, pp. 7290-7297, 2014.

[89] M. F. M. Arani and E. F. El-Saadany, "Implementing virtual inertia in dfigbased wind power generation," IEEE Transactions on Power Systems, vol. 28, no. 2, pp. 1373-1384, 2012.

[90] J. Van de Vyver, J. D. De Kooning, B. Meersman, L. Vandevelde, and T. L. Vandoorn, "Droop control as an alternative inertial response strategy for the synthetic inertia on wind turbines," IEEE Transactions on Power Systems, vol. 31, no. 2, pp. 1129-1138, 2015.

[91] F. Bassi, L. Caciolli, G. Giannuzzi, N. Corsi, and A. Giorgi, "Use of hidden inertia from wind generation for frequency support in power grids," in 2016 AEIT International Annual Conference (AEIT), pp. 1-6, IEEE, 2016.

[92] F. M. Gonzalez-Longatt, "Impact of emulated inertia from wind power on under-frequency protection schemes of future power systems," Journal of Modern Power Systems and Clean Energy, vol. 4, no. 2, pp. 211-218, 2016. 



\section{A. Índices de calidad}

Los índices de impacto se han obtenido a través de la aplicación de Journal Citation Reports de Web of Science. Se muestran a continuación los índices de impacto y cuartil de cada revista de los artículos incluidos en esta tesis doctoral. En el caso de los artículos aceptados en el año 2020, se incluyen los datos del año 2019, al ser los más actualizados en el momento de depositar la presente tesis doctoral.

- Power systems with high renewable energy sources: A review of inertia and frequency control strategies over time

Publicado en Renewable \& Sustainable Energy Reviews en el año 2019. La revista tuvo ese año un factor de impacto de 12.110, estando posicionada en Q1 para las categorías Green \& sustainable science \& technology y Energy \& fuels, en posiciones $1 / 41$ y $7 / 112$, respectivamente.

- An adaptive frequency strategy for variable speed wind turbines: application to high wind integration into power systems.

Publicado en Energies en el año 2018. La revista tuvo ese año un factor de impacto de 2.707, estando posicionada en Q3 para la categoría Energy \& fuels, en posición 56/103.

- Fast power reserve emulation strategy for VSWT supporting frequency control in multi-area power systems.

Publicado en Energies en el año 2018. La revista tuvo ese año un factor de impacto de 2.707, estando posicionada en Q3 para la categoría Energy \& fuels, en posición 56/103.

- Frequency control analysis based on unit commitment schemes with high wind power integration: A Spanish isolated power system case study.

Publicado en International Journal of Electrical Power \& Energy Systems en el año 2020. En el año 2019, la revista tuvo un factor de impacto de 3.588, estando posicionada en Q1 para la categoría Engineering, electrical \& electronic, en posición 66/266.

- Analysis of power system inertia estimation in high wind power plant integration scenarios.

Publicado en IET Renewable Power Generation en el año 2019. La revista tuvo ese año un factor de impacto de 3.894, estando posicionada en Q2, Q2 y Q1 para las categorías Green \& sustainable science \& technology, Energy \& fuels y Engineering, electrical \& electronic, en posiciones 18/41, 43/112 y 57/266, respectivamente.

- An adaptive control scheme for variable speed wind turbines providing frequency regulation in isolated power systems with thermal generation.

Publicado en Energies en el año 2020. En el año 2019, la revista tuvo un 
factor de impacto de 2.702, estando posicionada en Q3 para la categoría Energy \& fuels, en posición 63/112.

- Hybrid wind-PV frequency control strategy under variable weather conditions in isolated power systems

Publicado en Sustainability en el año 2020. En el año 2019, la revista tuvo un factor de impacto de 2.576, estando posicionada en Q2 y Q3 para las categorías Green \& sustainable science \& technology y Environmental sciences, en posiciones 120/265 y 26/41, respectivamente.

- Extensive frequency response and inertia analysis under high RES integration scenarios: application to the European interconnected power system

Publicado en IET Renewable Power Generation en el año 2020. En el año 2019, la revista tuvo un factor de impacto de 3.894, estando posicionada en Q2, Q2 y Q1 para las categorías Green \& sustainable science \& technology, Energy \& fuels y Engineering, electrical \& electronic, en posiciones 18/41, 43/112 y 57/266, respectivamente. 